듬 SCHOOL of GRADUATE STUDIES

EAST TENNESSEE STATE UNIVERSITY
East Tennessee State University Digital Commons@ East Tennessee State University

$8-2012$

\title{
Application of Multivariate Statistical Methodology to Model Factors Influencing Fate and Transport of Fecal Pollution in Surface Waters
}

Kimberlee K. Hall

East Tennessee State University

Follow this and additional works at: https://dc.etsu.edu/etd

Part of the Environmental Health Commons

\section{Recommended Citation}

Hall, Kimberlee K., "Application of Multivariate Statistical Methodology to Model Factors Influencing Fate and Transport of Fecal Pollution in Surface Waters" (2012). Electronic Theses and Dissertations. Paper 1221. https://dc.etsu.edu/etd/1221

This Dissertation - Open Access is brought to you for free and open access by the Student Works at Digital Commons @ East Tennessee State University. It has been accepted for inclusion in Electronic Theses and Dissertations by an authorized administrator of Digital Commons @ East

Tennessee State University. For more information, please contact digilib@etsu.edu. 
Application of Multivariate Statistical Methodology to Model Factors Influencing Fate and Transport of Fecal Pollution in Surface Waters

\author{
A dissertation \\ presented to \\ the faculty of the Department of Environmental Health \\ East Tennessee State University \\ In partial fultillment \\ of the requirements for the degree \\ Doctor of Philosophy in Environmental Health Sciences \\ by \\ Kimberlee K Hall \\ August 2012 \\ Philip Scheuerman, Ph.D., Chair \\ Kurt Maier, Ph.D. \\ Ranjan Chakraborty, Ph.D. \\ Eric Mustain, Ph.D. \\ Nathan Fethke, Ph.D.
}

Keywords: water, fecal pollution, multivariate statistics 


\section{ABSTRACT}

Application of Multivariate Statistical Methodology to Model Factors Influencing Fate and Transport of Fecal Pollution in Surface Waters

by

\section{Kimberlee K Hall}

Degraded surface water quality is a growing public health concern. While indicator organisms are frequently used as a surrogate measure of pathogen contamination, poor correlation is often observed between indicators and pathogens. Because of adverse health effects associated with poor water quality, an assessment of the factors influencing the fate and transport of fecal pollution is necessary to identify sources and effectively design and implement Best Management Practices (BMPs) to protect and restore surface water quality. Sinking Creek is listed on the State of Tennessee's 303D list as impaired due to pathogen contamination. The need to address the listing of this and other water bodies on the 303D list through the Total Maximum Daily Load (TMDL) process has resulted in increased research to find methods that effectively and universally identify sources of fecal pollution. The main objective of this research is to better understand how microbial, chemical, and physical factors influence pathogen fate and transport in Sinking Creek. This increased understanding can be used to improve source identification and remediation. To accomplish this objective, physical, chemical, and microbial water quality parameters were measured and the data were analyzed using multivariate statistical methods to identify those parameters influencing pathogen fate and transport. Physical, chemical, and microbial water and soil properties were also characterized along Sinking Creek to determine their influences on the introduction of fecal pollution to surface water. Results indicate that the 30 -day geometric mean of 
fecal indicator organisms is not representative of true watershed dynamics and that their presence does not correlate with the presence of bacterial, protozoan, or viral pathogens in Sinking Creek. The use of multivariate statistical analyses coupled with a targeted water quality-monitoring program has demonstrated that nonpoint sources of fecal pollution vary spatially and temporally and are related to land use patterns. It is suggested that this data analysis approach can be used to effectively identify nonpoint sources of fecal pollution in surface water. 


\section{DEDICATION}

This dissertation is dedicated to my parents. Their support throughout this journey has been immeasurable. 


\section{ACKNOWLEDGEMENTS}

I would like to thank the members of my dissertation committee, especially my committee chairman Dr. Phillip Scheuerman, for all of his time, guidance, and patience throughout the duration of this research. I would also like to thank everyone in the Environmental Health Sciences Laboratory, especially the graduate students for their

friendship and support. I am very grateful to Brian Evanshen and Chuck Patton for their support and advice throughout this research. This research was funded in part by a grant from the ETSU School of Graduate Studies and Graduate Council, and by a contract with the Tennessee Valley Authority (Award \#00025252). 


\section{CONTENTS}

Page

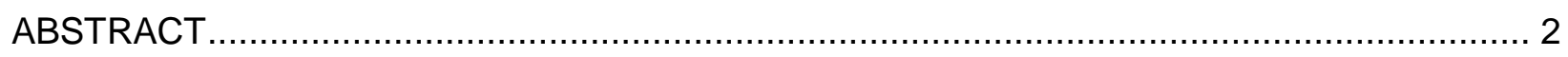

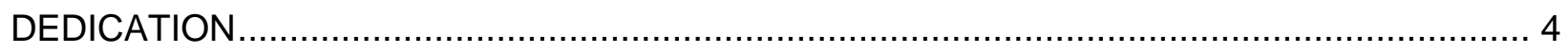

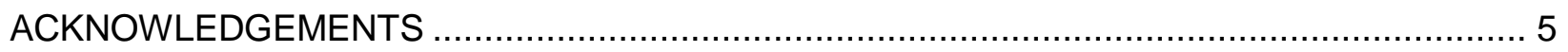

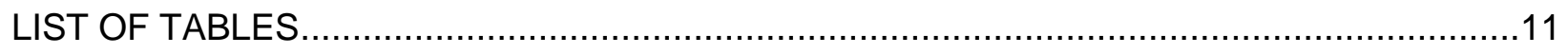

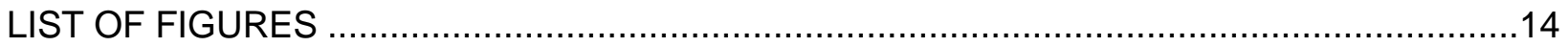

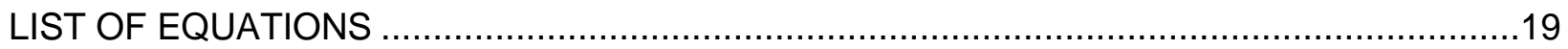

Chapter

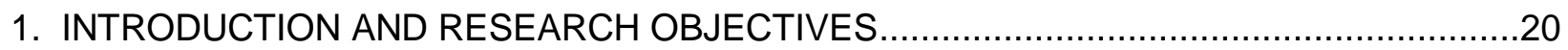

Bacterial Pathogens Associated with Waterborne Outbreaks ...........................................23

Protozoan Pathogens Associated with Waterborne Outbreaks .........................................27

Enteric Viruses Associated with Waterborne Outbreaks .........................................................31

Environmental Health Sciences Laboratory Water Quality Monitoring at East Tennessee State

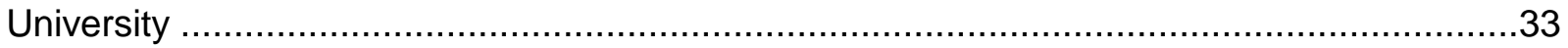

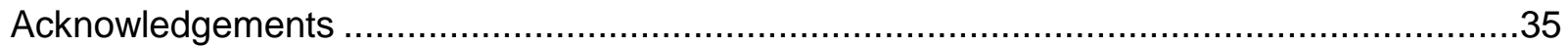

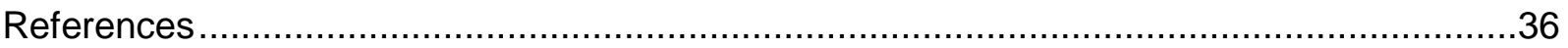

2. LABORATORY PERCENT RECOVERY STUDIES AND METHOD OPTIMIZATION FOR THE DETECTION OF BACTERIAL, VIRAL AND PROTOZOAN PATHOGENS IN

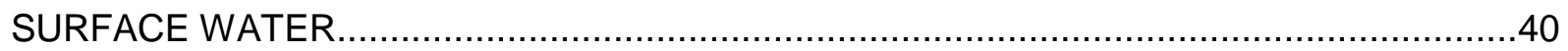

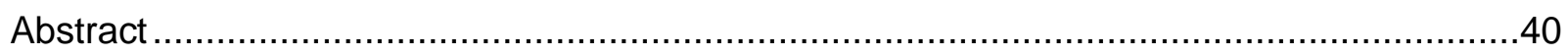

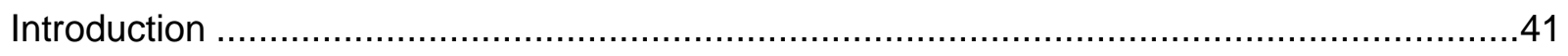

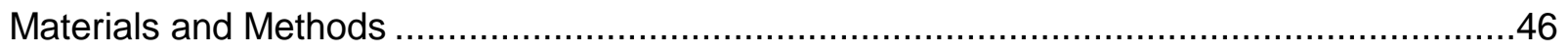

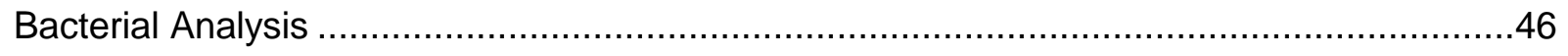

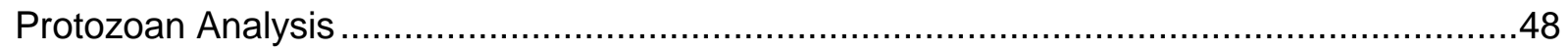

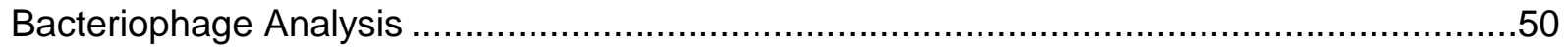

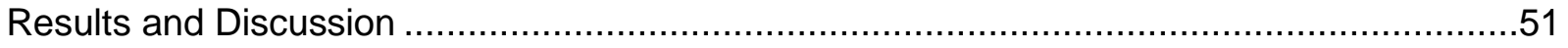




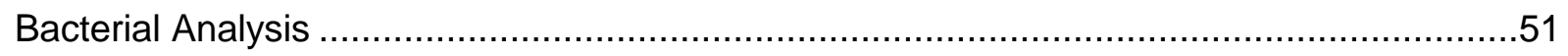

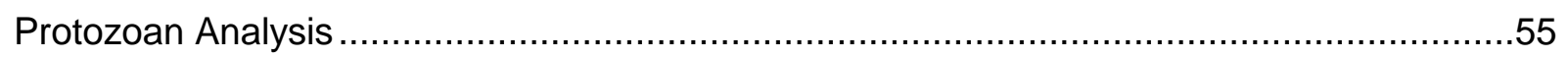

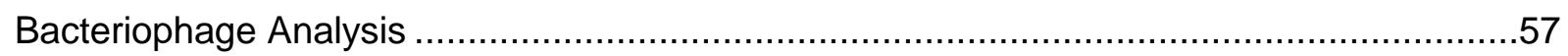

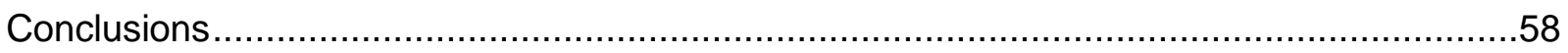

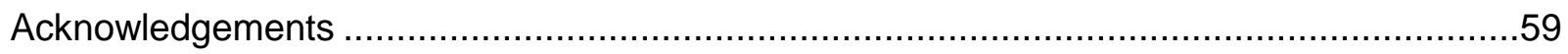

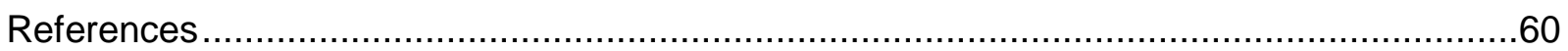

3. PHYSICAL, CHEMICAL, AND MICROBIAL WATER QUALITY TRENDS IN SINKING

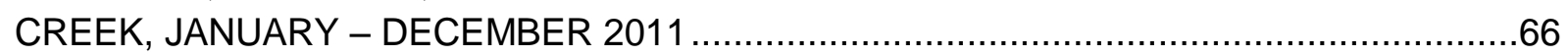

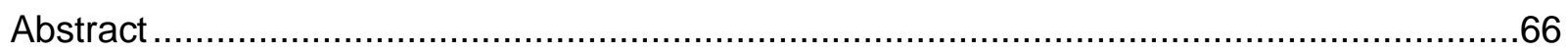

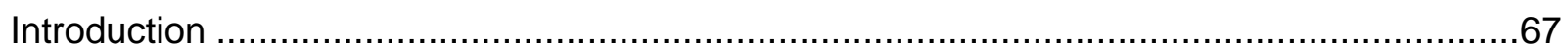

Sources, Fate, and Transport of Fecal Coliforms and Pathogens ....................................68

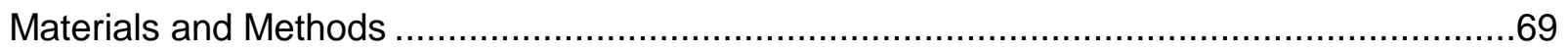

Sinking Creek Location and Water Quality Monitoring ……...........................................69

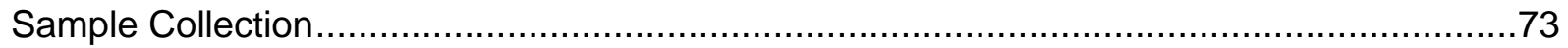

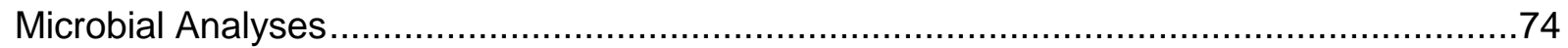

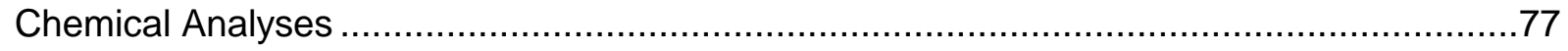

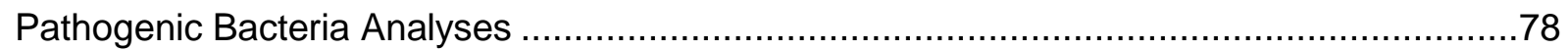

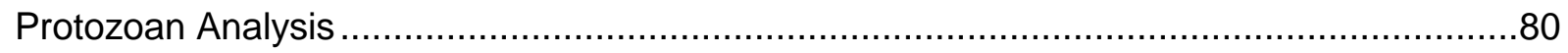

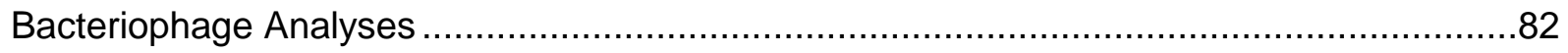

Data Analysis of Fecal Coliform Data and Pathogen Prevalence .......................................82

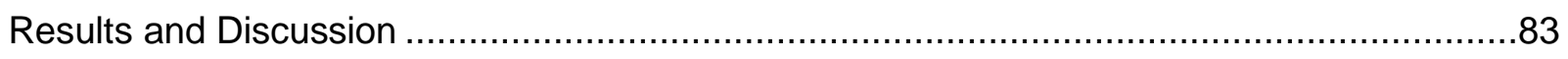

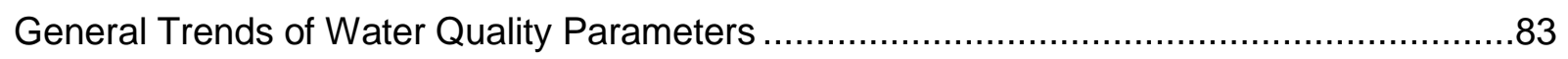

Comparison of Fecal Coliform Concentrations.............................................................101

Correlation Between Fecal Coliform Bacteria, E. coli, and Pathogens .............................106

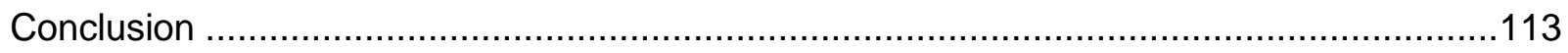

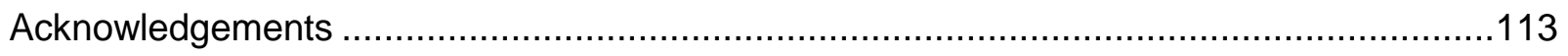

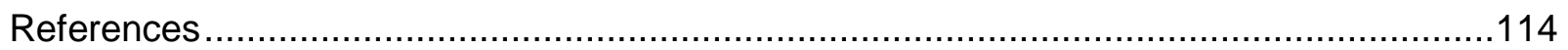


4. MULTIVARIATE STATISTICAL ANALYSES OF SINKING CREEK WATER QUALITY DATA TO IDENTIFY SOURCES OF FECAL POLLUTION IN RELATION TO LAND USE PATTERN...

Abstract 121

Introduction 121

Materials and Methods 129

Sinking Creek Location and Water Quality Monitoring .129

Sample Collection .133

Microbial Analyses .134

Chemical Analyses .137

Pathogenic Bacteria Analyses 138

Protozoan Analysis 140

Bacteriophage Analyses .142

Statistical Analysis 142

Results and Discussion .144

Canonical Correlation Analysis Interpretation .144

Canonical Correlation Analysis by Season .147

Canonical Correlation Analysis by Land Use .154

Canonical Discriminant Analysis .160

Conclusions .166

Acknowledgements .167

References. .168

5. CLASSIFICATION OF PHYICAL, CHEMICAL, AND MICROBIAL SOIL PROPERTIES AND THEIR INFLUENCE ON PATHOGEN FATE AND TRANSPORT

Abstract

Introduction

Methods .178

Sinking Creek Location and Water Quality Monitoring .178 


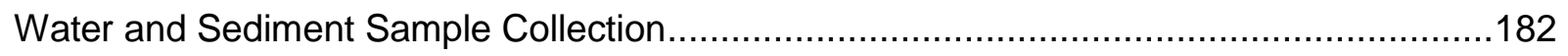

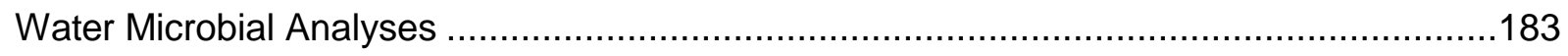

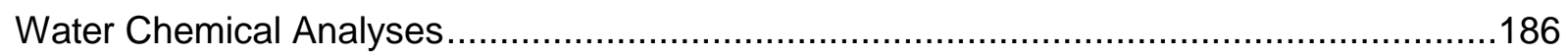

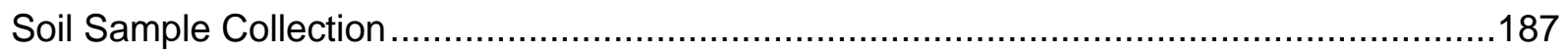

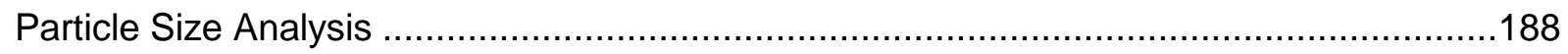

$\mathrm{pH}$

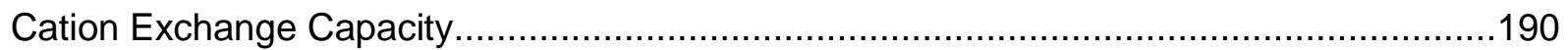

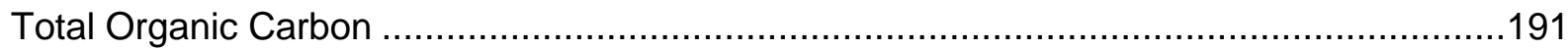

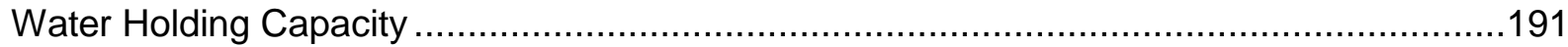

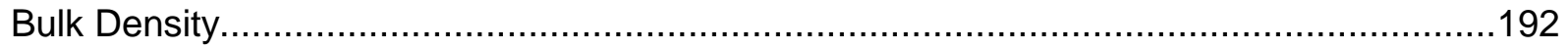

Data Analysis of Chemical and Physical Parameters..................................................193

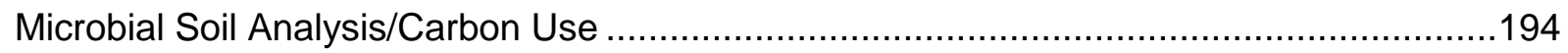

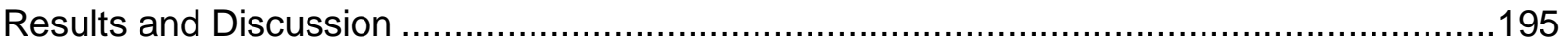

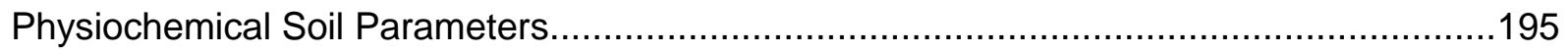

Influences of Physiochemical Soil Parameters on Water Quality .....................................207

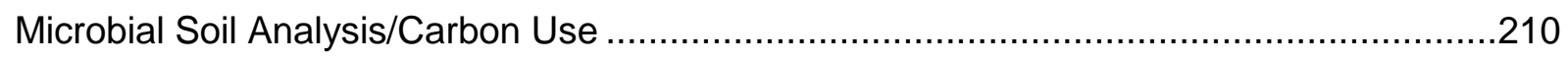

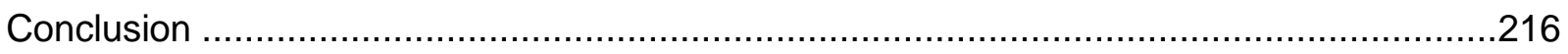

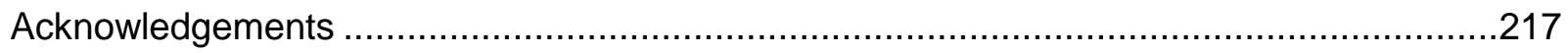

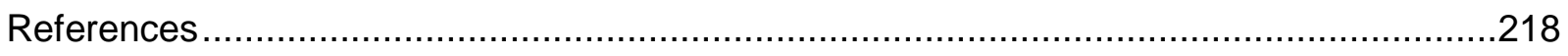

6. DEVELOPMENT OF MULTIPLE REGRESSION MODELS TO PREDICT SOURCES OF FECAL POLLUTION IN THE WATAUGA RIVER WATERSHED .....................................224

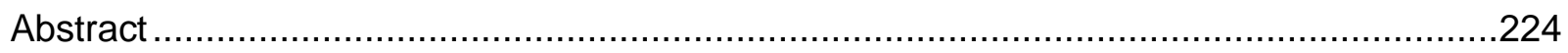

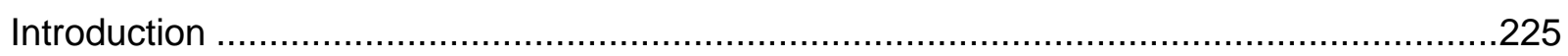

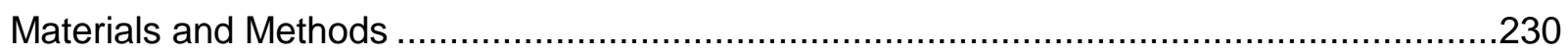

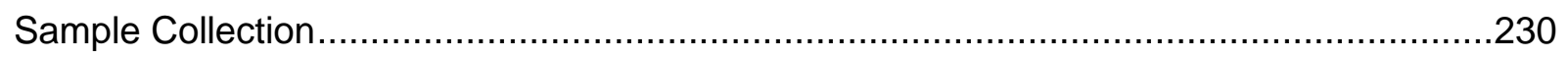

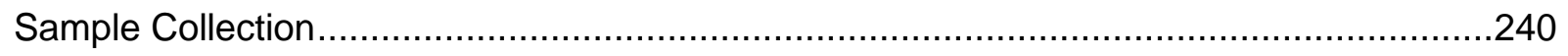

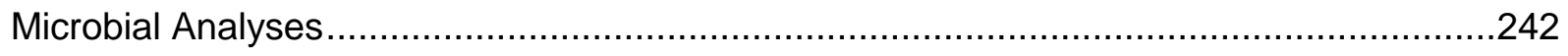




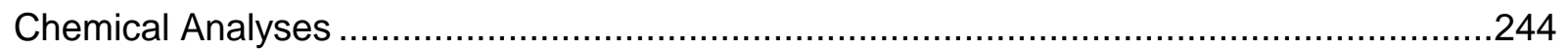

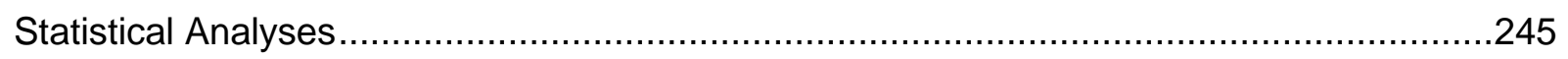

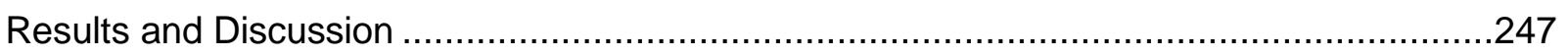

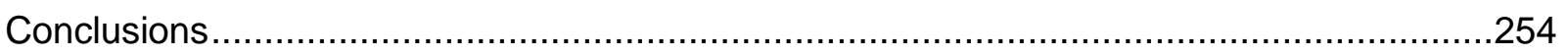

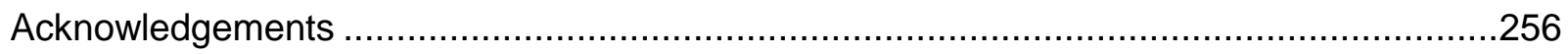

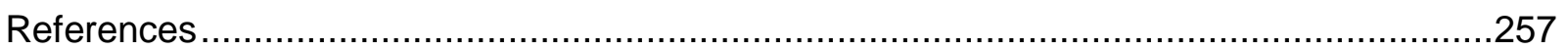

7. CONCLUSIONS AND RECOMMENDATIONS FOR FUTURE RESEARCH ....................259

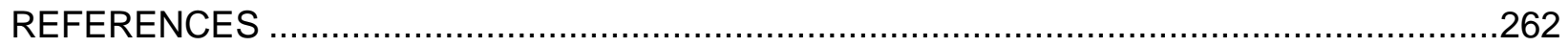

APPENDICES

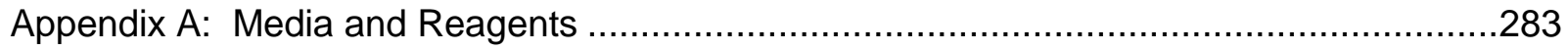

Appendix B: Water Quality Summary Statistics ………………………………….....28

Appendix C: Shigella spp. and E. coli 0157:H7 Gel Electrophoresis Pictures......................361

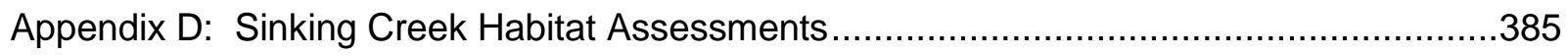

VITA 


\section{LIST OF TABLES}

Table

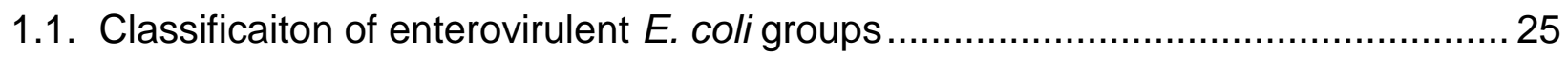

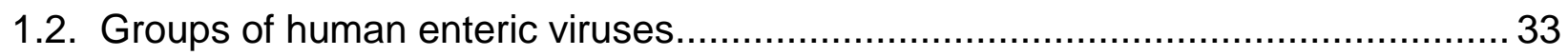

2.1. Published detection limits of Polymerase Chain Reaction (PCR) methods for the detection of E. coli O157:H7 and Shigella sp. ..................................................54

2.2. IPR results for filtered water sampled seeded Giardia lamblia cysts .....................55

2.3. IPR results for filtered water samples seeded latex beads as a surrogate

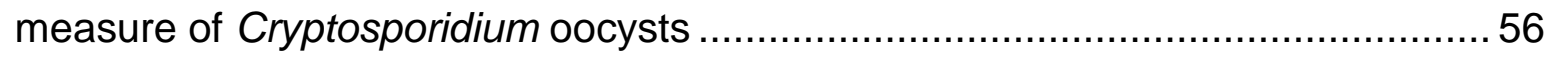

2.4. Published detection limits of USEPA method 1623 for the detection of Giardia and Cryptosporidium in water..................................................................... 57

2.5. IPR results for water samples seeded with a known concentration of

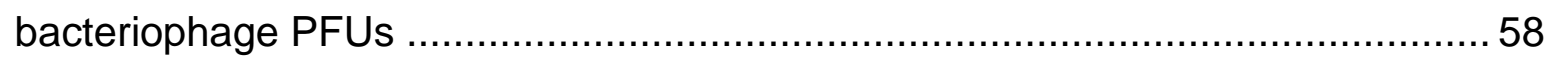

3.1. Sampling locations on Sinking Creek sampled during this study ........................ 71

3.2. Physical, chemical, and microbial water quality parameters measured................. 73

3.3. Regression statistics for pathogens vs. indicators ........................................ 107

4.1. Sampling locations on Sinking Creek sampled during this study ...................... 131

4.2. Physical, chemical, and microbial water quality parameters measured............... 133

4.3. Chemical and microbial variables included in canonical discriminant analysis

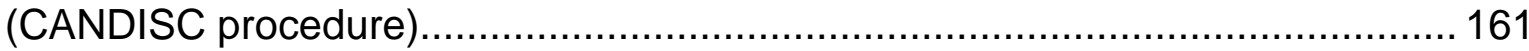

4.4. Description of canonical structure as determined using canonical discriminant analysis for Sinking Creek by season

4.5. Description of canonical structure as determined using canonical discriminant analysis for Sinking Creek by land use pattern .............................................. 165

5.1. Soil classification of monitored sites on Sinking Creek.................................... 174

5.2. Sampling locations on Sinking Creek sampled during this study for water quality

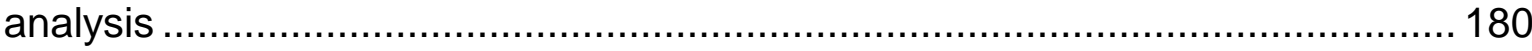

5.3. Physical, chemical, and microbial water quality parameters measured............... 183 
5.4. Analyzed soil parameters 188

5.5. Mean, standard deviation, and range of measured physical and chemical soil parameters 197

5.6. Description of canonical structure for physiochemical soil properties...... 206

5.7. Description of canonical structure for physiochemical soil properties and water quality variables 209

5.8. Carbon sources more commonly used at urban land use sites 213

5.9. Carbon sources more commonly used at agriculture and forest land use sites .. 215

6.1. Creeks monitored in this study within the Watauga River watershed. 231

6.2. Sampling locations on Boones Creek. 232

6.3. Sampling locations on Buffalo Creek 233

6.4. Sampling locations on Carroll Creek 234

6.5. Sampling locations on Cash Hollow Creek.................................................... 235

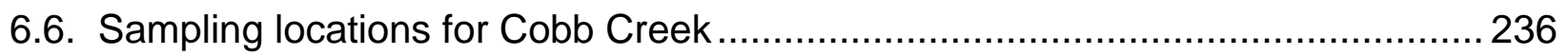

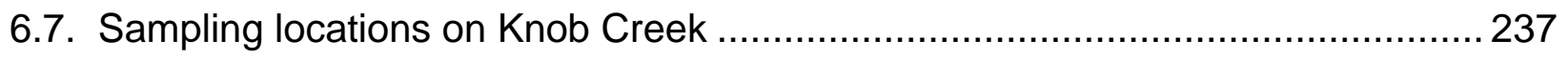

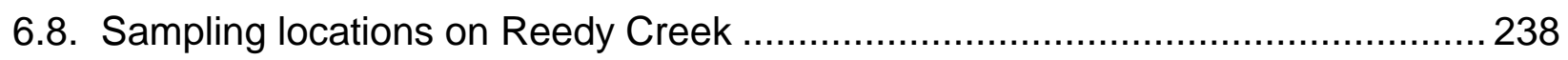

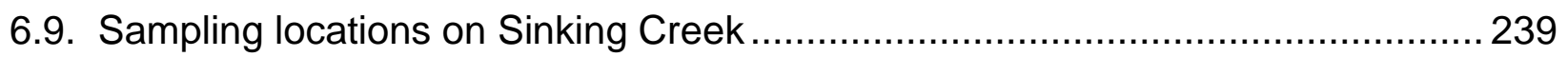

6.10. Physical, chemical, and microbial water quality parameters measured.............241

6.11. Chemical and microbial water quality parameters included in the full regression model

6.12. Significant chemical and microbial water quality parameters included in the stepwise regression model 2

6.13. Chemical and microbial water quality parameters identified by canonical discriminant analysis included in model 3 .....

6.14. Regression equations for the 3 developed models to predict land use in the Watauga River watershed.

6.15. Multiple regression statistics for the 3 multiple regression models applied to data from the Watauga River watershed. 
6.16. Regression statistics for the 3 developed models as applied to each creek to predict fecal pollution source..... 


\section{LIST OF FIGURES}

Figure

Page

1.1. Lifecycle of Giardia lamblia (image courtesy of CDC) …....................................28

1.2. Lifecycle of Cryptosporidium parvum (image courtesy of CDC) …....................... 30

2.1. Filtration apparatus used to sample Giardia and Cryptosporidium in laboratory seeded samples (USEPA, 2005)

2.2. Gel electrophoresis of $P C R$ products to determine the detection limit of E. coli O157:H7 using TSB and 1\% Tween as elution buffers

2.3. Gel electrophoresis of PCR products to determine the detection limit of Shigella flexneri using TSB and $1 \%$ Tween as elution buffers

3.1. Map of Sinking Creek sampling locations (sites sampled in this study are circled)

3.2. Filtration apparatus used to sample Giardia and Cryptosporidium in laboratory seeded samples (USEPA, 2005).

3.3. $\mathrm{pH}$ in the water of Sinking Creek by site and month .......................................... 84

3.4. Air temperature along Sinking Creek by site and month ................................... 84

3.5. Water temperature of Sinking Creek by site and month ..................................... 85

3.6. Dissolved oxygen of Sinking Creek by site and month ...................................... 85

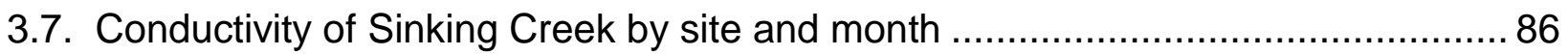

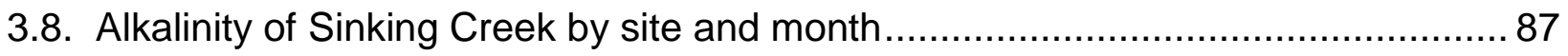

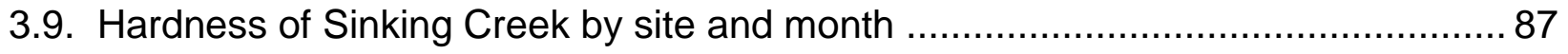

3.10. Discharge of Sinking Creek by site and month .............................................. 88

3.11. Geometric mean of total coliform concentrations in water in Sinking Creek by site and month

3.12. Geometric mean of fecal coliform concentrations in water in Sinking Creek by site and month

3.13. Geometric mean of total coliform concentrations in sediment in Sinking Creek by site and month. 
3.14. Geometric mean of fecal coliform concentrations in sediment in Sinking Creek by site and month. 90

3.15. E. coli concentrations in Sinking Creek by site and month . 91

3.16. Mean heterotrophic bacteria as determined by standard plate counts in Sinking Creek by site and month .

3.17. Mean acridine orange direct counts in Sinking Creek by site and month ............ 92

3.18. Mean acid phosphatase concentrations in Sinking Creek by site and month ...... 93

3.19. Mean alkaline phosphatase concentrations in Sinking Creek by site and month 93

3.20. Mean dehydrogenase concentrations in Sinking Creek by site and month .........94

3.21. Mean galactosidase concentrations in Sinking Creek by site and month .............94

3.22. Mean glucosidase concentrations in Sinking Creek by site and month ............... 95

3.23. Mean acid phosphatase (a), alkaline phosphatase (b), galactosidase (c), and glucosidase (d) concentrations in Sinking Creek by season (significant differences are indicated by different letters) ……........................................... 96

3.24. Giardia sp. concentrations in Sinking Creek by site and month ......................... 97

3.25. Cryptosporidium sp. concentrations in Sinking Creek by site and month ............ 97

3.26. Mean bacteriophage concentrations in Sinking Creek by site and month ............98

3.27. Mean nitrate concentrations in Sinking Creek by site and month ........................99

3.28. Mean phosphate concentrations in Sinking Creek by site and month ................. 99

3.29. Mean ammonia concentrations in Sinking Creek by site and month ................. 100

3.30. Mean biochemical oxygen demand in Sinking Creek by site and month ........... 100

3.31. Geometric mean of fecal coliform concentrations in Sinking Creek by season (significant differences are indicated by different letters) ................................ 101

3.32. Geometric mean of fecal coliform concentrations in Sinking Creek by land use (significant differences are indicated by different letters) ................................ 103

3.33. Geometric mean of fecal coliform concentrations in Sinking Creek by site (significant differences are indicated by different letters). 105 
3.34. Geometric mean of fecal coliform concentrations in Sinking Creek for winter (a), spring (b), summer (c), and fall (d) by site (significant differences are indicated by different letters) 106

3.35. Linear regression of Cryptosporidium sp. and E. coli (a) and fecal coliform bacteria (b)

3.36. Linear regression of Giardia sp. and E. coli (a) and fecal coliform bacteria (b) . 110

3.37. Linear regression male-specific bacteriophage with E. coli (a) and fecal coliform bacteria (b)

4.1. Map of Sinking Creek sampling locations (sites sampled in this study are circled).

4.2. Filtration apparatus used to sample Giardia and Cryptosporidium in laboratory seeded samples (USEPA, 2005)

4.3. Sinking Creek canonical loadings relating chemical water quality parameters to microbial water quality parameters to identify sources of fecal pollution

4.4. Sinking Creek canonical loadings observed during the winter months to relate chemical water quality parameters to microbial water quality parameters to identify sources of fecal pollution

4.5. Sinking Creek canonical loadings observed during the spring months to relate chemical water quality parameters to microbial water quality parameters to identify sources of fecal pollution

4.6. Sinking Creek canonical loadings observed during the summer months to relate chemical water quality parameters to microbial water quality parameters to identify sources of fecal pollution

4.7. Sinking Creek canonical loadings observed during the fall months to relate chemical water quality parameters to microbial water quality parameters to identify sources of fecal pollution

4.8. Sinking Creek canonical loadings observed at agricultural land use sites to relate chemical water quality parameters to microbial water quality parameters to identify sources of fecal pollution

4.9. Sinking Creek canonical loading observed at urban land use sites to relate chemical water quality parameters to microbial water quality parameters to identify sources of fecal pollution 
4.10. Sinking Creek canonical loadings observed at forest land use sites to relate chemical water quality parameters to microbial water quality parameters to identify sources of fecal pollution

4.11. Plot of canonical means determined using canonical discriminant analysis for Sinking Creek by season

4.12. Plot of canonical means determined using canonical discriminant analysis for Sinking Creek by land use pattern

5.1. Soil orders and the Watauga River watershed in Washington and Carter Counties, Tennessee (Reference for data used to generate figure, NRCS, 2010a-c)

5.2. Map of Sinking Creek sampling locations (sites sampled for water quality analysis in this study are circled).....

5.3. Mean texture composition values for silt (a), sand (b) and clay (c) (significant differences are indicated by different letters).

5.4. Mean total organic carbon values (significant differences are indicated by different letters)

5.5. Linear relationship between TOC and CEC …........................................... 200

5.6. Linear relationship between CEC and clay fraction .......................................... 201

5.7. Mean $\mathrm{pH}$ values by land use (significant differences are indicated by different letters) 201

5.8. Mean water holding capacity values (significant differences are indicated by different letters) 203

5.9. Linear relationship between WHC and CEC ................................................ 203

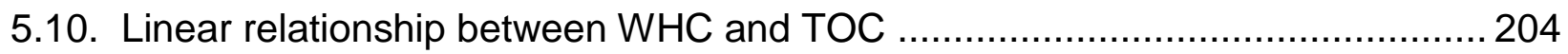

5.11. Mean bulk density values (significant differences are indicated by different letters) 205

5.12. Canonical means of physiochemical soil parameters by land use 206

5.13. Canonical means of physiochemical soil parameters and water quality parameters by land use 
5.14. Ordination produced from principal component analysis of soil samples by land use pattern

6.1. Framework for achieving the goals of the Clean Water Act (reproduced from USEPA 841-R-95-004, 1995) 


\section{LIST OF EQUATIONS}

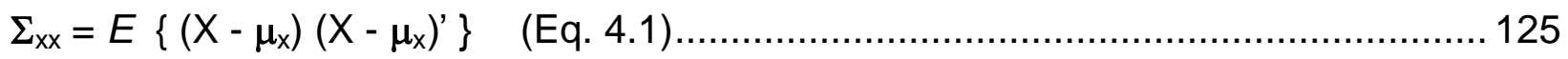

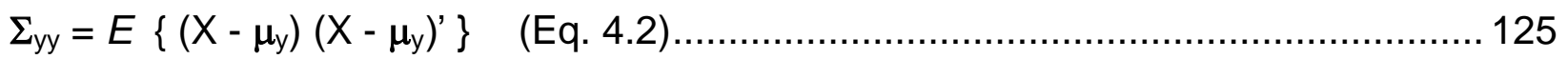

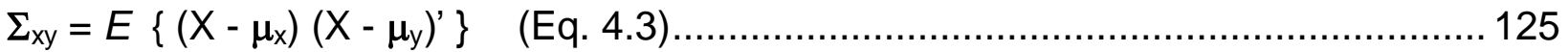

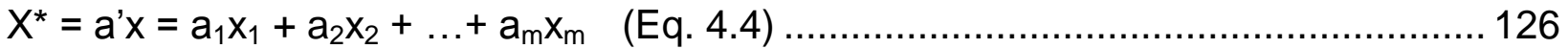

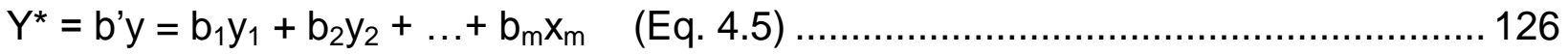

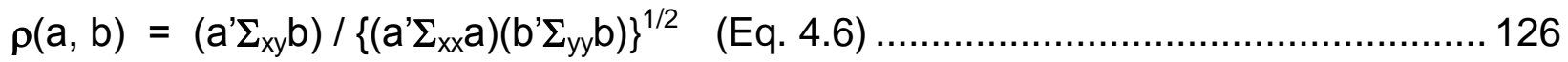

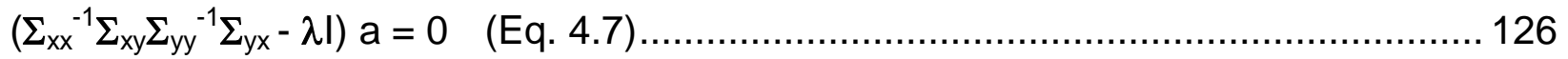

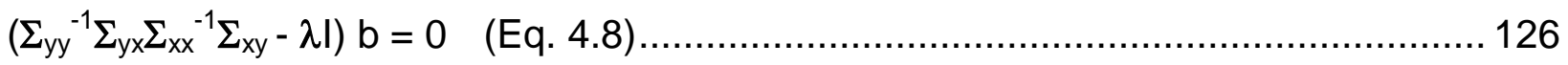

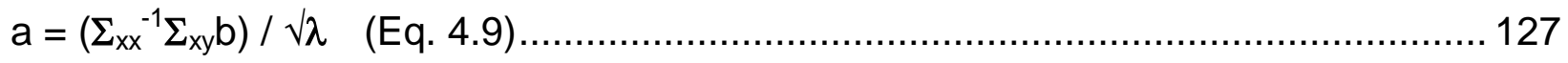

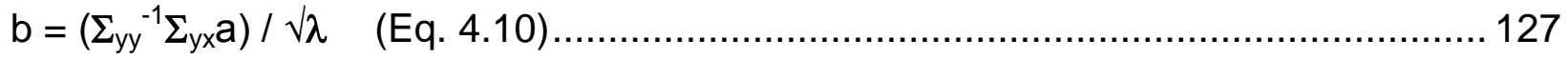

CEC $(\mathrm{meq} / 100 \mathrm{~g})=\mathrm{NH}_{4}{ }^{+}-\mathrm{N}^{+}(\mathrm{mg} / \mathrm{L}$ as $\mathrm{N}) / 14\left(\mathrm{NH}_{4}{ }^{+}-\mathrm{N}^{+}\right.$in extract $-\mathrm{NH}_{4}{ }^{+}-\mathrm{N}^{+}$in blank $)$

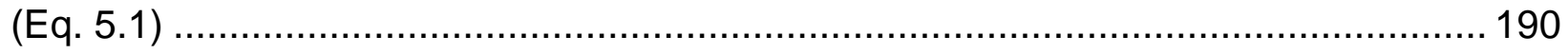

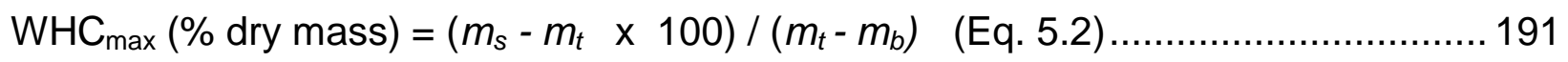

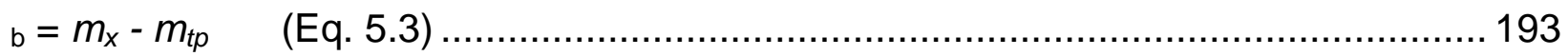

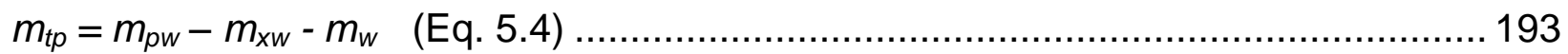

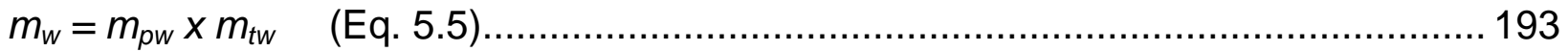

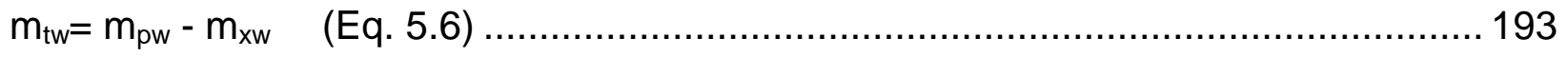

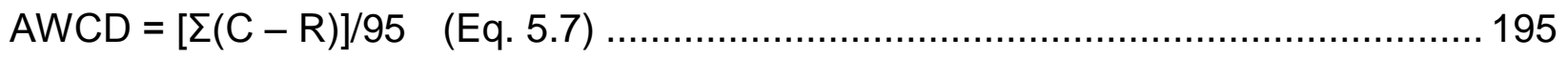

Transformed AWCD $=(\mathrm{C}-\mathrm{R}) /\{[\Sigma(\mathrm{C}-\mathrm{R})] / 95\} \quad$ (Eq. 5.8) …............................... 195

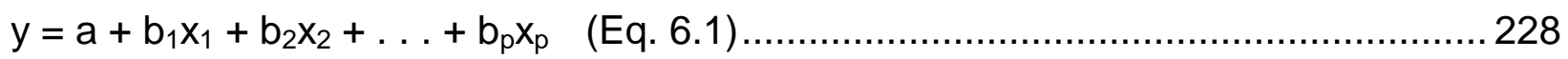




\section{CHAPTER 1}

\section{INTRODUCTION AND RESEARCH OBJECTIVES}

Waterborne disease through recreational contact remains an important public health threat. The Centers for Disease Control and Prevention (CDC) reported that there were 134 recreational water-associated outbreaks in 38 states and Puerto Rico in a recent report on outbreaks during 2007-2008 (Hlavsa et al. 2011). Acute gastrointestinal illness (AGI) accounted for $60.4 \%$ of the outbreaks and $89.3 \%(12,477)$ of the total cases. The remaining outbreaks were dermatologic (17.9\%) and acute respiratory illness (12.4\%). The etiology of the AGI cases reported were $74.1 \%$ Cryptosporidium sp., 6.2\% Norovirus, 4.9\% Shigella sp., 3.7\% E. coli O157:H7, and 3.7\% Giardia intestinalis.

In the United States, 41,288 impaired surface waters are listed on impaired waters (303d) lists. Of these impaired waters, 10,722 are impaired due to pathogen contamination and 236 pathogen-impaired waters are located in Tennessee (USEPA, 2010). The increased listings of surface waters on $303 d$ lists and subsequent development of Total Maximum Daily Loads (TMDL) have resulted in methods that effectively and universally identify sources of fecal pollution to avoid adverse human health outcomes associated with fecal contamination of surface waters such as the outbreak of Cryptosporidium in Milwaukee in 1993 (Mackenzie et al. 1993).

A fundamental requirement of methods that identify sources of fecal pollution to prevent waterborne disease outbreaks is understanding the processes that influence fate and transport of fecal indicators and pathogens from the various sources to the 
receiving waters. Variability in land use patterns, the types and nature of pollutants, climatic conditions, and watershed characteristics add to the difficulty of modeling fate and transport of fecal pollution. In addition, the interactions between chemical and microbial processes in the water add to the complexity of understanding pathogen loading and transport in the watershed. The need to address impaired waters through the TMDL process has led to an urgent need to develop methods that successfully identify the types and sources of fecal pollution. Pathogen TMDL development is currently based on a 30-day geometric mean that does not take into consideration seasonal effects, variability in land use patterns, or the influence of runoff events on water quality. Examining the influence of chemical, physical and microbial factors on the fate and transport of fecal pollution and pathogens can improve our understanding of these influences on water quality and help identify sources of fecal pollution to aid in effective TMDL development to protect surface water resources and human health.

The listing of pathogen-impaired waters on 303d lists is based on the use of indicator organisms as a surrogate measure of pathogen presence. Indicators of fecal pollution are frequently used to assess the extent of fecal pollution because it is not feasible to monitor surface waters for every pathogen. A successful fecal indicator should be associated with the source of the pathogen, be easily detectable, and respond to environmental conditions in a manner similar to that of the pathogen to help effectively protect human health. Total and fecal coliform bacteria, E. coli and Enterococci are commonly used indicators because of their association with fecal material and ease of monitoring. These indicators may be associated and correlated with fecal pollution (Schaffter and Parriaux, 2002; Gersberg et al. 2006), but they may 
also be contributed to surface waters by sources other than fecal material and may not respond to environmental conditions in the same manner as the pathogen. There is often a lack of correlation between fecal indicator bacteria and pathogen presence, that puts public health at risk (Harwood et al. 2005; Wu et al. 2011). The lack of correlation between fecal indicator bacteria and pathogens may be due to differences in excretion densities (Davenport et al. 1976) and regrowth and survival (Lemarchand et al. 2003) of fecal indicators in the environment. Bifidobacterium and Bacteriodes have been suggested as potential indicators of fecal pollution but do not survive as long as E. coli in the environment, thus indicating only recent fecal pollution events (Carillo et al. 1985; Kreader, 1998). Clostridium has also been proposed as a conservative estimator of protozoan contamination (Hörman et al. 2004), and f-RNA and somatic coliphages have been suggested as indicators of virus pollution (Sinton et al. 2002). Although these indicators have demonstrated some usefulness, no single indicator has been shown to effectively and universally identify the presence and source of fecal pollution.

Reliance on these indicators alone is not sufficient to protect surface water resources and human health and may hinder TMDL development and remediation efforts to remove impaired waters from $303 d$ lists. The shortcomings of conventional indicators and methods identifying sources of fecal pollution have spawned a need to identify and employ alternative methods of water quality monitoring program design, methods, and data analysis to better protect human health. Examining the relationships between indicator organisms and pathogen prevalence and the influences of chemical and microbial processes in surface water can improve our understanding of their influences on water quality. A better understanding of those factors that influence 
pathogen loading can help identify sources of fecal pollution to aid in effective TMDL development and the protection of human health.

A Total Maximum Daily Load (TMDL) for E. coli was approved by the U.S. Environmental Protection Agency (USEPA) for Sinking Creek in 1998, a tributary of the Watauga River in Northeast Tennessee which has remained on the 303d list for continued failure to meet surface water quality standards for pathogens, thus impairing recreational use (TDEC, 2010). While it is known that Sinking Creek is not meeting surface water quality standards based on the monitoring of fecal indicator bacteria, sources of contamination and the factors that may be influencing pathogen loading remain unknown. To accurately determine the risk presented by contact with contaminated surface waters such as Sinking Creek an understanding of the bacterial, protozoan, and viral pathogens present is necessary.

\section{Bacterial Pathogens Associated with Waterborne Outbreaks}

Escherichia coli is a gram-negative bacillus in the family Enterobacteriaceae and is a common inhabitant of the gastrointestinal tract of warm-blooded animals. While most strains of E. coli are not pathogenic, some strains, such as $0157: \mathrm{H} 7$, are opportunistic pathogens. Enterohemorrhagic strains such as $\mathrm{O} 157: \mathrm{H} 7$ are capable of causing hemorrhagic colitis and hemolytic uremic syndrome in humans. Originating from cattle hosts, E. coli O157:H7 was first recognized in 1982 as an emerging pathogen (Riley and Remis, 1982) and is transmitted through fecal-oral contact. In Tennessee in 2008, 54 cases of E. coli O157:H7 were reported as a result of waterborne or foodborne outbreaks (Cooper et al. 2008). The infectious dose of E. coli 
O157:H7 has been reported to be as low as $100 \mathrm{CFU}$ in both humans and cattle (Hancock et al. 1997). Sources of infection include ingestion of fecally contaminated foods and water, particularly meats and unpasteurized foods. Incubation following ingestion ranges from $10-72$ hours.

E. coli $\mathrm{O} 157: \mathrm{H} 7$ has created a niche in the mucoual layer of the human colon, where it adheres to the intestinal epitheilium using fimbriae. The bacteria are able to exploit the host's ability to use gluconate more efficiently than resident species of the intestinal tract, as they inhibit protein synthesis by the production of verotoxins stx 1 and stx2. These verotoxins interfere with cellular respiration repair mechanisms and result in red blood cell damage. These virulence factors are recognized by the host immune response following insertion of the verotoxins into the host cell using the type III secretion system. Once the toxin is internalized, it is carried to the endoplasmic reticulum of the cell via the Golgi apparatus, ultimately arriving in the cytoplasm.

Symptoms of infection include diarrhea, vomiting, and dehydration for $3-5$ days and may result in death for young, elderly, and immunocompromised populations. In vitro studies have demonstrated that antibiotics can induce transcription of stx2 genes (Kimmitt et al. 2000). As a result, antibiotic treatment is not recommended for E. coli O157:H7 infection because of its association with an increased risk of hemolytic uremic syndrome (Wong et al. 2000). Only supportive therapy is used to treat symptoms of infection. Post-infection irritable bowel syndrome has been associated with E. coli O157:H7 infection (Marshall, 2009). In addition to enterohemorhagic strains, other groups of enterovirulent E. coli including enterotoxogenic, enteropathogenic, and 
enteroinvasive groups are capable of causing symptoms similar to those of $E$. coli O157:H7 through different modes of infection (Table 1.1).

Table 1.1. Classificaiton of enterovirulent E. coli groups

E. coli Group

Mode of Infection

Examples

\begin{tabular}{|c|c|c|}
\hline Enterotoxigenic & $\begin{array}{l}\text { Adherence to the intestinal epithelium and } \\
\text { secretion of either heat-stable and/or heat- } \\
\text { labile toxins }\end{array}$ & $\begin{array}{l}\text { E. coli } \mathrm{O} 6: \mathrm{H} 16 \\
\text { E. coli } \mathrm{O} 15: \mathrm{H} 11\end{array}$ \\
\hline Enteropathogenic & $\begin{array}{l}\text { Formation of lesions following adherence } \\
\text { to the intestinal cell wall resulting in } \\
\text { localized destruction and physical } \\
\text { alteration of the intestinal epithelium }\end{array}$ & $\begin{array}{l}\text { E. coli } \mathrm{O} 44 \\
\text { E. coli } \mathrm{O} 55\end{array}$ \\
\hline Enteroinvasive & $\begin{array}{c}\text { Invasion and destruction of intestinal } \\
\text { epithelium cells }\end{array}$ & $\begin{array}{l}\text { E. coli } \mathrm{O} 28 \\
\text { E. coliO112 }\end{array}$ \\
\hline
\end{tabular}

Outside of its preferred niche, E. coli $\mathrm{O} 157: \mathrm{H} 7$ is able to tolerate extreme environmental conditions, including acidic and dry conditions (Glass et al. 1992; Arnold and Kasper, 1995) and temperature fluctuations (Wang and Doyle, 1998). It has been reported to survive for 109 days in surface water and 97 days in cattle feces (Scott et al. 2006). Survival of $\mathrm{O} 157: \mathrm{H} 7$ is also affected by soil moisture, the presence of other microbes (Jiang et al. 2002), nutrient and mineral concentrations (Artz and Killham, 2002; Ravva and Korn, 2007), and UV light exposure (Sommer et al. 2000). Detection 
of the bacteria can be accomplished using several methodologies, including DNA, immunoassay and biochemical techniques.

Shigella sp. is a gram-negative bacillus in the family Enterobacteriaceae and is a facultative anaerobic bacterium. Shigella is a pathogenic organism primarily found in the mucosal layer of the human colon, as it is capable of surviving exposure to proteases and acids in the digestive tract. The ability of the bacterium to invade non-phagocytic cells using a type III secretion system allows the bacterium to inject toxins directly into the host cell (Yee et al. 1957). Following ingestion, the bacterium transverses the intestinal epithelial barrier through M-cells and gain access to lymphoid follicles containing tissue macrophages. After phagocytosis, the bacteria destroy the phagosome membrane and are free within the host cytoplasm. Within the cytoplasm, the bacterium secretes IpaB that binds to capase- 1 and induces macrophage apoptosis and the release of IL- 8 and IL-18. The release of IL- 8 and IL-18 results in acute colonic inflammation and tissue destruction. As with E. coli O157:H7, Shigella inhibits protein synthesis through the production of Shiga toxins and damages red blood cells.

Shigella is rarely found in animals other than man and the infectious dose ranges from $10^{1}-10^{4}$ organisms (Rowe and Gross, 1984). Infection occurs via the fecal-oral route and sources of infection include fecally contaminated foods and water. Incubation following ingestion ranges from $16-72$ hours. Symptoms of infection include abdominal cramps, diarrhea, and fever and can last from $2-7$ days. Antibiotic treatment is available for infection but is often not necessary as the disease is selflimiting. It has been reported that post-infection irritable bowel syndrome is associated with Shigella infection (Thabane et al. 2007). 
Outside of its niche, Shigella can survive in groundwater for up to 24 days (Goldshmid, 1972) and the half-life in fresh water ranges from $22.4-26.8$ hours at temperatures of $9.5-12.5^{\circ} \mathrm{C}$ (McFeters et al. 1974). Within the environment, nutrient availability is a stronger limiting factor for virulence compared to temperature (Durand and Björk, 2009) and maximum invasion is achieved under anaerobic conditions (Mareyn et al. 2005). Shigella spp. are the second most common etiological agent associated with waterborne outbreaks of infectious disease and have been associated with both drinking water and recreational swimming (Hlavsa et al. 2011). During 2008, E. coli $\mathrm{O} 157: \mathrm{H} 7$ and Shigella infections were responsible for $3.7 \%$ and $4.9 \%$ of $\mathrm{AGI}$ illnesses in the United States, respectively (Hlavsa et al. 2011). In Tennessee in 2008, 968 cases of Shigella sp. and zero cases of E. coli O157:H7 infections were reported as a result of waterborne or foodborne outbreaks in Tennessee (Cooper et al. 2008).

\section{Protozoan Pathogens Associated with Waterborne Outbreaks}

Giardia sp. is a parasitic facultative anaerobic protozoan within the phylum Sarcomastigophora that infects the gastrointestinal tract of humans and other warmblooded animals through fecal-oral contact. The organism forms oval shaped cysts approximately 8-12 $\mu \mathrm{m}$ in length and are transmitted via the fecal-oral route. Ingested cysts excyst in the intestinal tract and release 2 trophozoites that divide by binary fission. The organism attaches to the intestinal epithelium, where it interferes with the adsorption of fat-soluble vitamins within the gastrointestinal tract of the host organism

due to the inability of Giardia trophozoites to synthesize their own lipids. Glucose is the only carbohydrate metabolized by the organism via the glycolytic pathway, resulting in 
the production of ethanol, acetate and $\mathrm{CO}_{2}$. Energy is produced using substrate level phosphorylation, due to the lack of cytochrome-mediated oxidative phosphorylation and a functional TCA cycle (Lindmark, 1980). In the presence of oxygen, Giardia respires using a flavin, iron-sulfur protein-mediated electron transport system (Jarroll et al. 1989). Within the colon, the trophozoites begin to encyst and are passed into the environment (Figure 1.1).

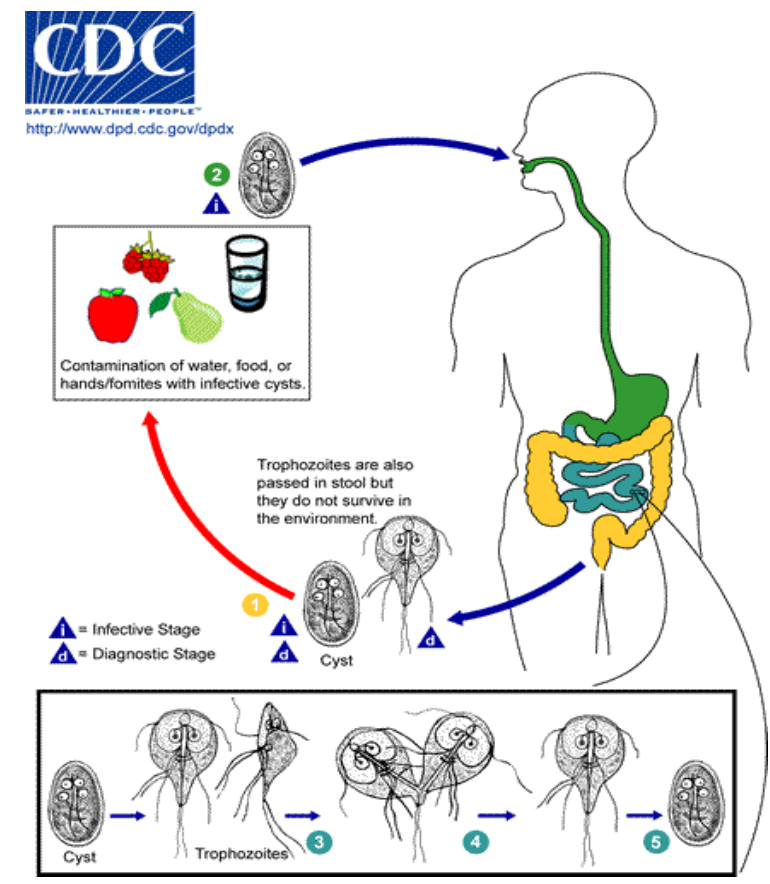

Figure 1.1. Lifecycle of Giardia lamblia (image courtesy of CDC)

Cysts are environmentally stable and able to withstand a variety of environmental conditions. Cysts have been reported to survive in surface waters for 28 days during warmer months and up to 56 days during winter months (deRegnier et al. 1989). Infection by Giardia occurs through fecal-oral contamination and can result in a disease state known as giardiasis or "backpackers disease" that is characterized by chronic diarrhea, fatigue, and weight loss. There is no treatment for infection, but supportive 
therapy is commonly used to prevent dehydration. Giardia was responsible for $3.7 \%$ of AGI cases in the United States during 2008 (Hlavsa et al. 2011). Two hundred fourteen cases of waterborne Giardia were reported in Tennessee in 2008 (Cooper et al. 2008).

Cryptosporidium parvum is a parasitic facultative anaerobic protozoan that infects the gastrointestinal tract of humans and other warm-blooded animals through fecal-oral contact. Cryptosporidium is classified in the phylum Apicomplexa. Oocysts measure 2-6 $\mu \mathrm{m}$ in diameter and infection also occurs via the fecal-oral route. Once oocysts are ingested, they release sporozoites into epithelial cells of the intestinal tract. The sporozoites then undergo asexual reproduction to form merozoites, which then form micro and macrogametocytes. The micro and macrogametocytes then form a zygote, which becomes a new oocyst and is passed in the feces (Figure 1.2). 


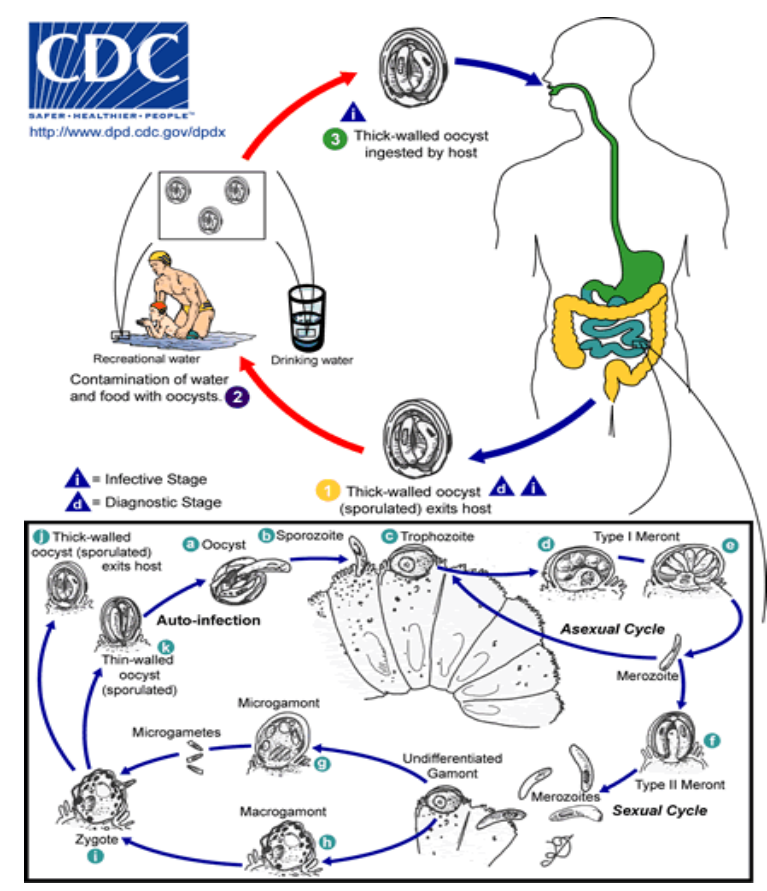

Figure 1.2. Lifecycle of Cryptosporidium parvum (image courtesy of CDC)

As with Giardia, Cryptosporidium interferes with the adsorption of fat-soluble vitamins within the gastrointestinal tract of the host organism, as it is unable to synthesize its own lipids and relies on a series of fatty acid metabolic enzymes to obtain the lipids necessary for biosynthesis (Xi et al. 2004). The organism also relies on amino acid uptake from its host using a series of amino acid transporters (Zhu, 2004). Its niche is within the intestinal epithelium, where it is contained within a host membranederived parasitophorous vacuole. Rather than become internalized within the host cell cytoplasm, the parasitophorous vacuole resides on the surface of the intestinal epithelial cell. This niche may provide some protection from the host's immune system but still take advantage of solute transport systems. Cryptosporidium relies on glycolysis for energy production, resulting in the production of lactate, acetate, and ethanol. Instead 
of employing the TCA cycle and oxidative phosphorylation, pyruvate:NADP ${ }^{+}$ oxidoreductase is used under anaerobic conditions, and an alternative oxidase system is used under aerobic conditions to economize ATP (Abrahamsen et al. 2004).

Although the organism's preferred niche is within the host intestinal epithelium, oocysts are environmentally stable and able to tolerate a range of environmental conditions similar to those of Giardia. Cryptosporidium is a common etiological agent associated with waterborne outbreaks and accounted for $74.1 \%$ of AGI cases in the United States in 2008 (Hlavsa et al. 2011), while 43 cases of waterborne Cryptosporidium were reported in Tennessee in 2008 (Cooper et al. 2008). Infection results in a disease state known as cryptosporidosis with symptoms similar to those of Giardia. Several treatments are available for infection with Giardia and Cryptosporidium including metronidazole, tinidazole, and nitazoxanide that may be used in nonimmunosuppressed patients to prevent complications of infection (Gardner and Hill, 2001; Baily and Erramouspe, 2004).

\section{Enteric Viruses Associated with Waterborne Outbreaks}

Over 100 human enteric viruses can exist in surface waters as a result of fecal contamination. The major groups of enteric viruses that are associated with fecal pollution are shown in Table 2. Ranging in size from $20-70 \mathrm{~nm}$, enteric viruses have icosahedral nucleocapsids and, depending on the group, can contain single or double stranded DNA, or single stranded RNA. Infection occurs through fecal oral contact and the viruses attack cells within the gastrointestinal tract resulting primarily in symptoms of gastroenteritis. As a result of infection within the gastrointestinal tract, virus particles 
are shed in large numbers. For instance, Rotavirus is excreted in numbers ranging from $10^{10}-10^{11}$ particles/g of stool (Shaw et al. 1995) and poliovirus is excreted in quantities of approximately $10^{10}$ particles/g of stool (Poyry et al. 1988). Vaccines have been developed for some enteric viruses to reduce the risk of disease outbreak. Vaccines including RotaTeq ${ }^{\circledR}$ and RotaRix ${ }^{\circledR}$ for rotavirus infection and inactivated polio vaccine are available and have been successful at reducing disease occurrence, but once infected, only supportive therapy is used to treat symptoms, as the disease is typically self limiting. 
Table 1.2. Groups of human enteric viruses

Virus Group

Enteroviruses

Poliovirus

Coxsackievirus

Echovirus

Enterovirus

Hepatitis A

Reovirus

Rotavirus

Adenovirus

Astrovirus

Torovirus

Caliciviruses

Hepatitis $E$

Norwalk virus

\section{Symptoms of Infection}

Meningitis, poliomyelitis

Malaise, rash, meningitis, encephalitis Meningitis, diarrhea, fever Meningitis, encephalitis, respiratory disease, fever Gastroenteritis, fever, malaise Gastroenteritis Gastroenteritis, respiratory disease, conjunctivitis Gastroenteritis Gastroenteritis Gastroenteritis Gastroenteritis Gastroenteritis

Environmental Health Sciences Laboratory Water Quality Monitoring at East Tennessee State University

This work is part of a larger project involving the routine monitoring of 9 creeks within the Watauga River watershed to identify impaired surface waters. The project described in this dissertation focused on Sinking Creek because of its inclusion on the 
State of Tennessee's 303d list and its land use characteristics that make it an excellent study site to better understand the relationship between fecal indictor bacteria and pathogen presence and the influence of physical, chemical, and microbial processes on pathogen fate and transport. The objectives of this research were to

1. Determine the ability of non-standardized methods to detect E. coli $\mathrm{O} 157: \mathrm{H} 7$, Shigella sp., Giardia sp., Cryptosporidium sp., and bacteriophages in seeded samples.

2. Assess the physical, chemical, and microbial water quality of Sinking Creek.

3. Survey the level of E. coli O157:H7, Shigella sp., Giardia sp., Cryptosporidium sp., and bacteriphages at 6 selected sites in Sinking Creek to assess the usefulness of fecal indicator bacteria as predictors of pathogen presence.

4. Characterize the physical, chemical, and microbial properties of soil along Sinking Creek to understand its role in physical, chemical, and microbial water quality in Sinking Creek.

5. Evaluate the use of multivariate statistical methodology to

a. understand the water and soil characteristics influencing the fate and transport of fecal pollution, and

b. identify nonpoint sources of fecal pollution as they relate to land use patterns in Sinking Creek. 


\section{$\underline{\text { Acknowledgements }}$}

This work was funded in part by a grant from the ETSU School of Graduate Studies and Graduate Council, and by a contract with the Tennessee Valley Authority (Award \#00025252). 


\section{$\underline{\text { References }}$}

Abrahamsen MS, Templeton TJ, Enomoto S, Abrahante JE, Zhu G, Lancto CA, Deng M, Liu C, Widmer G, Tzipori S, Buck GA, et al. 2004. Complete genome sequence of the apicomplexan, Cryptosporidium parvum. Science. 1126:1-10

Arnold KW, Kaspar CW. 1995. Starvation- and stationary-phase-induced acid tolerance in Escherichia coli O157:H7. Appl. Environ. Microbiol. 61:2037-2039

Artz RRE, Killham K. 2002. Survival of Escherichia coli O157:H7 in private drinking water wells: influences of protozoan grazing and elevated copper concentrations. FEMS Microbiol. Lett. 216:117-112

Bailey JM, Erramouspe J. 2004. Nitazoxanide treatment for giardiasis and cryptosporidiosis in children. Ann. Pharmacother. 38:634-640

Carrillo M, Estrada E, Hazen TC. 1985. Survival and enumeration of the fecal indicators Bifidobacterium adolescentis and Escherichia coli in a tropical rain forest watershed. Appl. Environ. Microbiol. 50:468-476

Cooper SR, Taylor CR, Jones TF. 2008. Communicable and Environmental Disease Services Annual Report, 2008. Tennessee Department of Health Communicable and Environmental Disease Services. Nashville TN USA

Davenport CV, Sparrow EB. Gordon, R.C. 1976. Fecal indicator bacteria persistence under natural conditions in an ice-covered river. Appl. Environ. Microbiol. 32:527-536

deRegnier DP, Cole L, Schupp DG, Erlandsen SL. 1989. Viability of Giardia cysts suspended in lake, river and tap water. Appl. Environ. Microbiol. 55:1223-1229.

Durand JMB, Björk GR. 2009. Metabolic control through ornithine and uracil of epithelial cell invasion by Shigella flexneri. Microbiology. 155:2498-2508

Gardner TB, Hill DR. 2001. Treatment of Giardiasis. Clin. Microbiol. Rev. 14:114-128

Gersberg RM, Rose MA, Robles-Sikisaka R, Dhar AK. 2006. Quantitative detection of Hepatitis A virus and enteroviruses near the United States-Mexico border and correlation with levels of fecal indicator bacteria. Appl. Environ. Microbiol. 72:74387444

Glass KA, Loeffelholz JM, Ford JP, Doyle MP. 1992. Fate of Escherichia coli O157:H7 as affected by $\mathrm{pH}$ or sodium chloride and in fermented, dry sausage. Appl. Environ. Microbiol. 58:2513-2516 
Goldshmid J. 1972. Effect of dissolved salts on the filtration of coliform bacteria in sand dunes. $6^{\text {th }}$ International Water Pollution Research Conference, Jerusalem, Israel

Hancock DD, Besser TE, Rice DH. 1997. The ecology of Escherichia coli O157:H7 in cattle and the impact of management practices. In VTEC '97. Conference proceedings of the $3^{\text {rd }}$ International Symposium and Workshop on Shiga Toxin (Verocytotoxin) - Producing Escherichia coli infections, $22^{\text {nd }}-26^{\text {th }}$ June, 1997, Baltimore, Maryland.

Harwood VJ, Levine AD, Scott TM, Chivukula V, Lukasik J, Farrah SR, Rose JB. 2005. Validity of the indicator organism paradigm for pathogen reduction in reclaimed water and public health protection. Appl. Environ. Microbiol. 71:3163-3170

Hlavsa MC, Roberts VA, Anderson AR, Hill VR, Kahler AM, Orr M, Garrison LE. 2011. Surveillance for waterborne disease outbreaks and other health events associated with recreational water --- United States, 2007--2008. MMWR. Surveillance summaries: Morbidity and mortality weekly report. Surveillance summaries / CDC 60 (12) (September 23): 1-32

Hörman, A, Rimhanen-Finne R, Maunula L, von Bonsdorff CH, Torvela N, Heikinheimo A, Hänninen ML. 2004. Campylobacter spp., Giardia spp., Cryptosporidium spp., Noroviruses, and Indicator Organisms in Surface Water in Southwestern Finland, 2000-2001. Appl. Environ. Microbiol. 70:87-95

Jarroll EL, Manning P, Berranda A, Hare D, Lindmark DG. 1989. Biochemistry and metabolism of Giardia. J. Protozool. 36:190-197

Jiang X, Morgan J, Doyle MP. 2002. Fate of Escherichia coli O157:H7 in manureamended soil. Appl. Environ. Microbiol. 68:2605-2609

Kimmitt PT, Harwood CR, Barer MR. 2000. Toxin gene expression by shiga toxinproducing Escherichia coli: the role of antibiotics and the bacterial SOS response. Imerg. Infect. Dis. 6:458-465

Kreader CA. 1998. Persistence of PCR-detectable Bacteroides distasonis from human feces in river water. Appl. Environ. Microbiol. 64:4103-4105

Lemarchand K, Lebaron P. 2003. Occurrence of Salmonella spp. and Cryptosporidium spp. in a French coastal watershed: relationship with fecal indicators. FEMS Microbiol. Lett. 218:203-209

Lindmark DG. 1980. Energy metabolism of the anaerobic protozoon Giardia lamblia. Mol. Biochem. Parasitol. 1:1-12

Mareyn B, Sansonetti P, Tang C. 2005. The host environment primes Shigella for invasion. Nature. 440:428 
McFeters GA, Bissonette GK, Jezeski JJ. 1974. Comparative survival of indicator bacteria and enteric pathogens in well water. Appl. Microbiol. 27:823

Poyry T, Tenvik M, Hovi T. 1988. Viruses in sewage waters during and after a poliomyelitis outbreak and subsequent nationwide oral poliovirus vaccination campaign in Finland. Appl. Envion. Microbial. 54:371-374

Ravva SV, Korn A. 2007. Extractable organic components and nutrients in wastewater from dairy lagoons influence the growth and survival of Escherichia coli O157:H7. Appl. Environ. Microbiol. 73:2191-2198

Riley LW, Remis RS. 1983. Hemorrhagic colitis associated with a rare Escherichia coli serotype. N. Engl. L. Med. 308:681-685

Rowe B, Gross RJ. 1984. Facultatively anaerobic gram negative rods. Genus II. Shigella. In Bergey's Manual of Systematic Bacteriology, N.R. Krieg and J.G. Holt, eds (423-327). Williams and Wilkins, Baltimore, MD

Schaffter N, Parriaux A. 2002. Pathogenic-bacterial water contamination in mountainous catchments. Wat. Res. 36:131-139

Scott L, McGee P, Sheridan JJ, Earley B, Leonard N. 2006. A comparison of the survival in feces and water of Escherichia coli $0157: \mathrm{H} 7$ grown under laboratory conditions obtained from cattle feces. J. Food Protect. 69:6-11

Shaw RD, Hempson SJ, Mackow ER. 1995. Rotavirus diarrhea is caused by nonreplicating viral particles. J. Virol. 69:5946-5950

Sinton LW, Hall CH, Lynch PA, Davies-Colley RJ. 2002. Sunlight inactivation of fecal indicator bacteria and bacteriophages from waste stabilization pond effluent in fresh and saline waters. Appl. Environ. Microbiol. 68:1122-1131

Sommer R, Lhotsky M, Haider T, Cabaj A. 2000. UV inactivation, liquid holding recovery and photoreactivation of Escherichia coli $\mathrm{O} 157: \mathrm{H} 7$ and other pathogenic Escherichia coli strains in water. J. Food Protect. 63:1015-1020

TDEC. 2010. 2010 303(d) Report, The Status of Water Quality in Tennessee, August 2010. State of Tennessee, Department of Environment and Conservation, Division of Water Pollution Control, Nashville TN USA

Thabane M, Kottachchi DT, Marshall JK. 2007. Systematic review and meta-analysis: the incidence and prognosis of post-infectious irritable bowel syndrome. Aliment. Pharmacol. Ther. 15:535-544 
United States Environmental Protection Agency. 2010. National summary of impaired waters and TMDL information. United States Environmental Protection Agency, Washington DC USA

Wang G, Doyle MP. 1998. Survival of enterohemorrhagic Escherichia coli O157:H7 in water. J. Food Protect. 61:662-667

Wong CS, Jelacic S, Habeeb RL, Watkins SL, Tarr PI. 2000. The risk of the hemolytic-uremic syndrome after antibiotic treatment of Escherichia coli O157:H7 infections. N. Eng. J. Med. 342:1930-1936

Wu J, Long SC, Das D, Dorner MS. 2011. Are microbial indicators and pathogens related? A statistical analysis of 40 years of research. J. Water Health. 9:265-278

Xi P, Widmer G, Wang Y, Ozaki LS, Alves JM, Serrano MG, Pulu D, Manque P, Akiyoshi D, Mackey AJ, Pearson WR, et al. 2004. The genome of Cryptosporidium hominis. Nature. 431:1107-1112

Yee RB, Pan SF, Gezon HM. 1957. Studies on the metabolism of Shigella. J. Bacteriol. 75:51-55

Zhu F, Rogeli S, Kieft TL. 2005. Rapid detection of Escherichia coli O157:H7 by immunomagnetic separation and real-time PCR. Int. J. Food Protect. 99:47-57 
CHAPTER 2

\title{
LABORATORY PERCENT RECOVERY STUDIES AND METHOD OPTIMIZATION FOR THE DETECTION OF BACTERIAL, VIRAL AND PROTOZOAN PATHOGENS IN SURFACE WATER
}

K.K. Hall and P.R. Scheuerman

\begin{abstract}
$\underline{\text { Abstract }}$
Indicators of fecal pollution are frequently used to assess the extent of fecal pollution because it is not feasible to monitor surface waters for every pathogen. A successful fecal indicator should be associated with the source of the pathogen, be easily detectable, and respond to environmental conditions in a manner similar to that of the pathogen to help effectively protect human health. The inclusion of Sinking Creek on the State of Tennessee's 303d list due to pathogen contamination is based on the monitoring of fecal coliform bacteria, but it is not known what specific pathogens may be present and there has been no direct monitoring of specific pathogens to assess the ability of fecal indicator bacteria to predict the presence of pathogens. It may be necessary to monitor directly for pathogens, but it is difficult to accurately determine pathogen concentrations in surface waters due to a lack of standard methods and variability in pathogen recovery of published methods. In order to determine the ability of the pathogen detection methods, percent recovery $(\mathrm{PR})$ analyses were performed using published methods for the detection of E. coli O157:H7, Shigella sp., Giardia sp., Cryptosporidium sp., and MS2 bacteriophage. Observed detection limits for the E. coli O157:H7 and Shigella sp. differed from published detection limits, while detection limits
\end{abstract}


for Giardia sp., Cryptosporidium sp., and MS2 bacteriophage were within reported ranges.

\section{$\underline{\text { Introduction }}$}

Fecal coliform bacteria and E. coli are commonly used as indicators of fecal pollution and pathogen prevalence in part because they are easy to detect in environmental samples using standardized methods. Total and fecal coliform bacteria and $E$. coli can easily be detected in surface waters using the membrane filtration and Colilert ${ }^{\mathrm{TM}}$ methods described in Standard Methods for the Examination of Water and Wastewater (APHA, 1992). These standardized methods have been demonstrated to reliably detect fecal pollution indicators in surface water and can provide results within 24 hours.

The inclusion of Sinking Creek on the State of Tennessee's 303d list by the Tennessee Department of Environment and Conservation (TDEC) due to pathogen contamination is based on the monitoring of $E$. coli as an indicator of fecal pollution (TDEC, 2010). Although some studies have demonstrated the ability to predict pathogen presence using fecal indicator bacteria (Schaffter and Parriaux, 2002; Gersberg et al. 2006), it is not known if fecal indicator bacteria in Sinking Creek are successfully predicting the presence of pathogens.

Direct monitoring of pathogens in surface water is complicated by the difficulty and expense of monitoring for the vast number of pathogens associated with fecal pollution and, in some cases, lack of standardized methods. Various non-molecular and molecular methodologies have been developed and used in an effort to quickly identify 
and quantify pathogens in surface waters. One of the main obstacles of method development is the inability to routinely and accurately detect pathogens between methods and between the types of sample analyzed.

Culture and biochemical methods are commonly used for the identification of bacterial pathogens including E. coli $\mathrm{O} 157: \mathrm{H} 7$ and Shigella. Detection of E. coli O157:H7 can be accomplished using Sorbitol-MacConkey (SMAC) medium (March and Ratnam 1986; Nataro and Kaper, 1998). This agar replaces lactose with sorbitol and exploits the inability of $E$. coli $\mathrm{O} 157: \mathrm{H} 7$ to ferment sorbitol unlike other E. coli strains. As a result, E. coli $\mathrm{O} 157: \mathrm{H} 7$ colonies appear colorless while other colonies of $E$. coli appear red. Although SMAC medium relies on biochemical properties to identify E. coli O157: $\mathrm{H} 7$, false positives have been observed in part due to the limited selectivity of SMAC medium (Schets et al. 2005). A standard method for the culturing of Shigella sp. has been described using Xylose Lysine Deoxycholate (XLD) medium and Triple Sugar Iron (TSI) slant test (APHA, 1992). Colonies appearing red on XLD agar are considered to be Shigella sp. or Salmonella sp. Red colonies are tested using the TSI slant test, and samples positive for Shigella $s p$. will have a red slant indicating a lack of lactose and sucrose fermentation and a yellow butt indicating glucose fermentation and acid production.

Biochemical testing using API® strips has been used to confirm the presence of E. coli O157:H7 and Shigella sp. in environmental samples based on the biochemical profiles of the organisms (Faith et al. 1996, Shere et al. 2002; Hsu et al. 2010). These methods have proven successful in identifying various pathogenic bacteria in environmental samples and can be quickly and inexpensively performed. However, 
their application to impaired waters may delay or impede the protection of public health due to need for sample incubation (usually 24 hours) and inability to detect viable but non-culturable (VBNC) organisms (Roszak and Colwell 1987; Byrd et al. 1991; Wang and Doyle 1998).

Culture methods for the detection and quantification of bacteriophages have also been described (USEPA, 2001a; USEPA, 2001b) and are commonly used as a surrogate measure of virus pollution (Wentsel et al. 1982; Stetler, 1984; Havelaar et al.1993). Using an E. coli host strain, bacteriophages are enumerated using either a single or double agar layer procedure. Bacteriphages will infect and lyse the host cells, resulting in the formation of plaques that are enumerated following 24 hours of incubation. These methods are relatively quick (24h) and easy to perform compared to virus cell culture methods (up to 3 weeks), and are considered to represent suitable indicators of enteric virus pollution.

Immunological methods for the detection of E. coli O157:H7, Shigella sp., Giardia, and Cryptosporidium have been proposed to overcome the challenges presented by culturing and biochemical methods. Enzyme-linked immunosorbent assays (ELISA) and immunomagnetic separation methods have been developed to identify bacterial pathogens including E. coli $\mathrm{O} 157: \mathrm{H} 7$ and Shigella sp. in environmental samples and rely on the reactivity of specific antibodies with the sample. Both ELISA and immunomagnetic separation methods have been shown to more accurately and quickly identify the presence of E. coli $\mathrm{O} 157: \mathrm{H} 7$ and Shigella sp. in human and environmental samples compared to culture methods (Islam et al. 1993b; Dylla et al. 1995; Park et al. 1996; Fratamico and Strobaugh, 1998; Zhu et al. 2005). In addition to 
their use for the detection of bacterial pathogens, immunomagnetic separation and immunofluorescent methods have been applied to protozoan pathogen detection including Giardia and Cryptosporidium (USEPA 2005). Immunomagnetic separation and immunofluorescent methods have been shown to be insensitive to environmental interferences including highly turbid surface waters (LeChevallier et al. 1995; Bukhari et al. 1998; Rochelle et al. 1999; McCuin et al. 2001) but are subject to recovery losses during filtration, elution, and centrifugation of the sample (LeChevallier et al. 1995; Hu et al. 2004). Immunological methods provide relatively quick results (24 hours), can be easily performed, but may be subject to cross-reactivity of antibodies resulting in false positive results (Sauch 1985; Rice et al. 1992; Islam et al. 1993a; Koompapong et al. 2009).

Molecular methods including polymerase chain reaction (PCR) are widely used for the detection of a variety of pathogens including E. coli O157:H7, Shigella sp. Giardia sp., Crytposporidium sp., and bacteriophages in environmental samples. Based on the replication of a particular gene sequence specific to the pathogen of interest, PCR methods have become popular for their ability to provide quicker identification and confirmation of pathogen presence beyond traditional culture or biochemical methods. The speed of analysis, typically a few hours, combined with method sensitivity and ability to detect VBNC organisms make PCR methods appealing for the identification of pathogens in surface water (Josephson et al.1993; Abd-El-Haleem et al. 2003). Numerous qualitative and quantitative PCR methods have been used either on their own or in combination with culture or immunological methods for the identification of bacterial pathogens, pathogenic protozoa, and bacteriophage in surface waters based 
on DNA primers, annealing temperatures and reaction components (Bej et al. 1991; Mahbubani et al. 1992; Johnson et al. 1995; Rose et al. 1997; Puig et al. 2000; Campbell et al. 2001; Guy et al. 2003; Ibekwe and Grieve, 2003). Although PCR methods for the identification of pathogens can be rapidly completed and highly sensitive, they are often difficult to standardize and apply to environmental samples due to inhibiting substances in the soil and water matrix such as humic acids (Tebbe and Vahjenm 1993; Campbell et al. 2001; Bhagwat, 2003). Environmental stress has also been shown to affect the stability of the target gene further complicating the sensitivity of the method (Cooley et al. 2010).

There are inherent positive and negative aspects associated with each of the various methodologies available for the detection of pathogens in surface water. To overcome the issues of selectivity and VBNC bacteria, published PCR methods were selected for the analysis of E. coli O157:H7 and Shigella sp. in this study (Bej et al. 1991; Theron et al. 2003). Standardized methods were selected for the detection of Giardia, Cryptosporidium, and bacteriophages (USEPA, 2001a; USEPA, 2001b; USEPA, 2005). The recovery efficiencies of each method may vary from the published detection limits based on the type of sample and the particular analytical laboratory. To address these issues, each method was subjected to PR analyses to determine the sensitivity of each method prior to the collection and analysis of field samples. 


\section{Materials and Methods}

Bacterial Analysis

Stock culture of E. coli O157:H7 (ATCC $\circledast$ Number $43895^{\mathrm{TM}}$ ) and Shigella flexneril (ATCC $\AA$ Number $12022^{\mathrm{TM}}$ ) were obtained from the American Type Culture Collection (ATCC $\AA$ ). E. coli O157:H7 was cultured using tryptic soy agar (TSA) and Shigella flexneri was cultured using nutrient agar. A known number of colony forming units (CFUs) of each bacterial strain were seeded into $100 \mathrm{ml}$ samples of tap water dechlorinated with sodium thiosulfate. For E. coli O157:H7, water samples were seeded with 10, 25, and $50 \mathrm{CFU} / 100 \mathrm{ml}$ and filtered. For detection limit determination of Shigella flexneri, water samples were seeded with 10, 25, and 50CFU/100ml and filtered. Following filtration, the samples were eluted with either tryptic soy broth (TSB) or $1 \%$ Tween solution to assess the bacterial elution using each solution. The filter was then washed with $10 \mathrm{ml}$ of a $1 \%$ Tween 80 solution and centrifuged for 10 minutes to create a cell pellet. The supernatant was removed and the cell pellet was washed twice with $10 \mathrm{ml}$ phosphate buffered saline. Fifty microliters of diethylpyrocarbonate solution was added to the final cell pellet and subjected to 6 freeze-thaw cycles at $-20^{\circ} \mathrm{C}$ and $100^{\circ} \mathrm{C}$, respectively.

PCR amplification for E. coli O157:H7 was performed as described by Kimura et al. (2000) using primers EC-1 (GGCAGCCAGCATTTTTTA) and EC-2 (CACCCAACAGAGAAGCCA) for the chuA gene. The final 50 $\mu$ I PCR mixture contained 2.5X PCR buffer ( $\mathrm{mM} \mathrm{MgCl}_{2}, 10 \mathrm{mM}$ Tris- $\left.\mathrm{HCl}, 50 \mathrm{mM} \mathrm{KCl}\right), 0.8 \mathrm{mM}$ of each deoxynucleoside triphosphate (dATP, dCTP, dGTP, and dTTP), $4 \mu \mathrm{M}$ concentrations of each primer, $5 \cup$ Taq DNA polymerase (Fisher Scientific, Pittsburg, PA) and $5 \mu$ l of the 
resuspended cell pellet. The PCR mixture was subjected to an initial denaturation step at $95^{\circ} \mathrm{C}$ for 5 minutes, followed by 35 cycles of 1 minute denaturation at $94^{\circ} \mathrm{C}, 2$ minutes of annealing at $42^{\circ} \mathrm{C}$, and 5 minutes of primer extension at $72^{\circ} \mathrm{C}$. A final extension step was performed at $72^{\circ} \mathrm{C}$ for 10 minutes using a BioRad Thermocycler PCR Machine (BioRad, Hurcules, CA). PCR products were resolved on a $2 \%$ agarose gel for $1.5 \mathrm{~h}$ at $80 \mathrm{~V}$ and subjected to ethidium bromide staining to visualize DNA base pair bands. The presence of a 901 base pair band indicated a sample positive for E. coli O157:H7.

PCR amplification for Shigella sp. was performed as described by Theron et al. (2001). Thirty cycles of a seminested PCR reaction were performed using primers $\mathrm{H} 8$ (GTTCCTTGACCGCCTTTCCGATAC) and H15 (GCCGGTCAGCCACCCTC) for the ipaH gene (Islam, et al. 1993a) in the first round of PCR. The 50 $\mu$ reaction volume contained 1X PCR buffer ( $\mathrm{mM} \mathrm{MgCl}_{2}, 10 \mathrm{mM}$ Tris- $\left.\mathrm{HCl}, 50 \mathrm{mM} \mathrm{KCl}\right), 0.1 \mathrm{mM}$ of each deoxynucleoside triphosphate (dATP, dCTP, dGTP, and dTTP), 24pmol of H8 primer, 34pmol of H15 primer, 1U Taq DNA polymerase (Fisher Scientific, Pittsburg, PA), and $10 \mu \mathrm{l}$ of resuspended cell pellet. The PCR mixture was subjected to an initial denaturation step at $94^{\circ} \mathrm{C}$ for 3 minutes, followed by 10 cycles of 1 minute denaturation at $94^{\circ} \mathrm{C}, 1$ minute of annealing at $60^{\circ} \mathrm{C}$, and 1 minute of primer extension at $72^{\circ} \mathrm{C}$. One microliter of PCR product from the first PCR round was added to a reaction tube containing the reagents described above, with the addition of $31 \mathrm{pmol}$ of $\mathrm{H} 10$ primer (CATTTCCTTCACGGCAGTGGA) described by Hartman et al. (1990). An initial denaturation step was performed at $94^{\circ} \mathrm{C}$ for 3 minutes, followed by 20 cycles of 1 minute denaturation at $94^{\circ} \mathrm{C}, 1$ minute of annealing at $60^{\circ} \mathrm{C}$, and 1 minute of primer extension at $72^{\circ} \mathrm{C}$. A final extension step was performed at $72^{\circ} \mathrm{C}$ for 7 minutes using a 
BioRad Thermocycler PCR Machine (BioRad, Hurcules, CA). PCR products were resolved on a $2 \%$ agarose gel for $1.5 \mathrm{~h}$ at $80 \mathrm{~V}$ and subjected to ethidium bromide staining to visualize DNA base pair bands. The presence of both a 401 and 620 base pair band indicated a sample positive for Shigella sp.

\section{Protozoan Analysis}

PR analyses for Giardia and Cryptosporidium were performed using a stock concentration of Giardia lamblia cycts (Human Isolate H-3, Waterborne Inc.). A stock solution of 12,500 Giardia lamblia cysts was seeded into a carboy containing $20 \mathrm{~L}$ of tap water dechlorinated with sodium thiosulfate. A filtration apparatus was assembled (Figure 2.1) and the entire 20L sample filtered though an Envirochek ${ }^{\mathrm{TM}}$ sampling filter

(Pall Corporation, Ann Arbor, MI) powered by an electric water pump and Badger ${ }^{\mathrm{TM}}$ flow meter at a flow rate of $2.5 \mathrm{~L}$ per minute.

Filters were initially washed by adding $120 \mathrm{ml}$ of elution buffer to the filter capsule and placing on a wrist action shaker for 30 minutes. The elution buffer was removed and the filter capsule broken open and the filter cut out using a sterile razor blade and hand washed using $120 \mathrm{ml}$ of elution buffer. The buffer was then added to a sterile $250 \mathrm{ml}$ centrifuge tube containing the elution buffer from the initial wash on the wrist action shaker. The samples were centrifuged at $2,300 \times \mathrm{g}$ for $30 \mathrm{~min}$ and the supernatant removed. The concentrated pellet collected was subjected to an immunofluorescent assay using the Waterborne Aqua-Glo ${ }^{\mathrm{TM}} \mathrm{G} / \mathrm{C}$ Direct FL antibody stain (Waterborne, Inc. New Orleans, LA) as described by the manufacturer. The 
prepared slides were examined at 200X using the Olympus BH2 epifluorescent microscope (Olympus, New Hyde Park, NY).

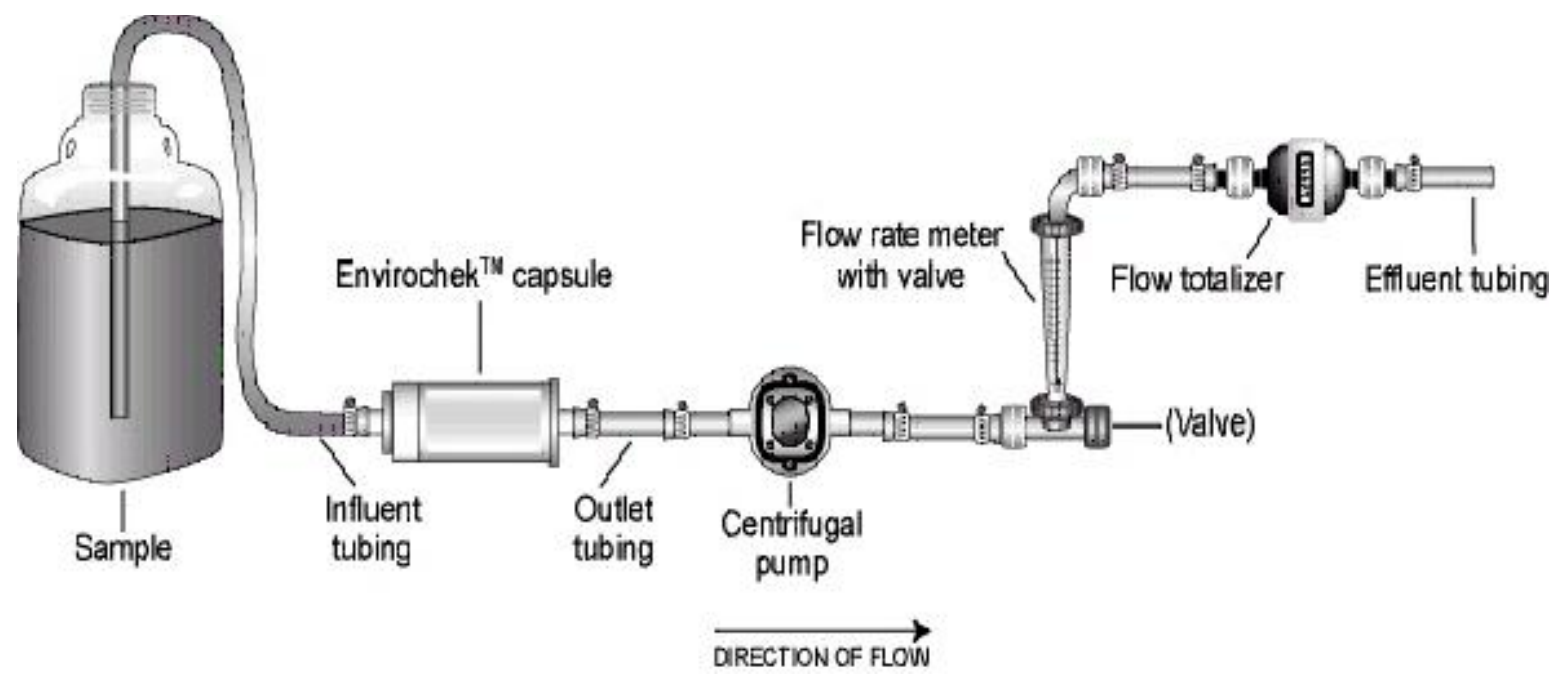

Figure 2.1. Filtration apparatus used to sample Giardia and Cryptosporidium in laboratory seeded samples (USEPA, 2005)

Fluorescently-labeled carboxylate modified polystyrene latex beads with a mean particle size of $2 \mu \mathrm{m}$ (Sigma-Aldrich) were used in PR analyses as a substitute for Cryptosporidium oocysts because of similarity in size. The seeding and recovery procedures for the latex beads were performed using the methods described for Giardia lamblia seeding samples. The prepared IFA slides and recovered pellets were enumerated microscopically at $200 \mathrm{X}$ on a hemacytometer using a using the Olympus BH2 epifluorescent microscope (Olympus, New Hyde Park, NY) to determine the percent of beads recovered. 


\section{Bacteriophage Analysis}

PR analyses for bacteriphage were performed using MS2 bacteriophage (ATCC $\AA$ Number $15597-1 \mathrm{~B}^{\mathrm{TM}}$ ) and E. coli C3000 (ATCC $\AA$ Number $15597^{\mathrm{TM}}$ ) as a host strain. The host strain was cultured using ATCC 271 broth $(10 \mathrm{~g} / \mathrm{L}$ tryptone, $1 \mathrm{~g} / \mathrm{L}$ yeast extract, $8 \mathrm{~g} \mathrm{NaCl}, 10 \mathrm{ml} / \mathrm{L}$ of $10 \%$ glucose solution, $2 \mathrm{ml} / \mathrm{L}$ of $1 \mathrm{M} \mathrm{CaCl}_{2}, 1 \mathrm{ml} / \mathrm{L}$ of $10 \mathrm{mg} / \mathrm{ml}$ thiamine) at $37^{\circ} \mathrm{C}$. An overnight culture of the host strain was prepared the day before analysis by inoculating a $30 \mathrm{ml}$ ATCC broth culture with the host strain. On the day of analysis, $100 \mu \mathrm{l}$ of the prepared overnight culture of the host strain was inoculated into a $30 \mathrm{ml}$ of fresh ATCC 271 broth and incubated at $37^{\circ} \mathrm{C}$ until log phase was reached ( 4h). This culture was used to propogate the MS2 bacteriophage for PR analyses.

Five hundred microliters of each MS2 dilution was added to a test tube containing $5 \mathrm{ml}$ of $0.7 \%$ ATCC® 271 agar (ATCC® 271 broth with $1.4 \mathrm{~g} / \mathrm{L}$ agar) and $100 \mu \mathrm{l}$ of host bacteria. The tubes were gently mixed and poured onto a plate containing $1.5 \%$ ATCC 271 agar (ATCC $\circledast 271$ broth with $18 \mathrm{~g} / \mathrm{L}$ agar). Plates were allowed to solidify prior to incubation at $37^{\circ} \mathrm{C}$ for $24 \mathrm{~h}$ and plaque forming units (PFUs) were enumerated. Following bactriophage enumeration of the culture, a known number of PFUs were seeded into $10 \mathrm{ml}$ tap water samples with sodium thiosulfate to remove any chlorine residual and analyzed in using USEPA method 1062 to determine the percent of bacteriophages recovered and the method detection limit. 


\section{$\underline{\text { Results and Discussion }}$}

\section{Bacterial Analysis}

The results of PCR and gel electrophoresis are shown in Figure 2.2. Both the TSB and 1\% Tween solution were successful in eluting bacteria from the filters containing 25 and 50 CFUs but not the filter containing 10CFUs. The intensity of the target 901 base pair bands for the samples eluted with 1\% Tween suggest that it more successful at eluting bacteria from the filter than TSB because of its surfactant properties.
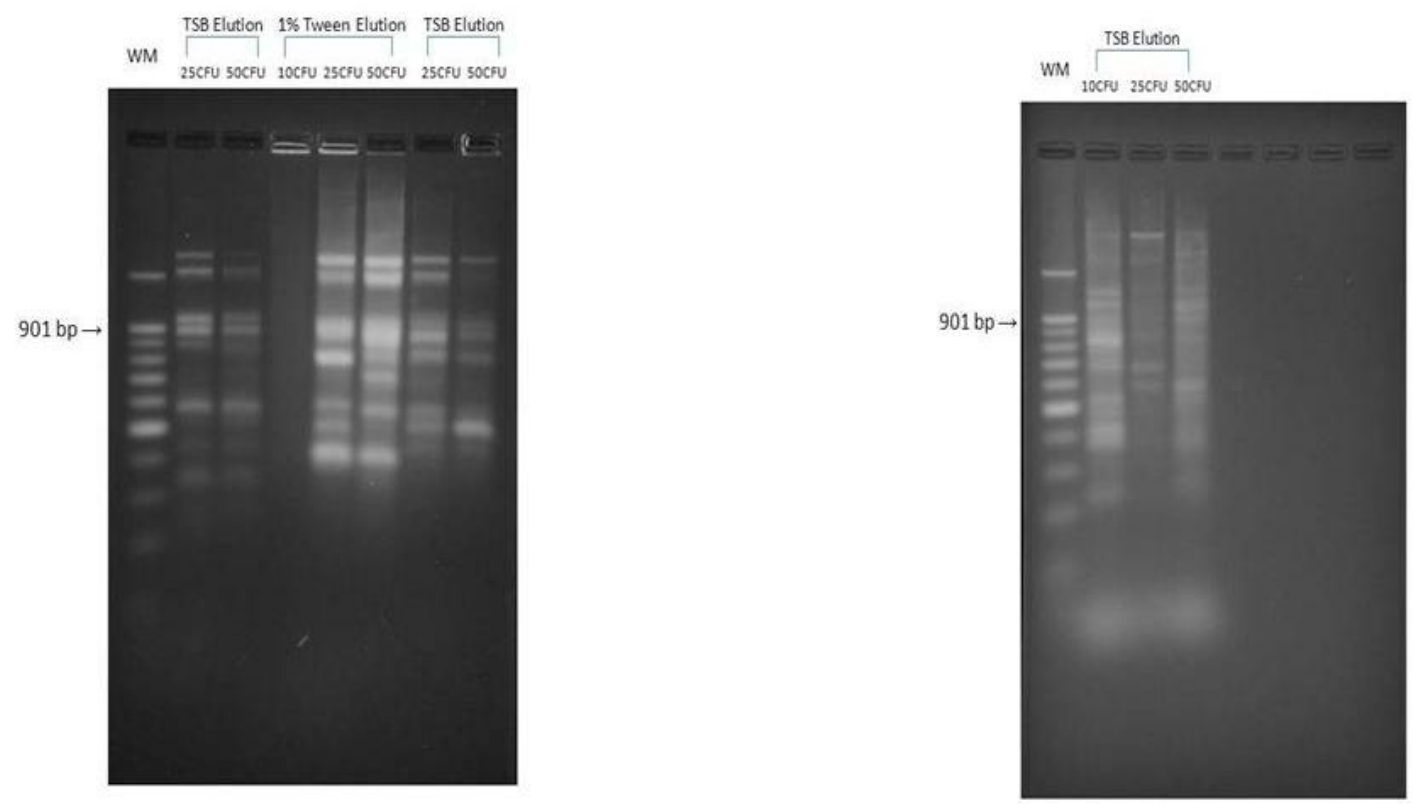

Figure 2.2. Gel electrophoresis of PCR products to determine the detection limit of $\mathrm{E}$. coli $\mathrm{O} 157: \mathrm{H} 7$ using TSB and 1\% Tween as elution buffers 
The results of PCR and gel electrophoresis are shown in Figure 2.3. In this instance, Shigella was not recovered in samples eluted with TSB but the target 620 and 401 base pair bands were detected for all seeded concentrations. As with E. coli O157:H7, the 1\% Tween solution may be more successful eluting bacteria from the filter because of its surfactant properties.

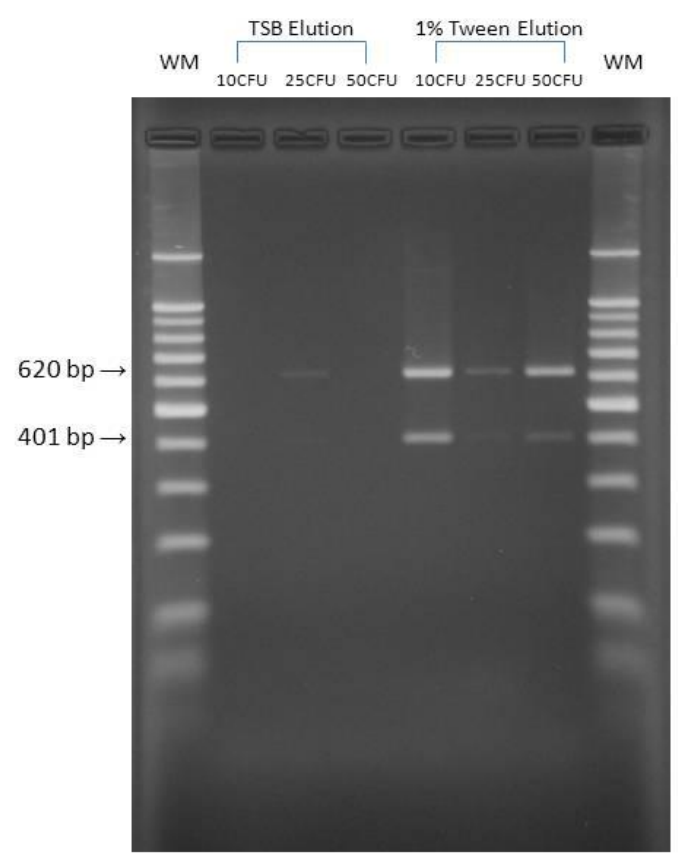

Figure 2.3. Gel electrophoresis of PCR products to determine the detection limit of Shigella flexneri using TSB and 1\% Tween as elution buffers

The use of PCR methods for the analysis of E. coli O157:H7 and Shigella sp. in surface water samples were selected for their greater speed and selectivity than the traditional plating methods and their ability to detect VBNC organisms. The detection limits determined in this study for both E. coli $\mathrm{O} 157: \mathrm{H} 7$ and Shigella sp. vary greatly 
compared to published detection limits in environmental samples and clinical isolates (Table 2.1). PCR analyses for the detection of E. coli O157:H7 and Shigella sp. varied based on the type of sample, but wastewater and surface water generally display the highest detection limits (Ibekwe et al. 2002; Ibekwe et al. 2003; Barak et al. 2005; Hsu et al. 2007). Higher detection limits in these types of samples are most likely due to the presence of PCR inhibitors such as humic acids that may be present during isolation and purification of the sample (Tebbe and Vahjen, 1992). 
Table 2.1. Published detection limits of Polymerase Chain Reaction (PCR) methods for the detection of E. coli O157:H7 and Shigella sp.

\begin{tabular}{|c|c|c|c|c|}
\hline Organism & Sample Type & Type of PCR Method & Detection Limit & Reference \\
\hline Shigella sonnei & Surface water & PCR & $1.7-24.7 \mathrm{CFU} / 50 \mathrm{ml}$ & Hsu et al. (2007) \\
\hline Shigella dysenteriae & Surface water & PCR & $270-8000 \mathrm{CFU} / 50 \mathrm{ml}$ & Hsu et al. (2007) \\
\hline Shigella flexneri & Sea water & Multiplex PCR & $10-100 \mathrm{CFU}$ & Kong et al. (2002) \\
\hline Shigella spp. & Surface water & Semi-nested PCR & $14 \mathrm{CFU} / \mathrm{ml}$ & Theron et al. (2002) \\
\hline Shigella spp. & Surface water & Enrichment/real time PCR & 1.8 CFU/100ml & Maheux et al. (2011) \\
\hline Shigella flenxeri & Stool & Multiplex PCR & 300 cells $/ g$ & Oyofo et al. (1996) \\
\hline Shigella dysenteriae & Surface water & PCR & $27.5 \mathrm{CFU} / 100 \mathrm{ml}$ & Liu et al. (2009) \\
\hline E. coli O157:H7 & Irrigation water & Real time PCR & 10 - $1000 \mathrm{CFU} /$ reaction & Barak et al. (2005) \\
\hline E. coli O157:H7 & Drinking water/soil & Multiplex PCR & $1 \mathrm{CFU} / \mathrm{ml}, 2 \mathrm{CFU} / \mathrm{g}$ & Campbell et al. (2001) \\
\hline E. coli O157:H7 & Wastewater & $\begin{array}{l}\text { Multiplex fluorogenic RT- } \\
\text { PCR }\end{array}$ & $6,400 \mathrm{CFU} / \mathrm{ml}$ & lbekwe et al. (2002) \\
\hline E. coli O157:H7 & Surface water/soil & Real time PCR & $\begin{array}{l}3,500 \mathrm{CFU} / \mathrm{ml}, 26,000 \\
\mathrm{CFU} / \mathrm{g}\end{array}$ & lbekwe et al. (2003) \\
\hline E. coli O157:H7 & Surface water & $\begin{array}{l}\text { Reverse transcriptase } \\
\text { PCR }\end{array}$ & $7 \mathrm{CFU} / \mathrm{L}$ & Liu et al. (2008) \\
\hline E. coli O157:H7 & Surface water & RT-PCR & $1.8 \mathrm{CFU} / 100 \mathrm{ml}$ & Maheux et al. (2011) \\
\hline E. coli $\mathrm{O} 157: \mathrm{H} 7$ & Clinical isolates & RT-PCR & 30 cells & Morin et al. (2004) \\
\hline E. coli O157:H7 & Drinking water & Culture/q-PCR & 500 cells & Sen et al. (2011) \\
\hline E. coli O157:H7 & Drinking water & PCR & $1 \mathrm{cell} / \mathrm{ml}$ & Bej et al. (1991) \\
\hline E. coli O157:H7 & Water & Enrichment/PCR & $3 \mathrm{CFU} / \mathrm{L}$ & Bonetta et al. (2011) \\
\hline
\end{tabular}




\section{Protozoan Analysis}

Four water samples were seeded with Giardia lamblia cysts and analyzed for PR determination. Two seeding concentrations (625 cysts/L and 2,500 cysts/L) were analyzed to assess the recovery efficiency of different protozoan concentrations. The average percent recovery of the seeded water samples was $35.7 \%$ and the concentration of cysts in the sample does not seem to improve recovery efficiencies (Table 2.2). Three water samples were seeded with latex beads to assess the ability of the analytical methods to recover Cryptosporidium oocysts. The average percent recovery of the seeded water samples was $35.3 \%$ (Table 2.3 ). According to the USEPA, method 1623 recoveries range from $11-100 \%$ for Giardia and $14-100 \%$ for Cryptosporidium and are considered acceptable (USEPA, 2005). The results of the PR analyses are within the USEPA established acceptable detection range.

Table 2.2. IPR results for filtered water sampled seeded Giardia lamblia cysts

\begin{tabular}{lcr}
\hline $\begin{array}{l}\text { Number of Seeded Giardia } \\
\text { Cysts }\end{array}$ & $\begin{array}{c}\text { Number of Giardia Cysts } \\
\text { Recovered }\end{array}$ & Percent Recovery \\
\hline 12,500 & 3800 & $30.4 \%$ \\
12,500 & 6750 & $54.0 \%$ \\
12,500 & 5625 & $45 \%$ \\
50,000 & 6745 & $13.5 \%$ \\
& & Average $35.7 \%$ \\
\hline
\end{tabular}


Table 2.3. IPR results for filtered water samples seeded latex beads as a surrogate measure of Cryptosporidium oocysts

\section{Number of Seeded Latex Beads Number of Latex Beads Percent Recovery
Recovered}
$8.6 \times 10^{7}$
$1.4 \times 10^{7}$
$16.3 \%$
$8.6 \times 10^{7}$
$2.1 \times 10^{7}$
$24.4 \%$
$8.6 \times 10^{7}$
$5.6 \times 10^{7}$
$65.1 \%$

Average $35.3 \%$

Much variability has been reported in Giardia cyst and Cryptosporidium oocyst recovery using USEPA method 1623 (Table 2.4). Most loss of cyst and oocyst is reported to occur during the elution and concentration steps, and the smaller size of Cryptosporidium oocysts $(2-6 \mu \mathrm{m})$ is responsible for the lower recovery efficiencies compared to Giardia cysts $(8-12 \mu \mathrm{m})$ (LeChevallier et al. 1995; Hu et al. 2004). It has also been reported that the presence of organic and inorganic particles in surface waters resulting in increased turbidity may impede Giardia and Cryptosporidium recovery (Nieeminski et al. 1995; DiGiorgio et al. 2002; Krometis et al. 2009). The presence of organic material may interfere with adsorption and absorption of cysts and oocysts to the filter and influence recovery during the elution procedure. To address these potential interferences, hand washing of the filter was performed following elution for 30 minutes using a wrist action shaker to improve elution efficiency. 
Table 2.4. Published detection limits of USEPA method 1623 for the detection of Giardia and Cryptosporidium in water

\section{Average Giardia Recovery}

$11-100 \%$

$22 \%$ [Range 3-45\%]

Site 1: $61 \pm 0.06 \%$ SE

Site 2: $0.83 \pm 0.01 \%$ SE

$51.4 \pm 12.6 \% \mathrm{SD}$

$9.1 \%$

$48 \%$

\section{Average Cryptosporidium} Recovery

$14-100 \%$

17\% [Range 0-074\%]

Site 1: $43 \pm 0.01 \%$ SE

Site 2: $37 \pm 0.05 \%$ SE

$40.4 \pm 17.8 \%$ SD

$2.8 \%$

$42 \%$

\section{Reference}

EPA (2005)

Krometis et al. (2009)

DiGiorgio et al. (2002)

McCuin et al. (2003)

Clancy et al. (1994)

Nieminski et al. (1995)

Bacteriophage Analysis

MS2 bacteriophage were isolated and enumerated from a secondary effluent sample collected at Knob Creek Wastewater Treatment Facility using the double agar layer method. Three tap water samples treated with sodium thiosulfate to neutralize chlorine residual were seeded with a known concentration of bacteriophage PFUs/ml and subjected to the described isolation procedures in triplicate. Analysis of the seeded samples resulted in complete recovery of the seeded bacteriophage PFUs (Table 2.5). The ability of this method to detect $1 \mathrm{PFU} / \mathrm{ml}$ is reliant on the filtration of the raw water sample to remove any bacteria that may inhibit the growth of the host bacteria and the use of a pure host bacterial culture (E. coli C3000). It should be noted that the bacteriophage detected in this assay and the recovery of bacteriophage in 
environmental samples are somewhat limited because of specificity of the $E$. coli host strain used.

Table 2.5. IPR results for water samples seeded with a known concentration of bacteriophage PFUs

\section{Concentration of Seeded Bacteriophage}

Concentration of Recovered Bacteriophage

Percent Recovery

\begin{tabular}{lcc}
\hline $1 \mathrm{PFU} / \mathrm{ml}$ & $1 \mathrm{PFU} / \mathrm{ml}$ & $100 \%$ \\
$5 \mathrm{PFU} / \mathrm{ml}$ & $5 \mathrm{PFU} / \mathrm{ml}$ & $100 \%$ \\
$10 \mathrm{PFU} / \mathrm{ml}$ & $10 \mathrm{PFU} / \mathrm{ml}$ & $100 \%$ \\
\hline
\end{tabular}

\section{$\underline{\text { Conclusions }}$}

The observed PR tests and detection limits determined in these experiments demonstrate variability when compared to the recovery efficiencies of the published methods. The detection limits of E. coli O157:H7 and Shigella sp. using PCR methods were determined to be 25 and 10 CFUs, respectively. Percent recoveries for Giardia (35.7\%) and Cryptosporidium (35.3\%) are within acceptable guidelines described in USEPA method 1623, but it may be difficult to compare these recoveries to those of environmental samples based on the influences of organic and inorganic materials in surface waters. The PR test of bacteriophage samples demonstrated $100 \%$ recovery of samples seeded with $1 \mathrm{PFU} / \mathrm{ml}$ of MS2 bacteriophage. 


\section{Acknowledgements}

This work was funded in part by a grant from the ETSU School of Graudate Studies and Graduate Council, and by a contract with the Tennessee Valley Authority (Award \# 00025252). 


\section{$\underline{\text { References }}$}

Abd-El-Haleem D, Kheiralla HZH, Zaki S, Rushdy AA, Abd-El-Rahiem W. 2003. Multiplex-PCR and PCR-RFLP assays to monitor water quality against pathogenic bacteria. J. Environ. Monit. 5:865-870

APHA. 1992. Standard methods for the examination of water and wastewater. $18^{\text {th }}$ edition. American Public Health Association. Washington, D.C.

Barak JD, Sananikone K, Delwiche MJ. 2005. Comparison of primers for the detection of pathogenic Escherichia coli using real-time PCR. Lett. Appl. Microbiol. 41:112118

Bej AK, DiCesare JL, Haff L, Atlas RM. 1991. Detection of Escherichia coli and Shigella spp. in water by using the polymerase chain reaction and gene probes for uid. Appl. Environ. Microbiol. 57:1013-1017

Bhagwat AA. 2003. Simultaneous detection of Escherichia coli O157:H7, Listeria monocytogenes and Salmonella strains by real-time PCR. Int. J. Food Protect. $84: 217-224$

Bonetta S, Borelli E, Bonetta S, Conio O, Palumbo F, Carraro E. 2011. Development of a PCR protocol for the detection of Escherichia coli and Salmonella sp. in surface water. Environ. Monit. Assess. 177:493-503

Bukhari Z, McCuin RM, Fricker CR, Clancy JL. 1998. Immunomagnetic separation of Cryptosporidium parvum from source water samples of various turbidities. Appl. Environ. Microbiol. 64:4495-4499

Byrd JJ, Xu HS, Colwell RR. 1991 Viable but nonculturable bacteria in drinking water. Appl. Environ. Microbiol. 57:875-878

Campbell GR, Prosser J, Glover A, Killham K. 2001. Detection of Escherichia coli O157:H7 in soil and water using multiplex PCR. J. Appl. Microbiol. 91:1004-1010

Cooley MB, Carychao D, Nguyen K, Whitehand L, Mandrell R. 2010. Effects of environmental stress on stability of tandem repeats in Escherichia coli O157:H7. Appl. Environ. Microbiol. 76:3398-4000

DiGiorgio CL, Gonzalez DA, Huitt CC. 2002. Cryptosporidium and Giardia recoveries in natural waters by using Environmental Protection Agency method 1623. Appl. Environ. Microbiol. 68:5952-5955 
Dylla BL, Vetter EA, Hughes JG, Cockerill III FR. 1995. Evaluation of an immunoassay for direct detection of Escherichia coli $\mathrm{O} 157$ in stool specimens. Appl. Environ. Microbiol. 33:222-224

Faith NG, Shere JA, Brosch R, Arnold KW, Ansay SE, Lee M-S, Luchansky JB, Kaspar CW. 1996. Prevalence and clonal nature of Escherichia coli O157:H7 on dairy farms in Wisconsin. Appl. Environ. Microbiol. 62:1519-1525

Fratamico PM, Stobaugh TP. 1998. Evaluation of an enzyme-linked immunosorbent assay, direct immunofluorescent filter technique, and multiplex polymerase chain reaction for detection of Escherichia coli O157:H7 seeded in beef carcass wash water. J. Food Protect. 61:934-938

Gersberg RM, Rose MA, Robles-Sikisaka R, Dhar AK. 2006. Quantitative detection of Hepatitis A virus and enteroviruses near the United States-Mexico border and correlation with levels of fecal indicator bacteria. Appl. Environ. Microbiol. 72:74387444

Guy RA, Payment P, Krull UJ, Horgen PA. 2003. Real-time PCR for quantification of Giardia and Cryptosporidium in environmental water samples and sewage. Appl. Environ. Microbiol. 69:5178-5185

Hartman AB, Venkatesan MM, Oaks EV, van Buysse JM. 1990. Sequence and molecular characterization of multicopy invasion plasmid antigen gene, $\mathrm{ipaH}$, of Shigella flexneri. J. Bacterial. 172:1905-1915

Havelaar AH, van Olphen M, Drost YC. 1993. F-specific RNA bacteriophages are adequate model organisms for enteric viruses in fresh water. Appl. Environ. Microbiol. 59:2956-2962

Hsu WB, Want JH, Chen PC, Lu YS, Chen JH. 2007. Detecting low concentrations of Shigella sonnei in environmental samples by PCR. FEMS Microbiol. Lett. 270:291298

Hsu BM, Wu SF, Huang SW, Tseng YJ, Ji DD, Chen JS, Shih FC. 2010. Differentiation and identification of Shigella spp. and enteroinvasive Escherichia coli in environmental waters by a molecular method and biochemical test. Wat. Res. 44:949-955

Hu J, Feng Y, Ong SL, Ng WJ, Song L, Tan X, Chu X. 2004. Improvement of recoveries for the determination of protozoa Cryptosporidium and Giardia in water using method 1623. J. Microbiol. Methods. 58:321-325 
Islam MS, Hasan MK, Hiah MA, Sur GC, Felsenstein A, Venkatesan M, Sack RB, Albert MJ. 1993a. Use of polymerase chain reaction and fluorescent-antibody methods for detecting viable but nonculturable Shigella dysenteriae Type 1 in laboratory microcosms. Appl. Environ. Microbial. 59:536-540

Ibekwe AM, Watt PM, Grieve CM, Sharma VK, Lyons SR. 2002. Multiplex fluorogenic real-time PCR for detection and quantification of Escherichia coli O157:H7 in dairy wastewater wetlands. Appl. Environ. Microbiol. 68:4853-4862

Ibekwe AM, Grieve CM. 2003. Detection and quantification of Escherichia coli O157:H7 in environmental samples by real-time PCR. J. Appl. Microbiol. 94:421431

Islam MS, Hasan MK, Hiah MA, Sur GC, Felsenstein A, Venkatesan M, Sack RB, Albert MJ. 1993a. Use of polymerase chain reaction and fluorescent-antibody methods for detecting viable but nonculturable Shigella dysenteriae Type 1 in laboratory microcosms. Appl. Environ. Microbial. 59:536-540

Islam D, Tzipori S, Islam M, Lindberg AA. 1993b. Rapid detection of Shigella dysenteriae and Shigella flexneri in faeces by an immunomagnetic assay with monoclonal antibodies. Eur. J. Clin. Micribiol. Infect. Dis. 12:25-32

Johnson DW, Pieniazek NJ, Griffin DW, Misener L. 1995. Development of a PCR protocol for sensitive detection of Cryptosporidium oocysts in water samples. Appl. Environ. Microbiol. 61:3849-3855

Josephson KL, Gerba CP, Pepper IL. 1993. Polymerase chain reaction detection of nonviable bacterial pathogens. Appl. Environ. Microbiol. 59:3513-3515

Kimura R, Mandrell RE, Galland JC, Hyatt D, Riley LW. 2000. Restriction-site-specific PCR as a rapid test to detect enterohemorrhagic Escherichia coli O157:H7 strains in environmental samples. Appl. Environ. Microbiol. 66:2513-2519

Kong RYC, Lee SKY, Law TWF, Law SHW, Wu RSS. 2002. Rapid detection of six types of bacterial pathogens in marine waters using multiplex PCR. Wat. Res. 36:2802-2812

Koompapong K, Sutthikornchai C, Sukthana Y. 2009. Cryptosporidium oocyst detection in water samples: floatation technique enhanced with immunofluorescence is as effective as immunomagnetic separation method. Korean J. Parasitol. 47:353357

Krometis LAH, Characklis GW, Sobsey MD. 2009. Identification of particle size classes inhibiting protozoan recovery from surface water samples via US Environmental Protection Agency method 1623. Appl. Environ. Microbiol. 75:6619-6621 
LeChevallier MW, Norton WD, Siegel JE, Abbaszadegan M. 1995. Evaluation of the immunofluorescent procedure for detection of Giardia cysts and Cryptosporidium oocysts in water. Appl. Envioron. Microbiol. 61:690-697

Mahbubani MH, Bej AK, Perlin MH, Schaefer FW, Jakubowski W, Atlas RM. 1992. Differentiation of Giardia duodenalis from other Giardia spp. by using polymerase chain reaction and gene probes. J. Clin. Microbiol. 30:74-80

Maheax AF, Bissonnette L, Boissinot M, Bernier JLT, Huppé V, Picard FJ, Bérubé E, Bergeron MG. 2011. Rapid concentration and molecular enrichment approach for sensitive detection of Escherichia coli and Shigella species in potable water samples. Appl. Environ. Microbiol. 77:6199-6207

March SB, Ratnam S. 1986. Sorbitol-MacConkey medium for detection of Escherichia coli O157:H7 associated with hemorrhagic colitis. Appl. Environ. Microbiol. 23:869872

McCuin RM, Bukhari Z, Sobrinho J, Clancy JL. 2001. Recovery of Cryptosporidium oocysts and Giardia cysts from source water concentrates using immunomagnetic separation. J. Microbiol. Methods. 45:69-76

Morin NJ, Gong Z, Li XF. 2004. Reverse transcription-multiplex PCR assay for simultaneous detection of Escherichia coli O157:H7, Vibrio cholera Ol and Salmonella typhi. Clin. Chem. 50:2037-2044

Nataro JP, Kaper JB. 1998. Diarrheagenic Escherichia coli. J. Microbiol. Rev. 11:142201

Nieminski EC, Schaefer III FW, Ongerth J.E. 1995. Comparison of two methods for detection of Giardia cysts and Cryptosporidium oocysts in water. Appl. Environ. Microbiol. 61:1714-1719

Oyofo GA, Mohran ZS, El-etr SH. Wasfy MO, Peruski, Jr. LF. 1996. Detection of enterotoxigenic Escherichia coli, Shigella and Campylobacter spp. by multiplex PCR assay. J. Diarrheal Dis. Res. 14:207-210

Park CH, Vandel NM, Hixon DL. 1996. Rapid immunoassay for detection of Escherichia coli $\mathrm{O} 157$ directly from stool specimens. J. Clin. Microbiol. 34:988-990

Puig M, Pina S, Lucena F, Jofre J, Girones R. 2000. Description of a DNA amplification procedure for the detection of bacteriophages of Bacteroides fragilis HSP40 in environmental samples. J. Virol. Methods. 89:159-166

Rochelle PA, De Leon R, Johnson A, Stewart MH, Wolfe RL. 1999. Evaluation of immunomagnetic separation for recovery of infectious Cryptosporidium oocysts from environmental samples. Appl. Environ. Microbiol. 65:841-845 
Rose JB, Zhou X, Griffin DW, Paul JH. 1997. Comparison of PCR and plaque assay for detection and enumeration of coliphage in polluted marine waters. Appl. Environ. Microbiol. 63:4564-4566

Roszak DB, Colwell RR. 1987. Survival strategies of bacteria in the natural environment. Microbiol. Rev. 51:365-379

Sauch JF. 1985. Use of immunofluorescence and phase-contrast microscopy for detection and identification of Giardia cysts in water samples. Appl. Environ. Microbiol. 50:1434-1438

Schaffter N, Parriaux A. 2002. Pathogenic-bacterial water contamination in mountainous catchments. Wat. Res. 36:131-139

Schets FM, During M, Italiaander R, Heijnen L, Rutjes SA, van der Zwaluw WK, de Roda Husman AM. 2005. Escherichia coli O157:H7 in drinking water from private water supplies in the Netherlands. Wat. Res. 39:4485-4493

Sen K, Sinclair JL, Boczek L, Rice EW. 2011. Development of a sensitive detection method for stressed E. coli O157:H7 in source and finished drinking water by culture-qPCR. Environ. Sci. Technol. 45:2250-2256

Shere JA, Kaspar CW, Bartlett KJ, Linden SE, Norell B, Francey S, Schaefer DM. 2002. Shedding of Escherichia coli $\mathrm{O} 157: \mathrm{H} 7$ in dairy cattle housed in a confined environment following waterborne inoculation. Appl. Environ. Microbiol. 68:19471954

Stetler RE. 1984. Coliphages as indicators of enteroviruses. Appl. Environ. Microbiol. 48:668-670

TDEC. 2010. 2010 303(d) Report, The Status of Water Quality in Tennessee, August 2010. State of Tennessee, Department of Environment and Conservation, Division of Water Pollution Control, Nashville TN USA

Tebbe CC, Vahjen W. 1993. Interference of humic acids and DNA extracted directly from soil in detection and transformation of recombinant DNA from bacteria and yeast. Appl. Environ. Microbiol. 59:2657-2665

Theron J, Morar D, Du Prees M, Brozel VS, Venter SN. 2001. A sensitive semi-nested PCR method for the detection of Shigella in spiked environmental water samples. Wat. Res. 35:869-874

USEPA. 2001a. Method 1601: Male-specific $(F+)$ and somatic coliphage in water by two-step enrichment procedure. April 2001. United States Environmental Protection Agency, Washington D.C. USA 
USEPA. 2001b. Method 1602: Male-specific $(F+)$ and Somatic Coliphage in Water by Single Agar Layer (SAL) Procedure. April 2001. United States Environmental Protection Agency, Washington D.C. USA

USEPA. 2005. Method 1623: Cryptosporidium and Giardia in Water by Filtration/IMS/FA. December 2005. United States Environmental Protection Agency, Washington D.C. USA

Wang G, Doyle MP. 1998. Survival of enterohemorrhagic Escherichia coli O157:H7 in water. J. Food Protect. 61:662-667

Wentsel RS, O'Neill PE, Kitchens JF. 1982. Evaluation of coliphage detection as a rapid indicator of water quality. Appl. Environ. Microbiol. 43:430-434

Zhu F, Rogeli S, Kieft TL. 2005. Rapid detection of Escherichia coli O157:H7 by immunomagnetic separation and real-time PCR. Int. J. Food Protect. 99:47-57 


\title{
CHAPTER 3
}

\section{PHYSICAL, CHEMICAL, AND MICROBIAL WATER QUALITY TRENDS IN SINKING} CREEK, JANUARY - DECEMBER 2011

\author{
K.K. Hall and P.R. Scheuerman
}

\begin{abstract}
$\underline{\text { Abstract }}$
A Total Maximum Daily Load (TMDL) was approved by the U.S. Environmental Protection Agency (USEPA) for Sinking Creek, a tributary of the Watauga River in Northeast Tennessee, in 1998. Sinking Creek has since remained on the State of Tennessee's 303d list for continued failure to meet surface water quality standards for pathogens, thus impairing recreational use. While Sinking Creek is not meeting surface water quality standards, the factors influencing pathogen loading are unknown. The inclusion of Sinking Creek on the state of Tennessee's 303d list due to pathogen contamination is based on the monitoring of fecal indicator bacteria, but it is not known what specific pathogens may be present. The objectives of this experiment was to 1) assess the physical, chemical, and microbial water quality in Sinking Creek, and 2) to determine the usefulness of fecal indicator bacteria as predictors of E. coli O157:H7, Shigella sp., Giardia sp., Cryptosporidium sp., and bacteriophage. Elevated concentrations of fecal indicator bacteria suggest that Sinking Creek is impaired by fecal pollution but fecal indicator bacteria concentrations do not correlate with pathogen presence, suggesting that fecal indicator bacteria do not accurately predict pathogen presence.
\end{abstract}




\section{$\underline{\text { Introduction }}$}

In 2002, Dulaney and co-workers initially selected 14 sites in Sinking Creek for fecal coliform monitoring based on their proximity to livestock and human populations, which may serve as sources of fecal pollution (Dulaney et al. 2003). The physical, chemical, and microbial water quality of Sinking Creek have since been monitored using this targeted sampling approach following its inclusion on the State of Tennessee's 303d list for pathogen impairment based on the monitoring of fecal indicator bacteria. Fecal coliform bacteria are commonly used as a surrogate measure of pathogen contamination in surface waters because they are easy to detect using inexpensive methods compared to methods for the monitoring of every pathogen. Some studies have observed a correlation between indicator organisms and pathogens (Payment and Franco 1993; Schaffter and Parriaux, 2002; Gersberg et al. 2006). Despite the advantages of monitoring fecal indicator bacteria and their occasional correlation with pathogen presence, a lack of correlation between the presence of fecal indicator bacteria and pathogens is more often observed (Goyal et al. 1977; Carrillo et al. 1985; Havelaar et al. 1993; Harwood et al. 2005). The lack of correlation observed between fecal coliform bacteria and pathogens may be due to differences in excretion densities and transport behaviors of pathogens and indicators (Lemarchand and Lebaron, 2003), regrowth of fecal indicators (Howell et al. 1996), survival of fecal coliforms compared to pathogens (McFeters et al. 1974; Scott et al. 2006) and physiochemical water and soil parameters (Burton et al. 1987; Gantzer et al. 2001). 
$\underline{\text { Sources, Fate, and Transport of Fecal Coliforms and Pathogens }}$

Fate and transport of fecal coliforms and pathogens are dependent on several physical, chemical, and microbial processes in water. The transport of the pathogen from the source to water, transport following entry into the water, and pathogen survival in the water influence pathogen fate and transport in surface waters. Fecal coliform concentrations in Sinking Creek have been consistently above regulatory limits and display seasonal variation (Hall et al. 2011). Seasonal variability of fecal coliform concentrations in water is often influenced by water chemistry (McFeters and Stuart, 1972) temperature (Hunter et al. 1999), rainfall and discharge (Lipp et al. 2001), dissolved oxygen (Hanes et al. 1964), UV light exposure (McCambridge and McMeekin, 1981; Davies and Evison, 1991), organic matter concentrations (Orlab 1956), predators (McCambridge and McMeekin, 1981) and heavy metals (Jana and Chattacharya, 1988). Partitioning of fecal coliforms into the gas-water interface (Powelson and Mills, 2001), and deposition into sediment and subsequent resuspension can influence fecal coliform concentrations in water (Sherer et al. 1992; Crabill et al. 1999).

In addition to seasonal variability, land use patterns significantly influence fecal coliform concentrations in Sinking Creek (Hall et al. 2011). Sinking Creek undergoes a rapid transition from forest to urban and agricultural land use. Agricultural activity is a common contributor to increased fecal coliform and nutrient concentrations in surface waters (Lenat and Crawford 1994; Whiles et al. 2000; Tong and Chen 2002). Spatial patterns (Hunsaker and Levine; 1995), agricultural densities (Harding et al. 1999), ecological patterns (Buck and Townsend, 2004), surface runoff, rainfall, and stream characteristics (Sheshane et al. 2005) influence agricultural contribution to fecal 
pollution. Urban runoff also influences water quality primarily due to impervious surfaces and residential activity. Additional pollution sources that contribute to fecal and nutrient pollution include septic systems, storm sewers, and fertilizer application (Olyphant et al. 2003; Ning et al. 2006; Zeilhofer et al. 2006). Six sites on Sinking Creek were monitored monthly from January 2011 through December 2011 to assess physical, chemical, and microbial water quality in relation to land use and to better understand the influences of these parameters on surface water quality. In addition, the presence and concentrations of E. coli O157:H7, Shigella sp., Giardia sp., Cryptosporidium sp., and bacteriophages were determined to assess the usefulness of fecal coliform bacteria as indicators of pathogen pollution.

\section{Materials and Methods}

Sinking Creek Location and Water Quality Monitoring

The Sinking Creek sub-watershed (06010103130) is one of 13 sub-watersheds that belong to the Watauga River watershed (TDEC, 2000a). Sinking Creek is a 9.8 mile long tributary of the Watauga River partially located in Washington and Carter Counties in Tennessee. The headwaters of Sinking Creek are located on Buffalo Mountain and it enters the Watauga River at mile 19.9. The main land uses within the 13.1 square mile drainage basin of the Sinking Creek watershed include: forest (65.5\%), urban (25.3\%), and agricultural areas (9.0\%) (TDEC 2000b). There are 19.8 impaired stream miles in the Sinking Creek watershed including tributaries (TDEC, 2000b). 
Upstream locations on Buffalo Mountain are forested, and land use transitions to urban, followed by agricultural land use at downstream sites. Fourteen sites were initially selected for routine water quality monitoring in 2002 and are described in Table 3.1 and Figure 3.1. From these 14 sampling locations, 2 sites were randomly selected from each land use classification and sampled monthly for the physical, chemical, and microbial parameters described in Table 3.2. The sites selected for representation of agricultural land use were sites 2 and 4, sites selected to represent urban land use were sites 7 and 10, and sites 13 and 14 represented forested land use. 
Table 3.1. Sampling locations on Sinking Creek sampled during this study

\begin{tabular}{|c|c|c|c|c|c|}
\hline $\begin{array}{l}\text { Site } \\
\text { Number }\end{array}$ & Site Location & $\begin{array}{l}\text { Predominant Land } \\
\text { Use }\end{array}$ & Physical Description & $\begin{array}{l}\text { Habitat } \\
\text { Assessment } \\
\text { Score (\%) }\end{array}$ & $\begin{array}{l}\text { Latitude/Longitude } \\
\text { Coordinates and } \\
\text { Elevation }\end{array}$ \\
\hline 2 & $\begin{array}{l}\text { Upstream of Bob Peoples } \\
\text { bridge on Sinking Creek Road }\end{array}$ & Agriculture & $\begin{array}{l}\text { Moderately eroded banks with little } \\
\text { vegetation buffer or riparian zone. } \\
\text { Creek bed predominantly cobble and gravel }\end{array}$ & $52 \%$ & $\begin{array}{c}19.837^{\prime} \mathrm{N}, 18.254^{\prime} \mathrm{W} \\
1530 \mathrm{ft}\end{array}$ \\
\hline 4 & $\begin{array}{l}\text { Upstream of crossing on Joe } \\
\text { Carr Road }\end{array}$ & Agriculture & $\begin{array}{l}\text { Moderately eroded banks with poor bank } \\
\text { stability and little vegetative buffer or riparian } \\
\text { zone. } \\
\text { Creek bed predominantly boulders, cobble } \\
\text { and gravel }\end{array}$ & $43 \%$ & $\begin{array}{c}19.594^{\prime} \mathrm{N}, 18.5799^{\prime} \mathrm{W} \\
1552 \mathrm{ft}\end{array}$ \\
\hline 7 & $\begin{array}{l}\text { Upstream of bridge on Miami } \\
\text { Drive, King Springs Baptist } \\
\text { Church }\end{array}$ & Urban & $\begin{array}{l}\text { Heavily eroded left bank, concrete bank on } \\
\text { right with no vegetative buffer or riparian } \\
\text { zone. } \\
\text { Creek bed predominantly cobble }\end{array}$ & $53 \%$ & $\begin{array}{c}18.772^{\prime} \mathrm{N}, 19.685^{\prime} \mathrm{W} \\
1583 \mathrm{ft}\end{array}$ \\
\hline 10 & $\begin{array}{l}\text { Upstream of bridge crossing } \\
\text { Sinking Creek at Hickory } \\
\text { Springs Road }\end{array}$ & Urban & $\begin{array}{l}\text { Heavily eroded banks with no vegetative } \\
\text { buffer. } \\
\text { Creek bed predominantly boulders and } \\
\text { cobble }\end{array}$ & $57 \%$ & $\begin{array}{l}17.431^{\prime} \mathrm{N}, 21.397 \text { ' W } \\
1720 \mathrm{ft}\end{array}$ \\
\hline 13 & $\begin{array}{l}\text { Upstream of road crossing on } \\
\text { Jim McNeese Road }\end{array}$ & Forest & $\begin{array}{l}\text { No visible bank erosion with moderate } \\
\text { riparian zone. } \\
\text { Creek bed predominantly boulders and } \\
\text { cobble }\end{array}$ & $71 \%$ & $\begin{array}{l}16.035^{\prime} \mathrm{N}, 22.163^{\prime} \mathrm{W} \\
2048 \mathrm{ft}\end{array}$ \\
\hline 14 & $\begin{array}{l}\text { Downstream of path crossing } \\
\text { at Dry Springs Road }\end{array}$ & Forest & $\begin{array}{l}\text { No visible bank erosion with optimal riparian } \\
\text { zone and vegetative buffer. } \\
\text { Creek bed predominantly boulders, cobble } \\
\text { and gravel }\end{array}$ & $83 \%$ & $\begin{array}{l}14.800^{\prime} \mathrm{N}, 22.033^{\prime} \mathrm{W} \\
2148 \mathrm{ft}\end{array}$ \\
\hline
\end{tabular}




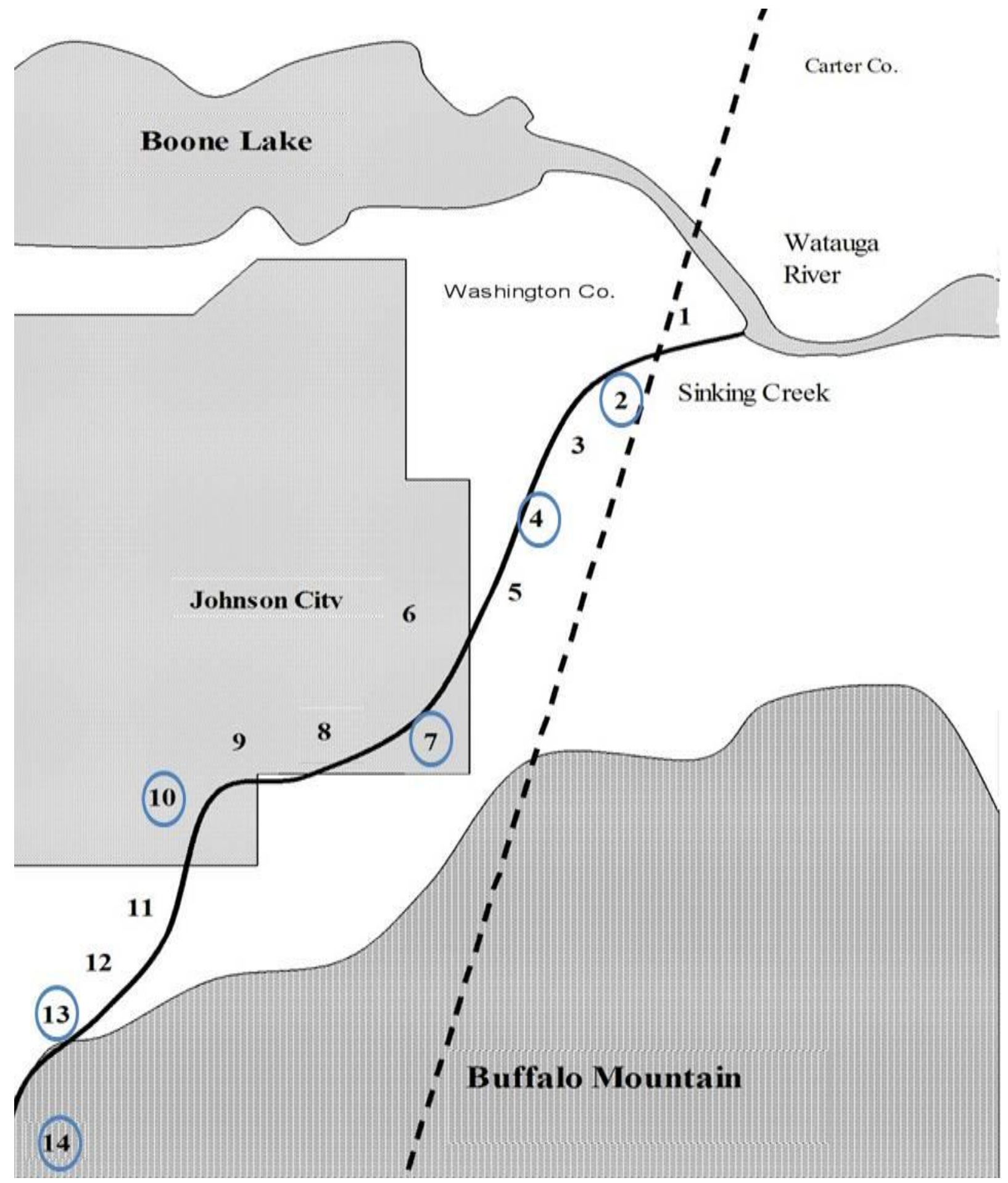

Figure 3.1. Map of Sinking Creek sampling locations (sites sampled in this study are circled). 
Table 3.2. Physical, chemical, and microbial water quality parameters measured

\begin{tabular}{|c|c|c|c|}
\hline Parameter & Abbreviation & Units & Holding Time \\
\hline $\mathrm{pH}$ & $\mathrm{pH}$ & $\mathrm{pH}$ & Field measurement \\
\hline Water temperature & WT & ${ }^{\circ} \mathrm{C}$ & Field measurement \\
\hline Air temperature & AT & ${ }^{\circ} \mathrm{C}$ & Field measurement \\
\hline Dissolved oxygen & DO & $\mathrm{mg} / \mathrm{l}$ as $\mathrm{O}_{2}$ & Field measurement \\
\hline Conductivity & Cond & $\mu$ mohs & Field measurement \\
\hline Fecal coliform in water & FCW & $\mathrm{CFU} / 100 \mathrm{ml}$ & $6 h$ \\
\hline Total coliform in water & TCW & CFU/100ml & $6 \mathrm{~h}$ \\
\hline Fecal coliform in sediment & FCS & $\mathrm{CFU} / 100 \mathrm{ml}$ & $6 \mathrm{~h}$ \\
\hline Total coliform in sediment & TCS & $\mathrm{CFU} / 100 \mathrm{ml}$ & $6 h$ \\
\hline Colilert & Colilert & $\mathrm{CFU} / 100 \mathrm{ml}$ & $6 \mathrm{~h}$ \\
\hline Standard plate count & SPC & $\mathrm{CFU} / \mathrm{ml}$ & $6 \mathrm{~h}$ \\
\hline Acridine orange direct counts & AODC & cells/g sediment & $6 \mathrm{~h}$ \\
\hline Acid phosphatase & AcidP & $\mu \mathrm{g} / \mathrm{g}$ sediment & $24 \mathrm{~h}$ \\
\hline Alkaline phosphatase & AlkP & $\mu \mathrm{g} / \mathrm{g}$ sediment & $24 \mathrm{~h}$ \\
\hline Dehydrogenase & $\mathrm{DHA}$ & $\mu \mathrm{g} / \mathrm{g}$ sediment & $24 \mathrm{~h}$ \\
\hline Galactosidase & Gal & $\mu \mathrm{g} / \mathrm{g}$ sediment & $24 \mathrm{~h}$ \\
\hline Glucosidase & Glu & $\mu \mathrm{g} / \mathrm{g}$ sediment & $24 \mathrm{~h}$ \\
\hline Nitrates & $\mathrm{NO}_{3}$ & $\mathrm{mg} / \mathrm{l}$ & $24 \mathrm{~h}$ \\
\hline Phosphates & $\mathrm{PO}_{4}^{2-}$ & $\mathrm{mg} / \mathrm{l}$ & $24 \mathrm{~h}$ \\
\hline Ammonia & $\mathrm{NH}_{3}^{+}$ & $\mathrm{mg} / \mathrm{l}$ & $24 \mathrm{~h}$ \\
\hline Biochemical oxygen demand & $\mathrm{BOD}_{5}$ & $\mathrm{mg} / \mathrm{l}$ & $24 \mathrm{~h}$ \\
\hline Hardness & Hard & $\mathrm{mg} / \mathrm{l}$ & $48 \mathrm{~h}$ \\
\hline Alkalinity & Alk & $\mathrm{mg} / \mathrm{l}$ & $24 \mathrm{~h}$ \\
\hline E. coli O157:H7 & O157:H7 & $\mathrm{CFU} / 100 \mathrm{ml}$ & $24 \mathrm{~h}$ \\
\hline Shigella sp. & Shigella & CFU/100ml & $24 \mathrm{~h}$ \\
\hline Giardia sp. & Giardia & Cysts/l & $72 \mathrm{~h}$ \\
\hline Cryptosporidium sp. & Crypto & Oocysts/l & $72 \mathrm{~h}$ \\
\hline F+ - specific bacteriophage & bacteriophage & $\mathrm{PFU} / \mathrm{ml}$ & $48 \mathrm{~h}$ \\
\hline
\end{tabular}

\section{Sample Collection}

Water samples were collected monthly from 6 pre-selected sites on Sinking Creek from January 2011 through December 2011 and were analyzed for the variables described in Table 2. Water samples for total and fecal coliform bacteria (TC/FC), standard plate counts (SPC), E. coli 057:H7, Shigella sp., and bacteriophage analyses were collected and analyzed in triplicate (SPC samples analyzed in duplicate) in sterile, 
1-L Nalgene ${ }^{\mathrm{TM}}$ bottles. Water samples for Colilert $\Theta$ analyses were collected in sterile 100ml plastic bottles (IDEXX Laboratories, Westbrook, Maine). Water samples for nitrates $\left(\mathrm{NO}_{3}{ }^{-}\right)$, phosphates $\left(\mathrm{PO}_{4}{ }^{-}\right)$, ammonia $\left(\mathrm{NH}_{3}{ }^{+}\right), 5$-day biochemical oxygen demand $\left(\mathrm{BOD}_{5}\right)$, alkalinity, and hardness were collected and analyzed in triplicate in sterile 2-L Nalgene ${ }^{\mathrm{TM}}$ bottles. Sediment samples for TC/FC in water, microbial enzyme activity (MEA), and acridine orange direct counts (AODC) were collected in $20 z$ sterile WhirlPak ${ }^{\mathrm{TM}}$ bags. All samples were transported to the laboratory on ice and analyzed within the holding times described in Table 3.2. Field measurements for $\mathrm{pH}$, air and water temperature, dissolved oxygen, and conductivity were also collected at each site.

Quality assurance and quality control (QA/QC) practices included the analysis of chemical parameters consisted of one trip blank, one field blank, a negative control, one replicate, one spiked sample, and one quality control standard. QA/QC practices included in the analysis of microbial parameters included the analysis of one trip blank, one field blank, a negative control, and a positive control. A secondary wastewater effluent sample was used as the positive control for TC/FC, Colilert®, SPC, and bacteriophage analyses. Laboratory strains of E. coli O157:H7 and Shigella flexneri (ATCC $®$ Number $43895^{\mathrm{TM}}$ and ATCC ${ }^{\circledR} 12022^{\mathrm{TM}}$, respectively) were used to seed water samples that served as a positive control for PCR analysis.

\section{Microbial Analyses}

TC/FC analyses for water samples were conducted according to Standard Methods for Examination of Water and Wastewater (APHA, 1992). Briefly, $0.5 \mathrm{ml}$ of water were filtered through a $0.45 \mu \mathrm{m}$ membrane filter (EMD Millipore, Billerica, $M A)$ and 
the filter placed in a petri dish containing an absorbent pad (EMD Millipore, Billerica, MA) with $2 \mathrm{ml}$ of $\mathrm{m}$-Endo media for total coliform analysis or $\mathrm{m}-\mathrm{FC}$ media for fecal coliform analysis. All plates were inverted and enumerated following $24 \mathrm{~h}$ incubation at $37^{\circ} \mathrm{C}$ and $44.5^{\circ} \mathrm{C}$ for total coliform and fecal coliforms, respectively. For TC/FC sediment analyses, $0.5 \mathrm{~g}$ of sediment was added to $25 \mathrm{ml}$ of sterile water $+1 \%$ Tween 80. The samples were vortexed and allowed to settle for 30 minutes, and $0.5 \mathrm{ml}$ of the buffer suspension was filtered according to Standard Methods for Examination of Water and Wastewater as described above (APHA, 1992).

SPC were conducted according to Standard Methods for Examination of Water and Wastewater (APHA, 1992) using R2A agar. One milliliter of water was placed in the center of a sterile petri dish (Fisher Scientific, Pittsburgh, PA) and 10ml of R2A agar was added to the dish. The plate was swirled in a figure eight motion to allow the sample to disperse in the media and cover the plate. Plates were allowed to solidify and were enumerated following incubation at $25^{\circ} \mathrm{C}$ for $48 \mathrm{~h}$. Escherichia coli concentrations were determined using the Colilert@ Quanti-Tray method (APHA, 1995). To each $100 \mathrm{ml}$ water sample, a packet of Defined Substrate Technology ${ }^{\circledR}(\mathrm{DST} \circledast)$ reagent (IDEXX Laboratories, Westbrook, Maine) was added and mixed. The sample was then poured into a Quanti-Tray ${ }^{\circledR}$, sealed using the Quanti-Tray ${ }^{\circledR}$ sealer, and incubated for $24 \mathrm{~h}$ at $37^{\circ} \mathrm{C}$. E. coli were then enumerated using the Standard Method most probable number (MPN) procedure. Samples for water TC/FC were processed in triplicate and samples for sediment TC/FC were processed in duplicate. SPC were processed in duplicate and one Colilert® sample was processed for each site. 
MEA analyses were conducted and included acid and alkaline phosphatases, glucosidase, galactosidase, and dehydrogenase activities. For each enzyme analyzed, $1 \mathrm{~g}$ of sediment was added to a test tube containing a specific buffer and enzyme. Sediment samples for acid phosphatase were mixed with $4 \mathrm{ml}$ of $1 \mathrm{M}$ TRIS buffer ( $\mathrm{pH}$ 4.8) and $4 \mathrm{ml}$ of $1 \mathrm{M}$ TRIS buffer $(\mathrm{pH}) 8.4$ for alkaline phosphatase. For both acid and alkaline phosphatase, $1 \mathrm{ml}$ of $1 \mathrm{M}$ TRIS buffer with $0.1 \%$ phosphatase substrate $(\mathrm{pH} 7.6)$ was added to each tube (Sayler et al. 1979). Sediment samples for galactosidase and glucosidase activities were mixed with $4 \mathrm{ml}$ of $0.1 \mathrm{M}$ phosphate buffer $(\mathrm{pH} 9.0)$. Galactosidase activity was measured by adding $1 \mathrm{ml}$ of $0.01 \mathrm{M}$ phosphate buffer with $0.15 \% \mathrm{p}$-nitrophenyl- $\beta$-D-galactopyranoside as an indicator of galactosidase activity. One milliliter of $0.01 \mathrm{M}$ phosphate buffer with $0.15 \% 4$-nitrophenyl- $\beta$-D-glucopyranoside was used as an indicator to assess glucosidase activities (Morrison et al. 1977). Following addition of buffers and indicators, all tubes were vortexted and incubated at $25^{\circ} \mathrm{C}$ for $24 \mathrm{~h}$. Acid and alkaline phosphatase, galactosidase, and glucosidase activities were determined using a spectrophotometer at an absorbance of $418 \mathrm{~nm}$.

For dehydrogenase (DHA) activity, $1 \mathrm{~g}$ of sediment was added to a test tube containing $2 \mathrm{ml}$ of $0.1 \mathrm{M}$ phosphate buffer $(\mathrm{pH} 7.6)$ and $1 \mathrm{ml}$ of $0.5 \%$ iodonitrotetrazolium chloride (INT) salt solution. The samples were vortexed and incubated in the dark at $25^{\circ} \mathrm{C}$ for 45 minutes. One milliliter of the sample was filtered through a $0.22 \mu \mathrm{m}$ porosity cellulose membrane (GE Water and Process Technologies, Trevose, PA) and allowed to dry at room temperature. The membrane, was then added to a test tube containing $5 \mathrm{ml}$ of dimethyl sulfoxide, vortexted to dissolve the membrane, and incubated in the 
dark at $25^{\circ} \mathrm{C}$ for $24 \mathrm{~h}$. Dehydrogenase activity was then determined using a spectrophotometer at an absorbance of $460 \mathrm{~nm}$.

AODC analysis was performed as described by Ghiorse and Balkwill (1983). Three hundred milligrams of sediment was added to $30 \mathrm{ml}$ of sterile PBS+Tween 80 , vortexed for $60 \mathrm{~s}$, and allowed to settle for $3 \mathrm{~h}$. Two hundred fifty microliters of the suspension was mixed with $5 \mathrm{ml}$ sterile water $+500 \mu \mathrm{l}$ acridine orange stain, and samples were vortexed for $30 \mathrm{~s}$. Samples were filtered using $25 \mathrm{~mm}, 0.2 \mu \mathrm{m}$ pore polycarbonate nucleopore filters (Osmonics, Inc., Minnetonka, MN), and the filters were mounted and fixed on slides for enumeration at 1000X using the Olympus $\mathrm{BH} 2$ epifluorescent microscope (Olympus, New Hyde Park, NY). One sediment sample was processed per site and 3 microscopic fields were enumerated on each slide.

\section{Chemical Analyses}

$\mathrm{NO}_{3}{ }^{-}, \mathrm{PO}_{4}{ }^{-}, \mathrm{NH}_{3}{ }^{+}$, alkalinity, and hardness analyses were performed in triplicate using colorimetric $\mathrm{HACH}^{\mathrm{TM}}$ methods and $\mathrm{HACH}^{\mathrm{TM}}$ reagents as described by the manufacturer ( $\mathrm{HACH}$ Company, Loveland, $\mathrm{CO}$ ). Briefly, $\mathrm{NO}_{3}{ }^{-}, \mathrm{PO}_{4}{ }^{-}, \mathrm{NH}_{3}{ }^{+}$analyses were conducted by adding $10 \mathrm{ml}$ of water to a vial containing the appropriate reagent packet; NitraVer5, PhosVer3 and salicylate/ammonia cyanurate reagents, respectively. The vials were shaken to dissolve the reagent and samples were analyzed using pocket colorimeters specific to the nutrient of interest. Alkalinity and hardness analyses were conducted using $100 \mathrm{ml}$ sample volumes and a digital titrator. For alkalinity determination, 1 packet of phenolthalein indicator and bromcresol green-methyl red indicator were added to the sample and mixed. The sample was then titrated with $1.6 \mathrm{~N}$ 
sulfuric acid to a grey-green endpoint. For hardness determination, 1 packet of ManVer2 reagent and $2 \mathrm{ml}$ of hardness buffer $(\mathrm{pH} \mathrm{10})$ were added to the $100 \mathrm{ml}$ sample and mixed. The sample was then titrated with $0.8 \mathrm{~N}$ Ethylenediaminetetraacetic acid (EDTA) to a blue endpoint. $\mathrm{BOD}_{5}$ analyses were conducted according to Standard Methods for Examination of Water and Wastewater (APHA, 1992). Wheaton BOD bottles (Wheaton Science Products, Millville, $\mathrm{NJ}$ ) were completely filled with sample water and capped with glass stoppers to ensure no air bubbles were present. Initial (Day 0) and final (Day 5) dissolved oxygen concentrations were measured using the YSI Model 5000 dissolved oxygen meter (YSI Inc., Yellow Springs, OH).

\section{Pathogenic Bacteria Analyses}

Samples for E. coli O157:H7 and Shigella sp. were analyzed in triplicate. The method used for the filtration and isolation of the bacteria is described by Bej et al. (1991). One hundred milliliters of water was collected and filtered through a $0.22 \mu \mathrm{m}$ membrane filter. The filter was then washed with $10 \mathrm{ml}$ of a $1 \%$ Tween 80 solution and centrifuged for 10 minutes to create a cell pellet. The supernatant was removed and the cell pellet was washed twice with $10 \mathrm{ml}$ phosphate buffered saline. Fifty microliters of diethylpyrocarbonate solution was added to the final cell pellet and subjected to 6 freeze-thaw cycles at $-20^{\circ} \mathrm{C}$ and $100^{\circ} \mathrm{C}$, respectively.

PCR amplification for E. coli O157:H7 was performed as described by Kimura et al. (2000) using primers EC-1 (GGCAGCCAGCATTTTTTTA) and EC-2 (CACCCAACAGAGAAGCCA) for the chuA gene. The final 50 $\mu$ I PCR mixture contained 2.5X PCR buffer ( $\mathrm{mM} \mathrm{MgCl}_{2}, 10 \mathrm{mM}$ Tris- $\left.\mathrm{HCl}, 50 \mathrm{mM} \mathrm{KCl}\right), 0.8 \mathrm{mM}$ of each 
deoxynucleoside triphosphate (dATP, dCTP, dGTP, and dTTP), $4 \mu \mathrm{M}$ concentrations of each primer, $5 \cup$ Taq DNA polymerase (Fisher Scientific, Pittsburg, PA) and $5 \mu$ l of the resuspended cell pellet. The PCR mixture was subjected to an initial denaturation step at $95^{\circ} \mathrm{C}$ for 5 minutes, followed by 35 cycles of 1 minute denaturation at $94^{\circ} \mathrm{C}, 2$ minutes of annealing at $42^{\circ} \mathrm{C}$, and 5 minutes of primer extension at $72^{\circ} \mathrm{C}$. A final extension step was performed at $72^{\circ} \mathrm{C}$ for 10 minutes using a BioRad Thermocycler PCR Machine (BioRad, Hurcules, CA). PCR products were resolved on a $2 \%$ agarose gel for $1.5 \mathrm{~h}$ at $80 \mathrm{~V}$ and subjected to ethidium bromide staining to visualize DNA base pair bands. The presence of a 901 base pair band indicated a sample positive for E. coli $0157: \mathrm{H} 7$.

PCR amplification for Shigella sp. was performed as described by Theron et al. (2001). Thirty cycles of a seminested PCR reaction were performed using primers $\mathrm{H} 8$ (GTTCCTTGACCGCCTTTCCGATAC) and H15 (GCCGGTCAGCCACCCTC) for the ipaH gene (Islam, et al. 1993a) in the first round of PCR. The 50 $\mu$ reaction volume contained 1X PCR buffer ( $\mathrm{mM} \mathrm{MgCl}_{2}, 10 \mathrm{mM}$ Tris- $\left.\mathrm{HCl}, 50 \mathrm{mM} \mathrm{KCl}\right), 0.1 \mathrm{mM}$ of each deoxynucleoside triphosphate (dATP, dCTP, dGTP, and dTTP), 24pmol of H8 primer, 34pmol of H15 primer, 1U Taq DNA polymerase (Fisher Scientific, Pittsburg, PA), and $10 \mu \mathrm{l}$ of resuspended cell pellet. The PCR mixture was subjected to an initial denaturation step at $94^{\circ} \mathrm{C}$ for 3 minutes, followed by 10 cycles of 1 minute denaturation at $94^{\circ} \mathrm{C}, 1$ minute of annealing at $60^{\circ} \mathrm{C}$, and 1 minute of primer extension at $72^{\circ} \mathrm{C}$. One microliter of PCR product from the first PCR round was added to a reaction tube containing the reagents described above, with the addition of $31 \mathrm{pmol}$ of $\mathrm{H} 10$ primer (CATTTCCTTCACGGCAGTGGA) described by Hartman et al. (1990). An initial denaturation step was performed at $94^{\circ} \mathrm{C}$ for 3 minutes, followed by 20 cycles of 1 
minute denaturation at $94^{\circ} \mathrm{C}, 1$ minute of annealing at $60^{\circ} \mathrm{C}$, and 1 minute of primer extension at $72^{\circ} \mathrm{C}$. A final extension step was performed at $72^{\circ} \mathrm{C}$ for 7 minutes using a BioRad Thermocycler PCR Machine (BioRad, Hurcules, CA). PCR products were resolved on a $2 \%$ agarose gel for $1.5 \mathrm{~h}$ at $80 \mathrm{~V}$ and subjected to ethidium bromide staining to visualize DNA base pair bands. The presence of both a 401 and 620 base pair band indicated a sample positive for Shigella sp.

\section{Protozoan Analysis}

One water sample was collected and analyzed monthly at each site for the analysis of Giardia and Cryptosporidium. Samples were collected as described by USEPA method 1623 for water filtration (USEPA, 2005). One hundred liters of water were filtered at each site though Envirochek ${ }^{\mathrm{TM}}$ sampling filters (Pall Corporation, Ann Arbor, $\mathrm{MI}$ ) using a gas powered water pump and Badger ${ }^{\mathrm{TM}}$ flow meter at a rate of 2.5L/minute. The filtration apparatus was assembled as shown in Figure 3. 


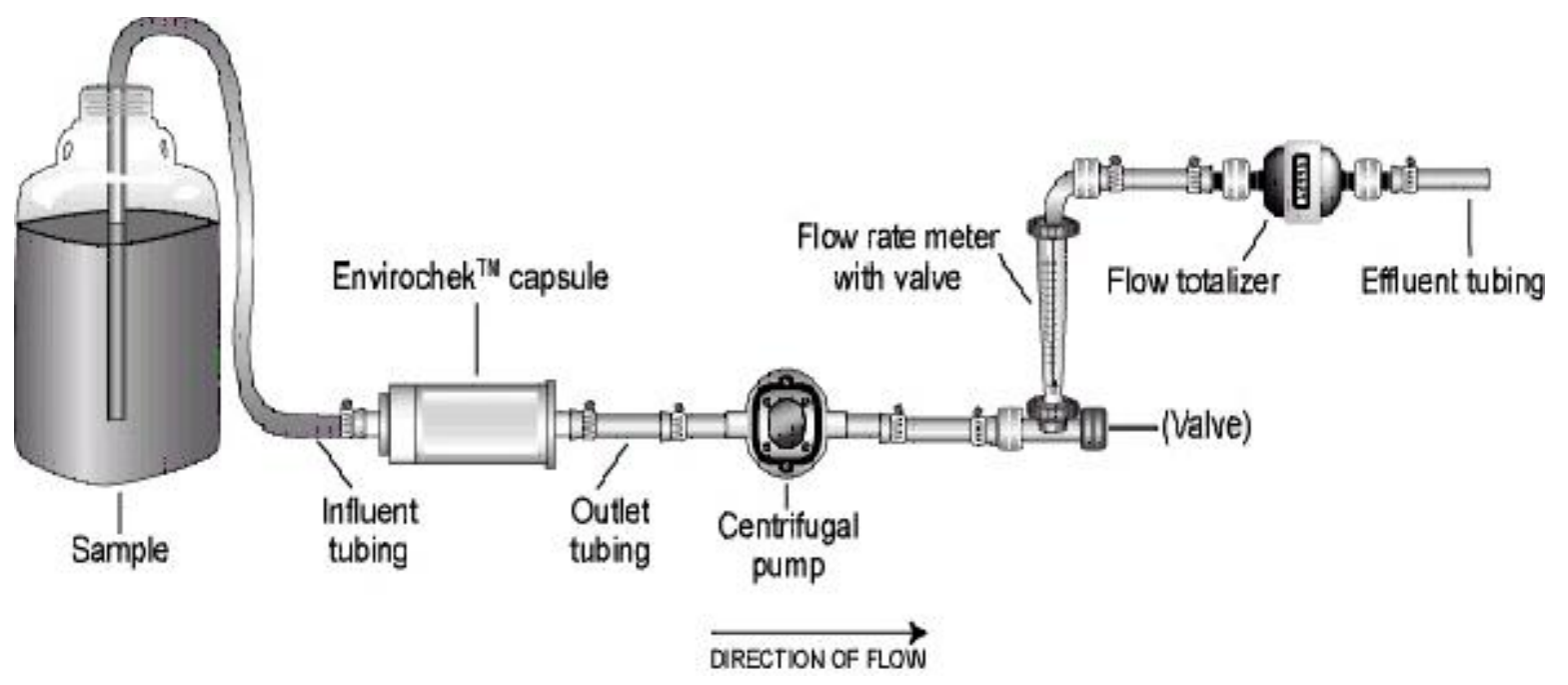

Figure 3.2. Filtration apparatus used to sample Giardia and Cryptosporidium in laboratory seeded samples (USEPA, 2005)

The filters were transported to the lab on ice and analyzed within $72 \mathrm{~h}$ of collection. Filters were initially washed by adding $120 \mathrm{ml}$ of elution buffer to the filter capsule and placing on a wrist action shaker for 30 minutes. The elution buffer was removed and the filter capsule broken open and the filter cut out using a sterile razor blade and hand washed using $120 \mathrm{ml}$ of elution buffer. The buffer was then added to a sterile $250 \mathrm{ml}$ centrifuge tube containing the elution buffer from the initial wash on the wrist action shaker. The samples were centrifuged at 2,300 $\mathrm{xg}$ for $30 \mathrm{~min}$ and the supernatant removed. The concentrated pellet collected was subjected to an immunofluorescent assay using the Waterborne Aqua-Glo ${ }^{\mathrm{TM}} \mathrm{G} / \mathrm{C}$ Direct FL antibody stain (Waterborne, Inc. New Orleans, LA) as described by the manufacturer. The prepared slides were examined at 200X using the Olympus BH2 epifluorescent microscope (Olympus, New Hyde Park, NY). 


\section{Bacteriophage Analyses}

Samples for bacteriophage analysis were collected and analyzed in triplicate using the double-layer agar procedure described in USEPA method 1601 (USEPA, 2001a) using E. coli $\mathrm{C} 3000$ as the host strain (ATCC $\AA$ Number $15597^{\mathrm{TM}}$ ). The host strain was cultured using ATCC 271 broth $(10 \mathrm{~g} / \mathrm{L}$ tryptone, $1 \mathrm{~g} / \mathrm{L}$ yeast extract, $8 \mathrm{~g} \mathrm{NaCl}$, $10 \mathrm{ml} / \mathrm{L}$ of $10 \%$ glucose solution, $2 \mathrm{ml} / \mathrm{L}$ of $1 \mathrm{M} \mathrm{CaCl}_{2}, 1 \mathrm{ml} / \mathrm{L}$ of $10 \mathrm{mg} / \mathrm{ml}$ thiamine) at $37^{\circ} \mathrm{C}$. An overnight culture of the host strain was prepared the day before analysis by inoculating a $30 \mathrm{ml}$ ATCC broth culture with the host strain. On the day of analysis, $100 \mu \mathrm{l}$ of the prepared overnight culture of the host strain was inoculated into a $30 \mathrm{ml}$ of fresh ATCC 271 broth and incubated at $37^{\circ} \mathrm{C}$ until log phase was reached ( 4h).

Ten milliliters of collected sample water were filtered through a syringe filter fitted with a $0.22 \mu \mathrm{m}$ membrane filter to remove bacteria and the filtrate was serially diluted in phosphate buffered water for analysis. Five hundred microliters of each dilution were added to a test tube containing $5 \mathrm{ml}$ of $0.7 \%$ ATCC $® 271$ agar (ATCC $\AA 271$ broth with $1.4 \mathrm{~g} / \mathrm{L}$ agar) and $100 \mu \mathrm{l}$ of host bacteria. The tubes were gently mixed and poured onto a plate containing 1.5\% ATCC 271 agar (ATCC® 271 broth with 18g/L agar). Plates were allowed to solidify prior to incubation at $37^{\circ} \mathrm{C}$ for $24 \mathrm{~h}$ and plaques were enumerated.

\section{Data Analysis of Fecal Coliform Data and Pathogen Prevalence}

Statistical analyses were performed using SAS/STAT software version 9.2 (SAS Institute, Cary, NC). Fecal coliform data were log transformed to achieve normality, and concentrations were compared by site, season, and land use pattern using the Analysis 
of Variance (ANOVA) procedure to assess the influences of spatial and temporal variability on fecal coliform concentrations. Linear regression analyses were also performed using the REG procedure to estimate the correlation between fecal indicator organisms (fecal coliform bacteria and E. coli) and pathogens to assess their usefulness as indicators of pathogen presence in Sinking Creek.

\section{$\underline{\text { Results and Discussion }}$}

\section{General Trends of Water Quality Parameters}

$\mathrm{pH}$ values (Figure 3.3) were within the acceptable range of $6.0-9.0$ for recreational activity throughout the duration of the study (TDEC, 2008). Fall air and water temperatures were lower than the winter, spring, and summer months (Figures 3.4 and 3.5). All water temperatures were within the acceptable range for recreational waters throughout the duration of the study, as the water temperature was not observed to exceed $30.5^{\circ} \mathrm{C}$ at any point and did not have a water change greater than $3^{\circ} \mathrm{C}$ between any 2 sampling locations (TDEC, 2008). Dissolved oxygen concentrations were higher during the winter months compared to other seasons (Figure 3.6) because cold water is able to hold more dissolved oxygen than warm water. 


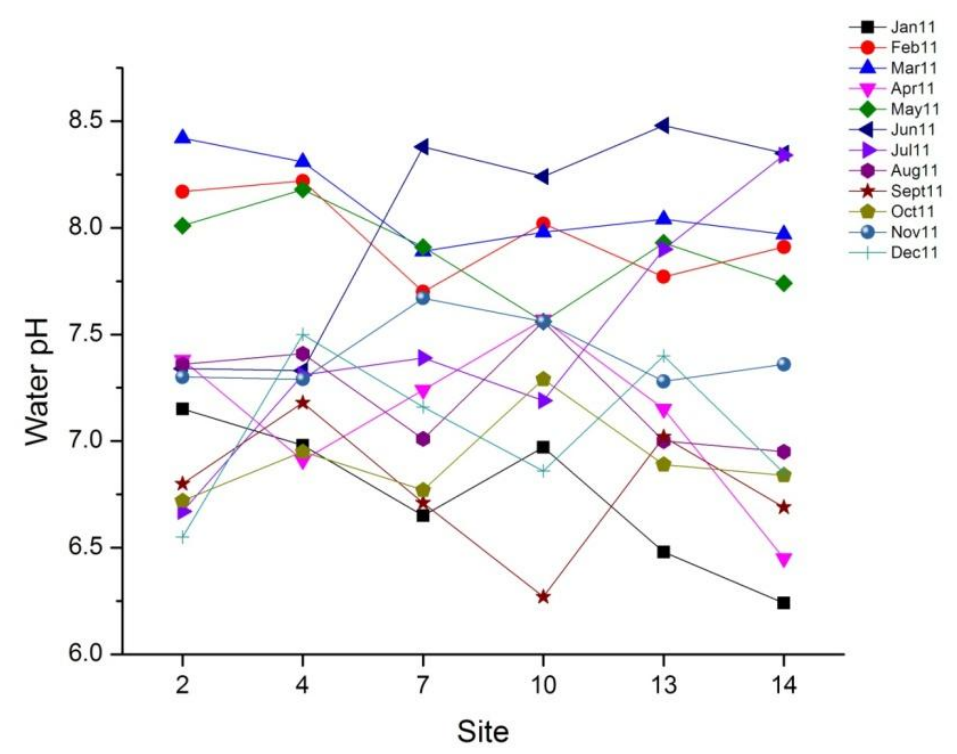

Figure 3.3. $\mathrm{pH}$ in the water of Sinking Creek by site and month

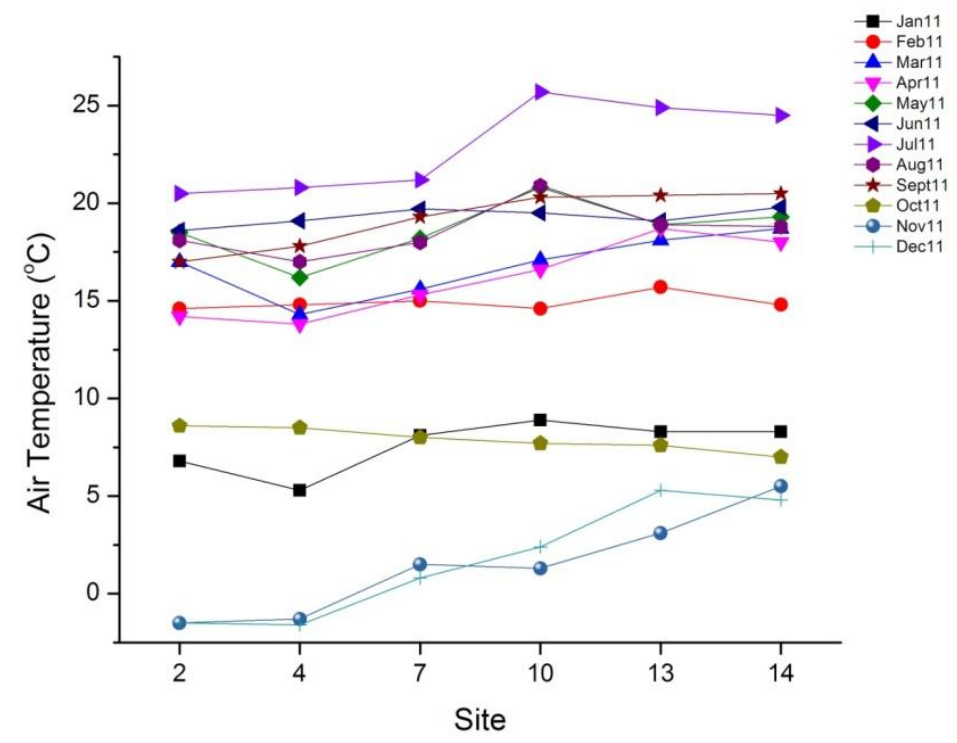

Figure 3.4. Air temperature along Sinking Creek by site and month 


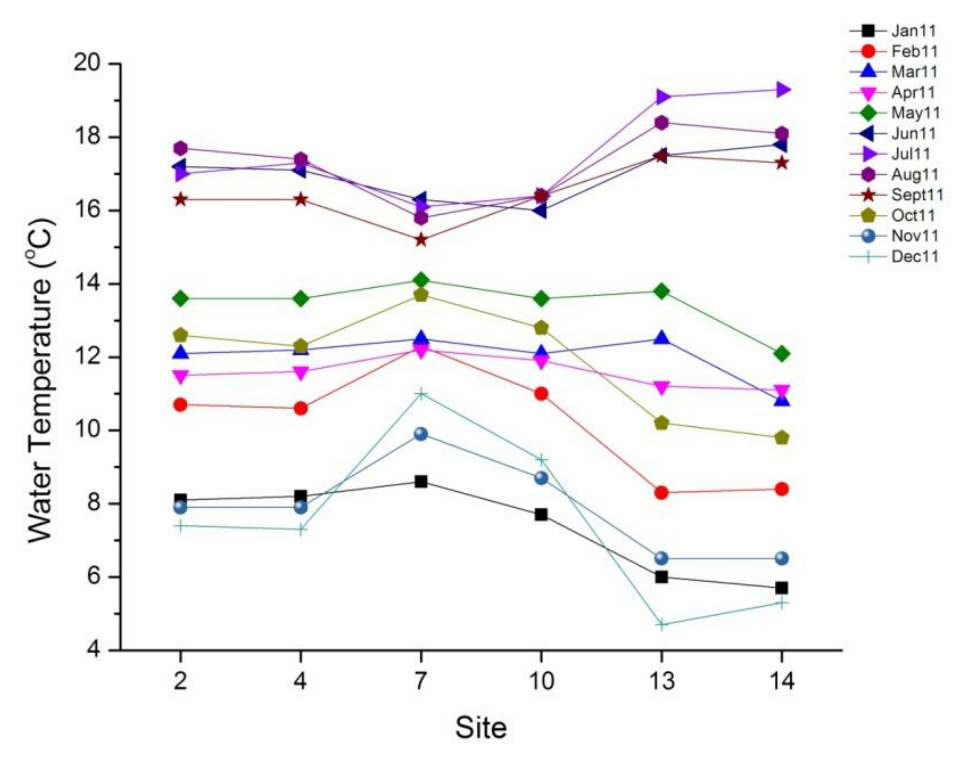

Figure 3.5. Water temperature of Sinking Creek by site and month

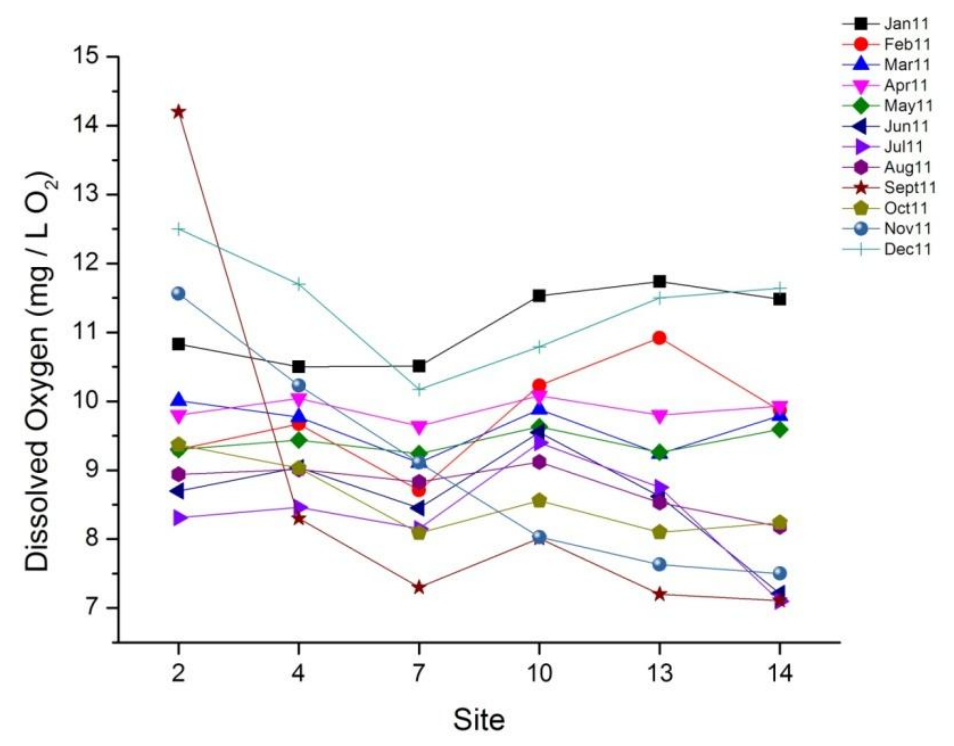

Figure 3.6. Dissolved oxygen of Sinking Creek by site and month

Conductivity is affected by the presence of ions and was shown to increase between upstream and downstream sites (Figure 3.7) in a similar pattern to that of 
alkalinity and hardness (Figures 3.8 and 3.9). This relationship is expected, as the cations contributing to alkalinity and hardness are introduced through runoff or organic matter addition, thus resulting in an increase of conductivity with distance downstream. Discharge also increased with distance downstream (Figure 3.10) due to increases in water depth and flow and creek width that also suggests that observed alkalinity and hardness concentrations are related to runoff and organic matter conditions.

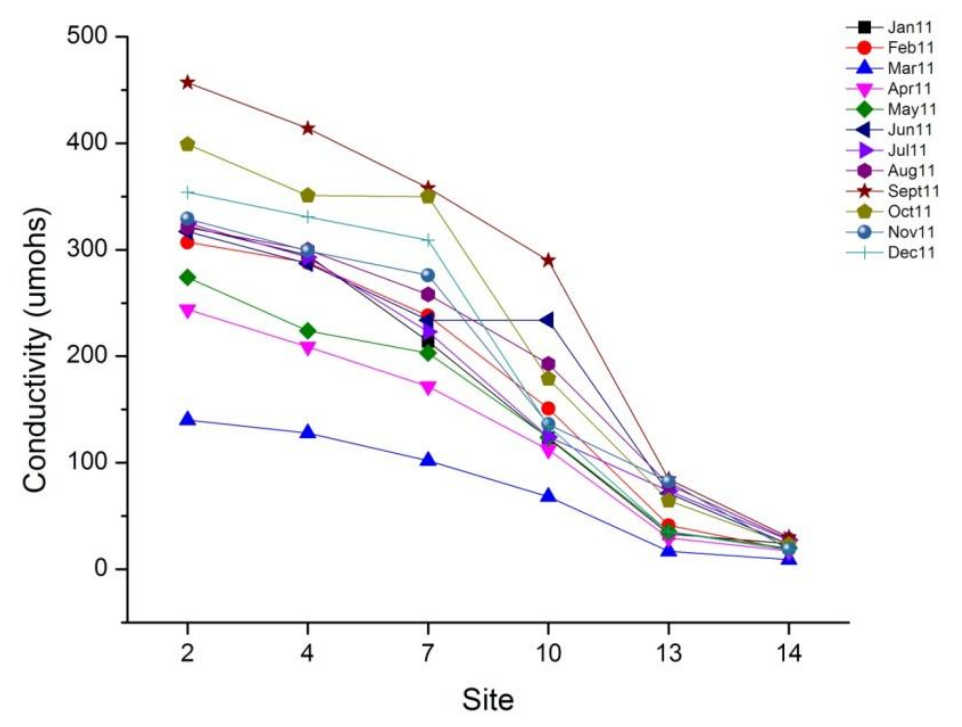

Figure 3.7. Conductivity of Sinking Creek by site and month 


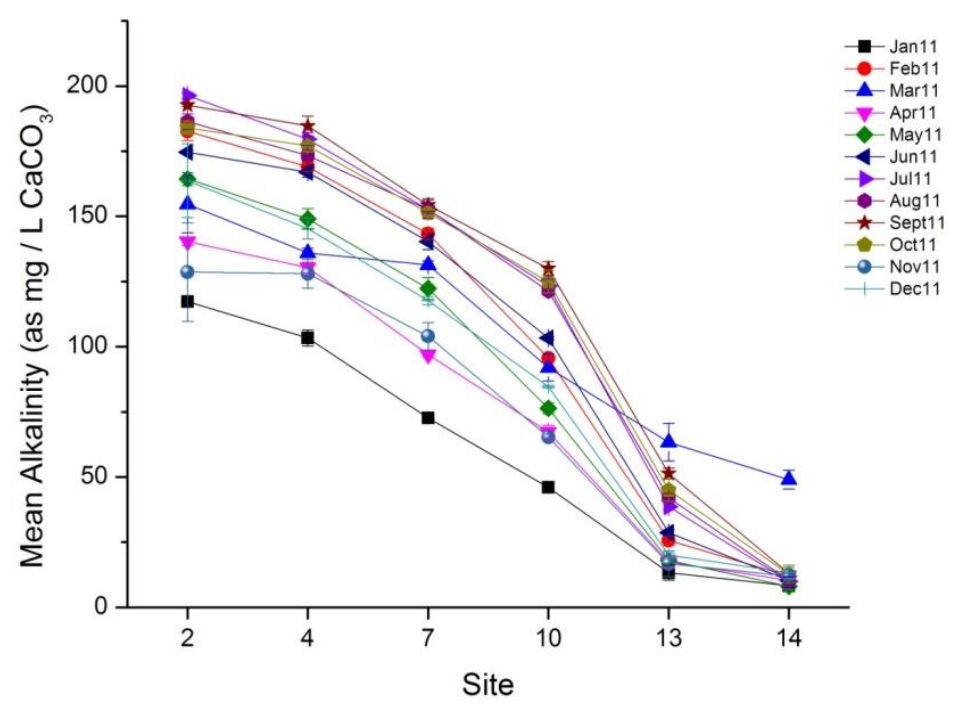

Figure 3.8. Alkalinity of Sinking Creek by site and month

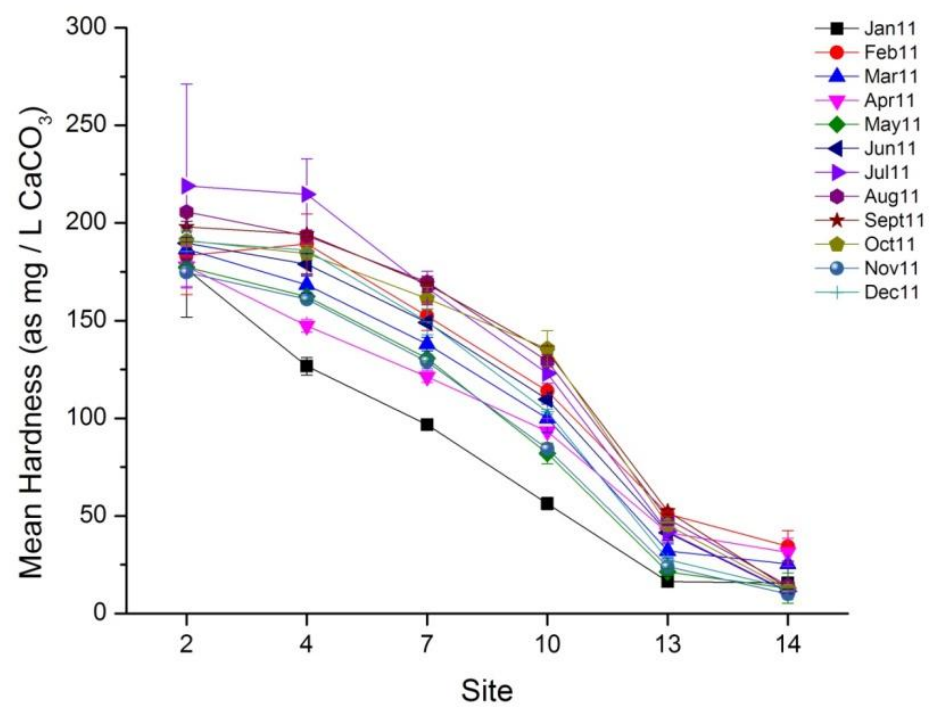

Figure 3.9. Hardness of Sinking Creek by site and month 


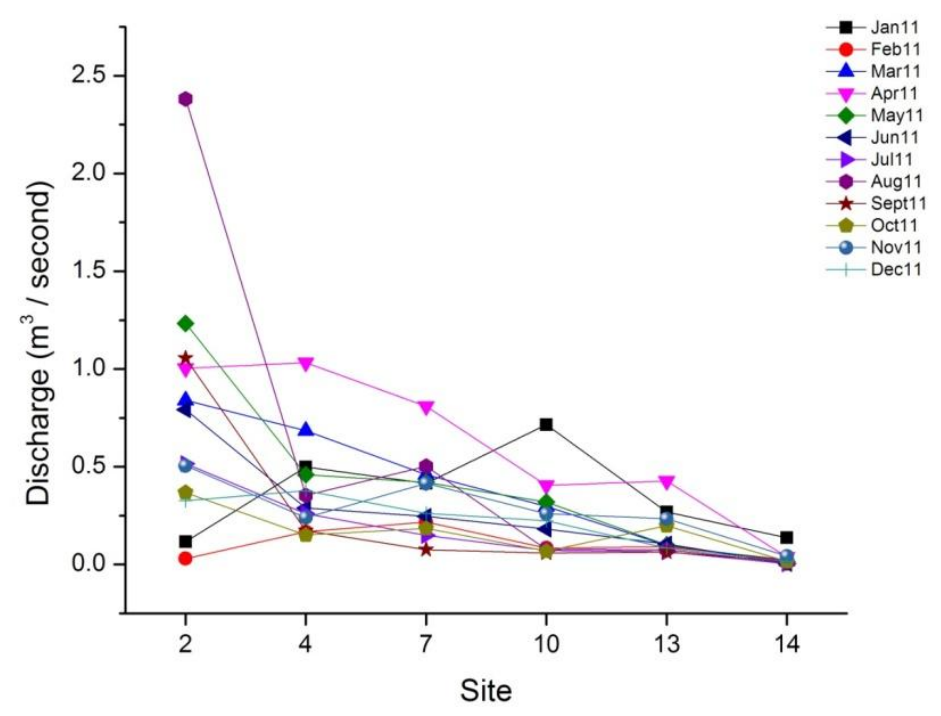

Figure 3.10. Discharge of Sinking Creek by site and month

Visual observation of total and fecal coliform concentrations in water demonstrates that the highest concentrations are at the downstream (agricultural) sites (Figures 3.11 and 3.12). Total and fecal coliform concentrations in sediment (Figure 3.13 and 3.14) are lower and show more fluctuation between sites compared to water concentrations. The lack of a total and fecal coliform trend based on site is likely a function of creek discharge because total and fecal coliform concentrations at those sites with lower discharges are more likely to partition into sediment (Jamison et al. 2003; Whitman and Nevers, 2003). E. coli concentrations and standard plate counts (Figures 3.15 and 3.16) also vary by season and site, as concentrations tend to be higher during the spring and summer months and increase with increasing distance downstream. 


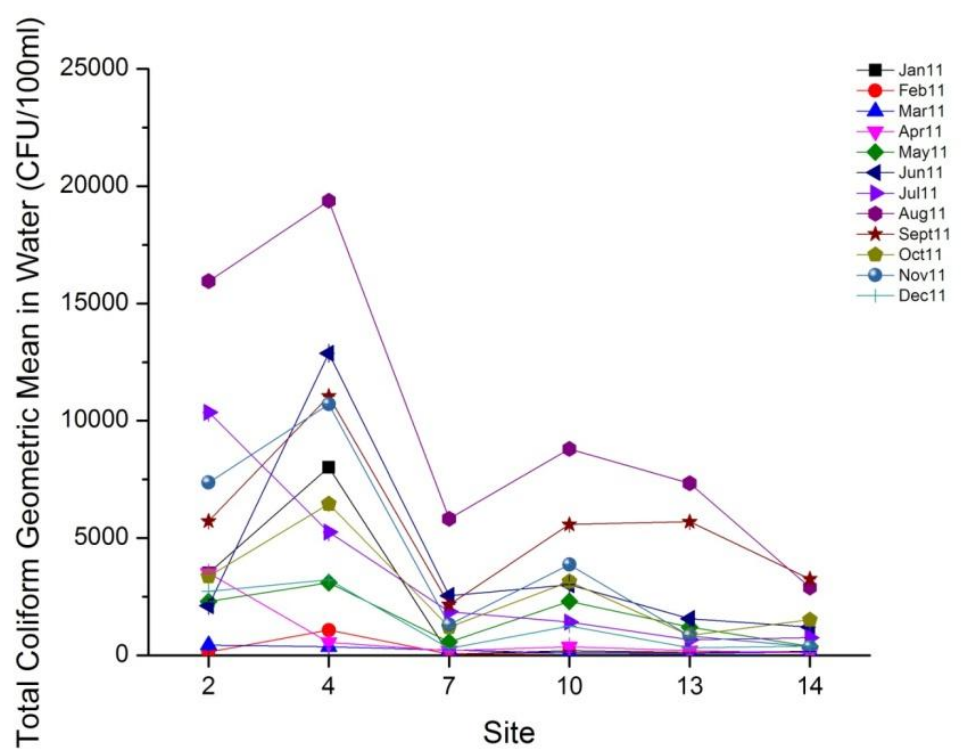

Figure 3.11. Geometric mean of total coliform concentrations in water in Sinking Creek by site and month

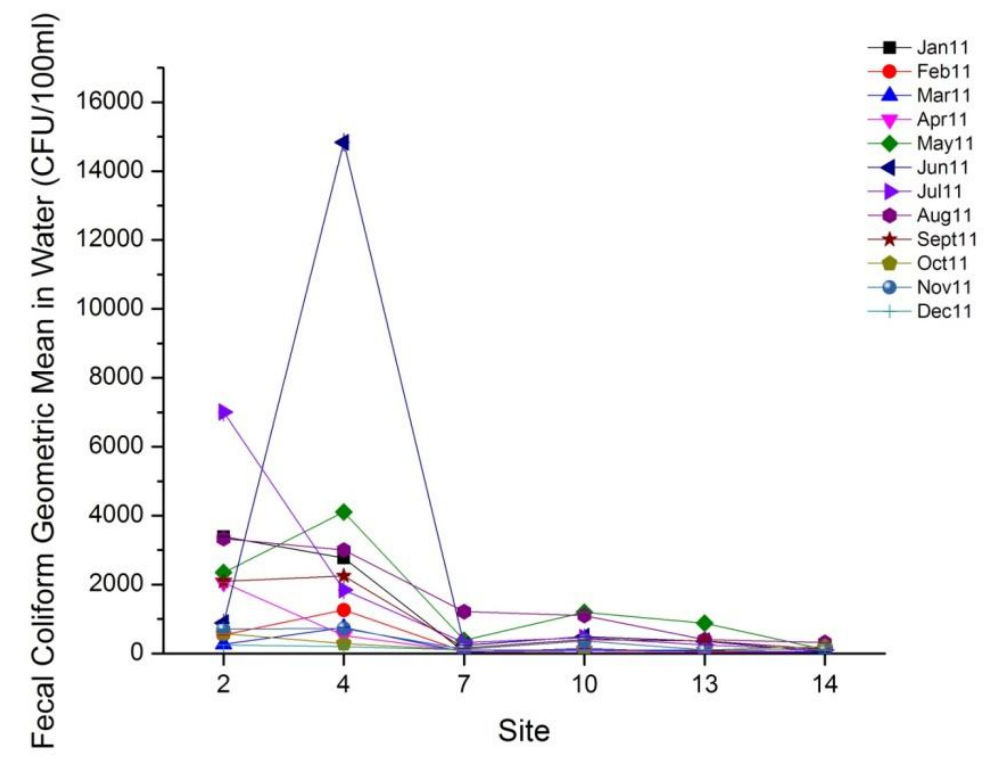

Figure 3.12. Geometric mean of fecal coliform concentrations in water in Sinking Creek by site and month 


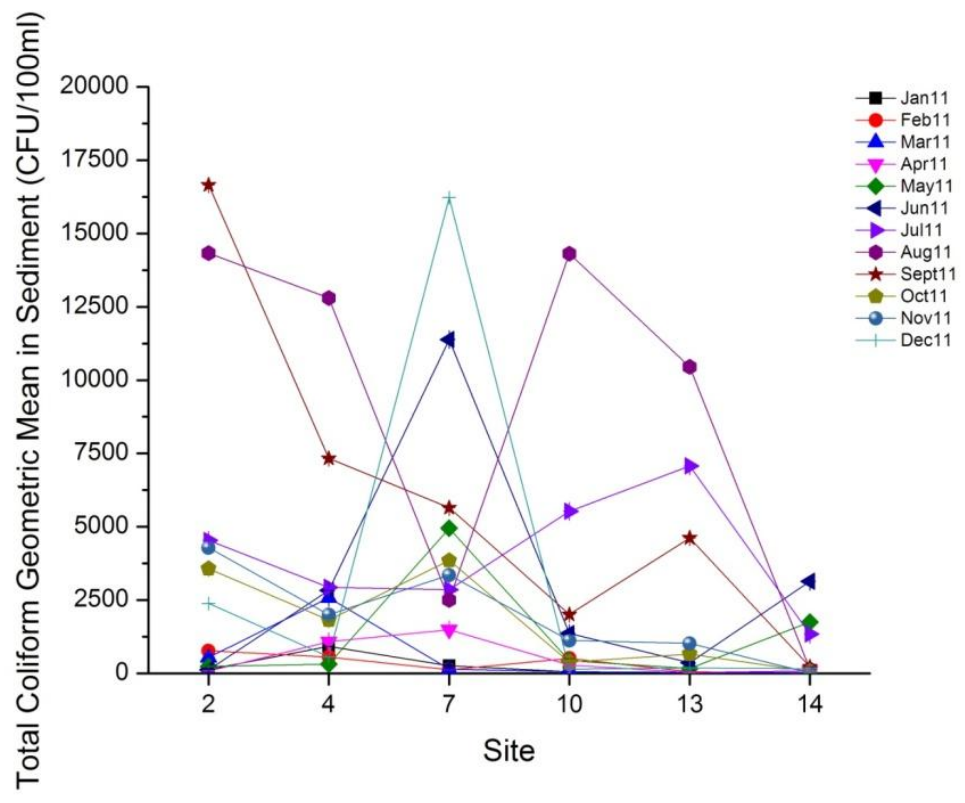

Figure 3.13. Geometric mean of total coliform concentrations in sediment in Sinking Creek by site and month

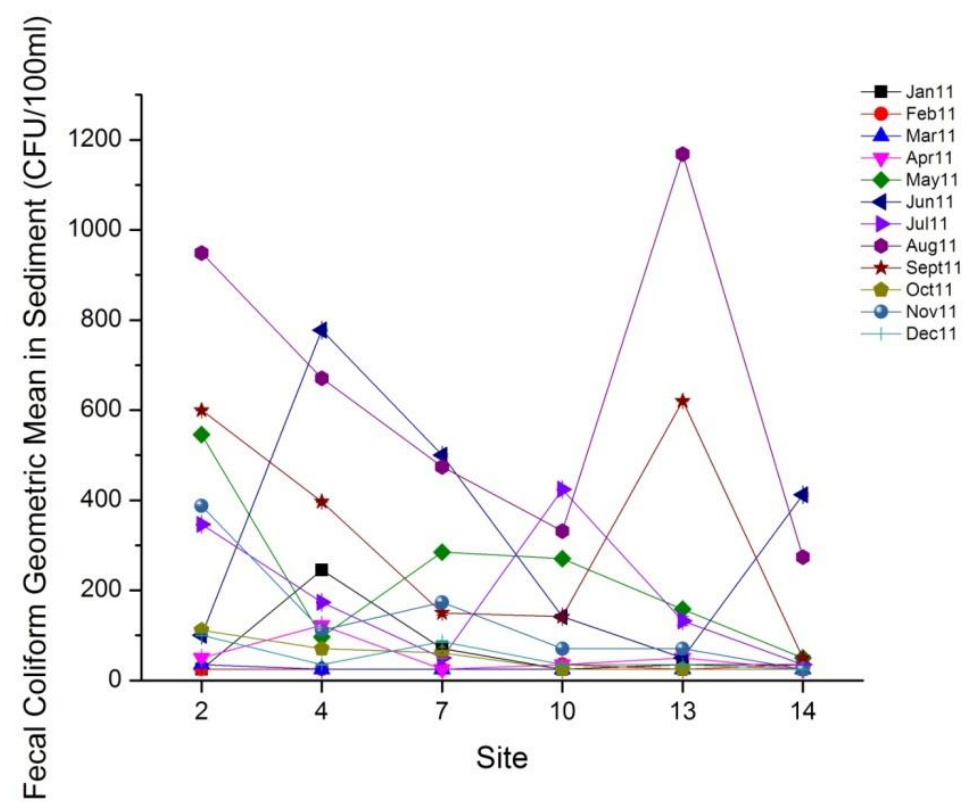

Figure 3.14. Geometric mean of fecal coliform concentrations in sediment in Sinking Creek by site and month 


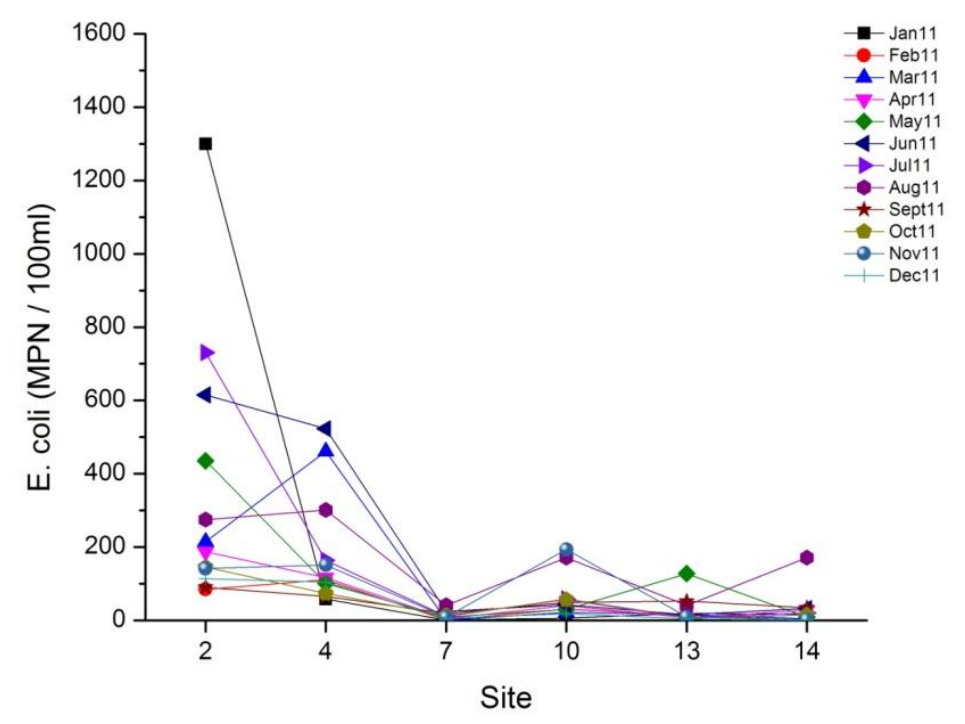

Figure 3.15. E. coli concentrations in Sinking Creek by site and month

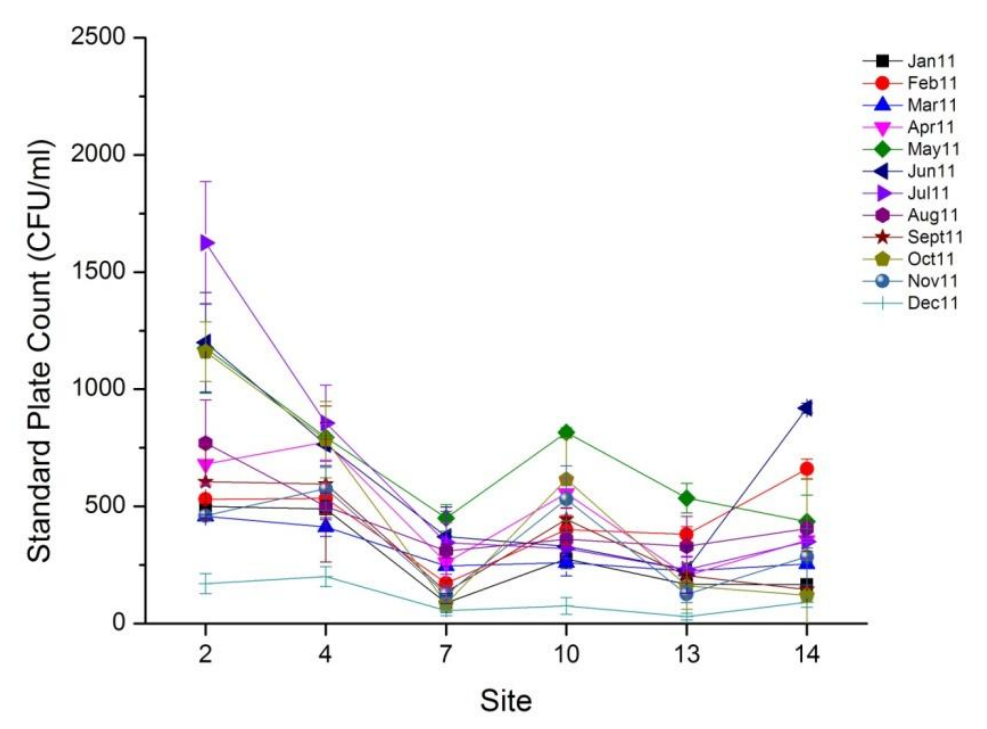

Figure 3.16. Mean heterotrophic bacteria as determined by standard plate counts in Sinking Creek by site and month 
Acridine orange direct counts, acid phosphatase, alkaline phosphatase, dehydrogenase, galactosidase, and glucosidase activities display seasonal and spatial variability of microbial activity in sediment (Figures $3.17-3.22$ ). ANOVA demonstrated significant seasonal differences for all MEAs except for dehydrogenase activity (Figure $3.23 \mathrm{a}-\mathrm{d}$ ). The significantly higher galactosidase and glucosidase concentrations during the fall and winter months indicates the ability of the microbial communities to use organic matter inputs, most likely in the form of leaf litter. The higher phosphatase concentrations observed during the fall also suggests the processing of organic matter by the microbial communities.

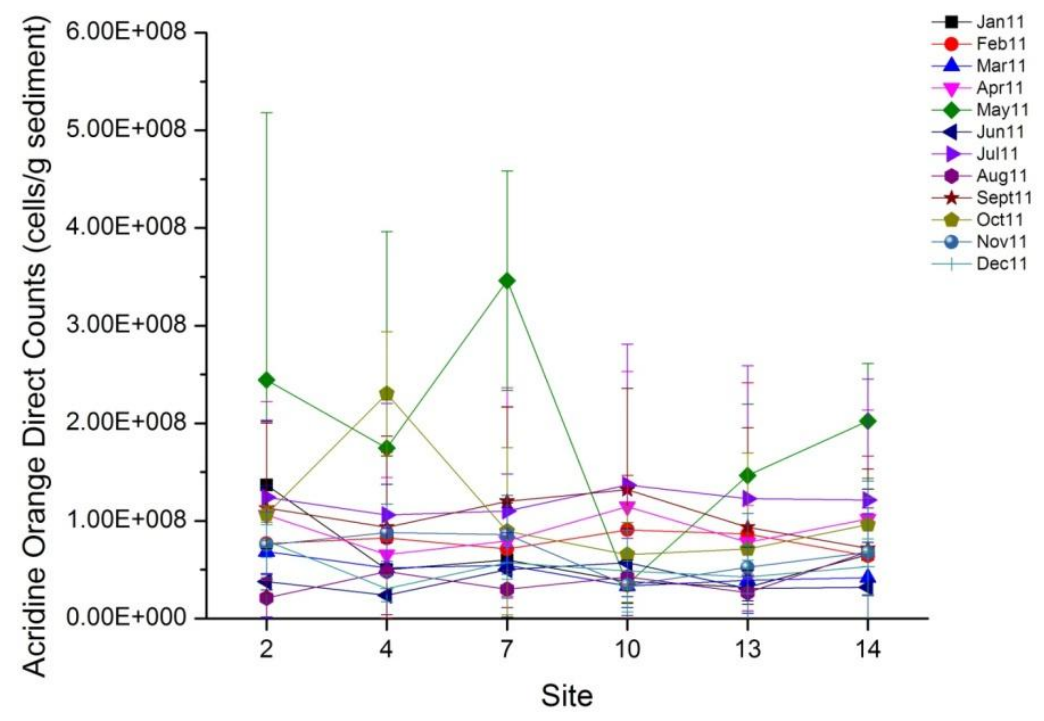

Figure 3.17. Mean acridine orange direct counts in Sinking Creek by site and month 


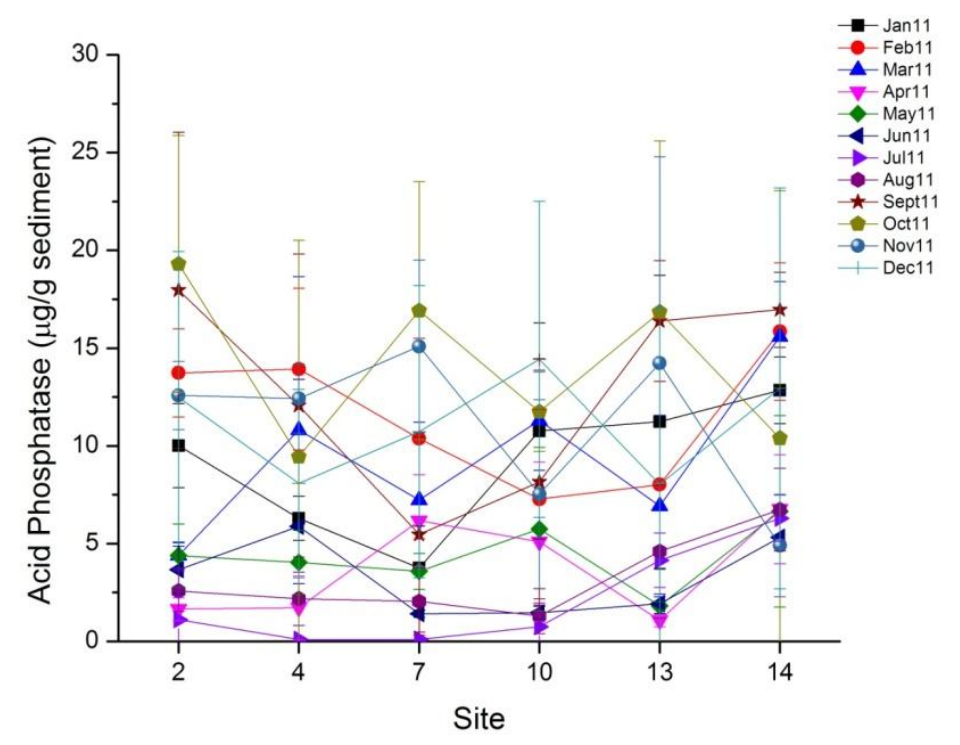

Figure 3.18. Mean acid phosphatase concentrations in Sinking Creek by site and month

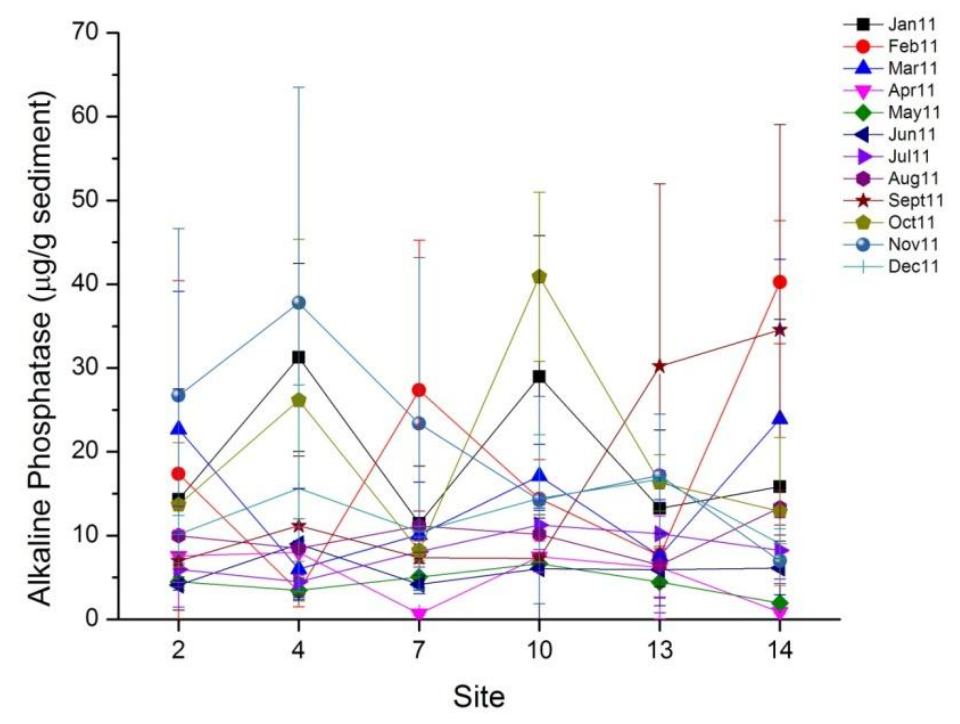

Figure 3.19. Mean alkaline phosphatase concentrations in Sinking Creek by site and month 


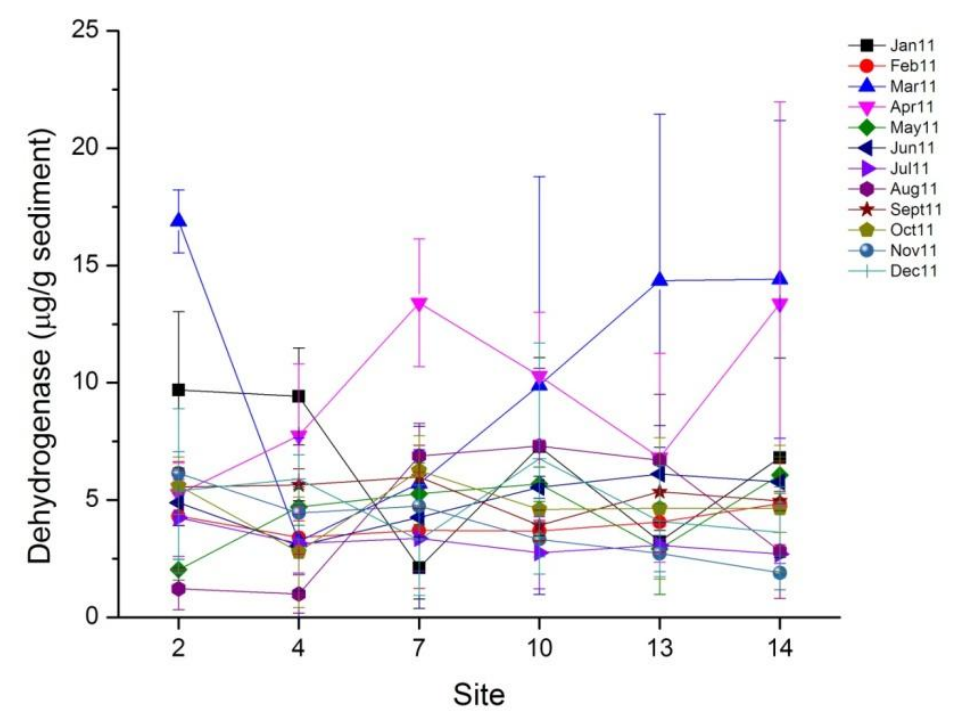

Figure 3.20. Mean dehydrogenase concentrations in Sinking Creek by site and month

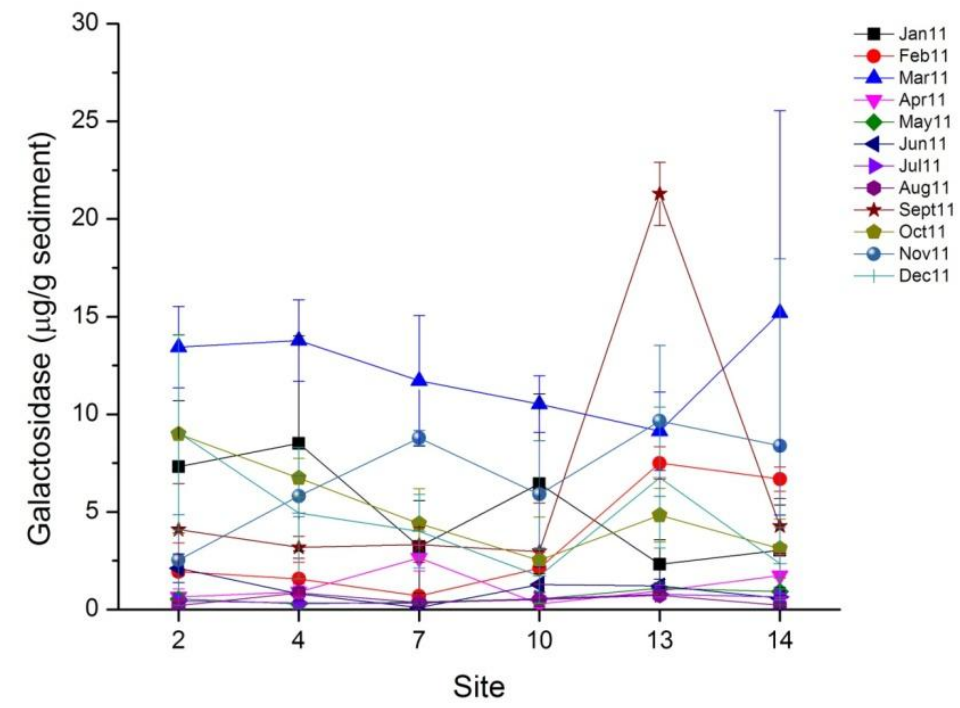

Figure 3.21. Mean galactosidase concentrations in Sinking Creek by site and month 


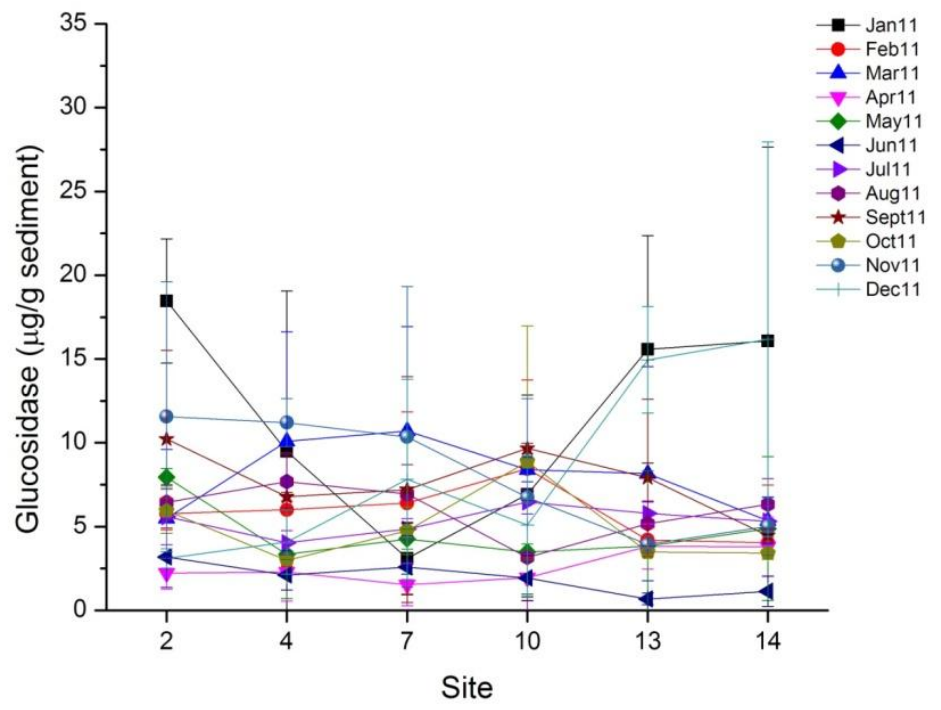

Figure 3.22. Mean glucosidase concentrations in Sinking Creek by site and month 
a

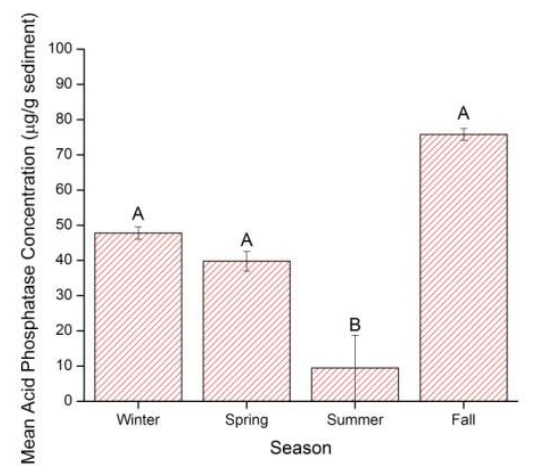

C

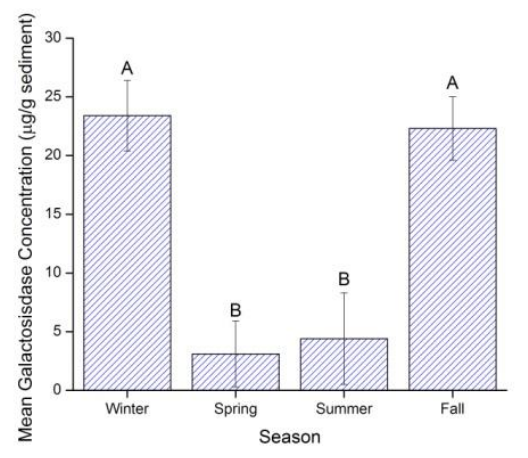

b

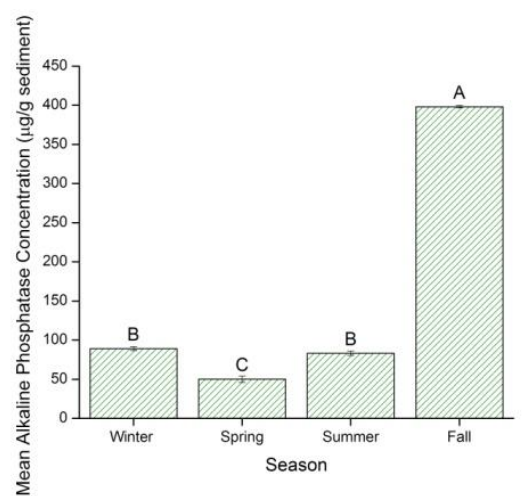

d

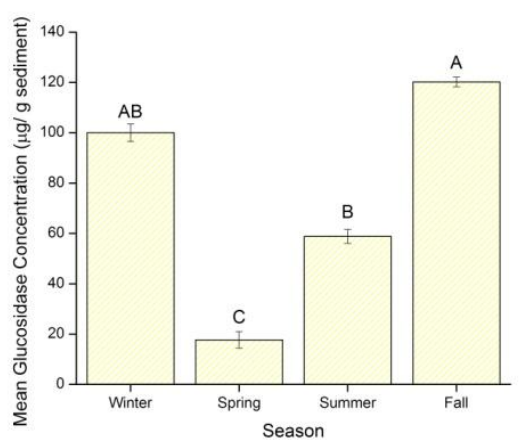

Figure 3.23. Mean acid phosphatase (a), alkaline phosphatase (b), galactosidase (c), and glucosidase (d) concentrations in Sinking Creek by season (significant differences are indicated by different letters)

E. coli O157:H7 was not detected in any field sample, and Shigella sp. was only detected at upstream sites in April 2011. Giardia sp., Cryptosporidium sp., and bacteriophage were detected at all sites and demonstrated spatial and temporal variability (Figures $3.24-3.26$ ). Giardia sp. and Cryptosporidium sp. were detected in $87.3 \%$ and $88.7 \%$ of samples, respectively, and bacteriophages were detected in $10.2 \%$ of samples. 


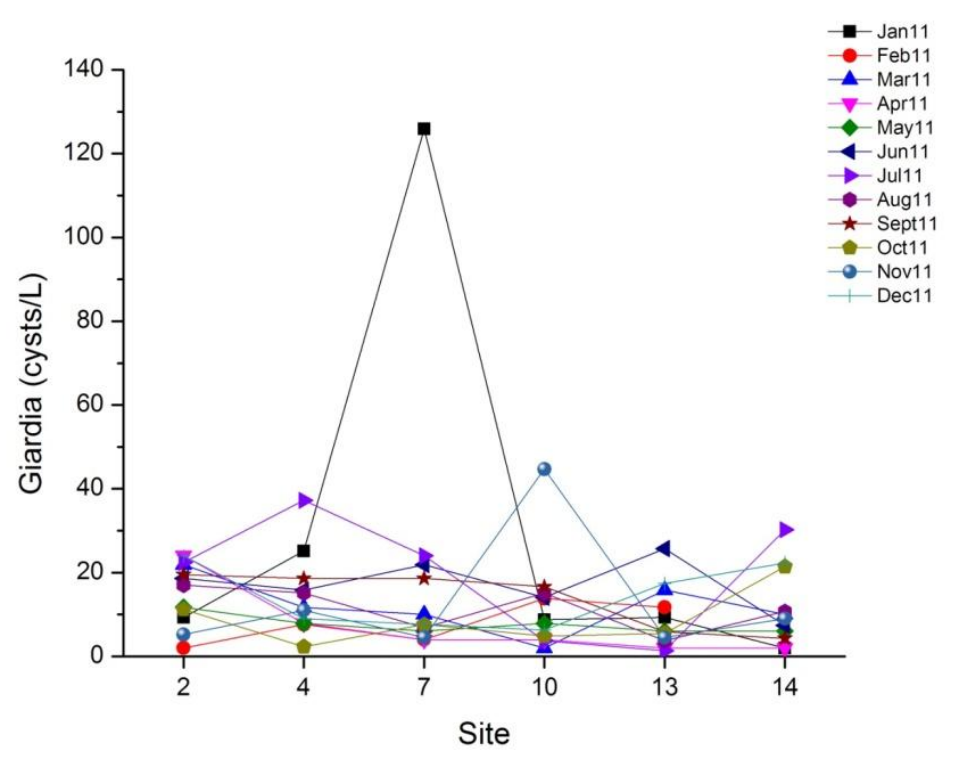

Figure 3.24. Giardia sp. concentrations in Sinking Creek by site and month

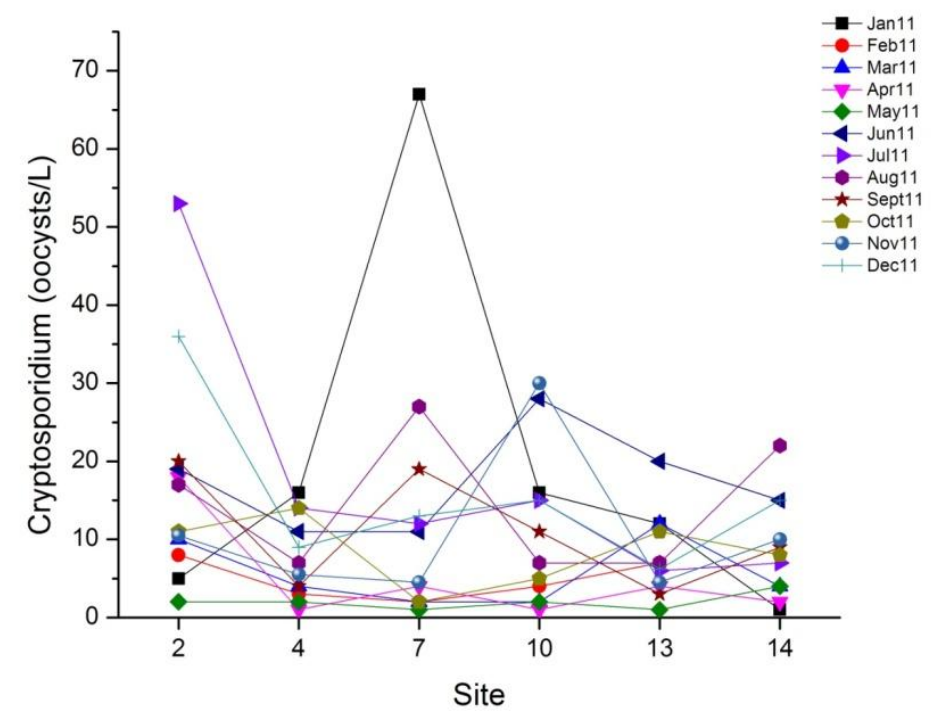

Figure 3.25. Cryptosporidium sp. concentrations in Sinking Creek by site and month 


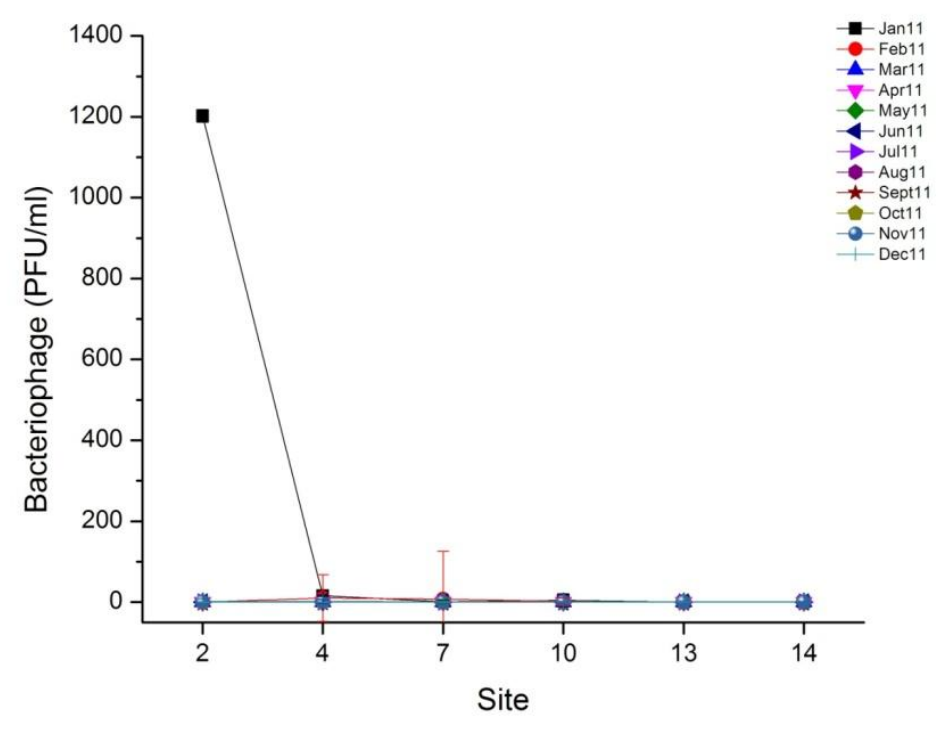

Figure 3.26. Mean bacteriophage concentrations in Sinking Creek by site and month

Seasonal and spatial variability in nutrient concentrations was observed (Figures 3.27 - 3.29). Nitrate, phosphate, and ammonia concentrations tended to increase with increasing distance downstream, suggesting the influence of surface runoff at urban and agricultural land use sites, yet these concentrations did not appear to contribute to aquatic plant or algal growth. Biochemical oxygen demand demonstrated temporal variability (Figure 3.30) with the highest concentrations of oxygen observed during the winter and spring months. The elevated $\mathrm{BOD}_{5}$ values during these months compared to other months may be influenced by the presence of organic matter and leaf litter introduced into Sinking Creek. 


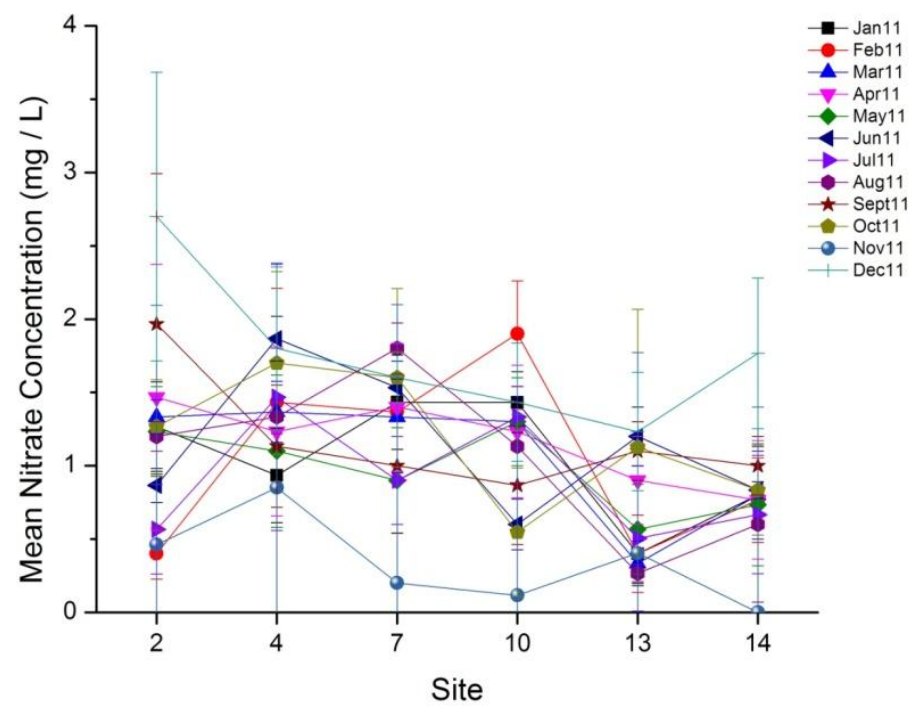

Figure 3.27. Mean nitrate concentrations in Sinking Creek by site and month

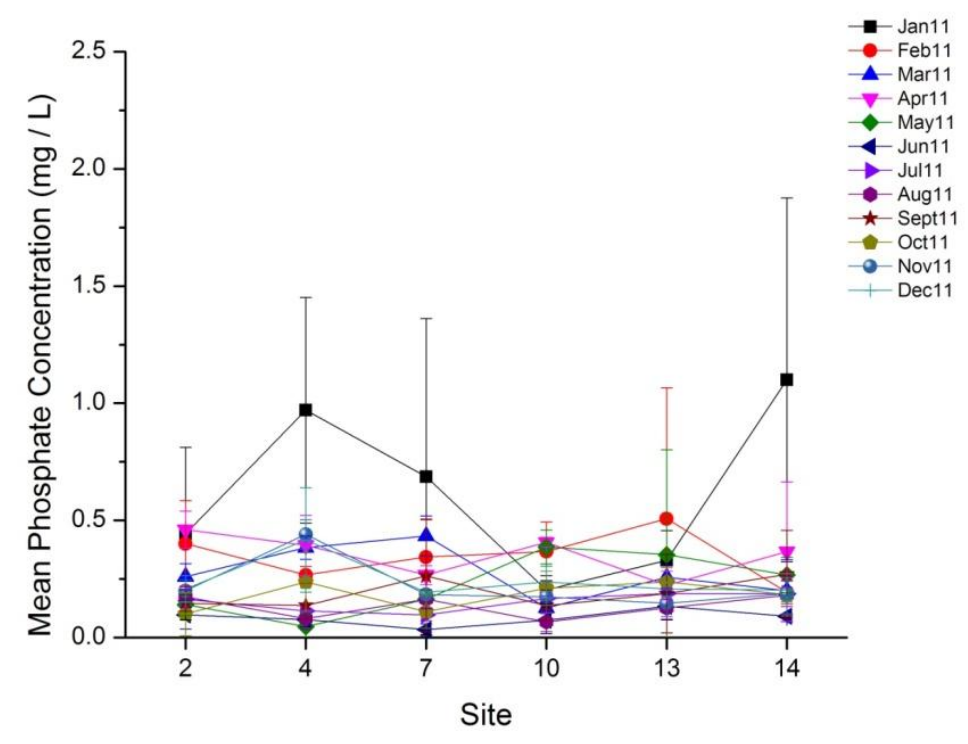

Figure 3.28. Mean phosphate concentrations in Sinking Creek by site and month 


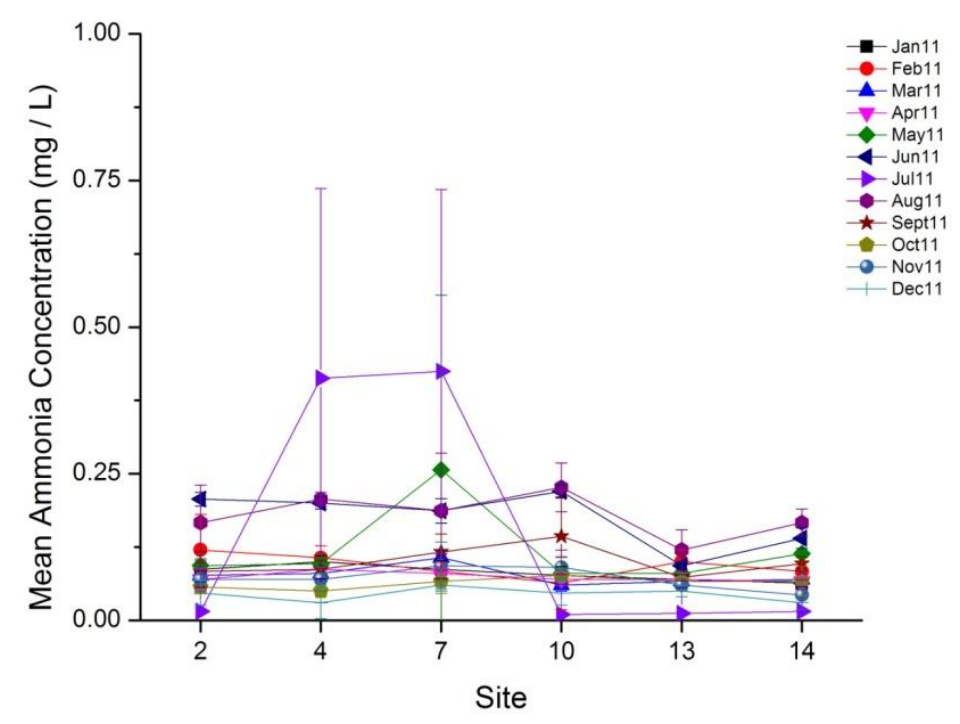

Figure 3.29. Mean ammonia concentrations in Sinking Creek by site and month

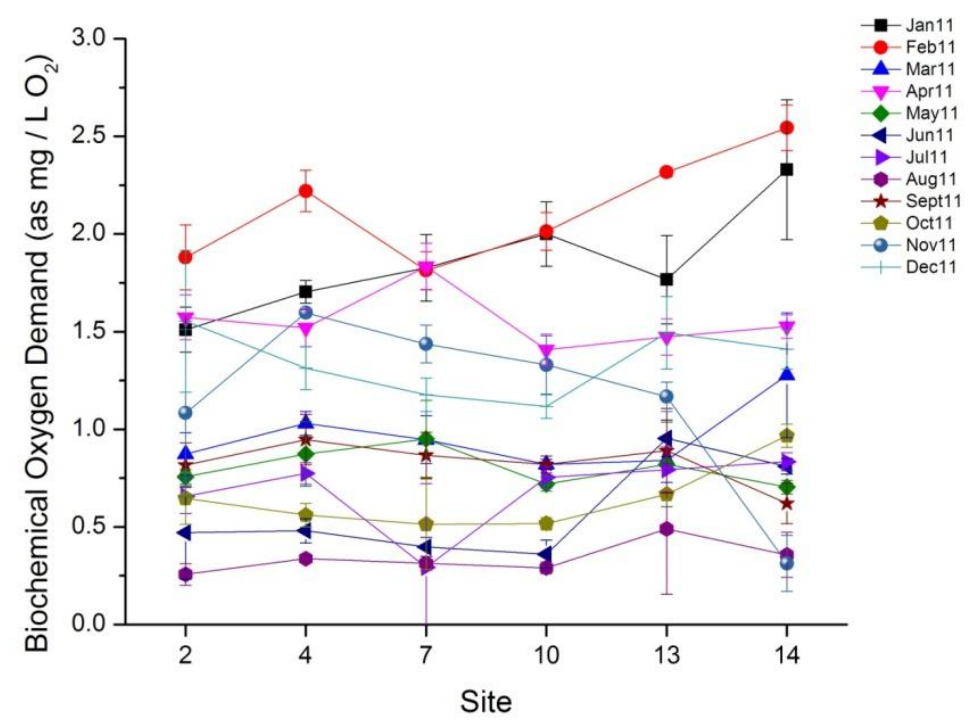

Figure 3.30. Mean biochemical oxygen demand in Sinking Creek by site and month 
Comparison of Fecal Coliform Concentrations

ANOVA for fecal coliform concentrations was performed by season, land use pattern, and site. Temporal (seasonal) variability was observed for fecal coliform concentrations (Figure 3.31). The winter and fall months had significantly lower fecal coliform concentrations compared to the spring and summer months. The significant differences observed between seasons indicate variation in climatic conditions, including rainfall, runoff events, and water temperature. Runoff events, warm temperatures, and the addition of organic matter contribute to the higher fecal coliform concentrations observed during the spring and summer months (Hunter et al. 1999; Hyland et al. 2003).

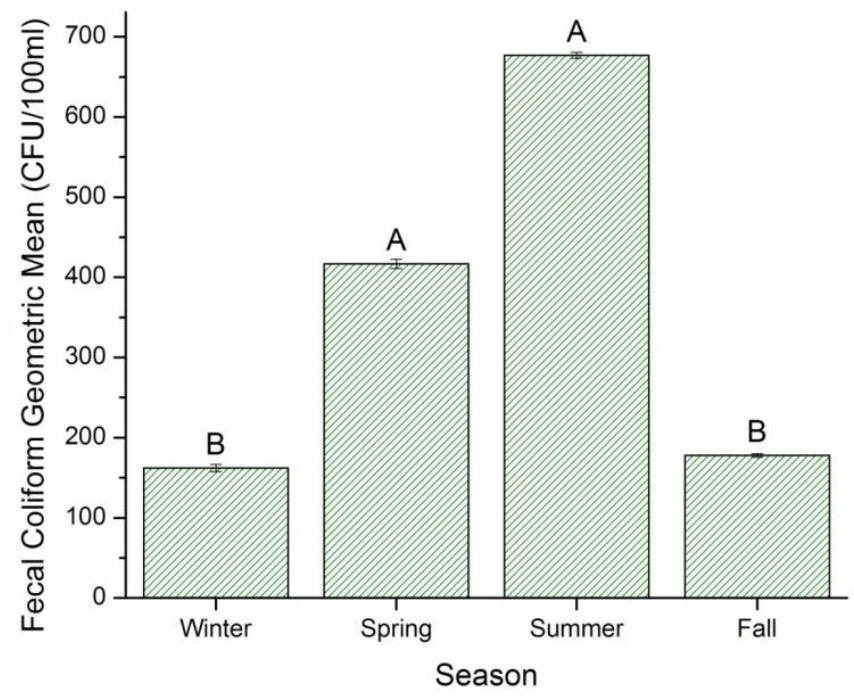

Figure 3.31. Geometric mean of fecal coliform concentrations in Sinking Creek by season (significant differences are indicated by different letters) 
Low flow conditions during spring and summer months and subsequent partitioning of fecal coliforms into the sediment could also account for the higher fecal coliform concentrations compared to the winter and fall months (Malan et al. 2003). Lower fecal coliform concentrations during the winter and fall may be the result of colder temperatures and fewer runoff events that contribute to fecal coliform loading during the fall and winter months. Seasonal variation in fecal coliform bacteria is commonly observed in surface water, as colder temperatures can reduce the survival of fecal coliform bacteria (Malan et al. 2003; Hörman et al. 2004). However, colder water temperatures during these months may also promote the survival of fecal coliform bacteria that were introduced during the spring and summer months (Smith et al. 1994, Maajel et al. 2003).

ANOVA of fecal coliform data by land use pattern demonstrated that significant differences for fecal coliform concentrations existed between the 3 land use patterns (Figure 3.32). The lowest fecal coliform concentrations were observed at forest land use sites (sites 13 and 14) and are just below the regulatory limit of $126 \mathrm{CFU} / 100 \mathrm{ml}$ for recreational water use at $117 \mathrm{CFU} / 100 \mathrm{ml}$. These sites are located on Buffalo Mountain at the headwaters of Sinking Creek. Although there are hiking and recreational trails, and some residential establishment in proximity to the headwaters of Sinking Creek, it is likely that fecal pollution at these sites is associated primarily with wildlife activity. 


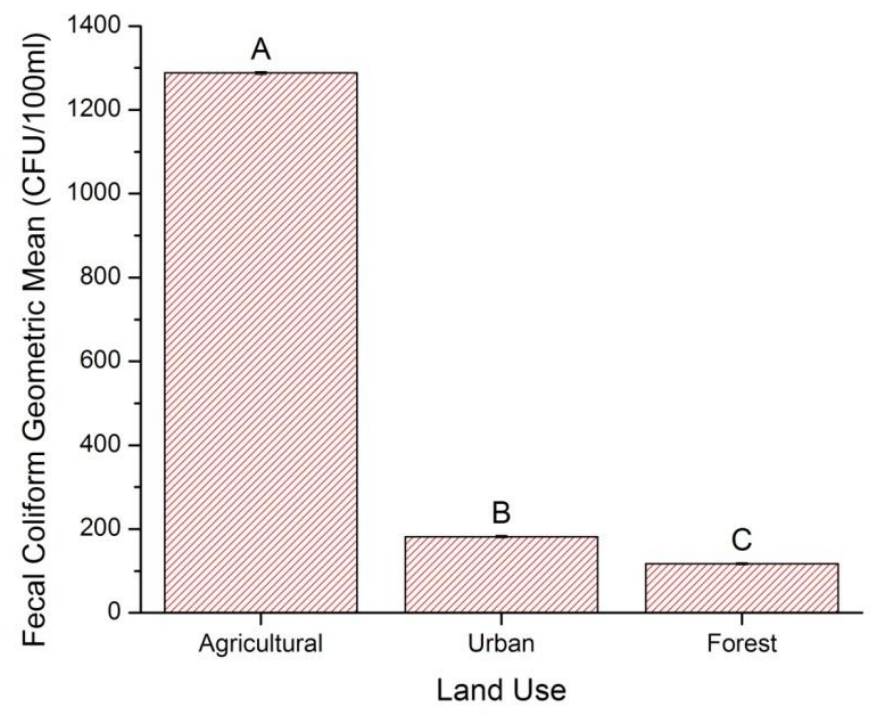

Figure 3.32. Geometric mean of fecal coliform concentrations in Sinking Creek by land use (significant differences are indicated by different letters)

Fecal coliform concentrations at urban sites are significantly higher than the concentrations at forested sites, suggesting that the addition of fecal pollution occurs with increasing distance downstream and is possibly influenced by impervious surfaces and runoff events (Kistemann et al. 2002). In addition to an influx of fecal coliform bacteria from surface runoff, resuspension from sediment (Goyal et al. 1977) can also result in higher fecal coliform concentrations following rainfall events. Sources contributing to fecal pollution in urban settings may include sources such as septic systems, storm sewers, and household pets (Weiskel et al. 1996; Olyphant et al. 2003; Ning et al. 2006; Zeilhofer et al. 2006). The deposition of fecal coliform bacteria at these sites may also occur by sedimentation, bank erosion, or the attachment of bacteria to particles (Vega et al. 1998; Lemarchand and Lebaron 2003). 
The highest fecal coliform concentrations were observed at agricultural land use sites. Agricultural activity is a common contributor to fecal coliform concentrations in surface water (Lenat and Crawford, 1994; Whiles et al. 2000; Tong and Chen, 2002). Direct deposition of fecal material into surface water and/or the continued release of fecal coliform bacteria from manure deposited on pastureland may be contributing to the observed fecal coliform concentrations at these sites (Thelin and Gifford, 1983). Once in the water, warmer water temperatures may also promote replication and survival of fecal coliform bacteria in water and sediment (Byappanahalli et al. 2003). In addition to these sources of fecal pollution at agricultural sites, spatial patterns (Hunsaker and Levine, 1995), agricultural densities (Harding et al. 1999), ecological patterns (Buck and Townsend, 2004), rainfall and subsequent surface runoff, and stream characteristics (Sheshane et al. 2005) can all influence fecal coliform loading into surface waters.

Fecal coliform concentrations were also analyzed by site over the entire sampling period to determine the extent of fecal pollution at each site to help identify areas of potential fecal pollution introduction. As previously seen with ANOVA by land use, spatial variability was observed (Figure 3.33). Agricultural sites had significantly higher fecal coliform concentrations compared to urban and forest land use sites, with peak fecal coliform concentrations at site 4 . Comparing fecal coliform concentrations by site and season assessed the combined effects of spatial and temporal variability on fecal coliform concentrations. 


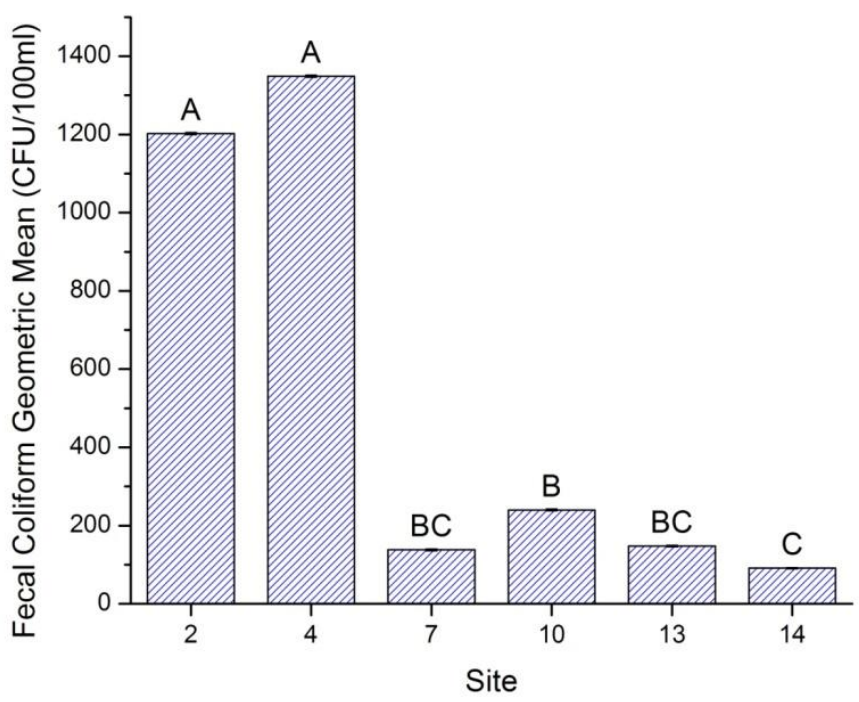

Figure 3.33. Geometric mean of fecal coliform concentrations in Sinking Creek by site (significant differences are indicated by different letters)

Fecal coliform concentrations at the agricultural sites were significantly higher during all seasons (Figure $3.34 \mathrm{a}-\mathrm{d}$ ). Significant increases in fecal coliform concentrations were observed between sites 4 and 7 for all seasons, suggesting that the bulk of fecal pollution occurred between these sites. During the winter and spring months, fecal coliform concentrations decreased between sites 2 and 4 . This suggests that there may be something inhibiting fecal coliform survival or transport such as colder temperatures (Hörman et al. 2004), settling into sediment (Gannon et al. 1983) or predation (Korhonen and Martikainen, 1991). In contrast, fecal coliform concentrations increase between sites 2 and 4 during the summer and fall months. This may be due to the continued introduction of fecal coliform bacteria downstream through runoff events and agricultural activities, or the influence of warmer water temperatures during the 
summer and fall months, and the addition of organic matter that promote survival of fecal coliform bacteria (Hunter et al. 1999; Hyland et al. 2003)

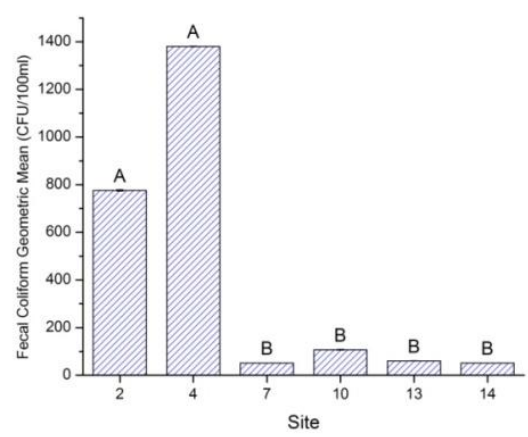

C

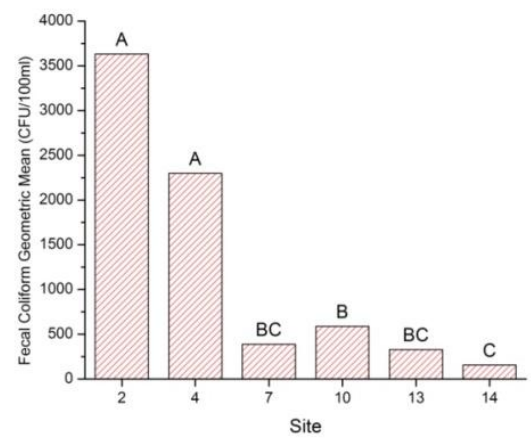

b

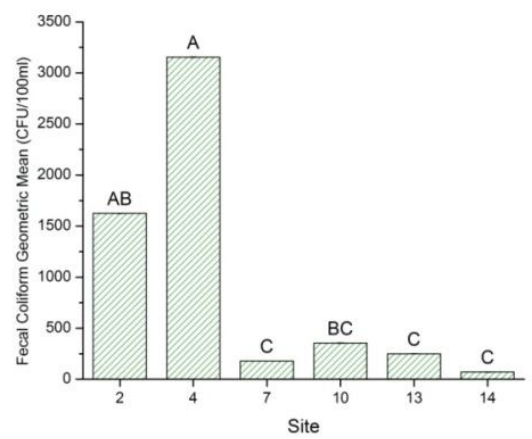

d

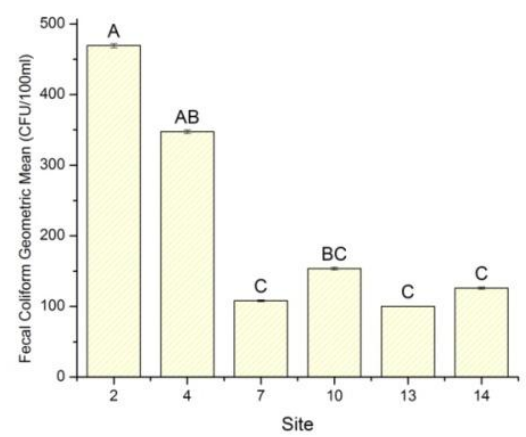

Figure 3.34. Geometric mean of fecal coliform concentrations in Sinking Creek for winter (a), spring (b), summer (c), and fall (d) by site (significant differences are indicated by different letters)

Correlation Between Fecal Coliform Bacteria, E. coli, and Pathogens

Regression analysis was performed to determine the ability of fecal coliform bacteria and E. coli to predict the presence of E. coli O157:H7, Shigella sp., Giardia sp., Cryptosporidium sp., and male specific $\left(\mathrm{F}^{+}\right)$bacteriophage. A complete lack of correlation was observed between E. coli or fecal coliform bacteria and the pathogenic bacteria of interest due to the failure to detect either organism in the field samples. The 
linear regression statistics for Giardia sp., Cryptosporidium sp., and male specific $\left(\mathrm{F}^{+}\right)$ bacteriophage, and the indicator organisms are displayed in Table 3.3.

Table 3.3. Regression statistics for pathogens vs. indicators

\begin{tabular}{lll}
\hline Pathogen vs. Indicator & $\mathbf{r}^{2}$ value & $\mathbf{p}$-value \\
\hline Giardia sp. vs. E. coli & 0.053 & $\mathrm{p}>0.03$ \\
Giardia sp. vs. fecal coliforms & 0.046 & $\mathrm{p}>0.04$ \\
Cryptosporidium sp. vs. E. coli & 0.123 & $\mathrm{p}>0.002$ \\
Cryptosporidium sp. vs. fecal coliforms & 0.116 & $\mathrm{p}>0.002$ \\
Bacteriophage vs. E. coli & -0.009 & $\mathrm{p}>0.54$ \\
Bacteriophage vs. fecal coliforms & -0.009 & $\mathrm{p}>0.56$ \\
\hline
\end{tabular}

These results suggest that neither $E$. coli nor fecal coliform bacteria are sufficient indicators of presence of pathogenic bacteria. The failure to detect $E$. coli $\mathrm{O} 157: \mathrm{H} 7$ or Shigella sp. may be due to the use of PCR methods in the absence of standardized methods. The speed of analysis, typically a few hours, combined with method sensitivity and ability to detect VBNC organisms make molecular methods such as PCR appealing for the identification of pathogens in surface water (Josephson et al.1993; Abd-El-Haleem et al. 2003). Although PCR methods for the identification of pathogens can be rapidly completed and highly sensitive, they are often difficult to standardize and apply to environmental samples due to inhibiting substances in the soil and water matrix such as humic acids (Tebbe and Vahjen, 1993; Campbell et al. 2001; Bhagwat, 2003). Environmental stress has also been shown to affect the stability of the target gene further complicating the sensitivity of the method (Cooley et al. 2010). These factors may have inhibited detection of E. coli O157:H7 and Shigella sp. in Sinking Creek. 
Figures $3.35(a$ and $b)$ and $3.36(a$ and $b)$ display the linear regression plots for E. coli or fecal coliform bacteria vs. Cryptosporidium sp. and Giardia sp. with their associated $r^{2}$ values. All 4 of the regression models are statistically significant $(p<$ $0.05)$, yet have low $r^{2}$ values. Indicating that little variability in protozoan concentrations is explained by either fecal coliform bacteria or E. coli concentrations. This indicates that fecal coliform bacteria and E. coli are poor predictors of protozoan contamination in Sinking Creek. Correlation between fecal coliform bacteria and Giardia sp. and Cryptosporidium sp. has been reported (LeChevallier et al. 1991; Touron et al. 2007), but the vast majority of studies do not show a correlation between fecal indicator organisms and protozoan pathogens (Rose et al. 1988; Lemarchand and Lebaron, 2003; Harwood et al. 2005). It may be possible that the observed differences in the literature are due in part to the types of water sampled. As reported by LeChevallier et al. (1991), water samples with higher fecal coliform concentrations have an increased probability that the pathogens will be present. It may also be possible that the protozoans isolated were associated with sediment that was filtered while the fecal indicator organisms were suspended in the water. 
a

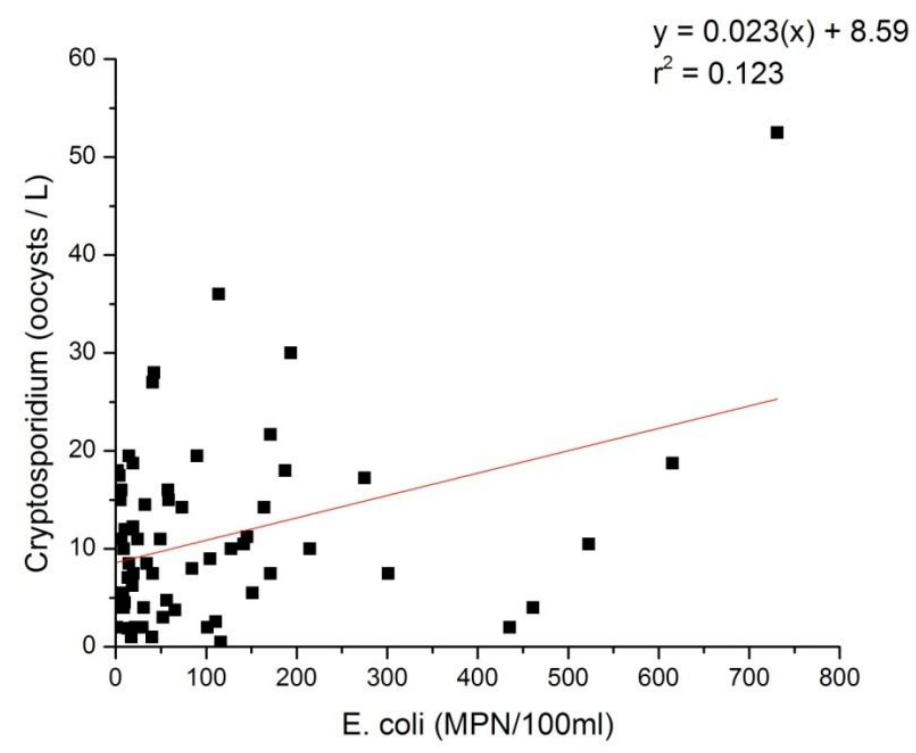

b

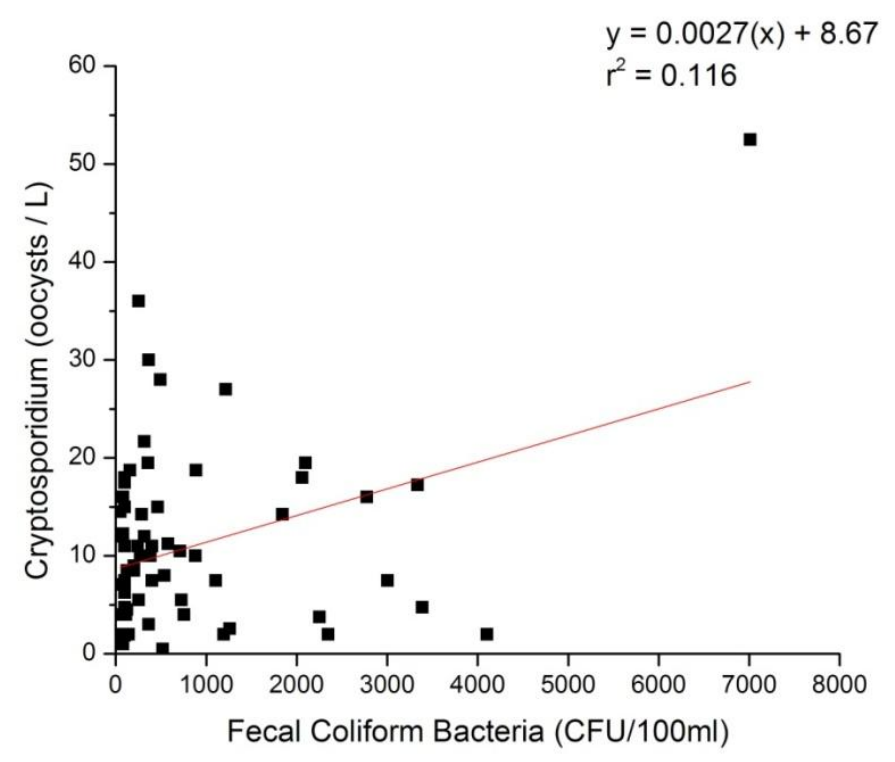

Figure 3.35. Linear regression of Cryptosporidium sp. and E. coli (a) and fecal coliform bacteria (b) 
a

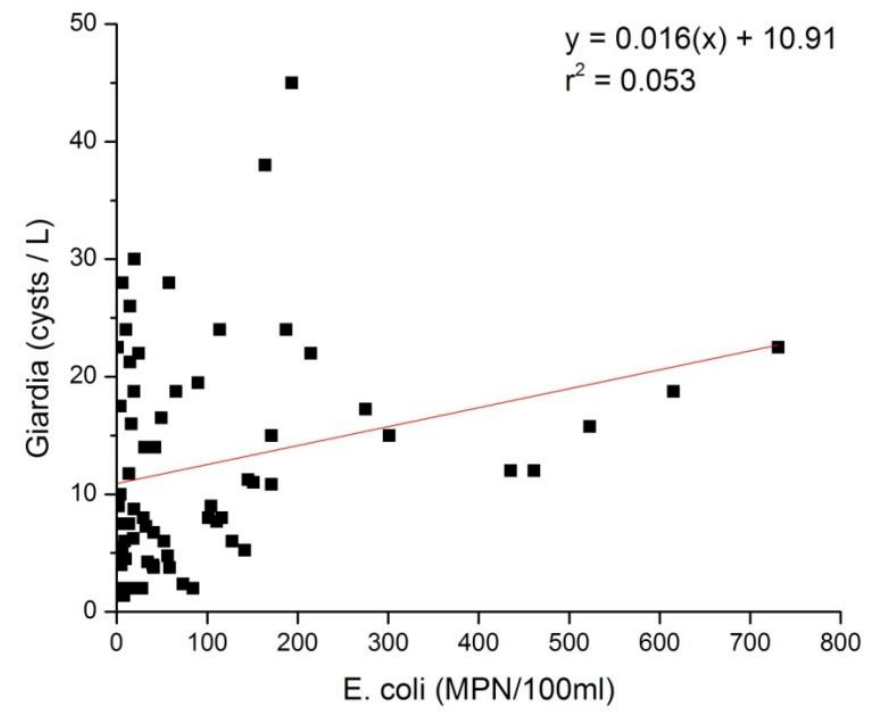

b

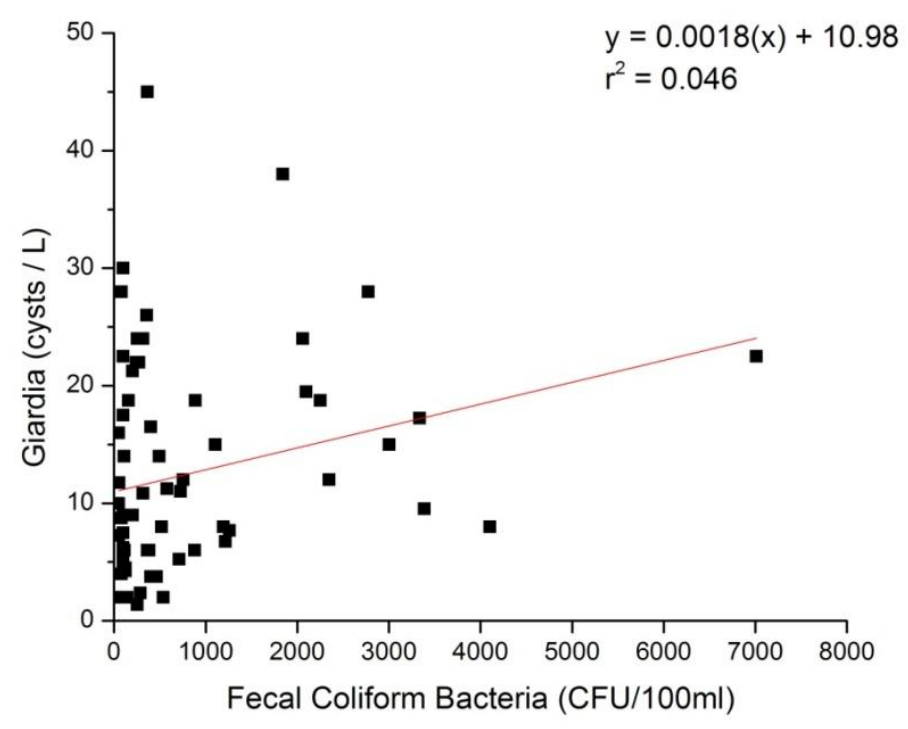

Figure 3.36. Linear regression of Giardia sp. and E. coli (a) and fecal coliform bacteria (b) 
Figure $3.37(a$ and $b)$ display the linear regression plots for E. coli and fecal coliform bacteria and male-specific bacteriophage with their associated $r^{2}$ values. A lack of correlation is often observed between enteric viruses and fecal indicator organisms (Gerba et al. 1979; Noble and Fuhrman 2001). As a result, alternative indicators of enteric viruses such as bacteriophages have been used as successful indicators of enteric virus pollution in surface waters (Wentsel et al. 1982; Stetler, 1984; Havelaar et al. 1993) and have been shown to correlate with fecal coliform concentrations (Kenard and Valentine 1974; Borrego et al. 1987). In this study, the regression models are not statistically significant, indicating that neither $E$. coli nor fecal coliform bacteria are sufficient indicators of the presence of bacteriophage prevalence. Assuming that bacteriophages are successful indicators of enteric virus pollution in surface waters, these results also suggest that indicator organisms are not sufficient predictors of enteric virus pollution in Sinking Creek. 
a

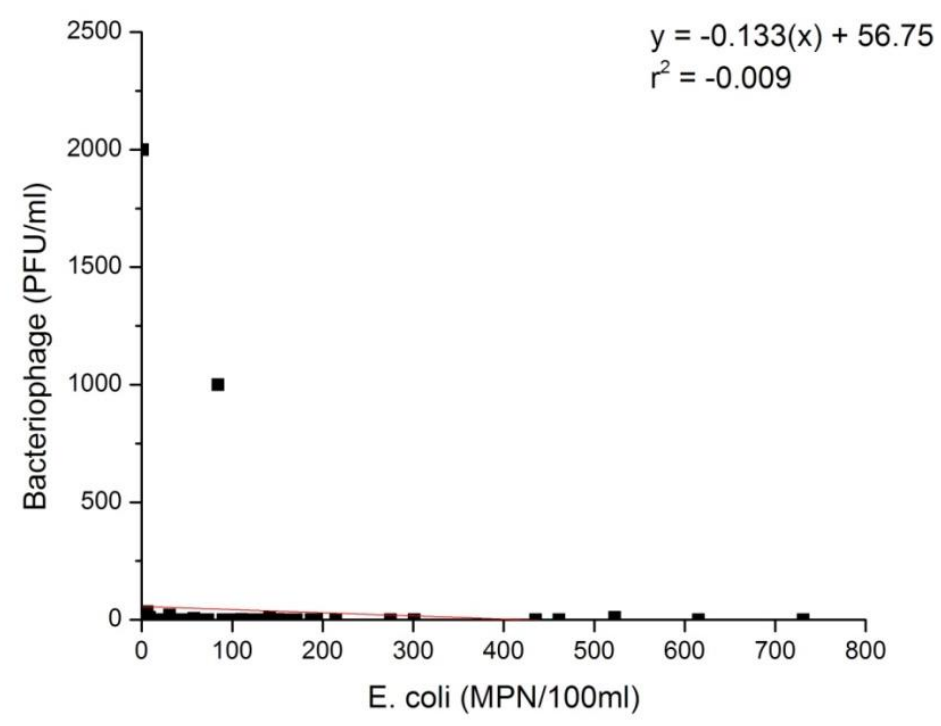

b

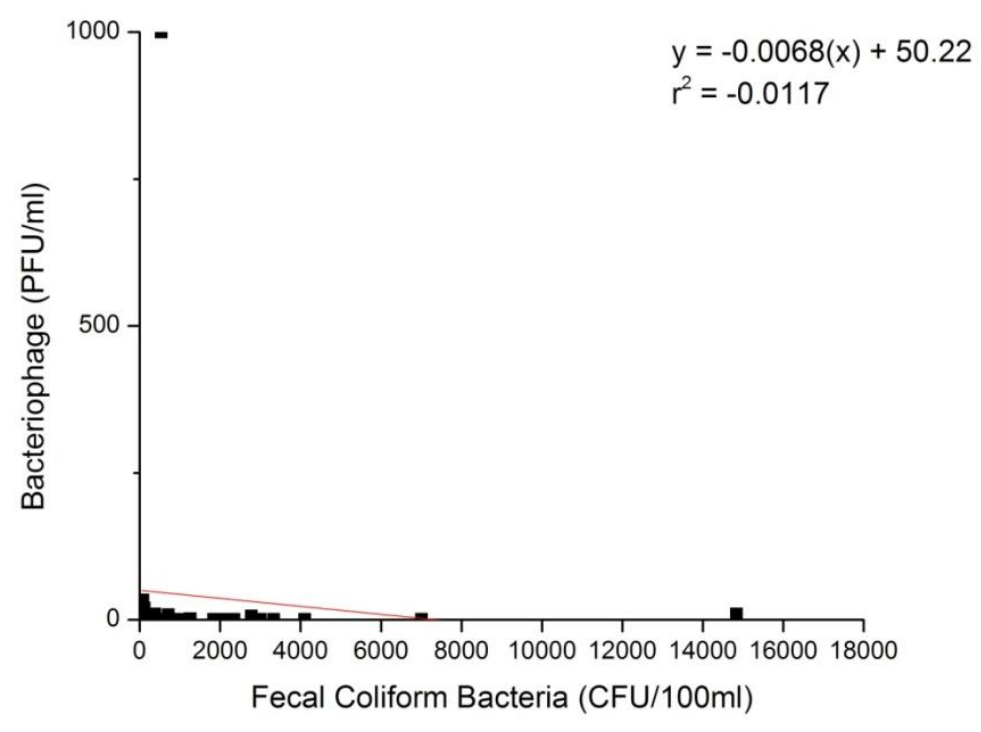

Figure 3.37. Linear regression male-specific bacteriophage with E. coli (a) and fecal coliform bacteria (b) 


\section{$\underline{\text { Conclusion }}$}

Physical, chemical, and microbial parameters were monitored monthly for one year to assess the water quality of Sinking Creek and display temporal and spatial variability. Fecal coliform data indicate that Sinking Creek is impaired, particularly at agricultural and urban land use sites. Linear regression analyses using $E$. coli and fecal coliform bacteria were performed to assess their usefulness as indicators of pathogen prevalence. Only regression analyses for fecal indicator organisms and protozoan pathogens were statistically significant, suggesting that the use of fecal indicators may overestimate the risk of pathogen exposure in Sinking Creek.

\section{Acknowledgements}

This work ws funded in part by a grant from the ETSU School of Graduate Studies and Graduate Council and by a contract with the Tennessee Valley Authority (Award \# 00025252). 


\section{$\underline{\text { References }}$}

Abd-El-Haleem D, Kheiralla HZH, Zaki S, Rushdy AA, Abd-El-Rahiem W. 2003. Multiplex-PCR and PCR-RFLP assays to monitor water quality against pathogenic bacteria. J. Environ. Monit. 5:865-870

APHA. 1992. Standard methods for the examination of water and wastewater. $18^{\text {th }}$ edition. American Public Health Association. Washington, D.C.

Bej AK, DiCesare JL, Haff L, Atlas RM. 1991. Detection of Escherichia coli and Shigella spp. in water by using the polymerase chain reaction and gene probes for uid. Appl. Environ. Microbiol. 57:1013-1017

Bhagwat AA. 2003. Simultaneous detection of Escherichia coli O157:H7, Listeria monocytogenes and Salmonella strains by real-time PCR. Int. J. Food Protect. $84: 217-224$

Borrego, J.J., Moriñigo, M.A., de Vicente, A., Córnax, R., Romero, P. 1987. Coliphages as an indicator of faecal pollution in water. Its relationship with indicator and pathogenic microorganisms. Wat. Res. 21:1473-1480

Buck ODKN, Townsend CR. 2004. Scale-dependence of land use effects on water quality of streams in agricultural catchments. Environ. Poll. 130:287-299

Burton, Jr. GA, Gunnison D, Lanza GR. 1987. Survival of pathogenic bacteria in various freshwater sediments. Appl. Environ. Microbiol. 53:633-638

Byappanahalli M, Fowler M, Shively D, Whitman R. 2003. Ubiquity and persistence of Escherichia coli in a Midwestern coastal stream. Appl. Environ. Microbiol. 69:45494555

Campbell GR, Prosser J, Glover A, Killham K. 2001. Detection of Escherichia coli O157:H7 in soil and water using multiplex PCR. J. Appl. Microbiol. 91:1004-1010

Carrillo M, Estrada E, Hazen TC. 1985. Survival and enumeration of the fecal indicators Bifidobacterium adolescentis and Escherichia coli in a tropical rain forest watershed. Appl. Environ. Microbiol. 50:468-476

Cooley MB, Carychao D, Nguyen K, Whitehand L, Mandrell R. 2010. Effects of environmental stress on stability of tandem repeats in Escherichia coli O157:H7. Appl. Environ. Microbiol. 76:3398-4000

Crabill C, Donald R, Snelling J, Fourst R, Southam G. 1999. The impact of sediment fecal coliform reservoiurs on seasonal water quality in Oak Creek, Arizona. Wat. Res. 33:2163-2171 
Davies CM, Evison LM. 1991. Sunlight and the survival of enteric bacteria in natural waters. J. Appl. Bacteriol. 70:265-274

Dulaney D, Scheuerman P, Maier K, Mustain E. 2003. Monitoring of selected bacteriological parameters associated with the Sinking Creek Total Maximum Daily Load (TMDL). Master's Thesis. Department of Environmental Health, East Tennessee State University

Gannon JJ, Busse MK, Schilliger JE. 1983. Fecal coliform disappearance in a river impoundment. Wat. Res. 17:1595-1601

Gantzer C, Lillerman L, Kuznetsov M, Oron G. 2001. Adsorption and survival of faecal coliforms, somatic coliphages and F-specific RNA phages in soil irrigated with wastewater. Wat.Sci. Technol. 43:117-124

Gerba CP, Goyal SM, LaBelle RL, Cech I, Bodgan GF. 1979. Failure of indicator bacteria to reflect the occurrence of enteroviruses in marine waters. Am. J. Pub. Health. 69:1116-1119

Gersberg RM, Rose MA, Robles-Sikisaka R, Dhar AK. 2006. Quantitative detection of Hepatitis A virus and enteroviruses near the United States-Mexico border and correlation with levels of fecal indicator bacteria. Appl. Environ. Microbiol. 72:74387444

Ghiorse WC, Balkwill DL. 1983. Enumeration and morphological characterization of bacteria indigenous to subsurface environments. Dev. Ind. Microbiol. 24:213-224

Goyal SM, Gerba CP, Melnick JL. 1977. Occurrence and distribution of bacterial indicators and pathogens in canal communities along the Texas coast. Appl. Environ. Microbiol. 34:139-149

Hall KK, Evanshen BG, Maier KJ, Scheureman PR. 2011. Analysis of water quality data using multivariate statistics to patterns associating land use to fecal pollution sources. $111^{\text {th }}$ Annual Meeting for the American Society for Microbiology, New Orleans, LA USA

Hanes NB, Sarles WB, Rohlich GA. 1964. Dissolved oxygen and survival of coliform organisms and enterococci. J. Am. Water. Works. Assoc. 56:441-446

Harding JS, Young RG, Hayes JW, Shearer KA, Stark JD. 1999. Changes in agricultural intensity and river health along a river continuum. Freshwater Biol. 42:345-357

Harwood VJ, Levine AD, Scott TM, Chivukula V, Lukasik J, Farrah SR, Rose JB. 2005. Validity of the indicator organism paradigm for pathogen reduction in reclaimed water and public health protection. Appl. Environ. Microbiol. 71:3163-3170 
Havelaar AH, van Olphen M, Drost YC. 1993. F-specific RNA bacteriophages are adequate model organisms for enteric viruses in fresh water. Appl. Environ. Microbiol. 59:2956-2962

Hörman, A, Rimhanen-Finne R, Maunula L, von Bonsdorff CH, Torvela N, Heikinheimo A, Hänninen ML. 2004. Campylobacter spp., Giardia spp., Cryptosporidium spp., Noroviruses, and Indicator Organisms in Surface Water in Southwestern Finland, 2000-2001. Appl. Environ. Microbiol. 70:87-95

Howell JM, Coyne MS, Cornelius PL. 1996. Effect of sediment particle size and temperature on fecal bacteria mortality rates and the fecal coliform/fecal streptococci ratio. J. Environ. Qual. 25:1216-1220

Hunsaker CT, Levine DA. 1995 . Hierarchical approaches to the study of water quality in rivers. BioSciences. 45:193-203

Hunter C, Perkins J, Tranter J, Gunn J. 1999. Agricultural land-use effects on the indicator bacterial quality of an upland stream in the Derbyshire Peak District in the U.K. Wat. Res. 33:3577-3586

Hyland R, Byrne J, Selinger B, Graham T, Thomas J, Townshend I, Gannon V. 2003. Spatial and temporal distribution of fecal indicator bacteria within the Oldman River Basin of Southern Alberta, Canada. Wat. Qual. Res. J. Canada. 38:15-32

Islam MS, Hasan MK, Hiah MA, Sur GC, Felsenstein A, Venkatesan M, Sack RB, Albert MJ. 1993a. Use of polymerase chain reaction and fluorescent-antibody methods for detecting viable but nonculturable Shigella dysenteriae Type 1 in laboratory microcosms. Appl. Environ. Microbial. 59:536-540

Jamison RC, Gordon RJ, Tattrie SC, Stratton GW. 2003. Sources and persistence of fecal coliform bacteria in a rural watershed. Water Qual. Res. J. Canada. 38:33-47

Jana S, Bhattacharya DN. 1988. Effect of heavy metals on growth population of a fecal coliform bacterium Escherichia coli in aquatic environment. Water, Air, and Soil Poll. 38:251-254

Josephson KL, Gerba CP, Pepper IL. 1993. Polymerase chain reaction detection of nonviable bacterial pathogens. Appl. Environ. Microbiol. 59:3513-3515

Kenard RP, Valentine RS. 1974. Rapid determination of the presence of enteric bacteria in water. Appl. Environ. Microbiol. 27:484-487

Kimura R, Mandrell RE, Galland JC, Hyatt D, Riley LW. 2000. Restriction-site-specific PCR as a rapid test to detect enterohemorrhagic Escherichia coli O157:H7 strains in environmental samples. Appl. Environ. Microbiol. 66:2513-2519 
Kistemann T, Claßen T, Koch C, Dangerdorf F, Fischeder R, Gebel J, Vacata V, Exner M. 2002. Microbial load of drinking water reservoir tributaries during extreme rainfall and runoff. Appl. Environ. Microbiol. 68:2188-2197

Korhonen LK, Martikainen PJ. 1991. Survival of Escherichia coli and Campylobacter jejuni in untreated and filtered lake water. J. Appl. Bacteriol. 71:379-382

LeChevallier MW, Norton WD, Lee RG. 1991. Occurrence of Giardia and Cryptosporidium in surface water supplies. Appl. Environ. Microbiol. 57:2610-2616

Lemarchand K, Lebaron P. 2003. Occurrence of Salmonella spp. and Cryptosporidium spp. in a French coastal watershed: relationship with fecal indicators. FEMS Microbiol. Lett. 218:203-209

Lenat DR, Crawford JK. 1994. Effects of land use on water quality and aquatic biota of three North Carolina Piedmont streams. Hydrobiologica. 284:185-200

Lipp EK, Kurz R, Vincent R, Rodriguez-Palacios C, Farrah SR, Rose JB. 2001. The effects of seasonal variability and weather on microbial fecal pollution and enteric pathogens in a subtropical estuary. Estuaries. 24:266-276

Maajel S, Mahjoubi A, Elazri C, Dukan S. 2003. Simultaneous effects of environmental factors on motile Aeromonas dynamics in urban effluent and in natural seawater. Wat. Res. 37:2865-2874

Malan H, Bath A, Day J, Joubert A. 2003. A simple flow-concentration modeling method for integrating water quality and water quality in rivers. Water SA. 29:305311

McCambridge J, McMeekin TA. 1981. Effect of solar radiation and predacious microorganisms on survival of fecal and other bacteria. App. Environ. Microbiol. 41:1083-1087

McFeters GA, Stuart, DG. 1972. Survival of coliform bacteria in natural waters: field and laboratory studies with membrane-filter chambers. Appl. Microbiol. 24:805-811

McFeters GA, Bissonette GK, Jezeski JJ. 1974. Comparative survival of indicator bacteria and enteric pathogens in well water. Appl. Microbiol. 27:823

Morrison SJ, King FD, Bobbie RJ, Beechtold RE, White DC. 1977. Evidence for microfloral succession on allochthonous plant littler in Apalachicola Bay, Florida, USA. Marine Bio. 41:229-240

Noble RT, Fuhrman JA. 2001. Enteroviruses detected by reverse transcriptase polymerase chain reaction from the coastal waters of Santa Monica Bay, California: low correlation to bacterial indicator levels. Hydrobiologia. 460:175-184 
Ning SK, Chang NB, Jeng KY, Tseng YH. 2006. Soil erosion and non-point source pollution impacts assessment with the aid of multi-temporal remote sensing images. J. Environ. Manage. 79:88-101

Olyphant GA, Thomal J, Whitman RL, Harper D. 2003. Characterization and statistical modeling of bacterial (Escherichia coli) outflows from watersheds that discharge into southern Lake Michigan. Environ. Monit. Assess. 81:289-300

Orlab GT. 1956. Viability of sewage bacteria in sea water. Sewage Ind. Wastes 28:1147-1167

Payment $\mathrm{P}$, Franco E. 1993. Clostridium perfringens and somatic coliphages as indicators of the efficiency of drinking water treatment for viruses and protozoan cysts. Appl. Environ. Microbiol. 59:2418-2424

Powelson DK, Mills AL. 2001. Bacterial enrichment at the gas water interface of a laboratory apparatus. Appl. Environ. Microbiol. 62:2593 - 2597

Rose JB, Darbin H, Gerba CP. 1988. Correlation of protozoa, Cryptosporidium and Giardia, with water quality variables in a watershed. Wat. Sci. Technol. 20:271-276

Sayler GS, Puziss M, Silver M. 1979. Alkaline phosphatase assay for freshwater sediments: application to perturbed sediment systems. Amer. Soc. Microbiol. 38:922-927

Schaffter N, Parriaux A. 2002. Pathogenic-bacterial water contamination in mountainous catchments. Wat. Res. 36:131-139

Scott L, McGee P, Sheridan JJ, Earley B, Leonard N. 2006. A comparison of the survival in feces and water of Escherichia coli $0157: \mathrm{H} 7$ grown under laboratory conditions obtained from cattle feces. J. Food Protect. 69:6-11

Sherer BM, Miner JR, Moore JA, Buckhouse JC. 1992. Indicator bacterial survival in stream sediments. J. Environ. Qual. 21:591-595

Sheshane SD, Harwood VJ, Whitlock JE, Rose JB. 2005. The influence of rainfall on the incidence of microbial faecal indicators and the dominant sources of faecal pollution in a Florida river. J. App. Microbiol. 98:1127-1136

Stetler RE. 1984. Coliphages as indicators of enteroviruses. Appl. Environ. Microbiol. 48:668-670

Tebbe CC, Vahjen W. 1993. Interference of humic acids and DNA extracted directly from soil in detection and transformation of recombinant DNA from bacteria and yeast. Appl. Environ. Microbiol. 59:2657-2665 
TDEC. 2000a. Watauga River Watershed (06010103) of the Tennessee River Basin. Water Quality Management plan. Tennessee Department of Environment and Conservation. Division of Water Pollution Control, Nashville TN USA

TDEC. 2000b. Total Maximum Daily Loads for fecal coliforms in Sinking Creek. Tennessee Department of Environment and Conservation, Division of Water Pollution Control, Nashville, TN USA

TDEC. 2008. Chapter 1200-4-3 General Water Quality Criteria. Tennessee Department of Environment and Conservation, Division of Water Pollution Control, Nashville, TN USA

Thelin R, Gifford GF. 1983. Fecal coliform release patterns from fecal material of cattle. J. Environ. Qual. 12:57-63

Tong STY, Chen W. 2002. Modeling the relationship between land use and surface water quality. J. Environ. Manage. 66:377-393

Touron A, Berthe T, Gargala G, Fournier M, Ratzjczak M, Servais P, Petit F. 2007. Assessment of faecal contamination and the relationship between pathogens and faecal bacterial indicators in an estuarine environment (Seine, France). Mar. Poll. Bull. 54:1141-1450

USEPA. 2001a. Method 1601: Male-specific $(F+)$ and somatic coliphage in water by two-step enrichment procedure. April 2001. United States Environmental Protection Agency, Washington D.C. USA

USEPA. 2005. Method 1623: Cryptosporidium and Giardia in Water by Filtration/IMS/FA. December 2005. United States Environmental Protection Agency, Washington D.C. USA

Vega M, Pardo R, Barrado E, Deban L. 1998. Assessment of seasonal and polluting effects on the quality of river water by exploratory data analysis. Wat. Res. 32:3581-3592

Weiskel PK, Howes BL, Heufelder GR. 1996. Coliform contamination of a coastal embayment: sources and transport pathways. Environ. Sci. Technol. 30:1872-1881

Wentsel RS, O'Neill PE, Kitchens JF. 1982. Evaluation of coliphage detection as a rapid indicator of water quality. Appl. Environ. Microbiol. 43:430-434

Whiles MR, Brock BL, Franzen AC, Dinsmore, II SC. 2000. Stream invertebrate communities, water quality, and land-use patterns in an agricultural drainage basin of Northeastern Nebraska, USA. Environ. Manage. 26:563-576 
Whitman RL, Nevers MB. 2003. Foreshore sand as a source of Escherichia coli in nearshore water of a Lake Michigan beach. Appl. Enviorn. Microbiol. 69:5555-5562

Zeilhofer P, Lima EBNR, Lima GAR. 2006. Spatial patterns of water quality in the Cuiaba River basin, Central Brazil. Environ. Monit. Assess. 123:41-62 


\title{
CHAPTER 4
}

\section{MULTIVARIATE STATISTICAL ANALYSES OF SINKING CREEK WATER QUALITY DATA TO IDENTIFY SOURCES OF FECAL POLLUTION IN RELATION TO LAND USE PATTERN}

\author{
K.K. Hall and P.R. Scheuerman
}

$\underline{\text { Abstract }}$

In the United States the increased listing of surface waters on impaired waters (303d) lists for pathogen impairment and the requirement to address these through the Total Maximum Daily Load (TMDL) process has resulted in increased need to develop methods that effectively and universally identify sources of fecal pollution. Pathogen TMDL development is currently based on a 30-day geometric mean, which does not take into consideration seasonal effects, variability in land use patterns, or the influence of runoff events on water quality. To account for these sources of variability, alternative water quality monitoring program design, methods, and data analysis may be necessary. This experiment used canonical correlation and canonical discriminant analyses to identify nonpoint sources of impairment in Sinking Creek. Results of these multivariate statistical analyses demonstrate that Sinking Creek is impacted by multiple nonpoint sources of impairment and souces of impairment are related to land use patterns.

\section{$\underline{\text { Introduction }}$}

Rapid growth and urbanization in many previously rural and agricultural regions is a significant factor influencing deterioration of surface water quality. The addition of surface water bodies to impaired waters (303d) lists for pathogen impairment and the 
need to address these through the Total Maximum Daily Load (TMDL) process has resulted in increased research to find methods that effectively and universally identify fecal pollution sources. A fundamental requirement to identify such methods is understanding the microbial and chemical processes that influence fate and transport of fecal indicators from various sources to receiving streams. Variability in land use patterns, the types and nature of pollutants, climatic conditions, and watershed characteristics add to the difficulty of modeling fate and transport of fecal pollution. In addition, the interactions between chemical and microbial processes in the water further add to the complexity of understanding pathogen loading and transport in the watershed.

In addition to the use of fecal indicator bacteria to predict pathogen prevalence, molecular methods such as ribotyping and pulsed-field gel electrophoresis have been suggested to address source identification of fecal pollution. Ribotyping and pulsedfield gel electrophoresis allow for the discrimination between human and nonhuman sources of fecal pollution but rely on large geographically specific genetic databases to correctly classify sources (Tynkkynen et al. 1999; Carson et al. 2001). While the use of these molecular methods may help identify more pathogens, their application still doesn't make it feasible to monitor for all pathogens. Non-molecular methods including antibiotic resistance analysis also allow for the classification of fecal pollution sources based on antibiotic resistance of bacteria from human and animal sources. As with ribotyping and pulsed-field gel electrophoresis, antibiotic resistance analysis requires a large database that may be geographically specific (Wiggins et al. 1999). Monitoring for fecal pollution using optical brighteners and caffeine indicate human sources of pollution 
but are sensitive to regional environmental conditions (Kramer et al. 1996; Buerge et al. 2003). Although these methods may be regionally successful at identifying sources of fecal pollution, they cannot be universally applied to all bodies of water to effectively identify and remediate fecal pollution to protect surface waters and public health.

Fecal pollution detection and source identification methods do not influence the correlations between indicators and pathogens, and they do not provide any additional information regarding fate and transport mechanisms of the fecal pollution from source to receiving waters. Reliance on these indicators alone is not sufficient to protect surface water resources and human health and may hinder TMDL development and remediation efforts to remove impaired waters from 303d lists. The United States Environmental Protection Agency (USEPA) recommends the use of a 30-day geometric mean of $E$. coli for the assessment of bacteriological water quality in recreational waters (USEPA, 1986). Several states, including Tennessee, rely on the 30-day geometric mean of fecal indicator bacteria to assess pathogen contamination and develop TMDLs that can prevent further pathogen pollution. However, the use of the 30-day geometric mean does not take into consideration seasonal effects, variability in land use patterns, or the influence of runoff events on water quality. TMDLs developed using this method do not provide sufficient data to identify the presence of pathogens or sources of fecal pollution based on a small sample size, and long-term monitoring may be necessary to fully assess the potential degree of pathogen contamination.

The shortcomings of conventional indicators and source identification methods of fecal pollution have spawned a need to identify and employ alternative methods of water quality monitoring program design, methods, and data analysis to better protect 
human health. Examining the influence of physical, chemical, and microbial water quality parameters on the fate and transport of fecal pollution using multivariate statistical approaches can improve our understanding of these influences on water quality, help identify sources of fecal pollution, and aid in effective TMDL development. To examine these relationships, multivariate statistical methods can be applied to water quality data to quantify the influence of nonpoint sources of pollution and to model the fate and transport of microbial and chemical pollutants.

Multivariate statistical methods including principal component analyses (PCA) can be applied to water quality data to quantify the influence of nonpoint sources of pollution and to model the fate and transport of microbial and chemical pollutants. Several studies have applied these techniques to better understand the microbial, physical, and chemical factors that influence water quality (Christophersen and Hooper, 1992; Vega et al. 1998; Bernard et al. 2004). However, PCA is used as a data reduction technique and is often applied to small environmental data sets. Rather than reduce the data set to identify the common factors influencing water quality, canonical correlation analyses (CCA) can be applied to large complex environmental data sets. Based on the linear relationships within and between data sets determined by CCA, a measure of the strength of association between the data sets can be determined (Johnson and Wichern, 1992). The application of separate regression analyses for each criterion measure defeats the purpose of having multiple criterion measures and doesn't take into consideration interrelationship among the criterion variables. 


\section{Canonical Correlation Analysis}

CCA is a multivariate statistical technique that can be used to better understand response measures that cannot be described using a single criterion. While multiple regression analysis involves finding a linear combination of predictor variables that best explain the variation in the criterion, canonical correlation analysis allows for the simultaneous analysis of several predictor and explanatory variables by determining the largest correlations within each data set and between the 2 data sets. Canonical correlation analysis first examines the linear combinations of the variables within the predictor and explanatory data sets (canonical variables) and then determines the largest correlation between the 2 data sets (canonical correlations). These calculated canonical correlations are a measure of the strength of association between the 2 data sets and help explain how chemical parameters influence fate and transport of fecal pollution (Hair et al. 1998).

The first step in canonical correlation analysis is the definition of variancecovariance matrices, where $\mathrm{X}^{\prime}$ is the dimensional vector of predictor variables, $\mathrm{Y}^{\prime}$ is the dimensional vector of the criterion measures, and $\mu_{\mathrm{x}}$ and $\mu_{\mathrm{y}}$ denote the respective mean vectors associated with the variables $\mathrm{X}$ and $\mathrm{Y}$ :

$$
\begin{array}{ll}
\Sigma_{\mathrm{xx}}=E\left\{\left(\mathrm{X}-\mu_{\mathrm{x}}\right)\left(\mathrm{X}-\mu_{\mathrm{x}}\right)^{\prime}\right\} & (\text { Eq. 4.1) } \\
\Sigma_{\mathrm{yy}}=E\left\{\left(\mathrm{X}-\mu_{\mathrm{y}}\right)\left(\mathrm{X}-\mu_{\mathrm{y}}\right)^{\prime}\right\} & (\text { Eq. 4.2) } \\
\Sigma_{\mathrm{xy}}=E\left\{\left(\mathrm{X}-\mu_{\mathrm{x}}\right)\left(\mathrm{X}-\mu_{\mathrm{y}}\right)^{\prime}\right\} & (\text { Eq. 4.3) }
\end{array}
$$

The objective of canonical correlation analysis is to find the linear combination of predictor variables that maximally correlates with the linear combination of explanatory 
variables using the dimensional vectors determined from the variance-covariance matrices, denoted as:

$$
\begin{aligned}
& X^{*}=a^{\prime} x=a_{1} x_{1}+a_{2} x_{2}+\ldots+a_{m} x_{m} \text { (Eq. 4.4) } \\
& Y^{*}=b^{\prime} y=b_{1} y_{1}+b_{2} y_{2}+\ldots+b_{m} x_{m} \text { (Eq. 4.5) }
\end{aligned}
$$

The correlation between $\mathrm{X}^{*}$ and $\mathrm{Y}^{*}$ is then determined by:

$$
\rho(a, b)=\left(a^{\prime} \Sigma_{x y} b\right) /\left\{\left(a^{\prime} \Sigma_{x x} a\right)\left(b^{\prime} \Sigma_{y y} b\right)\right\}^{1 / 2} \quad(\text { Eq. 4.6) }
$$

where $\rho$ represents the correlation coefficient. The correlation coefficient represents the maximum correlation between the canonical variates and the strength of the overall relationship between the predictor and explanatory data sets. The set of linear combinations that maximizes the correlation $\rho(a, b)$ is determined using the following equations where $I$ is the identity matrix and $\lambda$ is the largest eigenvalue of the product matrix:

$$
\begin{aligned}
& \left(\Sigma_{\mathrm{xx}}{ }^{-1} \Sigma_{\mathrm{xy}} \Sigma_{\mathrm{yy}}{ }^{-1} \Sigma_{\mathrm{yx}}-\lambda \mathrm{I}\right) \mathrm{a}=0 \\
& \left(\Sigma_{\mathrm{yy}}{ }^{-1} \Sigma_{\mathrm{yx}} \Sigma_{\mathrm{xx}}{ }^{-1} \Sigma_{\mathrm{xy}}-\lambda \mathrm{l}\right) \mathrm{b}=0
\end{aligned}
$$

The eigenvalue (squared canonical correlation coefficient) is an estimate of the amount of shared variance between the weighted canonical variates of the predictive and explanatory variables. The largest eigenvalue is the result of the nonzero eigenvector being multiplied by the matrix ( $)$. The eigenvalue is determined for the 2 sets of eigenvectors $\left(\Sigma_{\mathrm{xx}}{ }^{-1} \Sigma_{\mathrm{xy}} \Sigma_{\mathrm{yy}}{ }^{-1} \Sigma_{\mathrm{yx}}\right.$ and $\left.\Sigma_{\mathrm{yy}}{ }^{-1} \Sigma_{\mathrm{yx}} \Sigma_{\mathrm{xx}}{ }^{-1} \Sigma_{\mathrm{xy}}\right)$ and is used to scale the eigenvector. The eigenvectors associated with the eigenvalue will become the vector of coefficients for $a$ and $b$. Thus: 


$$
\begin{aligned}
& \mathrm{a}=\left(\Sigma_{\mathrm{xx}}{ }^{-1} \Sigma_{\mathrm{xy}} \mathrm{b}\right) / \sqrt{ } \lambda \quad \text { (Eq. 4.9) } \\
& \mathrm{b}=\left(\Sigma_{\mathrm{yy}}{ }^{-1} \Sigma_{\mathrm{yx}} \mathrm{a}\right) / \sqrt{ } \lambda \quad \text { (Eq. 4.10) }
\end{aligned}
$$

Therefore, the canonical weights $a_{1}$ and $b_{1}$ are the corresponding nonzero eigenvectors associated with the largest eigenvalue $\left(\lambda_{1}\right)$, and $a_{1} x$ and $b_{1} y$ are the first canonical variate pair. The process results in the successive extraction of canonical variates so the second pair is the second most highly correlated pair out of all possible linear combinations that are uncorrelated with the first canonical variate pair, resulting in the generation of pairs of canonical variates. Canonical loadings can also be used to interpret the overall canonical structure by assessing the contribution of each variable to the overall canonical structure. Canonical loadings measure the correlation between the original variables and the sets of canonical variates determined using equations 5.9 and 5.10. These loadings reflect the variance that the original variable shares with the canonical variate.

The application of canonical correlation analyses to water quality data to examine the influences and interactions between microbial, chemical, and physical water quality parameters has been used to identify pollution sources and coordinate remediation efforts (Gotz et al. 1998; Bonadonna et al. 2002; Zeng and Rasmussen, 2005). In this study, CCA can also be used to determine the relationship between chemical and microbial water quality parameters to assess their influence in the fate and transport of fecal indicator organisms and pathogens in Sinking Creek.

In addition to canonical correlation analysis, canonical discriminant analysis (CDA) can be used to better understand the factors that influence surface water quality 
and their relationship to land use patterns. CDA can be used to reveal patterns of pollution types based on sources and land use patterns. This technique identifies the canonical variables that find the maximum amount of separation to discriminate between groups based on the strength of the linear associations (i.e., site, season). Each linear combination of variables is a canonical variable. In this case, the variables are measured water quality parameters and the groups are land use patterns. A plot of the first 2 canonical variables will display the degree of discrimination between each group. By applying CDA to water quality data, it may be possible to identify common pollution sources based on the key discriminatory variables and associate them with specific land use patterns along Sinking Creek.

Physical, chemical, and microbial water quality data were collected from Sinking Creek to examine the usefulness of this methodology and identify nonpoint sources of pollution. In a previous study using regression analyses conducted on data collected from Sinking Creek, we demonstrated that chemical parameters (nitrates, phosphates, biochemical oxygen demand) did not individually correlate with fecal coliform concentrations (Hall et al. 2006). This lack of correlation suggests either no interaction or more complex interactions between water chemistry and pathogen fate and transport. If interaction is more complex then multivariate statistical techniques may be a better tool to understand the complex interactions and effectively identify the parameters that most influence watershed dynamics.

Using a targeted sampling program and statistical modeling to identify pollution sources is potentially a cost-effective method for water quality monitoring and assessment (Johnson and Wichern, 1992). While the statistical methodology is useful 
to identify pollution sources and can be applied to other large environmental data sets, the developed models may be specific to the individual water bodies or watersheds for which they are developed and may under-represent true watershed dynamics (Callies, 2005). However, we suggest that this data analysis approach can be successfully applied to other watersheds to better understand the influence of seasonal effects, variability in land use patterns, and runoff events on water quality. The objective of this group of experiments was to better understand the factors influencing the fate and transport of fecal pollution and identify nonpoint sources of fecal pollution as they relate to land use patterns in Sinking Creek using multivariate statistical analyses.

\section{Materials and Methods}

Sinking Creek Location and Water Quality Monitoring

The Sinking Creek sub-watershed (06010103130) is one of 13 sub-watersheds that belong to the Watauga River watershed (TDEC, 2000a). Sinking Creek is a 9.8 mile long tributary of the Watauga River partially located in Washington and Carter Counties in Tennessee. The headwaters of Sinking Creek are located on Buffalo Mountain and it enters the Watauga River at mile 19.9. The main land uses within the 13.1 square mile drainage basin of the Sinking Creek watershed include: forest (65.5\%), urban (25.3\%), and agricultural areas (9.0\%) (TDEC 2000b). There are 19.8 impaired stream miles in the Sinking Creek watershed including tributaries (TDEC, 2000b).

Upstream locations on Buffalo Mountain are forested, and land use transitions to urban, followed by agricultural land use at downstream sites. Fourteen sites were initially selected for routine water quality monitoring in 2002 and are described in Table 
4.1 and Figure 4.1. From these 14 sampling locations, 2 sites were randomly selected from each land use classification and sampled monthly for the physical, chemical, and microbial parameters described in Table 4.2. The sites selected for representation of agricultural land use were sites 2 and 4, sites selected to represent urban land use were sites 7 and 10, and sites 13 and 14 represented forested land use. 
Table 4.1. Sampling locations on Sinking Creek sampled during this study

\begin{tabular}{|c|c|c|c|c|c|}
\hline $\begin{array}{l}\text { Site } \\
\text { Number }\end{array}$ & Site Location & $\begin{array}{l}\text { Predominant Land } \\
\text { Use }\end{array}$ & Physical Description & $\begin{array}{l}\text { Habitat } \\
\text { Assessment } \\
\text { Score (\%) }\end{array}$ & $\begin{array}{l}\text { Latitude/Longitude } \\
\text { Coordinates and } \\
\text { Elevation }\end{array}$ \\
\hline 2 & $\begin{array}{l}\text { Upstream of Bob Peoples } \\
\text { bridge on Sinking Creek Road }\end{array}$ & Agriculture & $\begin{array}{l}\text { Moderately eroded banks with little } \\
\text { vegetation buffer or riparian zone. } \\
\text { Creek bed predominantly cobble and gravel }\end{array}$ & $52 \%$ & $\begin{array}{c}19.837^{\prime} \mathrm{N}, 18.254^{\prime} \mathrm{W} \\
1530 \mathrm{ft}\end{array}$ \\
\hline 4 & $\begin{array}{l}\text { Upstream of crossing on Joe } \\
\text { Carr Road }\end{array}$ & Agriculture & $\begin{array}{l}\text { Moderately eroded banks with poor bank } \\
\text { stability and little vegetative buffer or riparian } \\
\text { zone. } \\
\text { Creek bed predominantly boulders, cobble } \\
\text { and gravel }\end{array}$ & $43 \%$ & $\begin{array}{c}19.594^{\prime} \mathrm{N}, 18.579^{\prime} \mathrm{W} \\
1552 \mathrm{ft}\end{array}$ \\
\hline 7 & $\begin{array}{l}\text { Upstream of bridge on Miami } \\
\text { Drive, King Springs Baptist } \\
\text { Church }\end{array}$ & Urban & $\begin{array}{l}\text { Heavily eroded left bank, concrete bank on } \\
\text { right with no vegetative buffer or riparian } \\
\text { zone. } \\
\text { Creek bed predominantly cobble }\end{array}$ & $53 \%$ & $\begin{array}{c}18.7722^{\prime} \mathrm{N}, 19.685^{\prime} \mathrm{W} \\
1583 \mathrm{ft}\end{array}$ \\
\hline 10 & $\begin{array}{l}\text { Upstream of bridge crossing } \\
\text { Sinking Creek at Hickory } \\
\text { Springs Road }\end{array}$ & Urban & $\begin{array}{l}\text { Heavily eroded banks with no vegetative } \\
\text { buffer. } \\
\text { Creek bed predominantly boulders and } \\
\text { cobble }\end{array}$ & $57 \%$ & $\begin{array}{l}17.431^{\prime} \mathrm{N}, 21.397^{\prime} \mathrm{W} \\
1720 \mathrm{ft}\end{array}$ \\
\hline 13 & $\begin{array}{l}\text { Upstream of road crossing on } \\
\text { Jim McNeese Road }\end{array}$ & Forest & $\begin{array}{l}\text { No visible bank erosion with moderate } \\
\text { riparian zone. } \\
\text { Creek bed predominantly boulders and } \\
\text { cobble }\end{array}$ & $71 \%$ & $\begin{array}{l}16.035^{\prime} \mathrm{N}, 22.163^{\prime} \mathrm{W} \\
2048 \mathrm{ft}\end{array}$ \\
\hline 14 & $\begin{array}{l}\text { Downstream of path crossing } \\
\text { at Dry Springs Road }\end{array}$ & Forest & $\begin{array}{l}\text { No visible bank erosion with optimal riparian } \\
\text { zone and vegetative buffer. } \\
\text { Creek bed predominantly boulders, cobble } \\
\text { and gravel }\end{array}$ & $83 \%$ & $\begin{array}{l}14.800{ }^{\prime} \mathrm{N}, 22.033^{\prime} \mathrm{W} \\
2148 \mathrm{ft}\end{array}$ \\
\hline
\end{tabular}




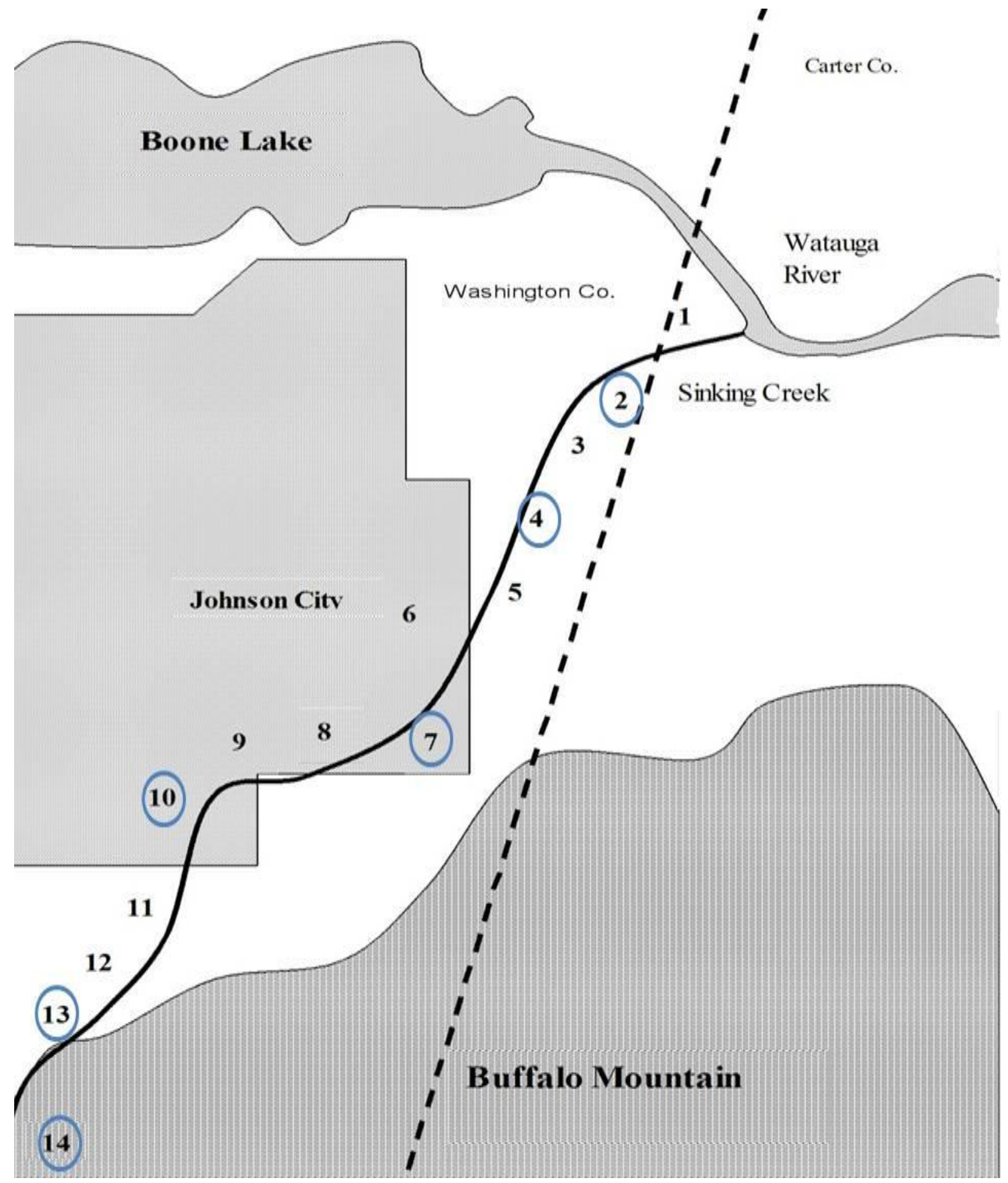

Figure 4.1. Map of Sinking Creek sampling locations (sites sampled in this study are circled). 
Table 4.2. Physical, chemical, and microbial water quality parameters measured

\begin{tabular}{|c|c|c|c|}
\hline Parameter & Abbreviation & Units & Holding Time \\
\hline $\mathrm{pH}$ & $\mathrm{pH}$ & $\mathrm{pH}$ & Field measurement \\
\hline Water temperature & WT & ${ }^{\circ} \mathrm{C}$ & Field measurement \\
\hline Air temperature & AT & ${ }^{\circ} \mathrm{C}$ & Field measurement \\
\hline Dissolved oxygen & DO & $\mathrm{mg} / \mathrm{l}$ as $\mathrm{O}_{2}$ & Field measurement \\
\hline Conductivity & Cond & umohs & Field measurement \\
\hline Fecal coliform in water & FCW & CFU/100ml & $6 h$ \\
\hline Total coliform in water & TCW & $\mathrm{CFU} / 100 \mathrm{ml}$ & $6 \mathrm{~h}$ \\
\hline Fecal coliform in sediment & FCS & $\mathrm{CFU} / 100 \mathrm{ml}$ & $6 \mathrm{~h}$ \\
\hline Total coliform in sediment & TCS & $\mathrm{CFU} / 100 \mathrm{ml}$ & $6 \mathrm{~h}$ \\
\hline Colilert & Colilert & $\mathrm{CFU} / 100 \mathrm{ml}$ & $6 \mathrm{~h}$ \\
\hline Standard plate count & SPC & $\mathrm{CFU} / \mathrm{ml}$ & $6 \mathrm{~h}$ \\
\hline Acridine orange direct counts & AODC & cells/g sediment & $6 \mathrm{~h}$ \\
\hline Acid phosphatase & AcidP & $\mu \mathrm{g} / \mathrm{g}$ sediment & $24 \mathrm{~h}$ \\
\hline Alkaline phosphatase & AlkP & $\mu \mathrm{g} / \mathrm{g}$ sediment & $24 \mathrm{~h}$ \\
\hline Dehydrogenase & $\mathrm{DHA}$ & $\mu \mathrm{g} / \mathrm{g}$ sediment & $24 \mathrm{~h}$ \\
\hline Galactosidase & Gal & $\mu \mathrm{g} / \mathrm{g}$ sediment & $24 \mathrm{~h}$ \\
\hline Glucosidase & Glu & $\mu \mathrm{g} / \mathrm{g}$ sediment & $24 \mathrm{~h}$ \\
\hline Nitrates & $\mathrm{NO}_{3}$ & $\mathrm{mg} / \mathrm{l}$ & $24 \mathrm{~h}$ \\
\hline Phosphates & $\mathrm{PO}_{4}^{2-}$ & $\mathrm{mg} / \mathrm{l}$ & $24 \mathrm{~h}$ \\
\hline Ammonia & $\mathrm{NH}_{3}^{+}$ & $\mathrm{mg} / \mathrm{l}$ & $24 \mathrm{~h}$ \\
\hline Biochemical oxygen demand & $\mathrm{BOD}_{5}$ & $\mathrm{mg} / \mathrm{l}$ & $24 \mathrm{~h}$ \\
\hline Hardness & Hard & $\mathrm{mg} / \mathrm{l}$ & $48 \mathrm{~h}$ \\
\hline Alkalinity & Alk & $\mathrm{mg} / \mathrm{l}$ & $24 \mathrm{~h}$ \\
\hline E. coli O157:H7 & O157:H7 & $\mathrm{CFU} / 100 \mathrm{ml}$ & $24 \mathrm{~h}$ \\
\hline Shigella sp. & Shigella & CFU/100ml & $24 \mathrm{~h}$ \\
\hline Giardia sp. & Giardia & Cysts/l & $72 \mathrm{~h}$ \\
\hline Cryptosporidium sp. & Crypto & Oocysts/l & $72 \mathrm{~h}$ \\
\hline F+ - specific bacteriophage & bacteriophage & $\mathrm{PFU} / \mathrm{ml}$ & $48 \mathrm{~h}$ \\
\hline
\end{tabular}

\section{Sample Collection}

Water samples were collected monthly from 6 pre-selected sites on Sinking Creek from January 2011 through December 2011 and were analyzed for the variables described in Table 4.2. Water samples for total and fecal coliform bacteria (TC/FC), standard plate counts (SPC), E. coli 057:H7, Shigella sp., and bacteriophage analyses were collected and analyzed in triplicate (SPC samples analyzed in duplicate) in sterile, 
1-L Nalgene ${ }^{\mathrm{TM}}$ bottles. Water samples for Colilert $\Theta$ analyses were collected in sterile 100ml plastic bottles (IDEXX Laboratories, Westbrook, Maine). Water samples for nitrates $\left(\mathrm{NO}_{3}{ }^{-}\right)$, phosphates $\left(\mathrm{PO}_{4}{ }^{-}\right)$, ammonia $\left(\mathrm{NH}_{3}{ }^{+}\right), 5$-day biochemical oxygen demand $\left(\mathrm{BOD}_{5}\right)$, alkalinity, and hardness were collected and analyzed in triplicate in sterile 2-L Nalgene ${ }^{\mathrm{TM}}$ bottles. Sediment samples for TC/FC in water, microbial enzyme activity (MEA), and acridine orange direct counts (AODC) were collected in $20 z$ sterile WhirlPak ${ }^{\mathrm{TM}}$ bags. All samples were transported to the laboratory on ice and analyzed within the holding times described in Table 3. Field measurements for $\mathrm{pH}$, air and water temperature, dissolved oxygen, and conductivity were also collected at each site.

Quality assurance and quality control (QA/QC) practices included the analysis of chemical parameters consisted of one trip blank, one field blank, a negative control, one replicate, one spiked sample, and one quality control standard. QA/QC practices included in the analysis of microbial parameters included the analysis of one trip blank, one field blank, a negative control, and a positive control. A secondary wastewater effluent sample was used as the positive control for TC/FC, Colilert®, SPC, and bacteriophage analyses. Laboratory strains of E. coli O157:H7 and Shigella flexneri (ATCC $®$ Number $43895^{\mathrm{TM}}$ and ATCC ${ }^{\circledR} 12022^{\mathrm{TM}}$, respectively) were used to seed water samples that served as a positive control for PCR analysis.

\section{Microbial Analyses}

TC/FC analyses for water samples were conducted according to Standard Methods for Examination of Water and Wastewater (APHA, 1992). Briefly, $0.5 \mathrm{ml}$ of water were filtered through a $0.45 \mu \mathrm{m}$ membrane filter (EMD Millipore, Billerica, $M A)$ and 
the filter placed in a petri dish containing an absorbent pad (EMD Millipore, Billerica, MA) with $2 \mathrm{ml}$ of $\mathrm{m}$-Endo media for total coliform analysis or $\mathrm{m}-\mathrm{FC}$ media for fecal coliform analysis. All plates were inverted and enumerated following $24 \mathrm{~h}$ incubation at $37^{\circ} \mathrm{C}$ and $44.5^{\circ} \mathrm{C}$ for total coliform and fecal coliforms, respectively. For TC/FC sediment analyses, $0.5 \mathrm{~g}$ of sediment was added to $25 \mathrm{ml}$ of sterile water $+1 \%$ Tween 80. The samples were vortexed and allowed to settle for 30 minutes, and $0.5 \mathrm{ml}$ of the buffer suspension was filtered according to Standard Methods for Examination of Water and Wastewater as described above (APHA, 1992).

SPC were conducted according to Standard Methods for Examination of Water and Wastewater (APHA, 1992) using R2A agar. One milliliter of water was placed in the center of a sterile petri dish (Fisher Scientific, Pittsburgh, PA) and 10ml of R2A agar was added to the dish. The plate was swirled in a figure eight motion to allow the sample to disperse in the media and cover the plate. Plates were allowed to solidify and were enumerated following incubation at $25^{\circ} \mathrm{C}$ for $48 \mathrm{~h}$. Escherichia coli concentrations were determined using the Colilert@ Quanti-Tray method (APHA, 1995). To each $100 \mathrm{ml}$ water sample, a packet of Defined Substrate Technology ${ }^{\circledR}(\mathrm{DST} \circledast)$ reagent (IDEXX Laboratories, Westbrook, Maine) was added and mixed. The sample was then poured into a Quanti-Tray ${ }^{\circledR}$, sealed using the Quanti-Tray ${ }^{\circledR}$ sealer, and incubated for $24 \mathrm{~h}$ at $37^{\circ} \mathrm{C}$. E. coli were then enumerated using the Standard Method most probable number (MPN) procedure. Samples for water TC/FC were processed in triplicate and samples for sediment TC/FC were processed in duplicate. SPC were processed in duplicate and one Colilert® sample was processed for each site. 
MEA analyses were conducted and included acid and alkaline phosphatases, glucosidase, galactosidase, and dehydrogenase activities. For each enzyme analyzed, $1 \mathrm{~g}$ of sediment was added to a test tube containing a specific buffer and enzyme. Sediment samples for acid phosphatase were mixed with $4 \mathrm{ml}$ of $1 \mathrm{M}$ TRIS buffer ( $\mathrm{pH}$ 4.8) and $4 \mathrm{ml}$ of $1 \mathrm{M}$ TRIS buffer $(\mathrm{pH}) 8.4$ for alkaline phosphatase. For both acid and alkaline phosphatase, $1 \mathrm{ml}$ of $1 \mathrm{M}$ TRIS buffer with $0.1 \%$ phosphatase substrate $(\mathrm{pH} 7.6)$ was added to each tube (Sayler et al. 1979). Sediment samples for galactosidase and glucosidase activities were mixed with $4 \mathrm{ml}$ of $0.1 \mathrm{M}$ phosphate buffer $(\mathrm{pH} 9.0)$. Galactosidase activity was measured by adding $1 \mathrm{ml}$ of $0.01 \mathrm{M}$ phosphate buffer with $0.15 \% \mathrm{p}$-nitrophenyl- $\beta$-D-galactopyranoside as an indicator of galactosidase activity. One milliliter of $0.01 \mathrm{M}$ phosphate buffer with $0.15 \% 4$-nitrophenyl- $\beta$-D-glucopyranoside was used as an indicator to assess glucosidase activities (Morrison et al. 1977). Following addition of buffers and indicators, all tubes were vortexted and incubated at $25^{\circ} \mathrm{C}$ for $24 \mathrm{~h}$. Acid and alkaline phosphatase, galactosidase, and glucosidase activities were determined using a spectrophotometer at an absorbance of $418 \mathrm{~nm}$.

For dehydrogenase (DHA) activity, $1 \mathrm{~g}$ of sediment was added to a test tube containing $2 \mathrm{ml}$ of $0.1 \mathrm{M}$ phosphate buffer $(\mathrm{pH} 7.6)$ and $1 \mathrm{ml}$ of $0.5 \%$ iodonitrotetrazolium chloride (INT) salt solution. The samples were vortexed and incubated in the dark at $25^{\circ} \mathrm{C}$ for 45 minutes. One milliliter of the sample was filtered through a $0.22 \mu \mathrm{m}$ porosity cellulose membrane (GE Water and Process Technologies, Trevose, PA) and allowed to dry at room temperature. The membrane, was then added to a test tube containing $5 \mathrm{ml}$ of dimethyl sulfoxide, vortexted to dissolve the membrane, and incubated in the 
dark at $25^{\circ} \mathrm{C}$ for $24 \mathrm{~h}$. Dehydrogenase activity was then determined using a spectrophotometer at an absorbance of $460 \mathrm{~nm}$.

AODC analysis was performed as described by Ghiorse and Balkwill (1983). Three hundred milligrams of sediment was added to $30 \mathrm{ml}$ of sterile PBS+Tween 80 , vortexed for $60 \mathrm{~s}$, and allowed to settle for $3 \mathrm{~h}$. Two hundred fifty microliters of the suspension was mixed with $5 \mathrm{ml}$ sterile water $+500 \mu \mathrm{l}$ acridine orange stain, and samples were vortexed for $30 \mathrm{~s}$. Samples were filtered using $25 \mathrm{~mm}, 0.2 \mu \mathrm{m}$ pore polycarbonate nucleopore filters (Osmonics, Inc., Minnetonka, MN), and the filters were mounted and fixed on slides for enumeration at 1000X using the Olympus $\mathrm{BH} 2$ epifluorescent microscope (Olympus, New Hyde Park, NY). One sediment sample was processed per site and 3 microscopic fields were enumerated on each slide.

\section{Chemical Analyses}

$\mathrm{NO}_{3}{ }^{-}, \mathrm{PO}_{4}{ }^{-}, \mathrm{NH}_{3}{ }^{+}$, alkalinity, and hardness analyses were performed in triplicate using colorimetric $\mathrm{HACH}^{\mathrm{TM}}$ methods and $\mathrm{HACH}^{\mathrm{TM}}$ reagents as described by the manufacturer ( $\mathrm{HACH}$ Company, Loveland, $\mathrm{CO}$ ). Briefly, $\mathrm{NO}_{3}{ }^{-}, \mathrm{PO}_{4}{ }^{-}, \mathrm{NH}_{3}{ }^{+}$analyses were conducted by adding $10 \mathrm{ml}$ of water to a vial containing the appropriate reagent packet; NitraVer5, PhosVer3 and salicylate/ammonia cyanurate reagents, respectively. The vials were shaken to dissolve the reagent and samples were analyzed using pocket colorimeters specific to the nutrient of interest. Alkalinity and hardness analyses were conducted using $100 \mathrm{ml}$ sample volumes and a digital titrator. For alkalinity determination, 1 packet of phenolthalein indicator and bromcresol green-methyl red indicator were added to the sample and mixed. The sample was then titrated with $1.6 \mathrm{~N}$ 
sulfuric acid to a grey-green endpoint. For hardness determination, 1 packet of ManVer2 reagent and $2 \mathrm{ml}$ of hardness buffer $(\mathrm{pH} \mathrm{10})$ were added to the $100 \mathrm{ml}$ sample and mixed. The sample was then titrated with $0.8 \mathrm{~N}$ Ethylenediaminetetraacetic acid (EDTA) to a blue endpoint. $\mathrm{BOD}_{5}$ analyses were conducted according to Standard Methods for Examination of Water and Wastewater (APHA, 1992). Wheaton BOD bottles (Wheaton Science Products, Millville, $\mathrm{NJ}$ ) were completely filled with sample water and capped with glass stoppers to ensure no air bubbles were present. Initial (Day 0) and final (Day 5) dissolved oxygen concentrations were measured using the YSI Model 5000 dissolved oxygen meter (YSI Inc., Yellow Springs, OH).

\section{Pathogenic Bacteria Analyses}

Samples for E. coli O157:H7 and Shigella sp. were analyzed in triplicate. The method used for the filtration and isolation of the bacteria is described by Bej et al. (1991). One hundred milliliters of water was collected and filtered through a $0.22 \mu \mathrm{m}$ membrane filter. The filter was then washed with $10 \mathrm{ml}$ of a $1 \%$ Tween 80 solution and centrifuged for 10 minutes to create a cell pellet. The supernatant was removed and the cell pellet was washed twice with $10 \mathrm{ml}$ phosphate buffered saline. Fifty microliters of diethylpyrocarbonate solution was added to the final cell pellet and subjected to 6 freeze-thaw cycles at $-20^{\circ} \mathrm{C}$ and $100^{\circ} \mathrm{C}$, respectively.

PCR amplification for E. coli O157:H7 was performed as described by Kimura et al. (2000) using primers EC-1 (GGCAGCCAGCATTTTTTTA) and EC-2 (CACCCAACAGAGAAGCCA) for the chuA gene. The final 50 $\mu$ I PCR mixture contained 2.5X PCR buffer ( $\mathrm{mM} \mathrm{MgCl}_{2}, 10 \mathrm{mM}$ Tris- $\left.\mathrm{HCl}, 50 \mathrm{mM} \mathrm{KCl}\right), 0.8 \mathrm{mM}$ of each 
deoxynucleoside triphosphate (dATP, dCTP, dGTP, and dTTP), $4 \mu \mathrm{M}$ concentrations of each primer, $5 \cup$ Taq DNA polymerase (Fisher Scientific, Pittsburg, PA) and $5 \mu$ l of the resuspended cell pellet. The PCR mixture was subjected to an initial denaturation step at $95^{\circ} \mathrm{C}$ for 5 minutes, followed by 35 cycles of 1 minute denaturation at $94^{\circ} \mathrm{C}, 2$ minutes of annealing at $42^{\circ} \mathrm{C}$, and 5 minutes of primer extension at $72^{\circ} \mathrm{C}$. A final extension step was performed at $72^{\circ} \mathrm{C}$ for 10 minutes using a BioRad Thermocycler PCR Machine (BioRad, Hurcules, CA). PCR products were resolved on a $2 \%$ agarose gel for $1.5 \mathrm{~h}$ at $80 \mathrm{~V}$ and subjected to ethidium bromide staining to visualize DNA base pair bands. The presence of a 901 base pair band indicated a sample positive for E. coli $0157: \mathrm{H} 7$.

PCR amplification for Shigella sp. was performed as described by Theron et al. (2001). Thirty cycles of a seminested PCR reaction were performed using primers $\mathrm{H} 8$ (GTTCCTTGACCGCCTTTCCGATAC) and H15 (GCCGGTCAGCCACCCTC) for the ipaH gene (Islam, et al. 1993a) in the first round of PCR. The 50 $\mu$ reaction volume contained 1X PCR buffer ( $\mathrm{mM} \mathrm{MgCl}_{2}, 10 \mathrm{mM}$ Tris- $\left.\mathrm{HCl}, 50 \mathrm{mM} \mathrm{KCl}\right), 0.1 \mathrm{mM}$ of each deoxynucleoside triphosphate (dATP, dCTP, dGTP, and dTTP), 24pmol of H8 primer, 34pmol of H15 primer, 1U Taq DNA polymerase (Fisher Scientific, Pittsburg, PA), and $10 \mu \mathrm{l}$ of resuspended cell pellet. The PCR mixture was subjected to an initial denaturation step at $94^{\circ} \mathrm{C}$ for 3 minutes, followed by 10 cycles of 1 minute denaturation at $94^{\circ} \mathrm{C}, 1$ minute of annealing at $60^{\circ} \mathrm{C}$, and 1 minute of primer extension at $72^{\circ} \mathrm{C}$. One microliter of PCR product from the first PCR round was added to a reaction tube containing the reagents described above, with the addition of $31 \mathrm{pmol}$ of $\mathrm{H} 10$ primer (CATTTCCTTCACGGCAGTGGA) described by Hartman et al. (1990). An initial denaturation step was performed at $94^{\circ} \mathrm{C}$ for 3 minutes, followed by 20 cycles of 1 
minute denaturation at $94^{\circ} \mathrm{C}, 1$ minute of annealing at $60^{\circ} \mathrm{C}$, and 1 minute of primer extension at $72^{\circ} \mathrm{C}$. A final extension step was performed at $72^{\circ} \mathrm{C}$ for 7 minutes using a BioRad Thermocycler PCR Machine (BioRad, Hurcules, CA). PCR products were resolved on a $2 \%$ agarose gel for $1.5 \mathrm{~h}$ at $80 \mathrm{~V}$ and subjected to ethidium bromide staining to visualize DNA base pair bands. The presence of both a 401 and 620 base pair band indicated a sample positive for Shigella sp.

\section{Protozoan Analysis}

One water sample was collected and analyzed monthly at each site for the analysis of Giardia and Cryptosporidium. Samples were collected as described by USEPA method 1623 for water filtration (USEPA, 2005). One hundred liters of water were filtered at each site though Envirochek ${ }^{\mathrm{TM}}$ sampling filters (Pall Corporation, Ann Arbor, $\mathrm{MI}$ ) using a gas powered water pump and Badger ${ }^{\mathrm{TM}}$ flow meter at a rate of 2.5L/minute. The filtration apparatus was assembled as shown in Figure 4.2. 


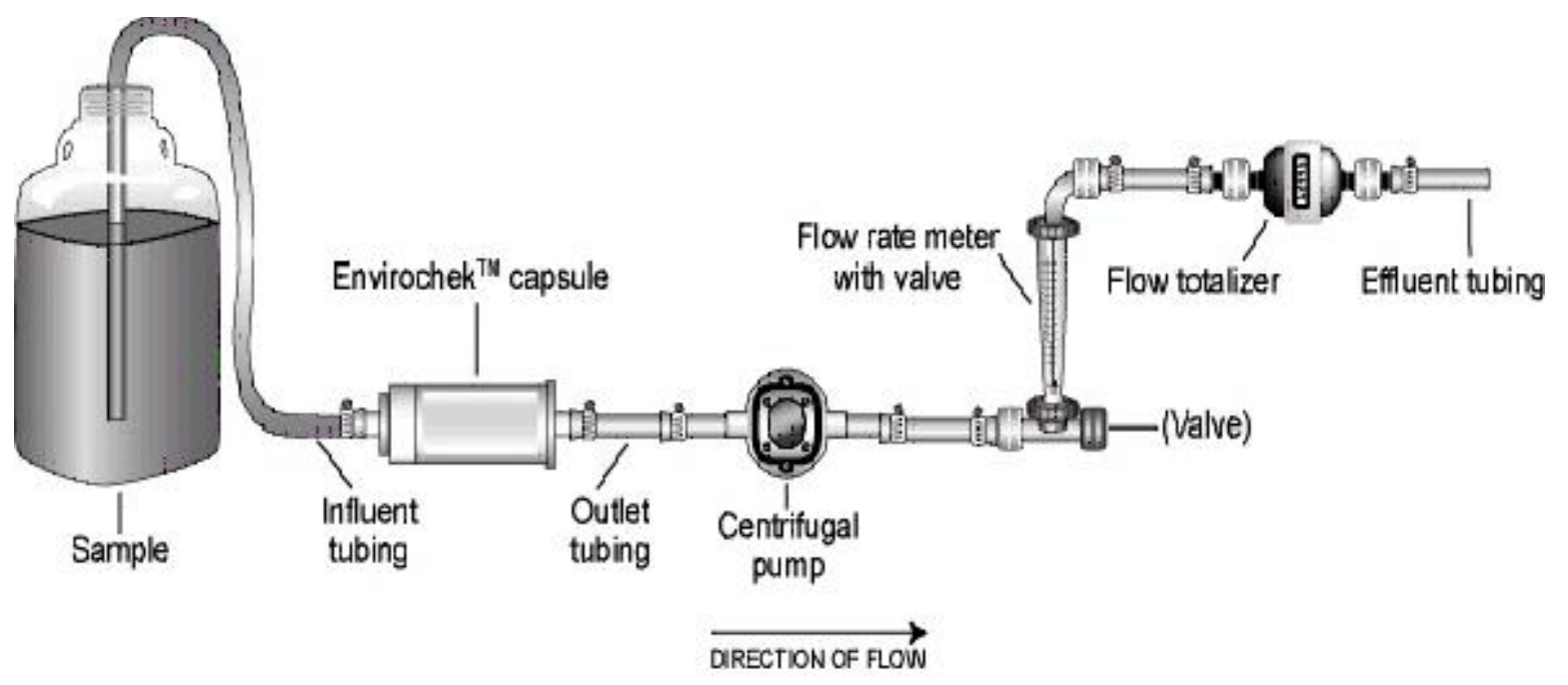

Figure 4.2. Filtration apparatus used to sample Giardia and Cryptosporidium in laboratory seeded samples (USEPA, 2005)

The filters were transported to the lab on ice and analyzed within $72 \mathrm{~h}$ of collection. Filters were initially washed by adding $120 \mathrm{ml}$ of elution buffer to the filter capsule and placing on a wrist action shaker for 30 minutes. The elution buffer was removed and the filter capsule broken open and the filter cut out using a sterile razor blade and hand washed using $120 \mathrm{ml}$ of elution buffer. The buffer was then added to a sterile $250 \mathrm{ml}$ centrifuge tube containing the elution buffer from the initial wash on the wrist action shaker. The samples were centrifuged at 2,300 $\mathrm{xg}$ for $30 \mathrm{~min}$ and the supernatant removed. The concentrated pellet collected was subjected to an immunofluorescent assay using the Waterborne Aqua-Glo ${ }^{\mathrm{TM}} \mathrm{G} / \mathrm{C}$ Direct FL antibody stain (Waterborne, Inc. New Orleans, LA) as described by the manufacturer. The prepared slides were examined at 200X using the Olympus $\mathrm{BH} 2$ epifluorescent microscope (Olympus, New Hyde Park, NY). 


\section{Bacteriophage Analyses}

Samples for bacteriophage analysis were collected and analyzed in triplicate using the double-layer agar procedure described in USEPA method 1601 (USEPA, 2001a) using $E$. coli $\mathrm{C} 3000$ as the host strain (ATCC $\AA$ Number $15597^{\mathrm{TM}}$ ). The host strain was cultured using ATCC 271 broth $(10 \mathrm{~g} / \mathrm{L}$ tryptone, $1 \mathrm{~g} / \mathrm{L}$ yeast extract, $8 \mathrm{~g} \mathrm{NaCl}$, $10 \mathrm{ml} / \mathrm{L}$ of $10 \%$ glucose solution, $2 \mathrm{ml} / \mathrm{L}$ of $1 \mathrm{M} \mathrm{CaCl}_{2}, 1 \mathrm{ml} / \mathrm{L}$ of $10 \mathrm{mg} / \mathrm{ml}$ thiamine) at $37^{\circ} \mathrm{C}$. An overnight culture of the host strain was prepared the day before analysis by inoculating a $30 \mathrm{ml}$ ATCC broth culture with the host strain. On the day of analysis, $100 \mu \mathrm{l}$ of the prepared overnight culture of the host strain was inoculated into a $30 \mathrm{ml}$ of fresh ATCC 271 broth and incubated at $37^{\circ} \mathrm{C}$ until log phase was reached ( 4h).

Ten milliliters of collected sample water were filtered through a syringe filter fitted with a $0.22 \mu \mathrm{m}$ membrane filter to remove bacteria and the filtrate was serially diluted in phosphate buffered water for analysis. Five hundred microliters of each dilution were added to a test tube containing $5 \mathrm{ml}$ of $0.7 \%$ ATCC $® 271$ agar (ATCC $\AA 271$ broth with $1.4 \mathrm{~g} / \mathrm{L}$ agar) and $100 \mu \mathrm{l}$ of host bacteria. The tubes were gently mixed and poured onto a plate containing 1.5\% ATCC 271 agar (ATCC $\AA 271$ broth with 18g/L agar). Plates were allowed to solidify prior to incubation at $37^{\circ} \mathrm{C}$ for $24 \mathrm{~h}$ and plaques were enumerated.

Statistical Analysis

Canonical correlation analysis was conducted to describe the relationship between the microbial and chemical data sets using SAS/STAT statistical software 
(SAS Institute, Cary, NC). In this study the canonical correlations are a measure of the strength of association between the chemical and microbial data sets and help explain how chemical parameters influence microbial fate and transport and how these interactions influence fecal coliform loading in the creek (Johnson and Wichern, 1992). Only canonical coefficients greater than 0.30 were considered to be important, as this is the value at which about $10 \%$ of the variance is explained by a given canonical coefficient (Hair et al. 1998).

Data were initially analyzed using the CANCORR procedure for the entire creek in an effort to determine the extent and types of pollution impacting Sinking Creek. The variables in the microbial data set for this CANCORR analysis included total and fecal coliform counts for water and sediment, Colilert, standard plate counts, acridine orange direct counts, acid phosphatase, alkaline phosphatase, galactosidase, glucosidase, $E$. coli O157:H7, Shigella sp., Giardia sp., Cryptosporidium sp., and bacteriophages. The variables in the chemical data set included total nitrates, total phosphates, ammonia, biochemical oxygen demand, alkalinity, and hardness. Additional CANCORR procedures were also conducted by the season and land use types in an attempt to identify common patterns associating spatial and temporal variability to sources of fecal pollution. The variables included in the chemical data set remained the same. Variables in the microbial data set included those mentioned above but without $E$. coli O157:H7, Shigella sp., Giardia sp., Cryptosporidium sp., and bacteriophages. Only the protozoans and bacteriophages were detected in the collected samples and their infrequent detection did not significantly correlate with fecal coliform bacteria or E. coli concentrations. The observed lack of correlation between the pathogens and 
indicators lead to their exclusion from the canonical correlation analysis, as they did not allow for the detection of significant correlations at the season, site, or land use level.

Discriminant analysis was performed using the CANDISC procedure to identify the canonical variables that allow for the maximum amount of separation to discriminate between groups based on the strength of the linear associations. CANDISC procedures the chemical and microbial parameters described in Table 4.2 and were performed at the season and land use levels.

\section{$\underline{\text { Results and Discussion }}$}

Canonical Correlation Analysis Interpretation

The first canonical correlation analysis was performed at the creek level (Figure 4.3) and the process for interpretation of the canonical correlation analysis is discussed using this analysis. 


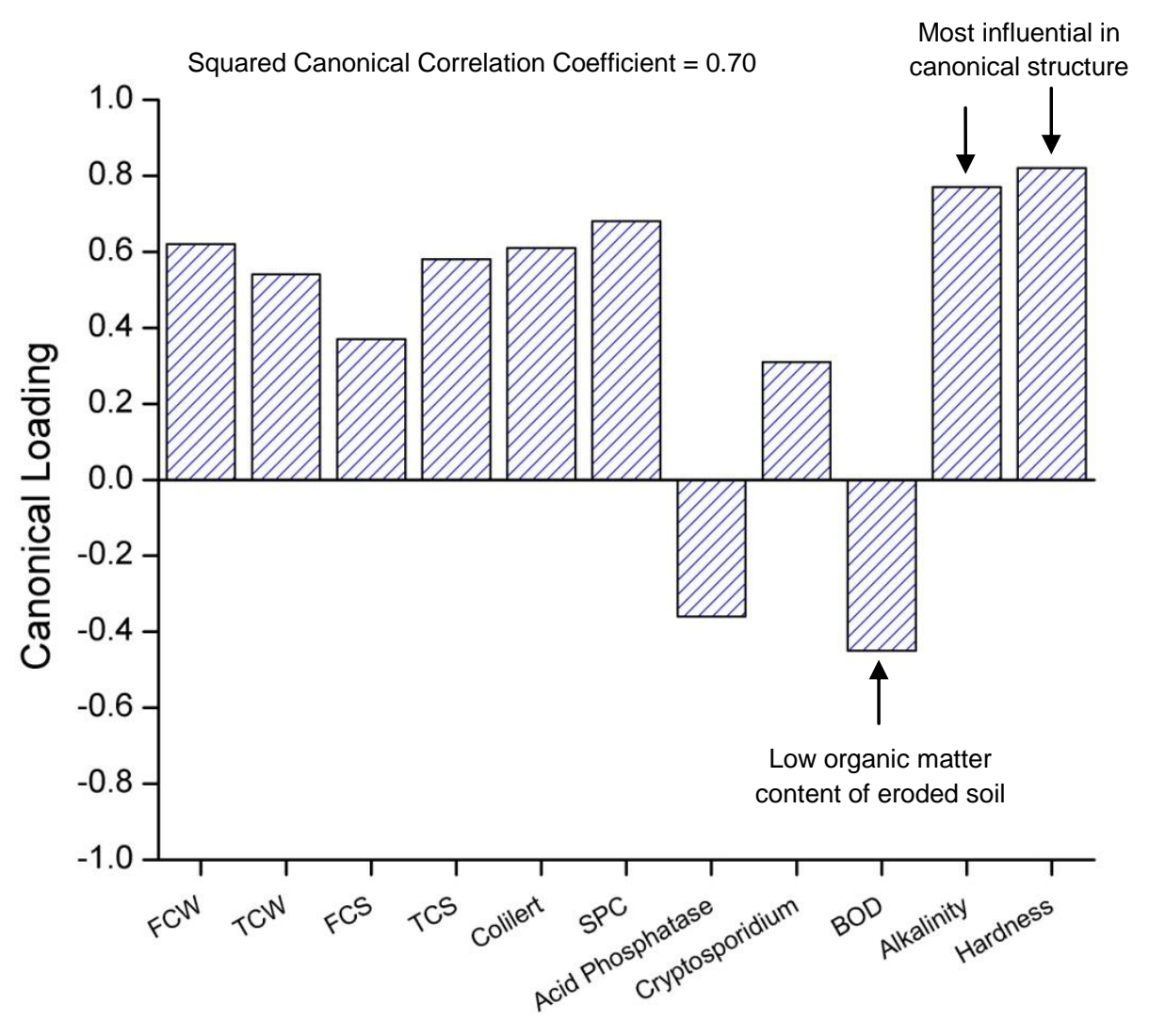

Figure 4.3. Sinking Creek canonical loadings relating chemical water quality parameters to microbial water quality parameters to identify sources of fecal pollution

The initial calculations determine the canonical correlation based on the variancecovariance matrices calculated using equations $4.1-4.3$. The adjusted canonical correlation, approximate standard error, and the squared canonical correlations for each pair of canonical variables are also determined. The first canonical correlation determined using equations 4.4 and 4.5 is 0.78 , which represents the highest correlation between any linear combination of microbial variables and any linear combination of chemical variables. The likelihood ratio and associated statistics are also provided for testing the hypothesis that the canonical correlations are zero. The first $p$-value is small (0.003), forcing the rejection of the null hypothesis at the 0.05 level. 
The null hypothesis states that there is no correlation between the data sets and its rejection is confirmed by four separate multivariate statistics and $\mathrm{F}$ approximations for the null hypothesis. Because the first set canonical variables are significant, only they need to be identified.

The raw canonical coefficients for the microbial and chemical variables are determined using equation 5.6 and are then standardized to account for the absence of equal variances. The standardized canonical coefficients show that the first pair of canonical variates in the microbial data set (determined using equations $5.7-5.10$ ) are the weighted sum of the variables for sediment total coliforms (0.34), standard plate counts (0.48), glucosidase activity, Giardia (-0.32), and Cryptosporidium (0.43). The standardized canonical coefficients show that the first pair of canonical variables in the chemical data set are the weighted sum of the variable for nitrates $(-0.38)$, biochemical oxygen demand (-0.41), alkalinity (-1.01), and hardness (1.96).

The standardized canonical coefficients are then used to determine the correlation between the canonical variables and the original variables. These values are referred to as canonical loadings and are useful to assess the contribution of that variable to the overall canonical function but do not indicate how the original variables contribute jointly to the canonical analysis. In our example, the canonical loadings of the microbial canonical variables show that total and fecal coliforms in water and sediment, E. coli, standard plate counts, acid phosphatase activity, and Cryptosporidium are significant, with standard plate counts and fecal coliforms in water being the most influential ( 0.68 and 0.62 , respectively). The first pair of chemical canonical variables show that $\mathrm{BOD}_{5}$, alkalinity, and hardness are significant, with alkalinity and hardness 
being the most influential ( 0.77 and 0.82 , respectively). The significance of the chemical and microbial variables indicates that these data sets are related. The extent of these relationships can be used to help identify the source(s) of fecal pollution.

Alkalinity and hardness are the chemical variables most contributing to the canonical structure. The ions that contribute to alkalinity and hardness concentrations in water may be introduced by the erosion of soil and geologic formations such as shale, sandstone, siltstone, and limestone. These metasedimentary rock formations are common in Northeast Tennessee, which is characterized by karst topography (NRCS, $2010 a-c)$ and are likely contributing to the observed alkalinity and hardness concentrations. The organic matter fraction of the eroded soil is likely contributing to the observed biochemical oxygen demand and is influencing the correlation between this chemical parameter and the microbial parameters. The correlation of alkalinity, hardness, and $\mathrm{BOD}_{5}$ with the microbial variables suggests that surface runoff containing eroded soil is a contributing factor to fecal pollution and heterotrophic activity in Sinking Creek.

\section{Canonical Correlation Analysis by Season}

The factors influencing the fate and transport of fecal indicator organisms demonstrated temporal variation. Canonical correlation analysis for the winter months indicate that fecal coliform bacteria are introduced by a combination of organic matter

and soil erosion (Figure 4.4) based on the significant canonical loadings for phosphates, ammonia, $\mathrm{BOD}_{5}$, alkalinity, hardness, fecal coliform, and heterotrophic bacteria concentrations in water. 


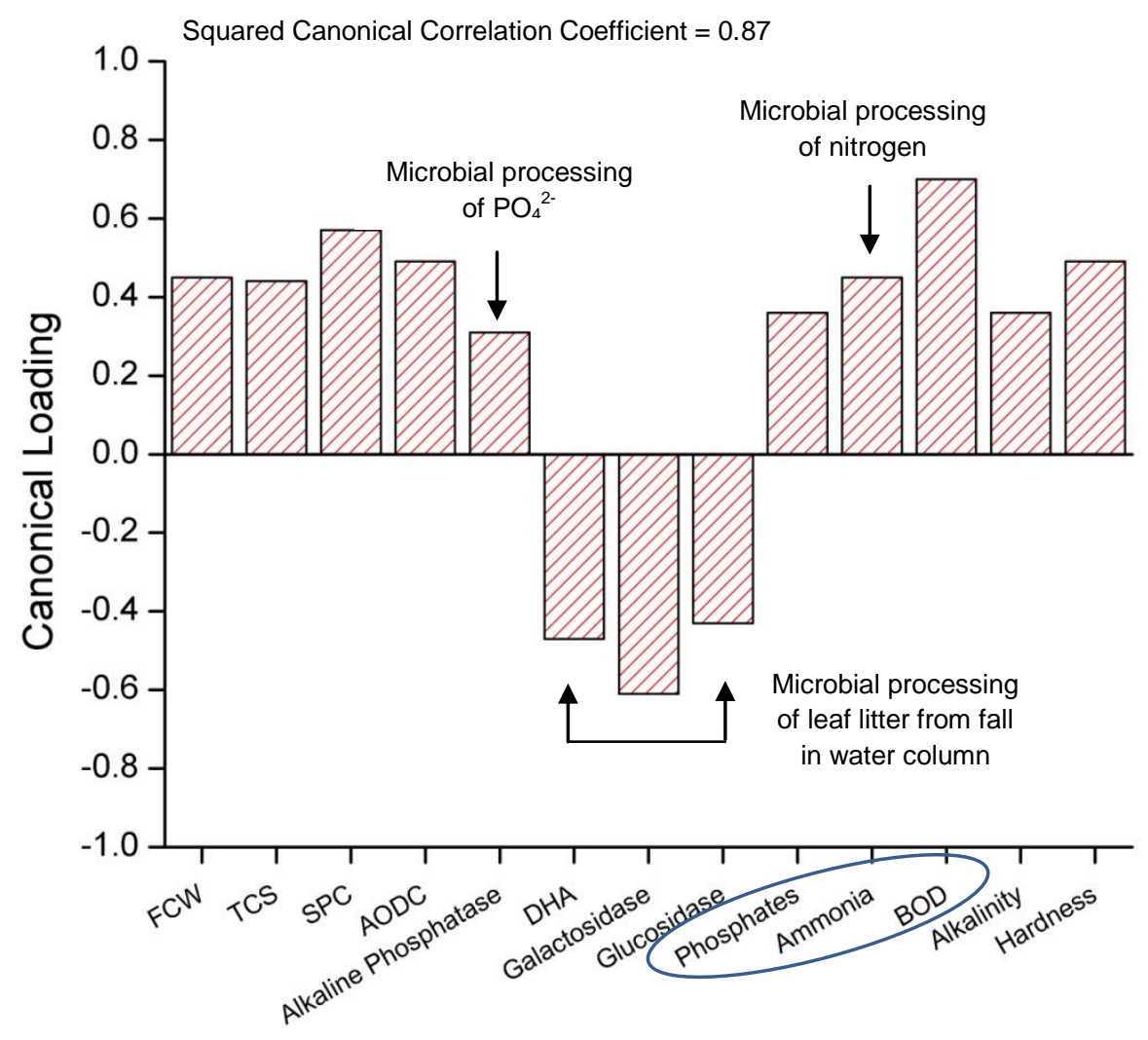

Figure 4.4. Sinking Creek canonical loadings observed during the winter months to relate chemical water quality parameters to microbial water quality parameters to identify sources of fecal pollution

The significant canonical loadings for alkalinity and hardness are likely the result of eroded soil containing fecal coliforms as described above. The high canonical loading for $\mathrm{BOD}_{5}$ suggests the influence of microbial activity on organic matter introduced with soil erosion. Ammonia concentrations may be the result of transformation of the nitrogen component of the organic matter, resulting in its conversion to inorganic nitrogen through ammonification. It may also be possible that the significance of $\mathrm{BOD}_{5}$, ammonia, and phosphates are the result of organic matter introduced from wastewater. Brasfield (1972) has demonstrated that phosphate 
concentrations in surface water positively correlate with total and fecal coliforms and may indicate the input of sewage into the receiving surface water body. It is likely that the addition of leaf litter during the fall account for the observed microbial activities in water and sediment, as the MEA variables also contribute to the overall canonical structure. Alkaline phosphatase activity is positively correlated with the chemical parameters, suggesting the ability of the sediment microbial community to process the added phosphates. The negative correlations of dehydrogenase, galactosidase, and glucosidase with the chemical parameters indicate that processing of the carbon content of the organic matter is being carried out by heterotrophic communities suspended in the water.

Canonical correlation analysis for the spring months demonstrate that fecal pollution is greatly associated with alkalinity, hardness, nitrates, and $\mathrm{BOD}_{5}$ (Figure 4.5). The significant loadings for these variables suggest that fecal pollution in water and sediment is the result of nutrient additions associated with the introduction of eroded soil thorough runoff events. In addition to the introduction of fecal coliforms in water through runoff events, the cations contributing to alkalinity and hardness concentrations may be influencing total and fecal coliform concentrations in sediment. As cation concentrations increase in surface water, they may adhere to the bacteria and organic matter, flocculate and settle out of the water column (Ayoub et al. 1999). This occurrence would likely account for the inverse relationship between fecal coliforms and $\mathrm{BOD}_{5}$, as alkalinity and hardness concentrations resulted in flocculation of bacteria and organic matter associated with the eroded soil, resulting in their partitioning into the sediment. 


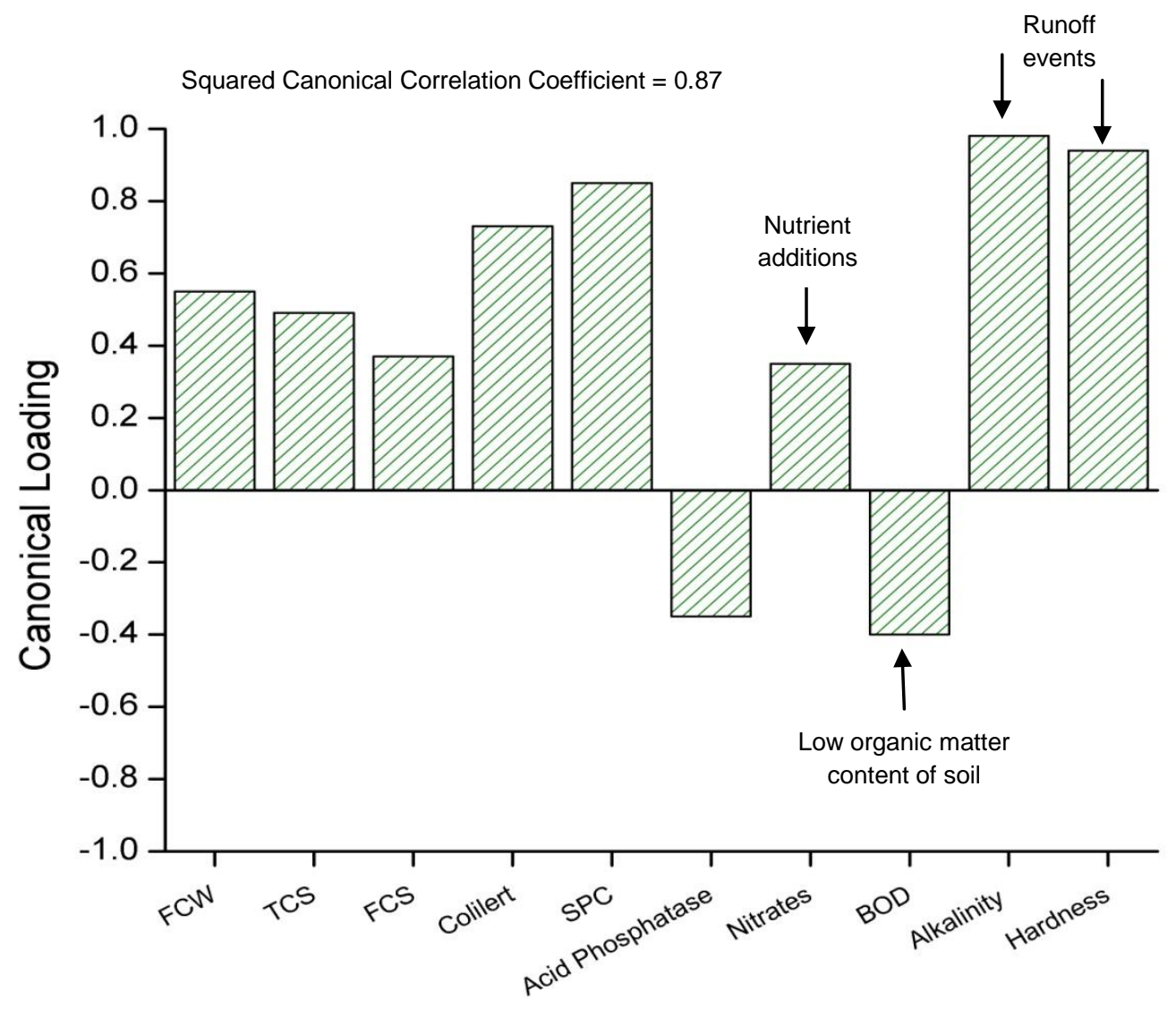

Figure 4.5. Sinking Creek canonical loadings observed during the spring months to relate chemical water quality parameters to microbial water quality parameters to identify sources of fecal pollution

The canonical structure for the summer months is similar to that of the spring months in that it suggests the influence of soil erosion and organic matter inputs on fecal pollution (Figure 4.6). In the first canonical structure, alkalinity and hardness are major contributors to the overall canonical structure, and total and fecal coliforms are likely introduced through runoff containing eroded soil. As described above, the introduced cations can adhere to bacteria and organic matter, causing flocculation and partitioning into the sediment. The influences of sediment partioning are evidenced by the second canonical structure. In addition to organic matter processing in the water 
column, organic matter is also being processed by sediment heterotrophic communities as evidenced by the significant canonical loadings for acid and alkaline phosphatases, galactosidase, and glucosidase. The significant loading for nitrates in the second canonical structure demonstrates a relationship between the 2 canonical structures. In the presence of organic matter, microbial populations can reduce nitrates resulting in increasing cation concentrations, which may result in bacterial settling into sediment (Ayoub et al. 1999), as is suggested by the first canonical structure. This relationship is further supported by the negative correlation of phosphates in the first canonical structure and the influence of $\mathrm{BOD}_{5}$ in the second canonical structure, which both suggest that fecal pollution is associated with a combination of organic matter and soil erosion containing nutrients. 


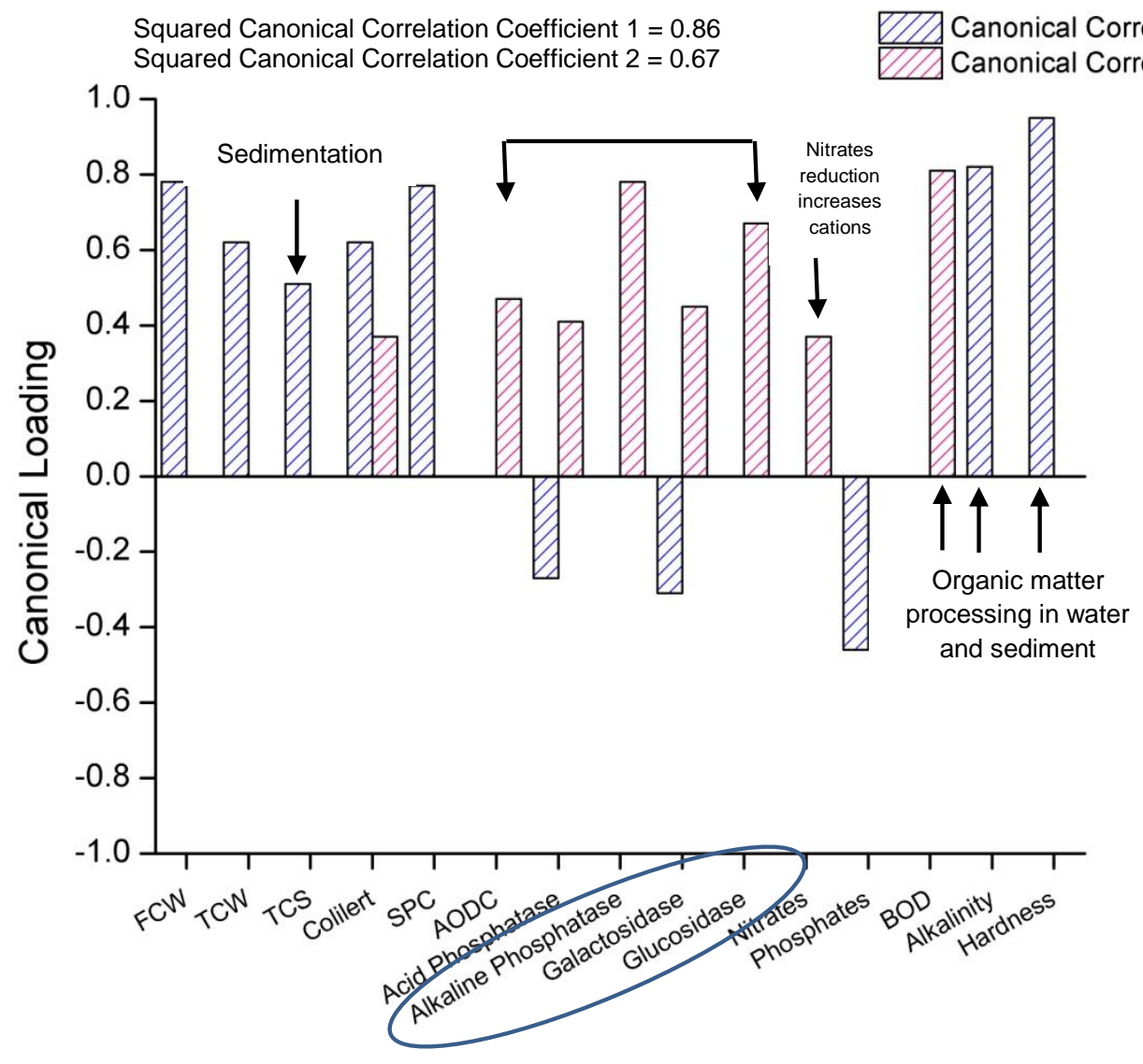

Figure 4.6. Sinking Creek canonical loadings observed during the summer months to relate chemical water quality parameters to microbial water quality parameters to identify sources of fecal pollution

Fecal pollution during the fall months is likely associated with surface runoff containing eroded soil and organic matter (Figure 4.7). In the first canonical structure, fecal indicators in both water and sediment are highly associated with nitrates, ammonia, $\mathrm{BOD}_{5}$, alkalinity, and hardness. The strong influence of $\mathrm{BOD}_{5}$, alkalinity, and hardness indicate the influence of eroded soil containing organic matter on the introduction of fecal indicator bacteria. High alkalinity and hardness concentrations can result from the input of humic acids and organic matter, which is supported by the 
significant correlation of total and fecal coliform concentrations with $\mathrm{BOD}_{5}$. The positive loadings for nitrates and ammonia in the first canonical variable also demonstrate the processing of the nitrogen content of the organic matter by heterotrophic communities via ammonification and nitrification in the water column. The loadings for these variables could also suggest that the introduction of fecal pollution is associated with sewage or septic effluent. The influence of organic matter processing in sediment is also evidenced by the second canonical structure. The negative correlation of $\mathrm{BOD}_{5}$ and the positive canonical loadings for glucosidase, total coliforms, and acridine orange direct counts suggests that there is also organic matter processing occurring in the sediment. Microbial populations can reduce nitrates in the presence of organic matter, thus increasing cation concentrations and contribute to elevated hardness and alkalinity concentrations. These elevated cation concentrations can result in flocculation of organic matter and heterotrophic bacteria (Ayoub et al. 1999). 


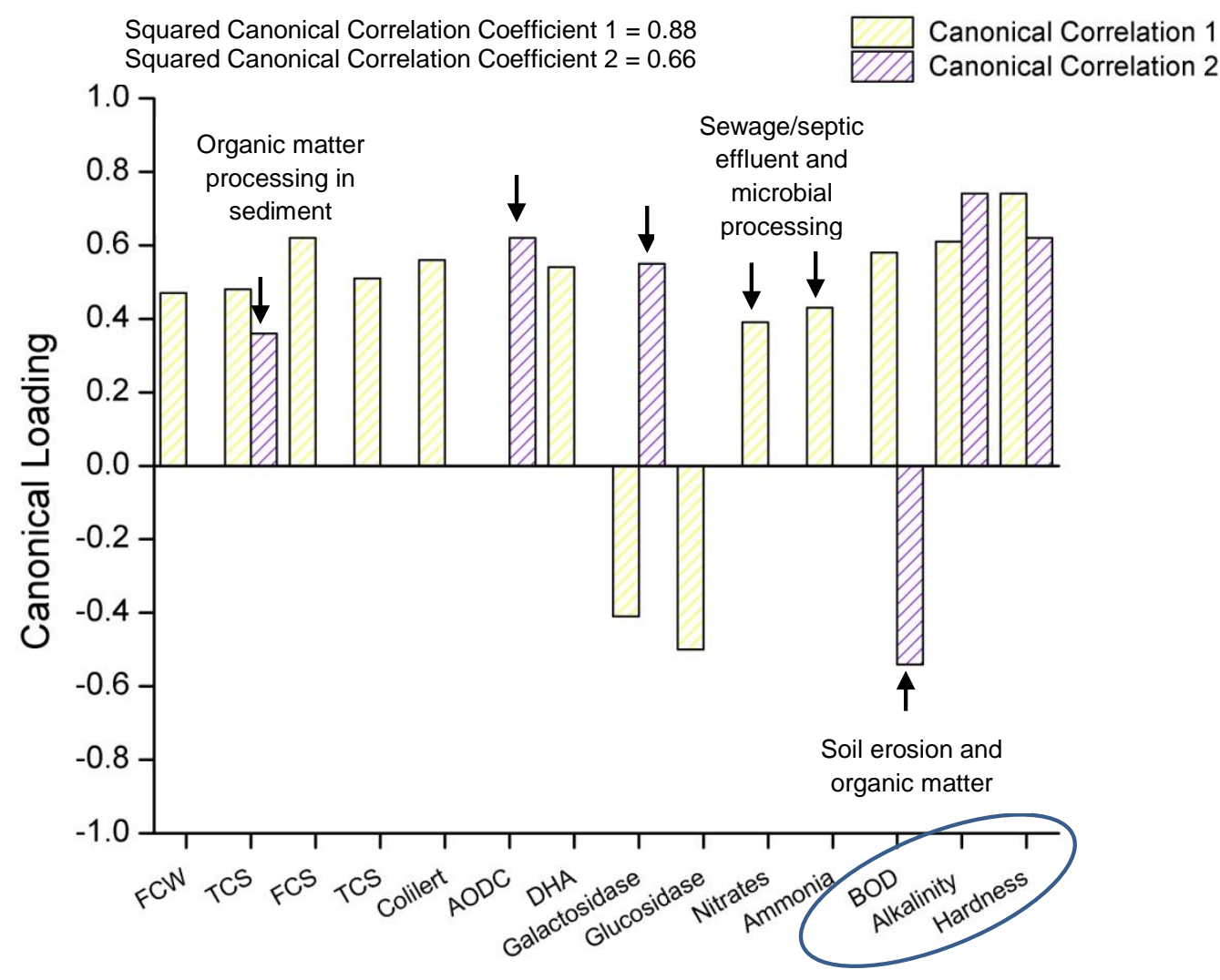

Figure 4.7. Sinking Creek canonical loadings observed during the fall months to relate chemical water quality parameters to microbial water quality parameters to identify sources of fecal pollution

Canonical Correlation Analysis by Land Use

Canonical correlation analyses were also conducted at the land use level to assess spatial variation. This approach was selected because canonical correlation analysis by site did not produce significant correlations for the individual urban land use sites and because of the low cumulative percentages of explained variance compared to those from grouping similar land use sites. The canonical structure for agricultural 
sites demonstrates that fecal pollution is associated with soil erosion and bacterial sedimentation (Figure 4.8).

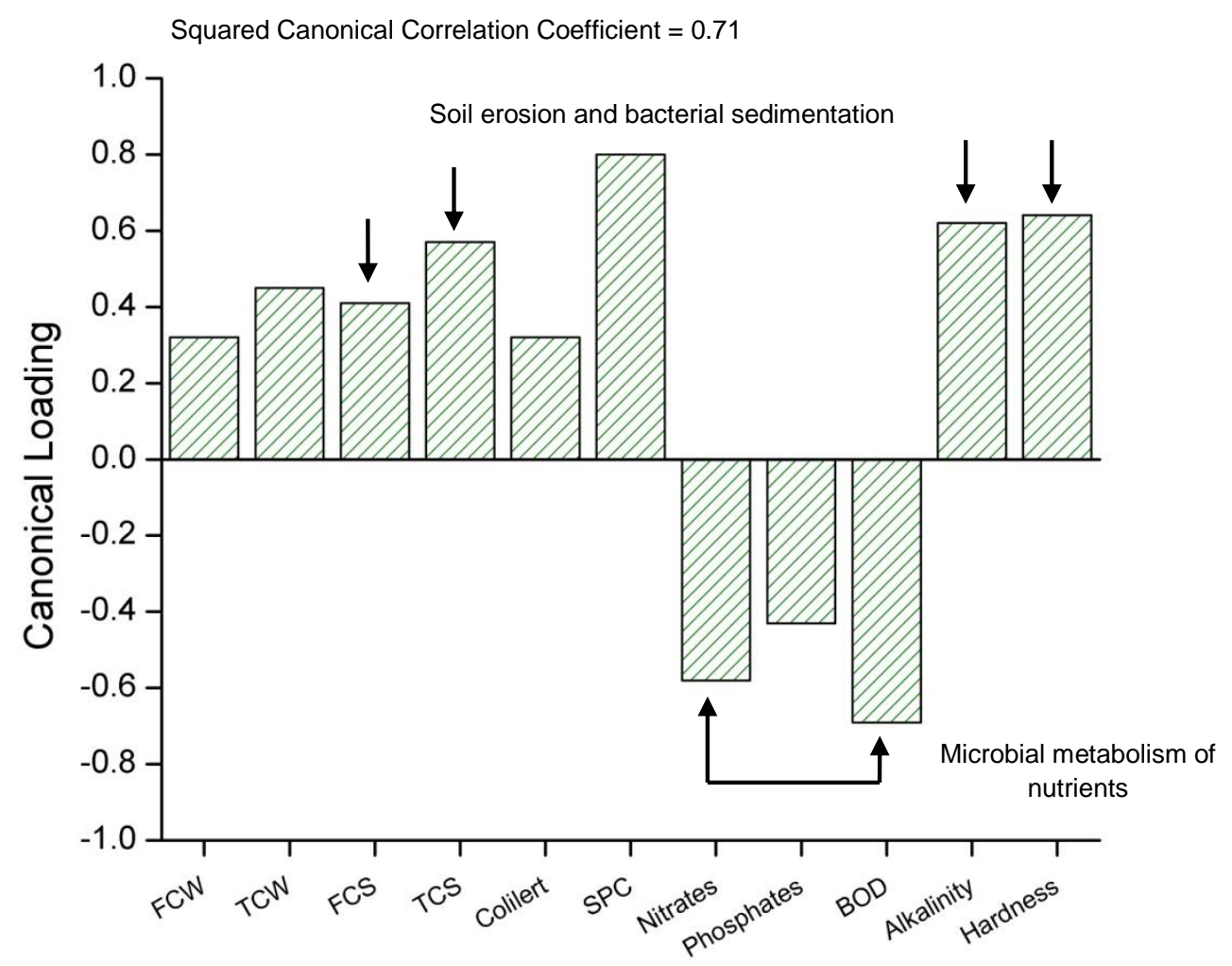

Figure 4.8. Sinking Creek canonical loadings observed at agricultural land use sites to relate chemical water quality parameters to microbial water quality parameters to identify sources of fecal pollution

The positive loadings for total and fecal coliforms in water and sediment and alkalinity and hardness suggest that eroded soil introduced through runoff events contribute to the observed heterotrophic bacteria concentrations. The negative loadings for nitrates, phosphate, and $\mathrm{BOD}_{5}$ suggest that these microbial populations are using available nutrients and organic matter. Fecal coliform survival is enhanced in water with 
moderate amounts of organic matter pollution (Whitman et al. 2006). The observed inverse relationship between fecal indicator bacteria and nutrient availability due to surface runoff and organic matter pollution may promote heterotrophic activity and fecal indicator organism survival or replication, resulting in an inaccurate indication of fecal pollution and pathogen prevalence.

Fecal pollution at urban land use sites is associated with runoff of eroded soil, as suggested by the correlation between fecal indicators in water and sediment and alkalinity (Figure 4.9). The inverse correlation between fecal indicators in water and sediment and $\mathrm{BOD}_{5}$ concentrations suggests that the introduction of organic matter may have an inhibitory effect on fecal coliform and heterotrophic bacteria concentrations. The processing of the organic matter by heterotrophic populations results in increased oxygen demand. The concentration of dissolved oxygen that is required to process the organic matter may not be available to the microbial population, resulting in the decrease of heterotrophic bacteria with increasing organic matter loads. 


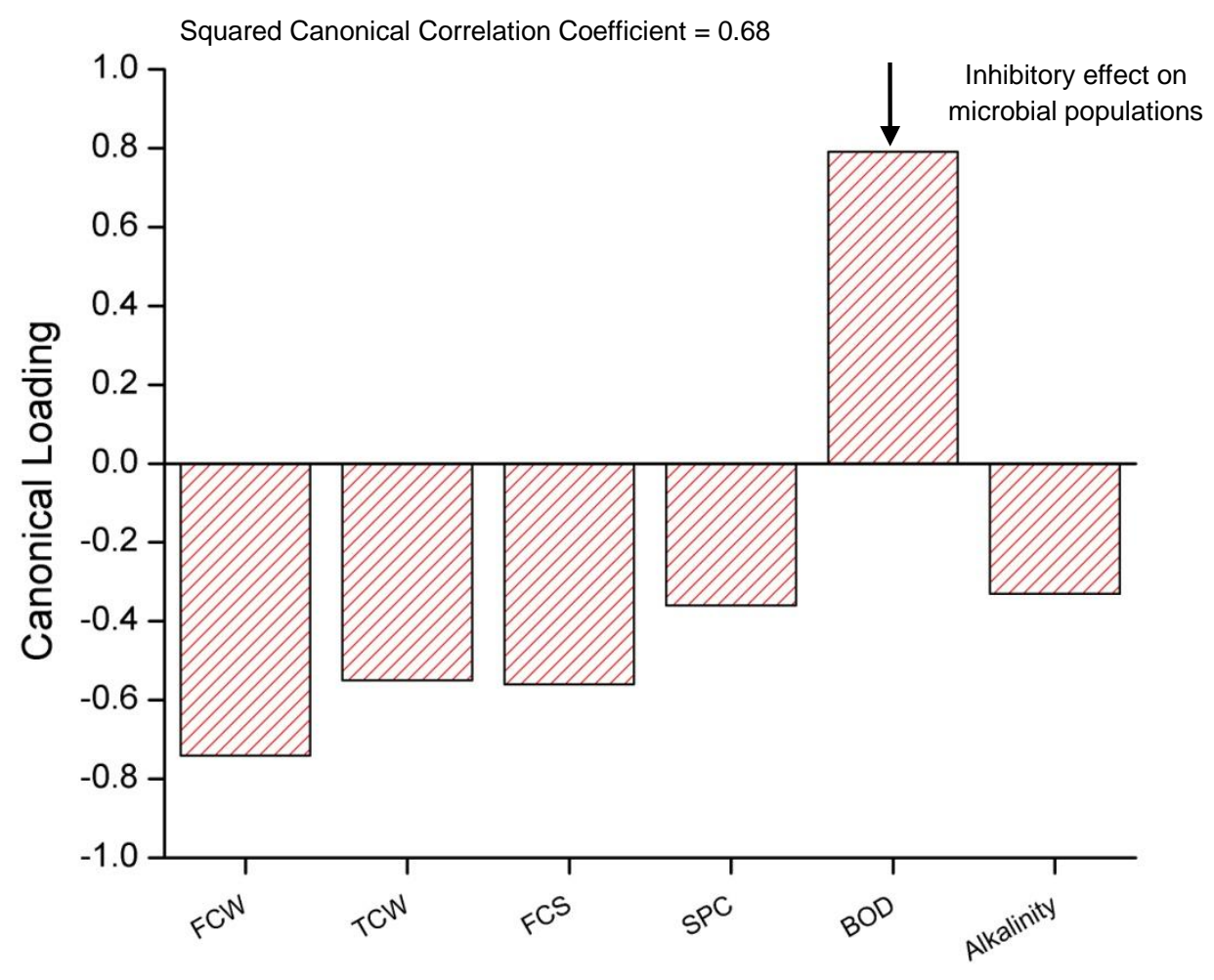

Figure 4.9. Sinking Creek canonical loading observed at urban land use sites to relate chemical water quality parameters to microbial water quality parameters to identify sources of fecal pollution

Similar to agricultural sites, fecal pollution at forested sites is associated with soil erosion and sedimentation (Table 4.10). The positive loadings for total and fecal coliforms in sediment with alkalinity and hardness suggest soil erosion introduces heterotrophic bacteria and that flocculation occurs as a result of increased cation concentrations from alkalinity and hardness. 


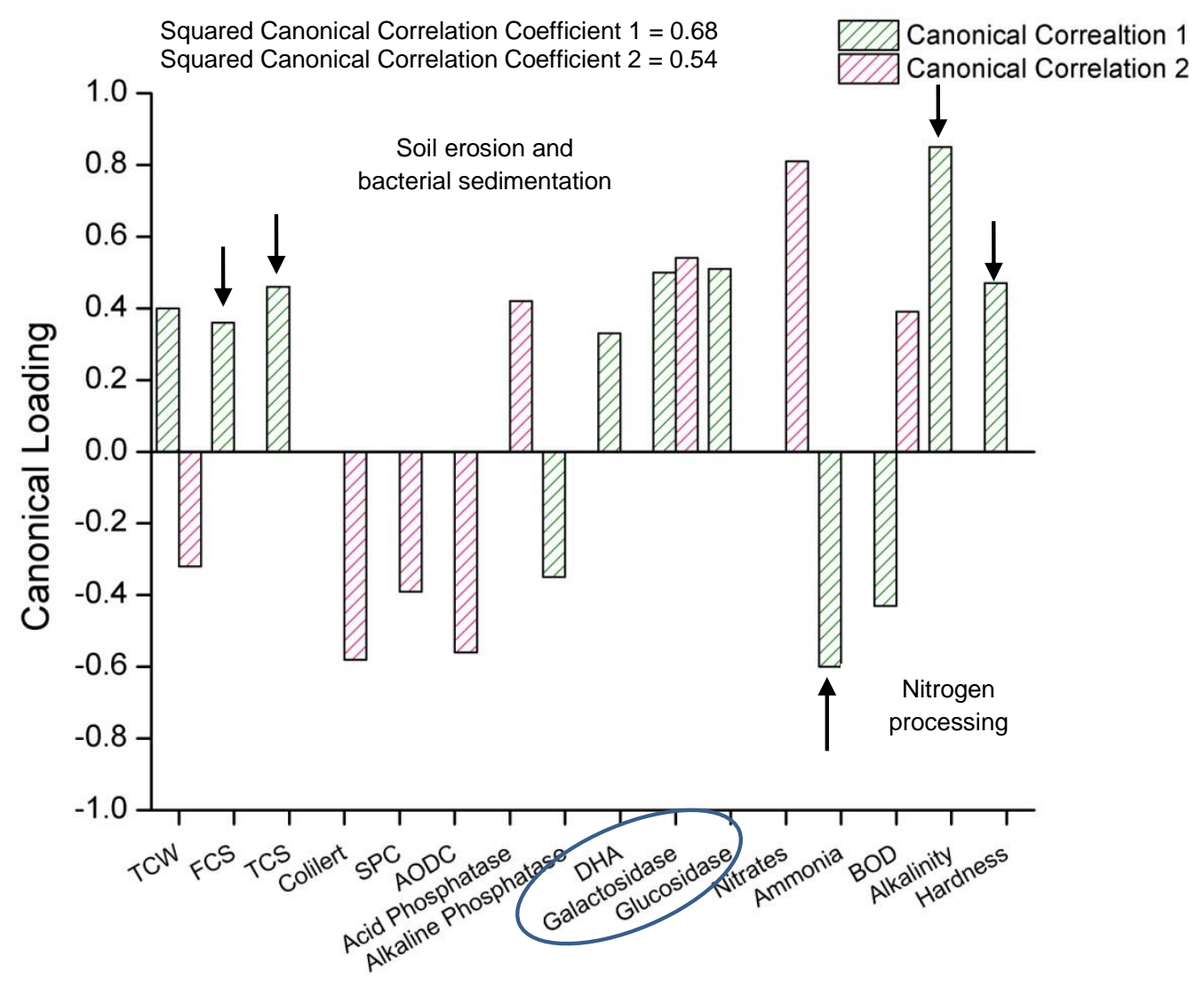

Figure 4.10. Sinking Creek canonical loadings observed at forest land use sites to relate chemical water quality parameters to microbial water quality parameters to identify sources of fecal pollution

As discussed previously, the cations associated with alkalinity and hardness may allow bacterial flocculation and settling into the sediment. The sedimentation of total and fecal coliforms is further suggested by their correlation with dehydrogenase, galactosidase, and glucosidase activities in sediment, indicating that heterotrophic bacteria in the sediment are actively processing the introduced organic matter associated with the eroded soil. The negative canonical loading for $\mathrm{BOD}_{5}$ and its inverse relationship with the microbial parameters also indicate that the processing of 
the organic matter is occurring in the sediments following organic matter settling. The negative canonical loading for ammonia also indicates the influence of organic matter processing by the microbial community in sediment. Ammonia is formed during the process of ammonification and is then readily converted to nitrite and nitrate through the process of nitrification. The inverse relationship between ammonia and the microbial variables suggests that the microbial community in the sediment is processing the nitrogen content of the organic matter following ammonification. The inverse relationship between fecal indicator and heterotrophic bacteria and nutrient availability and $\mathrm{BOD}_{5}$ in the second canonical structure suggests that the introduction of organic matter may not be the sole source of fecal pollution. The relationship between these variables suggests that there is the addition of organic matter, but that these microbial populations are using the available materials in a way that may promote replication of fecal indicators in the sediment. The combination of the first and second canonical structures suggests that in addition to organic matter contributing to fecal pollution, introduced fecal indicator organisms may be replicating in the environment providing an inaccurate indication of fecal pollution and pathogen prevalence at these sites.

Indicators of fecal pollution in Sinking Creek exhibit spatial and temporal variability both in the extent and sources of fecal pollution. Overall, the relatively high canonical communality coefficients for the chemical parameters observed for canonical correlation analyses by season and land use indicate that the chemical parameters are good predictors of fecal pollution in Sinking Creek. The canonical communality coefficients describe the proportion of each variable that is explained by the entire canonical structure and identify the variables that most contribute to the overall 
canonical structure. The squared canonical coefficients also suggests the ability of the chemical parameters to predict fecal pollution in Sinking Creek, as it indicates the variance in the microbial parameters that is explained by the chemical parameters.

\section{$\underline{\text { Canonical Discriminant Analysis }}$}

Canonical discriminant analyses were conducted to further identify common patterns associating fecal indicator organisms to pollution sources in the in Sinking Creek by season, site, and land use. The variables listed in Table 4.3 were included in the CANDISC analysis. Canonical discriminant analysis finds the linear combinations of variables that allow for the maximum separation between classes and determines the distance between class means (the mean of canonical variables for each data set). 
Table 4.3. Chemical and microbial variables included in canonical discriminant analysis (CANDISC procedure)

\begin{tabular}{lr}
\hline Variable & Units \\
\hline Fecal coliform in water & $\mathrm{CFU} / 100 \mathrm{ml}$ \\
Total coliform in water & $\mathrm{CFU} / 100 \mathrm{ml}$ \\
Fecal coliform in sediment & $\mathrm{CFU} / 100 \mathrm{ml}$ \\
Total coliform in sediment & $\mathrm{CFU} / 100 \mathrm{ml}$ \\
Colilert & $\mathrm{CFU} / 100 \mathrm{ml}$ \\
Standard plate count & $\mathrm{CFU} / \mathrm{ml}$ \\
Acridine orange direct & $\mathrm{cells} / \mathrm{g}$ \\
counts & sediment \\
Acid phosphatase & $\mu \mathrm{g} / \mathrm{g}$ sediment \\
Alkaline phosphatase & $\mu \mathrm{g} / \mathrm{g}$ sediment \\
Dehydrogenase & $\mu \mathrm{g} / \mathrm{g}$ sediment \\
Galactosidase & $\mu \mathrm{g} / \mathrm{g}$ sediment \\
Glucosidase & $\mu \mathrm{g} / \mathrm{g}$ sediment \\
Nitrates & $\mathrm{mg} / \mathrm{l}$ \\
Phosphates & $\mathrm{mg} / \mathrm{L}$ \\
Ammonia & $\mathrm{mg} / \mathrm{l}$ \\
Biochemical oxygen & $\mathrm{mg} / \mathrm{l}$ \\
demand & $\mathrm{mg} / \mathrm{l}$ \\
Hardness & $\mathrm{mg} / \mathrm{l}$ \\
Alkalinity & \\
\hline
\end{tabular}

The plot of canonical means by season is shown in Figure 4.11. The first canonical variable separates the spring and summer seasons by their increased total and fecal coliform concentrations in sediment, heterotrophic activity in water and the lowest galactosidase and phosphates and $\mathrm{BOD}_{5}$ concentrations (Table 4.4). The grouping of spring and summer suggest that these months are characterized by the setting of fecal pollution in sediment in relation to decreasing creek discharge (Table 1, Appendix A) 


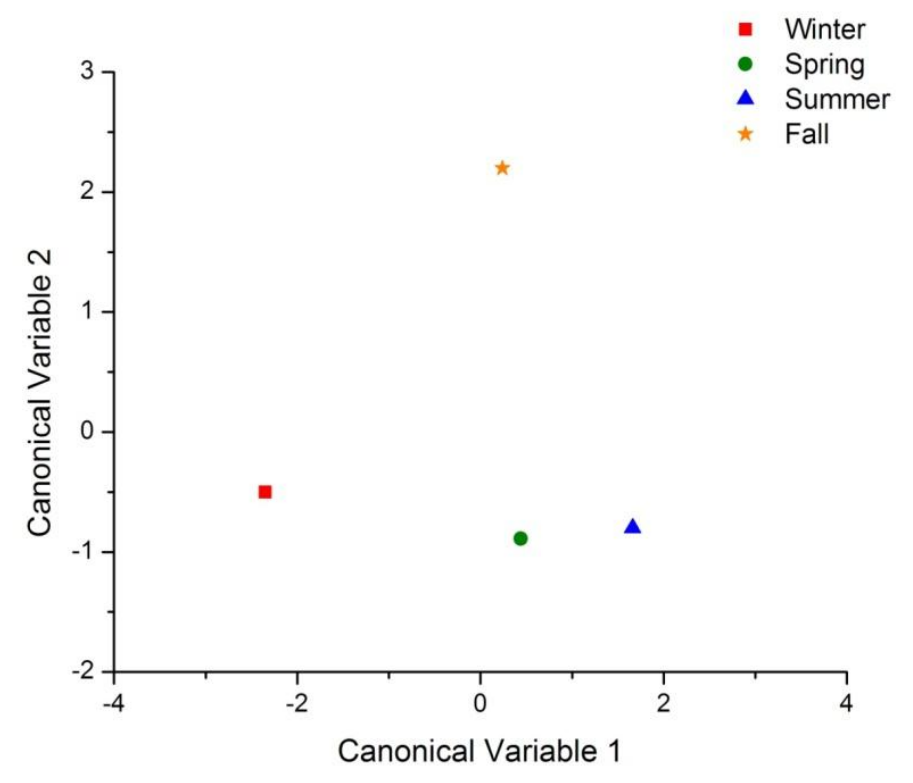

Figure 4.11. Plot of canonical means determined using canonical discriminant analysis for Sinking Creek by season 
Table 4.4. Description of canonical structure as determined using canonical discriminant analysis for Sinking Creek by season

Fecal coliforms in sediment $(0.55)$

Total coliforms in water $(0.55)$

Canonical Variable 1

Total coliforms in sediment $(0.50)$

Galactosidase (-0.41)

Phosphates $(-0.48)$

BOD $(-0.77)$

Acid Phosphatase (0.86)

Canonical Variable 2

Nitrates (0.40)

Galactosidase (0.32)

Fecal coliforms in sediment $(-0.34)$

The fall months are characterized by less settling of fecal coliforms in sediment and more organic matter introduction and processing by heterotrophic bacteria in both water and sediment. The second canonical variable separates the fall months from the other seasons by increased acid phosphatase, nitrate, and galactosidase concentrations and decreased fecal coliform concentrations in sediment. This separation suggests the greater influence of soil erosion on nutrient introductions and organic matter processing and less settling of fecal pollution in sediment during the fall compared to other seasons. During the winter months total and fecal coliform concentrations in water and sediment are at their lowest and heterotrophic communities in water and sediment are actively processing introduced organic matter. Winter 
months are characterized by less heterotrophic activity compared to the spring, summer, and fall months. However, there is more introduction and processing of organic matter introduced from soil erosion during this time as suggested by the influence of $\mathrm{BOD}_{5}$, phosphates and galactosidase on the canonical structure.

The canonical plot of means by land use is shown in Figure 4.12. The strong separation of all land use groups suggests the influence of land use type on fecal pollution in Sinking Creek. The first canonical separates the agricultural sites by increased alkalinity and hardness, E. coli, total and fecal coliform, standard plate count, and nitrate concentrations (Table 4.5).

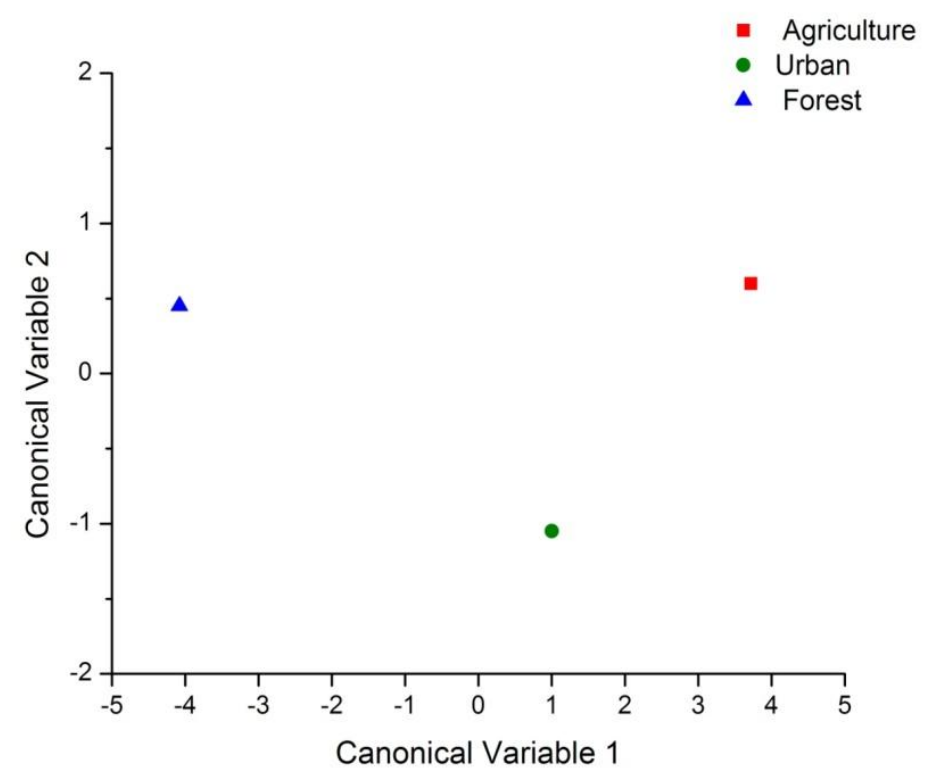

Figure 4.12. Plot of canonical means determined using canonical discriminant analysis for Sinking Creek by land use pattern 
Table 4.5. Description of canonical structure as determined using canonical discriminant analysis for Sinking Creek by land use pattern

Hardness (0.98)

Alkalinity (0.95)

E. coli $(0.50)$

Canonical Variable 1

Fecal coliforms in water $(0.47)$

Total coliforms in water $(0.46)$

Standard plate count $(0.45)$

Nitrates (0.39)

E. coli $(0.51)$

Canonical Variable 2

Standard plate count $(0.45)$

Fecal coliforms in water $(0.45)$

Total coliforms in water $(0.33)$

Nitrates $(-0.32)$

Alkalinity and hardness concentrations have the strongest influence on the first canonical variable, which suggests the influence of soil erosion on fecal pollution based on land use. Fecal pollution at agricultural sites is most influenced by runoff of eroded soil, followed by urban and forested land use sites. The likelihood of separation of land use sites by the first canonical variable is enhanced by the significantly different fecal coliform concentrations observed between land use classification and the highest fecal coliform concentrations observed at agricultural land use sites. The second canonical variable separates agricultural and forested from urban land use sites based on E. coli, 
total and fecal coliform, standard plate count, and nitrate concentrations. The negative influence of nitrates on the second canonical variable suggests that fecal pollution at these sites is associated with the processing of organic matter through nitrification. In contrast, fecal pollution at urban sites is likely due to the influence of nutrients with eroded soil and the processing of organic matter by heterotrophic bacteria. The similarities between agricultural and forested land use sites based on the second canonical variable is supported by similarities in their canonical structures (Figures 4.8 and 4.10 , respectively) both of which suggest that fecal pollution and organic matter is associated primarily with runoff of eroded soil.

\section{$\underline{\text { Conclusions }}$}

Using the Sinking Creek as a model, it has been demonstrated that the combined application of a targeted water quality monitoring program and multivariate statistical analyses are a useful tool to learn more about the responses of surface waters to anthropogenic stresses. Because the amounts and types of pollution, including fecal indicator bacteria, vary spatially and temporally, TMDL development may require multiyear data at multiple sampling points rather than the limited 30-day geometric mean that is currently used to more accurately reflect pollution loadings and patterns. The application of multivariate statistics to water quality data has been demonstrated to help improve our understanding of the interactions of physical, chemical, and microbial water quality parameters and their combined influences on water quality. A better understanding of loading patterns, temporal distribution, and spatial distribution should lead to the correct identification and quantification of nonpoint sources of fecal pollution, 
and subsequently better and faster BMP selection and implementation. It is suggested that this data analysis approach can be applied to other watersheds to identify common patterns associating pollution types to various sources and to effectively develop and implement BMPs to prevent and remediate the effects of rapid urbanization.

\section{Acknowledgements}

This work was funded in part by a grant from the ETSU School of Graduate Studies and Graduate Council and by a contract with the Tennessee Valley Authority (Award \# 00025252). 


\section{$\underline{\text { References }}$}

APHA. 1992. Standard methods for the examination of water and wastewater. $18^{\text {th }}$ edition. American Public Health Association. Washington, D.C.

Ayoub GM, Merhebi F, Acra A, El-Fadel M, Koopman B. 1999. Seawater bittern for the treatment of alkalized industrial effluents. Wat. Res. 34:640-656

Bej AK, DiCesare JL, Haff L, Atlas RM. 1991. Detection of Escherichia coli and Shigella spp. in water by using the polymerase chain reaction and gene probes for uid. Appl. Environ. Microbiol. 57:1013-1017

Bernard P, Antonie L, Bernard L. 2004. Principal component analysis: and appropriate tool for water quality evaluation and management - application to a tropical lake system. Ecological Modeling. 178:295-311

Bonadonna L, Briancesco R, Ottaviani M, Veschetti E. 2002. Occurrence of Cryptosporidium oocysts in sewage effluents and correlation with microbial, chemical and physical water variables. Environ. Monit. Assess. 75:241-252

Brasfield H. 1972. Environmental factors correlated with size of bacterial populations in a polluted stream. Appl. Environ. Microbiol. 24:349-352

Buerge IJ, Poiger T, Müller MD, Buse, HR. 2003. Caffeine, an anthropogenic marker for wastewater contamination of surface water. Environ. Sci. Technol. 37:691-700

Callies U. 2005. Interaction structures analyzed from water-quality data. Ecol. Model. $187: 475-490$

Carson CA, Shear BL, Ellersieck MR, Asfaw A. 2001. Identification of fecal Escherichia coli from humans and animals by ribotyping. Appl. Environ. Microbiol. 67:1503-1507

Christophersen N, Hooper RP. 1992. Multivariate analysis of stream water chemical data: the use of principal components analysis for the end-member mixing problem. Water Resources Research. 28:99-107

Ghiorse WC, Balkwill DL. 1983. Enumeration and morphological characterization of bacteria indigenous to subsurface environments. Dev. Ind. Microbiol. 24:213-224

Gotz R, Steiner B. Friesel P, Roch K, Walkow F, Maab V, Reincke H, Stachel B. 1998. Dioxin (PCDD/F) in the River Elbe - investigations of their origin by multivariate statistical methods. Chemosphere. 37:1987-2002

Hair JF, Anderson RE, Tatham RL, Black WC. 1998. Multivariate Data Analysis, $5^{\text {th }}$ edition. Prentice Hall, Englewood Cliffs, New Jersey 
Hall KK, Gallagher LK, Evanshen BG, Maier KJ, Scheuerman PR. 2006b. Comparison of microbial water quality parameters of four geographically similar creeks in northeast Tennessee. Abstract, $106^{\text {th }}$ Annual Meeting for the American Society for Microbiology, Orlando, Florida, USA

Islam MS, Hasan MK, Hiah MA, Sur GC, Felsenstein A, Venkatesan M, Sack RB, Albert MJ. 1993a. Use of polymerase chain reaction and fluorescent-antibody methods for detecting viable but nonculturable Shigella dysenteriae Type 1 in laboratory microcosms. Appl. Environ. Microbial. 59:536-540

Johnson RA, Wichern DW. 1992. Applied multivariate statistical analysis. Prentice Hall, Englewood Cliffs, New Jersey USA

Kimura R, Mandrell RE, Galland JC, Hyatt D, Riley LW. 2000. Restriction-site-specific PCR as a rapid test to detect enterohemorrhagic Escherichia coli O157:H7 strains in environmental samples. Appl. Environ. Microbiol. 66:2513-2519

Kramer JB, Canonica S, Hoigné J. 1996. Degradation of fluorescent whitening agents in sunlit natural waters. Enviorn. Sci. Technol. 30:2227-2234

Morrison SJ, King FD, Bobbie RJ, Beechtold RE, White DC. 1977. Evidence for microfloral succession on allochthonous plant littler in Apalachicola Bay, Florida, USA. Marine Bio. 41:229-240

NRCS. 2010a. Soil Survey Staff, Natural Resources Conservation Service, United States Department of Agriculture. Soil Survey Geographic (SSURGO) Database for Northeast Tennessee. Available online at http://soildatamart.nrcs.usda.gov Accessed 7-1-10

NRCS. 2010b. Soil Survey Staff, Natural Resources Conservation Service, United States Department of Agriculture. Web Soil Survey. Available online at http://websoilsurvey.nrcs.usda.gov Accessed 7-1-10

NRCS. 2010c. Soil Survey Staff, Natural Resources Conservation Service, United States Department of Agriculture. Official Soil Series Descriptions. Available online at http://soils.usda.gov/technical/classification/osd/index.html. Accessed on 7-1-10

Sayler GS, Puziss M, Silver M. 1979. Alkaline phosphatase assay for freshwater sediments: application to perturbed sediment systems. Amer. Soc. Microbiol. 38:922-927

TDEC. 2000a. Watauga River Watershed (06010103) of the Tennessee River Basin. Water Quality Management plan. Tennessee Department of Environment and Conservation. Division of Water Pollution Control, Nashville TN USA 
TDEC. 2000b. Total Maximum Daily Loads for fecal coliforms in Sinking Creek. Tennessee Department of Environment and Conservation, Division of Water Pollution Control, Nashville, TN USA

Theron J, Morar D, Du Prees M, Brozel VS, Venter SN. 2001. A sensitive semi-nested PCR method for the detection of Shigella in spiked environmental water samples. Wat. Res. 35:869-874

Tynkkynen S, Satokari R, Saarela M, Mattila-Sandholm T, Saxelin M. 1999. Comparison of ribotyping, randomly amplified polymorphic DNA analysis, and pulsed-field gel electrophoresis in typing of Lactobacillus rhamnosus and L. casei strains. Appl. Environ. Microbiol. 65:3908-3914

USEPA. 1986. Ambient water quality criteria for bacteria - 1986. January 1986. United States Environmental Protection Agency, Washington D.C. USA.

USEPA. 2001a. Method 1601: Male-specific $(F+)$ and somatic coliphage in water by two-step enrichment procedure. April 2001. United States Environmental Protection Agency, Washington D.C. USA

USEPA. 2005. Method 1623: Cryptosporidium and Giardia in Water by Filtration/IMS/FA. December 2005. United States Environmental Protection Agency, Washington D.C. USA

Vega M, Pardo R, Barrado E, Deban L. 1998. Assessment of seasonal and polluting effects on the quality of river water by exploratory data analysis. Wat. Res. 32:35813592

Whitman RL, Nevers MB, Byappanahalli MN. 2006. Examination of the watershedwide distribution of Escherichia coli along southern Lake Michigan: an integrated approach. Appl. Environ. Microbiol. 72:7301-7310

Wiggins BA, Andrews RW, Conway RA, Corr CL, Dobratz EJ, Dougherty DP, Eppard JR, Knupp SR, Limjoco MC, Mettenburg JM, et al. 1999. Use of antibiotic resistance analysis to identify nonpoint sources of fecal pollution. Appl. Environ. Microbiol. 65:3483-3486

Zeng X, Rasmussen TC. 2005. Multivariate statistical characterization of water quality in Lake Lanier, Georgia, USA. J. Environ. Qual. 34:1980 - 1991 


\title{
CHAPTER 5
}

\section{CLASSIFICATION OF PHYICAL, CHEMICAL, AND MICROBIAL SOIL PROPERTIES} AND THEIR INFLUENCE ON PATHOGEN FATE AND TRANSPORT

\author{
K.K. Hall and P.R. Scheuerman
}

\begin{abstract}
$\underline{\text { Abstract }}$
Interactions between physical, chemical, and microbial processes in soil add to the complexity of understanding pathogen fate and transport within a watershed. The purpose of this experiment was to characterize the soil within the Sinking Creek watershed based on physical and chemical properties. An understanding of the physical and chemical soil structure and microbial activities within the watershed can lead to a better understanding of pathogen loading into Sinking Creek and aid in the design and implementation of effective best management practices (BMPs). Results are not reflective of the full pedon structure and may not represent the heterogeneous nature of the soil, as samples were collected within $6-8$ inches of the soil surface. However, the physical, chemical, and microbial properties of the soil can help to understand soil structure and dynamics in the Sinking Creek watershed and its role in pathogen loading into receiving waters.
\end{abstract}

\section{$\underline{\text { Introduction }}$}

Soil formation is influenced by several factors including the nature of the parent material, climate, topography of the area, the presence and activity of organisms, and the length of time that the parent material is exposed to soil forming conditions. The variation in soil formation factors and activities is partially responsible for the 
heterogeneity of soil. The Sinking Creek watershed encompasses Washington and Carter Counties in Northeast Tennessee and the predominant soil orders are alfisols, inceptisols, and ultisols (Figure 5.1). Northeast Tennessee is characterized by karst topography, and soil formation is primarily due to alluvial and colluvial movement of metasedimentary rocks such as shale, sandstone, siltstone, and limestone (NRCS, 2010a).

Soil ratings and classifications as described by the Natural Resources Conservation Service (NRCS) for the 14 monitored sites on Sinking Creek are given in Table 5.1 (NRCS, 2010b). Alfisols are characterized as well developed, moderately leached forest soils with high fertility. Ultisols are heavily leached forest soils that exhibit intense weathering and leaching of calcium, magnesium, and potassium. Soils within this order are commonly thought of as "red clays" that are characteristic of the Southeast United States. Inceptisols are often found on steep slopes and on resistant parent material and lack a strongly defined set of characteristics as compared to other soil orders (NRCS, 1999). 

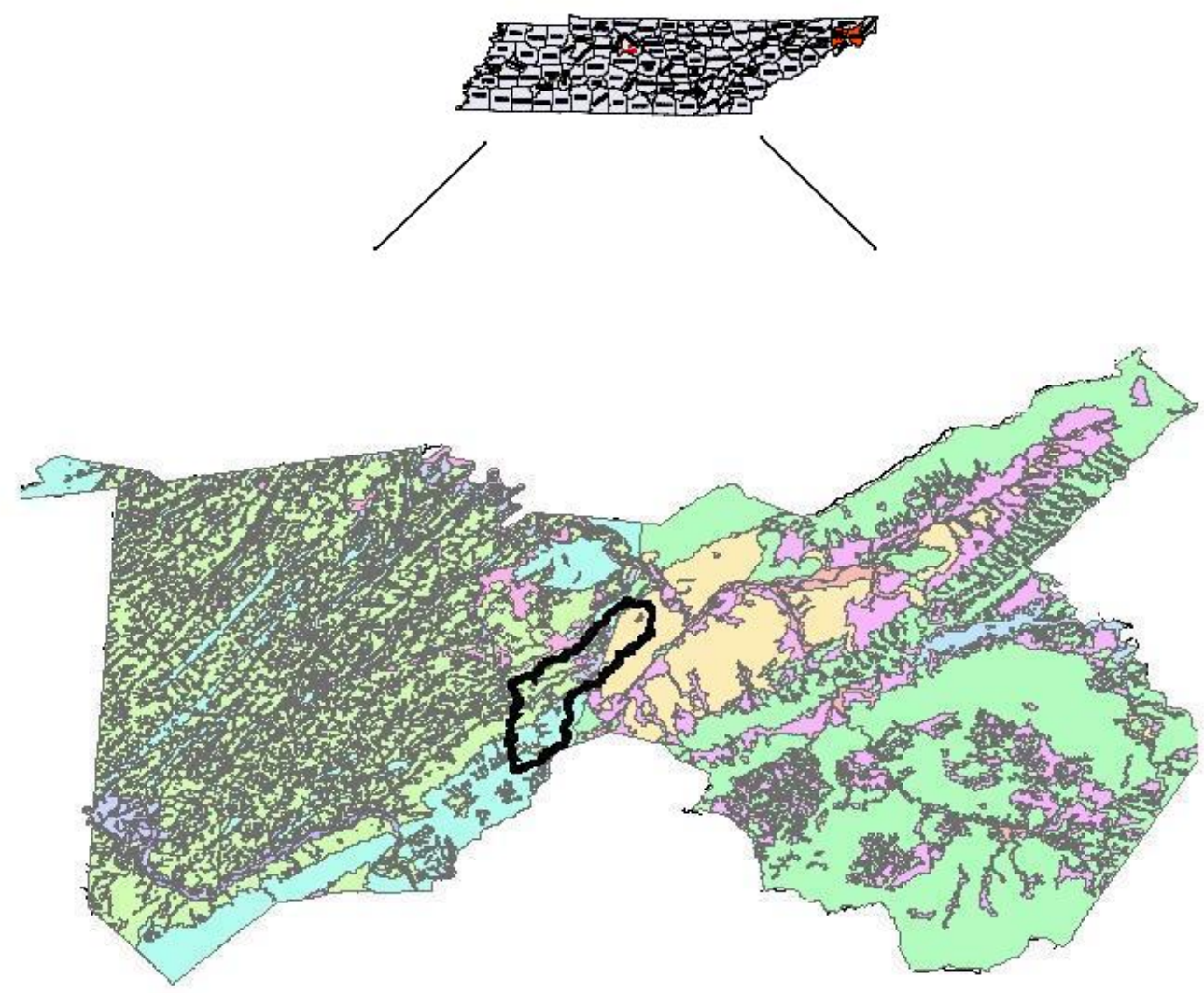

Washington County Soil Orders Carter County Soil Orders
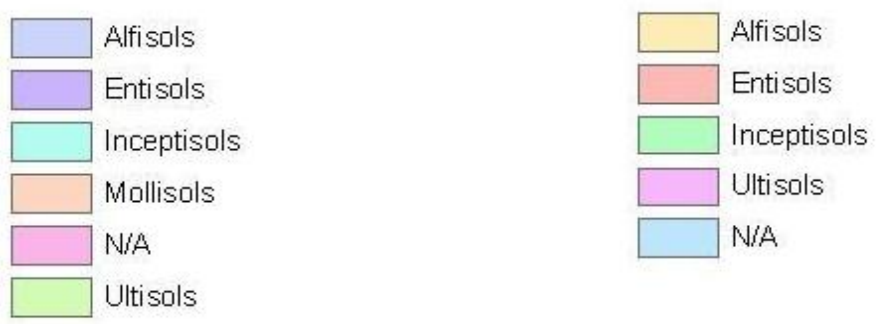

Figure 5.1. Soil orders and the Watauga River watershed in Washington and Carter Counties, Tennessee (Reference for data used to generate figure, NRCS, 2010a-c) 
Table 5.1. Soil classification of monitored sites on Sinking Creek

\begin{tabular}{|c|c|c|c|c|c|c|c|c|c|}
\hline Site & Land Use & Rating & Classification & $\begin{array}{l}\text { Textural } \\
\text { Classification }\end{array}$ & $\mathrm{pH}$ & $\begin{array}{l}\text { CEC } \\
\left(\mathrm{meq} / 100 \mathrm{~cm}^{3}\right)\end{array}$ & $\begin{array}{l}\text { Available Water } \\
(\mathrm{cm} / \mathrm{cm})\end{array}$ & $\begin{array}{l}\text { Organic Matter } \\
(\%)\end{array}$ & $\begin{array}{l}\text { Bulk Density } \\
\left(\mathrm{g} / \mathrm{cm}^{3}\right)\end{array}$ \\
\hline 1 & Agricultural & $\begin{array}{l}\text { Fine, mixed, thermic, } \\
\text { Typic Paleudalfs }\end{array}$ & $\begin{array}{l}\text { Braxton-talbott-rock } \\
\text { outcrop complex, } 12- \\
20 \% \text { slopes, eroded }\end{array}$ & Silt loam & 5.6 & 18.4 & 0.18 & 1.08 & $1.35-1.50$ \\
\hline 2 & Agricultural & $\begin{array}{l}\text { Fine, mixed, thermic, } \\
\text { Typic Paleudalfs }\end{array}$ & $\begin{array}{l}\text { Braxton-talbott-rock } \\
\text { outcrop complex, } 12- \\
20 \% \text { slopes, eroded }\end{array}$ & Silt loam & 5.6 & 18.4 & 0.18 & 1.08 & $1.35-1.50$ \\
\hline 3 & Agricultural & $\begin{array}{l}\text { Fine, mixed, thermic, } \\
\text { Typic Paleudalfs }\end{array}$ & $\begin{array}{l}\text { Baxton silt loam, } 2- \\
5 \% \text { slopes }\end{array}$ & Silt loam & 5.6 & 14.6 & 0.20 & 1.50 & $1.35-1.50$ \\
\hline 4 & Agricultural & $\begin{array}{l}\text { Fine, mixed, thermic, } \\
\text { Typic Paleudalfs }\end{array}$ & $\begin{array}{l}\text { Braxton silt loam, } 2- \\
5 \% \text { slopes }\end{array}$ & Silt loam & 5.6 & 14.6 & 0.20 & 1.50 & $1.35-1.50$ \\
\hline 5 & Agricultural & $\begin{array}{l}\text { Fine, mixed, active, } \\
\text { nonacidic, mesic } \\
\text { Fluvaquentic Endoaquepts }\end{array}$ & $\begin{array}{l}\text { Melvin silt loam, } 0-2 \% \\
\text { slopes, occasionally } \\
\text { flooded }\end{array}$ & Silt loam & 6.7 & 7.9 & 0.21 & 1.75 & $1.20-1.60$ \\
\hline 6 & Urban & $\begin{array}{l}\text { Fine, kaolinitic, thermic } \\
\text { Typic Paleudults }\end{array}$ & $\begin{array}{l}\text { Dewey-Udorthents- } \\
\text { Urban land } \\
\text { complexes, } 5-20 \% \\
\text { slopes }\end{array}$ & Silt loam & 5.5 & 8.2 & 0.20 & 1.17 & $1.30-1.45$ \\
\hline 7 & Urban & $\begin{array}{l}\text { Fine, kaolinitic, thermic } \\
\text { Typic Paleudults }\end{array}$ & $\begin{array}{l}\text { Dewey-Udorthents- } \\
\text { Urban land } \\
\text { complexes, 5-20\% } \\
\text { slopes }\end{array}$ & Silt loam & 5.5 & 8.2 & 0.20 & 1.17 & $1.30-1.45$ \\
\hline 8 & Urban & Not available & $\begin{array}{l}\text { Urban land- } \\
\text { Udorthents complex }\end{array}$ & NA & NA & NA & NA & NA & NA \\
\hline 9 & Urban & $\begin{array}{l}\text { Fine-loamy, siliceous, } \\
\text { semiactiv e, thermic } \\
\text { Fluvaquentic Eutrudepts }\end{array}$ & $\begin{array}{l}\text { Hamblen loam, } 0-3 \% \\
\text { slopes, occasionally } \\
\text { flooded }\end{array}$ & Loam & 6.2 & 7.3 & 0.19 & 2.0 & $1.30-1.45$ \\
\hline 10 & Urban & $\begin{array}{l}\text { Fine-loamy, siliceous, } \\
\text { semiactiv e, thermic } \\
\text { Fluvaquentic Eutrudepts }\end{array}$ & $\begin{array}{l}\text { Hamblen loam, 03-\% } \\
\text { slopes, occasionally } \\
\text { flooded }\end{array}$ & Loam & 6.2 & 7.3 & 0.19 & 2.0 & $1.30-1.45$ \\
\hline 11 & Urban & $\begin{array}{l}\text { Fine-loamy, siliceous, } \\
\text { semiactiv e, thermic } \\
\text { Fluvaquentic Eutrudepts }\end{array}$ & $\begin{array}{l}\text { Hamblen loam, 03-\% } \\
\text { slopes, occasionally } \\
\text { flooded }\end{array}$ & Loam & 6.2 & 7.3 & 0.19 & 2.0 & $1.30-1.45$ \\
\hline 12 & Urban & $\begin{array}{l}\text { Fine-loamy, siliceous, } \\
\text { semiactiv e, thermic } \\
\text { Fluvaquentic Eutrudepts }\end{array}$ & $\begin{array}{l}\text { Hamblen loam, 03-\% } \\
\text { slopes, occasionally } \\
\text { flooded }\end{array}$ & Loam & 6.2 & 7.3 & 0.19 & 2.0 & $1.30-1.45$ \\
\hline 13 & Forest & $\begin{array}{l}\text { Fine-loamy, siliceous, } \\
\text { semiactiv e, mesic typic } \\
\text { Hapludults }\end{array}$ & $\begin{array}{l}\text { Keener loam, 5-12\% } \\
\text { slopes }\end{array}$ & Loam & 4.8 & NA & 0.16 & 1.5 & $0.8-4.7$ \\
\hline 14 & Forest & $\begin{array}{l}\text { Fine-loamy, mixed, active } \\
\text { mesic Typic Hapludults }\end{array}$ & $\begin{array}{l}\text { Shelocta silt loam, } \\
35-50 \% \text { slopes }\end{array}$ & Silt loam & 5.0 & $2.2-8.3$ & 0.18 & 2.25 & $1.15-1.30$ \\
\hline
\end{tabular}


The classifications of soil from the 14 monitored sites on Sinking Creek include a combination of alluvial (sites 1-12) and colluvial soils (sites 13 and 14). Soil at the agricultural and urban land use sites are classified as being formed in alluvium and residuum weathered from limestone, and soil from the forest land use sites are classified as being formed in colluvium from shale, siltstone, and sandstone (NRCS, 1954; NRCS, 2004; NRCS, 2010c). Changes in land use have been shown to affect soil development and structure in agricultural and forested landscapes (Vacca, 2000; Greenwood and McKenzie, 2001; Li et al. 2007). Determination of soil structure and dynamics within the watershed as they pertain to land use patterns can help better understand the influence of soil in pathogen fate and transport and help identify and remediate sources of fecal pollution in Sinking Creek.

It has been demonstrated that fecal pollution in Sinking Creek is associated with runoff, primarily from agricultural land use sites (Dulaney et al. 2003; Hall et al. 2008; Hall et al. 2011), so it is crucial to understand the role of physiochemical soil parameters to better understand the fate and transport of these organisms from their sources to receiving streams. Pathogen fate and transport through the soil matrix is dependent on several physical, chemical, and microbial processes. The transport of the pathogen from the source to water, transport following entry into the water, and pathogen survival in the water require consideration (Bishop et al. 2005). Physiochemical soil properties such as particle and pore size, $\mathrm{pH}$, organic matter content, cation exchange capacity (CEC), and matric potential can influence sorption processes and pathogen transport. Bacterial cells will adsorb more to finer textured soils than to coarser textured soils (Abu-Ashour et al. 1998; Hijnen et al. 2005) and microbial retention increases as soil 
adhesion and sorption increase (Hörman et al. 2004). Microbial cell surface properties also influence their transport throughout the soil matrix (Pirszel et al. 1995), and cell characteristics such as length, surface charge, appendages, and the production of extracellular polysaccharides have been shown to impact bacterial movement throughout soil (Greenwood and McKenzie, 2001).

Physiochemical soil properties such as particle size, bulk density, water holding capacity, and cation exchange capacity contribute to soil saturation and can result in greater transport of bacteria because they inhibit filtration processes or prevent interaction between the microorganism and the soil matrix (Van Donsel et al. 1967; Yeager and O'Brian, 1979; Gagliardi and Karns, 2000). Differences in these soil properties as they relate to different land use patterns have been shown to influence runoff and drainage mechanisms (Kurz et al. 2006; Bormann et al. 2007). Physical characteristics including sunlight exposure, temperature (Hurst et al. 1980; Kemp et al. 1992), nutrient availability, extreme $\mathrm{pH}$ values (Huysman and Verstraete, 1993), and the presence of other microorganisms may also affect pathogen transport through soil (Wong and Griffin, 1976).

The microbial ecology of soil must be considered in addition to the physiochemical properties. Microbial properties of soil are some of the more difficult properties to characterize based on the great deal of diversity at the ecosystem, population and genetic levels. As with physiochemical soil parameters, the microbial properties can represent a dynamic system where the types and numbers of microorganisms may be altered with temporal and spatial changes (Anderson and Domsch, 1990; Yao et al. 2000). To better understand the microbial ecology of soils 
and characterize heterotrophic communities, methods such as Biolog® plates have been used (Biolog Inc., Hayward, CA).

These 96 well plates contain 95 different carbon substrates and rely on the ability of inoculated microbial populations to reduce tetrazolium violet. Originally used for the identification of bacterial isolates for strain identification, Biolog® plates have since been used with environmental samples to determine the microbial community structure (Garland and Mills, 1991; Winding, 1993; Zak et al. 1994). When applied to soil samples, the use of the different carbon sources by the inoculum generates a pattern that provides an indication of carbon use to understand how the microbial community contributes to organic matter processing in the environment to distinguish between soil types (Zak et al. 1994; Bossio and Scow, 1995). The community level approach to examining soil microbial ecology allows for a more sensitive measure of heterotrophic community structure (Garland and Mills, 1991).

To differentiate microbial communities based on spatial and temporal variability, statistical methods such as principle component analysis (PCA) can be used (Garland and Mills, 1991; Winding, 1993; Zak et al. 1994). PCA is a multivariate statistical procedure that computes principle components for every numerical variable (i.e., Biolog ${ }^{\circledR}$ substrates), each of which is a linear combination of the variables that account for the most variance explained by the fewest number of variables. Data are reduced based on the establishment of dimensions in the data with the first principle component accounting for the most variability and the second principle component accounting for the remaining variability not accounted for in the first principle component (Dillon and Goldstein, 1984). 
One of the main drawbacks associated with the use of Biolog® plates to understand microbial ecology includes the influence of inoculum density on the rate of color development, as it is unknown if all members of the microbial community contribute to the observed color development (Garland and Mills, 1991). Data can be transformed based on the average well color development (AWCD) to help reduce the influence of inoculum density on color development (Garland and Mills 1991). It should also be noted that the observed patterns of Biolog ${ }^{\circledR}$ analyses are a measurement of ability of the inoculum to use a carbon source and that the carbon sources used in the analysis may not be present in the environment.

The objective of this group of experiments was to determine physical, chemical, and microbial parameters of soil collected from the Sinking Creek watershed. Characterization of the soil within the watershed may help to better understand the interactions between physiochemical soil properties and microbial populations and the influence of these properties on pathogen fate and transport. Understanding these interactions can help to develop appropriate and successful best management practices to remediate fecal pollution and prevent future pollution events.

\section{Methods}

Sinking Creek Location and Water Quality Monitoring

The Sinking Creek sub-watershed (06010103130) is one of 13 sub-watersheds that belong to the Watauga River watershed (TDEC, 2000a). Sinking Creek is a 9.8 mile long tributary of the Watauga River partially located in Washington and Carter 
Counties in Tennessee. The headwaters of Sinking Creek are located on Buffalo Mountain and it enters the Watauga River at mile 19.9. The main land uses within the 13.1 square mile drainage basin of the Sinking Creek watershed include: forest (65.5\%), urban (25.3\%), and agricultural areas (9.0\%) (TDEC 2000b). There are 19.8 impaired stream miles in the Sinking Creek watershed including tributaries (TDEC, 2000b).

Upstream locations on Buffalo Mountain are forested, and land use transitions to urban, followed by agricultural land use at downstream sites. Fourteen sites were initially selected for routine water quality monitoring in 2002 and are described in Table 5.1 and Figure 5.2. From these 14 sampling locations, 2 sites were randomly selected from each land use classification and sampled monthly for the physical, chemical, and microbial parameters described Table 5.2. The sites selected for representation of agricultural land use were sites 2 and 4, sites selected to represent urban land use were sites 7 and 10, and sites 13 and 14 represented forested land use. 
Table 5.2. Sampling locations on Sinking Creek sampled during this study for water quality analysis

\begin{tabular}{|c|c|c|c|c|c|}
\hline $\begin{array}{l}\text { Site } \\
\text { Number }\end{array}$ & Site Location & $\begin{array}{l}\text { Predominant Land } \\
\text { Use }\end{array}$ & Physical Description & $\begin{array}{l}\text { Habitat } \\
\text { Assessment } \\
\text { Score (\%) }\end{array}$ & $\begin{array}{l}\text { Latitude/Longitude } \\
\text { Coordinates and } \\
\text { Elevation }\end{array}$ \\
\hline 2 & $\begin{array}{l}\text { Upstream of Bob Peoples } \\
\text { bridge on Sinking Creek Road }\end{array}$ & Agriculture & $\begin{array}{l}\text { Moderately eroded banks with little } \\
\text { vegetation buffer or riparian zone. } \\
\text { Creek bed predominantly cobble and gravel }\end{array}$ & $52 \%$ & $\begin{array}{c}19.837^{\prime} \mathrm{N}, 18.254^{\prime} \mathrm{W} \\
1530 \mathrm{ft}\end{array}$ \\
\hline 4 & $\begin{array}{l}\text { Upstream of crossing on Joe } \\
\text { Carr Road }\end{array}$ & Agriculture & $\begin{array}{l}\text { Moderately eroded banks with poor bank } \\
\text { stability and little vegetative buffer or riparian } \\
\text { zone. } \\
\text { Creek bed predominantly boulders, cobble } \\
\text { and gravel }\end{array}$ & $43 \%$ & $\begin{array}{c}19.594^{\prime} \mathrm{N}, 18.5799^{\prime} \mathrm{W} \\
1552 \mathrm{ft}\end{array}$ \\
\hline 7 & $\begin{array}{l}\text { Upstream of bridge on Miami } \\
\text { Drive, King Springs Baptist } \\
\text { Church }\end{array}$ & Urban & $\begin{array}{l}\text { Heavily eroded left bank, concrete bank on } \\
\text { right with no vegetative buffer or riparian } \\
\text { zone. } \\
\text { Creek bed predominantly cobble }\end{array}$ & $53 \%$ & $\begin{array}{c}18.772^{\prime} \mathrm{N}, 19.685^{\prime} \mathrm{W} \\
1583 \mathrm{ft}\end{array}$ \\
\hline 10 & $\begin{array}{l}\text { Upstream of bridge crossing } \\
\text { Sinking Creek at Hickory } \\
\text { Springs Road }\end{array}$ & Urban & $\begin{array}{l}\text { Heavily eroded banks with no vegetative } \\
\text { buffer. } \\
\text { Creek bed predominantly boulders and } \\
\text { cobble }\end{array}$ & $57 \%$ & $\begin{array}{l}17.431^{\prime} \mathrm{N}, 21.397 \text { ' W } \\
1720 \mathrm{ft}\end{array}$ \\
\hline 13 & $\begin{array}{l}\text { Upstream of road crossing on } \\
\text { Jim McNeese Road }\end{array}$ & Forest & $\begin{array}{l}\text { No visible bank erosion with moderate } \\
\text { riparian zone. } \\
\text { Creek bed predominantly boulders and } \\
\text { cobble }\end{array}$ & $71 \%$ & $\begin{array}{l}16.035^{\prime} \mathrm{N}, 22.163^{\prime} \mathrm{W} \\
2048 \mathrm{ft}\end{array}$ \\
\hline 14 & $\begin{array}{l}\text { Downstream of path crossing } \\
\text { at Dry Springs Road }\end{array}$ & Forest & $\begin{array}{l}\text { No visible bank erosion with optimal riparian } \\
\text { zone and vegetative buffer. } \\
\text { Creek bed predominantly boulders, cobble } \\
\text { and gravel }\end{array}$ & $83 \%$ & $\begin{array}{l}14.800^{\prime} \mathrm{N}, 22.033^{\prime} \mathrm{W} \\
2148 \mathrm{ft}\end{array}$ \\
\hline
\end{tabular}




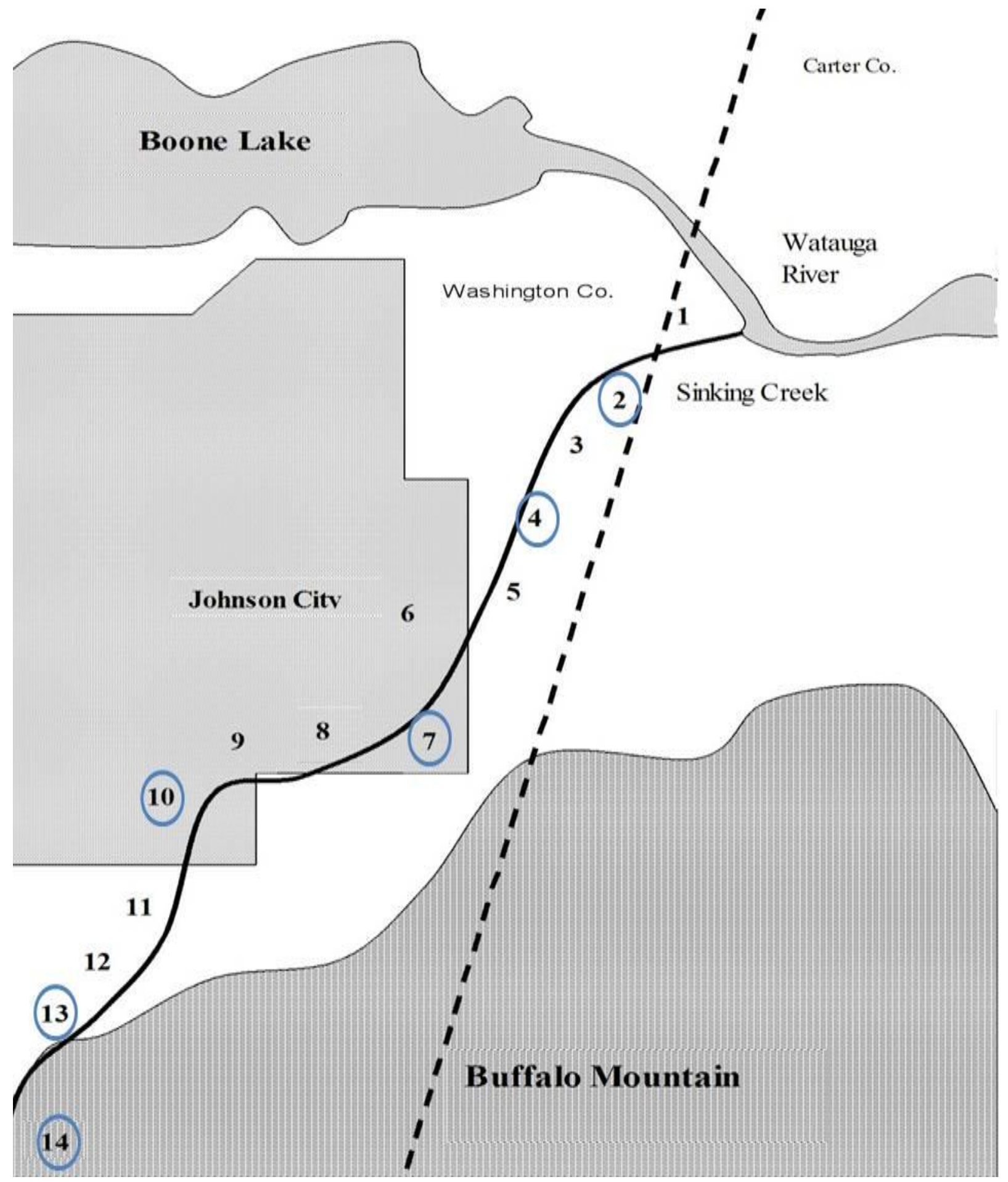

Figure 5.2. Map of Sinking Creek sampling locations (sites sampled for water quality analysis in this study are circled). 


\section{Water and Sediment Sample Collection}

Water samples were collected monthly from 6 pre-selected sites on Sinking Creek from January 2011 through December 2011 and were analyzed for the variables described in Table 2. Water samples for total and fecal coliform bacteria (TC/FC), standard plate counts (SPC), E. coli 057:H7, Shigella sp., and bacteriophage analyses were collected and analyzed in triplicate (SPC samples analyzed in duplicate) in sterile, 1-L Nalgene ${ }^{\mathrm{TM}}$ bottles. Water samples for Colilert ${ }^{\circledR}$ analyses were collected in sterile 100ml plastic bottles (IDEXX Laboratories, Westbrook, Maine). Water samples for nitrates $\left(\mathrm{NO}_{3}{ }^{-}\right)$, phosphates $\left(\mathrm{PO}_{4}{ }^{-}\right)$, ammonia $\left(\mathrm{NH}_{3}{ }^{+}\right)$, 5-day biochemical oxygen demand $\left(\mathrm{BOD}_{5}\right)$, alkalinity, and hardness were collected and analyzed in triplicate in sterile 2-L Nalgene ${ }^{\mathrm{TM}}$ bottles. Sediment samples for TC/FC in water, microbial enzyme activity (MEA), and acridine orange direct counts (AODC) were collected in $20 z$ sterile WhirlPak ${ }^{\mathrm{TM}}$ bags. All samples were transported to the laboratory on ice and analyzed within the holding times described in Table 5.3. Field measurements for $\mathrm{pH}$, air and water temperature, dissolved oxygen, and conductivity were also collected at each site.

Quality assurance and quality control (QA/QC) practices included the analysis of chemical parameters consisted of one trip blank, one field blank, a negative control, one replicate, one spiked sample, and one quality control standard. QA/QC practices included in the analysis of microbial parameters included the analysis of one trip blank, one field blank, a negative control, and a positive control. A secondary wastewater effluent sample was used as the positive control for TC/FC, Colilert®, SPC, and bacteriophage analyses. Laboratory strains of E. coli O157:H7 and Shigella flexneri 
(ATCC $®$ Number $43895^{\mathrm{TM}}$ and ATCC $\AA 12022^{\mathrm{TM}}$, respectively) were used to seed water samples that served as a positive control for PCR analysis.

Table 5.3. Physical, chemical, and microbial water quality parameters measured

\begin{tabular}{|c|c|c|c|}
\hline Parameter & Abbreviation & Units & Holding Time \\
\hline $\mathrm{pH}$ & $\mathrm{pH}$ & $\mathrm{pH}$ & Field measurement \\
\hline Water temperature & WT & ${ }^{\circ} \mathrm{C}$ & Field measurement \\
\hline Air temperature & AT & ${ }^{\circ} \mathrm{C}$ & Field measurement \\
\hline Dissolved oxygen & DO & $\mathrm{mg} / \mathrm{l}$ as $\mathrm{O}_{2}$ & Field measurement \\
\hline Conductivity & Cond & umohs & Field measurement \\
\hline Fecal coliform in water & FCW & CFU/100ml & $6 \mathrm{~h}$ \\
\hline Total coliform in water & TCW & CFU/100ml & $6 h$ \\
\hline Fecal coliform in sediment & FCS & CFU/100ml & $6 h$ \\
\hline Total coliform in sediment & TCS & $\mathrm{CFU} / 100 \mathrm{ml}$ & $6 h$ \\
\hline Colilert & Colilert & CFU/100ml & $6 h$ \\
\hline Standard plate count & SPC & $\mathrm{CFU} / \mathrm{ml}$ & $6 h$ \\
\hline Acridine orange direct counts & AODC & cells/g sediment & $6 h$ \\
\hline Acid phosphatase & AcidP & $\mu \mathrm{g} / \mathrm{g}$ sediment & $24 h$ \\
\hline Alkaline phosphatase & AlkP & $\mu \mathrm{g} / \mathrm{g}$ sediment & $24 h$ \\
\hline Dehydrogenase & $\mathrm{DHA}$ & $\mu \mathrm{g} / \mathrm{g}$ sediment & $24 h$ \\
\hline Galactosidase & Gal & $\mu \mathrm{g} / \mathrm{g}$ sediment & $24 h$ \\
\hline Glucosidase & Glu & $\mu \mathrm{g} / \mathrm{g}$ sediment & $24 h$ \\
\hline Nitrates & $\mathrm{NO}_{3}$ & $\mathrm{mg} / \mathrm{l}$ & $24 \mathrm{~h}$ \\
\hline Phosphates & $\mathrm{PO}_{4}^{2-}$ & $\mathrm{mg} / \mathrm{l}$ & $24 \mathrm{~h}$ \\
\hline Ammonia & $\mathrm{NH}_{3}^{+}$ & $\mathrm{mg} / \mathrm{l}$ & $24 h$ \\
\hline Biochemical oxygen demand & $\mathrm{BOD}_{5}$ & $\mathrm{mg} / \mathrm{l}$ & $24 \mathrm{~h}$ \\
\hline Hardness & Hard & $\mathrm{mg} / \mathrm{l}$ & $48 h$ \\
\hline Alkalinity & Alk & $\mathrm{mg} / \mathrm{l}$ & $24 h$ \\
\hline E. coli O157: $\mathrm{H} 7$ & O157:H7 & $\mathrm{CFU} / 100 \mathrm{ml}$ & $24 \mathrm{~h}$ \\
\hline Shigella sp. & Shigella & $\mathrm{CFU} / 100 \mathrm{ml}$ & $24 \mathrm{~h}$ \\
\hline Giardia sp. & Giardia & Cysts/l & $72 h$ \\
\hline Cryptosporidium sp. & Crypto & Oocysts/l & $72 h$ \\
\hline$F_{+}-$specific bacteriophage & bacteriophage & $\mathrm{PFU} / \mathrm{ml}$ & $48 \mathrm{~h}$ \\
\hline
\end{tabular}

Water Microbial Analyses

TC/FC analyses for water samples were conducted according to Standard Methods for Examination of Water and Wastewater (APHA, 1992). Briefly, 0.5ml of 
water were filtered through a $0.45 \mu \mathrm{m}$ membrane filter (EMD Millipore, Billerica, MA) and the filter placed in a petri dish containing an absorbent pad (EMD Millipore, Billerica, $\mathrm{MA}$ ) with $2 \mathrm{ml}$ of $\mathrm{m}$-Endo media for total coliform analysis or $\mathrm{m}$-FC media for fecal coliform analysis. All plates were inverted and enumerated following $24 \mathrm{~h}$ incubation at $37^{\circ} \mathrm{C}$ and $44.5^{\circ} \mathrm{C}$ for total coliform and fecal coliforms, respectively. For TC/FC sediment analyses, $0.5 \mathrm{~g}$ of sediment was added to $25 \mathrm{ml}$ of sterile water $+1 \%$ Tween 80. The samples were vortexed and allowed to settle for 30 minutes, and $0.5 \mathrm{ml}$ of the buffer suspension was filtered according to Standard Methods for Examination of Water and Wastewater as described above (APHA, 1992).

SPC were conducted according to Standard Methods for Examination of Water and Wastewater (APHA, 1992) using R2A agar. One milliliter of water was placed in the center of a sterile petri dish (Fisher Scientific, Pittsburgh, PA) and 10ml of R2A agar was added to the dish. The plate was swirled in a figure eight motion to allow the sample to disperse in the media and cover the plate. Plates were allowed to solidify and were enumerated following incubation at $25^{\circ} \mathrm{C}$ for $48 \mathrm{~h}$. Escherichia coli concentrations were determined using the Colilert@ Quanti-Tray method (APHA, 1995). To each $100 \mathrm{ml}$ water sample, a packet of Defined Substrate Technology ${ }^{\circledR}$ (DST $\left.{ }^{\circledR}\right)$ reagent (IDEXX Laboratories, Westbrook, Maine) was added and mixed. The sample was then poured into a Quanti-Tray ${ }^{\circledR}$, sealed using the Quanti-Tray® sealer, and incubated for $24 \mathrm{~h}$ at $37^{\circ} \mathrm{C}$. E. coli were then enumerated using the Standard Method most probable number (MPN) procedure. Samples for water TC/FC were processed in triplicate and samples for sediment TC/FC were processed in duplicate. SPC were processed in duplicate and one Colilert® sample was processed for each site. 
MEA analyses were conducted and included acid and alkaline phosphatases, glucosidase, galactosidase, and dehydrogenase activities. For each enzyme analyzed, $1 \mathrm{~g}$ of sediment was added to a test tube containing a specific buffer and enzyme. Sediment samples for acid phosphatase were mixed with $4 \mathrm{ml}$ of $1 \mathrm{M}$ TRIS buffer ( $\mathrm{pH}$ 4.8) and $4 \mathrm{ml}$ of $1 \mathrm{M}$ TRIS buffer $(\mathrm{pH}) 8.4$ for alkaline phosphatase. For both acid and alkaline phosphatase, $1 \mathrm{ml}$ of $1 \mathrm{M}$ TRIS buffer with $0.1 \%$ phosphatase substrate $(\mathrm{pH} 7.6)$ was added to each tube (Sayler et al. 1979). Sediment samples for galactosidase and glucosidase activities were mixed with $4 \mathrm{ml}$ of $0.1 \mathrm{M}$ phosphate buffer $(\mathrm{pH} 9.0)$. Galactosidase activity was measured by adding $1 \mathrm{ml}$ of $0.01 \mathrm{M}$ phosphate buffer with $0.15 \% \mathrm{p}$-nitrophenyl- $\beta$-D-galactopyranoside as an indicator of galactosidase activity. One milliliter of $0.01 \mathrm{M}$ phosphate buffer with $0.15 \% 4$-nitrophenyl- $\beta$-D-glucopyranoside was used as an indicator to assess glucosidase activities (Morrison et al. 1977). Following addition of buffers and indicators, all tubes were vortexted and incubated at $25^{\circ} \mathrm{C}$ for $24 \mathrm{~h}$. Acid and alkaline phosphatase, galactosidase, and glucosidase activities were determined using a spectrophotometer at an absorbance of $418 \mathrm{~nm}$.

For dehydrogenase (DHA) activity, $1 \mathrm{~g}$ of sediment was added to a test tube containing $2 \mathrm{ml}$ of $0.1 \mathrm{M}$ phosphate buffer $(\mathrm{pH} 7.6)$ and $1 \mathrm{ml}$ of $0.5 \%$ iodonitrotetrazolium chloride (INT) salt solution. The samples were vortexed and incubated in the dark at $25^{\circ} \mathrm{C}$ for 45 minutes. One milliliter of the sample was filtered through a $0.22 \mu \mathrm{m}$ porosity cellulose membrane (GE Water and Process Technologies, Trevose, PA) and allowed to dry at room temperature. The membrane, was then added to a test tube containing $5 \mathrm{ml}$ of dimethyl sulfoxide, vortexted to dissolve the membrane, and incubated in the 
dark at $25^{\circ} \mathrm{C}$ for $24 \mathrm{~h}$. Dehydrogenase activity was then determined using a spectrophotometer at an absorbance of $460 \mathrm{~nm}$.

AODC analysis was performed as described by Ghiorse and Balkwill (1983). Three hundred milligrams of sediment was added to $30 \mathrm{ml}$ of sterile PBS+Tween 80 , vortexed for $60 \mathrm{~s}$, and allowed to settle for $3 \mathrm{~h}$. Two hundred fifty microliters of the suspension was mixed with $5 \mathrm{ml}$ sterile water $+500 \mu \mathrm{l}$ acridine orange stain, and samples were vortexed for $30 \mathrm{~s}$. Samples were filtered using $25 \mathrm{~mm}, 0.2 \mu \mathrm{m}$ pore polycarbonate nucleopore filters (Osmonics, Inc., Minnetonka, MN), and the filters were mounted and fixed on slides for enumeration at 1000X using the Olympus $\mathrm{BH} 2$ epifluorescent microscope (Olympus, New Hyde Park, NY). One sediment sample was processed per site and 3 microscopic fields were enumerated on each slide.

\section{Water Chemical Analyses}

$\mathrm{NO}_{3}{ }^{-}, \mathrm{PO}_{4}{ }^{-}, \mathrm{NH}_{3}{ }^{+}$, alkalinity, and hardness analyses were performed in triplicate using colorimetric $\mathrm{HACH}^{\mathrm{TM}}$ methods and $\mathrm{HACH}^{\mathrm{TM}}$ reagents as described by the manufacturer ( $\mathrm{HACH}$ Company, Loveland, $\mathrm{CO}$ ). Briefly, $\mathrm{NO}_{3}{ }^{-}, \mathrm{PO}_{4}{ }^{-}, \mathrm{NH}_{3}{ }^{+}$analyses were conducted by adding $10 \mathrm{ml}$ of water to a vial containing the appropriate reagent packet; NitraVer5, PhosVer3 and salicylate/ammonia cyanurate reagents, respectively. The vials were shaken to dissolve the reagent and samples were analyzed using pocket colorimeters specific to the nutrient of interest. Alkalinity and hardness analyses were conducted using $100 \mathrm{ml}$ sample volumes and a digital titrator. For alkalinity determination, 1 packet of phenolthalein indicator and bromcresol green-methyl red indicator were added to the sample and mixed. The sample was then titrated with $1.6 \mathrm{~N}$ 
sulfuric acid to a grey-green endpoint. For hardness determination, 1 packet of ManVer2 reagent and $2 \mathrm{ml}$ of hardness buffer $(\mathrm{pH} \mathrm{10})$ were added to the $100 \mathrm{ml}$ sample and mixed. The sample was then titrated with $0.8 \mathrm{~N}$ Ethylenediaminetetraacetic acid (EDTA) to a blue endpoint. $\mathrm{BOD}_{5}$ analyses were conducted according to Standard Methods for Examination of Water and Wastewater (APHA, 1992). Wheaton BOD bottles (Wheaton Science Products, Millville, NJ) were completely filled with sample water and capped with glass stoppers to ensure no air bubbles were present. Initial (Day 0) and final (Day 5) dissolved oxygen concentrations were measured using the YSI Model 5000 dissolved oxygen meter (YSI Inc., Yellow Springs, OH).

\section{$\underline{\text { Soil Sample Collection }}$}

For analysis of chemical and physical soil parameters, samples were collected at the 14 established sites assigned by the Environmental Health Sciences Laboratory. Fifteen samples were collected from each site $(n=210)$. This sample size was based on previously collected physical and chemical soil data on Sinking Creek at $\alpha=0.05$ (Hall, 2006a). Soil was collected using a soil auger within 6 to 8 inches of the soil surface and placed into a sterile sampling bag. Samples were transported to the laboratory, spread in a $3 \mathrm{~cm}$ thick layer on drying trays, and allowed to dry. Clods were broken with a rolling pin and the samples were passed through a $2 \mathrm{~mm}$ sieve to remove the gravel fraction. The $<2 \mathrm{~mm}$ fraction was transferred back to the sampling bag until further use and analyzed for the paramters listed in Table 5.4. 
Table 5.4. Analyzed soil parameters

$$
\begin{array}{ll} 
& \text { Particle Size (\% sand, silt and clay) } \\
\text { Physical Parameters } & \text { Total Organic Carbon (\% organic carbon) } \\
& \text { Water Holding Capacity (\%) } \\
\text { Bulk Density }\left(\mathrm{g} / \mathrm{cm}^{3}\right)
\end{array}
$$

Chemical Parameters

$\mathrm{pH}$

Cation Exchange Capacity (meq/100g soil)

Samples for microbial analysis were collected quarterly from the 6 selected sites described in Table 5.2. Fifteen samples were collected from each site per quarter $(n=$ 360). Soil was collected using a soil auger within 6 inches of the soil surface and placed in a sterile sampling bag. Samples were transported to the laboratory and processed within $48 \mathrm{~h}$ of arrival.

\section{Particle Size Analysis}

Particle size analysis was performed as described by The Soil Science Society of America and The American Society of Agronomy (Klute 1996). Twenty to 40 grams were weighed and placed into a $250 \mathrm{ml}$ centrifuge tube containing $100 \mathrm{ml} \mathrm{DI}$ water and $10 \mathrm{ml}$ of $1.0 \mathrm{M}$ sodium acetate $(\mathrm{pH} 5.0)$. Tubes were mixed for $1 \mathrm{~min}$., centrifuged for 10 min., and the supernatant discarded. Samples were washed twice with DI water. To remove organic matter, $25 \mathrm{ml}$ of $\mathrm{DI}$ water $+5 \mathrm{ml}$ of $\mathrm{H}_{2} \mathrm{O}_{2}$ were added to the soil sample. Samples were allowed to cool following frothing and this step was repeated until there was no further frothing activity. Samples were then heated to $90^{\circ} \mathrm{C}$ until a bleached 
color was reached and frothing ceased. To remove iron oxides, $150 \mathrm{ml}$ of $0.3 \mathrm{M}$ sodium citrate/sodium bicarbonate solution was added. Samples were shaken for $30 \mathrm{~min}$ and placed in an $80^{\circ} \mathrm{C}$ water bath for 20 min. with intermittent agitation. Samples were removed from the water bath and $10 \mathrm{ml}$ of $10 \% \mathrm{NaCl}$ solution was added. The samples were shaken for 1 minute and centrifuged for 10 minutes. The samples were washed twice with DI water and shaken overnight in $100 \mathrm{ml}$ of sodium hexametaphosphate (HMP). Samples were then quantitatively transferred to 1- $\mathrm{L}$ graduated cylinders and the volume adjusted to $1 \mathrm{~L}$ with $\mathrm{DI}$ water. The graduated cylinders were inverted several times to mix the sample and hydrometer measurements were taken at $30 \mathrm{~s}, 60 \mathrm{~s}, 1.5 \mathrm{~h}$, and $24 \mathrm{~h}$. The hydrometer was rinsed and dried between each sample and reading, and a blank solution was measured for every 15 samples.

$\underline{\mathrm{pH}}$

Soil $\mathrm{pH}$ analyses were performed as described by The Soil Science Society of America and The American Society of Agronomy (Sparks, 1996). Ten grams of soil was added to $10 \mathrm{ml} \mathrm{DI}$ water, and the slurry was stirred for 30 s and allowed to settle for 10 minutes. Using a calibrated pH meter (Fisher Accumet Model 230A), pH was determined for each sample by lowering the electrode into the slurry at the soil-water interface. The $\mathrm{pH}$ was read to the nearest tenth of a unit while the slurry was slowly stirred. The probe was rinsed between each sample and reading and was standardized every 15 samples. 


\section{Cation Exchange Capacity}

Cation exchange capacity (CEC) was determined using an ammonium acetate adapted method from Chapman (Chapman 1965). Twenty-five grams of soil were mixed with $125 \mathrm{ml}$ of $1 \mathrm{M} \mathrm{NH}_{4} \mathrm{OAc}$, shaken, and allowed to stand for 16h. A Buchner funnel apparatus was assembled. Ashless, quantitative Whatman® filter papers (Florham Park, New Jersey) were placed in the funnel, moistened with DI water, and the soil was filtered. The filtrate was refiltered through the soil until it was clear. The soil was then washed 4 times with $25 \mathrm{ml}$ of $1 \mathrm{M} \mathrm{NH}_{4} \mathrm{OAc}$ and the leachate discarded. The soil was then washed 8 times with $10 \mathrm{ml}$ of $95 \%$ ethanol and the leachate discarded. To obtain the adsorbed $\mathrm{NH}_{4}{ }^{+}$, the soil was leached 8 times with $25 \mathrm{ml}$ of $1 \mathrm{M} \mathrm{KCl}$. The leachate was collected in a $250 \mathrm{ml}$ volumetric flask and brought to volume using $1 \mathrm{M} \mathrm{KCl}$. Colorimetric detection of $\mathrm{NH}_{4}{ }^{+}-\mathrm{N}^{+}$in the $\mathrm{KCl}$ extract was determined using a Nessler Method adapted from Standard Methods for the Examination of Water and Wastewater $4500-\mathrm{NH}_{3} \mathrm{~B}$ and $\mathrm{C}$. To $25 \mathrm{ml}$ of $\mathrm{Dl}$ water, $250 \mu \mathrm{l}$ of sample was added and mixed. Three drops each of mineral stabilizer and polyvinyl alcohol dispersing agent were added to the sample and mixed. Nessler reagent was then added ( $1 \mathrm{ml})$ to each sample, mixed, and allowed to sit for 1 min. Ten milliliters of sample were then read using the $\mathrm{HACH}^{\mathrm{TM}}$ DR5000 Spectrophotometer (Loveland, CO). CEC (meq/100g) was determined using the equation:

CEC $($ meq/100g $)=\mathrm{NH}_{4}{ }^{+}-\mathrm{N}^{+}(\mathrm{mg} / \mathrm{L}$ as N$) / 14\left(\mathrm{NH}_{4}{ }^{+}-\mathrm{N}^{+}\right.$in extract $-\mathrm{NH}_{4}{ }^{+}-\mathrm{N}^{+}$in blank) (Eq. 5.1) 


\section{$\underline{\text { Total Organic Carbon }}$}

Total organic carbon (TOC) was determined using a method described by The Soil Science Society of America and The American Society of Agronomy (Sparks, 1996). Two milliliters of concentrated $\mathrm{HCl}$ was added to $1 \mathrm{~g}$ of soil in glass vials. The samples were allowed to sit until frothing ceased and were then placed in a $103^{\circ} \mathrm{C}$ oven to dry. After drying, 30mg was weighed, placed in a quartz crucible, and analyzed using the Elementar ${ }^{\mathrm{TM}}$ LiquiTOC Analyzer (Elementar Analysensysteme, Hanau, Germany). A standard curve was constructed for every site using sodium bicarbonate standards, and this curve was used to determine the total organic carbon present in the sample.

\section{Water Holding Capacity}

Water holding capacity (WHC) was determined as described by Whilke (2005). Thirty grams of soil were weighed and placed in a cylinder with a plugged base. To the cylinders, $30 \mathrm{ml}$ of DI water was added and the samples were allowed to sit for $1 \mathrm{~h}$. Following this time, the plug was removed from the cylinder and the excess water was allowed to drain. The moist soil was placed in a dry pre-weighed beaker and weighed. The beaker of moist soil was then dried overnight in a $105^{\circ} \mathrm{C}$ oven and weighed after it was cooled. WHC was determined using the following equation:

$$
\mathrm{WHC}_{\max }(\% \text { dry mass })=\left(m_{s}-m_{t} \times 100\right) /\left(m_{t}-m_{b}\right) \quad(\text { Eq. 5.2) }
$$


where:

\author{
$m_{s} \quad$ mass of beaker containing the water saturated soil $(\mathrm{g})$ \\ $m_{t} \quad$ mass of beaker containing the oven dried soil $(\mathrm{g})$ \\ $m_{b} \quad$ mass of beaker $(\mathrm{g})$
}

\title{
Bulk Density
}

Bulk density was determined in the field using the excavation method as described by Whilke (2005). The soil surface was leveled off using a straight metal blade, and a hole was dug to avoid compaction of the sides. The excavated soil was placed in a heavy paper-lined soil sampling bag (Fisher Scientific Inc., Pittsburgh, PA) and transported to the laboratory for further analysis. The hole was lined with plastic film and filled with sand. The surface was leveled and care was taken not to compact the sand. The sand was then excavated and the volume determined using a graduated cylinder. In the laboratory, the mass of the excavated soil was determined, and stones and gravel were separated from the fine soil using a $2 \mathrm{~mm}$ sieve. The dry stones and gravel were then weighed, dried in a $105^{\circ} \mathrm{C}$ oven, and reweighed after cooling. The water content of the fine soil was determined by weighing $5 \mathrm{~g}$ of the sample in a $105^{\circ} \mathrm{C}$ oven and reweighing after cooling. Bulk density was determined using the following equations: 


$$
\begin{aligned}
& \varphi_{\mathrm{b}}=\underline{m_{x}-m_{t p}} \\
& m_{t p}=m_{p w}-m_{x w}-m_{w} \\
& m_{w}=m_{p w} \times m_{t w} \\
& m_{t w}=m_{p w}-m_{x w}
\end{aligned}
$$

where:

$\varphi_{b} \quad$ bulk density $\left(\mathrm{g} / \mathrm{cm}^{3}\right)$

$m_{x} \quad$ mass of stones and dry gravel $(g)$

$m_{t p} \quad$ mass of dry fine soil $(\mathrm{g})$

$V \quad$ volume of the hole $\left(\mathrm{cm}^{3}\right)$

$m_{p w} \quad$ mass of excavated moist soil $(\mathrm{g})$

$m_{w} \quad$ mass of the water excavated from the fine soil (g)

w water content of the excavated moist fine soil (g/g oven-dried soil)

$$
\begin{aligned}
& m_{t w} \quad \text { mass of the moist fine soil }(\mathrm{g}) \\
& m_{x w} \quad \text { mass of the moist gravel and stones }(\mathrm{g})
\end{aligned}
$$

\section{Data Analysis of Chemical and Physical Parameters}

All data analyses were performed using SAS/STAT statistical software (SAS Institute, Cary, NC). Data were tested for normality using the Shapiro-Wilk test. WHC, 
CEC, and particle sizes were normally distributed. Bulk density, $\mathrm{pH}$ and TOC displayed a lognormal distribution and were log transformed to achieve normality. Parameter comparisons between land uses were performed using ANOVA tests and significant differences between sites were detected using Tukey's test. Linear regressions were performed using the normally distributed data set for each parameter.

\section{Microbial Soil Analysis/Carbon Use}

Fifteen soil samples were collected and assayed for each of the 6 sites to examine carbon use patterns of the microbial community on a quarterly basis. One gram of collected soil was added to $20 \mathrm{ml}$ of sterile phosphate buffered saline and vortexed to disperse soil particles. One hundred fifty microliters of the soil solution was pipetted into each of the 96 wells on a Biolog® GN2 plates as described by the manufacturer (Biolog Inc., Hayward, CA) for the identification of gram negative bacteria. Each well contained a different carbon substrate, and use of that carbon substrate by the microbial population resulted in the reduction of tetrazolium violet resulting in development of a purple color. Plates were incubated at $28^{\circ} \mathrm{C}$ for $24 \mathrm{~h}$ and read using the Multiskan MMC 5111340 microplate reader (Fisher Scientific, Pittsburgh, PA) at an optical density of $570 \mathrm{~nm}$.

The measured absorbances for each well were standardized by subtracting the blank absorbance to determine the raw differences. Wells were considered positive if the raw difference was greater than or equal to the average absorbance of all 95 wells. The average well color development (AWCD) value for each well was determined using the following equation to express overall color development: 


$$
\begin{aligned}
& \text { AWCD }=[\Sigma(\mathrm{C}-\mathrm{R})] / 95 \quad(\text { Eq. 5.7) } \\
& \text { where: } \\
& \qquad \begin{array}{l}
\mathrm{C}=\text { absorbance of the control well } \\
\mathrm{R}=\text { absorbance of the response well }
\end{array}
\end{aligned}
$$

Data were transformed for analysis using the AWCD for each plate determined by the following equation:

$$
\text { Transformed AWCD }=(C-R) /\{[\Sigma(C-R)] / 95\} \text { (Eq. 5.8) }
$$

Transformed AWCD values were analyzed at the land use level using the PRINCOMP procedure in SAS/STAT statistical software (SAS Institute, Cary, NC) to determine carbon use patterns based on land use type.

\section{$\underline{\text { Results and Discussion }}$}

\section{Physiochemical Soil Parameters}

Summary statistics for the measured soil parameters are provided in Table 5.5. Results are not reflective of the full pedon structure and may not represent the heterogeneous nature of the soil, as samples were collected from the $\mathrm{O}$ and $\mathrm{A}$ horizons within $6-8$ inches of the soil surface. These surface layers were analyzed as they are thought to be the most responsible for the transport of microorganisms into surface waters. The results of particle size analyses from the collected samples are shown in Figure 5.3. Significant differences in particle sizes were observed between all land use 
groups, and these results demonstrate that the soil analyzed from every site can be classified as sandy soil. 
Table 5.5. Mean, standard deviation, and range of measured physical and chemical soil parameters

\begin{tabular}{|c|c|c|c|c|c|c|c|}
\hline Site & Land Use & $\begin{array}{l}\text { Textural } \\
\text { Classification }\end{array}$ & $\mathrm{pH}$ & CEC (meq/100g) & $\begin{array}{l}\text { Water Holding } \\
\text { Capacity (\%) }\end{array}$ & $\begin{array}{l}\text { Total Organic } \\
\text { Carbon (\%) }\end{array}$ & $\begin{array}{l}\text { Bulk Density } \\
\left(\mathrm{g} / \mathrm{cm}^{3}\right)\end{array}$ \\
\hline 1 & Agricultural & Sand & $\begin{array}{l}6.95(0.44) \\
{[6.0-7.3]}\end{array}$ & $\begin{array}{l}0.03(0.01) \\
{[0.015-0.05]}\end{array}$ & $\begin{array}{l}17.90(11.78) \\
{[3.76-44.85]}\end{array}$ & $\begin{array}{l}2.38(1.93) \\
{[0.31-7.53]}\end{array}$ & $\begin{array}{l}1.02(0.18) \\
{[0.47-2.29]}\end{array}$ \\
\hline 2 & Agricultural & Sand & $\begin{array}{l}7.08(0.23) \\
{[6.7-7.4]}\end{array}$ & $\begin{array}{l}0.05(0.02) \\
{[0.008-0.08]}\end{array}$ & $\begin{array}{l}54.36(12.68) \\
{[33.31-84.20]}\end{array}$ & $\begin{array}{l}4.12(2.92) \\
{[0.76-11.89]}\end{array}$ & $\begin{array}{l}0.61(0.38) \\
{[0.14-1.34]}\end{array}$ \\
\hline 3 & Agricultural & Sand & $\begin{array}{l}7.71(0.24) \\
{[6.7-7.6]}\end{array}$ & $\begin{array}{l}0.06(0.02) \\
{[0.02-0.09]}\end{array}$ & $\begin{array}{l}65.10(16.44) \\
{[41.28-86.85]}\end{array}$ & $\begin{array}{l}10.94(7.20) \\
{[0.98-22.53]}\end{array}$ & $\begin{array}{l}0.64(0.28) \\
{[0.21-1.01]}\end{array}$ \\
\hline 4 & Agricultural & Sand & $\begin{array}{l}6.98(0.44) \\
{[5.6-7.4]}\end{array}$ & $\begin{array}{l}0.04(0.04) \\
{[0.01-0.19]}\end{array}$ & $\begin{array}{l}51.71(17.15) \\
{[31.37-96.10]}\end{array}$ & $\begin{array}{l}4.70(8.06) \\
{[0.63-33.06]}\end{array}$ & $\begin{array}{l}0.45(0.23) \\
{[0.18-0.81]}\end{array}$ \\
\hline 5 & Agricultural & Sand & $\begin{array}{l}6.84(0.27) \\
{[6.5-7.2]}\end{array}$ & $\begin{array}{l}0.04(0.01) \\
{[0.02-0.05]}\end{array}$ & $\begin{array}{l}57.69(7.65) \\
{[43.77-70.95]}\end{array}$ & $\begin{array}{l}9.61(6.69) \\
{[1.51-25.13]}\end{array}$ & $\begin{array}{l}0.35(0.18) \\
{[0.10-0.60]}\end{array}$ \\
\hline 6 & Urban & Sand & $\begin{array}{l}6.78(0.54) \\
{[5.8-7.5]}\end{array}$ & $\begin{array}{l}0.04(0.1) \\
{[0.01-0.05]}\end{array}$ & $\begin{array}{l}53.28(8.85) \\
{[30.87-60.52]}\end{array}$ & $\begin{array}{l}5.67(3.14) \\
{[0.99-10.41]}\end{array}$ & $\begin{array}{l}1.15(0.66) \\
{[0.21-2.77]}\end{array}$ \\
\hline 7 & Urban & Sand & $\begin{array}{l}7.18(0.15) \\
{[6.9-7.4]}\end{array}$ & $\begin{array}{l}0.05(0.03) \\
{[0.02-0.09]}\end{array}$ & $\begin{array}{l}62.14(17.02) \\
{[31.65-88.15]}\end{array}$ & $\begin{array}{l}6.38(5.35) \\
{[1.33-19.28]}\end{array}$ & $\begin{array}{l}0.32(0.31) \\
{[0.03-1.13]}\end{array}$ \\
\hline 8 & Urban & Sand & $\begin{array}{l}7.21(0.10) \\
{[7.0-7.4]}\end{array}$ & $\begin{array}{l}0.07(0.07) \\
{[0.04-0.08]}\end{array}$ & $\begin{array}{l}66.31(6.48) \\
{[55.20-81.54]}\end{array}$ & $\begin{array}{l}6.12(3.40) \\
{[0.59-12.49]}\end{array}$ & $\begin{array}{l}1.28(0.78) \\
{[0.13-2.84]}\end{array}$ \\
\hline 9 & Urban & Sand & $\begin{array}{l}6.93(0.20) \\
{[6.7-7.1]}\end{array}$ & $\begin{array}{l}0.06(0.02) \\
{[0.02-0.08]}\end{array}$ & $\begin{array}{l}57.42(12.58) \\
{[31.55-77.12]}\end{array}$ & $\begin{array}{l}7.15(5.65) \\
{[1.36-21.98]}\end{array}$ & $\begin{array}{l}0.44(0.30) \\
{[0.09-1.09]}\end{array}$ \\
\hline 10 & Urban & Sand & $\begin{array}{l}6.68(0.30) \\
{[5.7-7.0]}\end{array}$ & $\begin{array}{l}0.05(0.01) \\
0.03-0.07]\end{array}$ & $\begin{array}{l}63.38(8.72) \\
{[52.17-76.12]}\end{array}$ & $\begin{array}{l}10.52(5.25) \\
{[4.90-23.60]}\end{array}$ & $\begin{array}{l}0.56(0.39) \\
{[0.21-1.49]}\end{array}$ \\
\hline 11 & Urban & Sand & $\begin{array}{l}6.79(0.35) \\
{[5.9-7.1]}\end{array}$ & $\begin{array}{l}0.06(0.01) \\
{[0.03-0.08]}\end{array}$ & $\begin{array}{l}63.29(7.57) \\
{[48.18-75.78]}\end{array}$ & $\begin{array}{l}5.71(2.45) \\
{[3.69-10.66]}\end{array}$ & $\begin{array}{l}0.41(0.44) \\
{[0.04-1.47]}\end{array}$ \\
\hline 12 & Urban & Sand & $\begin{array}{l}7.21(0.10) \\
{[7.1-7.4]}\end{array}$ & $\begin{array}{l}0.07(0.07) \\
{[0.05-0.14)}\end{array}$ & $\begin{array}{l}66.78(6.66) \\
{[52.24-78.13]}\end{array}$ & $\begin{array}{l}21.13(6.73) \\
{[9.13-35.57]}\end{array}$ & $\begin{array}{l}1.22(0.83) \\
{[0.16-2.71]}\end{array}$ \\
\hline 13 & Forest & Sand & $\begin{array}{l}6.20(0.66) \\
{[4.7-7.1]}\end{array}$ & $\begin{array}{l}0.05(0.03) \\
{[0.01-0.11]}\end{array}$ & $\begin{array}{l}59.57(18.00) \\
{[33.08-88.92]}\end{array}$ & $\begin{array}{l}24.04(24.17) \\
{[1.83-65.47]}\end{array}$ & $\begin{array}{l}1.32(0.94) \\
{[0.20-2.99]}\end{array}$ \\
\hline 14 & Forest & Sand & $\begin{array}{l}5.43(0.25) \\
{[5.1-6.0]}\end{array}$ & $\begin{array}{l}0.05(0.02) \\
{[0.02-0.08]}\end{array}$ & $\begin{array}{l}63.27(13.91) \\
{[36.04-85.28]}\end{array}$ & $\begin{array}{l}31.23(27.47) \\
{[0.76-84.24]}\end{array}$ & $\begin{array}{l}0.62(0.53) \\
{[0.07-1.81]}\end{array}$ \\
\hline
\end{tabular}



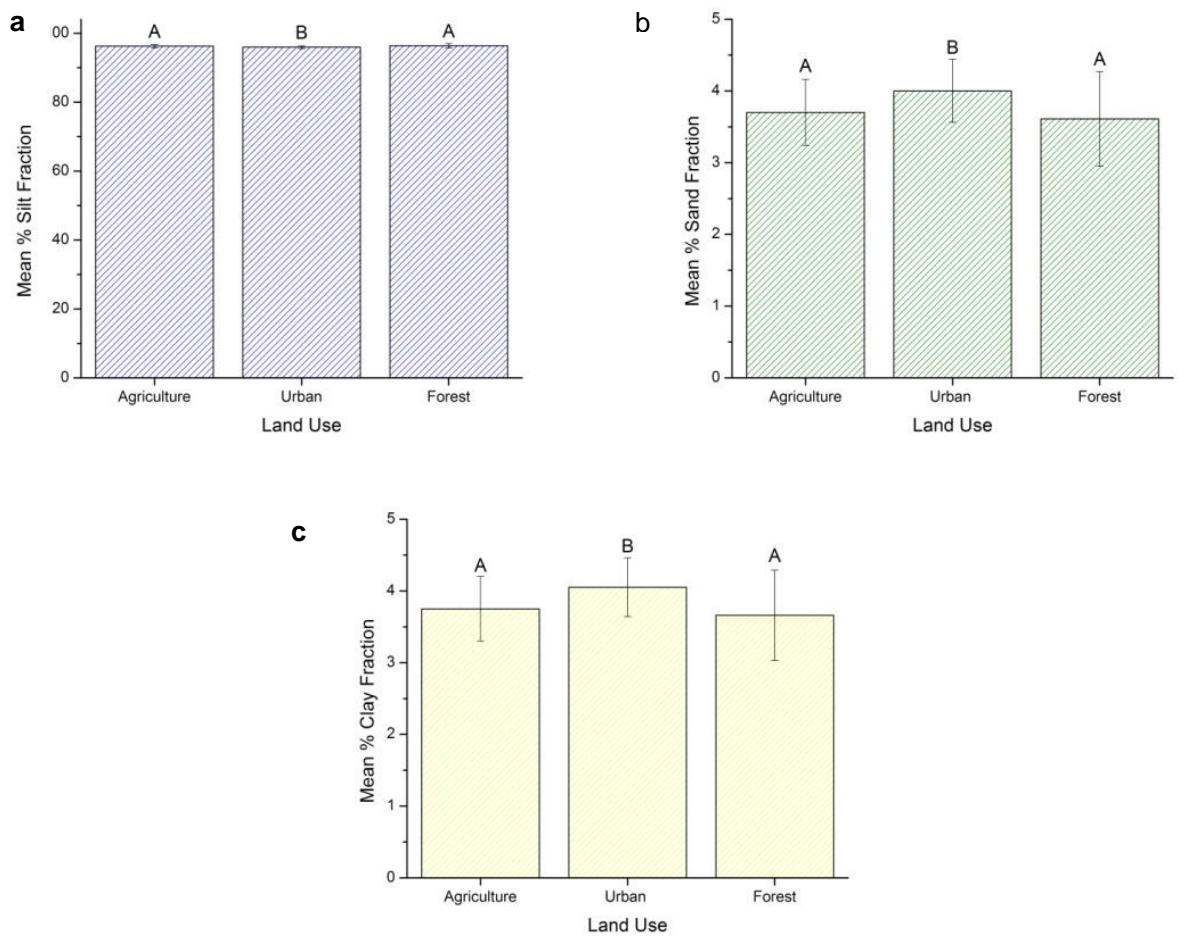

Figure 5.3. Mean texture composition values for silt (a), sand (b) and clay (c) (significant differences are indicated by different letters)

Statistically significant differences in organic matter content were observed between all land use groups (Figure 5.4). The increased percentages of total organic carbon at urban and forest land use sites is expected based on the presence of leaf litter and plant matter in the upper soil surface. These findings can also be explained by the observed particle sizes, as more carbon is typically found in coarse soils than in clays (Peinemann et al. 2000). The presence of organic matter can improve overall soil quality through nutrient cycling and can increase soil acidity through the release of $\mathrm{CO}_{2}$ (Zhang et al. 2008), yet decomposition rates are also slowed by low $\mathrm{pH}$ values (Motavalli, 1995). 


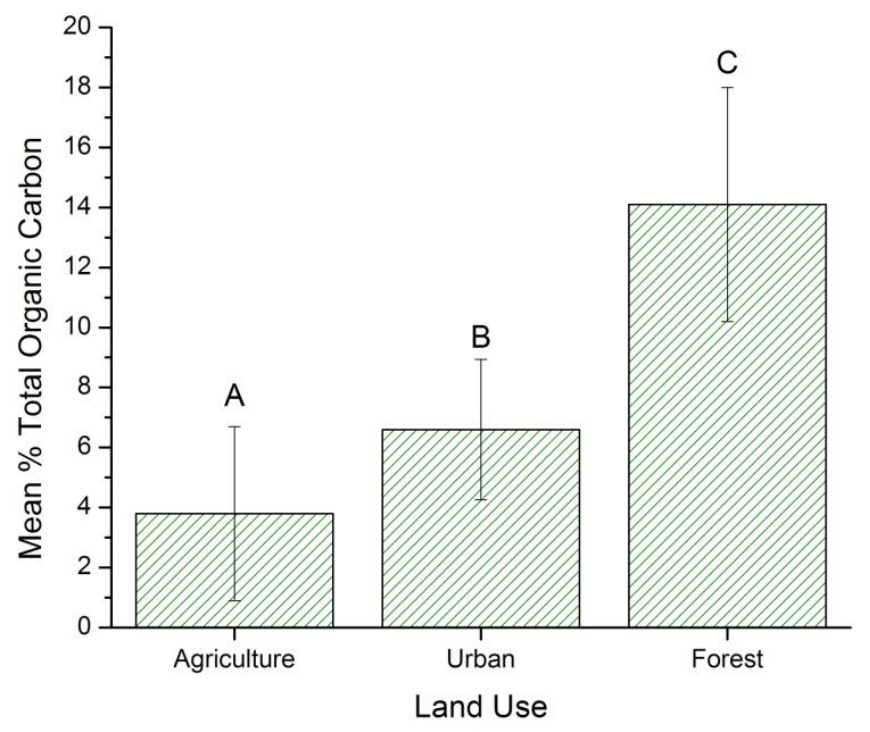

Figure 5.4. Mean total organic carbon values (significant differences are indicated by different letters)

The relatively low CEC activity can likely be attributed to the high fraction of sand in the samples and the lack of negatively charged binding sites on sand particles. The presence of charged carboxyl groups on organic matter and low percent fractions of clay in the upper soil horizons likely contributed to the observed low CEC activity (Parfitt et al. 1995, Schjønning, 1999). CEC activity of the collected soil may be due to the presence of organic matter which can block available binding sites for CEC activity (Peinemann et al. 2000), as demonstrated by the significant correlation between the organic matter and CEC (Figure 5.5). Though the presence of clay particles can also influence CEC, organic matter has a greater influence on CEC activity compared to particle size (Peinemann et al. 2000). Figure 5.6 suggests that clay content also influences $\mathrm{CEC}$ but not as strongly as organic matter content. Soil pH results are 
displayed in Figure 5.7 and the lowest $\mathrm{pH}$ values were observed at the forest sites.

Acidic soils have been shown to slow decomposition rates (Motavalli, 1995). The low $\mathrm{pH}$ values at forested sites along with the presence of leaf litter help explain the higher organic matter contents observed at the forested sites.

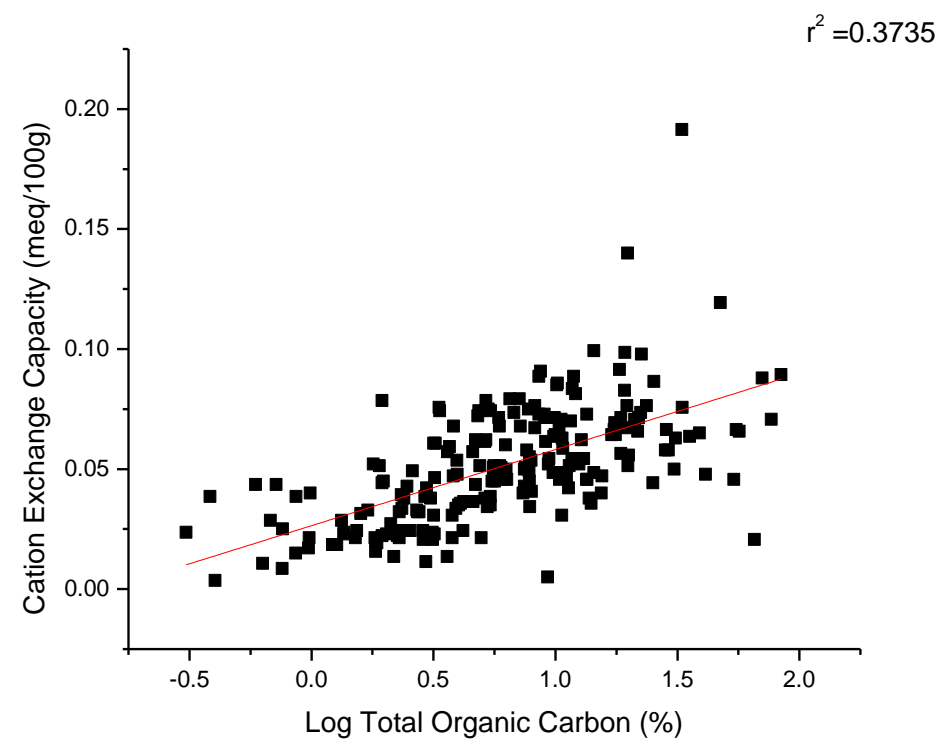

Figure 5.5. Linear relationship between TOC and CEC 


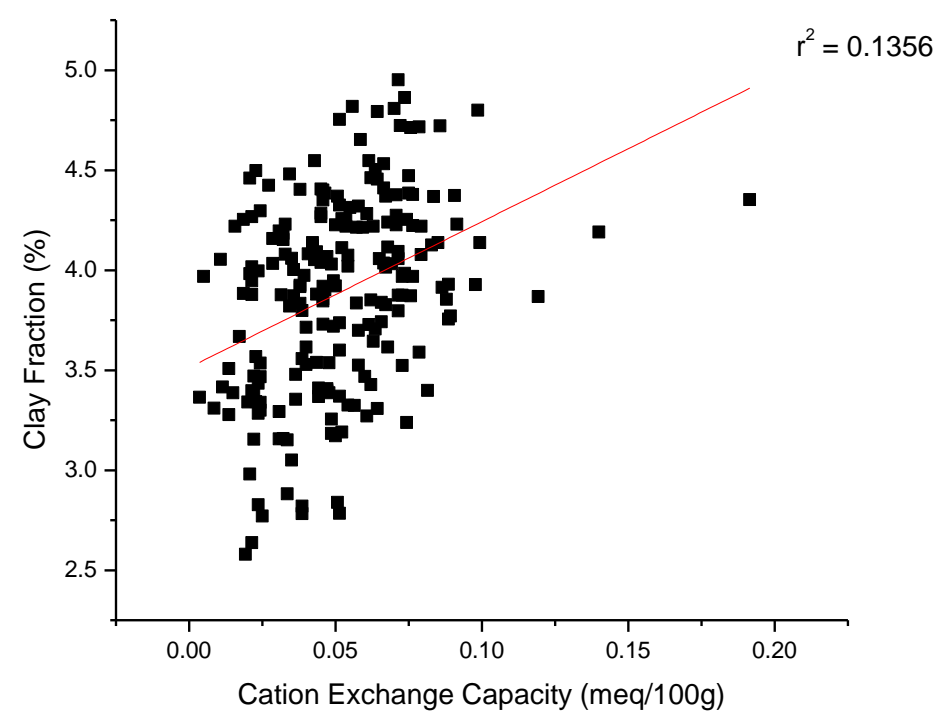

Figure 5.6. Linear relationship between CEC and clay fraction

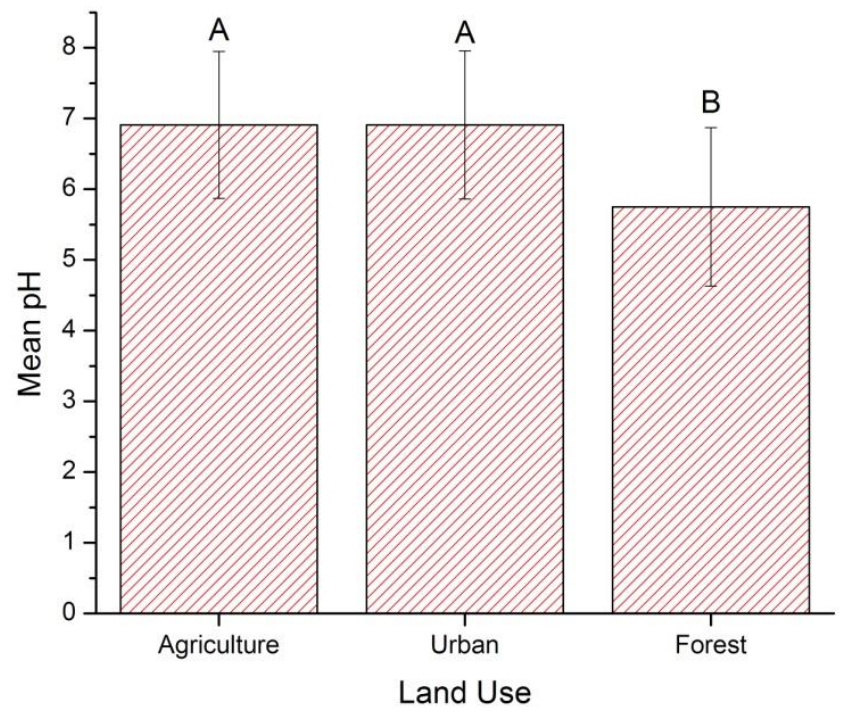

Figure 5.7. Mean pH values by land use (significant differences are indicated by different letters) 
Observed water holding capacity percentages are displayed in Figure 5.8. Agricultural sites have a significantly lower water holding capacity compared to urban and forest land use sites. Agricultural sites along Sinking Creek had been affected by drought conditions at the time of soil sampling and site 1 the only site that had a dry creek bed at the time of sampling. The lack of water at this site may have influenced sedimentation of silt and clay particles, resulting in the observed low water holding capacity compared to other sites along Sinking Creek (Jenny, 1980). An expected, significant correlation was observed between CEC and WHC (Figure 5.9). Low CEC values are the result of a lack of negatively charged binding sites from either clay particles or the presence of organic matter. CEC values increase as binding sites become available and these binding sites can also retain moisture. A significant correlation is also observed between organic matter content and water holding capacity (Figure 5.10). This observation is also expected, as water content and holding capacity are related to organic matter content (Kemmitt et al. 2006; Li et al. 2007). This finding also supports the previous suggestion that the presence of organic matter is more influential than clay particles in CEC activity of these soils. 


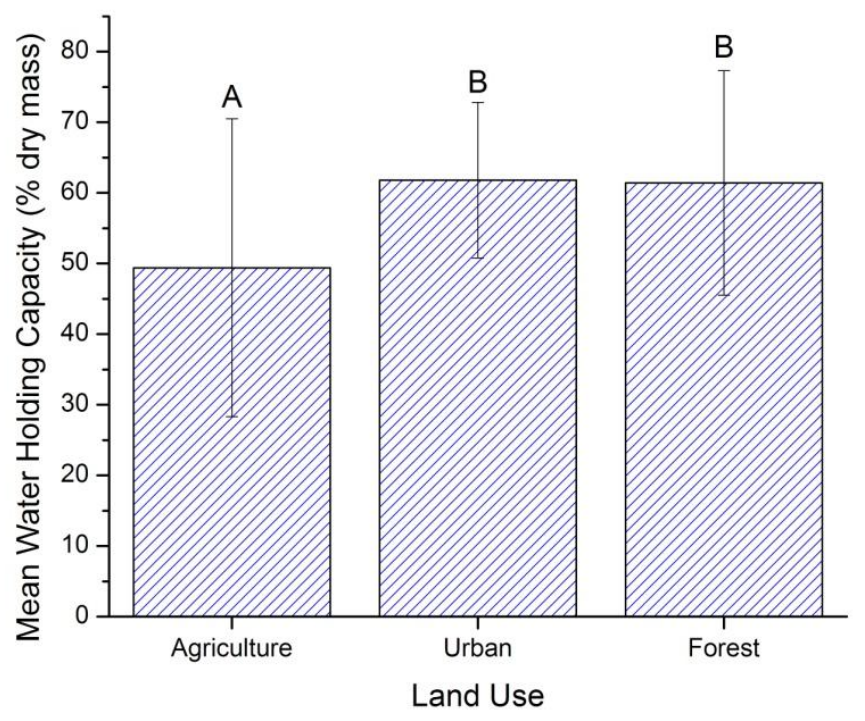

Figure 5.8. Mean water holding capacity values (significant differences are indicated by different letters)

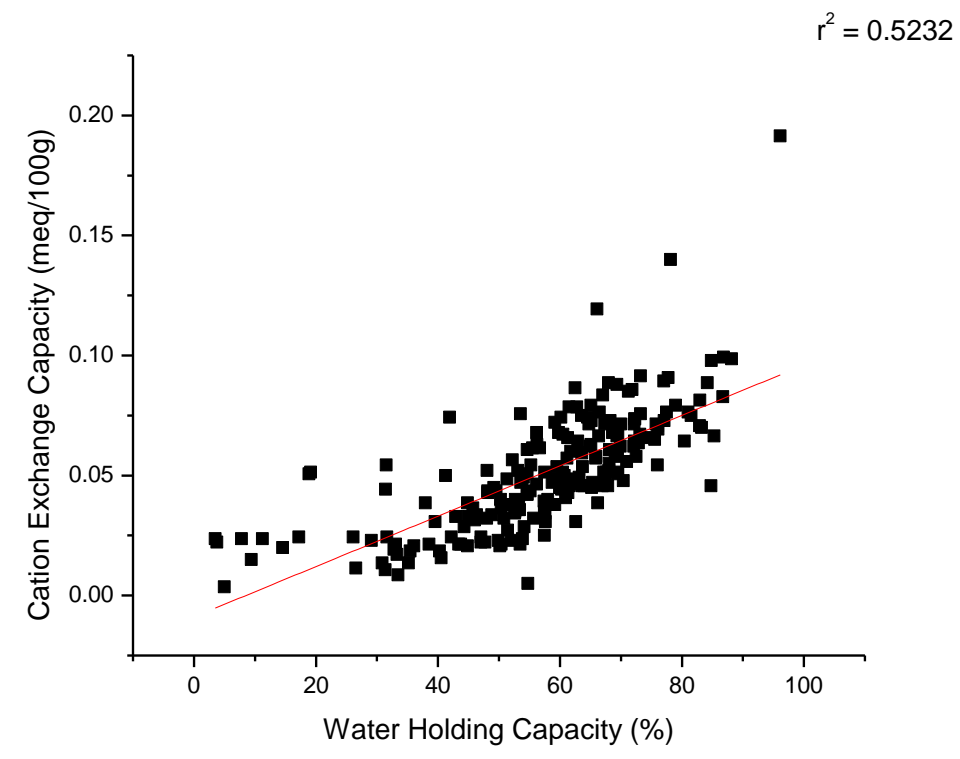

Figure 5.9. Linear relationship between WHC and CEC 


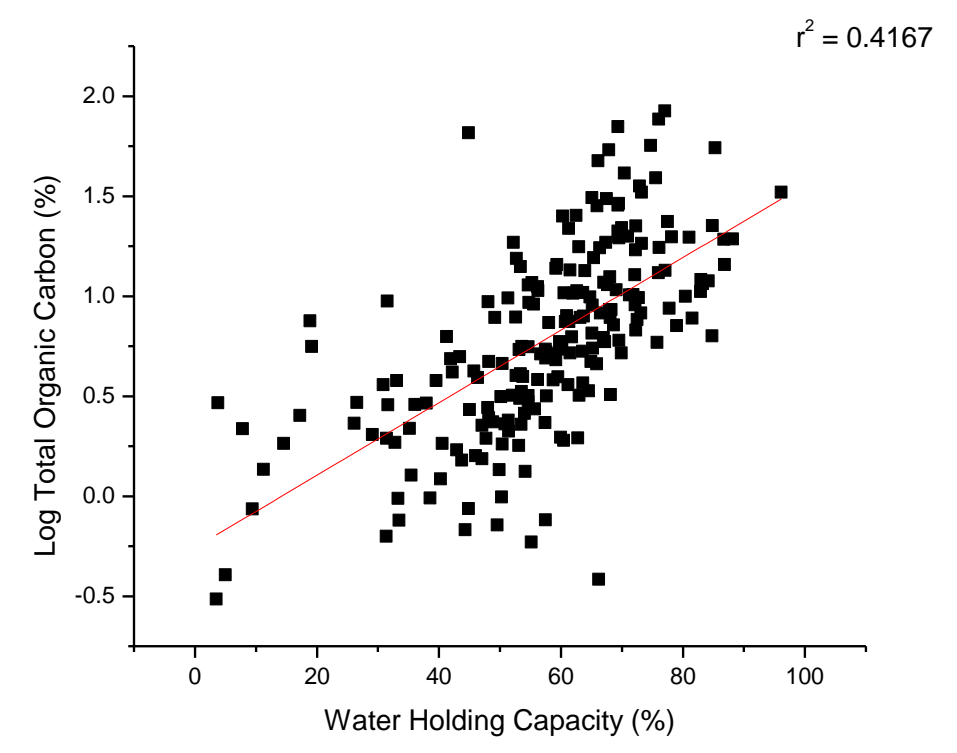

Figure 5.10. Linear relationship between WHC and TOC

Bulk density observations did not vary between land use groups (Figure 5.11) as was expected due to the coarse texture of the soils. Bulk density is a function of organic matter and an inverse relationship exists between these parameters ( $\mathrm{Li}$ et al. 2007). Results from these soils indicate an almost absent correlation between bulk density and organic matter. An inverse relationship between WHC and bulk density should also be observed, as an increase in bulk density should result in a decrease of soil porosity and, consequently, WHC (Li et al. 2007). Similar to the observed relationship between bulk density and organic matter, there is almost no correlation between the 2 parameters. 


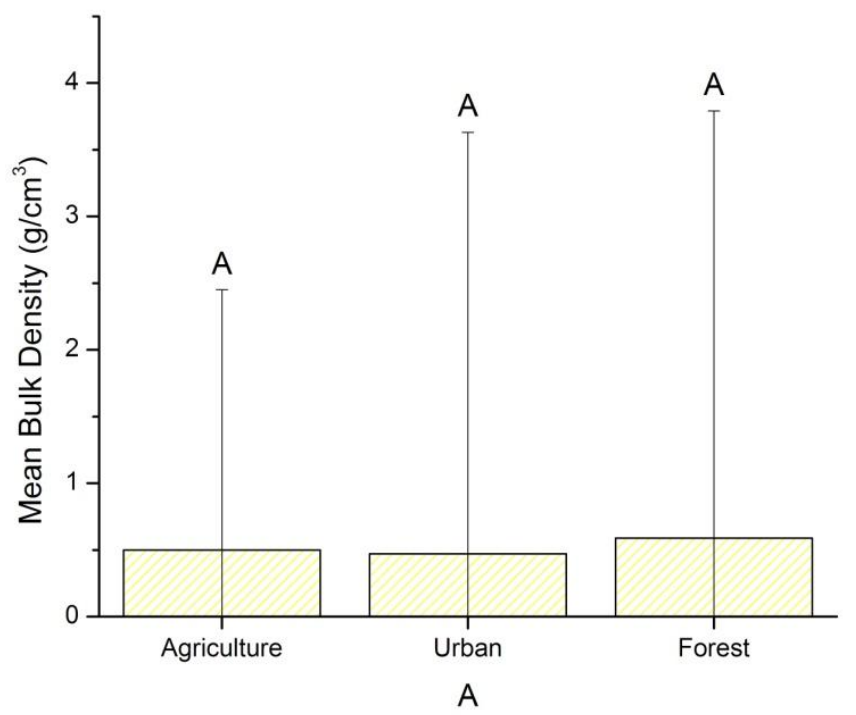

Figure 5.11. Mean bulk density values (significant differences are indicated by different letters)

Canonical discriminant analysis based on the measured physiochemical soil parameters demonstrates variability based on land use (Figure 5.12, Table 5.6). Agriculture and urban land use sites are nearly identical along the first canonical variable, which is defined by higher $\mathrm{pH}$ values and low TOC concentrations compared to forest land use sites. Separation is seen between all land use groups along the second canonical variable. This canonical variable is defined by particle size, CEC, and WHC. 


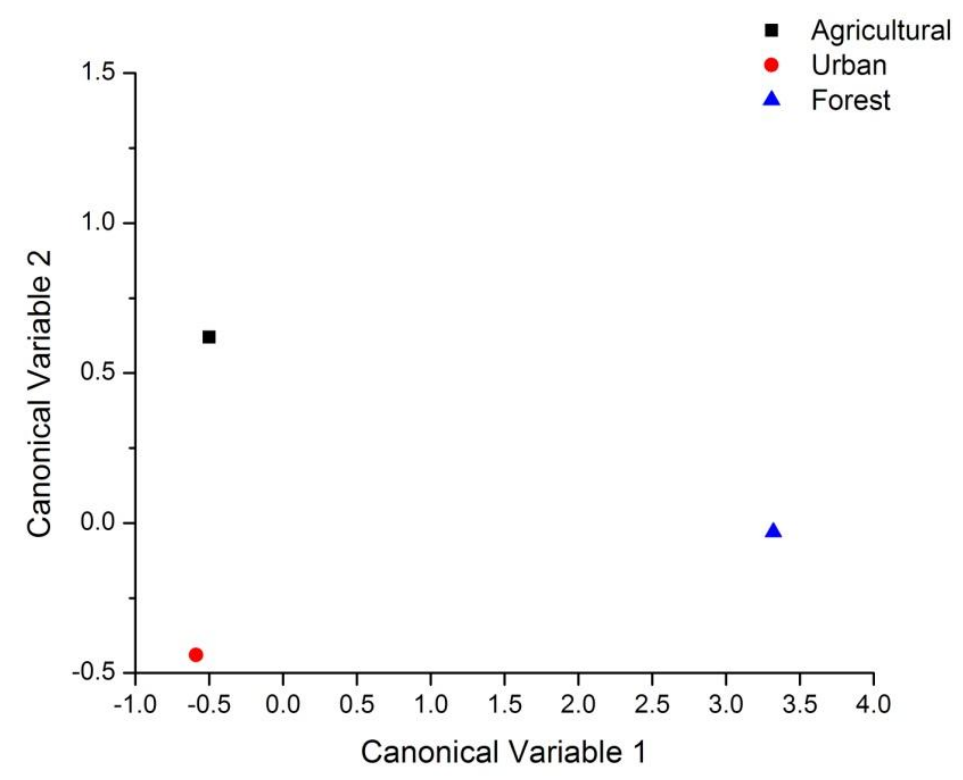

Figure 5.12. Canonical means of physiochemical soil parameters by land use

Table 5.6. Description of canonical structure for physiochemical soil properties

Canonical Variable

Variables Describing the Canonical Structure
$\mathrm{pH}(-0.89)$

Total Organic Carbon (0.63)

\% Silt Fraction (0.59)

Cation Exchange Capacity (-0.49)

Canonical Variable 2

$\%$ Sand Fraction (-0.59)

$\%$ Clay Fraction $(-0.64)$

Water Holding Capacity $(-0.77)$ 
Influences of Physiochemical Soil Parameters on Water Quality

Canonical correlation analysis of physiochemical soil parameters and pathogen concentrations did not reveal any significant correlations, which was expected based on the failure to detect E. coli $\mathrm{O} 157: \mathrm{H7}$ or Shigella $s p$. and the infrequent detection of Giardia, Cryptosporidium or bacteriophage. Although no significant correlations were observed between soil parameters and pathogen presence, physiochemical properties including matric potential, cation exchange capacity, and sorption processes can aid in the prevention of pathogen introduction into surface water. The low CEC values observed in this study combined with the ability of Giardia and Cryptosporidium to adhere to soil particle and enter the water as free individuals (Dai et al. 2003) may account for the observed protozoan concentrations in Sinking Creek.

Canonical discriminant analysis was also conducted to determine the influence of physiochemical soil parameters on fecal pollution in Sinking Creek and assess the usefulness of soil properties in predicting water quality. Physiochemical soil properties demonstrate predictive ability of surface water quality based on land use (Figure 5.13, Table 5.7). The strong separation of all land use groups suggests the influence of soil erosion and soil particle size on fecal pollution loading in Sinking Creek. The first canonical variable is influenced greatly by alkalinity and hardness. The ions that contribute to alkalinity and hardness concentrations in water may be introduced by the erosion of soil and geologic formations such as shale, sandstone, siltstone, and limestone, all of which are commonly found in Northeast Tennessee. Agricultural sites are most impacted by soil erosion, followed by urban sites. Forest land use sites are influenced by surface runoff to a lesser extent than are agricultural and urban land use 
sites. The presence and erosion of sandy soils at these sites likely contribute to fecal coliform and E. coli loading into Sinking Creek, as microorganisms will adsorb more to finer textured soils than to coarse textured soils (Abu-Ashour et al. 1998; Hijnen et al. 2005). Compared to silt and clay particles, sand particles have a smaller surface area and thus less potential for microbial adsorption (Aislabie et al. 2001; Chu et al. 2003). This becomes particularly important as microbial movement through soil is primarily affected by adsorption and filtration processes (McLeod et al. 2001). Without these processes, microorganisms can move quickly through soils into receiving waters.

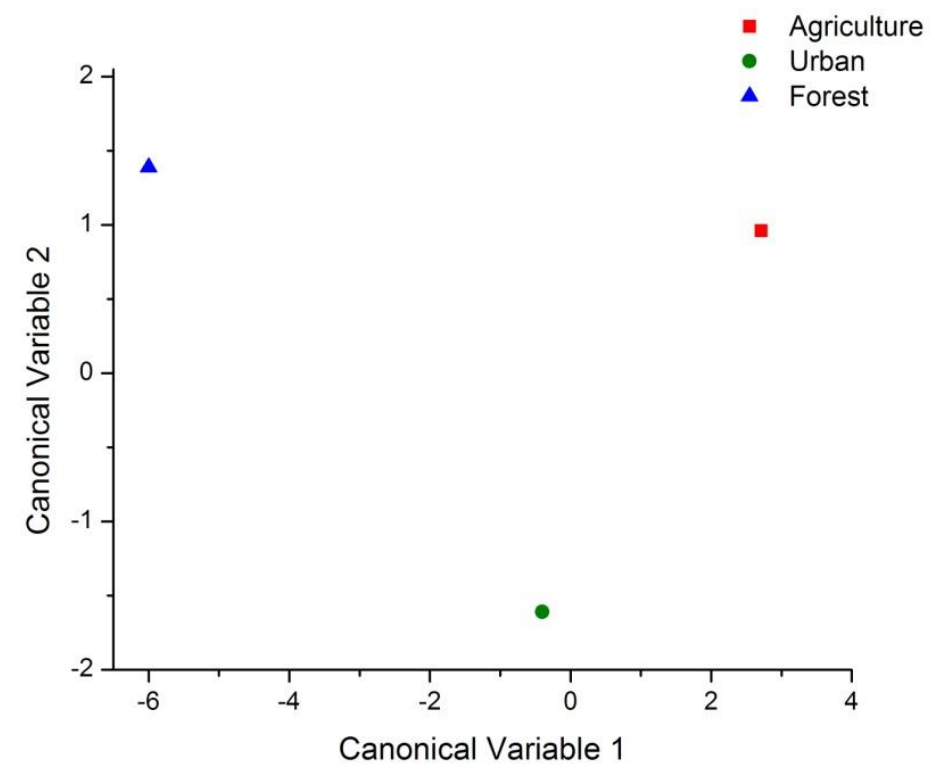

Figure 5.13. Canonical means of physiochemical soil parameters and water quality parameters by land use 
Table 5.7. Description of canonical structure for physiochemical soil properties and water quality variables

Canonical Variable 1

Hardness (0.96)

Alkalinity (0.92)

Soil pH (0.66)

Total Coliforms in Water (0.48)

Colilert (0.46)

Fecal Coliforms in Water (0.44)

Nitrates (0.41)

Fecal Coliforms in Sediment (0.34)

Soil Total Organic Carbon (-0.56)

Canonical Variable 2

$\%$ Silt Fraction (0.46)

Colilert (0.39)

Soil Total Organic Carbon (0.35)

Fecal Coliforms in Water (0.34)

Soil pH (-0.39)

$\%$ Sand Fraction (-0.45)

$\%$ Clay Fraction (-0.50)

The second canonical variable is defined by soil particle size measures. Urban sites are characterized by higher clay fractions compared to agricultural and forest land use sites, and likely result in greater microbial retention as a result of adsorption and filtration processes. The influence of soil particle size and $\mathrm{pH}$ along the second canonical variable may account for differences in fecal coliform and $E$. coli 
concentrations between urban and agriculture land use patterns. Total organic carbon concentrations also influence the second canonical variable, and it would appear that organic matter has a strong influence on microbial fate and transport in soil in the Sinking Creek watershed at forest and agricultural land use sites compared to urban land use sites. Organic matter has been shown to be a significant factor influencing microbial transport through soil, even more so than CEC (Stevik et al. 1999). The inclusion of total organic carbon in the canonical discriminant structure suggests the influence of organic matter on microbial fate and transport in soil at these land use sites. Leaf litter incorporated at the soil surface may be significantly contributing to microbial surface runoff compared to subsurface transport and deposition because of the reliance of surface transport through the soil matrix by microorganisms (Agnelli, 2004; Atalay et al. 2007). These results suggest that physiochemical soil properties influence the observed water quality and that soil characteristics have some predictive value in determining fecal coliform and E. coli loading in Sinking Creek, as soil erosion, particle size, and total organic carbon concentrations influence the transport of fecal pollution from source to receiving waters.

\section{Microbial Soil Analysis/Carbon Use}

Transformed AWCD values were analyzed at the land use level using principal component analysis to determine carbon use patterns based on land use type. Distinct patterns of carbon use were observed based on land use (Figure 5.14). Similar PC scores were observed for the first principal component, which explains $66.2 \%$ of the total variance in microbial activity. The use of $\mathrm{N}$-acetyl-D-galactosamine, adonitol, D- 
arabitol, L-fucose, m-inositol, lactulose, cis-aconitic acid, citric acid, $\beta$-hydroxybutyric acid, $\alpha$-ketogluaric acid, D-saccharic acid, 2,3-butanediol, L-aspartic acid, L-theronine, inosine, bromocuccinic acid, and 2-aminoethanol did not differ based on land use patterns. The poor correlation of a these carbon sources to land use does not necessarily indicate that the carbon source was poorly used at any particular land use type but that their use was not significantly different between land use patterns. It should be noted that the carbon sources used are a measure of functional potential and are not reflective of in situ microbial activity (Garland and Mills, 1991).

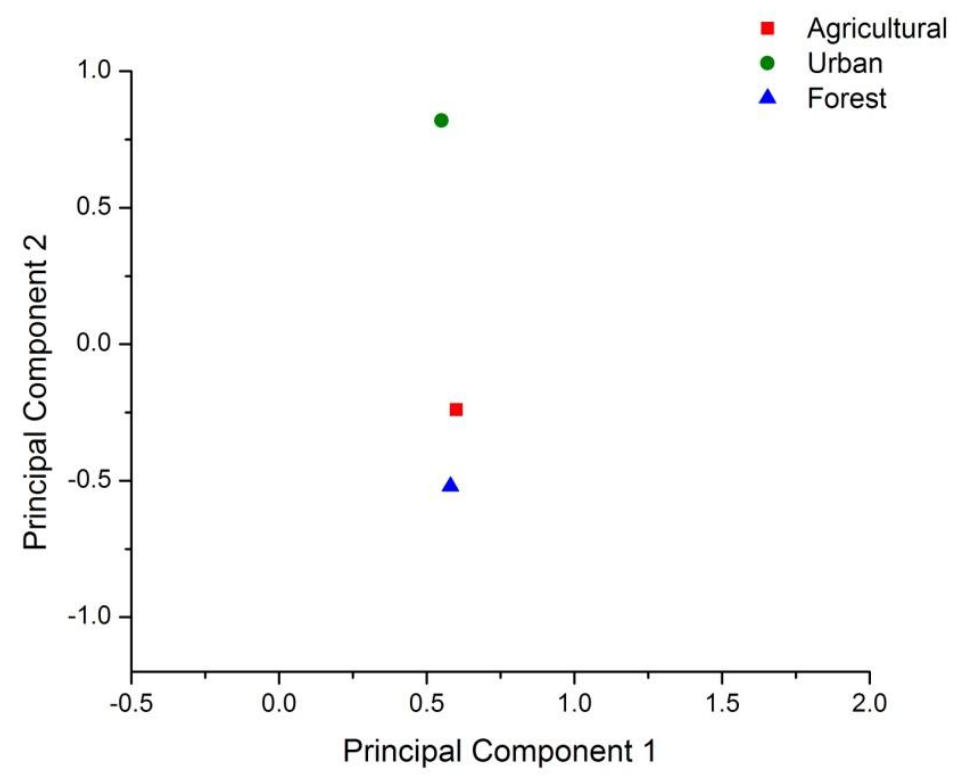

Figure 5.14. Ordination produced from principal component analysis of soil samples by land use pattern

The higher PC values for the urban land use classification along the second principal component indicate a greater response to particular carbon sources by these microbial communities and account for $19.3 \%$ of the variance in the data (Table 5.8). 
Microbial communities at urban land use sites were able to use all of the 9 carbon source categories except for polymers. The carbohydrates more commonly and frequently used by microbial communities at urban land sites are ubiquitous in the environment or exist as a metabolite of carbohydrate use. Fructose, an isomer of glucose, can be produced by the hydrolysis of raffinose. Its use can result in the production of other metabolites that are frequently metabolized at urban land use sites. Lactose and melibiose can both be hydrolyzed to produce glucose and galactose that can then be used by the microbial community. Metabolism of melibiose can also result in the production of lactose, maltose, sucrose, and trehalose. Mannitol may be present as a metabolite of fructose or fermentation products and its oxidation results in the production of mannose, which is also used at urban land use sites. Sorbitol and Larabinose are obtained by the reduction of glucose Maltose is produced by the breakdown of starch, a product of carbohydrate fermentation, and metabolites may include lactose, melibiose, sucrose, and trehalose. 
Table 5.8. Carbon sources more commonly used at urban land use sites

$\begin{array}{lc}\text { Carbohydrates } & \text { Amides } \\ \text { L-Arabinose } & \text { Succinamic Acid } \\ \text { D-Fructose } & \text { Glucuronamide } \\ \text { D-Galactose } & \text { Phosphorylated Chemicals } \\ \text { Gentiobiose } & \text { D,L-a-Glycerol Phosphate } \\ \text { a-D-Glucose } & \\ \text { a-Lactose } & \text { Amino Acids } \\ \text { Maltose } & \text { D-Alanine } \\ \text { D-Mannitol } & \text { L-Alanyl-Glycine } \\ \text { D-Mannose } & \text { L-Glutamic Acid } \\ \text { D-Melibiose } & \text { Glycyl-L-Glutamic Acid } \\ \text { D-Psicose } & \text { Hydroxy-L-Proline } \\ \text { D-Raffinose } & \text { L-Leucine } \\ \text { L-Rhamnose } & \text { L-Phenylalanine } \\ \text { D-Sorbitol } & \text { L-Proline } \\ \text { Sucrose } & \text { L-Pyroglutamic Acid } \\ & \\ \text { Carboxylic Acids } & \text { Aromatic Chemicals } \\ \text { Formic Acid } & \text { Thymidine } \\ \text { D-Galactonic Acid Lactone } & \text { Uridine } \\ \text { D-Galacturonic Acid } & \\ \text { D-Gluconic Acid } & \text { Amines } \\ \text { D-Glucoronic Acid } & \text { Phenylethylamine } \\ \text { Y-Hydroxybutyric Acid } & \\ \text { D,L-Lactic Acid } & \text { Esters } \\ \text { Propionic Acid } & \text { Methylpyruvate } \\ \text { Succinic Acid } & \\ & \\ \text { Alcohols } & \\ \text { Glycerol } & \end{array}$

Carboxylic acids are weak organic acids that are metabolized using the Krebs Cycle. The carboxylic acids used are typically the weak acids of carbohydrates that were more commonly used at urban land use sites. The amides used at these sites are the hydrolyzed forms of their carboxylic acids and the ester used is also a product of condensation of an alcohol with a carboxylic acid. Amino acids are used to build proteins, provide energy, and produce aromatic chemicals. Some of the amino acids more easily used at these sites suggest anthropogenic influences on functional potential. Glutamic acids are commonly used as food additives (MSG) and as pesticides, L-proline is used in pharmaceutical and biotechnical applications, and L- 
pyroglutamic acid is used as dietary supplements. The ability of the microbial community to use aromatic chemicals including thymidine and uridine produced from amino acids is evident at urban sites. The increased use of thymidine and leucine has been associated with an increase in heavy metals (Díaz-Raviña and Bååth, 1996). In addition to potential anthropogenic influences from amino acids, amines such as phenylethylamine are also associated with therapeutic drugs (Paetsch and Greenshaw 1993).

Similarly, the lower PC values for the agricultural and forest sites compared to those at urban sites along the second principal component indicate lower responses to particular carbon sources by the microbial communities (Table 5.9). Carbon source use at these sites was different from that at urban sites, as microbial were able to use all 9 of the carbon source categories. Those carbohydrates more frequently used at these sites tend to be more complex sugars. Cellobiose is the product of the microbial metabolism of cellulose, a component of plant cell walls that is introduced as detritus. The ability of the microbial communities to use cellobiose suggests that microbial communities are frequently processing organic matter and detritus at these sites. Sugar alcohols were also frequently used as carbon sources, including $i$-erythritol and xylitol. The phosphorylated chemicals that are used are intermediates of glycolysis and the pentose phosphate pathway. The ability of the microbial communities to use polymers in addition to phosphorylated chemicals may suggest the microbial communities are capable of degrading complex sugars or that these carbon sources are metabolized when additional carbon sources are not available. Carbon sources may be limited at agricultural land use sites depending on seasonality and the removal of vegetation 
resulting in a limited availability of organic matter. Similarly, seasonal effects of detritus may account for the use of these compounds at forest sites. The carboxylic acids and amino acids used at these sites also reflect metabolites of the carbohydrates that are more commonly used. The ability of the microbial communities to use urocanic acid from histadine catabolism is often associated with mammalian skin and sweat and suggests the influence of livestock and wildlife populations at these land use sites. The influence of wildlife is also supported by the use of putrescine at these land use sites, indicating the ability of the microbial communities to use decomposing organisms (Paczowski and Schütz, 2011).

Table 5.9. Carbon sources more commonly used at agriculture and forest land use sites

\begin{tabular}{lc}
\hline Carbohydrates & Amino Acids \\
N-Acetyl-D-Glucosamine & L-Alanine \\
Cellobiose & L-Asparagine \\
-Erythritol & Glycyl-L-Aspartic Acid \\
$\alpha$-D-Glucose & L-Histadine \\
$\beta$-Methylglucoside & --Ornithine \\
D-Trehalose & D-Serine \\
Turanose & L-Serine \\
Xylitol & D,L-Carnitine \\
Carboxylic Acids & --Aminobutyric Acid \\
Acetic Acid & Aromatic Chemicals \\
D-Gluconic Acid & Urocanic Acid \\
D-Glucosaminic Acid & Amines \\
$\alpha-$-Hydroxybuteric Acid & Putrescine \\
$p$-Hydroxyphenylacetic Acid & \\
Itaconic Acid & Esters \\
$\alpha-$-Ketovaleric Acid & Mono-Methylsuccinate \\
Malonic Acid & \\
Quinic Acid & Polymers \\
Sebacic Acid & Glycogen \\
& $\alpha$-Cyclodextrin \\
Amides & Dextrin \\
L-Alaninamide & Tween 80 \\
Phosphorylated Chemicals & Tween 40 \\
Glucose-1-Phosphate & \\
Glucose-6-Phosphate & \\
\hline
\end{tabular}


The difference in carbon source use by microbial communities by land use patterns indicates the ability of these microbial communities to use an array of carbon sources. Although all of the carbon sources were able to be used by the microbial communities, some microbial communities were more successful in the use of particular carbon sources than others. Overall, the more complex carbon sources were used by the microbial communities at agricultural and forest land use sites, suggesting more specialized microbial communities compared to those at urban land use sites that used simpler carbon sources more readily. Although the ability of the microbial communities to use some carbon sources associated with anthropogenic activity, these results should be interpreted with caution as the carbon utilization patterns are a measure of functional potential rather than of in situ activities.

\section{$\underline{\text { Conclusion }}$}

Because fecal pollution in the Sinking Creek watershed has been associated with surface runoff, it is necessary to understand the role of soil in the fate and transport of pathogens from sources to receiving waters. The objective of this group of experiments was to examine the physical and chemical soil properties at the 14 established water sampling sites on Sinking Creek to better understand the interactions between the soil structure and pathogens. Based on the coarse soil texture and presence of organic matter on the soil surface, it can be suggested that soil contributes to the introduction of fecal pollution into Sinking Creek. Understanding these interactions can lead to better design and implementation of BMPs to remediate and prevent fecal contamination in the Sinking Creek. Analysis of soil microbial activities indicates the ability of the 
microbial communities along Sinking Creek to use an array of sole carbon sources. Preferential use of these carbon sources is evident, as the microbial communities at urban land use sites tend to use simpler carbon sources and their metabolites while microbial communities at agricultural and forest land use sites appear to be more specialized in their ability to use complex carbon sources. The functional ability of these microbial communities to use carbon sources may help prevent the introduction of unwanted organic matter and fecal pollution in Sinking Creek. Future research should focus on the comparison and correlation of carbon sources used by microbial communities in stream sediments to those used by microbial communities in soil to further suggest sources of fecal pollution.

\section{Acknowledgements}

This work was funded in part by a grant from the ETSU School of Graduate Studies and Graduate Council and by a contract with the Tennessee Valley Authority (Award \# 00025252). 


\section{$\underline{\text { References }}$}

Abu-Ashour J, Joy DM, Lee H, Whiteley HR, Zelin S. 1998. Movement of bacteria in unsaturated soil columns with macropores. Am. Soc. Ag Eng. 41:1043-1050

Agnelli A. 2004. Distribution of microbial communities in a forest soil profile investigated by microbial biomass, soil respiration and DGGE of total and extracellular DNA. Soil Biol. Biochem. 36:859-868

Aislabie J. Smith JJ, Fraser R, McLeod M. 2001. Leaching of bacterial indicators of faecal contamination through four New Zealand soils. Aust. J. Soil Res. 39:13971406

Anderson TH, Domsch KH. 1990. Application of eco-physiological quotients $\left(q \mathrm{CO}_{2}\right.$ and $\left.q \mathrm{D}\right)$ on microbial biomasses from soils of different cropping histories. Soil. Biol. Biochem. 22:251-255

APHA. 1992. Standard methods for the examination of water and wastewater. $18^{\text {th }}$ edition. American Public Health Association. Washington, D.C.

Atalay A, Bronick C, Pao S, Mersie W. 2007. Nutrient and microbial dynamics in biosolids amended soils following rainfall simulation. Soil and Sediment 16:209-219

Bishop PL, Hively WD, Stedinger JR, Rafferty MR, Ljpersberger JL, Bloomfield JA. 2005. Multivariate analysis of paired watershed data to evaluate agricultural best management practice effects on stream water phosphorus. J. Environ. Qual. $34: 1087-1101$

Bormann H, Breuer L, Graff T, Huisman J. 2007. Analyzing the effects of soil properties changes associated with land use changes on the simulated water balance: A comparison of three hydrological catchment models for scenario analysis. Ecol. Model. 209:29-40

Bossio DA, Scow KM. 1995. Impact of carbon and flooding on the metabolic diversity of microbial communities in soils. Appl. Environ. Microbiol. 61:4043-4050

Chapman HD. 1965. Cation exchange capacity. In: C.A. Black (ed.) Methods of soil analysis - Chemical and microbiological properties. Agronomy 9: 891-901

Chu Y, Jin Y, Baumann T, Yates MV. 2003. Effect of soil properties on saturated and unsaturated virus transport through columns. J. Environ. Qual. 32:2017-2025

Dai X, Boll J. 2003. Evaluation of attachment of Cryptosporidium parvum and Giardia lamblia to soil particles. J. Environ. Qual. 32:296-304 
Díaz-Raviña M, Bååth E. 1996. Thymidine and leucine incorporation into bacteria from soils experimentally contaminated with heavy metals. Appl. Soil. Ecol. 3:225-234

Dillon WR, Goldstein M. 1984. Multivariate analysis: methods and applications. John Wiley and Sons Press, New York, New York

Dulaney D, Scheuerman P, Maier K, Mustain E. 2003. Monitoring of selected bacteriological parameters associated with the Sinking Creek Total Maximum Daily Load (TMDL). Master's Thesis. Department of Environmental Health, East Tennessee State University

Gagliardi JV, Karns JS. 2000. Leaching of Escherichia coli O157:H7 in diverse soils under various agricultural management practices. Appl. Environ. Microbiol. 66:877883

Garland JL, Mills AL. 1991. Classification and characterization of heterotrohic microbial communities on the basis of patterns of community-level sole-carbon-source utilization. Appl. Environ. Microbiol. 57:2351-2359

Ghiorse WC, Balkwill DL. 1983. Enumeration and morphological characterization of bacteria indigenous to subsurface environments. Dev. Ind. Microbiol. 24:213-224

Greenwood KL, McKenzie BM. 2001. Grazing effects on soil physical properties and the consequences for pastures: a review. Aust. J. Exper. Ag. 41:1231-1250

Hair JF, Anderson RE, Tatham RL, Black WC. 1998. Multivariate Data Analysis, $5^{\text {th }}$ edition. Prentice Hall, Englewood Cliffs, New Jersey

Hall KK. 2006a. Analysis of Selected Soil Parameters for Soil Samples Collected Along Sinking Creek. Unpublished raw data, East Tennessee State University

Hall KK, Evanshen BG, Maier KJ, Scheureman PR. 2008. Application of multivariate statistical analyses to microbial water quality parameters in four geographically similar creeks in Northeast Tennessee to identify patterns associating land use to fecal pollution sources. Abstract, $107^{\text {th }}$ Annual Meeting for the American Society for Microbiology, Toronto, Ontario, Canada

Hall KK, Evanshen BG, Maier KJ, Scheureman PR. 2011. Analysis of water quality data using multivariate statistics to patterns associating land use to fecal pollution sources. $111^{\text {th }}$ Annual Meeting for the American Society for Microbiology, New Orleans, LA USA

Hijnen WAM, Brouwer-Hanzens AJ, Charles KJ, Medema GJ. 2005. Transport of MS2 phage, Escherichia coli, Clostridium perfringens, Cryptosporidium parvum, and Giardia intestinalis in a gravel and a sandy soil. Environ. Sci. Technol. 39:78607868 
Hörman, A, Rimhanen-Finne R, Maunula L, von Bonsdorff CH, Torvela N, Heikinheimo A, Hänninen ML. 2004. Campylobacter spp., Giardia spp., Cryptosporidium spp., Noroviruses, and Indicator Organisms in Surface Water in Southwestern Finland, 2000-2001. Appl. Environ. Microbiol. 70:87-95

Hurst CJ, Gerba CP, Cech I. 1980. Effects of environmental variables and soil characteristics on virus survival in soil. Appl. Environ. Microbiol. 40:1067-1079

Huysman F, Verstraete W. 1993. Effect of cell surface characteristics on the adhesion of bacteria to soil particles. Biol. Fertil. Soils. 16:21-26

Jenny H. 1980. The soil resource: Origin and behavior. Springer-Verlag. New York City, New York, USA

Johnson RA, Wichern DW. 1992. Applied multivariate statistical analysis. Prentice Hall, Englewood Cliffs, New Jersey USA

Kemmitt S, Wright D, Goulding K. Jones D. 2006. pH regulation of carbon and nitrogen dynamics in two agricultural soils. Soil Biol. Biochem. 38:898-911

Kemp JS, Paterson E, Gammack SM, Cresser MS, Killham K. 1992. Leaching of genetically modified Pseudomonas fluorescens through organic soils: Influence of temperature, soil, pH and roots. Biol. Fertil. Soils. 13:218-224

Klute A. 1996. Methods of soil analysis - physical methods. Soil Science Society of America and American Society of Agronomy, Madison, Wisconsin, USA

Kurz I, Oreilly C, Tunney H. 2006. Impact of cattle on soil physical properties and nutrient concentrations in overland flow from pasture in Ireland. Ag. Eco. Environ. 113:378-390

Li X, Li F, Zed R, Zhan Z. 2007. Soil physical properties and their relations to organic carbon pools as affected by land use in an alpine pastureland. Geoderma 139:98105

McLeod M, Aislabie J, Smith J, Fraser R, Roberts A, Taylor M. 2001. Viral and chemical tracer movement through contrasting soils. J. Environ. Qual. 30:21342140

Morrison SJ, King FD, Bobbie RJ, Beechtold RE, White DC. 1977. Evidence for microfloral succession on allochthonous plant littler in Apalachicola Bay, Florida, USA. Marine Bio. 41:229-240

Motavalli P. 1995. Soil pH and organic $\mathrm{C}$ dynamics in tropical forest soils: Evidence from laboratory and simulation studies. Soil Biol. Biochem. 27:1589-1599 
NRCS. 1954. Soil Survey of Washington County, Tennessee. Natural Resources Conservation Service, United States Department of Agriculture

NRCS. 1999. Soil Survey Staff. Soil taxonomy: A basic system of soil classification for making and interpreting soil surveys. $2^{\text {nd }}$ edition. Natural Resources Conservations Services, United States Department of Agriculture Handbook

NRCS. 2004. Soil Survey of Carter County, Tennessee. Natural Resources Conservation Service, United States Department of Agriculture

NRCS. 2010a. Soil Survey Staff, Natural Resources Conservation Service, United States Department of Agriculture. Soil Survey Geographic (SSURGO) Database for Northeast Tennessee. Available online at http://soildatamart.nrcs.usda.gov Accessed 7-1-10

NRCS. 2010b. Soil Survey Staff, Natural Resources Conservation Service, United States Department of Agriculture. Web Soil Survey. Available online at http://websoilsurvey.nrcs.usda.gov Accessed 7-1-10

NRCS. 2010c. Soil Survey Staff, Natural Resources Conservation Service, United States Department of Agriculture. Official Soil Series Descriptions. Available online at http://soils.usda.gov/technical/classification/osd/index.html. Accessed on 7-1-10

Paczowski S, Schütz S. 2011. Post-mortem volatiles of vertebrate tissue. Appl. Microbiol. Biotechnol. 91:917-935

Paetsch PR, Greenshaw AJ. 1993. Down-regulation of $\beta$-adrenergic and dopaminergic receptors induced by 2-phenylethylamine. Cell Mol. Neurobiol. 13:203-215

Parfitt RL, Giltrap DJ, Whitton JS. 1995. Contribution of organic matter and clay minerals to the cation exchange capacity of soils. Comm. Soil. Sci. Plant. Anal. $26: 1343-1355$

Peinemann N, Amiotti NM, Zalba P, Villamil MB. 2000. Effect of clay minerals and organic matter on the cation exchange capacity of silt fractions. J. Plant Nut. Soil. Sci. $163: 47-52$

Pirszel J, Pawlik B, Skowrofinski T. 1995. Cation-exchange capacity of algae and cyanobacteria: a parameter of their metal sorption abilities. J. Indust. Microbiol. Biotech. 14:319-322

Sayler GS, Puziss M, Silver M. 1979. Alkaline phosphatase assay for freshwater sediments: application to perturbed sediment systems. Amer. Soc. Microbiol. 38:922-927 
Schjønning P. 1999. Turnover of organic matter in differently textured soils I. Physical characteristics of structurally disturbed and intact soils. Geoderma 89:177-198

Sparks DL. 1996. Methods of soil analysis - chemical methods. Soil Science Society of America and American Society of Agronomy, Madison, Wisconsin, USA

Stevik TK, Ausland G, Hanssen JF, Jenssen PD. 1999. The influence of physical and chemical factors on the transport of $E$. coli through biological filters for wastewater purification. Wat. Res. 33:3701-3706

TDEC. 2000a. Watauga River Watershed (06010103) of the Tennessee River Basin. Water Quality Management plan. Tennessee Department of Environment and Conservation. Division of Water Pollution Control, Nashville TN USA

TDEC. 2000b. Total Maximum Daily Loads for fecal coliforms in Sinking Creek. Tennessee Department of Environment and Conservation, Division of Water Pollution Control, Nashville, TN USA

Vacca A. 2000. Effect of land use on forest floor and soil of a Quercus suber L. forest in Gallura (Sardinia, Italy. Land Deg. Devel. 11:167-180

Van Donsel DJ, Geldreich EE, Clarke NA. 1967. Seasonal variation in survival of indicator bacteria in soil and their contribution to storm-water pollution. Appl. Environ. Microbiol. 15:1362-1370

Whilke BM. 2005. Determination of chemical and physical soil properties. In: Margesin, R., F Schinner (ed.) Manual of soil analysis: monitoring and assessing soil bioremediation. Springer-Verlag, New York City, New York, USA

Winding A. 1993. Fingerprinting bacterial soil communities using Biolog® microtiter plates, p. 85-94. In K. Ritz, J. Dighten, and K.E. Giller (ed.), Beyond the biomass: compositional and functional analysis of soil microbial communities. John Wiley and Sons Ltd., Chichester, United Kingdom

Wong PTW, Griffin DM. 1976. Bacterial movement at high matric potentials - I. In artificial and natural soils. Soil Boil. Biochem. 8:215-218

Yeager JG, O'Brian RT. 1979. Enterovirus inactivation in soil. Appl. Environ. Microbiol. 38:694-701

Yao H, He Z, Wilson MJ, Campbell DD. 2000. Microbial biomass and community structure in a sequence of soils with increasing fertility and changing land use. Micro. Ecol. 40:223-237

Zak JC, Willig MR, Moorhead DL, Wildman HG. 1994. Functional diversity of microbial communities: a quantitative approach. Soil Biol. Biochem. 26:1101-1108 
Zhang YL, Dai JL, Wang RQ, Zhang J. 2008. Effects of long-term sewage irrigation on agricultural soil microbial structural and functional characterizations in Shandong, China. Eur. J. Soil Biol. 44:84-91 


\title{
CHAPTER 6
}

\section{DEVELOPMENT OF MULTIPLE REGRESSION MODELS TO PREDICT SOURCES OF FECAL POLLUTION IN THE WATAUGA RIVER WATERSHED}

\author{
K.K. Hall and P.R. Scheuerman
}

\begin{abstract}
$\underline{\text { Abstract }}$
The increased listings of surface waters on 303d lists and the need to address these through the Total Maximum Daily Load (TMDL) process has resulted in increased research to identify methods that effectively and universally identify the types and sources of fecal pollution to avoid adverse human health outcomes associated with fecal contamination of surface waters. In addition to correctly identifying the nature of pollutants and their sources, these methods should also be efficient and cost effective to ensure the maximum use of available resources to improve surface water quality. The current method of TMDL development is based on a watershed approach to identify stressors and monitor remediation efforts. This decision-making tool uses a strategic approach to quantify point and nonpoint sources of pollution and focuses on improved management decisions to implement the most effective best management practices (BMPs) to improve water quality and remove impaired waters from $303 \mathrm{~d}$ lists. The objective of this experiment was to assess the usefulness of the watershed scale approach to TMDL development by developing and applying multiple regression models based on the Sinking Creek data collected in this study and determine if the developed model correctly classified land use patterns using 7 additional creeks within the Watauga River watershed. Correct land use classification using a multiple regression model for an entire watershed can help in the selection and implementation of effective
\end{abstract}


BMPs based on water quality within the Watauga River watershed to remove waters from the 303d list.

\section{$\underline{\text { Introduction }}$}

The watershed approach to TMDL development as described by the United States Environmental Protection Agency (USEPA) takes a comprehensive approach to water resource management by focusing on the identification of stressors using monitoring data and ongoing water quality assessments to assess remediation efforts at the watershed level (USEPA, 1995). Watershed assessments involve (1) targeting priority problems, (2) using the efforts of stakeholders, (3) developing integrative solutions, and (4) measuring the success of the program (USEPA 1995). The ultimate goal of this decision-making tool is to effectively identify and quantify point and nonpoint sources of pollution to develop effective TMDLs that will improve water quality resulting in delisting of the water body from the $303 \mathrm{~d}$ list, resulting in the protection of public and environmental health. This approach relies heavily on the application of strategic programs involving state water quality, health agencies, and stakeholders to identify, prioritize, and remediate water quality issues. The foundation of the watershed approach involves programs and activities to control point sources, restore habitats, monitor water quality, develop TMDLs, and enforce regulations to ultimately protect human and environmental health (Figure 6.1). The Tennessee Department of Environment and Conservation (TDEC) is currently involved in the identification of priority problems through water quality assessments and subsequent development of TMDLs for impaired watersheds. The development of TMDLs at the watershed level, as 
opposed to individual water bodies, has been recommended by the USEPA in an effort to assess water quality management decisions more efficiently and allow for the focused application of financial resources on priority areas.

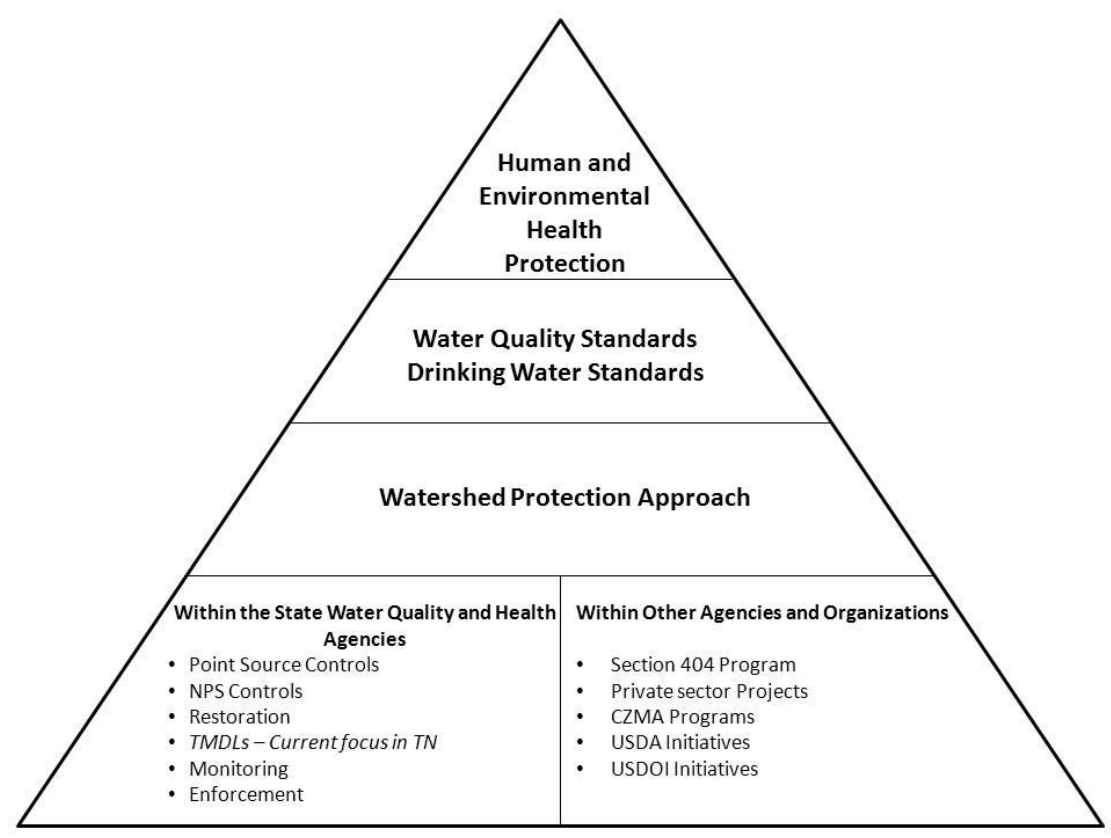

Figure 6.1. Framework for achieving the goals of the Clean Water Act (reproduced from USEPA 841-R-95-004, 1995)

The debate over what methods are able to effectively and efficiently address the quantity and sources of impairment in a watershed as it pertains to TMDL development has been ongoing. Several methods including ribotyping, pulsed-field gel electrophoresis, and antibiotic resistance analysis have been applied to correctly identify nonpoint sources of fecal pollution in surface waters. Ribotyping and pulsedfield gel electrophoresis allow for the discrimination between human and nonhuman sources of fecal pollution but rely on large geographically specific genetic databases to correctly classify sources (Tynkkynen et al. 1999; Carson et al. 2001). Similar to 
ribotyping and pulsed-field gel electrophoresis, antibiotic resistance analysis also allows for the classification of fecal pollution sources based on antibiotic resistance of bacteria from human and animal sources. A major disadvantage of antibiotic resistance analysis is that it requires a large database that may be geographically specific (Wiggins et al. 1999). Although these methods may be regionally successful at identifying sources of fecal pollution, they cannot be universally applied to effectively identify and remediate fecal pollution to protect surface waters and public health.

The successful approach for the accurate identification of pollution sources to develop TMDLs that effectively reduce pollution is reliant on understanding the water quality variables and watershed characteristics that are most influencing water quality. Current pathogen TMDL development is based on the limited 30-day geometric mean that does not take into consideration seasonal effects, variability in land use patterns, or the influence of runoff events on water quality. TMDLs developed on a based on the 30-day geometric mean do not provide sufficient data to identify the presence of pathogens or sources of fecal pollution because they are based on a small sample size that may overlook sources of variability within the watershed.

The shortcomings of conventional methods of source identification suggest that alternative methods of water quality monitoring program design and data analysis are needed to better protect surface water resources. This research has suggested the use of canonical correlation and canonical discriminant analyses based on land use patterns to understand the influences of spatial and temporal variability on fecal pollution in Sinking Creek located in the Watauga River watershed. This approach for identifying the water quality variables that are most associated with fecal pollution may be more 
successful at predicting water quality than more common data analysis methods, including multiple regression analysis.

An extension of simple linear regression, multiple regression analysis is a multivariate statistical tool that allows for the determination of a single dependent response variable based on several explanatory variables as described by:

$$
y=a+b_{1} x_{1}+b_{2} x_{2}+\ldots+b_{p} x_{p} \quad \text { (Eq. 6.1) }
$$

where $y$ is the predictor value, $a, b_{1}, b_{2} \ldots b_{p}$ are constants and $x_{1}, x_{2} \ldots x_{p}$ are the variables from which the prediction is made. The model is developed based on the variables that significantly contribute to the correct identification of the land use patterns (agriculture, urban, and forest). A successful model should be able to correctly classify the predictor variable based on the input of water quality data. Multiple regression models are commonly applied to water quality data to identify those water quality variables that are associated with fecal pollution (Ellis and Rodrigues, 1995; Mehaffey et al. 2005; Schoonover and Lockaby, 2005; Ham et al. 2009; Desai et al. 2010).

The successful development and application of a single multiple regression model from one water body to predict land use patterns, and the types and sources of pollution associated with those land use patterns, to others within a watershed can help meet the goals of the watershed approach to water resource management (Mehaffey et al. 2005). The simplicity of applying one model that correctly predicts land use patterns across an entire watershed can help reduce of the number of resources necessary to identify sources of impairment within individual bodies of water. This can further lead to the development and implementation of watershed TMDLs that have successfully 
quantified point source and nonpoint source pollutants and identified their sources using time and cost effective methods. TMDLs that accurately reflect the extent and sources of pollution, and the variables contributing to water quality within the watershed are more likely to be successful at reducing pollution through the identification of priority areas and the implementation of successful BMPs to remove waters from 303d lists.

The objective of this experiment was to determine if a multiple regression model developed from one creek within the watershed was successful in predicting land use patterns and fecal pollution sources in additional creeks in the Watauga River watershed. Three multiple regression models were developed using the chemical and microbial water quality data collected during this study to assess the usefulness of multiple regression analysis compared to canonical discriminant analysis to classify land uses. The first regression model included all of the monitored chemical and microbial water quality parameters. The second model included only those chemical and microbial water quality parameters that were significant based on stepwise regression $(p<0.05)$, and the third model used those chemical and microbial water quality parameters identified by canonical discriminant analysis as most influencing water quality by land use. These multiple regression models were then applied to water quality data previously collected from 8 creeks within the Watauga River watershed (including Sinking Creek) to assess their ability to correctly classify land use classifications. 


\section{Materials and Methods}

Sample Collection

The Watauga River watershed (HUC 06010103) is located in Carter, Johnson, Sullivan, Unicoi, and Washington Counties in Eastern Tennessee. Since 2003, creeks within the watershed were monitored to assess overall physical, chemical, and microbial water quality and to identify sources of impairment (Table 6.1). Sampling sites for each creek were selected using a targeted sampling approach and land use patterns were identified at each site (Tables 6.2 - 6.9). Ten sites on Boones Creek were monitored monthly from April 2005 to March 2006 and quarterly until December 2008. Twelve sites on Buffalo Creek were monitored monthly from June 2004 to June 2005 and quarterly until December 2008. Four sites on Carroll Creek and five sites on Reedy Creek were monitored monthly from June 2006 to May 2007 and quarterly until February 2008. Nine sites on Cash Hollow were monitored monthly from June 2003 to May 2004 and quarterly until October 2008. Eight sites on Knob Creeks were monitored monthly from June 2007 to April 2008. Fourteen sites on Sinking Creek were monitored monthly from June 2003 to May 2004 and quarterly until August 2011. 
Table 6.1. Creeks monitored in this study within the Watauga River watershed

\begin{tabular}{|c|c|c|c|}
\hline Creek & Waterbody ID & Location & Land Use \\
\hline Boones Creek & TN 06010103006-1000 & Washington & $\begin{array}{r}\text { Combination of agricultural } \\
\text { and urban }\end{array}$ \\
\hline Buffalo Creek & TN 06010103011-1000 & Carter & $\begin{array}{r}\text { Combination of agricultural } \\
\text { and urban }\end{array}$ \\
\hline Carroll Creek & TN 06010103006-0100 & Washington & $\begin{array}{r}\text { Combination of agricultural } \\
\text { and urban }\end{array}$ \\
\hline Cash Hollow Creek & TN 06010103635-0100 & Washington & $\begin{array}{r}\text { Transition from urban to } \\
\text { agricultural }\end{array}$ \\
\hline Knob Creek & TN 06010103635-1000 & Washington & $\begin{array}{r}\text { Transition from agricultural to } \\
\text { urban land use }\end{array}$ \\
\hline Reedy Creek & TN 06010103061-1000 & Washington & $\begin{array}{r}\text { Transition from agricultural to } \\
\text { urban }\end{array}$ \\
\hline Sinking Creek & TN 06010103046-1000 & Washington/Carter & $\begin{array}{r}\text { Transition from forest to urban } \\
\text { to agricultural }\end{array}$ \\
\hline
\end{tabular}




\section{Table 6.2. Sampling locations on Boones Creek}

\begin{tabular}{|c|c|c|c|}
\hline Site Number & Site Description and Location & Land Use & Creek Characteristics \\
\hline 1 & $\begin{array}{l}\text { Upstream of bridge on Tavern Hill Road } \\
\text { N } 36^{\circ} 18.947^{\prime} \text {, W } 82^{\circ} 28.940^{\prime}\end{array}$ & Agricultural & Fine sediment \\
\hline 2 & $\begin{array}{l}\text { Downstream of first bridge on Hales Road } \\
\text { N } 36^{\circ} 19.216^{\prime}, \text { W } 82^{\circ} 28.702^{\prime}\end{array}$ & Agriculture & Fine sediment \\
\hline 3 & $\begin{array}{l}\text { Downstream of bridge at tributary on Hales Road } \\
\text { N } 36^{\circ} 19.209^{\prime}, \text { W } 82^{\circ} 28.221^{\prime}\end{array}$ & Agriculture & Fine sediment \\
\hline 4 & $\begin{array}{l}\text { Downstream of bridge on Bugaboo Springs Road } \\
\text { N } 36^{\circ} 19.956^{\prime} \text {, W } 82^{\circ} 28.065^{\prime}\end{array}$ & Agricultural & $\begin{array}{r}\text { Fine sediment with } \\
\text { cobbles }\end{array}$ \\
\hline 5 & $\begin{array}{l}\text { Upstream of bridge on Ridges Club Drive } \\
\text { N } 36^{\circ} 20.463^{\prime} \text {, W } 82^{\circ} 27.425^{\prime}\end{array}$ & Urban & $\begin{array}{r}\text { Fine sediment with } \\
\text { cobble }\end{array}$ \\
\hline 6 & $\begin{array}{l}\text { Downstream of bridge on Highland Church Road } \\
\qquad N 36^{\circ} 21.166^{\prime}, \text { W } 82^{\circ} 26.766^{\prime}\end{array}$ & Agricultural & Fine sediment \\
\hline 7 & $\begin{array}{l}\text { Downstream of I26 overpass on Memory Gardens Road } \\
\qquad N 36^{\circ} 22.774^{\prime} \text {, W } 82^{\circ} 25.491^{\prime}\end{array}$ & Urban & $\begin{array}{l}\text { Fine sediment with gravel } \\
\text { and cobble }\end{array}$ \\
\hline 8 & $\begin{array}{l}\text { Downstream of bridge off Quality Circle } \\
\text { N } 36^{\circ} 22.912^{\prime}, \text { W } 82^{\circ} 24.930^{\prime}\end{array}$ & Urban & $\begin{array}{r}\text { Gravel, cobble and } \\
\text { boulders }\end{array}$ \\
\hline 9 & $\begin{array}{l}\text { Downstream of bridge on Flourville Road } \\
\text { N } 36^{\circ} 23.511^{\prime}, \text { W } 82^{\circ} 24.086^{\prime}\end{array}$ & Agricultural & $\begin{array}{l}\text { Fine sediment with } \\
\text { cobble and boulders }\end{array}$ \\
\hline 10 & $\begin{array}{l}\text { Mouth of Boones Creek at Boone Lake } \\
\text { N } 36^{\circ} 23.460^{\prime}, \text { W } 82^{\circ} 23.752^{\prime}\end{array}$ & Urban & $\begin{array}{r}\text { Gravel, cobble and } \\
\text { boulders }\end{array}$ \\
\hline
\end{tabular}




\section{Table 6.3. Sampling locations on Buffalo Creek}

\begin{tabular}{|c|c|c|c|}
\hline $\begin{array}{l}\text { Site } \\
\text { Number }\end{array}$ & Site Description and Location & Land Use & Creek Characteristics \\
\hline 1 & $\begin{array}{l}\text { US23 at Howard Gouge Road } \\
\text { N } 36^{\circ} 12.596^{\prime} \text {, W } 82^{\circ} 20.815^{\prime}\end{array}$ & Urban & Gravel \\
\hline 2 & $\begin{array}{l}\text { Downstream of pump station on US23 } \\
\quad \text { N } 36^{\circ} 12.864^{\prime}, \text { W } 82^{\circ} 20.630^{\prime}\end{array}$ & Urban & Fine sediment with cobble \\
\hline 3 & $\begin{array}{l}\text { Downstream of output pipe on Sugar Hollow } \\
\text { Road } \\
\text { N } 36^{\circ} 13.283^{\prime} \text {, W } 82^{\circ} 20.384^{\prime}\end{array}$ & Urban & Cobble and boulders \\
\hline 4 & $\begin{array}{c}\text { Upstream of bridge on Golf Course Drive at } \\
\text { Buffalo Mountain Resort } \\
\text { N } 36^{\circ} 13.287^{\prime}, \text { W } 82^{\circ} 19.916^{\prime}\end{array}$ & Urban & Cobble \\
\hline 5 & $\begin{array}{c}\text { Downstream from golf course outflow at } \\
\text { Country Club Drive } \\
\text { N } 36^{\circ} 14.114, \text { W } 82^{\circ} 19.690\end{array}$ & Urban & Cobble \\
\hline 6 & $\begin{array}{l}\text { Upstream of bridge on Marbleton Road } \\
\quad \text { N } 36^{\circ} 15.085^{\prime} \text {, W } 82^{\circ} 19.257^{\prime}\end{array}$ & Agricultural & Cobble \\
\hline 7 & $\begin{array}{l}\text { Wiseman Feed and Seed next to Fagan Road } \\
\qquad N 36^{\circ} 15.461^{\prime}, \text { W } 82^{\circ} 19.254^{\prime}\end{array}$ & Agricultural & Cobble \\
\hline 8 & $\begin{array}{l}\text { Downstream of Dave Renfro Bridge } \\
\text { N } 36^{\circ} 15.922^{\prime} \text {, W } 82^{\circ} 18.977^{\prime}\end{array}$ & Agricultural & $\begin{array}{r}\begin{array}{r}\text { Fine sediment with cobble and } \\
\text { boulders }\end{array}\end{array}$ \\
\hline 9 & $\begin{array}{l}\text { Upstream of bridge at Okalona Road and } \\
\text { Bishop Road intersection } \\
\text { N } 36^{\circ} 17.111^{\prime}, \text { W } 82^{\circ} 18.505^{\prime}\end{array}$ & Urban & Gravel and cobbles \\
\hline 10 & $\begin{array}{l}\text { Walking bridge at Milligan College } \\
\text { N } 36^{\circ} 18.042^{\prime}, \text { W } 82^{\circ} 17.835^{\prime}\end{array}$ & Urban & Gravel and cobbles \\
\hline 11 & $\begin{array}{l}\text { Downstream of bridge on Reeser Road } \\
\text { N } 36^{\circ} 18.443^{\prime} \text {, W } 82^{\circ} 17.503^{\prime}\end{array}$ & Urban & Gravel and cobbles \\
\hline 12 & $\begin{array}{l}\text { Elizabethton Little League Park } \\
\text { N } 36^{\circ} 19.548^{\prime}, \text { W } 82^{\circ} 16.335^{\prime}\end{array}$ & Urban & Gravel and cobbles \\
\hline
\end{tabular}




\section{Table 6.4. Sampling locations on Carroll Creek}

\begin{tabular}{|c|c|c|c|}
\hline Site Number & Site Description and Location & Land Use & Creek Characteristics \\
\hline 1 & $\begin{array}{c}\text { Upstream of bridge on Carroll Creek } \\
\text { Road at Tara Court } \\
\text { N } 36^{\circ} 21.627^{\prime} \text {, W } 82^{\circ} 24.929^{\prime}\end{array}$ & Agricultural & Gravel and cobble \\
\hline 2 & $\begin{array}{c}\text { Upstream of overpass on Carroll Creek } \\
\text { Road behind Food City } \\
\text { N } 36^{\circ} 22.638^{\prime}, \text { W } 82^{\circ} 24.548^{\prime}\end{array}$ & Agricultural & Gravel and cobble \\
\hline 3 & $\begin{array}{c}\text { Upstream from tree at Carroll Creek } \\
\text { Road at Ranch Road } \\
\text { N } 36^{\circ} 22.940^{\prime}, \text { W } 82^{\circ} 24.068^{\prime}\end{array}$ & Agricultural & Gravel and cobble with boulders \\
\hline 4 & $\begin{array}{l}\text { Cedar Point Road at Cedar Point Place } \\
\text { N } 36^{\circ} 23.184^{\prime}, \text { W } 82^{\circ} 23.585^{\prime}\end{array}$ & Urban & Gravel and cobble with boulders \\
\hline
\end{tabular}


Table 6.5. Sampling locations on Cash Hollow Creek

\begin{tabular}{|c|c|c|c|}
\hline Site Number & Site Description and Location & Land Use & Creek Characteristics \\
\hline 1 & $\begin{array}{l}\text { Upstream of crossing under Woodland Avenue } \\
\qquad N 36^{\circ} 20.881^{\prime} \text {, W } 82^{\circ} 20.795^{\prime}\end{array}$ & Urban & Fine sediment with cobble \\
\hline 2 & $\begin{array}{l}\text { Upstream of crossing under Crystal Springs } \\
\text { Road } \\
\text { N } 36^{\circ} 20.877^{\prime} \text {, W } 82^{\circ} 20.804^{\prime}\end{array}$ & Urban & Fine sediment with cobble \\
\hline 3 & $\begin{array}{l}\text { Downstream of crossing under Crystal Springs } \\
\text { Road } \\
\text { N } 36^{\circ} 20.883^{\prime} \text {, W } 82^{\circ} 20.806^{\prime}\end{array}$ & Urban & Fine sediment with cobble \\
\hline 4 & $\begin{array}{l}\text { Upstream of crossing under Lakeview Avenue } \\
\text { N } 36^{\circ} 21.135^{\prime} \text {, W } 82^{\circ} 20.686^{\prime}\end{array}$ & Urban & Fine sediment \\
\hline 5 & $\begin{array}{c}\text { Upstream of inflow from Convenience Center } \\
\text { for Household Waste } \\
\text { N } 36^{\circ} 21.712^{\prime} \text {, W } 82^{\circ} 20.280^{\prime}\end{array}$ & Urban & Cobble \\
\hline 6 & $\begin{array}{l}\text { Downstream of inflow from Convenience } \\
\text { Center for Household Waste } \\
\text { N } 36^{\circ} 21.715^{\prime}, \text { W } 82^{\circ} 20.280^{\prime}\end{array}$ & Urban & Cobble \\
\hline 7 & $\begin{array}{c}\text { Upstream of Morning Star Church on Cash } \\
\text { Hollow Road } \\
\text { N } 36^{\circ} 22.022^{\prime} \text {, W } 82^{\circ} 20.527\end{array}$ & Urban & Cobble \\
\hline 8 & $\begin{array}{l}\text { Downstream of small bridge on Cash Hollow } \\
\text { Road } \\
\text { N } 36^{\circ} 22.683^{\prime} \text {, W } 82^{\circ} 21.043^{\prime}\end{array}$ & Agricultural & Fine sediment with cobble \\
\hline 9 & $\begin{array}{c}\text { Upstream of boundary fence on Cash Hollow } \\
\text { Road and Austin Springs Road } \\
\text { N } 36^{\circ} 22.829^{\prime} \text {, W } 82^{\circ} 21.286^{\prime}\end{array}$ & Agricultural & Fine sediment with gravel \\
\hline
\end{tabular}


Table 6.6. Sampling locations for Cobb Creek

\begin{tabular}{|c|c|c|c|}
\hline Site Number & Site Description and Location & Land Use & Creek Characteristics \\
\hline 1 & $\begin{array}{l}\text { Downstream of bridge near Mountcastle Shopping } \\
\text { Center } \\
\qquad N 36^{\circ} 20.328 \text {, W } 82^{\circ} 22.106^{\prime}\end{array}$ & Urban & Cobbles and boulders \\
\hline 2 & $\begin{array}{l}\text { Upstream of overpass on Silverdale Drive } \\
\text { N } 36^{\circ} 21.072^{\prime}, \text { W } 82^{\circ} 22.421^{\prime}\end{array}$ & Urban & $\begin{array}{r}\text { Fine sediment with } \\
\text { cobbles }\end{array}$ \\
\hline 3 & $\begin{array}{c}\text { Downstream of trees on West Brook Lane and } \\
\text { Oakland Avenue } \\
\text { N } 36^{\circ} 21.214^{\prime}, \text { W } 82^{\circ} 21.503\end{array}$ & Urban & Fine sedimen \\
\hline 4 & $\begin{array}{c}\text { Upstream of bridge on Austin Springs Road at } \\
\text { Mary's Salads } \\
\text { N } 36^{\circ} 22.081^{\prime}, \text { W } 82^{\circ} 21.275^{\prime}\end{array}$ & Urban & Fine sediment \\
\hline 5 & $\begin{array}{c}\text { Downstream of Brush Creek Wastewater } \\
\text { Treatment Plant } \\
\text { N } 36^{\circ} 22.376^{\prime}, \text { W } 82^{\circ} 21.296^{\prime}\end{array}$ & Urban & $\begin{array}{r}\text { Fine sediment and } \\
\text { cobbles }\end{array}$ \\
\hline
\end{tabular}




\section{Table 6.7. Sampling locations on Knob Creek}

\begin{tabular}{|c|c|c|c|}
\hline Site Number & Site Description and Location & Land Use & Creek Characteristics \\
\hline 1 & $\begin{array}{l}\text { Downstream of bridge on John France Road } \\
\text { N } 36^{\circ} 19.12 .7^{\prime}, \text { W } 82^{\circ} 28.13 .2^{\prime}\end{array}$ & Agricultural & Fine sediment \\
\hline 2 & $\begin{array}{c}\text { Downstream of bridge at intersection of } \\
\text { Claude Simmons Road and Moss Circle } \\
\text { N } 36^{\circ} 19^{\prime} .447^{\prime}, \text { W } 82^{\circ} 25.392^{\prime}\end{array}$ & Agricultural & Fine sediment \\
\hline 3 & $\begin{array}{c}\text { Downstream of bridge at gauging station } \\
\text { next to Headtown Road } \\
\text { N } 36^{\circ} 19.127^{\prime}, \text { W } 82^{\circ} 28.132^{\prime}\end{array}$ & Agricultural & Fine sediment with cobble \\
\hline 4 & $\begin{array}{l}\text { Downstream from stream intersection at } \\
\text { Knob Creek Road and Fairridge Road } \\
\text { N } 36^{\circ} 20.275^{\prime} \text {, W } 82^{\circ} 24.387^{\prime}\end{array}$ & Agricultural & Cobble \\
\hline 5 & $\begin{array}{l}\text { Downstream from gauging station next to } \\
\text { tributary on Knob Creek Road } \\
\text { N } 36^{\circ} 20.283^{\prime} \text {, W } 82^{\circ} 24.330^{\prime}\end{array}$ & Urban & $\begin{array}{r}\text { Fine sediment with cobble } \\
\text { and boulders }\end{array}$ \\
\hline 6 & $\begin{array}{l}\text { Parking area at Café Pacifica on Oakland } \\
\text { Avenue } \\
\text { N } 36^{\circ} 20.556^{\prime} \text {, W } 82^{\circ} 24.162^{\prime}\end{array}$ & Urban & Cobble and boulders \\
\hline 7 & $\begin{array}{c}\text { Northeast intersection of Oakland Avenue } \\
\text { and N. Roan Street } \\
\text { N } 36^{\circ} 21.379^{\prime}, \text { W } 82^{\circ} 23.148^{\prime}\end{array}$ & Urban & Fine sediment with cobble \\
\hline 8 & $\begin{array}{c}\text { Big Valley Road } \\
\text { N 36 } 2.211^{\prime}, \text { W } 82^{\circ} 22.304^{\prime}\end{array}$ & Urban & Cobble and boulders \\
\hline
\end{tabular}




\section{Table 6.8. Sampling locations on Reedy Creek}

\begin{tabular}{|c|c|c|c|}
\hline Site Number & Site Description and Location & Land Use & Creek Characteristics \\
\hline 1 & $\begin{array}{l}\text { Stream crossing at Old Stage Road } \\
\quad \text { N } 36^{\circ} 22.410^{\prime}, W 82^{\circ} 27.030^{\prime}\end{array}$ & Agricultural & Fine sediment \\
\hline 2 & $\begin{array}{l}\text { Boone Road off Old Stage Road } \\
\text { N } 36^{\circ} 23.043^{\prime} \text {, W } 82^{\circ} 26.319^{\prime}\end{array}$ & Agricultural & Cobble \\
\hline 3 & $\begin{array}{c}\text { Old Gray Station Road at The Ruritan } \\
\text { Turkey Shoot Club } \\
\text { N } 36^{\circ} 23.753 \text {, W } 82^{\circ} 26.449\end{array}$ & Agricultural & Cobble \\
\hline 4 & $\begin{array}{l}\text { Downstream of bridge on White Street } \\
\text { N } 36^{\circ} 24.328^{\prime}, \text { W } 82^{\circ} 24.605^{\prime}\end{array}$ & Agricultural & Cobble \\
\hline 5 & $\begin{array}{l}\text { Cove entrance to Boone Lake on Crouch } \\
\text { Road } \\
\text { N } 36^{\circ} 23.297, \text { W } 82^{\circ} 24.345\end{array}$ & Urban & Cobble and boulders \\
\hline
\end{tabular}


Table 6.9. Sampling locations on Sinking Creek

\begin{tabular}{|c|c|c|c|}
\hline Site Number & Site Description and Location & Land Use & $\begin{array}{r}\text { Creek } \\
\text { Characteristics }\end{array}$ \\
\hline 1 & $\begin{array}{l}\text { Downstream of Sinking Creek pump station on } \\
\text { Sinking Creek Road } \\
\text { N } 36^{\circ} 20.118^{\prime}, \text { W } 82^{\circ} 18.035^{\prime}\end{array}$ & Agricultural & $\begin{array}{r}\text { Cobble and } \\
\text { boulders }\end{array}$ \\
\hline 2 & $\begin{array}{l}\text { Upstream of Bob Peoples bridge on Sinking Creek } \\
\text { Road } \\
\qquad N 36^{\circ} 9.837^{\prime}, \text { W } 82^{\circ} 18.254^{\prime}\end{array}$ & Agricultural & $\begin{array}{r}\text { Gravel and } \\
\text { cobble }\end{array}$ \\
\hline 3 & $\begin{array}{l}\text { Upstream of Sinking Creek Church and North Road } \\
\text { N } 36^{\circ} 9.662^{\prime}, \text { W } 82^{\circ} 18.447^{\prime}\end{array}$ & Agricultural & $\begin{array}{r}\text { Gravel and } \\
\text { cobble }\end{array}$ \\
\hline 4 & $\begin{array}{l}\text { Upstream of crossing on Joe Carr Road } \\
\text { N } 36^{\circ} 9.594^{\prime}, \text { W } 82^{\circ} 18.579^{\prime}\end{array}$ & Agricultural & $\begin{array}{r}\text { Fine sediment } \\
\text { with cobble and } \\
\text { boulders }\end{array}$ \\
\hline 5 & $\begin{array}{l}\text { Upstream of bridge on Dave Buck Road } \\
\text { N } 36^{\circ} 9.113^{\prime}, \text { W } 82^{\circ} 19.290^{\prime}\end{array}$ & Agricultural & \\
\hline 6 & $\begin{array}{l}\text { Downstream of bridge on Daytona Drive, old Sinking } \\
\text { Creek pump station } \\
\text { N } 36^{\circ} 8.788^{\prime}, \text { W } 82^{\circ} 19.625^{\prime}\end{array}$ & Urban & $\begin{array}{r}\text { Cobble and } \\
\text { boulders }\end{array}$ \\
\hline 7 & $\begin{array}{c}\text { Upstream of bridge on Miami Drive, King Springs } \\
\text { Baptist Church } \\
\text { N } 36^{\circ} 8.772^{\prime} \text {, W } 82^{\circ} 19.685^{\prime}\end{array}$ & Urban & Cobble \\
\hline 8 & $\begin{array}{l}\text { Upstream of Bosch NPDES discharge point } \\
\text { N } 36^{\circ} 8.472^{\prime}, \text { W } 82^{\circ} 19.948^{\prime}\end{array}$ & Urban & Cobble \\
\hline 9 & $\begin{array}{l}\text { Upstream of Twin Oaks golf Course storage area on } \\
\text { Lafe Cox Drive } \\
\qquad N 36^{\circ} 7.887^{\prime}, \text { W } 82^{\circ} 20.741^{\prime}\end{array}$ & Urban & Cobble \\
\hline 10 & $\begin{array}{c}\text { Upstream of bridge crossing Sinking Creek at } \\
\text { Hickory Springs Road } \\
\text { N } 36^{\circ} 17.431^{\prime} \text {, W } 82^{\circ} 21.397^{\prime}\end{array}$ & Urban & $\begin{array}{l}\text { Gravel with } \\
\text { cobble and } \\
\text { boulders }\end{array}$ \\
\hline 11 & $\begin{array}{l}\text { Upstream of crossing at Miller Lane } \\
\quad \text { N } 36^{\circ} 17.105^{\prime}, \text { W } 82^{\circ} 21.800^{\prime}\end{array}$ & Urban & $\begin{array}{r}\text { Cobble and } \\
\text { boulders }\end{array}$ \\
\hline 12 & $\begin{array}{l}\text { Upstream of tributary on David Miller Road } \\
\text { N } 36^{\circ} 16.967^{\prime}, \text { W } 82^{\circ} 21.970^{\prime}\end{array}$ & Urban & Cobble \\
\hline 13 & $\begin{array}{l}\text { Upstream of road crossing on Jim McNeese Road } \\
\qquad N 36^{\circ} 16.035^{\prime}, \text { W } 82^{\circ} 22.163^{\prime}\end{array}$ & Forest & $\begin{array}{r}\text { Cobble and } \\
\text { boulders }\end{array}$ \\
\hline 14 & $\begin{array}{l}\text { Downstream of path crossing at Dry Springs Road } \\
\qquad N 36^{\circ} 14.800^{\prime}, \text { W } 82^{\circ} 22.033^{\prime}\end{array}$ & Forest & $\begin{array}{r}\text { Gravel with } \\
\text { cobble and } \\
\text { boulders }\end{array}$ \\
\hline
\end{tabular}




\section{Sample Collection}

Water samples for total and fecal coliform bacteria (TC/FC), standard plate counts (SPC), analyses were collected and analyzed in triplicate (SPC samples analyzed in duplicate) in sterile, 1-L Nalgene ${ }^{\mathrm{TM}}$ bottles. Water samples for Colilert ${ }^{\circledR}$ analyses were collected in sterile $100 \mathrm{ml}$ plastic bottles (IDEXX Laboratories, Westbrook, Maine). Water samples for nitrates $\left(\mathrm{NO}_{3}{ }^{-}\right)$, phosphates $\left(\mathrm{PO}_{4}{ }^{-}\right)$, ammonia $\left(\mathrm{NH}_{3}{ }^{+}\right)$, 5-day biochemical oxygen demand $\left(\mathrm{BOD}_{5}\right)$, alkalinity, and hardness were collected and analyzed in triplicate in sterile 2-L Nalgene ${ }^{\mathrm{TM}}$ bottles. Sediment samples for TC/FC in water, microbial enzyme activity (MEA), and acridine orange direct counts (AODC) were collected in $20 z$ sterile Whirl-Pak ${ }^{\mathrm{TM}}$ bags. All samples were transported to the laboratory on ice and analyzed within the holding times described in Table 6.10. Field measurements for $\mathrm{pH}$, air and water temperature, dissolved oxygen, and conductivity were also collected at each site. 
Table 6.10. Physical, chemical, and microbial water quality parameters measured

\begin{tabular}{|c|c|c|c|}
\hline Parameter & Abbreviation & Units & Holding Time \\
\hline $\mathrm{pH}$ & $\mathrm{pH}$ & $\mathrm{pH}$ & Field measurement \\
\hline Water temperature & WT & ${ }^{\circ} \mathrm{C}$ & Field measurement \\
\hline Air temperature & AT & ${ }^{\circ} \mathrm{C}$ & Field measurement \\
\hline Dissolved oxygen & DO & $\mathrm{mg} / \mathrm{l}$ as $\mathrm{O}_{2}$ & Field measurement \\
\hline Conductivity & Cond & $\mu \mathrm{mohs}$ & Field measurement \\
\hline Fecal coliform in water & FCW & CFU/100ml & $6 h$ \\
\hline Total coliform in water & TCW & $\mathrm{CFU} / 100 \mathrm{ml}$ & $6 h$ \\
\hline Fecal coliform in sediment & FCS & CFU/100ml & $6 h$ \\
\hline Total coliform in sediment & TCS & $\mathrm{CFU} / 100 \mathrm{ml}$ & $6 h$ \\
\hline Colilert & Colilert & $\mathrm{CFU} / 100 \mathrm{ml}$ & $6 h$ \\
\hline Standard plate count & SPC & $\mathrm{CFU} / \mathrm{ml}$ & $6 h$ \\
\hline Acridine orange direct counts & AODC & cells/g sediment & $6 \mathrm{~h}$ \\
\hline Acid phosphatase & AcidP & $\mu \mathrm{g} / \mathrm{g}$ sediment & $24 h$ \\
\hline Alkaline phosphatase & AlkP & $\mu \mathrm{g} / \mathrm{g}$ sediment & $24 h$ \\
\hline Dehydrogenase & $\mathrm{DHA}$ & $\mu \mathrm{g} / \mathrm{g}$ sediment & $24 h$ \\
\hline Galactosidase & Gal & $\mu \mathrm{g} / \mathrm{g}$ sediment & $24 h$ \\
\hline Glucosidase & Glu & $\mu \mathrm{g} / \mathrm{g}$ sediment & $24 h$ \\
\hline Nitrates & $\mathrm{NO}_{3}$ & $\mathrm{mg} / \mathrm{l}$ & $24 h$ \\
\hline Phosphates & $\mathrm{PO}_{4}^{2-}$ & $\mathrm{mg} / \mathrm{l}$ & $24 \mathrm{~h}$ \\
\hline Ammonia & $\mathrm{NH}_{3}^{+}$ & $\mathrm{mg} / \mathrm{l}$ & $24 \mathrm{~h}$ \\
\hline Biochemical oxygen demand & $\mathrm{BOD}_{5}$ & $\mathrm{mg} / \mathrm{l}$ & $24 h$ \\
\hline Hardness & Hard & $\mathrm{mg} / \mathrm{l}$ & $48 \mathrm{~h}$ \\
\hline Alkalinity & Alk & $\mathrm{mg} / \mathrm{l}$ & $24 \mathrm{~h}$ \\
\hline
\end{tabular}

Quality assurance and quality control (QA/QC) practices included the analysis of chemical parameters consisted of one trip blank, one field blank, a negative control, one replicate, one spiked sample, and one quality control standard. QA/QC practices included in the analysis of microbial parameters included the analysis of one trip blank, one field blank, a negative control, and a positive control. A secondary wastewater effluent sample was used as the positive control for TC/FC, Colilert®, SPC, and bacteriophage analyses. Laboratory strains of E. coli O157:H7 and Shigella flexneri 
(ATCC $₫$ Number $43895^{\mathrm{TM}}$ and ATCC $₫ 12022^{\mathrm{TM}}$, respectively) were used to seed water samples that served as a positive control for PCR analysis.

\section{Microbial Analyses}

TC/FC analyses for water samples were conducted according to Standard Methods for Examination of Water and Wastewater (APHA, 1992). Briefly, $0.5 \mathrm{ml}$ of water were filtered through a $0.45 \mu \mathrm{m}$ membrane filter (EMD Millipore, Billerica, MA) and the filter placed in a petri dish containing an absorbent pad (EMD Millipore, Billerica, MA) with $2 \mathrm{ml}$ of $\mathrm{m}$-Endo media for total coliform analysis or $\mathrm{m}$-FC media for fecal coliform analysis. All plates were inverted and enumerated following $24 \mathrm{~h}$ incubation at $37^{\circ} \mathrm{C}$ and $44.5^{\circ} \mathrm{C}$ for total coliform and fecal coliforms, respectively. For TC/FC sediment analyses, $0.5 \mathrm{~g}$ of sediment was added to $25 \mathrm{ml}$ of sterile water $+1 \%$ Tween 80. The samples were vortexed and allowed to settle for 30 minutes, and $0.5 \mathrm{ml}$ of the buffer suspension was filtered according to Standard Methods for Examination of Water and Wastewater as described above (APHA, 1992).

SPC were conducted according to Standard Methods for Examination of Water and Wastewater (APHA, 1992) using R2A agar. One milliliter of water was placed in the center of a sterile petri dish (Fisher Scientific, Pittsburgh, PA) and 10ml of R2A agar was added to the dish. The plate was swirled in a figure eight motion to allow the sample to disperse in the media and cover the plate. Plates were allowed to solidify and were enumerated following incubation at $25^{\circ} \mathrm{C}$ for $48 \mathrm{~h}$. Escherichia coli

concentrations were determined using the Colilert@ Quanti-Tray method (APHA, 1995). To each $100 \mathrm{ml}$ water sample, a packet of Defined Substrate Technology ${ }^{\circledR}(\mathrm{DST} \circledast)$ 
reagent (IDEXX Laboratories, Westbrook, Maine) was added and mixed. The sample was then poured into a Quanti-Tray ${ }^{\circledR}$, sealed using the Quanti-Tray® sealer, and incubated for $24 \mathrm{~h}$ at $37^{\circ} \mathrm{C}$. E. coli were then enumerated using the Standard Method most probable number (MPN) procedure. Samples for water TC/FC were processed in triplicate and samples for sediment TC/FC were processed in duplicate. SPC were processed in duplicate and one Colilert® sample was processed for each site.

MEA analyses were conducted and included acid and alkaline phosphatases, glucosidase, galactosidase, and dehydrogenase activities. For each enzyme analyzed, $1 \mathrm{~g}$ of sediment was added to a test tube containing a specific buffer and enzyme. Sediment samples for acid phosphatase were mixed with $4 \mathrm{ml}$ of $1 \mathrm{M}$ TRIS buffer ( $\mathrm{pH}$ 4.8) and $4 \mathrm{ml}$ of $1 \mathrm{M}$ TRIS buffer $(\mathrm{pH}) 8.4$ for alkaline phosphatase. For both acid and alkaline phosphatase, $1 \mathrm{ml}$ of $1 \mathrm{M}$ TRIS buffer with $0.1 \%$ phosphatase substrate $(\mathrm{pH} 7.6)$ was added to each tube (Sayler et al. 1979). Sediment samples for galactosidase and glucosidase activities were mixed with $4 \mathrm{ml}$ of $0.1 \mathrm{M}$ phosphate buffer $(\mathrm{pH} 9.0)$. Galactosidase activity was measured by adding $1 \mathrm{ml}$ of $0.01 \mathrm{M}$ phosphate buffer with $0.15 \% \mathrm{p}$-nitrophenyl- $\beta$-D-galactopyranoside as an indicator of galactosidase activity. One milliliter of $0.01 \mathrm{M}$ phosphate buffer with $0.15 \% 4$-nitrophenyl- $\beta$-D-glucopyranoside was used as an indicator to assess glucosidase activities (Morrison et al. 1977). Following addition of buffers and indicators, all tubes were vortexted and incubated at $25^{\circ} \mathrm{C}$ for $24 \mathrm{~h}$. Acid and alkaline phosphatase, galactosidase, and glucosidase activities were determined using a spectrophotometer at an absorbance of $418 \mathrm{~nm}$.

For dehydrogenase (DHA) activity, $1 \mathrm{~g}$ of sediment was added to a test tube containing $2 \mathrm{ml}$ of $0.1 \mathrm{M}$ phosphate buffer $(\mathrm{pH} 7.6)$ and $1 \mathrm{ml}$ of $0.5 \%$ iodonitrotetrazolium 
chloride (INT) salt solution. The samples were vortexed and incubated in the dark at $25^{\circ} \mathrm{C}$ for 45 minutes. One milliliter of the sample was filtered through a $0.22 \mu \mathrm{m}$ porosity cellulose membrane (GE Water and Process Technologies, Trevose, PA) and allowed to dry at room temperature. The membrane, was then added to a test tube containing $5 \mathrm{ml}$ of dimethyl sulfoxide, vortexted to dissolve the membrane, and incubated in the dark at $25^{\circ} \mathrm{C}$ for $24 \mathrm{~h}$. Dehydrogenase activity was then determined using a spectrophotometer at an absorbance of $460 \mathrm{~nm}$.

AODC analysis was performed as described by Ghiorse and Balkwill (1983). Three hundred milligrams of sediment was added to $30 \mathrm{ml}$ of sterile PBS+Tween 80 , vortexed for $60 \mathrm{~s}$, and allowed to settle for $3 \mathrm{~h}$. Two hundred fifty microliters of the suspension was mixed with $5 \mathrm{ml}$ sterile water $+500 \mu$ lacridine orange stain, and samples were vortexed for $30 \mathrm{~s}$. Samples were filtered using $25 \mathrm{~mm}, 0.2 \mu \mathrm{m}$ pore polycarbonate nucleopore filters (Osmonics, Inc., Minnetonka, MN), and the filters were mounted and fixed on slides for enumeration at 1000X using the Olympus $\mathrm{BH} 2$ epifluorescent microscope (Olympus, New Hyde Park, NY). One sediment sample was processed per site and 3 microscopic fields were enumerated on each slide.

\section{$\underline{\text { Chemical Analyses }}$}

$\mathrm{NO}_{3}{ }^{-}, \mathrm{PO}_{4}^{-}, \mathrm{NH}_{3}{ }^{+}$, alkalinity, and hardness analyses were performed in triplicate using colorimetric $\mathrm{HACH}^{\mathrm{TM}}$ methods and $\mathrm{HACH}^{\mathrm{TM}}$ reagents as described by the manufacturer ( $\mathrm{HACH}$ Company, Loveland, $\mathrm{CO}$ ). Briefly, $\mathrm{NO}_{3}{ }^{-}, \mathrm{PO}_{4}{ }^{-}, \mathrm{NH}_{3}{ }^{+}$analyses were conducted by adding $10 \mathrm{ml}$ of water to a vial containing the appropriate reagent packet; NitraVer5, PhosVer3 and salicylate/ammonia cyanurate reagents, respectively. 
The vials were shaken to dissolve the reagent and samples were analyzed using pocket colorimeters specific to the nutrient of interest. Alkalinity and hardness analyses were conducted using $100 \mathrm{ml}$ sample volumes and a digital titrator. For alkalinity determination, 1 packet of phenolthalein indicator and bromcresol green-methyl red indicator were added to the sample and mixed. The sample was then titrated with $1.6 \mathrm{~N}$ sulfuric acid to a grey-green endpoint. For hardness determination, 1 packet of ManVer2 reagent and $2 \mathrm{ml}$ of hardness buffer $(\mathrm{pH} \mathrm{10})$ were added to the $100 \mathrm{ml}$ sample and mixed. The sample was then titrated with $0.8 \mathrm{~N}$ Ethylenediaminetetraacetic acid (EDTA) to a blue endpoint. $\mathrm{BOD}_{5}$ analyses were conducted according to Standard Methods for Examination of Water and Wastewater (APHA, 1992). Wheaton BOD bottles (Wheaton Science Products, Millville, NJ) were completely filled with sample water and capped with glass stoppers to ensure no air bubbles were present. Initial (Day 0) and final (Day 5) dissolved oxygen concentrations were measured using the YSI Model 5000 dissolved oxygen meter (YSI Inc., Yellow Springs, OH).

\section{$\underline{\text { Statistical Analyses }}$}

Three multiple regression models were developed using the Sinking Creek data collected in this study in SAS/STAT software v.9.2 (SAS Institute, Cary, NC). The first model (model 1) contained all of the measured chemical and microbial water quality parameters (Table 6.11). The second model (model 2) contained only significant variables identified by stepwise regression (Table 6.12), and the third model (model 3) contained significant variables identified by canonical discriminant analysis (Table 6.13). All water quality data collected from Sinking Creek during this study and from the 
additional creeks in the Watauga River watershed were log transformed to achieve a normal distribution and land use patterns were coded as follows: $(1)=$ agriculture, $(2)=$ urban, and $(3)=$ forest. Only those parameters that were significant at the $p<0.05$ level were considered significant and included in the stepwise regression model and canonical discriminant model. The multiple regression equations were then applied to water quality data collected from Boones, Buffalo, Carroll, Cash Hollow, Cobb, Knob, Reedy, and Sinking Creeks to assess the ability of the models to correctly classify land use patterns within the Watauga River watershed. Data from these creeks were also pooled and the ability of the Sinking Creek model to predict land use patterns was assessed at the watershed level.

Table 6.11. Chemical and microbial water quality parameters included in the full regression model

\begin{tabular}{ll}
\hline Variable & Abbreviation \\
& \\
\hline Fecal coliform in water & FCW \\
Total coliform in water & TCW \\
Fecal coliform in sediment & FCS \\
Total coliform in sediment & TCS \\
Colilert & Colilert \\
Standard plate count & SPC \\
Acridine orange direct counts & $\mathrm{AODC}$ \\
Acid phosphatase & AcidP \\
Alkaline phosphatase & AlkP \\
Dehydrogenase & $\mathrm{DHA}^{-}$ \\
Galactosidase & Gal \\
Glucosidase & $\mathrm{Glu}^{2}$ \\
Nitrates & $\mathrm{NO}_{3}{ }^{2-}$ \\
Phosphates & $\mathrm{PO}_{4}{ }^{-}$ \\
Ammonia & $\mathrm{NH}_{3}{ }^{+}$ \\
Biochemical oxygen demand & $\mathrm{BOD}_{5}$ \\
Alkalinity & $\mathrm{Alk}$ \\
Hardness & $\mathrm{Hard}$ \\
& \\
\hline
\end{tabular}


Table 6.12. Significant chemical and microbial water quality parameters included in the stepwise regression model 2

\begin{tabular}{ll}
\hline Variable & Abbreviation \\
\hline & \\
\hline Fecal coliform water & FCW \\
Fecal coliform sediment & FCS \\
Colilert & Colilert \\
Nitrates & $\mathrm{NO}_{3}^{-}$ \\
Biochemical Oxygen Demand & $\mathrm{BOD}$ \\
Alkalinity & Alk \\
Hardness & Hard \\
\hline
\end{tabular}

Table 6.13. Chemical and microbial water quality parameters identified by canonical discriminant analysis included in model 3

\begin{tabular}{ll}
\hline Variable & Abbreviation \\
\hline Fecal coliform water & FCW \\
Colilert & Colilert \\
Alkalinity & Alk \\
Hardness & Hard \\
\hline
\end{tabular}

\section{$\underline{\text { Results and Discussion }}$}

Regression equations for the 3 models are in Table 6.14. The first model contained all of the measured chemical and microbial water quality parameters. The second model contained only significant variables identified by stepwise regression $(p<$ 0.05), and the third model contained significant variables identified by canonical discriminant analysis. All of the regression models were statistically significant $(p<$ 0.0001 ), suggesting the ability of the models to successfully predict land use patterns in Sinking Creek based on the measured water quality parameters. 
Table 6.14. Regression equations for the 3 developed models to predict land use in the Watauga River watershed

\begin{tabular}{|c|c|c|c|}
\hline Model & Regression Equation & Adjusted $r^{2}$ & $p$ - value \\
\hline 1 & $\begin{array}{l}\mathrm{LU}=\left(\log (\mathrm{FCW})^{\star}-0.20-\log (\mathrm{TCW})^{\star} 0.02+\log (\mathrm{FCS})^{\star} 0.18-\log (\mathrm{TCS})^{\star} 0.06-\right. \\
\log (\text { Colilert })^{\star} 0.24-\log \left(\mathrm{NO}_{3}\right)^{*} 0.35-\log \left(\mathrm{PO}_{4}\right)^{\star} 0.06+\log \left(\mathrm{NH}_{3}\right)^{\star} 0.03-\log (\mathrm{BOD})^{\star} 0.35- \\
\log (\mathrm{Alk})^{*} 0.55-\log (\mathrm{Hard})^{\star} 0.70-\log (\mathrm{SPC})^{*} 0.17-\log (\mathrm{AODC})^{\star} 0.04-\log (\mathrm{AcidP})^{\star} 0.04+ \\
\left.\log (\mathrm{AlkP})^{*} 0.02+\log (\mathrm{DHA})^{\star} 0.12+\log (\text { Galact })^{\star} 0.02-\log (\mathrm{Gluc})^{\star} 0.03\right)+5.62\end{array}$ & $r^{2}=0.87$ & $<0.0001$ \\
\hline 2 & $\begin{array}{l}\mathrm{LU}=\left(\log (\mathrm{FCW})^{\star}-0.20+\log (\mathrm{FCS})^{\star} 0.18-\log (\text { Colilert })^{\star} 0.24-\log \left(\mathrm{NO}_{3}\right)^{\star} 0.35-\right. \\
\left.\log (\mathrm{BOD})^{\star} 0.35-\log (\text { Alkalinity })^{\star} 0.55-\log (\text { Hardness })^{\star} 0.70\right)+5.62\end{array}$ & $r^{2}=0.88$ & $<0.0001$ \\
\hline 3 & $\begin{array}{l}\mathrm{LU}=\left(\log (\text { Colilert })^{\star}-0.28-\log \left(\mathrm{NO}_{3}\right)^{\star} 0.34-\log (\text { Hardness })^{\star} 0.94-\log (\mathrm{FCW})^{\star} 0.12-\right. \\
\left.\log (\text { Alkalinity })^{\star} 0.34\right)+5.15\end{array}$ & $r^{2}=0.85$ & $<0.0001$ \\
\hline
\end{tabular}

Abbreviations: $\mathrm{FCW}=$ fecal coliforms in water, $\mathrm{TCW}=$ total coliforms in water, $\mathrm{FCS}=$ fecal coliforms in sediment, $\mathrm{TCS}=$ total coliforms in sediment, Colilert $=E$ coli, $\mathrm{NO}_{3}{ }^{-}=$nitrates, $\mathrm{PO}_{4}{ }^{2-}=$ phosphates, $\mathrm{NH}_{3}=$ ammonia, $\mathrm{BOD}=$ biochemical oxygen demand, Alk = alkalinity, Hard = hardness, $\mathrm{SPC}=$ standard plate count, $\mathrm{AODC}=$ acridine orange direct counts, $\mathrm{AcidP}=$ acid phosphatase, $\mathrm{AlkP}=$ alkaline phosphatase, $\mathrm{DHA}=$ dehydrogenase, Galact $=$ galactosidase, Gluc $=$ glucosidase 
The models were then applied at the watershed level to water quality data collected from 8 creeks within the Watauga River watershed (Table 6.15). All 3 models remained statistically significant $(p<0.0001)$ when applied to the Watauga River watershed data. Despite their significance, models 1 and 2 were only able to describe a relatively small amount of the variability within the data set based on their $r^{2}$ values. These low $r^{2}$ values reflect the influence of variability between water bodies within the same watershed. The water quality variables that are most influential in determining sources of impairment based on land use patterns in Sinking Creek are not the same throughout the watershed. For example, the variables influential in Boones, Cash Hollow, Cobb, Knob, and Reedy Creeks were similar and included total and fecal coliforms in water and sediment, nitrates, phosphates, alkalinity, hardness, and galactosidase. The variables influential in Buffalo and Carroll Creeks included fecal coliforms in water and sediment, hardness, and biochemical oxygen demand. The lower $r^{2}$ in model 2 compared to the model 1 reflects the influence of those chemical and microbial parameters throughout the entire watershed that were found to be insignificant during stepwise regression analysis of the collected Sinking Creek data. Those parameters identified as insignificant in model 2 include: total coliform bacteria in water and sediment, standard plate counts, acridine orange direct counts, acid and alkaline phosphatase, dehydrogenase, galactosidase, glucosidase, phosphates, and ammonia. 
Table 6.15. Multiple regression statistics for the 3 multiple regression models applied to data from the Watauga River watershed

\begin{tabular}{lll}
\hline Model & $\mathbf{p}$ - value & Adjusted $\mathbf{r}^{2}$ \\
\hline 1 & $p<0.0001$ & 0.02 \\
2 & $p<0.0001$ & 0.01 \\
3 & $p<0.0001$ & 0.35 \\
\hline
\end{tabular}

Model 3 was also significant and accounted for more variability at the watershed level compared to models 1 and 2 . This model was developed using those variables found to be significantly contributing to the discrimination between land use patterns in Sinking Creek based on canonical discriminant analysis. This result suggests that prior determination of the chemical and microbial water quality variables that are most associated with degraded water quality as they pertain to land use patterns in one stream are similar to those variables contributing to degraded water quality throughout the entire watershed. This result highlights the combined usefulness of multivariate statistical analyses such as canonical discriminant and multiple regression analyses.

The multiple regression models were also applied at the creek level to determine if the model could successfully predict land use patterns and subsequent sources of impairment (Table 6.16). Models 1 and 2 were unable to predict land use patterns in all of the creeks except for Sinking Creek. The inability of a these models to accurately identify and classify sources of water quality impairment based on land use patterns suggests that the variables that are associated with water quality impairments within and between the surface waters of the watershed are different and that a simple multiple regression model may not be sufficient to identify sources of impairment as 
they relate to land use. The ability of these regression models to predict land use patterns in previously collected data from Sinking Creek from 2003 - 2011 demonstrates that those variables most influencing water quality in Sinking Creek are influenced to some extent by temporal variability. Seasonality and succession of the stream system over time likely contribute to the inability of the models to account for all of the variability in Sinking Creek.

Table 6.16. Regression statistics for the 3 developed models as applied to each creek to predict fecal pollution source

\begin{tabular}{|c|c|c|c|}
\hline Model & Creek & Adjusted $r^{2}$ & $p$ - value \\
\hline 1 & $\begin{array}{l}\text { Boones Creek } \\
\text { Buffalo Creek } \\
\text { Carroll Creek } \\
\text { Cash Hollow Creek } \\
\text { Knob Creek } \\
\text { Reedy Creek } \\
\text { Sinking Creek }\end{array}$ & $\begin{array}{l}0.0003 \\
0.002 \\
0.0003 \\
0.001 \\
0.001 \\
0.001 \\
0.08\end{array}$ & $\begin{array}{l}p=0.27 \\
p=0.11 \\
p=0.81 \\
p=0.51 \\
p=0.28 \\
p=0.59 \\
p<0.0001\end{array}$ \\
\hline 2 & $\begin{array}{l}\text { Boones Creek } \\
\text { Buffalo Creek } \\
\text { Carroll Creek } \\
\text { Cash Hollow Creek } \\
\text { Knob Creek } \\
\text { Reedy Creek } \\
\text { Sinking Creek }\end{array}$ & $\begin{array}{l}0.0004 \\
0.0007 \\
0.0003 \\
0.0001 \\
0.0008 \\
0.0002 \\
0.34\end{array}$ & $\begin{array}{l}p=0.26 \\
p=0.21 \\
p=0.81 \\
p=0.83 \\
p=0.37 \\
p=0.83 \\
p<0.0001\end{array}$ \\
\hline 3 & $\begin{array}{l}\text { Boones Creek } \\
\text { Buffalo Creek } \\
\text { Carroll Creek } \\
\text { Cash Hollow Creek } \\
\text { Knob Creek } \\
\text { Reedy Creek } \\
\text { Sinking Creek }\end{array}$ & $\begin{array}{l}0.02 \\
0.04 \\
0.05 \\
0.004 \\
0.08 \\
0.25 \\
0.74\end{array}$ & $\begin{array}{l}p=0.04 \\
p=0.0012 \\
p=0.10 \\
p=0.78 \\
p=0.008 \\
p<0.0001 \\
p<0.0001\end{array}$ \\
\hline
\end{tabular}

Model 3 was more successful at predicting land use patterns at the creek level compared to models 1 and 2 . This model included the variables that were identified through canonical discriminant analysis as those that allow for the most discrimination 
between land use classifications based on water quality in Sinking Creek during 2011. Model 3 was able to predict land use patterns in all creeks with the exception of Carroll and Cash Hollow Creeks, with the greatest amount of variability accounted for within the previously collected Sinking Creek data. The failure of model 3 to predict land use and sources of impairment in Carroll and Cash Hollow Creeks is most likely due to the influence of unidentified nonpoint sources of fecal pollution in these creeks. Although all 3 models were statistically significant, model 3 developed using the chemical and microbial water quality variables that discriminate based on land use in Sinking Creek accounted for the most variability at the watershed and creek level. This finding suggests that canonical discriminant and multiple regression analyses can be used together to analyze water quality data and determine sources of impairment based on land use patterns.

The inability of models 1 and 2 and limited predictability of model 3 to successfully predict the land use classifications of these creeks agrees with results of previous studies conducted in the Watauga River watershed. These studies indicate that there is variability in the extent and sources of pollution within the watershed, and that the application of multivariate statistical analyses to water quality data can help identify those variables that contribute to degraded surface water quality differ based on land use patterns (Hall et al. 2007; 2008; 2011). The inability of these regression models to predict land use classifications throughout the watershed further supports these previous findings and suggests that those variables related to fecal pollution may vary spatially and temporally within a watershed. 
The watershed TMDL approach does not account for sources of variability within the entire watershed and are currently based on a limited 30-day geometric mean. Canonical discriminant analysis can be used to address these sources of variability by identifying those variables that are most influencing water quality. It has been reported that multiple regression models developed from data collected from creeks should be used with caution as they may not be representative of all streams within the watershed or reflect true watershed dynamics (Schoonover and Lockaby, 2006; Toor et al. 2008; Kang et al. 2010). The results of this study support these findings and further suggest that TMDL development may require long term monitoring to correctly identify and quantify pollution sources using multivariate statistics methods such as canonical discriminant analysis. It can be argued that the use of long-term water quality monitoring at multiple sites and multivariate data analyses for each creek within a watershed are neither time nor cost effective for successful TMDL development. However, the use of resources to ensure the effective identification and quantification of sources of impairment and accounting for variability within the watershed may demonstrate long-term cost effectiveness. Correctly identifying and classifying sources of fecal pollution using multivariate statistical tools and understanding sources of variability can help in the development of effective TMDLs. If an ineffective TMDL is developed based on limited data that does not reflect true watershed dynamics, successful BMPs cannot be implemented to prevent and remediate surface water impairment for an entire watershed.

The objectives of the watershed approach as described by the USEPA for effective and efficient water resource management involves the identification of priority 
areas, the development and implementation of integrative solutions, and the measurement of the success of the program. The additional key component in this process involves the inclusion of stakeholders throughout the process, as they are the individuals who stand to benefit most from the water resource. One of the main benefits of this approach to water resource management is the efficient use of limited time and financial resources in assessing water quality, determining sources of impairment, preventing future pollution events, and remediating current degraded surface waters to remove them from impaired waters lists.

However, the foundation of this watershed approach involves the accurate identification of point and nonpoint sources of pollutants and addressing these through the development of TMDLs to protect human and environmental health. The success of this watershed approach is contingent on the development of TMDLs that accurately quantify point and nonpoint sources of pollution and that reflect true watershed dynamics by accounting for those sources of variability within and between the surface waters composing the watershed. This study has demonstrated that the failure to consider sources of variability including land use patterns and differences in the water quality parameters that most influence overall water quality can set the stage for the failure of the watershed approach to manage water resources.

\section{$\underline{\text { Conclusions }}$}

Current water quality assessment and protection is involved the development of TMDLs at the watershed level to address these degraded resources. However, the effectiveness of watershed TMDLs to address water quality impairments through the 
development and implementation of BMPs involving stakeholders has yet to be determined. This study suggests that the development of TMDLs at the watershed level may not accurately reflect true watershed dynamics and that the failure to consider sources of variability within and between water bodies in the same watershed may impede the development and implementation of successful BMPs to remove water bodies from the State of Tennessee's 303d list. The failure to consider sources of variability within and between water bodies in the same watershed can lead to incorrectly identification and quantification of surface water pollutants. This ultimately has the potential to hinder the effectiveness of TMDLs by requiring additional time and money to be spent re-assessing priority areas, identifying sources of impairment and implementing applicable BMPs to restore and protect water quality. As a result, the use of the watershed approach to address surface water quality issues may require more time and money to correctly identify and reduce water pollutants following their failure to remove impaired surface waters from 303d lists. It is therefore imperative that TMDL development focus on sources of variability within and between surface waters. Giving consideration to these sources of variability using targeted, long-term monitoring programs, and canonical discriminant analysis combined with multiple regression analysis can improve our identification and quantification of nonpoint sources of pollution, thus allowing us to assess the effectiveness of TMDLs and implement the appropriate BMPs that result in the greatest reduction of water pollutants in an effort to protect human and environmental health. 


\section{$\underline{\text { Acknowledgements }}$}

This work was funded in part by a grant from the ETSU School of Graduate

Studies and Graduate Council and by a contract with the Tennessee Valley Authority (Award \# 00025252). 


\section{$\underline{\text { References }}$}

APHA. 1992. Standard methods for the examination of water and wastewater. $18^{\text {th }}$ edition. American Public Health Association. Washington, D.C.

Carson CA, Shear BL, Ellersieck MR, Asfaw A. 2001. Identification of fecal Escherichia coli from humans and animals by ribotyping. Appl. Environ. Microbiol. 67:1503-1507

Desai AM, Rifai H, Heifer E, Moreno N, Stein R. 2010. Statistical investigations into indicator bacteria concentrations in Houston metropolitan watersheds. Wat. Environ. Res. 82:302-318

Ellis KV, Rodrigues PCC. 1995. Multiple regression design equations for stabilization ponds. Wat. Res. 25:2509-2519

Ghiorse WC, Balkwill DL. 1983. Enumeration and morphological characterization of bacteria indigenous to subsurface environments. Dev. Ind. Microbiol. 24:213-224

Hall KK, Gallagher LK, Evanshen BG, Maier KJ, Scheureman PR. 2007. Comparison of Microbial Water Quality Parameters in Four Geographically Similar Creeks in Northeast Tennessee Using Multivariate Statistical Analyses - American Society for Microbiology, 2007, $107^{\text {th }}$ General Meeting, Toronto, Canada

Hall KK, Evanshen BG, Maier KJ, Scheureman PR. 2008. Application of multivariate statistical analyses to microbial water quality parameters in four geographically similar creeks in Northeast Tennessee to identify patterns associating land use to fecal pollution sources. Abstract, $107^{\text {th }}$ Annual Meeting for the American Society for Microbiology, Toronto, Ontario, Canada

Hall KK, Evanshen BG, Maier KJ, Scheureman PR. 2011. Analysis of water quality data using multivariate statistics to patterns associating land use to fecal pollution sources. $111^{\text {th }}$ Annual Meeting for the American Society for Microbiology, New Orleans, LA USA

Ham Y-S, Kobori H, Takasago M. 2009. Effects of combined sewer overflow and stormwater on indicator bacteria concentrations in the Tama River due to the high population density of Tokyo metropolitan area. Environ. Monit. Assess. 152:459468

Kang JH, Lee SW, Cho KH, Ki SJ, Cha SM, Kim JH. 2010. Linking land-use type and stream water quality using spatial data of fecal indicator bacteria and heavy metals in the Yeongsan river basin. Wat. Res. 44:4143-4157 
Mehaffey MH, Nas MS, Wade TG, Ebert DW, Jones KB, Rager A. 2005. Linking land cover and water quality in New York City's water supply watersheds. Environ. Monit. Assess. 107:29-44

Morrison SJ, King FD, Bobbie RJ, Beechtold RE, White DC. 1977. Evidence for microfloral succession on allochthonous plant littler in Apalachicola Bay, Florida, USA. Marine Bio. 41:229-240

Sayler GS, Puziss M, Silver M. 1979. Alkaline phosphatase assay for freshwater sediments: application to perturbed sediment systems. Amer. Soc. Microbiol. 38:922-927

Schoonover JE, Lockaby BG. 2006. Land cover impacts on stream nutrients and fecal coliform in the lower Piedmont of West Georgia. J. Hydrol. 331:371-382

Toor GS, Harmel RD, Haggard BE, Schmidt G. 2008. Evaluation of regression methodology with low-frequency water quality sampling to estimate constituent loads for ephemeral watersheds in Texas. J. Environ. Qual. 37:1847-1854

Tynkkynen S, Satokari R, Saarela M, Mattila-Sandholm T, Saxelin M. 1999. Comparison of ribotyping, randomly amplified polymorphic DNA analysis, and pulsed-field gel electrophoresis in typing of Lactobacillus rhamnosus and L. casei strains. Appl. Environ. Microbiol. 65:3908-3914

USEPA. 1995. Watershed Protection: A Statewide Approach EPA 841-R-95-004. August 1995. United States Environmental Protection Agency, Washington D.C., USA

Wiggins BA, Andrews RW, Conway RA, Corr CL, Dobratz EJ, Dougherty DP, Eppard JR, Knupp SR, Limjoco MC, Mettenburg JM, et al. 1999. Use of antibiotic resistance analysis to identify nonpoint sources of fecal pollution. Appl. Environ. Microbiol. 65:3483-3486 


\section{CHAPTER 7}

\section{CONCLUSIONS AND RECOMMENDATIONS FOR FUTURE RESEARCH}

Using a combination of a targeted water quality monitoring program and multivariate statistical analyses to identify sources of anthropogenic stress, the following conclusions can be made:

1. Linear regression analyses of fecal indicator organisms and pathogens were statistically significant but low $\left(r^{2} \leq 0.12\right.$ for Cryptosporidium and $\leq 0.05$ for Giardia) for protozoan pathogens but not statistically significant for bacterial or viral pathogens. This suggests that the use of fecal indicators may not accurately estimate the risk of pathogen exposure in Sinking Creek.

2. Spatial and temporal variability in the amounts and types of pollution, including fecal indicator bacteria, indicate that TMDL development may require multi-year data at multiple sampling points rather than the limited 30-day geometric mean to more accurately reflect pollution loadings and patterns in Sinking Creek.

3. A better understanding of loading patterns and temporal and spatial distribution using canonical correlation and canonical discriminant analyses may lead to the correct identification of nonpoint sources of fecal pollution in relation to land use patterns. This data analysis approach can be applied to other watersheds to identify common patterns associating pollution types to various sources, and to effectively develop and implement BMPs to prevent and remediate the effects of rapid urbanization. 
4. Understanding the influence of physical, chemical, and microbial soil properties in soil adjacent to each stream on water quality can lead to better design and implementation of BMPs to remediate and prevent fecal contamination in the Sinking Creek. It is likely that physiochemical soil properties including coarse soil texture and presence of organic matter on the soil surface contribute to the introduction of fecal pollution into Sinking Creek. The functional ability of soil microbial communities to use a variety of carbon sources may help prevent the introduction of unwanted organic matter and fecal pollution into surface waters.

5. Failure to consider sources of variability within and between water bodies in the same watershed may impede the development and implementation of successful BMPs to protect and remediate impaired surface waters. TMDLs developed at the watershed level that do not consider sources of variability may not accurately reflect true watershed dynamics.

6. Considering sources of physical, chemical, and microbial variability in surface waters using targeted long-term monitoring programs, and canonical discriminant analysis combined with multiple regression analysis can improve our identification and quantification of nonpoint sources of pollution. This understanding can allow for the assessment of the effective TMDLs and implementation of the appropriate BMPs that result in the greatest reduction of water pollutants to protect human and environmental health.

Recommendations for future research include the application of this alternative method of water quality monitoring to additional watersheds to further assess its usefulness in identifying nonpoint sources of fecal pollution. In addition to using this 
approach in relation to land use patterns, it is also suggested that this data analysis approach could be used to identify nonpoint sources of fecal pollution as they relate to habitat assessment. The use of habitat assessment scores instead of land use patterns take into consideration site specific characteristics such as riparian buffers, substrate composition, bank stability, and vegetation. Future research should focus on the comparison and correlation of carbon sources used by microbial communities in stream sediments to those used by microbial communities in soil to further suggest sources of fecal pollution. 


\section{REFERENCES}

Abd-El-Haleem D, Kheiralla HZH, Zaki S, Rushdy AA, Abd-El-Rahiem W. 2003. Multiplex-PCR and PCR-RFLP assays to monitor water quality against pathogenic bacteria. J. Environ. Monit. 5:865-870

Abu-Ashour J, Joy DM, Lee H, Whiteley HR, Zelin S. 1998. Movement of bacteria in unsaturated soil columns with macropores. Am. Soc. Ag Eng. 41:1043-1050

Abrahamsen MS, Templeton TJ, Enomoto S, Abrahante JE, Zhu G, Lancto CA, Deng M, Liu C, Widmer G, Tzipori S, Buck GA, et al. 2004. Complete genome sequence of the apicomplexan, Cryptosporidium parvum. Science. 1126:1-10

Agnelli A. 2004. Distribution of microbial communities in a forest soil profile investigated by microbial biomass, soil respiration and DGGE of total and extracellular DNA. Soil Biol. Biochem. 36:859-868

Aislabie J. Smith JJ, Fraser R, McLeod M. 2001. Leaching of bacterial indicators of faecal contamination through four New Zealand soils. Aust. J. Soil Res. 39:13971406

APHA. 1992. Standard methods for the examination of water and wastewater. $18^{\text {th }}$ edition. American Public Health Association. Washington, D.C.

Anderson TH, Domsch KH. 1990. Application of eco-physiological quotients $\left(q \mathrm{CO}_{2}\right.$ and $\left.q \mathrm{D}\right)$ on microbial biomasses from soils of different cropping histories. Soil. Biol. Biochem. 22:251-255

Arnold KW, Kaspar CW. 1995. Starvation- and stationary-phase-induced acid tolerance in Escherichia coli O157:H7. Appl. Environ. Microbiol. 61:2037-2039

Artz RRE, Killham K. 2002. Survival of Escherichia coli O157:H7 in private drinking water wells: influences of protozoan grazing and elevated copper concentrations. FEMS Microbiol. Lett. 216:117-112

Atalay A, Bronick C, Pao S, Mersie W. 2007. Nutrient and microbial dynamics in biosolids amended soils following rainfall simulation. Soil and Sediment 16:209-219

Ayoub GM, Merhebi F, Acra A, El-Fadel M, Koopman B. 1999. Seawater bittern for the treatment of alkalized industrial effluents. Wat. Res. 34:640-656

Bailey JM, Erramouspe J. 2004. Nitazoxanide treatment for giardiasis and cryptosporidiosis in children. Ann. Pharmacother. 38:634-640 
Barak JD, Sananikone K, Delwiche MJ. 2005. Comparison of primers for the detection of pathogenic Escherichia coli using real-time PCR. Lett. Appl. Microbiol. 41:112118

Bej AK, DiCesare JL, Haff L, Atlas RM. 1991. Detection of Escherichia coli and Shigella spp. in water by using the polymerase chain reaction and gene probes for uid. Appl. Environ. Microbiol. 57:1013-1017

Bernard P, Antonie L, Bernard L. 2004. Principal component analysis: and appropriate tool for water quality evaluation and management - application to a tropical lake system. Ecological Modeling. 178:295-311

Bhagwat AA. 2003. Simultaneous detection of Escherichia coli O157:H7, Listeria monocytogenes and Salmonella strains by real-time PCR. Int. J. Food Protect. $84: 217-224$

Bishop PL, Hively WD, Stedinger JR, Rafferty MR, Ljpersberger JL, Bloomfield JA. 2005. Multivariate analysis of paired watershed data to evaluate agricultural best management practice effects on stream water phosphorus. J. Environ. Qual. $34: 1087-1101$

Bonadonna L, Briancesco R, Ottaviani M, Veschetti E. 2002. Occurrence of Cryptosporidium oocysts in sewage effluents and correlation with microbial, chemical and physical water variables. Environ. Monit. Assess. 75:241-252

Bonetta S, Borelli E, Bonetta S, Conio O, Palumbo F, Carraro E. 2011. Development of a PCR protocol for the detection of Escherichia coli and Salmonella sp. in surface water. Environ. Monit. Assess. 177:493-503

Bormann H, Breuer L, Graff T, Huisman J. 2007. Analyzing the effects of soil properties changes associated with land use changes on the simulated water balance: A comparison of three hydrological catchment models for scenario analysis. Ecol. Model. 209:29-40

Borrego, J.J., Moriñigo, M.A., de Vicente, A., Córnax, R., Romero, P. 1987. Coliphages as an indicator of faecal pollution in water. Its relationship with indicator and pathogenic microorganisms. Wat. Res. 21:1473-1480

Bossio DA, Scow KM. 1995. Impact of carbon and flooding on the metabolic diversity of microbial communities in soils. Appl. Environ. Microbiol. 61:4043-4050

Brasfield H. 1972. Environmental factors correlated with size of bacterial populations in a polluted stream. Appl. Environ. Microbiol. 24:349-352

Buck ODKN, Townsend CR. 2004. Scale-dependence of land use effects on water quality of streams in agricultural catchments. Environ. Poll. 130:287-299 
Buerge IJ, Poiger T, Müller MD, Buse, HR. 2003. Caffeine, an anthropogenic marker for wastewater contamination of surface water. Environ. Sci. Technol. 37:691-700

Bukhari Z, McCuin RM, Fricker CR, Clancy JL. 1998. Immunomagnetic separation of Cryptosporidium parvum from source water samples of various turbidities. Appl. Environ. Microbiol. 64:4495-4499

Burton, Jr. GA, Gunnison D, Lanza GR. 1987. Survival of pathogenic bacteria in various freshwater sediments. Appl. Environ. Microbiol. 53:633-638

Byappanahalli M, Fowler M, Shively D, Whitman R. 2003. Ubiquity and persistence of Escherichia coli in a Midwestern coastal stream. Appl. Environ. Microbiol. 69:45494555

Byrd JJ, Xu HS, Colwell RR. 1991 Viable but nonculturable bacteria in drinking water. Appl. Environ. Microbiol. 57:875-878

Callies U. 2005. Interaction structures analyzed from water-quality data. Ecol. Model. $187: 475-490$

Campbell GR, Prosser J, Glover A, Killham K. 2001. Detection of Escherichia coli O157:H7 in soil and water using multiplex PCR. J. Appl. Microbiol. 91:1004-1010

Carrillo M, Estrada E, Hazen TC. 1985. Survival and enumeration of the fecal indicators Bifidobacterium adolescentis and Escherichia coli in a tropical rain forest watershed. Appl. Environ. Microbiol. 50:468-476

Carson CA, Shear BL, Ellersieck MR, Asfaw A. 2001. Identification of fecal Escherichia coli from humans and animals by ribotyping. Appl. Environ. Microbiol. 67:1503-1507

Chapman HD. 1965. Cation exchange capacity. In: C.A. Black (ed.) Methods of soil analysis - Chemical and microbiological properties. Agronomy 9: 891-901

Christian L. Lauber CL, Strickland MS, Bradford MA, Fierer N. 2008. The influence of soil properties on the structure of bacterial and fungal communities across land-use types. Soil Biol. Biochem. 40:2407-2415

Christophersen N, Hooper RP. 1992. Multivariate analysis of stream water chemical data: the use of principal components analysis for the end-member mixing problem. Water Resources Research. 28:99-107

Chu Y, Jin Y, Baumann T, Yates MV. 2003. Effect of soil properties on saturated and unsaturated virus transport through columns. J. Environ. Qual. 32:2017-2025

Clancy JL, Gollnitz WD, Tabib Z. 1994. Commercial labs: how accurate are they? J. Am. Wat. Works. Assoc. 86:89-97 
Cooley MB, Carychao D, Nguyen K, Whitehand L, Mandrell R. 2010. Effects of environmental stress on stability of tandem repeats in Escherichia coli O157:H7. Appl. Environ. Microbiol. 76:3398-4000

Cooper SR, Taylor CR, Jones TF. 2008. Communicable and Environmental Disease Services Annual Report, 2008. Tennessee Department of Health Communicable and Environmental Disease Services. Nashville TN USA

Crabill C, Donald R, Snelling J, Fourst R, Southam G. 1999. The impact of sediment fecal coliform reservoiurs on seasonal water quality in Oak Creek, Arizona. Wat. Res. 33:2163-2171

Dai X, Boll J. 2003. Evaluation of attachment of Cryptosporidium parvum and Giardia lamblia to soil particles. J. Environ. Qual. 32:296-304

Davenport CV, Sparrow EB. Gordon, R.C. 1976. Fecal indicator bacteria persistence under natural conditions in an ice-covered river. Appl. Environ. Microbiol. 32:527-536

Davies CM, Evison LM. 1991. Sunlight and the survival of enteric bacteria in natural waters. J. Appl. Bacteriol. 70:265 - 274

deRegnier DP, Cole L, Schupp DG, Erlandsen SL. 1989. Viability of Giardia cysts suspended in lake, river and tap water. Appl. Environ. Microbiol. 55:1223-1229.

Desai AM, Rifai H, Heifer E, Moreno N, Stein R. 2010. Statistical investigations into indicator bacteria concentrations in Houston metropolitan watersheds. Wat. Environ. Res. 82:302-318

Díaz-Raviña M, Bååth E. 1996. Thymidine and leucine incorporation into bacteria from soils experimentally contaminated with heavy metals. Appl. Soil. Ecol. 3:225-234

DiGiorgio CL, Gonzalez DA, Huitt CC. 2002. Cryptosporidium and Giardia recoveries in natural waters by using Environmental Protection Agency method 1623. Appl. Environ. Microbiol. 68:5952-5955

Dillon WR, Goldstein M. 1984. Multivariate analysis: methods and applications. John Wiley and Sons Press, New York, New York

Dulaney D, Scheuerman P, Maier K, Mustain E. 2003. Monitoring of selected bacteriological parameters associated with the Sinking Creek Total Maximum Daily Load (TMDL). Master's Thesis. Department of Environmental Health, East Tennessee State University 
Durand JMB, Björk GR. 2009. Metabolic control through ornithine and uracil of epithelial cell invasion by Shigella flexneri. Microbiology. 155:2498-2508

Dylla BL, Vetter EA, Hughes JG, Cockerill III FR. 1995. Evaluation of an immunoassay for direct detection of Escherichia coli O157 in stool specimens. Appl. Environ. Microbiol. 33:222-224

Ellis KV, Rodrigues PCC. 1995. Multiple regression design equations for stabilization ponds. Wat. Res. 25:2509-2519

Faith NG, Shere JA, Brosch R, Arnold KW, Ansay SE, Lee M-S, Luchansky JB, Kaspar CW. 1996. Prevalence and clonal nature of Escherichia coli O157:H7 on dairy farms in Wisconsin. Appl. Environ. Microbiol. 62:1519-1525

Fontes DE, Mills AL, Hornberger GM, Herman JS. 1991. Physical and chemical factors influencing transport of microorganisms through porous media. Appl. Environ. Microbiol. 57:2473-2481

Fratamico PM, Stobaugh TP. 1998. Evaluation of an enzyme-linked immunosorbent assay, direct immunofluorescent filter technique, and multiplex polymerase chain reaction for detection of Escherichia coli O157:H7 seeded in beef carcass wash water. J. Food Protect. 61:934-938

Gagliardi JV, Karns JS. 2000. Leaching of Escherichia coli O157:H7 in diverse soils under various agricultural management practices. Appl. Environ. Microbiol. 66:877883

Gannon JJ, Busse MK, Schilliger JE. 1983. Fecal coliform disappearance in a river impoundment. Wat. Res. 17:1595-1601

Gannon JT, Manlial VB, Alexander M. 1991. Relationship between cell surface properties and transport of bacteria through soil. Appl. Environ Microbiol. 57:190193

Garland JL, Mills AL. 1991. Classification and characterization of heterotrohic microbial communities on the basis of patterns of community-level sole-carbon-source utilization. Appl. Environ. Microbiol. 57:2351-2359

Gantzer C, Lillerman L, Kuznetsov M, Oron G. 2001. Adsorption and survival of faecal coliforms, somatic coliphages and F-specific RNA phages in soil irrigated with wastewater. Wat.Sci. Technol. 43:117-124

Gardner TB, Hill DR. 2001. Treatment of Giardiasis. Clin. Microbiol. Rev. 14:114-128 
Gerba CP, Goyal SM, LaBelle RL, Cech I, Bodgan GF. 1979. Failure of indicator bacteria to reflect the occurrence of enteroviruses in marine waters. Am. J. Pub. Health. 69:1116-1119

Gersberg RM, Rose MA, Robles-Sikisaka R, Dhar AK. 2006. Quantitative detection of Hepatitis A virus and enteroviruses near the United States-Mexico border and correlation with levels of fecal indicator bacteria. Appl. Environ. Microbiol. 72:74387444

Ghiorse WC, Balkwill DL. 1983. Enumeration and morphological characterization of bacteria indigenous to subsurface environments. Dev. Ind. Microbiol. 24:213-224

Glass KA, Loeffelholz JM, Ford JP, Doyle MP. 1992. Fate of Escherichia coli O157:H7 as affected by $\mathrm{pH}$ or sodium chloride and in fermented, dry sausage. Appl. Environ. Microbiol. 58:2513-2516

Goldshmid J. 1972. Effect of dissolved salts on the filtration of coliform bacteria in sand dunes. $6^{\text {th }}$ International Water Pollution Research Conference, Jerusalem, Israel

Gotz R, Steiner B. Friesel P, Roch K, Walkow F, Maab V, Reincke H, Stachel B. 1998. Dioxin (PCDD/F) in the River Elbe - investigations of their origin by multivariate statistical methods. Chemosphere. 37:1987-2002

Goyal SM, Gerba CP, Melnick JL. 1977. Occurrence and distribution of bacterial indicators and pathogens in canal communities along the Texas coast. Appl. Environ. Microbiol. 34:139-149

Greenwood KL, McKenzie BM. 2001. Grazing effects on soil physical properties and the consequences for pastures: a review. Aust. J. Exper. Ag. 41:1231-1250

Guy RA, Payment P, Krull UJ, Horgen PA. 2003. Real-time PCR for quantification of Giardia and Cryptosporidium in environmental water samples and sewage. Appl. Environ. Microbiol. 69:5178-5185

Hair JF, Anderson RE, Tatham RL, Black WC. 1998. Multivariate Data Analysis, $5^{\text {th }}$ edition. Prentice Hall, Englewood Cliffs, New Jersey

Hall KK. 2006a. Analysis of Selected Soil Parameters for Soil Samples Collected Along Sinking Creek. Unpublished raw data, East Tennessee State University

Hall KK, Gallagher LK, Evanshen BG, Maier KJ, Scheuerman PR. 2006b. Comparison of microbial water quality parameters of four geographically similar creeks in northeast Tennessee. Abstract, $106^{\text {th }}$ Annual Meeting for the American Society for Microbiology, Orlando, Florida, USA 
Hall KK, Gallagher LK, Evanshen BG, Maier KJ, Scheureman PR. 2007. Comparison of Microbial Water Quality Parameters in Four Geographically Similar Creeks in Northeast Tennessee Using Multivariate Statistical Analyses - American Society for Microbiology, 2007, $107^{\text {th }}$ General Meeting, Toronto, Canada

Hall KK, Evanshen BG, Maier KJ, Scheureman PR. 2008. Application of multivariate statistical analyses to microbial water quality parameters in four geographically similar creeks in Northeast Tennessee to identify patterns associating land use to fecal pollution sources. Abstract, $107^{\text {th }}$ Annual Meeting for the American Society for Microbiology, Toronto, Ontario, Canada

Hall KK, Evanshen BG, Maier KJ, Scheureman PR. 2011. Analysis of water quality data using multivariate statistics to patterns associating land use to fecal pollution sources. $111^{\text {th }}$ Annual Meeting for the American Society for Microbiology, New Orleans, LA USA

Ham Y-S, Kobori H, Takasago M. 2009. Effects of combined sewer overflow and stormwater on indicator bacteria concentrations in the Tama River due to the high population density of Tokyo metropolitan area. Environ. Monit. Assess. 152:459468

Hancock DD, Besser TE, Rice DH. 1997. The ecology of Escherichia coli O157:H7 in cattle and the impact of management practices. In VTEC '97. Conference proceedings of the $3^{\text {rd }}$ International Symposium and Workshop on Shiga Toxin (Verocytotoxin) - Producing Escherichia coli infections, $22^{\text {nd }}-26^{\text {th }}$ June, 1997, Baltimore, Maryland.

Hanes NB, Sarles WB, Rohlich GA. 1964. Dissolved oxygen and survival of coliform organisms and enterococci. J. Am. Water. Works. Assoc. 56:441-446

Harding JS, Young RG, Hayes JW, Shearer KA, Stark JD. 1999. Changes in agricultural intensity and river health along a river continuum. Freshwater Biol. 42:345-357

Hartman AB, Venkatesan MM, Oaks EV, van Buysse JM. 1990. Sequence and molecular characterization of multicopy invasion plasmid antigen gene, $\mathrm{ipaH}$, of Shigella flexneri. J. Bacterial. 172:1905-1915

Harwood VJ, Levine AD, Scott TM, Chivukula V, Lukasik J, Farrah SR, Rose JB. 2005. Validity of the indicator organism paradigm for pathogen reduction in reclaimed water and public health protection. Appl. Environ. Microbiol. 71:3163-3170

Havelaar AH, van Olphen M, Drost YC. 1993. F-specific RNA bacteriophages are adequate model organisms for enteric viruses in fresh water. Appl. Environ. Microbiol. 59:2956-2962 
Hlavsa MC, Roberts VA, Anderson AR, Hill VR, Kahler AM, Orr M, Garrison LE. 2011. Surveillance for waterborne disease outbreaks and other health events associated with recreational water --- United States, 2007--2008. MMWR. Surveillance summaries: Morbidity and mortality weekly report. Surveillance summaries / CDC 60 (12) (September 23): 1-32

Hijnen WAM, Brouwer-Hanzens AJ, Charles KJ, Medema GJ. 2005. Transport of MS2 phage, Escherichia coli, Clostridium perfringens, Cryptosporidium parvum, and Giardia intestinalis in a gravel and a sandy soil. Environ. Sci. Technol. 39:78607868

Hörman, A, Rimhanen-Finne R, Maunula L, von Bonsdorff $\mathrm{CH}$, Torvela N, Heikinheimo A, Hänninen ML. 2004. Campylobacter spp., Giardia spp., Cryptosporidium spp., Noroviruses, and Indicator Organisms in Surface Water in Southwestern Finland, 2000-2001. Appl. Environ. Microbiol. 70:87-95

Howell JM, Coyne MS, Cornelius PL. 1996. Effect of sediment particle size and temperature on fecal bacteria mortality rates and the fecal coliform/fecal streptococci ratio. J. Environ. Qual. 25:1216-1220

Hsu WB, Want JH, Chen PC, Lu YS, Chen JH. 2007. Detecting low concentrations of Shigella sonnei in environmental samples by PCR. FEMS Microbiol. Lett. 270:291298

Hsu BM, Wu SF, Huang SW, Tseng YJ, Ji DD, Chen JS, Shih FC. 2010. Differentiation and identification of Shigella spp. and enteroinvasive Escherichia coli in environmental waters by a molecular method and biochemical test. Wat. Res. 44:949-955

Hu J, Feng Y, Ong SL, Ng WJ, Song L, Tan X, Chu X. 2004. Improvement of recoveries for the determination of protozoa Cryptosporidium and Giardia in water using method 1623. J. Microbiol. Methods. 58:321-325

Hunsaker CT, Levine DA. 1995. Hierarchical approaches to the study of water quality in rivers. BioSciences. 45:193-203

Hunter C, Perkins J, Tranter J, Gunn J. 1999. Agricultural land-use effects on the indicator bacterial quality of an upland stream in the Derbyshire Peak District in the U.K. Wat. Res. 33:3577-3586

Hurst CJ, Gerba CP, Cech I. 1980. Effects of environmental variables and soil characteristics on virus survival in soil. Appl. Environ. Microbiol. 40:1067-1079

Huysman F, Verstraete W. 1993. Effect of cell surface characteristics on the adhesion of bacteria to soil particles. Biol. Fertil. Soils. 16:21-26 
Hyland R, Byrne J, Selinger B, Graham T, Thomas J, Townshend I, Gannon V. 2003. Spatial and temporal distribution of fecal indicator bacteria within the Oldman River Basin of Southern Alberta, Canada. Wat. Qual. Res. J. Canada. 38:15-32

Ibekwe AM, Watt PM, Grieve CM, Sharma VK, Lyons SR. 2002. Multiplex fluorogenic real-time PCR for detection and quantification of Escherichia coli O157:H7 in dairy wastewater wetlands. Appl. Environ. Microbiol. 68:4853-4862

Ibekwe AM, Grieve CM. 2003. Detection and quantification of Escherichia coli O157:H7 in environmental samples by real-time PCR. J. Appl. Microbiol. 94:421431

Islam MS, Hasan MK, Hiah MA, Sur GC, Felsenstein A, Venkatesan M, Sack RB, Albert MJ. 1993a. Use of polymerase chain reaction and fluorescent-antibody methods for detecting viable but nonculturable Shigella dysenteriae Type 1 in laboratory microcosms. Appl. Environ. Microbial. 59:536-540

Islam D, Tzipori S, Islam M, Lindberg AA. 1993b. Rapid detection of Shigella dysenteriae and Shigella flexneri in faeces by an immunomagnetic assay with monoclonal antibodies. Eur. J. Clin. Micribiol. Infect. Dis. 12:25-32

Jamison RC, Gordon RJ, Tattrie SC, Stratton GW. 2003. Sources and persistence of fecal coliform bacteria in a rural watershed. Water Qual. Res. J. Canada. 38:33-47

Jana S, Bhattacharya DN. 1988. Effect of heavy metals on growth population of a fecal coliform bacterium Escherichia coli in aquatic environment. Water, Air, and Soil Poll. 38:251-254

Jarroll EL, Manning P, Berranda A, Hare D, Lindmark DG. 1989. Biochemistry and metabolism of Giardia. J. Protozool. 36:190-197

Jenny H. 1980. The soil resource: Origin and behavior. Springer-Verlag. New York City, New York, USA

Jiang X, Morgan J, Doyle MP. 2002. Fate of Escherichia coli O157:H7 in manureamended soil. Appl. Environ. Microbiol. 68:2605-2609

Johnson RA, Wichern DW. 1992. Applied multivariate statistical analysis. Prentice Hall, Englewood Cliffs, New Jersey USA

Johnson DW, Pieniazek NJ, Griffin DW, Misener L. 1995. Development of a PCR protocol for sensitive detection of Cryptosporidium oocysts in water samples. Appl. Environ. Microbiol. 61:3849-3855

Josephson KL, Gerba CP, Pepper IL. 1993. Polymerase chain reaction detection of nonviable bacterial pathogens. Appl. Environ. Microbiol. 59:3513-3515 
Kang JH, Lee SW, Cho KH, Ki SJ, Cha SM, Kim JH. 2010. Linking land-use type and stream water quality using spatial data of fecal indicator bacteria and heavy metals in the Yeongsan river basin. Wat. Res. 44:4143-4157

Kemp JS, Paterson E, Gammack SM, Cresser MS, Killham K. 1992. Leaching of genetically modified Pseudomonas fluorescens through organic soils: Influence of temperature, soil, pH and roots. Biol. Fertil. Soils. 13:218-224

Kemmitt S, Wright D, Goulding K. Jones D. 2006. pH regulation of carbon and nitrogen dynamics in two agricultural soils. Soil Biol. Biochem. 38:898-911

Kenard RP, Valentine RS. 1974. Rapid determination of the presence of enteric bacteria in water. Appl. Environ. Microbiol. 27:484-487

Kimmitt PT, Harwood CR, Barer MR. 2000. Toxin gene expression by shiga toxinproducing Escherichia coli: the role of antibiotics and the bacterial SOS response. Imerg. Infect. Dis. 6:458-465

Kimura R, Mandrell RE, Galland JC, Hyatt D, Riley LW. 2000. Restriction-site-specific PCR as a rapid test to detect enterohemorrhagic Escherichia coli O157:H7 strains in environmental samples. Appl. Environ. Microbiol. 66:2513-2519

Kistemann T, Claßen T, Koch C, Dangerdorf F, Fischeder R, Gebel J, Vacata V, Exner M. 2002. Microbial load of drinking water reservoir tributaries during extreme rainfall and runoff. Appl. Environ. Microbiol. 68:2188-2197

Klute A. 1996. Methods of soil analysis - physical methods. Soil Science Society of America and American Society of Agronomy, Madison, Wisconsin, USA

Kong RYC, Lee SKY, Law TWF, Law SHW, Wu RSS. 2002. Rapid detection of six types of bacterial pathogens in marine waters using multiplex PCR. Wat. Res. $36: 2802-2812$

Koompapong K, Sutthikornchai C, Sukthana Y. 2009. Cryptosporidium oocyst detection in water samples: floatation technique enhanced with immunofluorescence is as effective as immunomagnetic separation method. Korean J. Parasitol. 47:353357

Korhonen LK, Martikainen PJ. 1991. Survival of Escherichia coli and Campylobacter jejuni in untreated and filtered lake water. J. Appl. Bacteriol. 71:379-382

Kramer JB, Canonica S, Hoigné J. 1996. Degradation of fluorescent whitening agents in sunlit natural waters. Enviorn. Sci. Technol. 30:2227-2234

Kreader CA. 1998. Persistence of PCR-detectable Bacteroides distasonis from human feces in river water. Appl. Environ. Microbiol. 64:4103-4105 
Krometis LAH, Characklis GW, Sobsey MD. 2009. Identification of particle size classes inhibiting protozoan recovery from surface water samples via US Environmental Protection Agency method 1623. Appl. Environ. Microbiol. 75:6619-6621

Kurz I, Oreilly C, Tunney H. 2006. Impact of cattle on soil physical properties and nutrient concentrations in overland flow from pasture in Ireland. Ag. Eco. Environ. 113:378-390

LeChevallier MW, Norton WD, Lee RG. 1991. Occurrence of Giardia and Cryptosporidium in surface water supplies. Appl. Environ. Microbiol. 57:2610-2616

LeChevallier MW, Norton WD, Siegel JE, Abbaszadegan M. 1995. Evaluation of the immunofluorescent procedure for detection of Giardia cysts and Cryptosporidium oocysts in water. Appl. Envioron. Microbiol. 61:690-697

Lemarchand K, Lebaron P. 2003. Occurrence of Salmonella spp. and Cryptosporidium spp. in a French coastal watershed: relationship with fecal indicators. FEMS Microbiol. Lett. 218:203-209

Lenat DR, Crawford JK. 1994. Effects of land use on water quality and aquatic biota of three North Carolina Piedmont streams. Hydrobiologica. 284:185-200

Li X, Li F, Zed R, Zhan Z. 2007. Soil physical properties and their relations to organic carbon pools as affected by land use in an alpine pastureland. Geoderma 139:98105

Lindmark DG. 1980. Energy metabolism of the anaerobic protozoon Giardia lamblia. Mol. Biochem. Parasitol. 1:1-12

Lipp EK, Kurz R, Vincent R, Rodriguez-Palacios C, Farrah SR, Rose JB. 2001. The effects of seasonal variability and weather on microbial fecal pollution and enteric pathogens in a subtropical estuary. Estuaries. 24:266-276

Liu Y, Gilchrist A, Zhang J, Li WF. 2008. Detection of viable but nonculturable Escherichia coli O157:H7 bacteria in drinking water and river water. Appl. Environ. Microbiol. 74:1502-1507

Liu YJ, Zhang CM, Wang XC. 2009. Rapid detection of pathogenic bacteria in surface water by PCR with universal primers. Int. J. Environment and Pollution. 38:166-179

Maajel S, Mahjoubi A, Elazri C, Dukan S. 2003. Simultaneous effects of environmental factors on motile Aeromonas dynamics in urban effluent and in natural seawater. Wat. Res. 37:2865-2874 
Mackenzie WR, Hoxie NJ, Proctor ME, Gradus MS, Blair KA, Petersen DE, Kazmierczak JJ, Addiss DG, Fox KR, Rose JB, Davis JP. 1994. A massive outbreak in Milwaukee of Cryptosporidium infection transmitted through a public water supply. N. Eng. J. Med. 331:171-177

Mahbubani MH, Bej AK, Perlin MH, Schaefer FW, Jakubowski W, Atlas RM. 1992. Differentiation of Giardia duodenalis from other Giardia spp. by using polymerase chain reaction and gene probes. J. Clin. Microbiol. 30:74-80

Maheax AF, Bissonnette L, Boissinot M, Bernier JLT, Huppé V, Picard FJ, Bérubé E, Bergeron MG. 2011. Rapid concentration and molecular enrichment approach for sensitive detection of Escherichia coli and Shigella species in potable water samples. Appl. Environ. Microbiol. 77:6199-6207

Malan H, Bath A, Day J, Joubert A. 2003. A simple flow-concentration modeling method for integrating water quality and water quality in rivers. Water SA. 29:305311

March SB, Ratnam S. 1986. Sorbitol-MacConkey medium for detection of Escherichia coli O157:H7 associated with hemorrhagic colitis. Appl. Environ. Microbiol. 23:869872

Mareyn B, Sansonetti P, Tang C. 2005. The host environment primes Shigella for invasion. Nature. 440:428

Marshall J. 2009. Post-infectious irritable bowel syndrome following water contamination. Kidney International. 75:S42-S43

McCambridge J, McMeekin TA. 1981. Effect of solar radiation and predacious microorganisms on survival of fecal and other bacteria. App. Environ. Microbiol. 41:1083-1087

McCuin RM, Bukhari Z, Sobrinho J, Clancy JL. 2001. Recovery of Cryptosporidium oocysts and Giardia cysts from source water concentrates using immunomagnetic separation. J. Microbiol. Methods. 45:69-76

McCuin RM, Clancy JL. 2003. Modifications to United States Environmental Protection Agency method 1622 and 1623 for detection of Cryptosporidium oocysts and Giardia cysts in water. Appl. Environ. Microbiol. 69:267-274

McFeters GA, Stuart, DG. 1972. Survival of coliform bacteria in natural waters: field and laboratory studies with membrane-filter chambers. Appl. Microbiol. 24:805-811

McFeters GA, Bissonette GK, Jezeski JJ. 1974. Comparative survival of indicator bacteria and enteric pathogens in well water. Appl. Microbiol. 27:823 
McLeod M, Aislabie J, Smith J, Fraser R, Roberts A, Taylor M. 2001. Viral and chemical tracer movement through contrasting soils. J. Environ. Qual. 30:21342140

Mehaffey MH, Nas MS, Wade TG, Ebert DW, Jones KB, Rager A. 2005. Linking land cover and water quality in New York City's water supply watersheds. Environ. Monit. Assess. 107:29-44

Morin NJ, Gong Z, Li XF. 2004. Reverse transcription-multiplex PCR assay for simultaneous detection of Escherichia coli O157:H7, Vibrio cholera Ol and Salmonella typhi. Clin. Chem. 50:2037-2044

Morrison SJ, King FD, Bobbie RJ, Beechtold RE, White DC. 1977. Evidence for microfloral succession on allochthonous plant littler in Apalachicola Bay, Florida, USA. Marine Bio. 41:229-240

Motavalli P. 1995. Soil pH and organic $\mathrm{C}$ dynamics in tropical forest soils: Evidence from laboratory and simulation studies. Soil Biol. Biochem. 27:1589-1599

Mueller RF. 1996. Bacterial transport and colonization in low nutrient environments. Wat. Res. 30:2681-2690

Nataro JP, Kaper JB. 1998. Diarrheagenic Escherichia coli. J. Microbiol. Rev. 11:142201

Nieminski EC, Schaefer III FW, Ongerth J.E. 1995. Comparison of two methods for detection of Giardia cysts and Cryptosporidium oocysts in water. Appl. Environ. Microbiol. 61:1714-1719

Ning SK, Chang NB, Jeng KY, Tseng YH. 2006. Soil erosion and non-point source pollution impacts assessment with the aid of multi-temporal remote sensing images. J. Environ. Manage. 79:88-101

Noble RT, Fuhrman JA. 2001. Enteroviruses detected by reverse transcriptase polymerase chain reaction from the coastal waters of Santa Monica Bay, California: low correlation to bacterial indicator levels. Hydrobiologia. 460:175-184

NRCS. 1954. Soil Survey of Washington County, Tennessee. Natural Resources Conservation Service, United States Department of Agriculture

NRCS. 1999. Soil Survey Staff. Soil taxonomy: A basic system of soil classification for making and interpreting soil surveys. $2^{\text {nd }}$ edition. Natural Resources Conservations Services, United States Department of Agriculture Handbook

NRCS. 2004. Soil Survey of Carter County, Tennessee. Natural Resources Conservation Service, United States Department of Agriculture 
NRCS. 2010a. Soil Survey Staff, Natural Resources Conservation Service, United States Department of Agriculture. Soil Survey Geographic (SSURGO) Database for Northeast Tennessee. Available online at http://soildatamart.nrcs.usda.gov Accessed 7-1-10

NRCS. 2010b. Soil Survey Staff, Natural Resources Conservation Service, United States Department of Agriculture. Web Soil Survey. Available online at http://websoilsurvey.nrcs.usda.gov Accessed 7-1-10

NRCS. 2010c. Soil Survey Staff, Natural Resources Conservation Service, United States Department of Agriculture. Official Soil Series Descriptions. Available online at http://soils.usda.gov/technical/classification/osd/index.html. Accessed on 7-1-10

Olyphant GA, Thomal J, Whitman RL, Harper D. 2003. Characterization and statistical modeling of bacterial (Escherichia coli) outflows from watersheds that discharge into southern Lake Michigan. Environ. Monit. Assess. 81:289-300

Orlab GT. 1956. Viability of sewage bacteria in sea water. Sewage Ind. Wastes 28:1147-1167

Oyofo GA, Mohran ZS, El-etr SH. Wasfy MO, Peruski, Jr. LF. 1996. Detection of enterotoxigenic Escherichia coli, Shigella and Campylobacter spp. by multiplex PCR assay. J. Diarrheal Dis. Res. 14:207-210

Paczowski S, Schütz S. 2011. Post-mortem volatiles of vertebrate tissue. Appl. Microbiol. Biotechnol. 91:917-935

Paetsch PR, Greenshaw AJ. 1993. Down-regulation of $\beta$-adrenergic and dopaminergic receptors induced by 2-phenylethylamine. Cell Mol. Neurobiol. 13:203-215

Parfitt RL, Giltrap DJ, Whitton JS. 1995. Contribution of organic matter and clay minerals to the cation exchange capacity of soils. Comm. Soil. Sci. Plant. Anal. 26:1343-1355

Park CH, Vandel NM, Hixon DL. 1996. Rapid immunoassay for detection of Escherichia coli $\mathrm{O} 157$ directly from stool specimens. J. Clin. Microbiol. 34:988-990

Payment P, Franco E. 1993. Clostridium perfringens and somatic coliphages as indicators of the efficiency of drinking water treatment for viruses and protozoan cysts. Appl. Environ. Microbiol. 59:2418-2424

Peinemann N, Amiotti NM, Zalba P, Villamil MB. 2000. Effect of clay minerals and organic matter on the cation exchange capacity of silt fractions. J. Plant Nut. Soil. Sci. $163: 47-52$ 
Pirszel J, Pawlik B, Skowrofinski T. 1995. Cation-exchange capacity of algae and cyanobacteria: a parameter of their metal sorption abilities. J. Indust. Microbiol. Biotech. 14:319-322

Powelson DK, Mills AL. 2001. Bacterial enrichment at the gas water interface of a laboratory apparatus. Appl. Environ. Microbiol. 62:2593 - 2597

Poyry T, Tenvik M, Hovi T. 1988. Viruses in sewage waters during and after a poliomyelitis outbreak and subsequent nationwide oral poliovirus vaccination campaign in Finland. Appl. Envion. Microbial. 54:371-374

Puig M, Pina S, Lucena F, Jofre J, Girones R. 2000. Description of a DNA amplification procedure for the detection of bacteriophages of Bacteroides fragilis HSP40 in environmental samples. J. Virol. Methods. 89:159-166

Ravva SV, Korn A. 2007. Extractable organic components and nutrients in wastewater from dairy lagoons influence the growth and survival of Escherichia coli O157:H7. Appl. Environ. Microbiol. 73:2191-2198

Rice EW, Sowers EG, Johnson CH, Dunnigan ME, Strockbine NA, Edberg SC. 1992. Serological cross-reactions between Escherichia coli $\mathrm{O} 157$ and other species of the genus Escherichia. J. Clin. Microbiol. 30:1315-1316

Riley LW, Remis RS. 1983. Hemorrhagic colitis associated with a rare Escherichia coli serotype. N. Engl. L. Med. 308:681-685

Rochelle PA, De Leon R, Johnson A, Stewart MH, Wolfe RL. 1999. Evaluation of immunomagnetic separation for recovery of infectious Cryptosporidium oocysts from environmental samples. Appl. Environ. Microbiol. 65:841-845

Rose JB, Darbin H, Gerba CP. 1988. Correlation of protozoa, Cryptosporidium and Giardia, with water quality variables in a watershed. Wat. Sci. Technol. 20:271-276

Rose JB, Zhou X, Griffin DW, Paul JH. 1997. Comparison of PCR and plaque assay for detection and enumeration of coliphage in polluted marine waters. Appl. Environ. Microbiol. 63:4564-4566

Roszak DB, Colwell RR. 1987. Survival strategies of bacteria in the natural environment. Microbiol. Rev. 51:365-379

Rowe B, Gross RJ. 1984. Facultatively anaerobic gram negative rods. Genus II. Shigella. In Bergey's Manual of Systematic Bacteriology, N.R. Krieg and J.G. Holt, eds (423-327). Williams and Wilkins, Baltimore, MD. 
Sauch JF. 1985. Use of immunofluorescence and phase-contrast microscopy for detection and identification of Giardia cysts in water samples. Appl. Environ. Microbiol. 50:1434-1438

Sayler GS, Puziss M, Silver M. 1979. Alkaline phosphatase assay for freshwater sediments: application to perturbed sediment systems. Amer. Soc. Microbiol. 38:922-927

Schaffter N, Parriaux A. 2002. Pathogenic-bacterial water contamination in mountainous catchments. Wat. Res. 36:131-139

Schets FM, During M, Italiaander R, Heijnen L, Rutjes SA, van der Zwaluw WK, de Roda Husman AM. 2005. Escherichia coli O157:H7 in drinking water from private water supplies in the Netherlands. Wat. Res. 39:4485-4493

Schjønning P. 1999. Turnover of organic matter in differently textured soils I. Physical characteristics of structurally disturbed and intact soils. Geoderma 89:177-198

Schoonover JE, Lockaby BG. 2006. Land cover impacts on stream nutrients and fecal coliform in the lower Piedmont of West Georgia. J. Hydrol. 331:371-382

Scott L, McGee P, Sheridan JJ, Earley B, Leonard N. 2006. A comparison of the survival in feces and water of Escherichia coli $0157: \mathrm{H} 7$ grown under laboratory conditions obtained from cattle feces. J. Food Protect. 69:6-11

Sen K, Sinclair JL, Boczek L, Rice EW. 2011. Development of a sensitive detection method for stressed E. coli O157:H7 in source and finished drinking water by culture-qPCR. Environ. Sci. Technol. 45:2250-2256

Shaw RD, Hempson SJ, Mackow ER. 1995. Rotavirus diarrhea is caused by nonreplicating viral particles. J. Virol. 69:5946-5950

Sherer BM, Miner JR, Moore JA, Buckhouse JC. 1992. Indicator bacterial survival in stream sediments. J. Environ. Qual. 21:591-595

Shere JA, Kaspar CW, Bartlett KJ, Linden SE, Norell B, Francey S, Schaefer DM. 2002. Shedding of Escherichia coli $\mathrm{O} 157: \mathrm{H} 7$ in dairy cattle housed in a confined environment following waterborne inoculation. Appl. Environ. Microbiol. 68:19471954

Sheshane SD, Harwood VJ, Whitlock JE, Rose JB. 2005. The influence of rainfall on the incidence of microbial faecal indicators and the dominant sources of faecal pollution in a Florida river. J. App. Microbiol. 98:1127-1136 
Sinton LW, Hall CH, Lynch PA, Davies-Colley RJ. 2002. Sunlight inactivation of fecal indicator bacteria and bacteriophages from waste stabilization pond effluent in fresh and saline waters. Appl. Environ. Microbiol. 68:1122-1131

Smith JJ, Howington JP, McFeters GA. 1994. Survival, physiological response, and recovery of enteric bacteria exposed to a polar marine environment. Appl. Environ. Microbiol. 60:2977-2984

Sommer R, Lhotsky M, Haider T, Cabaj A. 2000. UV inactivation, liquid holding recovery and photoreactivation of Escherichia coli O157:H7 and other pathogenic Escherichia coli strains in water. J. Food Protect. 63:1015-1020

Sparks DL. 1996. Methods of soil analysis - chemical methods. Soil Science Society of America and American Society of Agronomy, Madison, Wisconsin, USA

Stetler RE. 1984. Coliphages as indicators of enteroviruses. Appl. Environ. Microbiol. 48:668-670

Stevik TK, Ausland G, Hanssen JF, Jenssen PD. 1999. The influence of physical and chemical factors on the transport of $E$. coli through biological filters for wastewater purification. Wat. Res. 33:3701-3706

Szakál D, Gadó I, Pál T. 2001. A colony blot immunoassay to detect enteroinvasive Escherichia coli and Shigella in water samples. J. Appl. Microbiol. 90:229-236

TDEC. 2000a. Watauga River Watershed (06010103) of the Tennessee River Basin. Water Quality Management plan. Tennessee Department of Environment and Conservation. Division of Water Pollution Control, Nashville TN USA

TDEC. 2000b. Total Maximum Daily Loads for fecal coliforms in Sinking Creek. Tennessee Department of Environment and Conservation, Division of Water Pollution Control, Nashville, TN USA

TDEC. 2008. Chapter 1200-4-3 General Water Quality Criteria. Tennessee Department of Environment and Conservation, Division of Water Pollution Control, Nashville, TN USA

TDEC. 2010. 2010 303(d) Report, The Status of Water Quality in Tennessee, August 2010. State of Tennessee, Department of Environment and Conservation, Division of Water Pollution Control, Nashville TN USA

Tebbe CC, Vahjen W. 1993. Interference of humic acids and DNA extracted directly from soil in detection and transformation of recombinant DNA from bacteria and yeast. Appl. Environ. Microbiol. 59:2657-2665 
Thabane M, Kottachchi DT, Marshall JK. 2007. Systematic review and meta-analysis: the incidence and prognosis of post-infectious irritable bowel syndrome. Aliment. Pharmacol. Ther. 15:535-544

Thelin R, Gifford GF. 1983. Fecal coliform release patterns from fecal material of cattle. J. Environ. Qual. 12:57-63

Theron J, Morar D, Du Prees M, Brozel VS, Venter SN. 2001. A sensitive semi-nested PCR method for the detection of Shigella in spiked environmental water samples. Wat. Res. 35:869-874

Tong STY, Chen W. 2002. Modeling the relationship between land use and surface water quality. J. Environ. Manage. 66:377-393

Toor GS, Harmel RD, Haggard BE, Schmidt G. 2008. Evaluation of regression methodology with low-frequency water quality sampling to estimate constituent loads for ephemeral watersheds in Texas. J. Environ. Qual. 37:1847-1854

Touron A, Berthe T, Gargala G, Fournier M, Ratzjczak M, Servais P, Petit F. 2007. Assessment of faecal contamination and the relationship between pathogens and faecal bacterial indicators in an estuarine environment (Seine, France). Mar. Poll. Bull. 54:1141-1450

Tynkkynen S, Satokari R, Saarela M, Mattila-Sandholm T, Saxelin M. 1999. Comparison of ribotyping, randomly amplified polymorphic DNA analysis, and pulsed-field gel electrophoresis in typing of Lactobacillus rhamnosus and L. casei strains. Appl. Environ. Microbiol. 65:3908-3914

USEPA. 1986. Ambient water quality criteria for bacteria - 1986. January 1986. United States Environmental Protection Agency, Washington D.C. USA.

USEPA. 1995. Watershed Protection: A Statewide Approach EPA 841-R-95-004. August 1995. United States Environmental Protection Agency, Washington D.C., USA

USEPA. 2001a. Method 1601: Male-specific $(F+)$ and somatic coliphage in water by two-step enrichment procedure. April 2001. United States Environmental Protection Agency, Washington D.C. USA

USEPA. 2001b. Method 1602: Male-specific $(F+)$ and Somatic Coliphage in Water by Single Agar Layer (SAL) Procedure. April 2001. United States Environmental Protection Agency, Washington D.C. USA

USEPA. 2005. Method 1623: Cryptosporidium and Giardia in Water by Filtration/IMS/FA. December 2005. United States Environmental Protection Agency, Washington D.C. USA 
USEPA. 2010. National summary of impaired waters and TMDL information. United States Environmental Protection Agency, Washington DC USA.

Vacca A. 2000. Effect of land use on forest floor and soil of a Quercus suber L. forest in Gallura (Sardinia, Italy. Land Deg. Devel. 11:167-180

Van Donsel DJ, Geldreich EE, Clarke NA. 1967. Seasonal variation in survival of indicator bacteria in soil and their contribution to storm-water pollution. Appl. Environ. Microbiol. 15:1362-1370

Vargas R, Hattori T. 1986. Protozoan predation of bacterial cells in soil aggregates. FEMS. Microbiol. Lett. 38:233-242

Vega M, Pardo R, Barrado E, Deban L. 1998. Assessment of seasonal and polluting effects on the quality of river water by exploratory data analysis. Wat. Res. 32:3581-3592

Wang G, Doyle MP. 1998. Survival of enterohemorrhagic Escherichia coli O157:H7 in water. J. Food Protect. 61:662-667

Weiskel PK, Howes BL, Heufelder GR. 1996. Coliform contamination of a coastal embayment: sources and transport pathways. Environ. Sci. Technol. 30:1872-1881

Wentsel RS, O'Neill PE, Kitchens JF. 1982. Evaluation of coliphage detection as a rapid indicator of water quality. Appl. Environ. Microbiol. 43:430-434

Whiles MR, Brock BL, Franzen AC, Dinsmore, II SC. 2000. Stream invertebrate communities, water quality, and land-use patterns in an agricultural drainage basin of Northeastern Nebraska, USA. Environ. Manage. 26:563-576

Whilke BM. 2005. Determination of chemical and physical soil properties. In: Margesin, R., F Schinner (ed.) Manual of soil analysis: monitoring and assessing soil bioremediation. Springer-Verlag, New York City, New York, USA

Whitman RL, Nevers MB. 2003. Foreshore sand as a source of Escherichia coli in nearshore water of a Lake Michigan beach. Appl. Enviorn. Microbiol. 69:5555-5562

Whitman RL, Nevers MB, Byappanahalli MN. 2006. Examination of the watershedwide distribution of Escherichia coli along southern Lake Michigan: an integrated approach. Appl. Environ. Microbiol. 72:7301-7310

Wiggins BA, Andrews RW, Conway RA, Corr CL, Dobratz EJ, Dougherty DP, Eppard JR, Knupp SR, Limjoco MC, Mettenburg JM, et al. 1999. Use of antibiotic resistance analysis to identify nonpoint sources of fecal pollution. Appl. Environ. Microbiol. 65:3483-3486 
Winding A. 1993. Fingerprinting bacterial soil communities using Biolog® microtiter plates, p. 85-94. In K. Ritz, J. Dighten, and K.E. Giller (ed.), Beyond the biomass: compositional and functional analysis of soil microbial communities. John Wiley and Sons Ltd., Chichester, United Kingdom

Wong PTW, Griffin DM. 1976. Bacterial movement at high matric potentials - I. In artificial and natural soils. Soil Boil. Biochem. 8:215-218

Wong CS, Jelacic S, Habeeb RL, Watkins SL, Tarr PI. 2000. The risk of the hemolytic-uremic syndrome after antibiotic treatment of Escherichia coli O157:H7 infections. N. Eng. J. Med. 342:1930-1936

Wu J, Long SC, Das D, Dorner MS. 2011. Are microbial indicators and pathogens related? A statistical analysis of 40 years of research. J. Water Health. 9:265-278

Xi P, Widmer G, Wang Y, Ozaki LS, Alves JM, Serrano MG, Pulu D, Manque P, Akiyoshi D, Mackey AJ, Pearson WR, et al. 2004. The genome of Cryptosporidium hominis. Nature. 431:1107-1112

Yao H, He Z, Wilson MJ, Campbell DD. 2000. Microbial biomass and community structure in a sequence of soils with increasing fertility and changing land use. Micro. Ecol. 40:223-237

Yeager JG, O'Brian RT. 1979. Enterovirus inactivation in soil. Appl. Environ. Microbiol. 38:694-701

Yee RB, Pan SF, Gezon HM. 1957. Studies on the metabolism of Shigella. J. Bacteriol. 75:51-55

Zak JC, Willig MR, Moorhead DL, Wildman HG. 1994. Functional diversity of microbial communities: a quantitative approach. Soil Biol. Biochem. 26:1101-1108

Zhang YL, Dai JL, Wang RQ, Zhang J. 2008. Effects of long-term sewage irrigation on agricultural soil microbial structural and functional characterizations in Shandong, China. Eur. J. Soil Biol. 44:84-91

Zhu G. 2004. Current progress in the fatty acid metabolism in Cryptosporidium parvum. J. Eukar. Microbiol. 51:381-388

Zhu F, Rogeli S, Kieft TL. 2005. Rapid detection of Escherichia coli O157:H7 by immunomagnetic separation and real-time PCR. Int. J. Food Protect. 99:47-57

Zeilhofer P, Lima EBNR, Lima GAR. 2006. Spatial patterns of water quality in the Cuiaba River basin, Central Brazil. Environ. Monit. Assess. 123:41-62 
Zeng X, Rasmussen TC. 2005. Multivariate statistical characterization of water quality in Lake Lanier, Georgia, USA. J. Environ. Qual. 34:1980 - 1991 


\section{APPENDICES}

\section{Appendix A: Media and Reagents}

Acridine Orange Stain, $0.1 \%$

$0.1 \mathrm{~g}$ of $\mathrm{AO}$

$100 \mathrm{~mL}$ of $\mathrm{dH}_{2} \mathrm{O}$.

Filter sterilize through a $0.2 \mu \mathrm{m}$ filter into a sterile glass bottle

Store at $4^{\circ} \mathrm{C}$

ATCC 271 Agar, $0.7 \%$

Prepare ATCC 271 broth as described above with the addition of $1.4 \mathrm{~g}$ agar/L

ATCC 271 Agar, $1.5 \%$

Prepare ATCC 271 broth as described with the addition of $18 \mathrm{~g}$ agar/L

ATCC 271 Broth

$10 \mathrm{~g}$ tryptone

$1 \mathrm{~g}$ yeast extract

$8 \mathrm{~g} \mathrm{NaCl}$

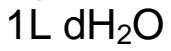

Autoclave at $121^{\circ} \mathrm{C}$ for 15 minutes and add the following reagents after autoclaving

$10 \mathrm{ml}$ of $10 \%$ glucose solution

$2 \mathrm{ml}$ of $1 \mathrm{M} \mathrm{CaCl} 2$

$1 \mathrm{ml}$ of $10 \mathrm{mg} / \mathrm{ml}$ thiamine

Diethylpyrocarbonate Treated Water, $0.05 \%$

$50 \mu$ liethylpyrocarbonate

$100 \mathrm{ml}$ sterile $\mathrm{dH}_{2} \mathrm{O}$

Filter sterilize through a $0.2 \mu \mathrm{m}$ filter into a sterile glass bottle

Store at $4^{\circ} \mathrm{C}$

Elution Buffer for Envirocheck ${ }^{\mathrm{TM}}$ Filter Capsules

$10 \mathrm{ml}$ of $10 \%$ Laureth-12 solution

$10 \mathrm{ml}$ of $1 \mathrm{M}$ Tris $(\mathrm{pH} 7.4)$

$2 \mathrm{ml}$ of $0.5 \mathrm{M}$ EDTA (pH 8.0)

$150 \mu$ l Antifoam A solution 
lodonitrotetrazolium Chloride Solution, $0.5 \%$

$0.5 \mathrm{~g}$ of INT (iodonitrotetrazolium chloride)

$90 \mathrm{~mL}$ of $\mathrm{dH}_{2} \mathrm{O}$

Mix INT in the dark for 30 minutes and bring volume to $100 \mathrm{ml}$

Filter sterilize through a $0.2 \mu \mathrm{m}$ filter into a sterile glass bottle

Store in the dark at $4^{\circ} \mathrm{C}$

$\underline{\text { m-Endo Medium }}$

$4.8 \mathrm{~g}$ of the $\mathrm{m}$-Endo broth base

$2 \mathrm{ml} 95 \%$ ethanol

$98 \mathrm{ml} \mathrm{dH_{2 } \mathrm { O }}$

Heat to boiling then promptly remove from hot plate

$\underline{\mathrm{m}-\mathrm{FC} \text { Medium }}$

$3.7 \mathrm{~g}$ of $\mathrm{m}-\mathrm{FC}$ broth base

$1 \mathrm{ml} 1 \%$ rosolic acid

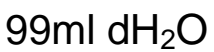

Heat to boiling then promptly remove from hot plate

Phosphate Buffer, $0.1 \mathrm{M}, \mathrm{pH} 7.6$

$1.56 \mathrm{~g} \mathrm{NaH}_{2} \mathrm{PO}_{4}$ (or $1.79 \mathrm{~g}$ of $\mathrm{NaH}_{2} \mathrm{PO}_{4} \cdot \mathrm{H}_{2} \mathrm{O}$ )

$12.35 \mathrm{~g} \mathrm{Na}_{2} \mathrm{HPO}_{4}$ (or $23.30 \mathrm{~g}$ of $\mathrm{Na}_{2} \mathrm{HPO}_{4} \cdot 7 \mathrm{H}_{2} \mathrm{O}$ )

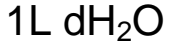

Autoclave at $121^{\circ} \mathrm{C}$ for 15 minutes

Store at $4^{\circ} \mathrm{C}$

Phosphate Buffer, $0.1 \mathrm{M}, \mathrm{pH} 9.0$

$1.84 \mathrm{~g}$ of $\mathrm{Na}_{2} \mathrm{HPO}_{4}$

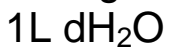

Autoclave at $121^{\circ} \mathrm{C}$ for 15 minutes

Store at $4^{\circ} \mathrm{C}$

Phosphate Buffer with $0.15 \%$ Galactosidase Indicator, $\mathrm{pH} 7.6$

$0.156 \mathrm{~g}$ of $\mathrm{NaH}_{2} \mathrm{PO}_{4}$ (or $0.179 \mathrm{~g}$ of $\mathrm{NaH}_{2} \mathrm{PO}_{4} \cdot \mathrm{H}_{2} \mathrm{O}$ )

$1.235 \mathrm{~g}$ of $\mathrm{Na}_{2} \mathrm{HPO}_{4}$ (or $2.330 \mathrm{~g}$ of $\mathrm{Na}_{2} \mathrm{HPO}_{4} \cdot{ }^{\cdot} \mathrm{H}_{2} \mathrm{O}$ )

$0.151 \mathrm{~g}$ of $\mathrm{p}$-nitrophenyl-B-D-galactopyranoside

$100 \mathrm{ml} \mathrm{dH}_{2} \mathrm{O}$

Filter sterilize through a $0.2 \mu \mathrm{m}$ filter into a sterile glass bottle Store at $4^{\circ} \mathrm{C}$ 
Phosphate Buffer with $0.15 \%$ Glucosidase Indicator, $\mathrm{pH} 7.6$

$0.156 \mathrm{~g}$ of $\mathrm{NaH}_{2} \mathrm{PO}_{4}$ (or $0.179 \mathrm{~g}$ of $\mathrm{NaH}_{2} \mathrm{PO}_{4} \cdot \mathrm{H}_{2} \mathrm{O}$ )

$1.235 \mathrm{~g}$ of $\mathrm{Na}_{2} \mathrm{HPO}_{4}$ (or $2.330 \mathrm{~g}$ of $\mathrm{Na}_{2} \mathrm{HPO}_{4} \cdot 7 \mathrm{H}_{2} \mathrm{O}$ )

$0.151 \mathrm{~g}$ of 4-nitrophenyl-B-D-glucopyranoside

$100 \mathrm{ml} \mathrm{dH}_{2} \mathrm{O}$

Filter sterilize through a $0.2 \mu \mathrm{m}$ filter into a sterile glass bottle Store at $4^{\circ} \mathrm{C}$

Phosphate Buffered Saline, $\mathrm{pH} 7.4$

$8 \mathrm{~g} \mathrm{NaCl}$

$0.2 \mathrm{~g} \mathrm{KCl}$

$1.44 \mathrm{~g} \mathrm{Na}_{2} \mathrm{HPO}_{4}$

$0.24 \mathrm{~g} \mathrm{KH}_{2} \mathrm{PO}_{4}$

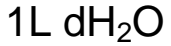

Autoclave at $121^{\circ} \mathrm{C}$ for 15 minutes

Store at $4^{\circ} \mathrm{C}$

Phosphate Buffered Saline + Tween 80, $\mathrm{pH} 7.2$

$140 \mathrm{~mL}$ of $0.2 \mathrm{M} \mathrm{NaH}_{2} \mathrm{PO}_{4}$

$360 \mathrm{~mL}$ of $0.2 \mathrm{M} \mathrm{Na}_{2} \mathrm{HPO}_{4}$

$10 \mathrm{ml}$ Tween 80

$1 \mathrm{~L} \mathrm{dH_{2 }} \mathrm{O}$

Autoclave at $121^{\circ} \mathrm{C}$ for 15 minutes Store at $4^{\circ} \mathrm{C}$

Phosphate Buffered Water

$10 \mathrm{~g}$ PBW powder

$1 \mathrm{~L} \mathrm{dH_{2 }} \mathrm{O}$

Autoclave at $121^{\circ} \mathrm{C}$ for 15 minutes Store at $4^{\circ} \mathrm{C}$

$\underline{\text { R2A Agar for Standard Plate Counts }}$

18.2g R2A agar

$1 \mathrm{~L} \mathrm{dH_{2 } \mathrm { O }}$

Autoclave at $121^{\circ} \mathrm{C}$ for 15 minutes 
Tris Buffer, $1 \mathrm{M}, \mathrm{pH} 4.8$

$0.60 \mathrm{~g}$ of TRIZMA Base

$15.76 \mathrm{~g}$ of TRIZMA HCl

$500 \mathrm{ml}$ of $\mathrm{dH}_{2} \mathrm{O}$

Autoclave at $121^{\circ} \mathrm{C}$ for 15 minutes

Store at $4^{\circ} \mathrm{C}$

Tris Buffer, $1 \mathrm{M}, \mathrm{pH} 8.6$

$6.06 \mathrm{~g}$ of TRIZMA Base

$1.92 \mathrm{~g}$ of TRIZMA HCl

$500 \mathrm{ml} \mathrm{dH}_{2} \mathrm{O}$

Autoclave at $121^{\circ} \mathrm{C}$ for 15 minutes

Store at $4^{\circ} \mathrm{C}$

Tris Buffer with $0.1 \%$ Phosphatase Substrate, $1 \mathrm{M}, \mathrm{pH} 7.6$

$0.21 \mathrm{~g}$ TRIZMA Base

$1.21 \mathrm{~g}$ of TRIZMA HCl

$0.1 \mathrm{~g}$ of phosphatase substrate

$100 \mathrm{ml} \mathrm{dH}_{2} \mathrm{O}$

Filter sterilize through a $0.2 \mu \mathrm{m}$ filter into a sterile glass bottle

Store at $4^{\circ} \mathrm{C}$

Tween $80,1 \%$

$5 \mathrm{ml}$ Tween 80

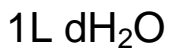

Autoclave at $121^{\circ} \mathrm{C}$ for 15 minutes

Store at $4^{\circ} \mathrm{C}$ 


\section{Appendix B: Water Quality Summary Statistics}

Table 1. Summary statistics for January 2011, site 2

\begin{tabular}{|c|c|c|c|}
\hline Variable & Mean & Std Dev & $\mathbf{N}$ \\
\hline Air Temperature $\left({ }^{\circ} \mathrm{C}\right)$ & 6.8 & 0 & 1 \\
\hline Water Temperature $\left({ }^{\circ} \mathrm{C}\right)$ & 8.1 & 0 & 1 \\
\hline $\mathrm{pH}$ & 7.2 & 0 & 1 \\
\hline Conductivity ( $\mu$ mohs) & 322 & 0 & 1 \\
\hline Dissolved Oxygen (mg/L as $\left.\mathrm{O}_{2}\right)$ & 10.8 & 0 & 1 \\
\hline Discharge $\left(\mathrm{m}^{3} / \mathrm{sec}\right)$ & 0.17 & 0 & 1 \\
\hline Fecal Coliform - Water (CFU/100ml) & 3433.3 & 665.8 & 3 \\
\hline Total Coliform - Water (CFU/100ml) & 4466.7 & 0.08 & 3 \\
\hline Fecal Coliform - Sediment (CFU/100ml) & 25.0 & 3931.1 & 2 \\
\hline Total Coliform - Sediment (CFU/100ml) & 387.5 & 0 & 2 \\
\hline Colilert (MPN/100ml) & 1299.7 & 512.7 & 1 \\
\hline Nitrates (mg/L) & 1.3 & 0 & 1 \\
\hline Phosphates (mg/L) & .44 & 0.37 & 3 \\
\hline Ammonia (mg/L) & .09 & 0.03 & 3 \\
\hline Biochemical Oxygen Demand $\left(\mathrm{mg} / \mathrm{L}\right.$ as $\left.\mathrm{O}_{2}\right)$ & 1.5 & 0.11 & 3 \\
\hline Alkalinity $\left(\mathrm{mg} / \mathrm{L}\right.$ as $\left.\mathrm{CaCO}_{3}\right)$ & 117.3 & 2.1 & 3 \\
\hline Hardness $\left(\mathrm{mg} / \mathrm{L}\right.$ as $\left.\mathrm{CaCO}_{3}\right)$ & 176.3 & 24.6 & 3 \\
\hline Standard Plate Count (CFU/ml) & 500.0 & 8.5 & 2 \\
\hline Acridine Orange Direct Counts (cells $/ g$ ) & $2.7 \times 10^{8}$ & $6.5 \times 10^{7}$ & 1 \\
\hline Acid Phosphatase $(\mu \mathrm{g} / \mathrm{g})$ & 50.1 & 10.8 & 3 \\
\hline Alkaline Phosphatase $(\mu \mathrm{g} / \mathrm{g})$ & 71.5 & 66.0 & 3 \\
\hline Dehydrogenase $(\mu \mathrm{g} / \mathrm{g})$ & 48.5 & 16.7 & 3 \\
\hline Galactosidase $(\mu \mathrm{g} / \mathrm{g})$ & 36.5 & 16.9 & 3 \\
\hline Glucosidase $(\mu \mathrm{g} / \mathrm{g})$ & 92.3 & 018.5 & 3 \\
\hline E. coli O157:H7 (CFU/100ml) & 12.5 & 0 & 3 \\
\hline Shigella sp. (CFU/100ml) & 5.0 & 0 & 3 \\
\hline Bacteriophage (PUF/mI) & $1.0 \times 10^{4}$ & $1.7 \times 10^{4}$ & 3 \\
\hline Giardia sp.(cysts/L) & 9.5 & 0 & 1 \\
\hline Cryptosporidium sp. (cysts/L) & 4.8 & 0 & 1 \\
\hline
\end{tabular}


Table 2. Summary statistics for January 2011 , site 4

\begin{tabular}{|c|c|c|c|}
\hline Variable & Mean & Std Dev & $\mathbf{N}$ \\
\hline Air Temperature $\left({ }^{\circ} \mathrm{C}\right)$ & 5.3 & 0 & 1 \\
\hline Water Temperature $\left({ }^{\circ} \mathrm{C}\right)$ & 8.2 & 0 & 1 \\
\hline $\mathrm{pH}$ & 7.0 & 0 & 1 \\
\hline Conductivity ( $\mu$ mohs) & 295.0 & 0 & 1 \\
\hline Dissolved Oxygen (mg/L as $\mathrm{O}_{2}$ ) & 10.5 & 0 & 1 \\
\hline Discharge $\left(\mathrm{m}^{3} / \mathrm{sec}\right)$ & 0.49 & 0 & 1 \\
\hline Fecal Coliform - Water (CFU/100ml) & 2933.3 & 1078.6 & 3 \\
\hline Total Coliform - Water (CFU/100ml) & 8033.3 & 568.6 & 3 \\
\hline Fecal Coliform - Sediment (CFU/100ml) & 250.0 & 70.7 & 2 \\
\hline Total Coliform - Sediment (CFU/100ml) & 1375.0 & 1449.6 & 2 \\
\hline Colilert (MPN/100ml) & 57.8 & 0 & 1 \\
\hline Nitrates (mg/L) & 0.93 & 0.32 & 1 \\
\hline Phosphates (mg/L) & 0.97 & 0.48 & 3 \\
\hline Ammonia $(\mathrm{mg} / \mathrm{L})$ & 0.10 & 0.01 & 3 \\
\hline Biochemical Oxygen Demand (mg/L as $\mathrm{O}_{2}$ ) & 1.7 & 0.06 & 3 \\
\hline Alkalinity $\left(\mathrm{mg} / \mathrm{L}\right.$ as $\left.\mathrm{CaCO}_{3}\right)$ & 103.3 & 3.1 & 3 \\
\hline Hardness (mg/L as $\left.\mathrm{CaCO}_{3}\right)$ & 126.7 & 4.5 & 3 \\
\hline Standard Plate Count (CFU/ml) & 488.0 & 36.8 & 2 \\
\hline Acridine Orange Direct Counts (cells/g) & $1.0 \times 10^{8}$ & $1.1 \times 10^{8}$ & 1 \\
\hline Acid Phosphatase $(\mu \mathrm{g} / \mathrm{g})$ & 31.5 & 5.6 & 3 \\
\hline Alkaline Phosphatase $(\mu \mathrm{g} / \mathrm{g})$ & 156.4 & 56.1 & 3 \\
\hline Dehydrogenase $(\mu \mathrm{g} / \mathrm{g})$ & 47.1 & 10.4 & 3 \\
\hline Galactosidase $(\mu \mathrm{g} / \mathrm{g})$ & 42.6 & 27.6 & 3 \\
\hline Glucosidase $(\mu \mathrm{g} / \mathrm{g})$ & 166.6 & 56.1 & 3 \\
\hline E. coli O157:H7 (CFU/100ml) & 12.5 & 0 & 3 \\
\hline Shigella sp. (CFU/100ml) & 5.0 & 0 & 3 \\
\hline Bacteriophage (PUF/mI) & 6.36 & 3.1 & 3 \\
\hline Giardia sp.(cysts/L) & 28.0 & 0 & 1 \\
\hline Cryptosporidium sp. (cysts/L) & 16.0 & 0 & 1 \\
\hline
\end{tabular}


Table 3. Summary statistics for January 2011 , site 7

\begin{tabular}{|c|c|c|c|}
\hline Variable & Mean & Std Dev & $\mathbf{N}$ \\
\hline Air Temperature $\left({ }^{\circ} \mathrm{C}\right)$ & 8.1 & 0 & 1 \\
\hline Water Temperature $\left({ }^{\circ} \mathrm{C}\right)$ & 8.6 & 0 & 1 \\
\hline $\mathrm{pH}$ & 6.7 & 0 & 1 \\
\hline Conductivity ( $\mu$ mohs) & 214.0 & 0 & 1 \\
\hline Dissolved Oxygen (mg/L as $\mathrm{O}_{2}$ ) & 10.5 & 0 & 1 \\
\hline Discharge $\left(\mathrm{m}^{3} / \mathrm{sec}\right)$ & 0.41 & 0 & 1 \\
\hline Fecal Coliform - Water (CFU/100ml) & 50.0 & 0 & 3 \\
\hline Total Coliform - Water (CFU/100ml) & 50.0 & 0 & 3 \\
\hline Fecal Coliform - Sediment (CFU/100ml) & 75.0 & 35.6 & 2 \\
\hline Total Coliform - Sediment (CFU/100ml) & 1337.5 & 1856.1 & 2 \\
\hline Colilert (MPN/100ml) & 1.0 & 0 & 1 \\
\hline Nitrates (mg/L) & 1.43 & 0.32 & 1 \\
\hline Phosphates (mg/L) & 0.67 & 0.67 & 3 \\
\hline Ammonia (mg/L) & 0.09 & 0.02 & 3 \\
\hline Biochemical Oxygen Demand (mg/L as $\mathrm{O}_{2}$ ) & 1.8 & 0.17 & 3 \\
\hline Alkalinity $\left(\mathrm{mg} / \mathrm{L}\right.$ as $\left.\mathrm{CaCO}_{3}\right)$ & 72.7 & 2.1 & 3 \\
\hline Hardness $\left(\mathrm{mg} / \mathrm{L}\right.$ as $\left.\mathrm{CaCO}_{3}\right)$ & 96.7 & 1.5 & 3 \\
\hline Standard Plate Count (CFU/ml) & 88.0 & 39.6 & 2 \\
\hline Acridine Orange Direct Counts (cells/g) & $1.2 \times 10^{8}$ & $5.8 \times 10^{7}$ & 1 \\
\hline Acid Phosphatase $(\mu \mathrm{g} / \mathrm{g})$ & 18.7 & 10.7 & 3 \\
\hline Alkaline Phosphatase $(\mu \mathrm{g} / \mathrm{g})$ & 57.4 & 34.1 & 3 \\
\hline Dehydrogenase $(\mu \mathrm{g} / \mathrm{g})$ & 10.6 & 6.7 & 3 \\
\hline Galactosidase $(\mu \mathrm{g} / \mathrm{g})$ & 16.1 & 11.8 & 3 \\
\hline Glucosidase $(\mu \mathrm{g} / \mathrm{g})$ & 15.4 & 10.8 & 3 \\
\hline E. coli 0157:H7 (CFU/100ml) & 12.5 & 0 & 3 \\
\hline Shigella sp. (CFU/100ml) & 5.0 & 0 & 3 \\
\hline Bacteriophage (PUF/ml) & 2.1 & 2.9 & 3 \\
\hline Giardia sp.(cysts/L) & 116.0 & 0 & 1 \\
\hline Cryptosporidium sp. (cysts/L) & 68.0 & 0 & 1 \\
\hline
\end{tabular}


Table 4. Summary statistics for January 2011 , site 10

\begin{tabular}{|c|c|c|c|}
\hline Variable & Mean & Std Dev & $\mathbf{N}$ \\
\hline Air Temperature $\left({ }^{\circ} \mathrm{C}\right)$ & 8.9 & 0 & 1 \\
\hline Water Temperature $\left({ }^{\circ} \mathrm{C}\right)$ & 7.7 & 0 & 1 \\
\hline $\mathrm{pH}$ & 7.0 & 0 & 1 \\
\hline Conductivity ( $\mu \mathrm{mohs})$ & 123.1 & 0 & 1 \\
\hline Dissolved Oxygen (mg/L as $\mathrm{O}_{2}$ ) & 11.5 & 0 & 1 \\
\hline Discharge $\left(\mathrm{m}^{3} / \mathrm{sec}\right)$ & 0.71 & 0 & 1 \\
\hline Fecal Coliform - Water (CFU/100ml) & 100.0 & 68.6 & 3 \\
\hline Total Coliform - Water (CFU/100ml) & 283.3 & 225.5 & 3 \\
\hline Fecal Coliform - Sediment (CFU/100ml) & 25.0 & 0 & 2 \\
\hline Total Coliform - Sediment (CFU/100ml) & 50.0 & 0 & 2 \\
\hline Colilert (MPN/100ml) & 6.3 & 0 & 1 \\
\hline Nitrates $(\mathrm{mg} / \mathrm{L})$ & 1.4 & 0.21 & 1 \\
\hline Phosphates (mg/L) & 0.20 & 0.06 & 3 \\
\hline Ammonia (mg/L) & 0.08 & 0.01 & 3 \\
\hline Biochemical Oxygen Demand (mg/L as $\mathrm{O}_{2}$ ) & 2.0 & 0.16 & 3 \\
\hline Alkalinity $\left(\mathrm{mg} / \mathrm{L}\right.$ as $\left.\mathrm{CaCO}_{3}\right)$ & 46.0 & 1.7 & 3 \\
\hline Hardness $\left(\mathrm{mg} / \mathrm{L}\right.$ as $\left.\mathrm{CaCO}_{3}\right)$ & 56.3 & 3.2 & 3 \\
\hline Standard Plate Count (CFU/ml) & 275.0 & 41.0 & 2 \\
\hline Acridine Orange Direct Counts (cells/g) & $7.5 \times 10^{7}$ & $2.2 \times 10^{7}$ & 1 \\
\hline Acid Phosphatase $(\mu \mathrm{g} / \mathrm{g})$ & 53.8 & 1 & 3 \\
\hline Alkaline Phosphatase $(\mu \mathrm{g} / \mathrm{g})$ & 288.5 & 27.6 & 3 \\
\hline Dehydrogenase $(\mu \mathrm{g} / \mathrm{g})$ & 36.4 & 165.2 & 3 \\
\hline Galactosidase $(\mu \mathrm{g} / \mathrm{g})$ & 32.3 & 18.9 & 3 \\
\hline Glucosidase $(\mu \mathrm{g} / \mathrm{g})$ & 140.4 & 23.0 & 3 \\
\hline E. coli 0157:H7 (CFU/100ml) & 12.5 & 0 & 3 \\
\hline Shigella sp. (CFU/100ml) & 5.0 & 0 & 3 \\
\hline Bacteriophage (PUF/ml) & 34.1 & 57.1 & 3 \\
\hline Giardia sp.(cysts/L) & 28.0 & 0 & 1 \\
\hline Cryptosporidium sp. (cysts/L) & 16.0 & 0 & 1 \\
\hline
\end{tabular}


Table 5. Summary statistics for January 2011, site 13

\begin{tabular}{llll}
\hline Variable & Mean & Std Dev & N \\
Air Temperature $\left({ }^{\circ} \mathrm{C}\right)$ & 8.3 & 0 & 1 \\
Water Temperature $\left({ }^{\circ} \mathrm{C}\right)$ & 6.0 & 0 & 1 \\
$\mathrm{pH}$ & 6.5 & 0 & 1 \\
Conductivity $(\mu \mathrm{mohs})$ & 33.1 & 0 & 1 \\
Dissolved Oxygen $\left(\mathrm{mg} / \mathrm{L}\right.$ as $\left.\mathrm{O}_{2}\right)$ & 11.7 & 0 & 1 \\
Discharge $\left(\mathrm{m}^{3} / \mathrm{sec}\right)$ & 0.27 & 0 & 1 \\
Fecal Coliform - Water $(\mathrm{CFU} / 100 \mathrm{ml})$ & 83.3 & 28.9 & 3 \\
Total Coliform - Water $(\mathrm{CFU} / 100 \mathrm{ml})$ & 133.3 & 57.7 & 3 \\
Fecal Coliform - Sediment $(\mathrm{CFU} / 100 \mathrm{ml})$ & 37.5 & 17.7 & 2 \\
Total Coliform - Sediment $(\mathrm{CFU} / 100 \mathrm{ml})$ & 37.5 & 17.7 & 2 \\
Colilert $(\mathrm{MPN} / 100 \mathrm{ml})$ & 18.9 & 0 & 1 \\
Nitrates $(\mathrm{mg} / \mathrm{L})$ & 0.40 & 0.20 & 1 \\
Phosphates $(\mathrm{mg} / \mathrm{L})$ & 0.33 & 0.13 & 3 \\
Ammonia $(\mathrm{mg} / \mathrm{L})$ & 0.07 & 0.01 & 3 \\
Biochemical Oxygen Demand $\left(\mathrm{mg} / \mathrm{L}\right.$ as $\left.\mathrm{O}_{2}\right)$ & 1.8 & 0.23 & 3 \\
Alkalinity $(\mathrm{mg} / \mathrm{L}$ as CaCO $)$ & 13.3 & 2.9 & 3 \\
Hardness $\left(\mathrm{mg} / \mathrm{L}\right.$ as CaCO $\left.{ }_{3}\right)$ & 16.3 & 2.5 & 3 \\
Standard Plate Count $(\mathrm{CFU} / \mathrm{ml})$ & 168.0 & 39.6 & 2 \\
Acridine Orange Direct Counts $(\mathrm{cells} / \mathrm{g})$ & $6.4 \times 10^{7}$ & $1.7 \times 10^{7}$ & 1 \\
Acid Phosphatase $(\mu \mathrm{gg} / \mathrm{g})$ & 56.2 & 37.5 & 3 \\
Alkaline Phosphatase $(\mu \mathrm{gg} / \mathrm{g})$ & 301.8 & 162.6 & 3 \\
Dehydrogenase $(\mu \mathrm{gg} / \mathrm{g})$ & 16.2 & 2.4 & 3 \\
Galactosidase $(\mu \mathrm{gg} / \mathrm{g})$ & 11.6 & 6.3 & 3 \\
Glucosidase $(\mu \mathrm{g} / \mathrm{g})$ & 77.9 & 33.9 & 3 \\
E. coli O157:H7 $(\mathrm{CFU} / 100 \mathrm{ml})$ & 12.5 & 0 & 3 \\
Shigella sp. $(\mathrm{CFU} / 100 \mathrm{ml})$ & 5.0 & 0 & 3 \\
Bacteriophage $(\mathrm{PUF} / \mathrm{ml})$ & 0.50 & 0 & 3 \\
Giardia $s p .(\mathrm{cysts} / \mathrm{L})$ & 8.75 & 0 & 1 \\
Cryptosporidium sp. $(\mathrm{cysts} / \mathrm{L})$ & 12.3 & 0 & 1 \\
\hline
\end{tabular}


Table 6. Summary statistics for January 2011, site 14

\begin{tabular}{|c|c|c|c|}
\hline Variable & Mean & Std Dev & $\mathbf{N}$ \\
\hline Air Temperature $\left({ }^{\circ} \mathrm{C}\right)$ & 8.3 & 0 & 1 \\
\hline Water Temperature $\left({ }^{\circ} \mathrm{C}\right)$ & 5.7 & 0 & 1 \\
\hline $\mathrm{pH}$ & 6.2 & 0 & 1 \\
\hline Conductivity ( $\mu$ mohs) & 24.1 & 0 & 1 \\
\hline Dissolved Oxygen (mg/L as $\mathrm{O}_{2}$ ) & 11.5 & 0 & 1 \\
\hline Discharge $\left(\mathrm{m}^{3} / \mathrm{sec}\right)$ & 0.14 & 0 & 1 \\
\hline Fecal Coliform - Water (CFU/100ml) & 50 & 0 & 3 \\
\hline Total Coliform - Water (CFU/100ml) & 216.6 & 144.3 & 3 \\
\hline Fecal Coliform - Sediment (CFU/100ml) & 37.5 & 17.7 & 2 \\
\hline Total Coliform - Sediment (CFU/100ml) & 37.5 & 17.7 & 2 \\
\hline Colilert (MPN/100ml) & 17.3 & 0 & 1 \\
\hline Nitrates (mg/L) & 0.80 & 0.30 & 1 \\
\hline Phosphates (mg/L) & 1.1 & 0.78 & 3 \\
\hline Ammonia (mg/L) & 0.06 & 0.01 & 3 \\
\hline Biochemical Oxygen Demand (mg/L as $\mathrm{O}_{2}$ ) & 2.3 & 0.35 & 3 \\
\hline Alkalinity $\left(\mathrm{mg} / \mathrm{L}\right.$ as $\left.\mathrm{CaCO}_{3}\right)$ & 8.3 & 0.58 & 3 \\
\hline Hardness $\left(\mathrm{mg} / \mathrm{L}\right.$ as $\left.\mathrm{CaCO}_{3}\right)$ & 15.7 & 3.1 & 3 \\
\hline Standard Plate Count (CFU/ml) & 166.0 & 2.8 & 2 \\
\hline Acridine Orange Direct Counts (cells/g) & $1.3 \times 10^{8}$ & $6.7 \times 10^{7}$ & 1 \\
\hline Acid Phosphatase $(\mu \mathrm{g} / \mathrm{g})$ & 64.2 & 8.6 & 3 \\
\hline Alkaline Phosphatase $(\mu \mathrm{g} / \mathrm{g})$ & 173.3 & 152.2 & 3 \\
\hline Dehydrogenase $(\mu \mathrm{g} / \mathrm{g})$ & 34.0 & 21.3 & 3 \\
\hline Galactosidase $(\mu \mathrm{g} / \mathrm{g})$ & 15.2 & 11.7 & 3 \\
\hline Glucosidase $(\mu \mathrm{g} / \mathrm{g})$ & 122.0 & 15.4 & 3 \\
\hline E. coli 0157:H7 (CFU/100ml) & 12.5 & 0 & 3 \\
\hline Shigella sp. (CFU/100ml) & 5.0 & 0 & 3 \\
\hline Bacteriophage (PUF/ml) & 0.50 & 0 & 3 \\
\hline Giardia sp.(cysts/L) & 2.0 & 0 & 1 \\
\hline Cryptosporidium sp. (cysts/L) & 1.0 & 0 & 1 \\
\hline
\end{tabular}


Table 7. Summary statistics for February 2011, site 2

\begin{tabular}{|c|c|c|c|}
\hline Variable & Mean & Std Dev & $\mathbf{N}$ \\
\hline Air Temperature $\left({ }^{\circ} \mathrm{C}\right)$ & 14.6 & 0 & 1 \\
\hline Water Temperature $\left({ }^{\circ} \mathrm{C}\right)$ & 10.7 & 0 & 1 \\
\hline $\mathrm{pH}$ & 8.2 & 0 & 1 \\
\hline Conductivity ( $\mu$ mohs) & 307.0 & 0 & 1 \\
\hline Dissolved Oxygen (mg/L as $\mathrm{O}_{2}$ ) & 9.3 & 0 & 1 \\
\hline Discharge $\left(\mathrm{m}^{3} / \mathrm{sec}\right)$ & 0.03 & 0 & 1 \\
\hline Fecal Coliform - Water (CFU/100ml) & 629.6 & 0 & 3 \\
\hline Total Coliform - Water (CFU/100ml) & 148.1 & 357.2 & 3 \\
\hline Fecal Coliform - Sediment (CFU/100ml) & 25.0 & 64.2 & 2 \\
\hline Total Coliform - Sediment (CFU/100ml) & 5950.0 & 0 & 2 \\
\hline Colilert (MPN/100ml) & 84.5 & 8343.86 & 1 \\
\hline Nitrates (mg/L) & 0.40 & 0 & 1 \\
\hline Phosphates (mg/L) & 0.40 & 0.17 & 3 \\
\hline Ammonia (mg/L) & .012 & 0.18 & 3 \\
\hline Biochemical Oxygen Demand (mg/L as $\mathrm{O}_{2}$ ) & 1.9 & 0.06 & 3 \\
\hline Alkalinity $\left(\mathrm{mg} / \mathrm{L}\right.$ as $\left.\mathrm{CaCO}_{3}\right)$ & 182.7 & 0.17 & 3 \\
\hline Hardness $\left(\mathrm{mg} / \mathrm{L}\right.$ as $\left.\mathrm{CaCO}_{3}\right)$ & 183.3 & 3.5 & 3 \\
\hline Standard Plate Count (CFU/ml) & 530.0 & 14.1 & 2 \\
\hline Acridine Orange Direct Counts (cells/g) & $1.5 \times 10^{8}$ & $3.8 \times 10^{7}$ & 1 \\
\hline Acid Phosphatase $(\mu \mathrm{g} / \mathrm{g})$ & 68.7 & 11.3 & 3 \\
\hline Alkaline Phosphatase $(\mu \mathrm{g} / \mathrm{g})$ & 207.4 & 12.4 & 3 \\
\hline Dehydrogenase $(\mu \mathrm{g} / \mathrm{g})$ & 21.6 & 11.6 & 3 \\
\hline Galactosidase $(\mu \mathrm{g} / \mathrm{g})$ & 9.7 & 7.4 & 3 \\
\hline Glucosidase $(\mu \mathrm{g} / \mathrm{g})$ & 288.3 & 47.3 & 3 \\
\hline E. coli 0157:H7 (CFU/100ml) & 12.5 & 0 & 3 \\
\hline Shigella sp. (CFU/100ml) & 5.0 & 0 & 3 \\
\hline Bacteriophage (PUF/ml) & 0.50 & 0 & 3 \\
\hline Giardia sp.(cysts/L) & 2.0 & 0 & 1 \\
\hline Cryptosporidium sp. (cysts/L) & 8.0 & 0 & 1 \\
\hline
\end{tabular}


Table 8. Summary statistics for February 2011, site 4

\begin{tabular}{|c|c|c|c|}
\hline Variable & Mean & Std Dev & $\mathbf{N}$ \\
\hline Air Temperature $\left({ }^{\circ} \mathrm{C}\right)$ & 14.8 & 0 & 1 \\
\hline Water Temperature $\left({ }^{\circ} \mathrm{C}\right)$ & 10.6 & 0 & 1 \\
\hline $\mathrm{pH}$ & 8.2 & 0 & 1 \\
\hline Conductivity ( $\mu$ mohs) & 288.0 & 0 & 1 \\
\hline Dissolved Oxygen (mg/L as $\mathrm{O}_{2}$ ) & 9.7 & 0 & 1 \\
\hline Discharge $\left(\mathrm{m}^{3} / \mathrm{sec}\right)$ & 0.17 & 0 & 1 \\
\hline Fecal Coliform - Water (CFU/100ml) & 1296.3 & 357.2 & 3 \\
\hline Total Coliform - Water (CFU/100ml) & 1407.4 & 1218.9 & 3 \\
\hline Fecal Coliform - Sediment (CFU/100ml) & 25.0 & 0 & 2 \\
\hline Total Coliform - Sediment (CFU/100ml) & 1600.0 & 2121.3 & 2 \\
\hline Colilert (MPN/100ml) & 110.6 & 0 & 1 \\
\hline Nitrates (mg/L) & 1.43 & 0.78 & 1 \\
\hline Phosphates (mg/L) & 0.26 & 0.04 & 3 \\
\hline Ammonia (mg/L) & 0.11 & 0.02 & 3 \\
\hline Biochemical Oxygen Demand (mg/L as $\mathrm{O}_{2}$ ) & 2.2 & 0.11 & 3 \\
\hline Alkalinity $\left(\mathrm{mg} / \mathrm{L}\right.$ as $\left.\mathrm{CaCO}_{3}\right)$ & 169.0 & 1.7 & 3 \\
\hline Hardness $\left(\mathrm{mg} / \mathrm{L}\right.$ as $\left.\mathrm{CaCO}_{3}\right)$ & 189.3 & 15.4 & 3 \\
\hline Standard Plate Count (CFU/ml) & 534.0 & 65.1 & 2 \\
\hline Acridine Orange Direct Counts (cells/g) & $1.6 \times 10^{8}$ & $8.7 \times 10^{7}$ & 1 \\
\hline Acid Phosphatase $(\mu \mathrm{g} / \mathrm{g})$ & 69.6 & 20.7 & 3 \\
\hline Alkaline Phosphatase $(\mu \mathrm{g} / \mathrm{g})$ & 167.2 & 92.5 & 3 \\
\hline Dehydrogenase $(\mu \mathrm{g} / \mathrm{g})$ & 17.0 & 3.5 & 3 \\
\hline Galactosidase $(\mu \mathrm{g} / \mathrm{g})$ & 7.9 & 4.2 & 3 \\
\hline Glucosidase $(\mu \mathrm{g} / \mathrm{g})$ & 70.3 & 56.1 & 3 \\
\hline E. coli O157:H7 (CFU/100ml) & 12.5 & 0 & 3 \\
\hline Shigella sp. (CFU/100ml) & 5.0 & 0 & 3 \\
\hline Bacteriophage (PUF/ml) & 334.2 & 576.6 & 3 \\
\hline Giardia sp.(cysts/L) & 7.7 & 0 & 1 \\
\hline Cryptosporidium sp. (cysts/L) & 2.6 & 0 & 1 \\
\hline
\end{tabular}


Table 9. Summary statistics for February 2011, site 7

\begin{tabular}{|c|c|c|c|}
\hline Variable & Mean & Std Dev & $\mathbf{N}$ \\
\hline Air Temperature $\left({ }^{\circ} \mathrm{C}\right)$ & 15.0 & 0 & 1 \\
\hline Water Temperature $\left({ }^{\circ} \mathrm{C}\right)$ & 12.3 & 0 & 1 \\
\hline $\mathrm{pH}$ & 7.7 & 0 & 1 \\
\hline Conductivity ( $\mu$ mohs) & 238.0 & 0 & 1 \\
\hline Dissolved Oxygen (mg/L as $\mathrm{O}_{2}$ ) & 8.7 & 0 & 1 \\
\hline Discharge $\left(\mathrm{m}^{3} / \mathrm{sec}\right)$ & 0.22 & 0 & 1 \\
\hline Fecal Coliform - Water (CFU/100ml) & 55.6 & 0 & 3 \\
\hline Total Coliform - Water (CFU/100ml) & 55.6 & 0 & 3 \\
\hline Fecal Coliform - Sediment (CFU/100ml) & 25.0 & 0 & 2 \\
\hline Total Coliform - Sediment (CFU/100ml) & 125.0 & 35.4 & 2 \\
\hline Colilert (MPN/100ml) & 1.0 & 0 & 1 \\
\hline Nitrates (mg/L) & 1.4 & 0.42 & 3 \\
\hline Phosphates (mg/L) & 0.34 & 0.16 & 3 \\
\hline Ammonia (mg/L) & 0.08 & 0.02 & 3 \\
\hline Biochemical Oxygen Demand (mg/L as $\mathrm{O}_{2}$ ) & 1.8 & 0.10 & 3 \\
\hline Alkalinity $\left(\mathrm{mg} / \mathrm{L}\right.$ as $\left.\mathrm{CaCO}_{3}\right)$ & 143.3 & 2.1 & 3 \\
\hline Hardness $\left(\mathrm{mg} / \mathrm{L}\right.$ as $\left.\mathrm{CaCO}_{3}\right)$ & 152.3 & 7.4 & 3 \\
\hline Standard Plate Count (CFU/ml) & 172.0 & 17.0 & 2 \\
\hline Acridine Orange Direct Counts (cells/g) & $1.4 \times 10^{8}$ & $1.4 \times 10^{7}$ & 1 \\
\hline Acid Phosphatase $(\mu \mathrm{g} / \mathrm{g})$ & 51.8 & 25.6 & 3 \\
\hline Alkaline Phosphatase $(\mu \mathrm{g} / \mathrm{g})$ & 236.7 & 83.7 & 3 \\
\hline Dehydrogenase $(\mu \mathrm{g} / \mathrm{g})$ & 18.5 & 12.4 & 3 \\
\hline Galactosidase $(\mu \mathrm{g} / \mathrm{g})$ & 3.5 & 0.27 & 3 \\
\hline Glucosidase $(\mu \mathrm{g} / \mathrm{g})$ & 32.0 & 27.2 & 3 \\
\hline E. coli O157:H7 (CFU/100ml) & 12.5 & 0 & 3 \\
\hline Shigella sp. (CFU/100ml) & 5.0 & 0 & 3 \\
\hline Bacteriophage (PUF/ml) & 667.0 & 1154.4 & 3 \\
\hline Giardia sp.(cysts/L) & 4.0 & 0 & 1 \\
\hline Cryptosporidium sp. (cysts/L) & 2.0 & 0 & 1 \\
\hline
\end{tabular}


Table 10. Summary statistics for February 2011, site 10

\begin{tabular}{|c|c|c|c|}
\hline Variable & Mean & Std Dev & $\mathbf{N}$ \\
\hline Air Temperature $\left({ }^{\circ} \mathrm{C}\right)$ & 14.6 & 0 & 1 \\
\hline Water Temperature $\left({ }^{\circ} \mathrm{C}\right)$ & 11.0 & 0 & 1 \\
\hline $\mathrm{pH}$ & 8.0 & 0 & 1 \\
\hline Conductivity ( $\mu$ mohs) & 150.9 & 0 & 1 \\
\hline Dissolved Oxygen (mg/L as $\mathrm{O}_{2}$ ) & 10.2 & 0 & 1 \\
\hline Discharge $\left(\mathrm{m}^{3} / \mathrm{sec}\right)$ & 0.1 & 0 & 1 \\
\hline Fecal Coliform - Water (CFU/100ml) & 129.6 & 84.9 & 3 \\
\hline Total Coliform - Water (CFU/100ml) & 111.13 & 0 & 3 \\
\hline Fecal Coliform - Sediment (CFU/100ml) & 337.5 & 17.7 & 2 \\
\hline Total Coliform - Sediment (CFU/100ml) & 3650.0 & 565.7 & 2 \\
\hline Colilert (MPN/100ml) & 330.9 & 0 & 1 \\
\hline Nitrates (mg/L) & 19 & 0.36 & 3 \\
\hline Phosphates (mg/L) & 0.36 & 0.13 & 3 \\
\hline Ammonia (mg/L) & 0.06 & 0.05 & 3 \\
\hline Biochemical Oxygen Demand (mg/L as $\mathrm{O}_{2}$ ) & 2.01 & 0.10 & 3 \\
\hline Alkalinity $\left(\mathrm{mg} / \mathrm{L}\right.$ as $\left.\mathrm{CaCO}_{3}\right)$ & 95.7 & 0.58 & 3 \\
\hline Hardness $\left(\mathrm{mg} / \mathrm{L}\right.$ as $\left.\mathrm{CaCO}_{3}\right)$ & 114.0 & 2.0 & 3 \\
\hline Standard Plate Count (CFU/ml) & 400.0 & 62.2 & 2 \\
\hline Acridine Orange Direct Counts (cells/g) & $1.8 \times 10^{8}$ & $5.5 \times 10^{7}$ & 1 \\
\hline Acid Phosphatase $(\mu \mathrm{g} / \mathrm{g})$ & 36.4 & 22.9 & 3 \\
\hline Alkaline Phosphatase $(\mu \mathrm{g} / \mathrm{g})$ & 71.9 & 23.4 & 3 \\
\hline Dehydrogenase $(\mu \mathrm{g} / \mathrm{g})$ & 18.4 & 2.3 & 3 \\
\hline Galactosidase $(\mu \mathrm{g} / \mathrm{g})$ & 10.6 & 4.1 & 3 \\
\hline Glucosidase $(\mu \mathrm{g} / \mathrm{g})$ & 83.0 & 46.7 & 3 \\
\hline E. coli 0157:H7 (CFU/100ml) & 12.5 & 0 & 3 \\
\hline Shigella sp. (CFU/100ml) & 5.0 & 0 & 3 \\
\hline Bacteriophage (PUF/ml) & 7.0 & 11.3 & 3 \\
\hline Giardia sp.(cysts/L) & 14.0 & 0 & 1 \\
\hline Cryptosporidium sp. (cysts/L) & 4.0 & 0 & 1 \\
\hline
\end{tabular}


Table 11. Summary statistics of February 2011, site 13

\begin{tabular}{|c|c|c|c|}
\hline Variable & Mean & Std Dev & $\mathbf{N}$ \\
\hline Air Temperature $\left({ }^{\circ} \mathrm{C}\right)$ & 15.7 & 0 & 1 \\
\hline Water Temperature $\left({ }^{\circ} \mathrm{C}\right)$ & 8.3 & 0 & 1 \\
\hline $\mathrm{pH}$ & 7.8 & 0 & 1 \\
\hline Conductivity ( $\mu$ mohs) & 41.1 & 0 & 1 \\
\hline Dissolved Oxygen (mg/L as $\mathrm{O}_{2}$ ) & 10.9 & 0 & 1 \\
\hline Discharge $\left(\mathrm{m}^{3} / \mathrm{sec}\right)$ & 0.09 & 0 & 1 \\
\hline Fecal Coliform - Water (CFU/100ml) & 55.5 & 0 & 3 \\
\hline Total Coliform - Water (CFU/100ml) & 129.6 & 84.7 & 3 \\
\hline Fecal Coliform - Sediment (CFU/100ml) & 25.0 & 0 & 2 \\
\hline Total Coliform - Sediment (CFU/100ml) & 50.0 & 0 & 2 \\
\hline Colilert (MPN/100ml) & 13.5 & 0 & 1 \\
\hline Nitrates $(\mathrm{mg} / \mathrm{L})$ & 0.40 & 0.26 & 3 \\
\hline Phosphates (mg/L) & 0.51 & 0.56 & 3 \\
\hline Ammonia (mg/L) & 0.10 & 0.02 & 3 \\
\hline Biochemical Oxygen Demand (mg/L as $\mathrm{O}_{2}$ ) & 2.3 & 0.02 & 3 \\
\hline Alkalinity $\left(\mathrm{mg} / \mathrm{L}\right.$ as $\left.\mathrm{CaCO}_{3}\right)$ & 25.7 & 1.5 & 3 \\
\hline Hardness $\left(\mathrm{mg} / \mathrm{L}\right.$ as $\left.\mathrm{CaCO}_{3}\right)$ & 51.0 & 1.0 & 3 \\
\hline Standard Plate Count (CFU/ml) & 380.0 & 33.9 & 2 \\
\hline Acridine Orange Direct Counts (cells/g) & $1.7 \times 10^{8}$ & $1.5 \times 10^{7}$ & 1 \\
\hline Acid Phosphatase $(\mu \mathrm{g} / \mathrm{g})$ & 134.1 & 51.3 & 3 \\
\hline Alkaline Phosphatase $(\mu \mathrm{g} / \mathrm{g})$ & 37.9 & 5.6 & 3 \\
\hline Dehydrogenase $(\mu \mathrm{g} / \mathrm{g})$ & 20.3 & 6.5 & 3 \\
\hline Galactosidase $(\mu \mathrm{g} / \mathrm{g})$ & 37.5 & 4.2 & 3 \\
\hline Glucosidase $(\mu \mathrm{g} / \mathrm{g})$ & 21.0 & 3.7 & 3 \\
\hline E. coli 0157:H7 (CFU/100ml) & 12.5 & 0 & 3 \\
\hline Shigella sp. (CFU/100ml) & 5.0 & 0 & 3 \\
\hline Bacteriophage (PUF/ml) & 0.50 & 0 & 3 \\
\hline Giardia sp.(cysts/L) & 11.8 & 0 & 1 \\
\hline Cryptosporidium sp. (cysts/L) & 7.1 & 0 & 1 \\
\hline
\end{tabular}


Table 12. Summary statistics for February 2011, site 14

\begin{tabular}{|c|c|c|c|}
\hline Variable & Mean & Std Dev & $\mathbf{N}$ \\
\hline Air Temperature $\left({ }^{\circ} \mathrm{C}\right)$ & 14.8 & 0 & 1 \\
\hline Water Temperature $\left({ }^{\circ} \mathrm{C}\right)$ & 8.4 & 0 & 1 \\
\hline $\mathrm{pH}$ & 7.9 & 0 & 1 \\
\hline Conductivity ( $\mu$ mohs) & 18.5 & 0 & 1 \\
\hline Dissolved Oxygen (mg/L as $\mathrm{O}_{2}$ ) & 9.9 & 0 & 1 \\
\hline Discharge $\left(\mathrm{m}^{3} / \mathrm{sec}\right)$ & 0.02 & 0 & 1 \\
\hline Fecal Coliform - Water (CFU/100ml) & 55.5 & 0 & 3 \\
\hline Total Coliform - Water (CFU/100ml) & 166.7 & 147.0 & 3 \\
\hline Fecal Coliform - Sediment (CFU/100ml) & 37.5 & 17.7 & 2 \\
\hline Total Coliform - Sediment (CFU/100ml) & 25.0 & 0 & 2 \\
\hline Colilert (MPN/100ml) & 1.0 & 0 & 1 \\
\hline Nitrates (mg/L) & 0.77 & 0.29 & 3 \\
\hline Phosphates (mg/L) & 0.19 & 0.05 & 3 \\
\hline Ammonia (mg/L) & 0.08 & 0.02 & 3 \\
\hline Biochemical Oxygen Demand (mg/L as $\mathrm{O}_{2}$ ) & 2.5 & 0.12 & 3 \\
\hline Alkalinity $\left(\mathrm{mg} / \mathrm{L}\right.$ as $\left.\mathrm{CaCO}_{3}\right)$ & 12.0 & 1.0 & 3 \\
\hline Hardness $\left(\mathrm{mg} / \mathrm{L}\right.$ as $\left.\mathrm{CaCO}_{3}\right)$ & 34.3 & 8.1 & 3 \\
\hline Standard Plate Count (CFU/ml) & 134.0 & 42.4 & 2 \\
\hline Acridine Orange Direct Counts (cells/g) & $1.3 \times 10^{8}$ & $1.0 \times 10^{8}$ & 1 \\
\hline Acid Phosphatase $(\mu \mathrm{g} / \mathrm{g})$ & 79.2 & 17.6 & 3 \\
\hline Alkaline Phosphatase $(\mu \mathrm{g} / \mathrm{g})$ & 201.3 & 36.7 & 3 \\
\hline Dehydrogenase $(\mu \mathrm{g} / \mathrm{g})$ & 24.2 & 9.1 & 3 \\
\hline Galactosidase $(\mu \mathrm{g} / \mathrm{g})$ & 33.8 & 3.1 & 3 \\
\hline Glucosidase $(\mu \mathrm{g} / \mathrm{g})$ & 20.2 & 17.2 & 3 \\
\hline E. coli O157:H7 (CFU/100ml) & 12.5 & 0 & 3 \\
\hline Shigella sp. (CFU/100ml) & 5.0 & 0 & 3 \\
\hline Bacteriophage (PUF/ml) & 0.50 & 0 & 3 \\
\hline Giardia sp.(cysts/L) & 0 & 0 & 0 \\
\hline Cryptosporidium sp. (cysts/L) & 0 & 0 & 0 \\
\hline
\end{tabular}


Table 13. Summary statistics for March 2011, site 2

\begin{tabular}{|c|c|c|c|}
\hline Variable & Mean & Std Dev & $\mathbf{N}$ \\
\hline Air Temperature $\left({ }^{\circ} \mathrm{C}\right)$ & 17.0 & 0 & 1 \\
\hline Water Temperature $\left({ }^{\circ} \mathrm{C}\right)$ & 12.1 & 0 & 1 \\
\hline $\mathrm{pH}$ & 8.4 & 0 & 1 \\
\hline Conductivity ( $\mu$ mohs) & 140.0 & 0 & 1 \\
\hline Dissolved Oxygen (mg/L as $\mathrm{O}_{2}$ ) & 10.0 & 0 & 1 \\
\hline Discharge $\left(\mathrm{m}^{3} / \mathrm{sec}\right)$ & 0.84 & 0 & 1 \\
\hline Fecal Coliform - Water (CFU/100ml) & 450.0 & 377.5 & 3 \\
\hline Total Coliform - Water (CFU/100ml) & 466.7 & 208.2 & 3 \\
\hline Fecal Coliform - Sediment (CFU/100ml) & 37.5 & 17.7 & 2 \\
\hline Total Coliform - Sediment (CFU/100ml) & 1075.0 & 1308.2 & 2 \\
\hline Colilert (MPN/100ml) & 214.3 & 0 & 1 \\
\hline Nitrates $(\mathrm{mg} / \mathrm{L})$ & 1.3 & 0.12 & 3 \\
\hline Phosphates (mg/L) & 0.26 & 0.06 & 3 \\
\hline Ammonia $(\mathrm{mg} / \mathrm{L})$ & 0.08 & 0.01 & 3 \\
\hline Biochemical Oxygen Demand (mg/L as $\mathrm{O}_{2}$ ) & 0.89 & 0.11 & 3 \\
\hline Alkalinity $\left(\mathrm{mg} / \mathrm{L}\right.$ as $\left.\mathrm{CaCO}_{3}\right)$ & 154.7 & 11.0 & 3 \\
\hline Hardness $\left(\mathrm{mg} / \mathrm{L}\right.$ as $\left.\mathrm{CaCO}_{3}\right)$ & 186.7 & 5.9 & 3 \\
\hline Standard Plate Count (CFU/ml) & 458.0 & 8.5 & 2 \\
\hline Acridine Orange Direct Counts (cells/g) & $1.3 \times 10^{8}$ & $6.8 \times 10^{7}$ & 1 \\
\hline Acid Phosphatase $(\mu \mathrm{g} / \mathrm{g})$ & 22.0 & 3.4 & 3 \\
\hline Alkaline Phosphatase $(\mu \mathrm{g} / \mathrm{g})$ & 113.5 & 82.2 & 3 \\
\hline Dehydrogenase $(\mu \mathrm{g} / \mathrm{g})$ & 84.4 & 6.7 & 3 \\
\hline Galactosidase $(\mu \mathrm{g} / \mathrm{g})$ & 67.2 & 10.4 & 3 \\
\hline Glucosidase $(\mu \mathrm{g} / \mathrm{g})$ & 274.6 & 206.0 & 3 \\
\hline E. coli 0157:H7 (CFU/100ml) & 12.5 & 0 & 3 \\
\hline Shigella sp. (CFU/100ml) & 5.0 & 0 & 3 \\
\hline Bacteriophage (PUF/ml) & 0.50 & 0 & 3 \\
\hline Giardia sp.(cysts/L) & 22.0 & 0 & 1 \\
\hline Cryptosporidium sp. (cysts/L) & 10.0 & 0 & 1 \\
\hline
\end{tabular}


Table 14. Summary statistics for March 2011, site 4

\begin{tabular}{|c|c|c|c|}
\hline Variable & Mean & Std Dev & $\mathbf{N}$ \\
\hline Air Temperature $\left({ }^{\circ} \mathrm{C}\right)$ & 14.3 & 0 & 1 \\
\hline Water Temperature $\left({ }^{\circ} \mathrm{C}\right)$ & 12.2 & 0 & 1 \\
\hline $\mathrm{pH}$ & 8.3 & 0 & 1 \\
\hline Conductivity ( $\mu$ mohs) & 128.0 & 0 & 1 \\
\hline Dissolved Oxygen (mg/L as $\mathrm{O}_{2}$ ) & 9.8 & 0 & 1 \\
\hline Discharge $\left(\mathrm{m}^{3} / \mathrm{sec}\right)$ & 0.68 & 0 & 1 \\
\hline Fecal Coliform - Water (CFU/100ml) & 766.7 & 152.8 & 3 \\
\hline Total Coliform - Water (CFU/100ml) & 900.0 & 1300.0 & 3 \\
\hline Fecal Coliform - Sediment (CFU/100ml) & 25.0 & 0 & 2 \\
\hline Total Coliform - Sediment (CFU/100ml) & 2775.0 & 1449.6 & 2 \\
\hline Colilert (MPN/100ml) & 461.1 & 0 & 1 \\
\hline Nitrates (mg/L) & 1.4 & 0.21 & 3 \\
\hline Phosphates (mg/L) & 0.39 & 0.05 & 3 \\
\hline Ammonia (mg/L) & 0.08 & 0.01 & 3 \\
\hline Biochemical Oxygen Demand (mg/L as $\mathrm{O}_{2}$ ) & 1.0 & 0.06 & 3 \\
\hline Alkalinity $\left(\mathrm{mg} / \mathrm{L}\right.$ as $\left.\mathrm{CaCO}_{3}\right)$ & 136.0 & 1.7 & 3 \\
\hline Hardness (mg/L as $\left.\mathrm{CaCO}_{3}\right)$ & 168.4 & 4.5 & 3 \\
\hline Standard Plate Count (CFU/ml) & 412.0 & 39.6 & 2 \\
\hline Acridine Orange Direct Counts (cells/g) & $1.0 \times 10^{8}$ & $8.5 \times 10^{7}$ & 1 \\
\hline Acid Phosphatase $(\mu \mathrm{g} / \mathrm{g})$ & 54.1 & 39.3 & 3 \\
\hline Alkaline Phosphatase $(\mu \mathrm{g} / \mathrm{g})$ & 30.0 & 17.0 & 3 \\
\hline Dehydrogenase $(\mu \mathrm{g} / \mathrm{g})$ & 16.2 & 22.0 & 3 \\
\hline Galactosidase $(\mu \mathrm{g} / \mathrm{g})$ & 68.9 & 10.4 & 3 \\
\hline Glucosidase $(\mu \mathrm{g} / \mathrm{g})$ & 504.2 & 326.1 & 3 \\
\hline E. coli O157:H7 (CFU/100ml) & 12.5 & 0 & 3 \\
\hline Shigella sp. (CFU/100ml) & 5.0 & 0 & 3 \\
\hline Bacteriophage (PUF/mI) & 0.50 & 0 & 3 \\
\hline Giardia sp.(cysts/L) & 12.0 & 0 & 1 \\
\hline Cryptosporidium sp. (cysts/L) & 4.0 & 0 & 1 \\
\hline
\end{tabular}


Table 15. Summary statistics for March 2011, site 7

\begin{tabular}{llll}
\hline Variable & Mean & Std Dev & N \\
Air Temperature $\left({ }^{\circ} \mathrm{C}\right)$ & 15.6 & 0 & 1 \\
Water Temperature $\left({ }^{\circ} \mathrm{C}\right)$ & 12.5 & 0 & 1 \\
$\mathrm{pH}$ & 7.9 & 0 & 1 \\
Conductivity $(\mu \mathrm{mohs})$ & 102.0 & 0 & 1 \\
Dissolved Oxygen $\left(\mathrm{mg} / \mathrm{L}\right.$ as $\left.\mathrm{O}_{2}\right)$ & 9.1 & 0 & 1 \\
Discharge $\left(\mathrm{m}^{3} / \mathrm{sec}\right)$ & 0.46 & 0 & 1 \\
Fecal Coliform - Water $(\mathrm{CFU} / 100 \mathrm{ml})$ & 50.0 & 0 & 3 \\
Total Coliform - Water $(\mathrm{CFU} / 100 \mathrm{ml})$ & 300.0 & 264.6 & 3 \\
Fecal Coliform - Sediment $(\mathrm{CFU} / 100 \mathrm{ml})$ & 25.0 & 0 & 2 \\
Total Coliform - Sediment $(\mathrm{CFU} / 100 \mathrm{ml})$ & 150.0 & 70.7 & 2 \\
Colilert $(\mathrm{MPN} / 100 \mathrm{ml})$ & 1.0 & 0 & 1 \\
Nitrates $(\mathrm{mg} / \mathrm{L})$ & 1.3 & 0.38 & 3 \\
Phosphates $(\mathrm{mg} / \mathrm{L})$ & 0.43 & 0.09 & 3 \\
Ammonia $(\mathrm{mg} / \mathrm{L})$ & 0.11 & 0.01 & 3 \\
Biochemical Oxygen Demand $\left(\mathrm{mg} / \mathrm{L}\right.$ as $\left.\mathrm{O}_{2}\right)$ & 0.95 & 0.12 & 3 \\
Alkalinity $(\mathrm{mg} / \mathrm{L}$ as CaCO $)$ & 131.3 & 1.5 & 3 \\
Hardness $\left(\mathrm{mg} / \mathrm{L}\right.$ as CaCO $\left.{ }_{3}\right)$ & 138.0 & 3.5 & 3 \\
Standard Plate Count $(\mathrm{CFU} / \mathrm{ml})$ & 246.0 & 127.3 & 2 \\
Acridine Orange Direct Counts $(\mathrm{cells} / \mathrm{g})$ & $1.0 \times 10^{8}$ & $3.3 \times 10^{7}$ & 1 \\
Acid Phosphatase $(\mu \mathrm{gg} / \mathrm{g})$ & 85.4 & 68.9 & 3 \\
Alkaline Phosphatase $(\mu \mathrm{gg} / \mathrm{g})$ & 50.5 & 31.5 & 3 \\
Dehydrogenase $(\mu \mathrm{gg} / \mathrm{g})$ & 28.5 & 7.23 & 3 \\
Galactosidase $(\mu \mathrm{gg} / \mathrm{g})$ & 58.6 & 316.7 & 3 \\
Glucosidase $(\mu \mathrm{g} / \mathrm{g})$ & 272.2 & 3189.6 & 3 \\
E. coli O157:H7 $(\mathrm{CFU} / 100 \mathrm{ml})$ & 12.5 & 0 & 3 \\
Shigella sp. $(\mathrm{CFU} / 100 \mathrm{ml})$ & 5.0 & 0 & 3 \\
Bacteriophage $(\mathrm{PUF} / \mathrm{ml})$ & 0.50 & 0 & 3 \\
Giardia $s p .(\mathrm{cysts} / \mathrm{L})$ & 10.0 & 0 & 1 \\
Cryptosporidium sp. $(\mathrm{cysts} / \mathrm{L})$ & 2.0 & 0 & 1 \\
\hline
\end{tabular}


Table 16. Summary statistics for March 2011, site 10

\begin{tabular}{llll}
\hline Variable & Mean & Std Dev & N \\
Air Temperature $\left({ }^{\circ} \mathrm{C}\right)$ & 17.1 & 0 & 1 \\
Water Temperature $\left({ }^{\circ} \mathrm{C}\right)$ & 12.1 & 0 & 1 \\
$\mathrm{pH}$ & 8.0 & 0 & 1 \\
Conductivity $(\mu \mathrm{mohs})$ & 68.0 & 0 & 1 \\
Dissolved Oxygen $\left(\mathrm{mg} / \mathrm{L}\right.$ as $\left.\mathrm{O}_{2}\right)$ & 9.9 & 0 & 1 \\
Discharge $\left(\mathrm{m}^{3} / \mathrm{sec}\right)$ & 0.30 & 0 & 1 \\
Fecal Coliform - Water $(\mathrm{CFU} / 100 \mathrm{ml})$ & 166.7 & 115.5 & 3 \\
Total Coliform - Water $(\mathrm{CFU} / 100 \mathrm{ml})$ & 133.3 & 144.3 & 3 \\
Fecal Coliform - Sediment $(\mathrm{CFU} / 100 \mathrm{ml})$ & 25.0 & 0 & 2 \\
Total Coliform - Sediment $(\mathrm{CFU} / 100 \mathrm{ml})$ & 50.0 & 0 & 2 \\
Colilert $(\mathrm{MPN} / 100 \mathrm{ml})$ & 21.6 & 0 & 1 \\
Nitrates $(\mathrm{mg} / \mathrm{L})$ & 1.3 & 0.17 & 3 \\
Phosphates $(\mathrm{mg} / \mathrm{L})$ & 0.12 & 0.03 & 3 \\
Ammonia $(\mathrm{mg} / \mathrm{L})$ & 0.06 & 0.01 & 3 \\
Biochemical Oxygen Demand $\left(\mathrm{mg} / \mathrm{L}\right.$ as $\left.\mathrm{O}_{2}\right)$ & 0.82 & 0.03 & 3 \\
Alkalinity $(\mathrm{mg} / \mathrm{L}$ as CaCO $)$ & 92.0 & 5.2 & 3 \\
Hardness $\left(\mathrm{mg} / \mathrm{L}\right.$ as CaCO $\left.{ }_{3}\right)$ & 100.0 & 7.2 & 3 \\
Standard Plate Count $(\mathrm{CFU} / \mathrm{ml})$ & 260.0 & 56.6 & 2 \\
Acridine Orange Direct Counts $(\mathrm{cells} / \mathrm{g})$ & $6.7 \times 10^{7}$ & $2.2 \times 10^{7}$ & 1 \\
Acid Phosphatase $(\mu \mathrm{gg} / \mathrm{g})$ & 56.5 & 12.8 & 3 \\
Alkaline Phosphatase $(\mu \mathrm{gg} / \mathrm{g})$ & 85.5 & 19.0 & 3 \\
Dehydrogenase $(\mu \mathrm{gg} / \mathrm{g})$ & 49.5 & 44.5 & 3 \\
Galactosidase $(\mu \mathrm{gg} / \mathrm{g})$ & 52.6 & 7.2 & 3 \\
Glucosidase $(\mu \mathrm{g} / \mathrm{g})$ & 420.0 & 36.3 & 3 \\
E. coli O157:H7 $(\mathrm{CFU} / 100 \mathrm{ml})$ & 12.5 & 0 & 3 \\
Shigella sp. $(\mathrm{CFU} / 100 \mathrm{ml})$ & 5.0 & 0 & 3 \\
Bacteriophage $(\mathrm{PUF} / \mathrm{ml})$ & 0.50 & 0 & 3 \\
Giardia $s p .(\mathrm{cysts} / \mathrm{L})$ & 2.0 & 0 & 1 \\
Cryptosporidium sp. $(\mathrm{cysts} / \mathrm{L})$ & 2.0 & 0 & 1 \\
\hline
\end{tabular}


Table 17. Summary statistics for March 2011, site 13

\begin{tabular}{|c|c|c|c|}
\hline Variable & Mean & Std Dev & $\mathbf{N}$ \\
\hline Air Temperature $\left({ }^{\circ} \mathrm{C}\right)$ & 18.1 & 0 & 1 \\
\hline Water Temperature $\left({ }^{\circ} \mathrm{C}\right)$ & 12.5 & 0 & 1 \\
\hline $\mathrm{pH}$ & 8.0 & 0 & 1 \\
\hline Conductivity ( $\mu$ mohs) & 17.0 & 0 & 1 \\
\hline Dissolved Oxygen (mg/L as $\mathrm{O}_{2}$ ) & 9.2 & 0 & 1 \\
\hline Discharge $\left(\mathrm{m}^{3} / \mathrm{sec}\right)$ & 0.1 & 0 & 1 \\
\hline Fecal Coliform - Water (CFU/100ml) & 50.0 & 0 & 3 \\
\hline Total Coliform - Water (CFU/100ml) & 83.3 & 28.7 & 3 \\
\hline Fecal Coliform - Sediment (CFU/100ml) & 25.0 & 0 & 2 \\
\hline Total Coliform - Sediment (CFU/100ml) & 37.5 & 17.7 & 2 \\
\hline Colilert (MPN/100ml) & 16.1 & 0 & 1 \\
\hline Nitrates (mg/L) & 0.33 & 0.15 & 3 \\
\hline Phosphates (mg/L) & 0.26 & 0.05 & 3 \\
\hline Ammonia (mg/L) & 0.07 & 0.01 & 3 \\
\hline Biochemical Oxygen Demand (mg/L as $\mathrm{O}_{2}$ ) & 0.84 & 0.11 & 3 \\
\hline Alkalinity $\left(\mathrm{mg} / \mathrm{L}\right.$ as $\left.\mathrm{CaCO}_{3}\right)$ & 63.3 & 7.2 & 3 \\
\hline Hardness $\left(\mathrm{mg} / \mathrm{L}\right.$ as $\left.\mathrm{CaCO}_{3}\right)$ & 32.0 & 3.6 & 3 \\
\hline Standard Plate Count (CFU/ml) & 224.0 & 0 & 2 \\
\hline Acridine Orange Direct Counts (cells/g) & $7.8 \times 10^{7}$ & $3.3 \times 10^{7}$ & 1 \\
\hline Acid Phosphatase $(\mu \mathrm{g} / \mathrm{g})$ & 34.6 & 23.2 & 3 \\
\hline Alkaline Phosphatase $(\mu \mathrm{g} / \mathrm{g})$ & 37.7 & 33.7 & 3 \\
\hline Dehydrogenase $(\mu \mathrm{g} / \mathrm{g})$ & 71.8 & 35.5 & 3 \\
\hline Galactosidase $(\mu \mathrm{g} / \mathrm{g})$ & 45.7 & 10.0 & 3 \\
\hline Glucosidase $(\mu \mathrm{g} / \mathrm{g})$ & 407.7 & 319.5 & 3 \\
\hline E. coli O157:H7 (CFU/100ml) & 12.5 & 0 & 3 \\
\hline Shigella sp. (CFU/100ml) & 5.0 & 0 & 3 \\
\hline Bacteriophage (PUF/ml) & 0.50 & 0 & 3 \\
\hline Giardia sp.(cysts/L) & 16.0 & 0 & 1 \\
\hline Cryptosporidium sp. (cysts/L) & 12.0 & 0 & 1 \\
\hline
\end{tabular}


Table 18. Summary statistics for March 2011, site 14

\begin{tabular}{|c|c|c|c|}
\hline Variable & Mean & Std Dev & $\mathbf{N}$ \\
\hline Air Temperature $\left({ }^{\circ} \mathrm{C}\right)$ & 18.7 & 0 & 1 \\
\hline Water Temperature $\left({ }^{\circ} \mathrm{C}\right)$ & 10.8 & 0 & 1 \\
\hline $\mathrm{pH}$ & 8.0 & 0 & 1 \\
\hline Conductivity ( $\mu$ mohs) & 9.0 & 0 & 1 \\
\hline Dissolved Oxygen (mg/L as $\mathrm{O}_{2}$ ) & 9.8 & 0 & 1 \\
\hline Discharge $\left(\mathrm{m}^{3} / \mathrm{sec}\right)$ & 0.02 & 0 & 1 \\
\hline Fecal Coliform - Water (CFU/100ml) & 50.0 & 0 & 3 \\
\hline Total Coliform - Water (CFU/100ml) & 166.7 & 115.5 & 3 \\
\hline Fecal Coliform - Sediment (CFU/100ml) & 25.0 & 0 & 2 \\
\hline Total Coliform - Sediment (CFU/100ml) & 37.5 & 17.7 & 2 \\
\hline Colilert (MPN/100ml) & 4.1 & 0 & 1 \\
\hline Nitrates (mg/L) & 0.80 & 0.30 & 3 \\
\hline Phosphates (mg/L) & 0.20 & 0.13 & 3 \\
\hline Ammonia (mg/L) & 0.07 & 0 & 3 \\
\hline Biochemical Oxygen Demand (mg/L as $\mathrm{O}_{2}$ ) & 1.3 & 0.32 & 3 \\
\hline Alkalinity $\left(\mathrm{mg} / \mathrm{L}\right.$ as $\left.\mathrm{CaCO}_{3}\right)$ & 49.0 & 3.6 & 3 \\
\hline Hardness $\left(\mathrm{mg} / \mathrm{L}\right.$ as $\left.\mathrm{CaCO}_{3}\right)$ & 25.3 & 1.5 & 3 \\
\hline Standard Plate Count (CFU/ml) & 174.0 & 8.5 & 2 \\
\hline Acridine Orange Direct Counts (cells/g) & $8.3 \times 10^{7}$ & $6.5 \times 10^{7}$ & 1 \\
\hline Acid Phosphatase $(\mu \mathrm{g} / \mathrm{g})$ & 77.9 & 14.1 & 3 \\
\hline Alkaline Phosphatase $(\mu \mathrm{g} / \mathrm{g})$ & 119.8 & 95.4 & 3 \\
\hline Dehydrogenase $(\mu \mathrm{g} / \mathrm{g})$ & 72.0 & 33.8 & 3 \\
\hline Galactosidase $(\mu \mathrm{g} / \mathrm{g})$ & 124.5 & 32.3 & 3 \\
\hline Glucosidase $(\mu \mathrm{g} / \mathrm{g})$ & 267.9 & 69.7 & 3 \\
\hline E. coli O157:H7 (CFU/100ml) & 12.5 & 0 & 3 \\
\hline Shigella sp. (CFU/100ml) & 5.0 & 0 & 3 \\
\hline Bacteriophage (PUF/ml) & 0.50 & 0 & 3 \\
\hline Giardia sp.(cysts/L) & 10.0 & 0 & 1 \\
\hline Cryptosporidium sp. (cysts/L) & 4.0 & 0 & 1 \\
\hline
\end{tabular}


Table 19. Summary statistics for April 2011, site 2

\begin{tabular}{|c|c|c|c|}
\hline Variable & Mean & Std Dev & $\mathbf{N}$ \\
\hline Air Temperature $\left({ }^{\circ} \mathrm{C}\right)$ & 14.2 & 0 & 1 \\
\hline Water Temperature $\left({ }^{\circ} \mathrm{C}\right)$ & 11.5 & 0 & 1 \\
\hline $\mathrm{pH}$ & 7.4 & 0 & 1 \\
\hline Conductivity ( $\mu$ mohs) & 244.0 & 0 & 1 \\
\hline Dissolved Oxygen (mg/L as $\mathrm{O}_{2}$ ) & 9.8 & 0 & 1 \\
\hline Discharge $\left(\mathrm{m}^{3} / \mathrm{sec}\right)$ & 1.0 & 0 & 1 \\
\hline Fecal Coliform - Water (CFU/100ml) & 2100.0 & 500.0 & 3 \\
\hline Total Coliform - Water (CFU/100ml) & 4666.7 & 4446.7 & 3 \\
\hline Fecal Coliform - Sediment (CFU/100ml) & 50.0 & 0 & 2 \\
\hline Total Coliform - Sediment (CFU/100ml) & 137.5 & 159.1 & 2 \\
\hline Colilert (MPN/100ml) & 187.2 & 0 & 1 \\
\hline Nitrates (mg/L) & 1.5 & 0.91 & 3 \\
\hline Phosphates (mg/L) & 0.45 & 0.08 & 3 \\
\hline Ammonia (mg/L) & 0.07 & 0.02 & 3 \\
\hline Biochemical Oxygen Demand (mg/L as $\mathrm{O}_{2}$ ) & 1.6 & 0.12 & 3 \\
\hline Alkalinity $\left(\mathrm{mg} / \mathrm{L}\right.$ as $\left.\mathrm{CaCO}_{3}\right)$ & 140.3 & 1.5 & 3 \\
\hline Hardness (mg/L as $\left.\mathrm{CaCO}_{3}\right)$ & 1177.7 & 10.3 & 3 \\
\hline Standard Plate Count (CFU/ml) & 680.0 & 84.9 & 2 \\
\hline Acridine Orange Direct Counts (cells/g) & $2.1 \times 10^{8}$ & $1.2 \times 10^{8}$ & 1 \\
\hline Acid Phosphatase $(\mu \mathrm{g} / \mathrm{g})$ & 8.2 & 2.9 & 3 \\
\hline Alkaline Phosphatase $(\mu \mathrm{g} / \mathrm{g})$ & 37.7 & 15.7 & 3 \\
\hline Dehydrogenase $(\mu \mathrm{g} / \mathrm{g})$ & 26.3 & 6.7 & 3 \\
\hline Galactosidase $(\mu \mathrm{g} / \mathrm{g})$ & 3.2 & 2.1 & 3 \\
\hline Glucosidase $(\mu \mathrm{g} / \mathrm{g})$ & 11.1 & 4.8 & 3 \\
\hline E. coli O157:H7 (CFU/100ml) & 12.5 & 0 & 3 \\
\hline Shigella sp. (CFU/100ml) & 5.0 & 0 & 3 \\
\hline Bacteriophage (PUF/mI) & 0.50 & 0 & 3 \\
\hline Giardia sp.(cysts/L) & 24.0 & 0 & 1 \\
\hline Cryptosporidium sp. (cysts/L) & 18.0 & 0 & 1 \\
\hline
\end{tabular}


Table 20. Summary statistics for April 2011, site 4

\begin{tabular}{|c|c|c|c|}
\hline Variable & Mean & Std Dev & $\mathbf{N}$ \\
\hline Air Temperature $\left({ }^{\circ} \mathrm{C}\right)$ & 13.8 & 0 & 1 \\
\hline Water Temperature $\left({ }^{\circ} \mathrm{C}\right)$ & 11.6 & 0 & 1 \\
\hline $\mathrm{pH}$ & 6.9 & 0 & 1 \\
\hline Conductivity ( $\mu$ mohs) & 209.0 & 0 & 1 \\
\hline Dissolved Oxygen (mg/L as $\mathrm{O}_{2}$ ) & 10.0 & 0 & 1 \\
\hline Discharge $\left(\mathrm{m}^{3} / \mathrm{sec}\right)$ & 1.0 & 0 & 1 \\
\hline Fecal Coliform - Water (CFU/100ml) & 533.3 & 152.8 & 3 \\
\hline Total Coliform - Water (CFU/100ml) & 1633.3 & 2227.9 & 3 \\
\hline Fecal Coliform - Sediment (CFU/100ml) & 175.0 & 176.8 & 2 \\
\hline Total Coliform - Sediment (CFU/100ml) & 2975.0 & 3924.4 & 2 \\
\hline Colilert (MPN/100ml) & 116.2 & 0 & 1 \\
\hline Nitrates (mg/L) & 1.2 & 0.58 & 3 \\
\hline Phosphates (mg/L) & 0.39 & 0.13 & 3 \\
\hline Ammonia (mg/L) & 0.09 & 0.01 & 3 \\
\hline Biochemical Oxygen Demand (mg/L as $\mathrm{O}_{2}$ ) & 1.5 & 0.10 & 3 \\
\hline Alkalinity $\left(\mathrm{mg} / \mathrm{L}\right.$ as $\left.\mathrm{CaCO}_{3}\right)$ & 130.3 & 2.1 & 3 \\
\hline Hardness (mg/L as $\left.\mathrm{CaCO}_{3}\right)$ & 147.3 & 3.2 & 3 \\
\hline Standard Plate Count (CFU/ml) & 775.0 & 77.8 & 2 \\
\hline Acridine Orange Direct Counts (cells/g) & $1.3 \times 10^{8}$ & $7.9 \times 10^{7}$ & 1 \\
\hline Acid Phosphatase $(\mu \mathrm{g} / \mathrm{g})$ & 8.6 & 8.1 & 3 \\
\hline Alkaline Phosphatase $(\mu \mathrm{g} / \mathrm{g})$ & 39.9 & 15.2 & 3 \\
\hline Dehydrogenase $(\mu \mathrm{g} / \mathrm{g})$ & 38.7 & 15.3 & 3 \\
\hline Galactosidase $(\mu \mathrm{g} / \mathrm{g})$ & 4.5 & 1.5 & 3 \\
\hline Glucosidase $(\mu \mathrm{g} / \mathrm{g})$ & 49.6 & 24.5 & 3 \\
\hline E. coli O157:H7 (CFU/100ml) & 12.5 & 0 & 3 \\
\hline Shigella sp. (CFU/100ml) & 5.0 & 0 & 3 \\
\hline Bacteriophage (PUF/mI) & 0.50 & 0 & 3 \\
\hline Giardia sp.(cysts/L) & 8.0 & 0 & 1 \\
\hline Cryptosporidium sp. (cysts/L) & 1.0 & 0 & 1 \\
\hline
\end{tabular}


Table 21. Summary statistics for April 2011, site 7

\begin{tabular}{|c|c|c|c|}
\hline Variable & Mean & Std Dev & $\mathbf{N}$ \\
\hline Air Temperature $\left({ }^{\circ} \mathrm{C}\right)$ & 15.3 & 0 & 1 \\
\hline Water Temperature $\left({ }^{\circ} \mathrm{C}\right)$ & 12.2 & 0 & 1 \\
\hline $\mathrm{pH}$ & 7.2 & 0 & 1 \\
\hline Conductivity ( $\mu$ mohs) & 171.7 & 0 & 1 \\
\hline Dissolved Oxygen (mg/L as $\mathrm{O}_{2}$ ) & 9.6 & 0 & 1 \\
\hline Discharge $\left(\mathrm{m}^{3} / \mathrm{sec}\right)$ & 0.01 & 0 & 1 \\
\hline Fecal Coliform - Water (CFU/100ml) & 66.7 & 28.9 & 3 \\
\hline Total Coliform - Water (CFU/100ml) & 1000.0 & 1645.5 & 3 \\
\hline Fecal Coliform - Sediment (CFU/100ml) & 25.0 & 0 & 2 \\
\hline Total Coliform - Sediment (CFU/100ml) & 1500.0 & 282.8 & 2 \\
\hline Colilert (MPN/100ml) & 5.2 & 0 & 1 \\
\hline Nitrates (mg/L) & 1.4 & 0.44 & 3 \\
\hline Phosphates (mg/L) & 0.27 & 0.04 & 3 \\
\hline Ammonia (mg/L) & 0.08 & 0.01 & 3 \\
\hline Biochemical Oxygen Demand (mg/L as $\mathrm{O}_{2}$ ) & 1.8 & 0.12 & 3 \\
\hline Alkalinity $\left(\mathrm{mg} / \mathrm{L}\right.$ as $\left.\mathrm{CaCO}_{3}\right)$ & 97.0 & 1.0 & 3 \\
\hline Hardness (mg/L as $\left.\mathrm{CaCO}_{3}\right)$ & 121.3 & 3.1 & 3 \\
\hline Standard Plate Count (CFU/ml) & 260.0 & 169.7 & 2 \\
\hline Acridine Orange Direct Counts (cells/g) & $1.6 \times 10^{8}$ & $1.6 \times 10^{8}$ & 1 \\
\hline Acid Phosphatase $(\mu \mathrm{g} / \mathrm{g})$ & 30.9 & 11.7 & 3 \\
\hline Alkaline Phosphatase $(\mu \mathrm{g} / \mathrm{g})$ & 3.3 & 0.75 & 3 \\
\hline Dehydrogenase $(\mu \mathrm{g} / \mathrm{g})$ & 67.0 & 13.6 & 3 \\
\hline Galactosidase $(\mu \mathrm{g} / \mathrm{g})$ & 13.2 & 3.3 & 3 \\
\hline Glucosidase $(\mu \mathrm{g} / \mathrm{g})$ & 7.7 & 6.3 & 3 \\
\hline E. coli O157:H7 (CFU/100ml) & 12.5 & 0 & 3 \\
\hline Shigella sp. (CFU/100ml) & 6.7 & 2.9 & 3 \\
\hline Bacteriophage (PUF/mI) & 0.50 & 0 & 3 \\
\hline Giardia sp.(cysts/L) & 4.0 & 0 & 1 \\
\hline Cryptosporidium sp. (cysts/L) & 4.0 & 0 & 1 \\
\hline
\end{tabular}


Table 22. Summary statistics for April 2011, site 10

\begin{tabular}{llll}
\hline Variable & Mean & Std Dev & N \\
Air Temperature $\left({ }^{\circ} \mathrm{C}\right)$ & 16.6 & 0 & 1 \\
Water Temperature $\left({ }^{\circ} \mathrm{C}\right)$ & 11.9 & 0 & 1 \\
$\mathrm{pH}$ & 7.6 & 0 & 1 \\
Conductivity $(\mu \mathrm{mohs})$ & 112.1 & 0 & 1 \\
Dissolved Oxygen $\left(\mathrm{mg} / \mathrm{L}\right.$ as $\left.\mathrm{O}_{2}\right)$ & 10.1 & 0 & 1 \\
Discharge $\left(\mathrm{m}^{3} / \mathrm{sec}\right)$ & 0.40 & 0 & 1 \\
Fecal Coliform - Water $(\mathrm{CFU} / 100 \mathrm{ml})$ & 100.0 & 86.6 & 3 \\
Total Coliform - Water $(\mathrm{CFU} / 100 \mathrm{ml})$ & 1700.0 & 2771.3 & 3 \\
Fecal Coliform - Sediment $(\mathrm{CFU} / 100 \mathrm{ml})$ & 37.5 & 17.7 & 2 \\
Total Coliform - Sediment $(\mathrm{CFU} / 100 \mathrm{ml})$ & 1612.5 & 2245.1 & 2 \\
Colilert $(\mathrm{MPN} / 100 \mathrm{ml})$ & 40.2 & 0 & 1 \\
Nitrates $(\mathrm{mg} / \mathrm{L})$ & 1.2 & 0.45 & 3 \\
Phosphates $(\mathrm{mg} / \mathrm{L})$ & 0.41 & 0.02 & 3 \\
Ammonia $(\mathrm{mg} / \mathrm{L})$ & 0.07 & 0.01 & 3 \\
Biochemical Oxygen Demand $\left(\mathrm{mg} / \mathrm{L}\right.$ as $\left.\mathrm{O}_{2}\right)$ & 1.4 & 0.1 & 3 \\
Alkalinity $(\mathrm{mg} / \mathrm{L}$ as CaCO $)$ & 67.3 & 2.5 & 3 \\
Hardness $(\mathrm{mg} / \mathrm{L}$ as CaCO 3$)$ & 93.3 & 6.7 & 3 \\
Standard Plate Count $(\mathrm{CFU} / \mathrm{ml})$ & 555.0 & 63.6 & 2 \\
Acridine Orange Direct Counts $(\mathrm{cells} / \mathrm{g})$ & $2.2 \times 10^{8}$ & $1.3 \times 10^{8}$ & 1 \\
Acid Phosphatase $(\mu \mathrm{gg} / \mathrm{g})$ & 39.8 & 8.1 & 3 \\
Alkaline Phosphatase $(\mu \mathrm{gg} / \mathrm{g})$ & 37.4 & 9.2 & 3 \\
Dehydrogenase $(\mu \mathrm{gg} / \mathrm{g})$ & 51.4 & 13.6 & 3 \\
Galactosidase $(\mu \mathrm{gg} / \mathrm{g})$ & 1.5 & 1.0 & 3 \\
Glucosidase $(\mu \mathrm{g} / \mathrm{g})$ & 9.7 & 6.8 & 3 \\
E. coli O157:H7 $(\mathrm{CFU} / 100 \mathrm{ml})$ & 12.5 & 0 & 3 \\
Shigella sp. $(\mathrm{CFU} / 100 \mathrm{ml})$ & 6.7 & 2.9 & 3 \\
Bacteriophage $(\mathrm{PUF} / \mathrm{ml})$ & 0.50 & 0 & 3 \\
Giardia $s p .(\mathrm{cysts} / \mathrm{L})$ & 4.0 & 0 & 1 \\
Cryptosporidium sp. $(\mathrm{cysts} / \mathrm{L})$ & 1.0 & 0 & 1 \\
\hline
\end{tabular}


Table 23. Summary statistics for April 2011, site 13

\begin{tabular}{|c|c|c|c|}
\hline Variable & Mean & Std Dev & $\mathbf{N}$ \\
\hline Air Temperature $\left({ }^{\circ} \mathrm{C}\right)$ & 18.7 & 0 & 1 \\
\hline Water Temperature $\left({ }^{\circ} \mathrm{C}\right)$ & 11.2 & 0 & 1 \\
\hline $\mathrm{pH}$ & 7.2 & 0 & 1 \\
\hline Conductivity ( $\mu$ mohs) & 29.4 & 0 & 1 \\
\hline Dissolved Oxygen (mg/L as $\mathrm{O}_{2}$ ) & 9.8 & 0 & 1 \\
\hline Discharge $\left(\mathrm{m}^{3} / \mathrm{sec}\right)$ & 0.43 & 0 & 1 \\
\hline Fecal Coliform - Water (CFU/100ml) & 50.0 & 0 & 3 \\
\hline Total Coliform - Water (CFU/100ml) & 583.3 & 880.8 & 3 \\
\hline Fecal Coliform - Sediment (CFU/100ml) & 62.5 & 53.0 & 2 \\
\hline Total Coliform - Sediment (CFU/100ml) & 37.5 & 17.7 & 2 \\
\hline Colilert (MPN/100ml) & 7.5 & 0 & 1 \\
\hline Nitrates $(\mathrm{mg} / \mathrm{L})$ & 0.90 & 0.30 & 3 \\
\hline Phosphates (mg/L) & 0.22 & 0.06 & 3 \\
\hline Ammonia $(\mathrm{mg} / \mathrm{L})$ & 0.07 & 0 & 3 \\
\hline Biochemical Oxygen Demand (mg/L as $\mathrm{O}_{2}$ ) & 1.5 & 0.10 & 3 \\
\hline Alkalinity $\left(\mathrm{mg} / \mathrm{L}\right.$ as $\left.\mathrm{CaCO}_{3}\right)$ & 17.3 & 2.1 & 3 \\
\hline Hardness $\left(\mathrm{mg} / \mathrm{L}\right.$ as $\left.\mathrm{CaCO}_{3}\right)$ & 41.3 & 3.5 & 3 \\
\hline Standard Plate Count (CFU/ml) & 205.0 & 77.8 & 2 \\
\hline Acridine Orange Direct Counts (cells/g) & $1.5 \times 10^{8}$ & $3.7 \times 10^{7}$ & 1 \\
\hline Acid Phosphatase $(\mu \mathrm{g} / \mathrm{g})$ & 53.3 & 15.9 & 3 \\
\hline Alkaline Phosphatase $(\mu \mathrm{g} / \mathrm{g})$ & 110.5 & 38.4 & 3 \\
\hline Dehydrogenase $(\mu \mathrm{g} / \mathrm{g})$ & 34.0 & 22.3 & 3 \\
\hline Galactosidase $(\mu \mathrm{g} / \mathrm{g})$ & 4.8 & 1.6 & 3 \\
\hline Glucosidase $(\mu \mathrm{g} / \mathrm{g})$ & 19.1 & 9.8 & 3 \\
\hline E. coli 0157:H7 (CFU/100ml) & 12.5 & 0 & 3 \\
\hline Shigella sp. (CFU/100ml) & 6.7 & 2.9 & 3 \\
\hline Bacteriophage (PUF/ml) & 0.50 & 0 & 3 \\
\hline Giardia sp.(cysts/L) & 2.0 & 0 & 1 \\
\hline Cryptosporidium sp. (cysts/L) & 4.0 & 0 & 1 \\
\hline
\end{tabular}


Table 24. Summary statistics for April 2011, site 14

\begin{tabular}{|c|c|c|c|}
\hline Variable & Mean & Std Dev & $\mathbf{N}$ \\
\hline Air Temperature $\left({ }^{\circ} \mathrm{C}\right)$ & 18.0 & 0 & 1 \\
\hline Water Temperature $\left({ }^{\circ} \mathrm{C}\right)$ & 11.1 & 0 & 1 \\
\hline $\mathrm{pH}$ & 6.5 & 0 & 1 \\
\hline Conductivity ( $\mu$ mohs) & 17.3 & 0 & 1 \\
\hline Dissolved Oxygen (mg/L as $\mathrm{O}_{2}$ ) & 9.9 & 0 & 1 \\
\hline Discharge $\left(\mathrm{m}^{3} / \mathrm{sec}\right)$ & 0.04 & 0 & 1 \\
\hline Fecal Coliform - Water (CFU/100ml) & 66.7 & 28.9 & 3 \\
\hline Total Coliform - Water (CFU/100ml) & 150.0 & 132.3 & 3 \\
\hline Fecal Coliform - Sediment (CFU/100ml) & 25.0 & 0 & 2 \\
\hline Total Coliform - Sediment (CFU/100ml) & 187.5 & 229.8 & 2 \\
\hline Colilert (MPN/100ml) & 27.9 & 0 & 1 \\
\hline Nitrates $(\mathrm{mg} / \mathrm{L})$ & 0.77 & 0.40 & 3 \\
\hline Phosphates (mg/L) & 0.37 & 0.30 & 3 \\
\hline Ammonia $(\mathrm{mg} / \mathrm{L})$ & 0.07 & 0.01 & 3 \\
\hline Biochemical Oxygen Demand (mg/L as $\mathrm{O}_{2}$ ) & 1.5 & 0.10 & 3 \\
\hline Alkalinity $\left(\mathrm{mg} / \mathrm{L}\right.$ as $\left.\mathrm{CaCO}_{3}\right)$ & 10.4 & 0.58 & 3 \\
\hline Hardness $\left(\mathrm{mg} / \mathrm{L}\right.$ as $\left.\mathrm{CaCO}_{3}\right)$ & 31.4 & 7.2 & 3 \\
\hline Standard Plate Count (CFU/ml) & 125.0 & 7.1 & 2 \\
\hline Acridine Orange Direct Counts (cells/g) & $2.0 \times 10^{8}$ & $1.1 \times 10^{8}$ & 1 \\
\hline Acid Phosphatase $(\mu \mathrm{g} / \mathrm{g})$ & 33.8 & 14.0 & 3 \\
\hline Alkaline Phosphatase $(\mu \mathrm{g} / \mathrm{g})$ & 4.3 & 0.83 & 3 \\
\hline Dehydrogenase $(\mu \mathrm{g} / \mathrm{g})$ & 66.9 & 43.0 & 3 \\
\hline Galactosidase $(\mu \mathrm{g} / \mathrm{g})$ & 8.7 & 5.5 & 3 \\
\hline Glucosidase $(\mu \mathrm{g} / \mathrm{g})$ & 19.0 & 8.9 & 3 \\
\hline E. coli 0157:H7 (CFU/100ml) & 12.5 & 0 & 3 \\
\hline Shigella sp. (CFU/100ml) & 8.3 & 2.9 & 3 \\
\hline Bacteriophage (PUF/ml) & 0.50 & 0 & 3 \\
\hline Giardia sp.(cysts/L) & 2.0 & 0 & 1 \\
\hline Cryptosporidium sp. (cysts/L) & 2.0 & 0 & 1 \\
\hline
\end{tabular}


Table 25. Summary statistics for May 2011, site 2

\begin{tabular}{|c|c|c|c|}
\hline Variable & Mean & Std Dev & $\mathbf{N}$ \\
\hline Air Temperature $\left({ }^{\circ} \mathrm{C}\right)$ & 18.5 & 0 & 1 \\
\hline Water Temperature $\left({ }^{\circ} \mathrm{C}\right)$ & 13.6 & 0 & 1 \\
\hline $\mathrm{pH}$ & 8.0 & 0 & 1 \\
\hline Conductivity ( $\mu$ mohs) & 274.0 & 0 & 1 \\
\hline Dissolved Oxygen (mg/L as $\mathrm{O}_{2}$ ) & 9.3 & 0 & 1 \\
\hline Discharge $\left(\mathrm{m}^{3} / \mathrm{sec}\right)$ & 1.2 & 0 & 1 \\
\hline Fecal Coliform - Water (CFU/100ml) & 2366.7 & 378.6 & 3 \\
\hline Total Coliform - Water (CFU/100ml) & 6066.7 & 8548.9 & 3 \\
\hline Fecal Coliform - Sediment (CFU/100ml) & 562.5 & 194.5 & 2 \\
\hline Total Coliform - Sediment (CFU/100ml) & 1100.0 & 1520.3 & 2 \\
\hline Colilert (MPN/100ml) & 435.2 & 0 & 1 \\
\hline Nitrates (mg/L) & 1.2 & 0.31 & 3 \\
\hline Phosphates (mg/L) & 0.14 & 0.05 & 3 \\
\hline Ammonia $(\mathrm{mg} / \mathrm{L})$ & 0.09 & 0.01 & 3 \\
\hline Biochemical Oxygen Demand (mg/L as $\mathrm{O}_{2}$ ) & 0.76 & 0.04 & 3 \\
\hline Alkalinity $\left(\mathrm{mg} / \mathrm{L}\right.$ as $\left.\mathrm{CaCO}_{3}\right)$ & 164.3 & 2.5 & 3 \\
\hline Hardness (mg/L as $\left.\mathrm{CaCO}_{3}\right)$ & 177.3 & 4.5 & 3 \\
\hline Standard Plate Count (CFU/ml) & 1175.0 & 190.9 & 2 \\
\hline Acridine Orange Direct Counts (cells/g) & $4.8 \times 10^{8}$ & $2.7 \times 10^{8}$ & 1 \\
\hline Acid Phosphatase $(\mu \mathrm{g} / \mathrm{g})$ & 21.9 & 8.1 & 3 \\
\hline Alkaline Phosphatase $(\mu \mathrm{g} / \mathrm{g})$ & 22.3 & 3.0 & 3 \\
\hline Dehydrogenase $(\mu \mathrm{g} / \mathrm{g})$ & 10.2 & 2.2 & 3 \\
\hline Galactosidase $(\mu \mathrm{g} / \mathrm{g})$ & 2.7 & 1.7 & 3 \\
\hline Glucosidase $(\mu \mathrm{g} / \mathrm{g})$ & 39.7 & 2.6 & 3 \\
\hline E. coli O157:H7 (CFU/100ml) & 12.5 & 0 & 3 \\
\hline Shigella sp. (CFU/100ml) & 5.0 & 0 & 3 \\
\hline Bacteriophage (PUF/mI) & 0.50 & 0 & 3 \\
\hline Giardia sp.(cysts/L) & 12.0 & 0 & 1 \\
\hline Cryptosporidium sp. (cysts/L) & 2.0 & 0 & 1 \\
\hline
\end{tabular}


Table 26. Summary statistics for May 2011, site 4

\begin{tabular}{|c|c|c|c|}
\hline Variable & Mean & Std Dev & $\mathbf{N}$ \\
\hline Air Temperature $\left({ }^{\circ} \mathrm{C}\right)$ & 16.2 & 0 & 1 \\
\hline Water Temperature $\left({ }^{\circ} \mathrm{C}\right)$ & 13.6 & 0 & 1 \\
\hline $\mathrm{pH}$ & 8.2 & 0 & 1 \\
\hline Conductivity ( $\mu$ mohs) & 224.0 & 0 & 1 \\
\hline Dissolved Oxygen (mg/L as $\mathrm{O}_{2}$ ) & 9.4 & 0 & 1 \\
\hline Discharge $\left(\mathrm{m}^{3} / \mathrm{sec}\right)$ & 0.46 & 0 & 1 \\
\hline Fecal Coliform - Water (CFU/100ml) & 4200.0 & 1113.6 & 3 \\
\hline Total Coliform - Water (CFU/100ml) & 5300.0 & 5915.2 & 3 \\
\hline Fecal Coliform - Sediment (CFU/100ml) & 100.0 & 35.4 & 2 \\
\hline Total Coliform - Sediment (CFU/100ml) & 2037.5 & 2846.1 & 2 \\
\hline Colilert (MPN/100ml) & 101.2 & 0 & 1 \\
\hline Nitrates (mg/L) & 1.1 & 0.52 & 3 \\
\hline Phosphates (mg/L) & 0.07 & 0.06 & 3 \\
\hline Ammonia (mg/L) & 0.10 & 0.02 & 3 \\
\hline Biochemical Oxygen Demand (mg/L as $\mathrm{O}_{2}$ ) & 0.87 & 0.17 & 3 \\
\hline Alkalinity $\left(\mathrm{mg} / \mathrm{L}\right.$ as $\left.\mathrm{CaCO}_{3}\right)$ & 149.0 & 4.0 & 3 \\
\hline Hardness (mg/L as $\left.\mathrm{CaCO}_{3}\right)$ & 162.3 & 2.1 & 3 \\
\hline Standard Plate Count (CFU/ml) & 975.0 & 7.1 & 2 \\
\hline Acridine Orange Direct Counts (cells/g) & $3.5 \times 10^{8}$ & $2.2 \times 10^{8}$ & 1 \\
\hline Acid Phosphatase $(\mu \mathrm{g} / \mathrm{g})$ & 20.2 & 8.2 & 3 \\
\hline Alkaline Phosphatase $(\mu \mathrm{g} / \mathrm{g})$ & 17.3 & 6.2 & 3 \\
\hline Dehydrogenase $(\mu \mathrm{g} / \mathrm{g})$ & 23.5 & 3.9 & 3 \\
\hline Galactosidase $(\mu \mathrm{g} / \mathrm{g})$ & 1.4 & 0.9 & 3 \\
\hline Glucosidase $(\mu \mathrm{g} / \mathrm{g})$ & 71.0 & 33.7 & 3 \\
\hline E. coli O157:H7 (CFU/100ml) & 12.5 & 0 & 3 \\
\hline Shigella sp. (CFU/100ml) & 5.0 & 0 & 3 \\
\hline Bacteriophage (PUF/mI) & 0.50 & 0 & 3 \\
\hline Giardia sp.(cysts/L) & 8.0 & 0 & 1 \\
\hline Cryptosporidium sp. (cysts/L) & 2.0 & 0 & 1 \\
\hline
\end{tabular}


Table 27. Summary statistics for May 2011, site 7

\begin{tabular}{|c|c|c|c|}
\hline Variable & Mean & Std Dev & $\mathbf{N}$ \\
\hline Air Temperature $\left({ }^{\circ} \mathrm{C}\right)$ & 18.2 & 0 & 1 \\
\hline Water Temperature $\left({ }^{\circ} \mathrm{C}\right)$ & 14.1 & 0 & 1 \\
\hline $\mathrm{pH}$ & 9.7 & 0 & 1 \\
\hline Conductivity ( $\mu$ mohs) & 203.0 & 0 & 1 \\
\hline Dissolved Oxygen (mg/L as $\mathrm{O}_{2}$ ) & 9.2 & 0 & 1 \\
\hline Discharge $\left(\mathrm{m}^{3} / \mathrm{sec}\right)$ & 0.42 & 0 & 1 \\
\hline Fecal Coliform - Water (CFU/100ml) & 433.3 & 251.7 & 3 \\
\hline Total Coliform - Water (CFU/100ml) & 1383.3 & 1376.9 & 3 \\
\hline Fecal Coliform - Sediment (CFU/100ml) & 287.5 & 53.0 & 2 \\
\hline Total Coliform - Sediment (CFU/100ml) & 4950.0 & 318.2 & 2 \\
\hline Colilert (MPN/100ml) & 8.6 & 0 & 1 \\
\hline Nitrates (mg/L) & 0.90 & 0.36 & 3 \\
\hline Phosphates (mg/L) & 0.16 & 0.04 & 3 \\
\hline Ammonia (mg/L) & 0.26 & 0.30 & 3 \\
\hline Biochemical Oxygen Demand (mg/L as $\mathrm{O}_{2}$ ) & 0.95 & 0.24 & 3 \\
\hline Alkalinity $\left(\mathrm{mg} / \mathrm{L}\right.$ as $\left.\mathrm{CaCO}_{3}\right)$ & 122.3 & 4.2 & 3 \\
\hline Hardness (mg/L as $\left.\mathrm{CaCO}_{3}\right)$ & 130.7 & 1.2 & 3 \\
\hline Standard Plate Count (CFU/ml) & 450.0 & 56.6 & 2 \\
\hline Acridine Orange Direct Counts (cells/g) & $6.7 \times 10^{8}$ & $1.1 \times 10^{8}$ & 1 \\
\hline Acid Phosphatase $(\mu \mathrm{g} / \mathrm{g})$ & 17.9 & 4.6 & 3 \\
\hline Alkaline Phosphatase $(\mu \mathrm{g} / \mathrm{g})$ & 73.5 & 75.6 & 3 \\
\hline Dehydrogenase $(\mu \mathrm{g} / \mathrm{g})$ & 26.3 & 6.5 & 3 \\
\hline Galactosidase $(\mu \mathrm{g} / \mathrm{g})$ & 2.0 & 0.42 & 3 \\
\hline Glucosidase $(\mu \mathrm{g} / \mathrm{g})$ & 77.0 & 94.1 & 3 \\
\hline E. coli O157:H7 (CFU/100ml) & 12.5 & 0 & 3 \\
\hline Shigella sp. (CFU/100ml) & 5.0 & 0 & 3 \\
\hline Bacteriophage (PUF/mI) & 3.7 & 5.5 & 3 \\
\hline Giardia sp.(cysts/L) & 6.0 & 0 & 1 \\
\hline Cryptosporidium sp. (cysts/L) & 10.0 & 0 & 1 \\
\hline
\end{tabular}


Table 28. Summary statistics for May 2011, site 10

\begin{tabular}{|c|c|c|c|}
\hline Variable & Mean & Std Dev & $\mathbf{N}$ \\
\hline Air Temperature $\left({ }^{\circ} \mathrm{C}\right)$ & 20.8 & 0 & 1 \\
\hline Water Temperature $\left({ }^{\circ} \mathrm{C}\right)$ & 13.6 & 0 & 1 \\
\hline $\mathrm{pH}$ & 7.6 & 0 & 1 \\
\hline Conductivity ( $\mu$ mohs) & 123.8 & 0 & 1 \\
\hline Dissolved Oxygen (mg/L as $\mathrm{O}_{2}$ ) & 9.6 & 0 & 1 \\
\hline Discharge $\left(\mathrm{m}^{3} / \mathrm{sec}\right)$ & 0.32 & 0 & 1 \\
\hline Fecal Coliform - Water (CFU/100ml) & 1200.0 & 173.2 & 3 \\
\hline Total Coliform - Water (CFU/100ml) & 3233.3 & 3010.5 & 3 \\
\hline Fecal Coliform - Sediment (CFU/100ml) & 275.0 & 70.7 & 2 \\
\hline Total Coliform - Sediment (CFU/100ml) & 3762.5 & 5285.6 & 2 \\
\hline Colilert (MPN/100ml) & 29.5 & 0 & 1 \\
\hline Nitrates (mg/L) & 1.3 & 0.30 & 3 \\
\hline Phosphates (mg/L) & 0.29 & 0.07 & 3 \\
\hline Ammonia (mg/L) & 0.08 & 0.01 & 3 \\
\hline Biochemical Oxygen Demand (mg/L as $\mathrm{O}_{2}$ ) & 0.72 & 0.04 & 3 \\
\hline Alkalinity $\left(\mathrm{mg} / \mathrm{L}\right.$ as $\left.\mathrm{CaCO}_{3}\right)$ & 76.3 & 2.1 & 3 \\
\hline Hardness (mg/L as $\left.\mathrm{CaCO}_{3}\right)$ & 82.0 & 5.3 & 3 \\
\hline Standard Plate Count (CFU/ml) & 815.0 & 21.2 & 2 \\
\hline Acridine Orange Direct Counts (cells/g) & $7.0 \times 10^{7}$ & $6.3 \times 10^{7}$ & 1 \\
\hline Acid Phosphatase $(\mu \mathrm{g} / \mathrm{g})$ & 54.6 & 29.8 & 3 \\
\hline Alkaline Phosphatase $(\mu \mathrm{g} / \mathrm{g})$ & 109.2 & 30.6 & 3 \\
\hline Dehydrogenase $(\mu \mathrm{g} / \mathrm{g})$ & 28.4 & 3.7 & 3 \\
\hline Galactosidase $(\mu \mathrm{g} / \mathrm{g})$ & 2.7 & 1.8 & 3 \\
\hline Glucosidase $(\mu \mathrm{g} / \mathrm{g})$ & 174.3 & 23.3 & 3 \\
\hline E. coli O157:H7 (CFU/100ml) & 12.5 & 0 & 3 \\
\hline Shigella sp. (CFU/100ml) & 5.0 & 0 & 3 \\
\hline Bacteriophage (PUF/mI) & 0.50 & 0 & 3 \\
\hline Giardia sp.(cysts/L) & 8.0 & 0 & 1 \\
\hline Cryptosporidium sp. (cysts/L) & 2.0 & 0 & 1 \\
\hline
\end{tabular}


Table 29. Summary statistics for May 2011, site 13

\begin{tabular}{llll}
\hline Variable & Mean & Std Dev & N \\
Air Temperature $\left({ }^{\circ} \mathrm{C}\right)$ & 18.9 & 0 & 1 \\
Water Temperature $\left({ }^{\circ} \mathrm{C}\right)$ & 13.8 & 0 & 1 \\
$\mathrm{pH}$ & 7.9 & 0 & 1 \\
Conductivity $(\mu \mathrm{mohs})$ & 35.2 & 0 & 1 \\
Dissolved Oxygen $\left(\mathrm{mg} / \mathrm{L}\right.$ as $\left.\mathrm{O}_{2}\right)$ & 9.3 & 0 & 1 \\
Discharge $\left(\mathrm{m}^{3} / \mathrm{sec}\right)$ & 0.10 & 0 & 1 \\
Fecal Coliform - Water $(\mathrm{CFU} / 100 \mathrm{ml})$ & 1066.7 & 763.8 & 3 \\
Total Coliform - Water $(\mathrm{CFU} / 100 \mathrm{ml})$ & 1566.7 & 1150.4 & 3 \\
Fecal Coliform - Sediment $(\mathrm{CFU} / 100 \mathrm{ml})$ & 175.0 & 106.1 & 2 \\
Total Coliform - Sediment $(\mathrm{CFU} / 100 \mathrm{ml})$ & 1131.3 & 1582.2 & 2 \\
Colilert $(\mathrm{MPN} / 100 \mathrm{ml})$ & 127.4 & 0 & 1 \\
Nitrates $(\mathrm{mg} / \mathrm{L})$ & 0.57 & 0.31 & 3 \\
Phosphates $(\mathrm{mg} / \mathrm{L})$ & 0.35 & 0.45 & 3 \\
Ammonia $(\mathrm{mg} / \mathrm{L})$ & 0.08 & 0 & 3 \\
Biochemical Oxygen Demand $\left(\mathrm{mg} / \mathrm{L}\right.$ as $\left.\mathrm{O}_{2}\right)$ & 0.82 & 0.22 & 3 \\
Alkalinity $(\mathrm{mg} / \mathrm{L}$ as CaCO $)$ & 18.0 & 1.0 & 3 \\
Hardness $(\mathrm{mg} / \mathrm{L}$ as CaCO 3$)$ & 21.3 & 1.5 & 3 \\
Standard Plate Count $(\mathrm{CFU} / \mathrm{ml})$ & 535.0 & 63.6 & 2 \\
Acridine Orange Direct Counts $(\mathrm{cells} / \mathrm{g})$ & $2.9 \times 10^{8}$ & $7.3 \times 10^{7}$ & 1 \\
Acid Phosphatase $(\mu \mathrm{gg} / \mathrm{g})$ & 91.0 & 10.4 & 3 \\
Alkaline Phosphatase $(\mu \mathrm{gg} / \mathrm{g})$ & 221.9 & 13.0 & 3 \\
Dehydrogenase $(\mu \mathrm{gg} / \mathrm{g})$ & 14.6 & 9.7 & 3 \\
Galactosidase $(\mu \mathrm{gg} / \mathrm{g})$ & 5.4 & 1.5 & 3 \\
Glucosidase $(\mu \mathrm{g} / \mathrm{g})$ & 56.5 & 11.1 & 3 \\
E. coli O157:H7 $(\mathrm{CFU} / 100 \mathrm{ml})$ & 12.5 & 0 & 3 \\
Shigella sp. $(\mathrm{CFU} / 100 \mathrm{ml})$ & 5.0 & 0 & 3 \\
Bacteriophage $(\mathrm{PUF} / \mathrm{ml})$ & 0.50 & 0 & 3 \\
Giardia $s p .(\mathrm{cysts} / \mathrm{L})$ & 6.0 & 0 & 1 \\
Cryptosporidium sp. $(\mathrm{cysts} / \mathrm{L})$ & 10.0 & 0 & 1 \\
\hline
\end{tabular}


Table 30. Summary statistics for May 2011, site 14

\begin{tabular}{|c|c|c|c|}
\hline Variable & Mean & Std Dev & $\mathbf{N}$ \\
\hline Air Temperature $\left({ }^{\circ} \mathrm{C}\right)$ & 19.3 & 0 & 1 \\
\hline Water Temperature $\left({ }^{\circ} \mathrm{C}\right)$ & 12.1 & 0 & 1 \\
\hline $\mathrm{pH}$ & 7.7 & 0 & 1 \\
\hline Conductivity ( $\mu$ mohs) & 19.8 & 0 & 1 \\
\hline Dissolved Oxygen (mg/L as $\mathrm{O}_{2}$ ) & 9.6 & 0 & 1 \\
\hline Discharge $\left(\mathrm{m}^{3} / \mathrm{sec}\right)$ & 0.01 & 0 & 1 \\
\hline Fecal Coliform - Water (CFU/100ml) & 233.3 & 317.5 & 3 \\
\hline Total Coliform - Water (CFU/100ml) & 566.7 & 503.3 & 3 \\
\hline Fecal Coliform - Sediment (CFU/100ml) & 62.5 & 53.0 & 2 \\
\hline Total Coliform - Sediment (CFU/100ml) & 2050.0 & 1520.3 & 2 \\
\hline Colilert (MPN/100ml) & 8.6 & 0 & 1 \\
\hline Nitrates (mg/L) & 0.73 & 0.42 & 3 \\
\hline Phosphates (mg/L) & 0.27 & 0.08 & 3 \\
\hline Ammonia (mg/L) & 0.11 & 0.01 & 3 \\
\hline Biochemical Oxygen Demand (mg/L as $\mathrm{O}_{2}$ ) & 0.70 & 0.04 & 3 \\
\hline Alkalinity $\left(\mathrm{mg} / \mathrm{L}\right.$ as $\left.\mathrm{CaCO}_{3}\right)$ & 8.0 & 2.0 & 3 \\
\hline Hardness (mg/L as $\left.\mathrm{CaCO}_{3}\right)$ & 13.0 & 7.8 & 3 \\
\hline Standard Plate Count (CFU/ml) & 280.0 & 113.1 & 2 \\
\hline Acridine Orange Direct Counts (cells/g) & $4.1 \times 10^{8}$ & $5.8 \times 10^{7}$ & 1 \\
\hline Acid Phosphatase $(\mu \mathrm{g} / \mathrm{g})$ & 190.9 & 246.4 & 3 \\
\hline Alkaline Phosphatase $(\mu \mathrm{g} / \mathrm{g})$ & 96.9 & 2.9 & 3 \\
\hline Dehydrogenase $(\mu \mathrm{g} / \mathrm{g})$ & 30.3 & 3.9 & 3 \\
\hline Galactosidase $(\mu \mathrm{g} / \mathrm{g})$ & 4.6 & 3.5 & 3 \\
\hline Glucosidase $(\mu \mathrm{g} / \mathrm{g})$ & 41.4 & 19.3 & 3 \\
\hline E. coli O157:H7 (CFU/100ml) & 12.5 & 0 & 3 \\
\hline Shigella sp. (CFU/100ml) & 5.0 & 0 & 3 \\
\hline Bacteriophage (PUF/mI) & 0.50 & 0 & 3 \\
\hline Giardia sp.(cysts/L) & 6.0 & 0 & 1 \\
\hline Cryptosporidium sp. (cysts/L) & 4.0 & 0 & 1 \\
\hline
\end{tabular}


Table 31. Summary statistics from June 2011, site 2

\begin{tabular}{llll}
\hline Variable & Mean & Std Dev & N \\
Air Temperature $\left({ }^{\circ} \mathrm{C}\right)$ & 18.6 & 0 & 1 \\
Water Temperature $\left({ }^{\circ} \mathrm{C}\right)$ & 17.2 & 0 & 1 \\
$\mathrm{pH}$ & 7.3 & 0 & 1 \\
Conductivity $(\mu \mathrm{mohs})$ & 217.0 & 0 & 1 \\
Dissolved Oxygen $\left(\mathrm{mg} / \mathrm{L}\right.$ as $\left.\mathrm{O}_{2}\right)$ & 8.7 & 0 & 1 \\
Discharge $\left(\mathrm{m}^{3} / \mathrm{sec}\right)$ & 0.80 & 0 & 1 \\
Fecal Coliform - Water $(\mathrm{CFU} / 100 \mathrm{ml})$ & 2516.7 & 2141.5 & 3 \\
Total Coliform - Water $(\mathrm{CFU} / 100 \mathrm{ml})$ & 10216.7 & 11063.9 & 3 \\
Fecal Coliform - Sediment $(\mathrm{CFU} / 100 \mathrm{ml})$ & 125.0 & 106.1 & 2 \\
Total Coliform - Sediment $(\mathrm{CFU} / 100 \mathrm{ml})$ & 175.0 & 174.8 & 2 \\
Colilert $(\mathrm{MPN} / 100 \mathrm{ml})$ & 615.2 & 0 & 1 \\
Nitrates $(\mathrm{mg} / \mathrm{L})$ & 0.87 & 0.12 & 3 \\
Phosphates $(\mathrm{mg} / \mathrm{L})$ & 0.10 & 0.06 & 3 \\
Ammonia $(\mathrm{mg} / \mathrm{L})$ & 0.20 & 0.02 & 3 \\
Biochemical Oxygen Demand $\left(\mathrm{mg} / \mathrm{L}\right.$ as $\left.\mathrm{O}_{2}\right)$ & 0.47 & 0.24 & 3 \\
Alkalinity $(\mathrm{mg} / \mathrm{L}$ as CaCO $)$ & 174.7 & 0.58 & 3 \\
Hardness $(\mathrm{mg} / \mathrm{L}$ as CaCO 3$)$ & 189.7 & 7.8 & 3 \\
Standard Plate Count $(\mathrm{CFU} / \mathrm{ml})$ & 1200.0 & 212.1 & 2 \\
Acridine Orange Direct Counts $(\mathrm{cells} / \mathrm{g})$ & $7.5 \times 10^{7}$ & $8.4 \times 10^{6}$ & 1 \\
Acid Phosphatase $(\mu \mathrm{gg} / \mathrm{g})$ & 107.4 & 71.2 & 3 \\
Alkaline Phosphatase $(\mu \mathrm{Hg} / \mathrm{g})$ & 203.6 & 28.6 & 3 \\
Dehydrogenase $(\mu \mathrm{gg} / \mathrm{g})$ & 24.5 & 4.9 & 3 \\
Galactosidase $(\mu \mathrm{gg} / \mathrm{g})$ & 10.6 & 3.7 & 3 \\
Glucosidase $(\mu \mathrm{g} / \mathrm{g})$ & 16.0 & 0.24 & 3 \\
E. coli O157:H7 $(\mathrm{CFU} / 100 \mathrm{ml})$ & 12.5 & 0 & 3 \\
Shigella sp. $(\mathrm{CFU} / 100 \mathrm{ml})$ & 5.0 & 0 & 3 \\
Bacteriophage $(\mathrm{PUF} / \mathrm{ml})$ & 0.50 & 0 & 3 \\
Giardia $s p .(\mathrm{cysts} / \mathrm{L})$ & 18.8 & 0 & 1 \\
Cryptosporidium sp. $(\mathrm{cysts} / \mathrm{L})$ & 18.8 & 0 & 1 \\
\hline
\end{tabular}


Table 32. Summary statistics for June 2011, site 4

\begin{tabular}{|c|c|c|c|}
\hline Variable & Mean & Std Dev & $\mathbf{N}$ \\
\hline Air Temperature $\left({ }^{\circ} \mathrm{C}\right)$ & 19.1 & 0 & 1 \\
\hline Water Temperature $\left({ }^{\circ} \mathrm{C}\right)$ & 17.1 & 0 & 1 \\
\hline $\mathrm{pH}$ & 7.3 & 0 & 1 \\
\hline Conductivity ( $\mu$ mohs) & 287.0 & 0 & 1 \\
\hline Dissolved Oxygen (mg/L as $\mathrm{O}_{2}$ ) & 9.0 & 0 & 1 \\
\hline Discharge $\left(\mathrm{m}^{3} / \mathrm{sec}\right)$ & 0.29 & 0 & 1 \\
\hline Fecal Coliform - Water (CFU/100ml) & 14900.0 & 1670.3 & 3 \\
\hline Total Coliform - Water (CFU/100ml) & 16300.0 & 10431.2 & 3 \\
\hline Fecal Coliform - Sediment (CFU/100ml) & 825.0 & 388.9 & 2 \\
\hline Total Coliform - Sediment (CFU/100ml) & 6050.0 & 7566.0 & 2 \\
\hline Colilert (MPN/100ml) & 522.6 & 0 & 1 \\
\hline Nitrates (mg/L) & 1.9 & 0.15 & 3 \\
\hline Phosphates (mg/L) & 0.08 & 0.03 & 3 \\
\hline Ammonia (mg/L) & 0.20 & 0.02 & 3 \\
\hline Biochemical Oxygen Demand (mg/L as $\mathrm{O}_{2}$ ) & 0.48 & 0.06 & 3 \\
\hline Alkalinity $\left(\mathrm{mg} / \mathrm{L}\right.$ as $\left.\mathrm{CaCO}_{3}\right)$ & 167.0 & 2.0 & 3 \\
\hline Hardness (mg/L as $\left.\mathrm{CaCO}_{3}\right)$ & 179.0 & 5.3 & 3 \\
\hline Standard Plate Count (CFU/ml) & 765.0 & 91.9 & 2 \\
\hline Acridine Orange Direct Counts (cells/g) & $4.7 \times 10^{7}$ & $5.3 \times 10^{7}$ & 1 \\
\hline Acid Phosphatase $(\mu \mathrm{g} / \mathrm{g})$ & 75.3 & 27.0 & 3 \\
\hline Alkaline Phosphatase $(\mu \mathrm{g} / \mathrm{g})$ & 449.5 & 329.8 & 3 \\
\hline Dehydrogenase $(\mu \mathrm{g} / \mathrm{g})$ & 15.2 & 9.6 & 3 \\
\hline Galactosidase $(\mu \mathrm{g} / \mathrm{g})$ & 3.9 & 1.7 & 3 \\
\hline Glucosidase $(\mu \mathrm{g} / \mathrm{g})$ & 10.6 & 4.5 & 3 \\
\hline E. coli O157:H7 (CFU/100ml) & 12.5 & 0 & 3 \\
\hline Shigella sp. (CFU/100ml) & 5.0 & 0 & 3 \\
\hline Bacteriophage (PUF/mI) & 3.7 & 5.5 & 3 \\
\hline Giardia sp.(cysts/L) & 15.8 & 0 & 1 \\
\hline Cryptosporidium sp. (cysts/L) & 10.5 & 0 & 1 \\
\hline
\end{tabular}


Table 33. Summary statistics for June 2011 , site 7

\begin{tabular}{llll}
\hline Variable & Mean & Std Dev & N \\
Air Temperature $\left({ }^{\circ} \mathrm{C}\right)$ & 19.7 & 0 & 1 \\
Water Temperature $\left({ }^{\circ} \mathrm{C}\right)$ & 16.3 & 0 & 1 \\
$\mathrm{pH}$ & 8.4 & 0 & 1 \\
Conductivity $(\mu \mathrm{mohs})$ & 234.0 & 0 & 1 \\
Dissolved Oxygen $\left(\mathrm{mg} / \mathrm{L}\right.$ as $\left.\mathrm{O}_{2}\right)$ & 8.5 & 0 & 1 \\
Discharge $\left(\mathrm{m}^{3} / \mathrm{sec}\right)$ & 0.25 & 0 & 1 \\
Fecal Coliform - Water $(\mathrm{CFU} / 100 \mathrm{ml})$ & 333.3 & 321.5 & 3 \\
Total Coliform - Water $(\mathrm{CFU} / 100 \mathrm{ml})$ & 2900.0 & 1708.8 & 3 \\
Fecal Coliform - Sediment $(\mathrm{CFU} / 100 \mathrm{ml})$ & 625.0 & 530.3 & 2 \\
Total Coliform - Sediment $(\mathrm{CFU} / 100 \mathrm{ml})$ & 11575.0 & 2934.5 & 2 \\
Colilert $(\mathrm{MPN} / 100 \mathrm{ml})$ & 24.4 & 0 & 1 \\
Nitrates $(\mathrm{mg} / \mathrm{L})$ & 1.5 & 0.06 & 3 \\
Phosphates $(\mathrm{mg} / \mathrm{L})$ & 0.03 & 0.03 & 3 \\
Ammonia $(\mathrm{mg} / \mathrm{L})$ & 0.19 & 0.04 & 3 \\
Biochemical Oxygen Demand $\left(\mathrm{mg} / \mathrm{L}\right.$ as $\left.\mathrm{O}_{2}\right)$ & 0.40 & 0.05 & 3 \\
Alkalinity $(\mathrm{mg} / \mathrm{L}$ as CaCO $)$ & 140.3 & 3.1 & 3 \\
Hardness $(\mathrm{mg} / \mathrm{L}$ as CaCO 3$)$ & 149.0 & 1.0 & 3 \\
Standard Plate Count $(\mathrm{CFU} / \mathrm{ml})$ & 370.0 & 127.3 & 2 \\
Acridine Orange Direct Counts $(\mathrm{cells} / \mathrm{g})$ & $1.0 \times 10^{8}$ & $6.3 \times 10^{7}$ & 1 \\
Acid Phosphatase $(\mu \mathrm{gg} / \mathrm{g})$ & 70.5 & 9.0 & 3 \\
Alkaline Phosphatase $(\mu \mathrm{Hg} / \mathrm{g})$ & 208.5 & 55.5 & 3 \\
Dehydrogenase $(\mu \mathrm{gg} / \mathrm{g})$ & 21.3 & 19.4 & 3 \\
Galactosidase $(\mu \mathrm{gg} / \mathrm{g})$ & 0.48 & 0.15 & 3 \\
Glucosidase $(\mu \mathrm{g} / \mathrm{g})$ & 12.9 & 2.0 & 3 \\
E. coli O157:H7 $(\mathrm{CFU} / 100 \mathrm{ml})$ & 12.5 & 0 & 3 \\
Shigella sp. $(\mathrm{CFU} / 100 \mathrm{ml})$ & 5.0 & 0 & 3 \\
Bacteriophage $(\mathrm{PUF} / \mathrm{ml})$ & 0.50 & 0 & 3 \\
Giardia $s p .(\mathrm{cysts} / \mathrm{L})$ & 22.0 & 0 & 1 \\
Cryptosporidium sp. $(\mathrm{cysts} / \mathrm{L})$ & 11.0 & 0 & 1 \\
\hline
\end{tabular}


Table 34. Summary statistics for June 2011, site 10

\begin{tabular}{|c|c|c|c|}
\hline Variable & Mean & Std Dev & $\mathbf{N}$ \\
\hline Air Temperature $\left({ }^{\circ} \mathrm{C}\right)$ & 19.5 & 0 & 1 \\
\hline Water Temperature $\left({ }^{\circ} \mathrm{C}\right)$ & 16.0 & 0 & 1 \\
\hline $\mathrm{pH}$ & 8.2 & 0 & 1 \\
\hline Conductivity ( $\mu$ mohs) & 234.0 & 0 & 1 \\
\hline Dissolved Oxygen (mg/L as $\mathrm{O}_{2}$ ) & 9.6 & 0 & 1 \\
\hline Discharge $\left(\mathrm{m}^{3} / \mathrm{sec}\right)$ & 0.18 & 0 & 1 \\
\hline Fecal Coliform - Water (CFU/100ml) & 500.0 & 100.0 & 3 \\
\hline Total Coliform - Water (CFU/100ml) & 4366.7 & 4554.5 & 3 \\
\hline Fecal Coliform - Sediment (CFU/100ml) & 225.0 & 247.5 & 2 \\
\hline Total Coliform - Sediment (CFU/100ml) & 4700.0 & 6364.0 & 2 \\
\hline Colilert (MPN/100ml) & 42.2 & 0 & 1 \\
\hline Nitrates (mg/L) & 0.60 & 0.17 & 3 \\
\hline Phosphates (mg/L) & 0.07 & 0.06 & 3 \\
\hline Ammonia $(\mathrm{mg} / \mathrm{L})$ & 0.22 & 0.02 & 3 \\
\hline Biochemical Oxygen Demand (mg/L as $\mathrm{O}_{2}$ ) & 0.36 & 0.07 & 3 \\
\hline Alkalinity $\left(\mathrm{mg} / \mathrm{L}\right.$ as $\left.\mathrm{CaCO}_{3}\right)$ & 103.3 & 0.60 & 3 \\
\hline Hardness (mg/L as $\left.\mathrm{CaCO}_{3}\right)$ & 109.7 & 1.5 & 3 \\
\hline Standard Plate Count (CFU/ml) & 330.0 & 28.3 & 2 \\
\hline Acridine Orange Direct Counts (cells/g) & $1.1 \times 10^{8}$ & $3.5 \times 10^{7}$ & 1 \\
\hline Acid Phosphatase $(\mu \mathrm{g} / \mathrm{g})$ & 73.1 & 16.4 & 3 \\
\hline Alkaline Phosphatase $(\mu \mathrm{g} / \mathrm{g})$ & 30.3 & 34.7 & 3 \\
\hline Dehydrogenase $(\mu \mathrm{g} / \mathrm{g})$ & 27.7 & 2.4 & 3 \\
\hline Galactosidase $(\mu \mathrm{g} / \mathrm{g})$ & 6.4 & 4.5 & 3 \\
\hline Glucosidase $(\mu \mathrm{g} / \mathrm{g})$ & 9.7 & 6.8 & 3 \\
\hline E. coli O157:H7 (CFU/100ml) & 12.5 & 0 & 3 \\
\hline Shigella sp. (CFU/100ml) & 5.0 & 0 & 3 \\
\hline Bacteriophage (PUF/ml) & 0.50 & 0 & 3 \\
\hline Giardia sp.(cysts/L) & 14.0 & 0 & 1 \\
\hline Cryptosporidium sp. (cysts/L) & 28.0 & 0 & 1 \\
\hline
\end{tabular}


Table 35. Summary statistics for June 2011, site 13

\begin{tabular}{|c|c|c|c|}
\hline Variable & Mean & Std Dev & $\mathbf{N}$ \\
\hline Air Temperature $\left({ }^{\circ} \mathrm{C}\right)$ & 19.1 & 0 & 1 \\
\hline Water Temperature $\left({ }^{\circ} \mathrm{C}\right)$ & 17.5 & 0 & 1 \\
\hline $\mathrm{pH}$ & 8.5 & 0 & 1 \\
\hline Conductivity ( $\mu \mathrm{mohs})$ & 71.3 & 0 & 1 \\
\hline Dissolved Oxygen (mg/L as $\mathrm{O}_{2}$ ) & 8.6 & 0 & 1 \\
\hline Discharge $\left(\mathrm{m}^{3} / \mathrm{sec}\right)$ & 0.10 & 0 & 1 \\
\hline Fecal Coliform - Water (CFU/100ml) & 366.7 & 115.5 & 3 \\
\hline Total Coliform - Water (CFU/100ml) & 1933.3 & 1616.6 & 3 \\
\hline Fecal Coliform - Sediment (CFU/100ml) & 62.5 & 53.0 & 2 \\
\hline Total Coliform - Sediment (CFU/100ml) & 1300.0 & 1767.8 & 2 \\
\hline Colilert (MPN/100ml) & 14.8 & 0 & 1 \\
\hline Nitrates $(\mathrm{mg} / \mathrm{L})$ & 1.2 & 0.20 & 3 \\
\hline Phosphates (mg/L) & 0.13 & 0.06 & 3 \\
\hline Ammonia (mg/L) & 0.09 & 0.01 & 3 \\
\hline Biochemical Oxygen Demand (mg/L as $\mathrm{O}_{2}$ ) & 0.95 & 0.10 & 3 \\
\hline Alkalinity $\left(\mathrm{mg} / \mathrm{L}\right.$ as $\left.\mathrm{CaCO}_{3}\right)$ & 28.7 & 1.2 & 3 \\
\hline Hardness $\left(\mathrm{mg} / \mathrm{L}\right.$ as $\left.\mathrm{CaCO}_{3}\right)$ & 41.3 & 4.0 & 3 \\
\hline Standard Plate Count (CFU/ml) & 230.1 & 99.0 & 2 \\
\hline Acridine Orange Direct Counts (cells/g) & $6.1 \times 10^{7}$ & $1.3 \times 10^{7}$ & 1 \\
\hline Acid Phosphatase $(\mu \mathrm{g} / \mathrm{g})$ & 96.2 & 24.8 & 3 \\
\hline Alkaline Phosphatase $(\mu \mathrm{g} / \mathrm{g})$ & 133.0 & 68.0 & 3 \\
\hline Dehydrogenase $(\mu \mathrm{g} / \mathrm{g})$ & 30.6 & 10.3 & 3 \\
\hline Galactosidase $(\mu \mathrm{g} / \mathrm{g})$ & 6.0 & 1.7 & 3 \\
\hline Glucosidase $(\mu \mathrm{g} / \mathrm{g})$ & 3.4 & 1.7 & 3 \\
\hline E. coli 0157:H7 (CFU/100ml) & 12.5 & 0 & 3 \\
\hline Shigella sp. (CFU/100ml) & 5.0 & 0 & 3 \\
\hline Bacteriophage (PUF/ml) & 0.50 & 0 & 3 \\
\hline Giardia sp.(cysts/L) & 26.0 & 0 & 1 \\
\hline Cryptosporidium sp. (cysts/L) & 19.0 & 0 & 1 \\
\hline
\end{tabular}


Table 36. Summary statistics for June 2011, site 14

\begin{tabular}{|c|c|c|c|}
\hline Variable & Mean & Std Dev & $\mathbf{N}$ \\
\hline Air Temperature $\left({ }^{\circ} \mathrm{C}\right)$ & 19.8 & 0 & 1 \\
\hline Water Temperature $\left({ }^{\circ} \mathrm{C}\right)$ & 17.8 & 0 & 1 \\
\hline $\mathrm{pH}$ & 8.4 & 0 & 1 \\
\hline Conductivity ( $\mu$ mohs) & 23.4 & 0 & 1 \\
\hline Dissolved Oxygen (mg/L as $\mathrm{O}_{2}$ ) & 7.2 & 0 & 1 \\
\hline Discharge $\left(\mathrm{m}^{3} / \mathrm{sec}\right)$ & 0.10 & 0 & 1 \\
\hline Fecal Coliform - Water (CFU/100ml) & 50.0 & 0 & 3 \\
\hline Total Coliform - Water (CFU/100ml) & 1833.3 & 2050.2 & 3 \\
\hline Fecal Coliform - Sediment (CFU/100ml) & 525.0 & 459.6 & 2 \\
\hline Total Coliform - Sediment (CFU/100ml) & 4700.0 & 4949.5 & 2 \\
\hline Colilert (MPN/100ml) & 32.2 & 0 & 1 \\
\hline Nitrates (mg/L) & 0.83 & 0.06 & 3 \\
\hline Phosphates (mg/L) & 0.90 & 0 & 3 \\
\hline Ammonia (mg/L) & 0.14 & 0.03 & 3 \\
\hline Biochemical Oxygen Demand (mg/L as $\mathrm{O}_{2}$ ) & 0.81 & 0.04 & 3 \\
\hline Alkalinity $\left(\mathrm{mg} / \mathrm{L}\right.$ as $\left.\mathrm{CaCO}_{3}\right)$ & 10.3 & 1.2 & 3 \\
\hline Hardness (mg/L as $\left.\mathrm{CaCO}_{3}\right)$ & 11.0 & 1.0 & 3 \\
\hline Standard Plate Count (CFU/ml) & 85.0 & 21.2 & 2 \\
\hline Acridine Orange Direct Counts (cells/g) & $6.4 \times 10^{7}$ & $4.6 \times 10^{7}$ & 1 \\
\hline Acid Phosphatase $(\mu \mathrm{g} / \mathrm{g})$ & 266.2 & 362.1 & 3 \\
\hline Alkaline Phosphatase $(\mu \mathrm{g} / \mathrm{g})$ & 67.2 & 47.3 & 3 \\
\hline Dehydrogenase $(\mu \mathrm{g} / \mathrm{g})$ & 28.9 & 6.2 & 3 \\
\hline Galactosidase $(\mu \mathrm{g} / \mathrm{g})$ & 2.9 & 2.8 & 3 \\
\hline Glucosidase $(\mu \mathrm{g} / \mathrm{g})$ & 5.7 & 4.5 & 3 \\
\hline E. coli O157:H7 (CFU/100ml) & 12.5 & 0 & 3 \\
\hline Shigella sp. (CFU/100ml) & 5.0 & 0 & 3 \\
\hline Bacteriophage (PUF/mI) & 0.50 & 0 & 3 \\
\hline Giardia sp.(cysts/L) & 7.3 & 0 & 1 \\
\hline Cryptosporidium sp. (cysts/L) & 15.0 & 0 & 1 \\
\hline
\end{tabular}


Table 37. Summary statistics for July 2011, site 2

\begin{tabular}{|c|c|c|c|}
\hline Variable & Mean & Std Dev & $\mathbf{N}$ \\
\hline Air Temperature $\left({ }^{\circ} \mathrm{C}\right)$ & 20.5 & 0 & 1 \\
\hline Water Temperature $\left({ }^{\circ} \mathrm{C}\right)$ & 17.0 & 0 & 1 \\
\hline $\mathrm{pH}$ & 6.7 & 0 & 1 \\
\hline Conductivity ( $\mu \mathrm{mohs}$ ) & 325.0 & 0 & 1 \\
\hline Dissolved Oxygen $\left(\mathrm{mg} / \mathrm{L}\right.$ as $\left.\mathrm{O}_{2}\right)$ & 8.3 & 0 & 1 \\
\hline Discharge $\left(\mathrm{m}^{3} / \mathrm{sec}\right)$ & 0.52 & 0 & 1 \\
\hline Fecal Coliform - Water (CFU/100ml) & 7066.7 & 261.6 & 3 \\
\hline Total Coliform - Water (CFU/100ml) & 14933.3 & 14204.7 & 3 \\
\hline Fecal Coliform - Sediment (CFU/100ml) & 350.0 & 70.7 & 2 \\
\hline Total Coliform - Sediment (CFU/100ml) & 8275.0 & 9693.4 & 2 \\
\hline Colilert (MPN/100ml) & 730.8 & 0 & 1 \\
\hline Nitrates (mg/L) & 0.57 & 0.31 & 3 \\
\hline Phosphates (mg/L) & 0.16 & 0.04 & 3 \\
\hline Ammonia (mg/L) & 0.06 & 0.02 & 3 \\
\hline Biochemical Oxygen Demand $\left(\mathrm{mg} / \mathrm{L}\right.$ as $\left.\mathrm{O}_{2}\right)$ & 0.67 & 0.09 & 3 \\
\hline Alkalinity $\left(\mathrm{mg} / \mathrm{L}\right.$ as $\left.\mathrm{CaCO}_{3}\right)$ & 196.3 & 1.2 & 3 \\
\hline Hardness $\left(\mathrm{mg} / \mathrm{L}\right.$ as $\left.\mathrm{CaCO}_{3}\right)$ & 219.0 & 52.2 & 3 \\
\hline Standard Plate Count (CFU/ml) & 1625.0 & 261.6 & 2 \\
\hline Acridine Orange Direct Counts (cells/g) & $2.5 \times 10^{8}$ & $7.9 \times 10^{7}$ & 1 \\
\hline Acid Phosphatase $(\mu \mathrm{g} / \mathrm{g})$ & 6.9 & 11.8 & 3 \\
\hline Alkaline Phosphatase $(\mu \mathrm{g} / \mathrm{g})$ & 29.8 & 22.5 & 3 \\
\hline Dehydrogenase $(\mu \mathrm{g} / \mathrm{g})$ & 21.2 & 8.2 & 3 \\
\hline Galactosidase $(\mu \mathrm{g} / \mathrm{g})$ & 2.2 & 1.7 & 3 \\
\hline Glucosidase $(\mu \mathrm{g} / \mathrm{g})$ & 27.9 & 8.3 & 3 \\
\hline E. coli O157:H7 (CFU/100ml) & 12.5 & 0 & 3 \\
\hline Shigella sp. (CFU/100ml) & 5.0 & 0 & 3 \\
\hline Bacteriophage (PUF/ml) & 0.50 & 0 & 3 \\
\hline Giardia sp.(cysts/L) & 22.5 & 0 & 1 \\
\hline Cryptosporidium sp. (cysts/L) & 52.5 & 0 & 1 \\
\hline
\end{tabular}


Table 38. Summary statistics for July 2011, site 4

\begin{tabular}{llll}
\hline Variable & Mean & Std Dev & N \\
Air Temperature $\left({ }^{\circ} \mathrm{C}\right)$ & 20.8 & 0 & 1 \\
Water Temperature $\left({ }^{\circ} \mathrm{C}\right)$ & 17.3 & 0 & 1 \\
$\mathrm{pH}$ & 7.3 & 0 & 1 \\
Conductivity $(\mu \mathrm{mohs})$ & 293.0 & 0 & 1 \\
Dissolved Oxygen $\left(\mathrm{mg} / \mathrm{L}\right.$ as $\left.\mathrm{O}_{2}\right)$ & 8.5 & 0 & 1 \\
Discharge $\left(\mathrm{m}^{3} / \mathrm{sec}\right)$ & 0.23 & 0 & 1 \\
Fecal Coliform - Water $(\mathrm{CFU} / 100 \mathrm{ml})$ & 1933.3 & 702.4 & 3 \\
Total Coliform - Water $(\mathrm{CFU} / 100 \mathrm{ml})$ & 9553.3 & 8333.9 & 3 \\
Fecal Coliform - Sediment $(\mathrm{CFU} / 100 \mathrm{ml})$ & 175.0 & 53.4 & 2 \\
Total Coliform - Sediment $(\mathrm{CFU} / 100 \mathrm{ml})$ & 3150.0 & 1626.4 & 2 \\
Colilert $(\mathrm{MPN} / 100 \mathrm{ml})$ & 164.0 & 0 & 1 \\
Nitrates $(\mathrm{mg} / \mathrm{L})$ & 1.5 & 0.91 & 3 \\
Phosphates $(\mathrm{mg} / \mathrm{L})$ & 0.10 & 0.01 & 3 \\
Ammonia $(\mathrm{mg} / \mathrm{L})$ & 0.32 & 0.41 & 3 \\
Biochemical Oxygen Demand $\left(\mathrm{mg} / \mathrm{L}\right.$ as $\left.\mathrm{O}_{2}\right)$ & 0.77 & 0.06 & 3 \\
Alkalinity $(\mathrm{mg} / \mathrm{L}$ as CaCO $)$ & 179.7 & 2.5 & 3 \\
Hardness $(\mathrm{mg} / \mathrm{L}$ as CaCO 3$)$ & 214.7 & 18.2 & 3 \\
Standard Plate Count $(\mathrm{CFU} / \mathrm{ml})$ & 855.0 & 162.6 & 2 \\
Acridine Orange Direct Counts $(\mathrm{cells} / \mathrm{g})$ & $2.1 \times 10^{8}$ & $1.1 \times 10^{8}$ & 1 \\
Acid Phosphatase $(\mu \mathrm{gg} / \mathrm{g})$ & 0.10 & 0 & 3 \\
Alkaline Phosphatase $(\mu \mathrm{gg} / \mathrm{g})$ & 22.4 & 4.5 & 3 \\
Dehydrogenase $(\mu \mathrm{gg} / \mathrm{g})$ & 15.7 & 6.3 & 3 \\
Galactosidase $(\mu \mathrm{gg} / \mathrm{g})$ & 1.7 & 1.6 & 3 \\
Glucosidase $(\mu \mathrm{g} / \mathrm{g})$ & 20.2 & 3.7 & 3 \\
E. coli O157:H7 $(\mathrm{CFU} / 100 \mathrm{ml})$ & 12.5 & 0 & 3 \\
Shigella sp. $(\mathrm{CFU} / 100 \mathrm{ml})$ & 5.0 & 0 & 3 \\
Bacteriophage $(\mathrm{PUF} / \mathrm{ml})$ & 0.50 & 0 & 3 \\
Giardia $s p .(\mathrm{cysts} / \mathrm{L})$ & 38.0 & 0 & 1 \\
Cryptosporidium sp. $(\mathrm{cysts} / \mathrm{L})$ & 14.3 & 0 & 1 \\
\hline
\end{tabular}


Table 39. Summary statistics for July 2011, site 7

\begin{tabular}{|c|c|c|c|}
\hline Variable & Mean & Std Dev & $\mathbf{N}$ \\
\hline Air Temperature $\left({ }^{\circ} \mathrm{C}\right)$ & 21.2 & 0 & 1 \\
\hline Water Temperature $\left({ }^{\circ} \mathrm{C}\right)$ & 16.1 & 0 & 1 \\
\hline $\mathrm{pH}$ & 7.4 & 0 & 1 \\
\hline Conductivity ( $\mu$ mohs) & 223.0 & 0 & 1 \\
\hline Dissolved Oxygen (mg/L as $\mathrm{O}_{2}$ ) & 8.2 & 0 & 1 \\
\hline Discharge $\left(\mathrm{m}^{3} / \mathrm{sec}\right)$ & 0.15 & 0 & 1 \\
\hline Fecal Coliform - Water (CFU/100ml) & 333.3 & 115.5 & 3 \\
\hline Total Coliform - Water (CFU/100ml) & 4000.0 & 3704.1 & 3 \\
\hline Fecal Coliform - Sediment (CFU/100ml) & 62.5 & 53.0 & 2 \\
\hline Total Coliform - Sediment (CFU/100ml) & 3350.0 & 2474.9 & 2 \\
\hline Colilert (MPN/100ml) & 10.4 & 0 & 1 \\
\hline Nitrates $(\mathrm{mg} / \mathrm{L})$ & 0.90 & 0.30 & 3 \\
\hline Phosphates (mg/L) & 0.10 & 0.03 & 3 \\
\hline Ammonia $(\mathrm{mg} / \mathrm{L})$ & 0.31 & 0.42 & 3 \\
\hline Biochemical Oxygen Demand (mg/L as $\mathrm{O}_{2}$ ) & 0.32 & 0.40 & 3 \\
\hline Alkalinity $\left(\mathrm{mg} / \mathrm{L}\right.$ as $\left.\mathrm{CaCO}_{3}\right)$ & 152.7 & 1.5 & 3 \\
\hline Hardness $\left(\mathrm{mg} / \mathrm{L}\right.$ as $\left.\mathrm{CaCO}_{3}\right)$ & 166.7 & 8.6 & 3 \\
\hline Standard Plate Count (CFU/ml) & 345 & 134.4 & 2 \\
\hline Acridine Orange Direct Counts (cells/g) & $2.2 \times 10^{8}$ & $3.8 \times 10^{7}$ & 1 \\
\hline Acid Phosphatase $(\mu \mathrm{g} / \mathrm{g})$ & 0.15 & 0.10 & 3 \\
\hline Alkaline Phosphatase $(\mu \mathrm{g} / \mathrm{g})$ & 40.4 & 9.2 & 3 \\
\hline Dehydrogenase $(\mu \mathrm{g} / \mathrm{g})$ & 16.8 & 7.0 & 3 \\
\hline Galactosidase $(\mu \mathrm{g} / \mathrm{g})$ & 1.62 & 0.53 & 3 \\
\hline Glucosidase $(\mu \mathrm{g} / \mathrm{g})$ & 24.2 & 3.1 & 3 \\
\hline E. coli 0157:H7 (CFU/100ml) & 12.5 & 0 & 3 \\
\hline Shigella sp. (CFU/100ml) & 5.0 & 0 & 3 \\
\hline Bacteriophage (PUF/ml) & 0.50 & 0 & 3 \\
\hline Giardia sp.(cysts/L) & 24.0 & 0 & 1 \\
\hline Cryptosporidium sp. (cysts/L) & 12.0 & 0 & 1 \\
\hline
\end{tabular}


Table 40. Summary statistics for July 2011, site 10

\begin{tabular}{|c|c|c|c|}
\hline Variable & Mean & Std Dev & $\mathbf{N}$ \\
\hline Air Temperature $\left({ }^{\circ} \mathrm{C}\right)$ & 25.7 & 0 & 1 \\
\hline Water Temperature $\left({ }^{\circ} \mathrm{C}\right)$ & 16.4 & 0 & 1 \\
\hline $\mathrm{pH}$ & 7.2 & 0 & 1 \\
\hline Conductivity ( $\mu$ mohs) & 124.3 & 0 & 1 \\
\hline Dissolved Oxygen (mg/L as $\mathrm{O}_{2}$ ) & 9.4 & 0 & 1 \\
\hline Discharge $\left(\mathrm{m}^{3} / \mathrm{sec}\right)$ & 0.07 & 0 & 1 \\
\hline Fecal Coliform - Water (CFU/100ml) & 700.0 & 519.6 & 3 \\
\hline Total Coliform - Water (CFU/100ml) & 3333.3 & 4738.5 & 3 \\
\hline Fecal Coliform - Sediment (CFU/100ml) & 450.0 & 212.1 & 2 \\
\hline Total Coliform - Sediment (CFU/100ml) & 5675.0 & 1803.1 & 2 \\
\hline Colilert (MPN/100ml) & 58.4 & 0 & 1 \\
\hline Nitrates $(\mathrm{mg} / \mathrm{L})$ & 1.3 & 0.21 & 3 \\
\hline Phosphates (mg/L) & 0.17 & 0.01 & 3 \\
\hline Ammonia $(\mathrm{mg} / \mathrm{L})$ & 0.11 & 0.01 & 3 \\
\hline Biochemical Oxygen Demand (mg/L as $\mathrm{O}_{2}$ ) & 0.75 & 0.06 & 3 \\
\hline Alkalinity $\left(\mathrm{mg} / \mathrm{L}\right.$ as $\left.\mathrm{CaCO}_{3}\right)$ & 123.3 & 2.5 & 3 \\
\hline Hardness $\left(\mathrm{mg} / \mathrm{L}\right.$ as $\left.\mathrm{CaCO}_{3}\right)$ & 123.0 & 5.2 & 3 \\
\hline Standard Plate Count (CFU/ml) & 320.0 & 42.4 & 2 \\
\hline Acridine Orange Direct Counts (cells/g) & $2.7 \times 10^{8}$ & $1.4 \times 10^{8}$ & 1 \\
\hline Acid Phosphatase $(\mu \mathrm{g} / \mathrm{g})$ & 4.6 & 4.8 & 3 \\
\hline Alkaline Phosphatase $(\mu \mathrm{g} / \mathrm{g})$ & 56.3 & 14.5 & 3 \\
\hline Dehydrogenase $(\mu \mathrm{g} / \mathrm{g})$ & 13.8 & 7.7 & 3 \\
\hline Galactosidase $(\mu \mathrm{g} / \mathrm{g})$ & 2.8 & 0.34 & 3 \\
\hline Glucosidase $(\mu \mathrm{g} / \mathrm{g})$ & 32.4 & 3.7 & 3 \\
\hline E. coli 0157:H7 (CFU/100ml) & 12.5 & 0 & 3 \\
\hline Shigella sp. (CFU/100ml) & 5.0 & 0 & 3 \\
\hline Bacteriophage (PUF/ml) & 0.50 & 0 & 3 \\
\hline Giardia sp.(cysts/L) & 3.8 & 0 & 1 \\
\hline Cryptosporidium sp. (cysts/L) & 15.0 & 0 & 1 \\
\hline
\end{tabular}


Table 41. Summary statistics for July 2011, site 13

\begin{tabular}{|c|c|c|c|}
\hline Variable & Mean & Std Dev & $\mathbf{N}$ \\
\hline Air Temperature $\left({ }^{\circ} \mathrm{C}\right)$ & 24.9 & 0 & 1 \\
\hline Water Temperature $\left({ }^{\circ} \mathrm{C}\right)$ & 19.1 & 0 & 1 \\
\hline $\mathrm{pH}$ & 7.9 & 0 & 1 \\
\hline Conductivity ( $\mu$ mohs) & 73.4 & 0 & 1 \\
\hline Dissolved Oxygen (mg/L as $\mathrm{O}_{2}$ ) & 8.8 & 0 & 1 \\
\hline Discharge $\left(\mathrm{m}^{3} / \mathrm{sec}\right)$ & 0.06 & 0 & 1 \\
\hline Fecal Coliform - Water (CFU/100ml) & 366.7 & 378.6 & 3 \\
\hline Total Coliform - Water (CFU/100ml) & $9 . .3$ & 808.3 & 3 \\
\hline Fecal Coliform - Sediment (CFU/100ml) & 362.5 & 477.3 & 2 \\
\hline Total Coliform - Sediment (CFU/100ml) & 7150.0 & 1484.9 & 2 \\
\hline Colilert (MPN/100ml) & 8.2 & 0 & 1 \\
\hline Nitrates $(\mathrm{mg} / \mathrm{L})$ & 0.50 & 0.50 & 3 \\
\hline Phosphates (mg/L) & 0.19 & 0.03 & 3 \\
\hline Ammonia $(\mathrm{mg} / \mathrm{L})$ & 0.06 & 0.01 & 3 \\
\hline Biochemical Oxygen Demand (mg/L as $\mathrm{O}_{2}$ ) & 0.080 & 0.12 & 3 \\
\hline Alkalinity $\left(\mathrm{mg} / \mathrm{L}\right.$ as $\left.\mathrm{CaCO}_{3}\right)$ & 38.7 & 1.2 & 3 \\
\hline Hardness $\left(\mathrm{mg} / \mathrm{L}\right.$ as $\left.\mathrm{CaCO}_{3}\right)$ & 42.0 & 5.6 & 3 \\
\hline Standard Plate Count (CFU/ml) & 230.0 & 56.6 & 2 \\
\hline Acridine Orange Direct Counts (cells/g) & $2.5 \times 10^{8}$ & $1.4 \times 10^{8}$ & 1 \\
\hline Acid Phosphatase $(\mu \mathrm{g} / \mathrm{g})$ & 20.7 & 6.9 & 3 \\
\hline Alkaline Phosphatase $(\mu \mathrm{g} / \mathrm{g})$ & 75.9 & 9.1 & 3 \\
\hline Dehydrogenase $(\mu \mathrm{g} / \mathrm{g})$ & 15.3 & 1.3 & 3 \\
\hline Galactosidase $(\mu \mathrm{g} / \mathrm{g})$ & 3.9 & 1.2 & 3 \\
\hline Glucosidase $(\mu \mathrm{g} / \mathrm{g})$ & 28.9 & 3.4 & 3 \\
\hline E. coli 0157:H7 (CFU/100ml) & 12.5 & 0 & 3 \\
\hline Shigella sp. (CFU/100ml) & 5.0 & 0 & 3 \\
\hline Bacteriophage (PUF/ml) & 0.50 & 0 & 3 \\
\hline Giardia sp.(cysts/L) & 1.4 & 0 & 1 \\
\hline Cryptosporidium sp. (cysts/L) & 5.5 & 0 & 1 \\
\hline
\end{tabular}


Table 42. Summary statistics for July 2011, site 14

\begin{tabular}{|c|c|c|c|}
\hline Variable & Mean & Std Dev & $\mathbf{N}$ \\
\hline Air Temperature $\left({ }^{\circ} \mathrm{C}\right)$ & 24.5 & 0 & 1 \\
\hline Water Temperature $\left({ }^{\circ} \mathrm{C}\right)$ & 19.3 & 0 & 1 \\
\hline $\mathrm{pH}$ & 8.3 & 0 & 1 \\
\hline Conductivity ( $\mu$ mohs) & 27.6 & 0 & 1 \\
\hline Dissolved Oxygen (mg/L as $\mathrm{O}_{2}$ ) & 7.1 & 0 & 1 \\
\hline Discharge $\left(\mathrm{m}^{3} / \mathrm{sec}\right)$ & 0.004 & 0 & 1 \\
\hline Fecal Coliform - Water (CFU/100ml) & 100 & 0 & 3 \\
\hline Total Coliform - Water (CFU/100ml) & 933.3 & 757.2 & 3 \\
\hline Fecal Coliform - Sediment (CFU/100ml) & 37.5 & 17.7 & 2 \\
\hline Total Coliform - Sediment (CFU/100ml) & 1350.0 & 212.1 & 2 \\
\hline Colilert (MPN/100ml) & 19.4 & 0 & 1 \\
\hline Nitrates $(\mathrm{mg} / \mathrm{L})$ & 0.67 & 0.40 & 3 \\
\hline Phosphates (mg/L) & 0.19 & 0.06 & 3 \\
\hline Ammonia $(\mathrm{mg} / \mathrm{L})$ & 0.04 & 0.02 & 3 \\
\hline Biochemical Oxygen Demand (mg/L as $\mathrm{O}_{2}$ ) & 0.83 & 0.05 & 3 \\
\hline Alkalinity $\left(\mathrm{mg} / \mathrm{L}\right.$ as $\left.\mathrm{CaCO}_{3}\right)$ & 10.0 & 2.0 & 3 \\
\hline Hardness $\left(\mathrm{mg} / \mathrm{L}\right.$ as $\left.\mathrm{CaCO}_{3}\right)$ & 11.3 & 0.58 & 3 \\
\hline Standard Plate Count (CFU/ml) & 320.0 & 70.7 & 2 \\
\hline Acridine Orange Direct Counts (cells/g) & $2.4 \times 10^{8}$ & $1.2 \times 10^{8}$ & 1 \\
\hline Acid Phosphatase $(\mu \mathrm{g} / \mathrm{g})$ & 31.5 & 5.9 & 3 \\
\hline Alkaline Phosphatase $(\mu \mathrm{g} / \mathrm{g})$ & 41.1 & 19.7 & 3 \\
\hline Dehydrogenase $(\mu \mathrm{g} / \mathrm{g})$ & 13.5 & 2.0 & 3 \\
\hline Galactosidase $(\mu \mathrm{g} / \mathrm{g})$ & 3.2 & 1.1 & 3 \\
\hline Glucosidase $(\mu \mathrm{g} / \mathrm{g})$ & 35.6 & 4.5 & 3 \\
\hline E. coli 0157:H7 (CFU/100ml) & 12.5 & 0 & 3 \\
\hline Shigella sp. (CFU/100ml) & 5.0 & 0 & 3 \\
\hline Bacteriophage (PUF/ml) & 0.50 & 0 & 3 \\
\hline Giardia sp.(cysts/L) & 30.0 & 0 & 1 \\
\hline Cryptosporidium sp. (cysts/L) & 7.5 & 0 & 1 \\
\hline
\end{tabular}


Table 43. Summary statistics for August 2011, site 2

\begin{tabular}{llll}
\hline Variable & Mean & Std Dev & N \\
Air Temperature $\left({ }^{\circ} \mathrm{C}\right)$ & 18.1 & 0 & 1 \\
Water Temperature $\left({ }^{\circ} \mathrm{C}\right)$ & 17.7 & 0 & 1 \\
$\mathrm{pH}$ & 7.4 & 0 & 1 \\
Conductivity $(\mu \mathrm{mohs})$ & 321.0 & 0 & 1 \\
Dissolved Oxygen $\left(\mathrm{mg} / \mathrm{L}\right.$ as $\left.\mathrm{O}_{2}\right)$ & 8.9 & 0 & 1 \\
Discharge $\left(\mathrm{m}^{3} / \mathrm{sec}\right)$ & 2.4 & 0 & 1 \\
Fecal Coliform - Water $(\mathrm{CFU} / 100 \mathrm{ml})$ & 3400.0 & 800.0 & 3 \\
Total Coliform - Water $(\mathrm{CFU} / 100 \mathrm{ml})$ & 16133.3 & 3028.8 & 3 \\
Fecal Coliform - Sediment $(\mathrm{CFU} / 100 \mathrm{ml})$ & 950.0 & 70.7 & 2 \\
Total Coliform - Sediment $(\mathrm{CFU} / 100 \mathrm{ml})$ & 1440.0 & 1979.9 & 2 \\
Colilert $(\mathrm{MPN} / 100 \mathrm{ml})$ & 275.0 & 0 & 1 \\
Nitrates $(\mathrm{mg} / \mathrm{L})$ & 1.2 & 0.10 & 3 \\
Phosphates $(\mathrm{mg} / \mathrm{L})$ & 0.17 & 0.05 & 3 \\
Ammonia $(\mathrm{mg} / \mathrm{L})$ & 0.08 & 0.03 & 3 \\
Biochemical Oxygen Demand $\left(\mathrm{mg} / \mathrm{L}\right.$ as $\left.\mathrm{O}_{2}\right)$ & 0.26 & 0.06 & 3 \\
Alkalinity $(\mathrm{mg} / \mathrm{L}$ as CaCO $)$ & 186.3 & 3.1 & 3 \\
Hardness $(\mathrm{mg} / \mathrm{L}$ as CaCO 3$)$ & 205.7 & 2.3 & 3 \\
Standard Plate Count $(\mathrm{CFU} / \mathrm{ml})$ & 770.0 & 183.8 & 2 \\
Acridine Orange Direct Counts $(\mathrm{cells} / \mathrm{g})$ & $4.2 \times 10^{7}$ & $1.9 \times 10^{7}$ & 1 \\
Acid Phosphatase $(\mu \mathrm{gg} / \mathrm{g})$ & 12.9 & 5.2 & 3 \\
Alkaline Phosphatase $(\mu \mathrm{gg} / \mathrm{g})$ & 50.0 & 17.4 & 3 \\
Dehydrogenase $(\mu \mathrm{gg} / \mathrm{g})$ & 6.1 & 4.5 & 3 \\
Galactosidase $(\mu \mathrm{gg} / \mathrm{g})$ & 1.0 & 0.33 & 3 \\
Glucosidase $(\mu \mathrm{g} / \mathrm{g})$ & 32.2 & 5.3 & 3 \\
E. coli O157:H7 $(\mathrm{CFU} / 100 \mathrm{ml})$ & 12.5 & 0 & 3 \\
Shigella sp. $(\mathrm{CFU} / 100 \mathrm{ml})$ & 5.0 & 0 & 3 \\
Bacteriophage $(\mathrm{PUF} / \mathrm{ml})$ & 0.50 & 0 & 3 \\
Giardia $s p .(\mathrm{cysts} / \mathrm{L})$ & 17.5 & 0 & 1 \\
Cryptosporidium sp. $(\mathrm{cysts} / \mathrm{L})$ & 17.5 & 0 & 1 \\
\hline
\end{tabular}


Table 44. Summary statistics for August 2011, site 4

\begin{tabular}{llll}
\hline Variable & Mean & Std Dev & N \\
Air Temperature $\left({ }^{\circ} \mathrm{C}\right)$ & 17.0 & 0 & 1 \\
Water Temperature $\left({ }^{\circ} \mathrm{C}\right)$ & 17.4 & 0 & 1 \\
$\mathrm{pH}$ & 7.4 & 0 & 1 \\
Conductivity $(\mu \mathrm{mohs})$ & 3000.0 & 0 & 1 \\
Dissolved Oxygen $\left(\mathrm{mg} / \mathrm{L}\right.$ as $\left.\mathrm{O}_{2}\right)$ & 9.0 & 0 & 1 \\
Discharge $\left(\mathrm{m}^{3} / \mathrm{sec}\right)$ & 0.35 & 0 & 1 \\
Fecal Coliform - Water $(\mathrm{CFU} / 100 \mathrm{ml})$ & 3133.3 & 1137.3 & 3 \\
Total Coliform - Water $(\mathrm{CFU} / 100 \mathrm{ml})$ & 20000.0 & 6428.1 & 3 \\
Fecal Coliform - Sediment $(\mathrm{CFU} / 100 \mathrm{ml})$ & 675.0 & 106.1 & 2 \\
Total Coliform - Sediment $(\mathrm{CFU} / 100 \mathrm{ml})$ & 12800.0 & 282.4 & 2 \\
Colilert $(\mathrm{MPN} / 100 \mathrm{ml})$ & 301.0 & 0 & 1 \\
Nitrates $(\mathrm{mg} / \mathrm{L})$ & 1.3 & 0.12 & 3 \\
Phosphates $(\mathrm{mg} / \mathrm{L})$ & 0.08 & 0.05 & 3 \\
Ammonia $(\mathrm{mg} / \mathrm{L})$ & 0.10 & 0.01 & 3 \\
Biochemical Oxygen Demand $\left(\mathrm{mg} / \mathrm{L}\right.$ as $\left.\mathrm{O}_{2}\right)$ & 0.34 & 0.02 & 3 \\
Alkalinity $(\mathrm{mg} / \mathrm{L}$ as CaCO $)$ & 173.3 & 2.1 & 3 \\
Hardness $(\mathrm{mg} / \mathrm{L}$ as CaCO 3$)$ & 193.3 & 1.2 & 3 \\
Standard Plate Count $(\mathrm{CFU} / \mathrm{ml})$ & 500.0 & 56.6 & 2 \\
Acridine Orange Direct Counts $(\mathrm{cells} / \mathrm{g})$ & $9.6 \times 10^{7}$ & $4.4 \times 10^{7}$ & 1 \\
Acid Phosphatase $(\mu \mathrm{gg} / \mathrm{g})$ & 10.9 & 6.8 & 3 \\
Alkaline Phosphatase $(\mu \mathrm{gg} / \mathrm{g})$ & 42.4 & 17.7 & 3 \\
Dehydrogenase $(\mu \mathrm{gg} / \mathrm{g})$ & 5.0 & 4.1 & 3 \\
Galactosidase $(\mu \mathrm{gg} / \mathrm{g})$ & 4.2 & 2.4 & 3 \\
Glucosidase $(\mu \mathrm{g} / \mathrm{g})$ & 38.4 & 7.9 & 3 \\
E. coli O157:H7 $(\mathrm{CFU} / 100 \mathrm{ml})$ & 12.5 & 0 & 3 \\
Shigella sp. $(\mathrm{CFU} / 100 \mathrm{ml})$ & 5.0 & 0 & 3 \\
Bacteriophage $(\mathrm{PUF} / \mathrm{ml})$ & 0.50 & 0 & 3 \\
Giardia $s p .(\mathrm{cysts} / \mathrm{L})$ & 15.0 & 0 & 1 \\
Cryptosporidium sp. $(\mathrm{cysts} / \mathrm{L})$ & 7.0 & 0 & 1 \\
\hline
\end{tabular}


Table 45. Summary statistics for August 2011, site 7

\begin{tabular}{|c|c|c|c|}
\hline Variable & Mean & Std Dev & $\mathbf{N}$ \\
\hline Air Temperature $\left({ }^{\circ} \mathrm{C}\right)$ & 18.0 & 0 & 1 \\
\hline Water Temperature $\left({ }^{\circ} \mathrm{C}\right)$ & 15.8 & 0 & 1 \\
\hline $\mathrm{pH}$ & 7.0 & 0 & 1 \\
\hline Conductivity ( $\mu$ mohs) & 258.0 & 0 & 1 \\
\hline Dissolved Oxygen (mg/L as $\mathrm{O}_{2}$ ) & 8.8 & 0 & 1 \\
\hline Discharge $\left(\mathrm{m}^{3} / \mathrm{sec}\right)$ & 0.50 & 0 & 1 \\
\hline Fecal Coliform - Water (CFU/100ml) & 1266.7 & 416.3 & 3 \\
\hline Total Coliform - Water (CFU/100ml) & 6333.3 & 2858.9 & 3 \\
\hline Fecal Coliform - Sediment (CFU/100ml) & 475.0 & 35.4 & 2 \\
\hline Total Coliform - Sediment (CFU/100ml) & 3400.0 & 3252.7 & 2 \\
\hline Colilert (MPN/100ml) & 41.0 & 0 & 1 \\
\hline Nitrates (mg/L) & 1.8 & 0.17 & 3 \\
\hline Phosphates (mg/L) & 0.16 & 0.04 & 3 \\
\hline Ammonia $(\mathrm{mg} / \mathrm{L})$ & 0.09 & 0.05 & 3 \\
\hline Biochemical Oxygen Demand (mg/L as $\mathrm{O}_{2}$ ) & 0.31 & 0.04 & 3 \\
\hline Alkalinity $\left(\mathrm{mg} / \mathrm{L}\right.$ as $\left.\mathrm{CaCO}_{3}\right)$ & 152.7 & 3.5 & 3 \\
\hline Hardness (mg/L as $\left.\mathrm{CaCO}_{3}\right)$ & 169.7 & 1.5 & 3 \\
\hline Standard Plate Count (CFU/ml) & 310.0 & 28.3 & 2 \\
\hline Acridine Orange Direct Counts (cells/g) & $6.0 \times 10^{7}$ & $1.9 \times 10^{7}$ & 1 \\
\hline Acid Phosphatase $(\mu \mathrm{g} / \mathrm{g})$ & 10.2 & 8.6 & 3 \\
\hline Alkaline Phosphatase $(\mu \mathrm{g} / \mathrm{g})$ & 55.7 & 9.0 & 3 \\
\hline Dehydrogenase $(\mu \mathrm{g} / \mathrm{g})$ & 34.4 & 7.0 & 3 \\
\hline Galactosidase $(\mu \mathrm{g} / \mathrm{g})$ & 1.8 & 0.68 & 3 \\
\hline Glucosidase $(\mu \mathrm{g} / \mathrm{g})$ & 34.7 & 8.7 & 3 \\
\hline E. coli O157:H7 (CFU/100ml) & 12.5 & 0 & 3 \\
\hline Shigella sp. (CFU/100ml) & 5.0 & 0 & 3 \\
\hline Bacteriophage (PUF/mI) & 0.50 & 0 & 3 \\
\hline Giardia sp.(cysts/L) & 6.8 & 0 & 1 \\
\hline Cryptosporidium sp. (cysts/L) & 27.0 & 0 & 1 \\
\hline
\end{tabular}


Table 46. Summary statistics from August 2011, site 10

\begin{tabular}{|c|c|c|c|}
\hline Variable & Mean & Std Dev & $\mathbf{N}$ \\
\hline Air Temperature $\left({ }^{\circ} \mathrm{C}\right)$ & 20.9 & 0 & 1 \\
\hline Water Temperature $\left({ }^{\circ} \mathrm{C}\right)$ & 16.4 & 0 & 1 \\
\hline $\mathrm{pH}$ & 7.6 & 0 & 1 \\
\hline Conductivity ( $\mu$ mohs) & 192.8 & 0 & 1 \\
\hline Dissolved Oxygen (mg/L as $\mathrm{O}_{2}$ ) & 9.1 & 0 & 1 \\
\hline Discharge $\left(\mathrm{m}^{3} / \mathrm{sec}\right)$ & 0.08 & 0 & 1 \\
\hline Fecal Coliform - Water (CFU/100ml) & 1200.0 & 529.1 & 3 \\
\hline Total Coliform - Water (CFU/100ml) & 9133.3 & 3177.0 & 3 \\
\hline Fecal Coliform - Sediment (CFU/100ml) & 375.0 & 247.5 & 2 \\
\hline Total Coliform - Sediment (CFU/100ml) & 15050.0 & 6576.1 & 2 \\
\hline Colilert (MPN/100ml) & 171.0 & 0 & 1 \\
\hline Nitrates (mg/L) & 1.1 & 0.25 & 3 \\
\hline Phosphates (mg/L) & 0.07 & 0.04 & 3 \\
\hline Ammonia (mg/L) & 0.11 & 0.02 & 3 \\
\hline Biochemical Oxygen Demand (mg/L as $\mathrm{O}_{2}$ ) & 0.30 & 0.03 & 3 \\
\hline Alkalinity $\left(\mathrm{mg} / \mathrm{L}\right.$ as $\left.\mathrm{CaCO}_{3}\right)$ & 121.3 & 0.58 & 3 \\
\hline Hardness (mg/L as $\left.\mathrm{CaCO}_{3}\right)$ & 129.3 & 3.2 & 3 \\
\hline Standard Plate Count (CFU/ml) & 360.0 & 42.4 & 2 \\
\hline Acridine Orange Direct Counts (cells/g) & $8.5 \times 10^{7}$ & $4.0 \times 10^{7}$ & 1 \\
\hline Acid Phosphatase $(\mu \mathrm{g} / \mathrm{g})$ & 6.4 & 4.5 & 3 \\
\hline Alkaline Phosphatase $(\mu \mathrm{g} / \mathrm{g})$ & 50.6 & 11.8 & 3 \\
\hline Dehydrogenase $(\mu \mathrm{g} / \mathrm{g})$ & 36.5 & 16.6 & 3 \\
\hline Galactosidase $(\mu \mathrm{g} / \mathrm{g})$ & 2.5 & 1.8 & 3 \\
\hline Glucosidase $(\mu \mathrm{g} / \mathrm{g})$ & 52.0 & 15.6 & 3 \\
\hline E. coli O157:H7 (CFU/100ml) & 12.5 & 0 & 3 \\
\hline Shigella sp. (CFU/100ml) & 5.0 & 0 & 3 \\
\hline Bacteriophage (PUF/mI) & 0.50 & 0 & 3 \\
\hline Giardia sp.(cysts/L) & 15.0 & 0 & 1 \\
\hline Cryptosporidium sp. (cysts/L) & 7.0 & 0 & 1 \\
\hline
\end{tabular}


Table 47. Summary statistics for August 2011, site 13

\begin{tabular}{|c|c|c|c|}
\hline Variable & Mean & Std Dev & $\mathbf{N}$ \\
\hline Air Temperature $\left({ }^{\circ} \mathrm{C}\right)$ & 18.9 & 0 & 1 \\
\hline Water Temperature $\left({ }^{\circ} \mathrm{C}\right)$ & 18.4 & 0 & 1 \\
\hline $\mathrm{pH}$ & 7.0 & 0 & 1 \\
\hline Conductivity ( $\mu$ mohs) & 79.5 & 0 & 1 \\
\hline Dissolved Oxygen (mg/L as $\mathrm{O}_{2}$ ) & 8.5 & 0 & 1 \\
\hline Discharge $\left(\mathrm{m}^{3} / \mathrm{sec}\right)$ & 0.07 & 0 & 1 \\
\hline Fecal Coliform - Water (CFU/100ml) & 466.7 & 305.5 & 3 \\
\hline Total Coliform - Water (CFU/100ml) & 7400.0 & 1249.0 & 3 \\
\hline Fecal Coliform - Sediment (CFU/100ml) & 1175.0 & 176.8 & 2 \\
\hline Total Coliform - Sediment (CFU/100ml) & 10450.0 & 70.7 & 2 \\
\hline Colilert (MPN/100ml) & 41.0 & 0 & 1 \\
\hline Nitrates (mg/L) & 0.27 & 0.06 & 3 \\
\hline Phosphates (mg/L) & 0.13 & 0.05 & 3 \\
\hline Ammonia (mg/L) & 0.06 & 0.02 & 3 \\
\hline Biochemical Oxygen Demand (mg/L as $\mathrm{O}_{2}$ ) & 0.50 & 0.33 & 3 \\
\hline Alkalinity $\left(\mathrm{mg} / \mathrm{L}\right.$ as $\left.\mathrm{CaCO}_{3}\right)$ & 42.0 & 1.7 & 3 \\
\hline Hardness $\left(\mathrm{mg} / \mathrm{L}\right.$ as $\left.\mathrm{CaCO}_{3}\right)$ & 48.3 & 2.5 & 3 \\
\hline Standard Plate Count (CFU/ml) & 330.0 & 127.3 & 2 \\
\hline Acridine Orange Direct Counts (cells/g) & $5.3 \times 10^{7}$ & $1.9 \times 10^{7}$ & 1 \\
\hline Acid Phosphatase $(\mu \mathrm{g} / \mathrm{g})$ & 33.4 & 2.6 & 3 \\
\hline Alkaline Phosphatase $(\mu \mathrm{g} / \mathrm{g})$ & 61.3 & 30.5 & 3 \\
\hline Dehydrogenase $(\mu \mathrm{g} / \mathrm{g})$ & 33.5 & 14.1 & 3 \\
\hline Galactosidase $(\mu \mathrm{g} / \mathrm{g})$ & 3.6 & 0.73 & 3 \\
\hline Glucosidase $(\mu \mathrm{g} / \mathrm{g})$ & 25.9 & 6.7 & 3 \\
\hline E. coli O157:H7 (CFU/100ml) & 12.5 & 0 & 3 \\
\hline Shigella sp. (CFU/100ml) & 5.0 & 0 & 3 \\
\hline Bacteriophage (PUF/ml) & 0.50 & 0 & 3 \\
\hline Giardia sp.(cysts/L) & 3.8 & 0 & 1 \\
\hline Cryptosporidium sp. (cysts/L) & 7.5 & 0 & 1 \\
\hline
\end{tabular}


Table 48. Summary statistics for August 2011, site 14

\begin{tabular}{|c|c|c|c|}
\hline Variable & Mean & Std Dev & $\mathbf{N}$ \\
\hline Air Temperature $\left({ }^{\circ} \mathrm{C}\right)$ & 18.8 & 0 & 1 \\
\hline Water Temperature $\left({ }^{\circ} \mathrm{C}\right)$ & 18.1 & 0 & 1 \\
\hline $\mathrm{pH}$ & 7.0 & 0 & 1 \\
\hline Conductivity ( $\mu$ mohs) & 28.2 & 0 & 1 \\
\hline Dissolved Oxygen (mg/L as $\mathrm{O}_{2}$ ) & 8.2 & 0 & 1 \\
\hline Discharge $\left(\mathrm{m}^{3} / \mathrm{sec}\right)$ & 0.01 & 0 & 1 \\
\hline Fecal Coliform - Water (CFU/100ml) & 333.3 & 115.5 & 3 \\
\hline Total Coliform - Water (CFU/100ml) & 3400.0 & 1907.9 & 3 \\
\hline Fecal Coliform - Sediment (CFU/100ml) & 275.0 & 35.4 & 2 \\
\hline Total Coliform - Sediment (CFU/100ml) & 150.0 & 70.7 & 2 \\
\hline Colilert (MPN/100ml) & 171.0 & 0 & 1 \\
\hline Nitrates (mg/L) & 0.60 & 0.53 & 3 \\
\hline Phosphates (mg/L) & 0.18 & 0.08 & 3 \\
\hline Ammonia (mg/L) & 0.08 & 0.01 & 3 \\
\hline Biochemical Oxygen Demand $\left(\mathrm{mg} / \mathrm{L}\right.$ as $\left.\mathrm{O}_{2}\right)$ & 0.36 & 0.12 & 3 \\
\hline Alkalinity $\left(\mathrm{mg} / \mathrm{L}\right.$ as $\left.\mathrm{CaCO}_{3}\right)$ & 10.3 & 0.58 & 3 \\
\hline Hardness (mg/L as $\left.\mathrm{CaCO}_{3}\right)$ & 14.3 & 1.2 & 3 \\
\hline Standard Plate Count (CFU/ml) & 375.0 & 35.4 & 2 \\
\hline Acridine Orange Direct Counts (cells/g) & $1.4 \times 10^{8}$ & $4.5 \times 10^{7}$ & 1 \\
\hline Acid Phosphatase $(\mu \mathrm{g} / \mathrm{g})$ & 33.7 & 10.6 & 3 \\
\hline Alkaline Phosphatase $(\mu \mathrm{g} / \mathrm{g})$ & 66.6 & 10.3 & 3 \\
\hline Dehydrogenase $(\mu \mathrm{g} / \mathrm{g})$ & 14.1 & 10.1 & 3 \\
\hline Galactosidase $(\mu \mathrm{g} / \mathrm{g})$ & 1.1 & 0.42 & 3 \\
\hline Glucosidase $(\mu \mathrm{g} / \mathrm{g})$ & 31.6 & 7.7 & 3 \\
\hline E. coli O157:H7 (CFU/100ml) & 12.5 & 0 & 3 \\
\hline Shigella sp. (CFU/100ml) & 5.0 & 0 & 3 \\
\hline Bacteriophage (PUF/mI) & 0.67 & 0.29 & 3 \\
\hline Giardia sp.(cysts/L) & 10.8 & 0 & 1 \\
\hline Cryptosporidium sp. (cysts/L) & 21.7 & 0 & 1 \\
\hline
\end{tabular}


Table 49. Summary statistics for September 2011, site 2

\begin{tabular}{|c|c|c|c|}
\hline Variable & Mean & Std Dev & $\mathbf{N}$ \\
\hline Air Temperature $\left({ }^{\circ} \mathrm{C}\right)$ & 17.0 & 0 & 1 \\
\hline Water Temperature $\left({ }^{\circ} \mathrm{C}\right)$ & 16.3 & 0 & 1 \\
\hline $\mathrm{pH}$ & 6.8 & 0 & 1 \\
\hline Conductivity ( $\mu$ mohs) & 457.0 & 0 & 1 \\
\hline Dissolved Oxygen (mg/L as $\mathrm{O}_{2}$ ) & 14.2 & 0 & 1 \\
\hline Discharge $\left(\mathrm{m}^{3} / \mathrm{sec}\right)$ & 1.1 & 0 & 1 \\
\hline Fecal Coliform - Water (CFU/100ml) & 2266.7 & 1154.7 & 3 \\
\hline Total Coliform - Water (CFU/100ml) & 9066.7 & 10515.4 & 3 \\
\hline Fecal Coliform - Sediment (CFU/100ml) & 625.0 & 247.5 & 2 \\
\hline Total Coliform - Sediment (CFU/100ml) & 16800.0 & 3111.3 & 2 \\
\hline Colilert (MPN/100ml) & 90.0 & 0 & 1 \\
\hline Nitrates $(\mathrm{mg} / \mathrm{L})$ & 2.0 & 1.0 & 3 \\
\hline Phosphates (mg/L) & 0.15 & 0.04 & 3 \\
\hline Ammonia $(\mathrm{mg} / \mathrm{L})$ & 0.08 & 0.02 & 3 \\
\hline Biochemical Oxygen Demand (mg/L as $\mathrm{O}_{2}$ ) & 0.82 & 0.12 & 3 \\
\hline Alkalinity $\left(\mathrm{mg} / \mathrm{L}\right.$ as $\left.\mathrm{CaCO}_{3}\right)$ & 192.7 & 0.58 & 3 \\
\hline Hardness $\left(\mathrm{mg} / \mathrm{L}\right.$ as $\left.\mathrm{CaCO}_{3}\right)$ & 198.0 & 7.8 & 3 \\
\hline Standard Plate Count (CFU/ml) & 605.0 & 162.6 & 2 \\
\hline Acridine Orange Direct Counts (cells/g) & $2.3 \times 10^{8}$ & $4.1 \times 10^{7}$ & 1 \\
\hline Acid Phosphatase $(\mu \mathrm{g} / \mathrm{g})$ & 89.8 & 40.5 & 3 \\
\hline Alkaline Phosphatase $(\mu \mathrm{g} / \mathrm{g})$ & 348.7 & 49.0 & 3 \\
\hline Dehydrogenase $(\mu \mathrm{g} / \mathrm{g})$ & 27.7 & 3.6 & 3 \\
\hline Galactosidase $(\mu \mathrm{g} / \mathrm{g})$ & 20.5 & 11.8 & 3 \\
\hline Glucosidase $(\mu \mathrm{g} / \mathrm{g})$ & 266.2 & 162.1 & 3 \\
\hline E. coli 0157:H7 (CFU/100ml) & 12.5 & 0 & 3 \\
\hline Shigella sp. (CFU/100ml) & 5.0 & 0 & 3 \\
\hline Bacteriophage (PUF/ml) & 0.50 & 0 & 3 \\
\hline Giardia sp.(cysts/L) & 19.5 & 0 & 1 \\
\hline Cryptosporidium sp. (cysts/L) & 19.5 & 0 & 1 \\
\hline
\end{tabular}


Table 50. Summary statistics for September 2011, site 4

\begin{tabular}{|c|c|c|c|}
\hline Variable & Mean & Std Dev & $\mathbf{N}$ \\
\hline Air Temperature $\left({ }^{\circ} \mathrm{C}\right)$ & 17.8 & 0 & 1 \\
\hline Water Temperature $\left({ }^{\circ} \mathrm{C}\right)$ & 16.3 & 0 & 1 \\
\hline $\mathrm{pH}$ & 7.2 & 0 & 1 \\
\hline Conductivity ( $\mu$ mohs) & 414.0 & 0 & 1 \\
\hline Dissolved Oxygen (mg/L as $\mathrm{O}_{2}$ ) & 8.3 & 0 & 1 \\
\hline Discharge $\left(\mathrm{m}^{3} / \mathrm{sec}\right)$ & 0.17 & 0 & 1 \\
\hline Fecal Coliform - Water (CFU/100ml) & 2400.0 & 1000.0 & 3 \\
\hline Total Coliform - Water (CFU/100ml) & 12133.3 & 5636.8 & 3 \\
\hline Fecal Coliform - Sediment (CFU/100ml) & 400.0 & 70.7 & 2 \\
\hline Total Coliform - Sediment (CFU/100ml) & 7600.0 & 2828.4 & 2 \\
\hline Colilert (MPN/100ml) & 65.4 & 0 & 1 \\
\hline Nitrates (mg/L) & 1.1 & 0.42 & 3 \\
\hline Phosphates (mg/L) & 0.14 & 0.06 & 3 \\
\hline Ammonia (mg/L) & 0.09 & 0.02 & 3 \\
\hline Biochemical Oxygen Demand (mg/L as $\mathrm{O}_{2}$ ) & 0.95 & 0.13 & 3 \\
\hline Alkalinity $\left(\mathrm{mg} / \mathrm{L}\right.$ as $\left.\mathrm{CaCO}_{3}\right)$ & 184.7 & 3.8 & 3 \\
\hline Hardness (mg/L as $\left.\mathrm{CaCO}_{3}\right)$ & 194.3 & 1.5 & 3 \\
\hline Standard Plate Count (CFU/ml) & 595.0 & 332.4 & 2 \\
\hline Acridine Orange Direct Counts (cells/g) & $1.9 \times 10^{8}$ & $9.4 \times 10^{7}$ & 1 \\
\hline Acid Phosphatase $(\mu \mathrm{g} / \mathrm{g})$ & 60.3 & 38.8 & 3 \\
\hline Alkaline Phosphatase $(\mu \mathrm{g} / \mathrm{g})$ & 246.6 & 123.9 & 3 \\
\hline Dehydrogenase $(\mu \mathrm{g} / \mathrm{g})$ & 28.2 & 3.5 & 3 \\
\hline Galactosidase $(\mu \mathrm{g} / \mathrm{g})$ & 15.9 & 2.8 & 3 \\
\hline Glucosidase $(\mu \mathrm{g} / \mathrm{g})$ & 338.8 & 12.8 & 3 \\
\hline E. coli O157:H7 (CFU/100ml) & 12.5 & 0 & 3 \\
\hline Shigella sp. (CFU/100ml) & 5.0 & 0 & 3 \\
\hline Bacteriophage (PUF/mI) & 0.50 & 0 & 3 \\
\hline Giardia sp.(cysts/L) & 18.8 & 0 & 1 \\
\hline Cryptosporidium sp. (cysts/L) & 3.8 & 0 & 1 \\
\hline
\end{tabular}


Table 51. Summary statistics for September 2011, site 7

\begin{tabular}{|c|c|c|c|}
\hline Variable & Mean & Std Dev & $\mathbf{N}$ \\
\hline Air Temperature $\left({ }^{\circ} \mathrm{C}\right)$ & 19.3 & 0 & 1 \\
\hline Water Temperature $\left({ }^{\circ} \mathrm{C}\right)$ & 15.2 & 0 & 1 \\
\hline $\mathrm{pH}$ & 6.7 & 0 & 1 \\
\hline Conductivity ( $\mu$ mohs) & 358.0 & 0 & 1 \\
\hline Dissolved Oxygen (mg/L as $\mathrm{O}_{2}$ ) & 7.3 & 0 & 1 \\
\hline Discharge $\left(\mathrm{m}^{3} / \mathrm{sec}\right)$ & 0.08 & 0 & 1 \\
\hline Fecal Coliform - Water (CFU/100ml) & 200.0 & 173.2 & 3 \\
\hline Total Coliform - Water (CFU/100ml) & 2466.7 & 1553.5 & 3 \\
\hline Fecal Coliform - Sediment (CFU/100ml) & 250.0 & 282.8 & 2 \\
\hline Total Coliform - Sediment (CFU/100ml) & 5650.0 & 212.1 & 2 \\
\hline Colilert (MPN/100ml) & 19.0 & 0 & 1 \\
\hline Nitrates (mg/L) & 1.0 & 0.46 & 3 \\
\hline Phosphates (mg/L) & 0.26 & 0.24 & 3 \\
\hline Ammonia (mg/L) & 0.12 & 0.03 & 3 \\
\hline Biochemical Oxygen Demand (mg/L as $\mathrm{O}_{2}$ ) & 0.87 & 0.12 & 3 \\
\hline Alkalinity $\left(\mathrm{mg} / \mathrm{L}\right.$ as $\left.\mathrm{CaCO}_{3}\right)$ & 154.3 & 2.5 & 3 \\
\hline Hardness $\left(\mathrm{mg} / \mathrm{L}\right.$ as $\left.\mathrm{CaCO}_{3}\right)$ & 168.7 & 4.0 & 3 \\
\hline Standard Plate Count (CFU/ml) & 135.0 & 49.5 & 2 \\
\hline Acridine Orange Direct Counts (cells/g) & $2.4 \times 10^{8}$ & $6.0 \times 10^{7}$ & 1 \\
\hline Acid Phosphatase $(\mu \mathrm{g} / \mathrm{g})$ & 27.4 & 25.0 & 3 \\
\hline Alkaline Phosphatase $(\mu \mathrm{g} / \mathrm{g})$ & 367.9 & 31.4 & 3 \\
\hline Dehydrogenase $(\mu \mathrm{g} / \mathrm{g})$ & 29.9 & 6.7 & 3 \\
\hline Galactosidase $(\mu \mathrm{g} / \mathrm{g})$ & 16.6 & 4.5 & 3 \\
\hline Glucosidase $(\mu \mathrm{g} / \mathrm{g})$ & 136.2 & 67.0 & 3 \\
\hline E. coli 0157:H7 (CFU/100ml) & 12.5 & 0 & 3 \\
\hline Shigella sp. (CFU/100ml) & 5.0 & 0 & 3 \\
\hline Bacteriophage (PUF/ml) & 0.50 & 0 & 3 \\
\hline Giardia sp.(cysts/L) & 18.8 & 0 & 1 \\
\hline Cryptosporidium sp. (cysts/L) & 18.8 & 0 & 1 \\
\hline
\end{tabular}


Table 52. Summary statistics for September 2011, site 10

\begin{tabular}{|c|c|c|c|}
\hline Variable & Mean & Std Dev & $\mathbf{N}$ \\
\hline Air Temperature $\left({ }^{\circ} \mathrm{C}\right)$ & 20.3 & 0 & 1 \\
\hline Water Temperature $\left({ }^{\circ} \mathrm{C}\right)$ & 16.4 & 0 & 1 \\
\hline $\mathrm{pH}$ & 6.3 & 0 & 1 \\
\hline Conductivity ( $\mu$ mohs) & 290.0 & 0 & 1 \\
\hline Dissolved Oxygen (mg/L as $\mathrm{O}_{2}$ ) & 8.0 & 0 & 1 \\
\hline Discharge $\left(\mathrm{m}^{3} / \mathrm{sec}\right)$ & 0.06 & 0 & 1 \\
\hline Fecal Coliform - Water (CFU/100ml) & 466.7 & 305.5 & 3 \\
\hline Total Coliform - Water (CFU/100ml) & 6200.0 & 2986.6 & 3 \\
\hline Fecal Coliform - Sediment (CFU/100ml) & 150.0 & 70.7 & 2 \\
\hline Total Coliform - Sediment (CFU/100ml) & 2075.0 & 742.5 & 2 \\
\hline Colilert (MPN/100ml) & 49.2 & 0 & 1 \\
\hline Nitrates (mg/L) & 0.87 & 0.40 & 3 \\
\hline Phosphates (mg/L) & 0.14 & 0.07 & 3 \\
\hline Ammonia $(\mathrm{mg} / \mathrm{L})$ & 0.14 & 0.07 & 3 \\
\hline Biochemical Oxygen Demand (mg/L as $\mathrm{O}_{2}$ ) & 0.82 & 0.04 & 3 \\
\hline Alkalinity $\left(\mathrm{mg} / \mathrm{L}\right.$ as $\left.\mathrm{CaCO}_{3}\right)$ & 130.0 & 2.6 & 3 \\
\hline Hardness (mg/L as $\left.\mathrm{CaCO}_{3}\right)$ & 134.0 & 3.0 & 3 \\
\hline Standard Plate Count (CFU/ml) & 445.0 & 49.5 & 2 \\
\hline Acridine Orange Direct Counts (cells/g) & $2.6 \times 10^{8}$ & $4.1 \times 10^{7}$ & 1 \\
\hline Acid Phosphatase $(\mu \mathrm{g} / \mathrm{g})$ & 40.8 & 31.5 & 3 \\
\hline Alkaline Phosphatase $(\mu \mathrm{g} / \mathrm{g})$ & 364.0 & 30.4 & 3 \\
\hline Dehydrogenase $(\mu \mathrm{g} / \mathrm{g})$ & 19.6 & 3.3 & 3 \\
\hline Galactosidase $(\mu \mathrm{g} / \mathrm{g})$ & 14.9 & 12.4 & 3 \\
\hline Glucosidase $(\mu \mathrm{g} / \mathrm{g})$ & 483.2 & 14.6 & 3 \\
\hline E. coli O157:H7 (CFU/100ml) & 12.5 & 0 & 3 \\
\hline Shigella sp. (CFU/100ml) & 5.0 & 0 & 3 \\
\hline Bacteriophage (PUF/ml) & 0.50 & 0 & 3 \\
\hline Giardia sp.(cysts/L) & 16.5 & 0 & 1 \\
\hline Cryptosporidium sp. (cysts/L) & 11.0 & 0 & 1 \\
\hline
\end{tabular}


Table 53. Summary statistics for September 2011, site 13

\begin{tabular}{|c|c|c|c|}
\hline Variable & Mean & Std Dev & $\mathbf{N}$ \\
\hline Air Temperature $\left({ }^{\circ} \mathrm{C}\right)$ & 20.4 & 0 & 1 \\
\hline Water Temperature $\left({ }^{\circ} \mathrm{C}\right)$ & 17.5 & 0 & 1 \\
\hline $\mathrm{pH}$ & 7.0 & 0 & 1 \\
\hline Conductivity ( $\mu$ mohs) & 84.5 & 0 & 1 \\
\hline Dissolved Oxygen (mg/L as $\mathrm{O}_{2}$ ) & 7.2 & 0 & 1 \\
\hline Discharge $\left(\mathrm{m}^{3} / \mathrm{sec}\right)$ & 0.06 & 0 & 1 \\
\hline Fecal Coliform - Water (CFU/100ml) & 400.0 & 200.0 & 3 \\
\hline Total Coliform - Water (CFU/100ml) & 5933.3 & 1942.5 & 3 \\
\hline Fecal Coliform - Sediment (CFU/100ml) & 625.0 & 106.1 & 2 \\
\hline Total Coliform - Sediment (CFU/100ml) & 4625.0 & 388.9 & 2 \\
\hline Colilert (MPN/100ml) & 52.4 & 0 & 1 \\
\hline Nitrates (mg/L) & 1.1 & 0.20 & 3 \\
\hline Phosphates (mg/L) & 0.19 & 0.17 & 3 \\
\hline Ammonia (mg/L) & 0.07 & 0.01 & 3 \\
\hline Biochemical Oxygen Demand (mg/L as $\mathrm{O}_{2}$ ) & 0.89 & 0.22 & 3 \\
\hline Alkalinity $\left(\mathrm{mg} / \mathrm{L}\right.$ as $\left.\mathrm{CaCO}_{3}\right)$ & 51.3 & 2.1 & 3 \\
\hline Hardness $\left(\mathrm{mg} / \mathrm{L}\right.$ as $\left.\mathrm{CaCO}_{3}\right)$ & 52.3 & 1.5 & 3 \\
\hline Standard Plate Count (CFU/ml) & 205.0 & 7.1 & 2 \\
\hline Acridine Orange Direct Counts (cells/g) & $1.9 \times 10^{8}$ & $1.3 \times 10^{8}$ & 1 \\
\hline Acid Phosphatase $(\mu \mathrm{g} / \mathrm{g})$ & 81.9 & 15.4 & 3 \\
\hline Alkaline Phosphatase $(\mu \mathrm{g} / \mathrm{g})$ & 248.7 & 75.8 & 3 \\
\hline Dehydrogenase $(\mu \mathrm{g} / \mathrm{g})$ & 26.7 & 0.17 & 3 \\
\hline Galactosidase $(\mu \mathrm{g} / \mathrm{g})$ & 106.4 & 8.1 & 3 \\
\hline Glucosidase $(\mu \mathrm{g} / \mathrm{g})$ & 195.9 & 112.6 & 3 \\
\hline E. coli O157:H7 (CFU/100ml) & 12.5 & 0 & 3 \\
\hline Shigella sp. (CFU/100ml) & 5.0 & 0 & 3 \\
\hline Bacteriophage (PUF/ml) & 0.50 & 0 & 3 \\
\hline Giardia sp.(cysts/L) & 6.0 & 0 & 1 \\
\hline Cryptosporidium sp. (cysts/L) & 3.0 & 0 & 1 \\
\hline
\end{tabular}


Table 54. Summary statistics from September 2011, site 14

\begin{tabular}{|c|c|c|c|}
\hline Variable & Mean & Std Dev & $\mathbf{N}$ \\
\hline Air Temperature $\left({ }^{\circ} \mathrm{C}\right)$ & 20.5 & 0 & 1 \\
\hline Water Temperature $\left({ }^{\circ} \mathrm{C}\right)$ & 17.3 & 0 & 1 \\
\hline $\mathrm{pH}$ & 6.7 & 0 & 1 \\
\hline Conductivity ( $\mu$ mohs) & 30.1 & 0 & 1 \\
\hline Dissolved Oxygen (mg/L as $\mathrm{O}_{2}$ ) & 7.1 & 0 & 1 \\
\hline Discharge $\left(\mathrm{m}^{3} / \mathrm{sec}\right)$ & 0.02 & 0 & 1 \\
\hline Fecal Coliform - Water (CFU/100ml) & 133.3 & 57.7 & 3 \\
\hline Total Coliform - Water (CFU/100ml) & 3466.7 & 1404.8 & 3 \\
\hline Fecal Coliform - Sediment (CFU/100ml) & 62.5 & 53.0 & 2 \\
\hline Total Coliform - Sediment (CFU/100ml) & 300.0 & 282.8 & 2 \\
\hline Colilert (MPN/100ml) & 24.2 & 0 & 1 \\
\hline Nitrates (mg/L) & 1.0 & 0.20 & 3 \\
\hline Phosphates (mg/L) & 0.27 & 0.19 & 3 \\
\hline Ammonia (mg/L) & 0.10 & 0.01 & 3 \\
\hline Biochemical Oxygen Demand $\left(\mathrm{mg} / \mathrm{L}\right.$ as $\left.\mathrm{O}_{2}\right)$ & 0.62 & 0.10 & 3 \\
\hline Alkalinity $\left(\mathrm{mg} / \mathrm{L}\right.$ as $\left.\mathrm{CaCO}_{3}\right)$ & 13.0 & 0 & 3 \\
\hline Hardness $\left(\mathrm{mg} / \mathrm{L}\right.$ as $\left.\mathrm{CaCO}_{3}\right)$ & 13.0 & 0 & 3 \\
\hline Standard Plate Count (CFU/ml) & 245.0 & 162.6 & 2 \\
\hline Acridine Orange Direct Counts (cells/g) & $1.4 \times 10^{8}$ & $4.7 \times 10^{7}$ & 1 \\
\hline Acid Phosphatase $(\mu \mathrm{g} / \mathrm{g})$ & 84.9 & 9.6 & 3 \\
\hline Alkaline Phosphatase $(\mu \mathrm{g} / \mathrm{g})$ & 268.2 & 44.3 & 3 \\
\hline Dehydrogenase $(\mu \mathrm{g} / \mathrm{g})$ & 24.8 & 2.1 & 3 \\
\hline Galactosidase $(\mu \mathrm{g} / \mathrm{g})$ & 21.4 & 7.0 & 3 \\
\hline Glucosidase $(\mu \mathrm{g} / \mathrm{g})$ & 223.0 & 21.6 & 3 \\
\hline E. coli 0157:H7 (CFU/100ml) & 12.5 & 0 & 3 \\
\hline Shigella sp. (CFU/100ml) & 5.0 & 0 & 3 \\
\hline Bacteriophage (PUF/ml) & 0.50 & 0 & 3 \\
\hline Giardia sp.(cysts/L) & 4.3 & 0 & 1 \\
\hline Cryptosporidium sp. (cysts/L) & 8.5 & 0 & 1 \\
\hline
\end{tabular}


Table 55. Summary statistics from October 2011, site 2

\begin{tabular}{|c|c|c|c|}
\hline Variable & Mean & Std Dev & $\mathbf{N}$ \\
\hline Air Temperature $\left({ }^{\circ} \mathrm{C}\right)$ & 8.6 & 0 & 1 \\
\hline Water Temperature $\left({ }^{\circ} \mathrm{C}\right)$ & 12.6 & 0 & 1 \\
\hline $\mathrm{pH}$ & 6.7 & 0 & 1 \\
\hline Conductivity ( $\mu \mathrm{mohs}$ ) & 399.0 & 0 & 1 \\
\hline Dissolved Oxygen (mg/L as $\mathrm{O}_{2}$ ) & 9.4 & 0 & 1 \\
\hline Discharge $\left(\mathrm{m}^{3} / \mathrm{sec}\right)$ & 0.37 & 0 & 1 \\
\hline Fecal Coliform - Water (CFU/100ml) & 600.0 & 200.0 & 3 \\
\hline Total Coliform - Water (CFU/100ml) & 3466.7 & 1026.3 & 3 \\
\hline Fecal Coliform - Sediment (CFU/100ml) & 150.0 & 141.4 & 2 \\
\hline Total Coliform - Sediment (CFU/100ml) & 3575.0 & 247.5 & 2 \\
\hline Colilert (MPN/100ml) & 145.0 & 0 & 1 \\
\hline Nitrates (mg/L) & 1.27 & 0.32 & 3 \\
\hline Phosphates (mg/L) & 0.10 & 0.10 & 3 \\
\hline Ammonia (mg/L) & 0.06 & 0.01 & 3 \\
\hline Biochemical Oxygen Demand (mg/L as $\mathrm{O}_{2}$ ) & 0.65 & 0.13 & 3 \\
\hline Alkalinity $\left(\mathrm{mg} / \mathrm{L}\right.$ as $\left.\mathrm{CaCO}_{3}\right)$ & 184.0 & 2.6 & 3 \\
\hline Hardness $\left(\mathrm{mg} / \mathrm{L}\right.$ as $\left.\mathrm{CaCO}_{3}\right)$ & 191.0 & 5.6 & 3 \\
\hline Standard Plate Count (CFU/ml) & 1160.0 & 127.3 & 2 \\
\hline Acridine Orange Direct Counts (cells/g) & $2.1 \times 10^{8}$ & $8.4 \times 10^{7}$ & 1 \\
\hline Acid Phosphatase $(\mu \mathrm{g} / \mathrm{g})$ & 96.5 & 32.8 & 3 \\
\hline Alkaline Phosphatase $(\mu \mathrm{g} / \mathrm{g})$ & 683.5 & 370.8 & 3 \\
\hline Dehydrogenase $(\mu \mathrm{g} / \mathrm{g})$ & 28.0 & 6.1 & 3 \\
\hline Galactosidase $(\mu \mathrm{g} / \mathrm{g})$ & 45.0 & 25.4 & 3 \\
\hline Glucosidase $(\mu \mathrm{g} / \mathrm{g})$ & 297.0 & 67.1 & 3 \\
\hline E. coli 0157:H7 (CFU/100ml) & 12.5 & 0 & 3 \\
\hline Shigella sp. (CFU/100ml) & 5.0 & 0 & 3 \\
\hline Bacteriophage (PUF/ml) & 0.50 & 0 & 3 \\
\hline Giardia sp.(cysts/L) & 11.3 & 0 & 1 \\
\hline Cryptosporidium sp. (cysts/L) & 11.3 & 0 & 1 \\
\hline
\end{tabular}


Table 56. Summary statistics from October 2011, site 4

\begin{tabular}{|c|c|c|c|}
\hline Variable & Mean & Std Dev & $\mathbf{N}$ \\
\hline Air Temperature $\left({ }^{\circ} \mathrm{C}\right)$ & 8.5 & 0 & 1 \\
\hline Water Temperature $\left({ }^{\circ} \mathrm{C}\right)$ & 12.3 & 0 & 1 \\
\hline $\mathrm{pH}$ & 7.0 & 0 & 1 \\
\hline Conductivity ( $\mu$ mohs) & 351.0 & 0 & 1 \\
\hline Dissolved Oxygen (mg/L as $\mathrm{O}_{2}$ ) & 9.0 & 0 & 1 \\
\hline Discharge $\left(\mathrm{m}^{3} / \mathrm{sec}\right)$ & 0.15 & 0 & 1 \\
\hline Fecal Coliform - Water (CFU/100ml) & 366.7 & 251.7 & 3 \\
\hline Total Coliform - Water (CFU/100ml) & 7133.3 & 3711.2 & 3 \\
\hline Fecal Coliform - Sediment (CFU/100ml) & 75.0 & 35.4 & 2 \\
\hline Total Coliform - Sediment (CFU/100ml) & 1925.0 & 883.9 & 2 \\
\hline Colilert (MPN/100ml) & 73.3 & 0 & 1 \\
\hline Nitrates (mg/L) & 1.7 & 0.62 & 3 \\
\hline Phosphates (mg/L) & 0.24 & 0.13 & 3 \\
\hline Ammonia (mg/L) & 0.05 & 0.01 & 3 \\
\hline Biochemical Oxygen Demand (mg/L as $\mathrm{O}_{2}$ ) & 0.56 & 0.06 & 3 \\
\hline Alkalinity $\left(\mathrm{mg} / \mathrm{L}\right.$ as $\left.\mathrm{CaCO}_{3}\right)$ & 177.0 & 2.0 & 3 \\
\hline Hardness $\left(\mathrm{mg} / \mathrm{L}\right.$ as $\left.\mathrm{CaCO}_{3}\right)$ & 184.3 & 3.2 & 3 \\
\hline Standard Plate Count (CFU/ml) & 785.0 & 162.6 & 2 \\
\hline Acridine Orange Direct Counts (cells/g) & $4.6 \times 10^{8}$ & $6.3 \times 10^{7}$ & 1 \\
\hline Acid Phosphatase $(\mu \mathrm{g} / \mathrm{g})$ & 138.8 & 36.5 & 3 \\
\hline Alkaline Phosphatase $(\mu \mathrm{g} / \mathrm{g})$ & 233.0 & 104.7 & 3 \\
\hline Dehydrogenase $(\mu \mathrm{g} / \mathrm{g})$ & 13.9 & 11.8 & 3 \\
\hline Galactosidase $(\mu \mathrm{g} / \mathrm{g})$ & 33.7 & 5.0 & 3 \\
\hline Glucosidase $(\mu \mathrm{g} / \mathrm{g})$ & 149.0 & 0.88 & 3 \\
\hline E. coli O157:H7 (CFU/100ml) & 12.5 & 0 & 3 \\
\hline Shigella sp. (CFU/100ml) & 5.0 & 0 & 3 \\
\hline Bacteriophage (PUF/ml) & 0.50 & 0 & 3 \\
\hline Giardia sp.(cysts/L) & 2.4 & 0 & 1 \\
\hline Cryptosporidium sp. (cysts/L) & 14.3 & 0 & 1 \\
\hline
\end{tabular}


Table 57. Summary statistics for October 2011, site 7

\begin{tabular}{|c|c|c|c|}
\hline Variable & Mean & Std Dev & $\mathbf{N}$ \\
\hline Air Temperature $\left({ }^{\circ} \mathrm{C}\right)$ & 8.0 & 0 & 1 \\
\hline Water Temperature $\left({ }^{\circ} \mathrm{C}\right)$ & 13.7 & 0 & 1 \\
\hline $\mathrm{pH}$ & 6.8 & 0 & 1 \\
\hline Conductivity ( $\mu \mathrm{mohs}$ ) & 350. & 0 & 1 \\
\hline Dissolved Oxygen (mg/L as $\mathrm{O}_{2}$ ) & 801 & 0 & 1 \\
\hline Discharge $\left(\mathrm{m}^{3} / \mathrm{sec}\right)$ & 0.18 & 0 & 1 \\
\hline Fecal Coliform - Water (CFU/100ml) & 100.0 & 0 & 3 \\
\hline Total Coliform - Water (CFU/100ml) & 1200.0 & 0 & 3 \\
\hline Fecal Coliform - Sediment (CFU/100ml) & 87.5 & 88.4 & 2 \\
\hline Total Coliform - Sediment (CFU/100ml) & 4925.0 & 4348.7 & 2 \\
\hline Colilert (MPN/100ml) & 13.5 & 0 & 1 \\
\hline Nitrates (mg/L) & 1.6 & 0.61 & 3 \\
\hline Phosphates (mg/L) & 0.11 & 0.07 & 3 \\
\hline Ammonia (mg/L) & 0.67 & 0.02 & 3 \\
\hline Biochemical Oxygen Demand (mg/L as $\mathrm{O}_{2}$ ) & 0.51 & 0.23 & 3 \\
\hline Alkalinity $\left(\mathrm{mg} / \mathrm{L}\right.$ as $\left.\mathrm{CaCO}_{3}\right)$ & 151.3 & 1.2 & 3 \\
\hline Hardness $\left(\mathrm{mg} / \mathrm{L}\right.$ as $\left.\mathrm{CaCO}_{3}\right)$ & 161.3 & 5.7 & 3 \\
\hline Standard Plate Count (CFU/ml) & 85.0 & 21.2 & 2 \\
\hline Acridine Orange Direct Counts (cells/g) & $1.7 \times 10^{8}$ & $8.6 \times 10^{7}$ & 1 \\
\hline Acid Phosphatase $(\mu \mathrm{g} / \mathrm{g})$ & 84.9 & 33.0 & 3 \\
\hline Alkaline Phosphatase $(\mu \mathrm{g} / \mathrm{g})$ & 410.0 & 58.0 & 3 \\
\hline Dehydrogenase $(\mu \mathrm{g} / \mathrm{g})$ & 31.3 & 7.4 & 3 \\
\hline Galactosidase $(\mu \mathrm{g} / \mathrm{g})$ & 22.0 & 8.9 & 3 \\
\hline Glucosidase $(\mu \mathrm{g} / \mathrm{g})$ & 237.8 & 70.4 & 3 \\
\hline E. coli 0157:H7 (CFU/100ml) & 12.5 & 0 & 3 \\
\hline Shigella sp. (CFU/100ml) & 5.0 & 0 & 3 \\
\hline Bacteriophage (PUF/ml) & 0.50 & 0 & 3 \\
\hline Giardia sp.(cysts/L) & 7.5 & 0 & 1 \\
\hline Cryptosporidium sp. (cysts/L) & 1.9 & 0 & 1 \\
\hline
\end{tabular}


Table 58. Summary statistics for October 2011, site 10

\begin{tabular}{|c|c|c|c|}
\hline Variable & Mean & Std Dev & $\mathbf{N}$ \\
\hline Air Temperature $\left({ }^{\circ} \mathrm{C}\right)$ & 7.7 & 0 & 1 \\
\hline Water Temperature $\left({ }^{\circ} \mathrm{C}\right)$ & 12.8 & 0 & 1 \\
\hline $\mathrm{pH}$ & 7.3 & 0 & 1 \\
\hline Conductivity ( $\mu$ mohs) & 178.9 & 0 & 1 \\
\hline Dissolved Oxygen (mg/L as $\mathrm{O}_{2}$ ) & 8.6 & 0 & 1 \\
\hline Discharge $\left(\mathrm{m}^{3} / \mathrm{sec}\right)$ & 0.07 & 0 & 1 \\
\hline Fecal Coliform - Water (CFU/100ml) & 100.0 & 0 & 3 \\
\hline Total Coliform - Water (CFU/100ml) & 3200.0 & 721.1 & 3 \\
\hline Fecal Coliform - Sediment (CFU/100ml) & 25.0 & 0 & 2 \\
\hline Total Coliform - Sediment (CFU/100ml) & 475.0 & 388.9 & 2 \\
\hline Colilert (MPN/100ml) & 56.3 & 0 & 1 \\
\hline Nitrates (mg/L) & 0.55 & 0.44 & 3 \\
\hline Phosphates (mg/L) & 0.21 & 0.07 & 3 \\
\hline Ammonia (mg/L) & 0.08 & 0.01 & 3 \\
\hline Biochemical Oxygen Demand (mg/L as $\mathrm{O}_{2}$ ) & 0.52 & 0.03 & 3 \\
\hline Alkalinity $\left(\mathrm{mg} / \mathrm{L}\right.$ as $\left.\mathrm{CaCO}_{3}\right)$ & 125.0 & 4.4 & 3 \\
\hline Hardness $\left(\mathrm{mg} / \mathrm{L}\right.$ as $\left.\mathrm{CaCO}_{3}\right)$ & 135.7 & 9.1 & 3 \\
\hline Standard Plate Count (CFU/ml) & 360.0 & 183.8 & 2 \\
\hline Acridine Orange Direct Counts (cells/g) & $1.3 \times 10^{8}$ & $4.9 \times 10^{7}$ & 1 \\
\hline Acid Phosphatase $(\mu \mathrm{g} / \mathrm{g})$ & 58.7 & 10.1 & 3 \\
\hline Alkaline Phosphatase $(\mu \mathrm{g} / \mathrm{g})$ & 204.5 & 50.5 & 3 \\
\hline Dehydrogenase $(\mu \mathrm{g} / \mathrm{g})$ & 23.0 & 5.9 & 3 \\
\hline Galactosidase $(\mu \mathrm{g} / \mathrm{g})$ & 12.6 & 11.1 & 3 \\
\hline Glucosidase $(\mu \mathrm{g} / \mathrm{g})$ & 170.9 & 75.0 & 3 \\
\hline E. coli O157:H7 (CFU/100ml) & 12.5 & 0 & 3 \\
\hline Shigella sp. (CFU/100ml) & 5.0 & 0 & 3 \\
\hline Bacteriophage (PUF/ml) & 0.67 & 0.28 & 3 \\
\hline Giardia sp.(cysts/L) & 4.8 & 0 & 1 \\
\hline Cryptosporidium sp. (cysts/L) & 4.8 & 0 & 1 \\
\hline
\end{tabular}


Table 59. Summary statistics for October 2011, site 13

\begin{tabular}{llll}
\hline Variable & Mean & Std Dev & N \\
Air Temperature $\left({ }^{\circ} \mathrm{C}\right)$ & 7.6 & 0 & 1 \\
Water Temperature $\left({ }^{\circ} \mathrm{C}\right)$ & 10.2 & 0 & 1 \\
$\mathrm{pH}$ & 6.9 & 0 & 1 \\
Conductivity $(\mu \mathrm{mohs})$ & 64.4 & 0 & 1 \\
Dissolved Oxygen $\left(\mathrm{mg} / \mathrm{L}\right.$ as $\left.\mathrm{O}_{2}\right)$ & 8.1 & 0 & 1 \\
Discharge $\left(\mathrm{m}^{3} / \mathrm{sec}\right)$ & 0.20 & 0 & 1 \\
Fecal Coliform - Water $(\mathrm{CFU} / 100 \mathrm{ml})$ & 100.0 & 0 & 3 \\
Total Coliform - Water $(\mathrm{CFU} / 100 \mathrm{ml})$ & 1200.0 & 1216.6 & 3 \\
Fecal Coliform - Sediment $(\mathrm{CFU} / 100 \mathrm{ml})$ & 25.0 & 0 & 2 \\
Total Coliform - Sediment $(\mathrm{CFU} / 100 \mathrm{ml})$ & 800.0 & 636.4 & 2 \\
Colilert $(\mathrm{MPN} / 100 \mathrm{ml})$ & 6.3 & 0 & 1 \\
Nitrates $(\mathrm{mg} / \mathrm{L})$ & 1.13 & 0.94 & 3 \\
Phosphates $(\mathrm{mg} / \mathrm{L})$ & 0.24 & 0.06 & 3 \\
Ammonia $(\mathrm{mg} / \mathrm{L})$ & 0.07 & 0.02 & 3 \\
Biochemical Oxygen Demand $\left(\mathrm{mg} / \mathrm{L}\right.$ as $\left.\mathrm{O}_{2}\right)$ & 0.67 & 0.02 & 3 \\
Alkalinity $(\mathrm{mg} / \mathrm{L}$ as CaCO $)$ & 45.0 & 4.4 & 3 \\
Hardness $\left(\mathrm{mg} / \mathrm{L}\right.$ as CaCO $\left.{ }_{3}\right)$ & 45.3 & 1.5 & 3 \\
Standard Plate Count $(\mathrm{CFU} / \mathrm{ml})$ & 160 & 99.0 & 2 \\
Acridine Orange Direct Counts $(\mathrm{cells} / \mathrm{g})$ & $1.4 \times 10^{8}$ & $9.8 \times 10^{7}$ & 1 \\
Acid Phosphatase $(\mu \mathrm{gg} / \mathrm{g})$ & 84.2 & 43.8 & 3 \\
Alkaline Phosphatase $(\mu \mathrm{gg} / \mathrm{g})$ & 815.2 & 168.0 & 3 \\
Dehydrogenase $(\mu \mathrm{gg} / \mathrm{g})$ & 23.2 & 15.0 & 3 \\
Galactosidase $(\mu \mathrm{gg} / \mathrm{g})$ & 24.1 & 6.9 & 3 \\
Glucosidase $(\mu \mathrm{g} / \mathrm{g})$ & 173.5 & 10.4 & 3 \\
E. coli O157:H7 $(\mathrm{CFU} / 100 \mathrm{ml})$ & 12.5 & 0 & 3 \\
Shigella sp. $(\mathrm{CFU} / 100 \mathrm{ml})$ & 5.0 & 0 & 3 \\
Bacteriophage $(\mathrm{PUF} / \mathrm{ml})$ & 0.50 & 0 & 3 \\
Giardia $s p .(\mathrm{cysts} / \mathrm{L})$ & 5.5 & 0 & 1 \\
Cryptosporidium sp. $(\mathrm{cysts} / \mathrm{L})$ & 11.0 & 0 & 1 \\
\hline
\end{tabular}


Table 60. Summary statistics for October 2011, site 14

\begin{tabular}{llll}
\hline Variable & Mean & Std Dev & $\mathbf{N}$ \\
Air Temperature $\left({ }^{\circ} \mathrm{C}\right)$ & 7.0 & 0 & 1 \\
Water Temperature $\left({ }^{\circ} \mathrm{C}\right)$ & 9.8 & 0 & 1 \\
pH & 6.8 & 0 & 1 \\
Conductivity $(\mu \mathrm{mohs})$ & 23.3 & 0 & 1 \\
Dissolved Oxygen $\left(\mathrm{mg} / \mathrm{L}\right.$ as $\left.\mathrm{O}_{2}\right)$ & 8.2 & 0 & 1 \\
Discharge $\left(\mathrm{m}^{3} / \mathrm{sec}\right)$ & 0.02 & 0 & 1 \\
Fecal Coliform - Water $(\mathrm{CFU} / 100 \mathrm{ml})$ & 200.0 & 0 & 3 \\
Total Coliform - Water $(\mathrm{CFU} / 100 \mathrm{ml})$ & 2466.7 & 2893.7 & 3 \\
Fecal Coliform - Sediment $(\mathrm{CFU} / 100 \mathrm{ml})$ & 25.0 & 0 & 2 \\
Total Coliform $-\mathrm{Sediment}(\mathrm{CFU} / 100 \mathrm{ml})$ & 112.5 & 123.7 & 2 \\
Colilert $(\mathrm{MPN} / 100 \mathrm{ml})$ & 14.6 & 0 & 1 \\
Nitrates $(\mathrm{mg} / \mathrm{L})$ & 0.83 & 0.31 & 3 \\
Phosphates $(\mathrm{mg} / \mathrm{L})$ & 0.18 & 0.09 & 3 \\
Ammonia $(\mathrm{mg} / \mathrm{L})$ & 0.07 & 0.03 & 3 \\
Biochemical Oxygen Demand $\left(\mathrm{mg} / \mathrm{L}\right.$ as $\left.\mathrm{O}_{2}\right)$ & 0.97 & 0.06 & 3 \\
Alkalinity $\left(\mathrm{mg} / \mathrm{L}\right.$ as CaCO $\left.{ }_{3}\right)$ & 12.7 & 3.5 & 3 \\
Hardness $\left(\mathrm{mg} / \mathrm{L}\right.$ as CaCO $\left.{ }_{3}\right)$ & 12.3 & 0.58 & 3 \\
Standard Plate Count $(\mathrm{CFU} / \mathrm{ml})$ & 1980.0 & 495.0 & 2 \\
Acridine Orange Direct Counts $(\mathrm{cells} / \mathrm{g})$ & $1.9 \times 10^{8}$ & $2.8 \times 10^{7}$ & 1 \\
Acid Phosphatase $(\mu \mathrm{gg} / \mathrm{g})$ & 144.6 & 29.6 & 3 \\
Alkaline Phosphatase $(\mu \mathrm{gg} / \mathrm{g})$ & 297.8 & 158.2 & 3 \\
Dehydrogenase $(\mu \mathrm{gg} / \mathrm{g})$ & 23.2 & 13.4 & 3 \\
Galactosidase $(\mu \mathrm{gg} / \mathrm{g})$ & 15.6 & 7.6 & 3 \\
Glucosidase $(\mu \mathrm{g} / \mathrm{g})$ & 170.5 & 18.1 & 3 \\
E. coli O157:H7 $(\mathrm{CFU} / 100 \mathrm{ml})$ & 12.5 & 0 & 3 \\
Shigella sp. $(\mathrm{CFU} / 100 \mathrm{ml})$ & 5.0 & 0 & 3 \\
Bacteriophage $(\mathrm{PUF} / \mathrm{ml})$ & 0.66 & 0.28 & 3 \\
Giardia sp. $(\mathrm{cysts} / \mathrm{L})$ & 21.3 & 0 & 1 \\
Cryptosporidium sp. $(\mathrm{cysts} / \mathrm{L})$ & 8.5 & 0 & 1 \\
\hline & & &
\end{tabular}


Table 61. Summary statistics from November 2011, site 2

\begin{tabular}{|c|c|c|c|}
\hline Variable & Mean & Std Dev & $\mathbf{N}$ \\
\hline Air Temperature $\left({ }^{\circ} \mathrm{C}\right)$ & -1.5 & 0 & 1 \\
\hline Water Temperature $\left({ }^{\circ} \mathrm{C}\right)$ & 7.9 & 0 & 1 \\
\hline $\mathrm{pH}$ & 7.3 & 0 & 1 \\
\hline Conductivity ( $\mu$ mohs) & 329.0 & 0 & 1 \\
\hline Dissolved Oxygen (mg/L as $\mathrm{O}_{2}$ ) & 11.6 & 0 & 1 \\
\hline Discharge $\left(\mathrm{m}^{3} / \mathrm{sec}\right)$ & 0.51 & 0 & 1 \\
\hline Fecal Coliform - Water (CFU/100ml) & 1300.0 & 1044.0 & 3 \\
\hline Total Coliform - Water (CFU/100ml) & 7666.7 & 2759.2 & 3 \\
\hline Fecal Coliform - Sediment (CFU/100ml) & 425.0 & 247.5 & 2 \\
\hline Total Coliform - Sediment (CFU/100ml) & 4325.0 & 883.9 & 2 \\
\hline Colilert (MPN/100ml) & 141.4 & 0 & 1 \\
\hline Nitrates $(\mathrm{mg} / \mathrm{L})$ & 1.6 & 0.46 & 3 \\
\hline Phosphates (mg/L) & 0.20 & 0.05 & 3 \\
\hline Ammonia (mg/L) & 0.07 & 0.02 & 3 \\
\hline Biochemical Oxygen Demand (mg/L as $\mathrm{O}_{2}$ ) & 1.1 & 0.43 & 3 \\
\hline Alkalinity $\left(\mathrm{mg} / \mathrm{L}\right.$ as $\left.\mathrm{CaCO}_{3}\right)$ & 128.7 & 18.9 & 3 \\
\hline Hardness $\left(\mathrm{mg} / \mathrm{L}\right.$ as $\left.\mathrm{CaCO}_{3}\right)$ & 174.7 & 2.1 & 3 \\
\hline Standard Plate Count (CFU/ml) & 460.0 & 0 & 2 \\
\hline Acridine Orange Direct Counts (cells/g) & $1.5 \times 10^{8}$ & $3.3 \times 10^{7}$ & 1 \\
\hline Acid Phosphatase $(\mu \mathrm{g} / \mathrm{g})$ & 62.9 & 8.8 & 3 \\
\hline Alkaline Phosphatase $(\mu \mathrm{g} / \mathrm{g})$ & 234.7 & 101.7 & 3 \\
\hline Dehydrogenase $(\mu \mathrm{g} / \mathrm{g})$ & 30.7 & 4.6 & 3 \\
\hline Galactosidase $(\mu \mathrm{g} / \mathrm{g})$ & 12.7 & 11.6 & 3 \\
\hline Glucosidase $(\mu \mathrm{g} / \mathrm{g})$ & 94.9 & 26.2 & 3 \\
\hline E. coli 0157:H7 (CFU/100ml) & 12.5 & 0 & 3 \\
\hline Shigella sp. (CFU/100ml) & 5.0 & 0 & 3 \\
\hline Bacteriophage (PUF/ml) & 4.9 & 7.6 & 3 \\
\hline Giardia sp.(cysts/L) & 5.3 & 0 & 1 \\
\hline Cryptosporidium sp. (cysts/L) & 10.5 & 0 & 1 \\
\hline
\end{tabular}


Table 62. Summary statistics for November 2011, site 4

\begin{tabular}{llll}
\hline Variable & Mean & Std Dev & $\mathbf{N}$ \\
Air Temperature $\left({ }^{\circ} \mathrm{C}\right)$ & -1.3 & 0 & 1 \\
Water Temperature $\left({ }^{\circ} \mathrm{C}\right)$ & 7.9 & 0 & 1 \\
pH & 7.3 & 0 & 1 \\
Conductivity $(\mu \mathrm{mohs})$ & 299.0 & 0 & 1 \\
Dissolved Oxygen $\left(\mathrm{mg} / \mathrm{L}\right.$ as $\left.\mathrm{O}_{2}\right)$ & 10.2 & 0 & 1 \\
Discharge $\left(\mathrm{m}^{3} / \mathrm{sec}\right)$ & 0.24 & 0 & 1 \\
Fecal Coliform - Water $(\mathrm{CFU} / 100 \mathrm{ml})$ & 800.0 & 400.0 & 3 \\
Total Coliform - Water $(\mathrm{CFU} / 100 \mathrm{ml})$ & 10933.3 & 2830.8 & 3 \\
Fecal Coliform - Sediment $(\mathrm{CFU} / 100 \mathrm{ml})$ & 150.0 & 141.4 & 2 \\
Total Coliform $-\mathrm{Sediment}(\mathrm{CFU} / 100 \mathrm{ml})$ & 2100.0 & 919.2 & 2 \\
Colilert $(\mathrm{MPN} / 100 \mathrm{ml})$ & 151.0 & 0 & 1 \\
Nitrates $(\mathrm{mg} / \mathrm{L})$ & 1.5 & 0.85 & 3 \\
Phosphates $(\mathrm{mg} / \mathrm{L})$ & 0.44 & 0.06 & 3 \\
Ammonia $(\mathrm{mg} / \mathrm{L})$ & 0.07 & 0.02 & 3 \\
Biochemical Oxygen Demand $\left(\mathrm{mg} / \mathrm{L}\right.$ as $\left.\mathrm{O}_{2}\right)$ & 1.6 & 0.02 & 3 \\
Alkalinity $\left(\mathrm{mg} / \mathrm{L}\right.$ as CaCO $\left.{ }_{3}\right)$ & 128.0 & 5.6 & 3 \\
Hardness $\left(\mathrm{mg} / \mathrm{L}\right.$ as CaCO $\left.{ }_{3}\right)$ & 161.0 & 1.7 & 3 \\
Standard Plate Count $(\mathrm{CFU} / \mathrm{ml})$ & 575.0 & 91.9 & 2 \\
Acridine Orange Direct Counts $(\mathrm{cells} / \mathrm{g})$ & $1.8 \times 10^{8}$ & $2.9 \times 10^{7}$ & 1 \\
Acid Phosphatase $(\mu \mathrm{gg} / \mathrm{g})$ & 62.1 & 8.8 & 3 \\
Alkaline Phosphatase $(\mu \mathrm{gg} / \mathrm{g})$ & 313.0 & 88.8 & 3 \\
Dehydrogenase $(\mu \mathrm{gg} / \mathrm{g})$ & 22.2 & 5.6 & 3 \\
Galactosidase $(\mu \mathrm{g} / \mathrm{g})$ & 29.0 & 5.2 & 3 \\
Glucosidase $(\mu \mathrm{g} / \mathrm{g})$ & 56.0 & 7.2 & 3 \\
E. coli O157:H7 $(\mathrm{CFU} / 100 \mathrm{ml})$ & 12.5 & 0 & 3 \\
Shigella sp. $(\mathrm{CFU} / 100 \mathrm{ml})$ & 5.0 & 0 & 3 \\
Bacteriophage $(\mathrm{PUF} / \mathrm{ml})$ & 4.0 & 6.0 & 3 \\
Giardia sp. $(\mathrm{cysts} / \mathrm{L})$ & 11.0 & 0 & 1 \\
Cryptosporidium sp. $(\mathrm{cysts} / \mathrm{L})$ & 5.0 & 0 & 1 \\
\hline & & &
\end{tabular}


Table 63. Summary statistics for November 2011, site 7

\begin{tabular}{llll}
\hline Variable & Mean & Std Dev & $\mathbf{N}$ \\
Air Temperature $\left({ }^{\circ} \mathrm{C}\right)$ & 1.5 & 0 & 1 \\
Water Temperature $\left({ }^{\circ} \mathrm{C}\right)$ & 9.9 & 0 & 1 \\
pH & 7.7 & 0 & 1 \\
Conductivity $(\mu \mathrm{mohs})$ & 276.0 & 0 & 1 \\
Dissolved Oxygen $\left(\mathrm{mg} / \mathrm{L}\right.$ as $\left.\mathrm{O}_{2}\right)$ & 9.1 & 0 & 1 \\
Discharge $\left(\mathrm{m}^{3} / \mathrm{sec}\right)$ & 0.41 & 0 & 1 \\
Fecal Coliform - Water $(\mathrm{CFU} / 100 \mathrm{ml})$ & 133.3 & 57.7 & 3 \\
Total Coliform - Water $(\mathrm{CFU} / 100 \mathrm{ml})$ & 1333.3 & 305.5 & 3 \\
Fecal Coliform - Sediment $(\mathrm{CFU} / 100 \mathrm{ml})$ & 175.0 & 35.4 & 2 \\
Total Coliform $-\mathrm{Sediment}(\mathrm{CFU} / 100 \mathrm{ml})$ & 3350.0 & 70.7 & 2 \\
Colilert $(\mathrm{MPN} / 100 \mathrm{ml})$ & 8.5 & 0 & 1 \\
Nitrates $(\mathrm{mg} / \mathrm{L})$ & 1.9 & 0.20 & 3 \\
Phosphates $(\mathrm{mg} / \mathrm{L})$ & 0.18 & 0.02 & 3 \\
Ammonia $(\mathrm{mg} / \mathrm{L})$ & 0.09 & 0.04 & 3 \\
Biochemical Oxygen Demand $\left(\mathrm{mg} / \mathrm{L}\right.$ as $\left.\mathrm{O}_{2}\right)$ & 1.4 & 0.10 & 3 \\
Alkalinity $\left(\mathrm{mg} / \mathrm{L}\right.$ as CaCO $\left.{ }_{3}\right)$ & 104.0 & 5.2 & 3 \\
Hardness $\left(\mathrm{mg} / \mathrm{L}\right.$ as CaCO $\left.{ }_{3}\right)$ & 129.0 & 3.6 & 3 \\
Standard Plate Count $(\mathrm{CFU} / \mathrm{ml})$ & 125.0 & 35.4 & 2 \\
Acridine Orange Direct Counts $(\mathrm{cells} / \mathrm{g})$ & $1.7 \times 10^{8}$ & $4.0 \times 10^{7}$ & 1 \\
Acid Phosphatase $(\mu \mathrm{gg} / \mathrm{g})$ & 75.5 & 22.1 & 3 \\
Alkaline Phosphatase $(\mu \mathrm{gg} / \mathrm{g})$ & 474.4 & 214.4 & 3 \\
Dehydrogenase $(\mu \mathrm{gg} / \mathrm{g})$ & 23.7 & 4.5 & 3 \\
Galactosidase $(\mu \mathrm{g} / \mathrm{g})$ & 43.9 & 1.9 & 3 \\
Glucosidase $(\mu \mathrm{g} / \mathrm{g})$ & 89.7 & 43.4 & 3 \\
E. coli O157:H7 $(\mathrm{CFU} / 100 \mathrm{ml})$ & 12.5 & 0 & 3 \\
Shigella sp. $(\mathrm{CFU} / 100 \mathrm{ml})$ & 5.0 & 0 & 3 \\
Bacteriophage $(\mathrm{PUF} / \mathrm{ml})$ & 0.94 & 0.76 & 3 \\
Giardia sp. $(\mathrm{cysts} / \mathrm{L})$ & 4.5 & 0 & 1 \\
Cryptosporidium sp. $(\mathrm{cysts} / \mathrm{L})$ & 4.5 & 0 & 1 \\
\hline & & &
\end{tabular}


Table 64. Summary statistics for November 2011, site 10

\begin{tabular}{llll}
\hline Variable & Mean & Std Dev & $\mathbf{N}$ \\
Air Temperature $\left({ }^{\circ} \mathrm{C}\right)$ & 1.3 & 0 & 1 \\
Water Temperature $\left({ }^{\circ} \mathrm{C}\right)$ & 8.7 & 0 & 1 \\
$\mathrm{pH}$ & 7.6 & 0 & 1 \\
Conductivity $(\mu \mathrm{mohs})$ & 136.1 & 0 & 1 \\
Dissolved Oxygen $\left(\mathrm{mg} / \mathrm{L}\right.$ as $\left.\mathrm{O}_{2}\right)$ & 8.0 & 0 & 1 \\
Discharge $\left(\mathrm{m}^{3} / \mathrm{sec}\right)$ & 0.26 & 0 & 1 \\
Fecal Coliform - Water $(\mathrm{CFU} / 100 \mathrm{ml})$ & 400.0 & 200.0 & 3 \\
Total Coliform - Water $(\mathrm{CFU} / 100 \mathrm{ml})$ & 3933.3 & 832.7 & 3 \\
Fecal Coliform - Sediment $(\mathrm{CFU} / 100 \mathrm{ml})$ & 75.0 & 35.4 & 2 \\
Total Coliform $-\mathrm{Sediment}(\mathrm{CFU} / 100 \mathrm{ml})$ & 1125.0 & 106.1 & 2 \\
Colilert $(\mathrm{MPN} / 100 \mathrm{ml})$ & 193.5 & 0 & 1 \\
Nitrates $(\mathrm{mg} / \mathrm{L})$ & 1.2 & 0.12 & 3 \\
Phosphates $(\mathrm{mg} / \mathrm{L})$ & 0.17 & 0.07 & 3 \\
Ammonia $(\mathrm{mg} / \mathrm{L})$ & 0.09 & 0.02 & 3 \\
Biochemical Oxygen Demand $\left(\mathrm{mg} / \mathrm{L}\right.$ as $\left.\mathrm{O}_{2}\right)$ & 1.3 & 0.15 & 3 \\
Alkalinity $\left(\mathrm{mg} / \mathrm{L}\right.$ as CaCO $\left.{ }_{3}\right)$ & 65.3 & 1.2 & 3 \\
Hardness $\left(\mathrm{mg} / \mathrm{L}\right.$ as CaCO $\left.{ }_{3}\right)$ & 84.3 & 2.1 & 3 \\
Standard Plate Count $(\mathrm{CFU} / \mathrm{ml})$ & 530.0 & 141.2 & 2 \\
Acridine Orange Direct Counts $(\mathrm{cells} / \mathrm{g})$ & $6.8 \times 10^{7}$ & $5.3 \times 10^{7}$ & 1 \\
Acid Phosphatase $(\mu \mathrm{gg} / \mathrm{g})$ & 37.7 & 24.1 & 3 \\
Alkaline Phosphatase $(\mu \mathrm{Hg} / \mathrm{g})$ & 283.8 & 122.7 & 3 \\
Dehydrogenase $(\mu \mathrm{gg} / \mathrm{g})$ & 16.6 & 3.7 & 3 \\
Galactosidase $(\mu \mathrm{gg} / \mathrm{g})$ & 29.5 & 13.8 & 3 \\
Glucosidase $(\mu \mathrm{g} / \mathrm{g})$ & 134.0 & 64.1 & 3 \\
E. coli O157:H7 $(\mathrm{CFU} / 100 \mathrm{ml})$ & 12.5 & 0 & 3 \\
Shigella sp. $(\mathrm{CFU} / 100 \mathrm{ml})$ & 5.0 & 0 & 3 \\
Bacteriophage $(\mathrm{PUF} / \mathrm{ml})$ & 0.64 & 0.24 & 3 \\
Giardia sp. $(\mathrm{cysts} / \mathrm{L})$ & 45.0 & 0 & 1 \\
Cryptosporidium sp. $(\mathrm{cysts} / \mathrm{L})$ & 30.0 & 0 & 1 \\
\hline & & &
\end{tabular}


Table 65. Summary statistics for November 2011, site 13

\begin{tabular}{|c|c|c|c|}
\hline Variable & Mean & Std Dev & $\mathbf{N}$ \\
\hline Air Temperature $\left({ }^{\circ} \mathrm{C}\right)$ & 3.1 & 0 & 1 \\
\hline Water Temperature $\left({ }^{\circ} \mathrm{C}\right)$ & 6.5 & 0 & 1 \\
\hline $\mathrm{pH}$ & 7.3 & 0 & 1 \\
\hline Conductivity ( $\mu$ mohs) & 82.3 & 0 & 1 \\
\hline Dissolved Oxygen (mg/L as $\mathrm{O}_{2}$ ) & 7.6 & 0 & 1 \\
\hline Discharge $\left(\mathrm{m}^{3} / \mathrm{sec}\right)$ & 0.23 & 0 & 1 \\
\hline Fecal Coliform - Water (CFU/100ml) & 100.0 & 0 & 3 \\
\hline Total Coliform - Water (CFU/100ml) & 933.3 & 503.3 & 3 \\
\hline Fecal Coliform - Sediment (CFU/100ml) & 75.0 & 35.4 & 2 \\
\hline Total Coliform - Sediment (CFU/100ml) & 1025.0 & 176.8 & 2 \\
\hline Colilert (MPN/100ml) & 9.7 & 0 & 1 \\
\hline Nitrates (mg/L) & 1.4 & 0.40 & 3 \\
\hline Phosphates (mg/L) & 0.15 & .06 & 3 \\
\hline Ammonia (mg/L) & 0.06 & 0.02 & 3 \\
\hline Biochemical Oxygen Demand $\left(\mathrm{mg} / \mathrm{L}\right.$ as $\left.\mathrm{O}_{2}\right)$ & 1.2 & 0.08 & 3 \\
\hline Alkalinity $\left(\mathrm{mg} / \mathrm{L}\right.$ as $\left.\mathrm{CaCO}_{3}\right)$ & 16.7 & 4.9 & 3 \\
\hline Hardness (mg/L as $\left.\mathrm{CaCO}_{3}\right)$ & 24.0 & 2.0 & 3 \\
\hline Standard Plate Count (CFU/ml) & 125.0 & 35.4 & 2 \\
\hline Acridine Orange Direct Counts (cells/g) & $1.0 \times 10^{8}$ & $5.5 \times 10^{7}$ & 1 \\
\hline Acid Phosphatase $(\mu \mathrm{g} / \mathrm{g})$ & 111.1 & 25.4 & 3 \\
\hline Alkaline Phosphatase $(\mu \mathrm{g} / \mathrm{g})$ & 858.6 & 367.7 & 3 \\
\hline Dehydrogenase $(\mu \mathrm{g} / \mathrm{g})$ & 13.6 & 3.9 & 3 \\
\hline Galactosidase $(\mu \mathrm{g} / \mathrm{g})$ & 48.3 & 19.3 & 3 \\
\hline Glucosidase $(\mu \mathrm{g} / \mathrm{g})$ & 196.5 & 26.0 & 3 \\
\hline E. coli O157:H7 (CFU/100ml) & 12.5 & 0 & 3 \\
\hline Shigella sp. (CFU/100ml) & 5.0 & 0 & 3 \\
\hline Bacteriophage (PUF/ml) & 1.0 & 0.87 & 3 \\
\hline Giardia sp.(cysts/L) & 4.5 & 0 & 1 \\
\hline Cryptosporidium sp. (cysts/L) & 4.5 & 0 & 1 \\
\hline
\end{tabular}


Table 66. Summary statistics for November 2011, site 14

\begin{tabular}{|c|c|c|c|}
\hline Variable & Mean & Std Dev & $\mathbf{N}$ \\
\hline Air Temperature $\left({ }^{\circ} \mathrm{C}\right)$ & 5.5 & 0 & 1 \\
\hline Water Temperature $\left({ }^{\circ} \mathrm{C}\right)$ & 6.5 & 0 & 1 \\
\hline $\mathrm{pH}$ & 7.4 & 0 & 1 \\
\hline Conductivity ( $\mu$ mohs) & 18.8 & 0 & 1 \\
\hline Dissolved Oxygen (mg/L as $\mathrm{O}_{2}$ ) & 7.5 & 0 & 1 \\
\hline Discharge $\left(\mathrm{m}^{3} / \mathrm{sec}\right)$ & 0.04 & 0 & 1 \\
\hline Fecal Coliform - Water (CFU/100ml) & 100.0 & 0 & 3 \\
\hline Total Coliform - Water (CFU/100ml) & 500.0 & 360.6 & 3 \\
\hline Fecal Coliform - Sediment (CFU/100ml) & 25.0 & 0 & 2 \\
\hline Total Coliform - Sediment (CFU/100ml) & 25.0 & 0 & 2 \\
\hline Colilert (MPN/100ml) & 2.0 & 0 & 1 \\
\hline Nitrates (mg/L) & 1.4 & 0 & 3 \\
\hline Phosphates (mg/L) & 0.19 & 0.09 & 3 \\
\hline Ammonia $(\mathrm{mg} / \mathrm{L})$ & 0.05 & 0.02 & 3 \\
\hline Biochemical Oxygen Demand (mg/L as $\mathrm{O}_{2}$ ) & 0.31 & 0.14 & 3 \\
\hline Alkalinity $\left(\mathrm{mg} / \mathrm{L}\right.$ as $\left.\mathrm{CaCO}_{3}\right)$ & 12.0 & 1.0 & 3 \\
\hline Hardness (mg/L as $\left.\mathrm{CaCO}_{3}\right)$ & 10.0 & 1.0 & 3 \\
\hline Standard Plate Count (CFU/ml) & 225.0 & 120.2 & 2 \\
\hline Acridine Orange Direct Counts (cells/g) & $1.4 \times 10^{8}$ & $7.3 \times 10^{7}$ & 1 \\
\hline Acid Phosphatase $(\mu \mathrm{g} / \mathrm{g})$ & 57.2 & 45.2 & 3 \\
\hline Alkaline Phosphatase $(\mu \mathrm{g} / \mathrm{g})$ & 348.7 & 17.6 & 3 \\
\hline Dehydrogenase $(\mu \mathrm{g} / \mathrm{g})$ & 9.5 & 3.6 & 3 \\
\hline Galactosidase $(\mu \mathrm{g} / \mathrm{g})$ & 128.0 & 27.4 & 3 \\
\hline Glucosidase $(\mu \mathrm{g} / \mathrm{g})$ & 250.6 & 85.7 & 3 \\
\hline E. coli O157:H7 (CFU/100ml) & 12.5 & 0 & 3 \\
\hline Shigella sp. (CFU/100ml) & 5.0 & 0 & 3 \\
\hline Bacteriophage (PUF/ml) & 0.63 & 0.23 & 3 \\
\hline Giardia sp.(cysts/L) & 9.0 & 0 & 1 \\
\hline Cryptosporidium sp. (cysts/L) & 18.0 & 0 & 1 \\
\hline
\end{tabular}


Table 67. Summary statistics for December 2011, site 2

\begin{tabular}{llll}
\hline Variable & Mean & Std Dev & $\mathbf{N}$ \\
Air Temperature $\left({ }^{\circ} \mathrm{C}\right)$ & -1.5 & 0 & 1 \\
Water Temperature $\left({ }^{\circ} \mathrm{C}\right)$ & 7.4 & 0 & 1 \\
pH & 6.6 & 0 & 1 \\
Conductivity $(\mu \mathrm{mohs})$ & 354.0 & 0 & 1 \\
Dissolved Oxygen $\left(\mathrm{mg} / \mathrm{L}\right.$ as $\left.\mathrm{O}_{2}\right)$ & 12.5 & 0 & 1 \\
Discharge $\left(\mathrm{m}^{3} / \mathrm{sec}\right)$ & 0.33 & 0 & 1 \\
Fecal Coliform - Water $(\mathrm{CFU} / 100 \mathrm{ml})$ & 266.7 & 115.5 & 3 \\
Total Coliform - Water $(\mathrm{CFU} / 100 \mathrm{ml})$ & 3400.0 & 2800.0 & 3 \\
Fecal Coliform - Sediment $(\mathrm{CFU} / 100 \mathrm{ml})$ & 100.0 & 0 & 2 \\
Total Coliform $-\mathrm{Sediment}(\mathrm{CFU} / 100 \mathrm{ml})$ & 2500.0 & 1060.7 & 2 \\
Colilert $(\mathrm{MPN} / 100 \mathrm{ml})$ & 113.7 & 0 & 1 \\
Nitrates $(\mathrm{mg} / \mathrm{L})$ & 2.7 & 0.98 & 3 \\
Phosphates $(\mathrm{mg} / \mathrm{L})$ & 0.21 & 0.06 & 3 \\
Ammonia $(\mathrm{mg} / \mathrm{L})$ & 0.09 & 0.04 & 3 \\
Biochemical Oxygen Demand $\left(\mathrm{mg} / \mathrm{L}\right.$ as $\left.\mathrm{O}_{2}\right)$ & 1.6 & 0.36 & 3 \\
Alkalinity $\left(\mathrm{mg} / \mathrm{L}\right.$ as CaCO $\left.{ }_{3}\right)$ & 163.7 & 14.2 & 3 \\
Hardness $\left(\mathrm{mg} / \mathrm{L}\right.$ as CaCO $\left.{ }_{3}\right)$ & 190.7 & 5.0 & 3 \\
Standard Plate Count $(\mathrm{CFU} / \mathrm{ml})$ & 170.0 & 42.4 & 2 \\
Acridine Orange Direct Counts $(\mathrm{cells} / \mathrm{g})$ & $1.6 \times 10^{8}$ & $1.7 \times 10^{7}$ & 1 \\
Acid Phosphatase $(\mu \mathrm{gg} / \mathrm{g})$ & 130.1 & 83.9 & 3 \\
Alkaline Phosphatase $(\mu \mathrm{gg} / \mathrm{g})$ & 507.2 & 113.2 & 3 \\
Dehydrogenase $(\mu \mathrm{gg} / \mathrm{g})$ & 27.0 & 17.5 & 3 \\
Galactosidase $(\mu \mathrm{g} / \mathrm{g})$ & 45.3 & 25.0 & 3 \\
Glucosidase $(\mu \mathrm{g} / \mathrm{g})$ & 154.7 & 28.7 & 3 \\
E. coli O157:H7 $(\mathrm{CFU} / 100 \mathrm{ml})$ & 12.5 & 0 & 3 \\
Shigella sp. $(\mathrm{CFU} / 100 \mathrm{ml})$ & 5.0 & 0 & 3 \\
Bacteriophage $(\mathrm{PUF} / \mathrm{ml})$ & 0.50 & 0 & 3 \\
Giardia sp. $(\mathrm{cysts} / \mathrm{L})$ & 24.0 & 0 & 1 \\
Cryptosporidium sp. $(\mathrm{cysts} / \mathrm{L})$ & 36.0 & 0 & 1 \\
\hline & & &
\end{tabular}


Table 68. Summary statistics for December 2011, site 4

\begin{tabular}{|c|c|c|c|}
\hline Variable & Mean & Std Dev & $\mathbf{N}$ \\
\hline Air Temperature $\left({ }^{\circ} \mathrm{C}\right)$ & -1.6 & 0 & 1 \\
\hline Water Temperature $\left({ }^{\circ} \mathrm{C}\right)$ & 7.3 & 0 & 1 \\
\hline $\mathrm{pH}$ & 7.5 & 0 & 1 \\
\hline Conductivity ( $\mu$ mohs) & 331.0 & 0 & 1 \\
\hline Dissolved Oxygen (mg/L as $\mathrm{O}_{2}$ ) & 11.7 & 0 & 1 \\
\hline Discharge $\left(\mathrm{m}^{3} / \mathrm{sec}\right)$ & 0.37 & 0 & 1 \\
\hline Fecal Coliform - Water (CFU/100ml) & 223.3 & 152.8 & 3 \\
\hline Total Coliform - Water (CFU/100ml) & 3666.7 & 2275.5 & 3 \\
\hline Fecal Coliform - Sediment (CFU/100ml) & 37.5 & 17.7 & 2 \\
\hline Total Coliform - Sediment (CFU/100ml) & 575.0 & 176.8 & 2 \\
\hline Colilert (MPN/100ml) & 104.3 & 0 & 1 \\
\hline Nitrates (mg/L) & 1.8 & 0.56 & 3 \\
\hline Phosphates (mg/L) & 0.42 & 0.22 & 3 \\
\hline Ammonia (mg/L) & 0.06 & 0.05 & 3 \\
\hline Biochemical Oxygen Demand (mg/L as $\mathrm{O}_{2}$ ) & 1.3 & 0.11 & 3 \\
\hline Alkalinity $\left(\mathrm{mg} / \mathrm{L}\right.$ as $\left.\mathrm{CaCO}_{3}\right)$ & 145.3 & 4.0 & 3 \\
\hline Hardness (mg/L as $\left.\mathrm{CaCO}_{3}\right)$ & 186.0 & 2.6 & 3 \\
\hline Standard Plate Count (CFU/ml) & 200.0 & 42.4 & 2 \\
\hline Acridine Orange Direct Counts (cells/g) & $6.1 \times 10^{7}$ & $1.3 \times 10^{7}$ & 1 \\
\hline Acid Phosphatase $(\mu \mathrm{g} / \mathrm{g})$ & 40.4 & 24.1 & 3 \\
\hline Alkaline Phosphatase $(\mu \mathrm{g} / \mathrm{g})$ & 335.7 & 184.4 & 3 \\
\hline Dehydrogenase $(\mu \mathrm{g} / \mathrm{g})$ & 29.5 & 5.1 & 3 \\
\hline Galactosidase $(\mu \mathrm{g} / \mathrm{g})$ & 24.7 & 16.8 & 3 \\
\hline Glucosidase $(\mu \mathrm{g} / \mathrm{g})$ & 67.5 & 78.1 & 3 \\
\hline E. coli O157:H7 (CFU/100ml) & 12.5 & 0 & 3 \\
\hline Shigella sp. (CFU/100ml) & 5.0 & 0 & 3 \\
\hline Bacteriophage (PUF/ml) & 0.50 & 0 & 3 \\
\hline Giardia sp.(cysts/L) & 9.0 & 0 & 1 \\
\hline Cryptosporidium sp. (cysts/L) & 9.0 & 0 & 1 \\
\hline
\end{tabular}


Table 69. Summary statistics for December 2011, site 7

\begin{tabular}{|c|c|c|c|}
\hline Variable & Mean & Std Dev & $\mathbf{N}$ \\
\hline Air Temperature $\left({ }^{\circ} \mathrm{C}\right)$ & 0.80 & 0 & 1 \\
\hline Water Temperature $\left({ }^{\circ} \mathrm{C}\right)$ & 11.0 & 0 & 1 \\
\hline $\mathrm{pH}$ & 7.2 & 0 & 1 \\
\hline Conductivity ( $\mu$ mohs) & 309.0 & 0 & 1 \\
\hline Dissolved Oxygen (mg/L as $\mathrm{O}_{2}$ ) & 10.2 & 0 & 1 \\
\hline Discharge $\left(\mathrm{m}^{3} / \mathrm{sec}\right)$ & 0.26 & 0 & 1 \\
\hline Fecal Coliform - Water (CFU/100ml) & 100.0 & 0 & 3 \\
\hline Total Coliform - Water (CFU/100ml) & 333.3 & 230.7 & 3 \\
\hline Fecal Coliform - Sediment (CFU/100ml) & 100.0 & 70.7 & 2 \\
\hline Total Coliform - Sediment (CFU/100ml) & 16400.0 & 3394.1 & 2 \\
\hline Colilert (MPN/100ml) & 5.2 & 0 & 1 \\
\hline Nitrates (mg/L) & 1.6 & 0.17 & 3 \\
\hline Phosphates (mg/L) & 0.19 & 0.01 & 3 \\
\hline Ammonia (mg/L) & 0.12 & 0.02 & 3 \\
\hline Biochemical Oxygen Demand (mg/L as $\mathrm{O}_{2}$ ) & 1.2 & 0.09 & 3 \\
\hline Alkalinity $\left(\mathrm{mg} / \mathrm{L}\right.$ as $\left.\mathrm{CaCO}_{3}\right)$ & 117.7 & 1.5 & 3 \\
\hline Hardness (mg/L as $\left.\mathrm{CaCO}_{3}\right)$ & 149.3 & 6.7 & 3 \\
\hline Standard Plate Count (CFU/ml) & 55.0 & 21.2 & 2 \\
\hline Acridine Orange Direct Counts (cells/g) & $1.1 \times 10^{8}$ & $1.7 \times 10^{7}$ & 1 \\
\hline Acid Phosphatase $(\mu \mathrm{g} / \mathrm{g})$ & 86.3 & 20.4 & 3 \\
\hline Alkaline Phosphatase $(\mu \mathrm{g} / \mathrm{g})$ & 522.5 & 32.6 & 3 \\
\hline Dehydrogenase $(\mu \mathrm{g} / \mathrm{g})$ & 16.4 & 11.8 & 3 \\
\hline Galactosidase $(\mu \mathrm{g} / \mathrm{g})$ & 20.1 & 9.4 & 3 \\
\hline Glucosidase $(\mu \mathrm{g} / \mathrm{g})$ & 79.8 & 52.4 & 3 \\
\hline E. coli O157:H7 (CFU/100ml) & 12.5 & 0 & 3 \\
\hline Shigella sp. (CFU/100ml) & 5.0 & 0 & 3 \\
\hline Bacteriophage (PUF/ml) & 0.50 & 0 & 3 \\
\hline Giardia sp.(cysts/L) & 7.5 & 0 & 1 \\
\hline Cryptosporidium sp. (cysts/L) & 15.0 & 0 & 1 \\
\hline
\end{tabular}


Table 70. Summary statistics for December 2011, site 10

\begin{tabular}{llll}
\hline Variable & Mean & Std Dev & $\mathbf{N}$ \\
Air Temperature $\left({ }^{\circ} \mathrm{C}\right)$ & 2.4 & 0 & 1 \\
Water Temperature $\left({ }^{\circ} \mathrm{C}\right)$ & 9.2 & 0 & 1 \\
pH & 6.8 & 0 & 1 \\
Conductivity $(\mu \mathrm{mohs})$ & 134.3 & 0 & 1 \\
Dissolved Oxygen $\left(\mathrm{mg} / \mathrm{L}\right.$ as $\left.\mathrm{O}_{2}\right)$ & 10.8 & 0 & 1 \\
Discharge $\left(\mathrm{m}^{3} / \mathrm{sec}\right)$ & 0.22 & 0 & 1 \\
Fecal Coliform - Water $(\mathrm{CFU} / 100 \mathrm{ml})$ & 100.0 & 0 & 3 \\
Total Coliform - Water $(\mathrm{CFU} / 100 \mathrm{ml})$ & 2066.7 & 2386.1 & 3 \\
Fecal Coliform - Sediment $(\mathrm{CFU} / 100 \mathrm{ml})$ & 37.5 & 17.7 & 2 \\
Total Coliform $-\mathrm{Sediment}(\mathrm{CFU} / 100 \mathrm{ml})$ & 437.5 & 583.4 & 2 \\
Colilert $(\mathrm{MPN} / 100 \mathrm{ml})$ & 18.3 & 0 & 1 \\
Nitrates $(\mathrm{mg} / \mathrm{L})$ & 1.4 & 0.40 & 3 \\
Phosphates $(\mathrm{mg} / \mathrm{L})$ & 0.24 & 0.07 & 3 \\
Ammonia $(\mathrm{mg} / \mathrm{L})$ & 0.09 & 0.04 & 3 \\
Biochemical Oxygen Demand $\left(\mathrm{mg} / \mathrm{L}\right.$ as $\left.\mathrm{O}_{2}\right)$ & 1.1 & 0.06 & 3 \\
Alkalinity $\left(\mathrm{mg} / \mathrm{L}\right.$ as CaCO $\left.{ }_{3}\right)$ & 84.7 & 0.58 & 3 \\
Hardness $\left(\mathrm{mg} / \mathrm{L}\right.$ as CaCO $\left.{ }_{3}\right)$ & 103.3 & 1.2 & 3 \\
Standard Plate Count $(\mathrm{CFU} / \mathrm{ml})$ & 75.0 & 35.4 & 2 \\
Acridine Orange Direct Counts $(\mathrm{cells} / \mathrm{g})$ & $9.8 \times 10^{7}$ & $4.2 \times 10^{7}$ & 1 \\
Acid Phosphatase $(\mu \mathrm{gg} / \mathrm{g})$ & 72.2 & 40.4 & 3 \\
Alkaline Phosphatase $(\mu \mathrm{gg} / \mathrm{g})$ & 721.9 & 381.0 & 3 \\
Dehydrogenase $(\mu \mathrm{gg} / \mathrm{g})$ & 33.8 & 24.6 & 3 \\
Galactosidase $(\mu \mathrm{g} / \mathrm{g})$ & 8.6 & 6.8 & 3 \\
Glucosidase $(\mu \mathrm{g} / \mathrm{g})$ & 106.7 & 49.7 & 3 \\
E. coli O157:H7 $(\mathrm{CFU} / 100 \mathrm{ml})$ & 12.5 & 0 & 3 \\
Shigella sp. $(\mathrm{CFU} / 100 \mathrm{ml})$ & 5.0 & 0 & 3 \\
Bacteriophage $(\mathrm{PUF} / \mathrm{ml})$ & 0.50 & 0 & 3 \\
Giardia sp. $(\mathrm{cysts} / \mathrm{L})$ & 6.3 & 0 & 1 \\
Cryptosporidium sp. $(\mathrm{cysts} / \mathrm{L})$ & 6.3 & 0 & 1 \\
\hline & & &
\end{tabular}


Table 71. Summary statistics for December 2011, site 13

\begin{tabular}{|c|c|c|c|}
\hline Variable & Mean & Std Dev & $\mathbf{N}$ \\
\hline Air Temperature $\left({ }^{\circ} \mathrm{C}\right)$ & 5.3 & 0 & 1 \\
\hline Water Temperature $\left({ }^{\circ} \mathrm{C}\right)$ & 4.7 & 0 & 1 \\
\hline $\mathrm{pH}$ & 7.4 & 0 & 1 \\
\hline Conductivity ( $\mu$ mohs) & 34.9 & 0 & 1 \\
\hline Dissolved Oxygen (mg/L as $\mathrm{O}_{2}$ ) & 11.5 & 0 & 1 \\
\hline Discharge $\left(\mathrm{m}^{3} / \mathrm{sec}\right)$ & 0.08 & 0 & 1 \\
\hline Fecal Coliform - Water (CFU/100ml) & 100.0 & 0 & 3 \\
\hline Total Coliform - Water (CFU/100ml) & 333.3 & 115.5 & 3 \\
\hline Fecal Coliform - Sediment (CFU/100ml) & 37.5 & 17.7 & 2 \\
\hline Total Coliform - Sediment (CFU/100ml) & 350.0 & 424.3 & 2 \\
\hline Colilert (MPN/100ml) & 4.1 & 0 & 1 \\
\hline Nitrates (mg/L) & 1.2 & 0.40 & 3 \\
\hline Phosphates (mg/L) & 0.21 & 0.03 & 3 \\
\hline Ammonia (mg/L) & 0.10 & 0.02 & 3 \\
\hline Biochemical Oxygen Demand (mg/L as $\mathrm{O}_{2}$ ) & 1.5 & 0.19 & 3 \\
\hline Alkalinity $\left(\mathrm{mg} / \mathrm{L}\right.$ as $\left.\mathrm{CaCO}_{3}\right)$ & 20.0 & 1.0 & 3 \\
\hline Hardness (mg/L as $\left.\mathrm{CaCO}_{3}\right)$ & 27.7 & 1.2 & 3 \\
\hline Standard Plate Count (CFU/ml) & 30.0 & 14.1 & 2 \\
\hline Acridine Orange Direct Counts (cells/g) & $8.5 \times 10^{7}$ & $1.7 \times 10^{7}$ & 1 \\
\hline Acid Phosphatase $(\mu \mathrm{g} / \mathrm{g})$ & 124.5 & 28.2 & 3 \\
\hline Alkaline Phosphatase $(\mu \mathrm{g} / \mathrm{g})$ & 835.6 & 16.7 & 3 \\
\hline Dehydrogenase $(\mu \mathrm{g} / \mathrm{g})$ & 20.8 & 11.8 & 3 \\
\hline Galactosidase $(\mu \mathrm{g} / \mathrm{g})$ & 33.8 & 18.0 & 3 \\
\hline Glucosidase $(\mu \mathrm{g} / \mathrm{g})$ & 74.8 & 15.9 & 3 \\
\hline E. coli O157:H7 (CFU/100ml) & 12.5 & 0 & 3 \\
\hline Shigella sp. (CFU/100ml) & 5.0 & 0 & 3 \\
\hline Bacteriophage (PUF/mI) & 0.50 & 0 & 3 \\
\hline Giardia sp.(cysts/L) & 17.5 & 0 & 1 \\
\hline Cryptosporidium sp. (cysts/L) & 17.5 & 0 & 1 \\
\hline
\end{tabular}


Table 72. Summary statistics for December 2011, site 14

\begin{tabular}{|c|c|c|c|}
\hline Variable & Mean & Std Dev & $\mathbf{N}$ \\
\hline Air Temperature $\left({ }^{\circ} \mathrm{C}\right)$ & 4.8 & 0 & 1 \\
\hline Water Temperature $\left({ }^{\circ} \mathrm{C}\right)$ & 5.3 & 0 & 1 \\
\hline $\mathrm{pH}$ & 6.9 & 0 & 1 \\
\hline Conductivity ( $\mu$ mohs) & 18.2 & 0 & 1 \\
\hline Dissolved Oxygen (mg/L as $\mathrm{O}_{2}$ ) & 11.6 & 0 & 1 \\
\hline Discharge $\left(\mathrm{m}^{3} / \mathrm{sec}\right)$ & 0.02 & 0 & 1 \\
\hline Fecal Coliform - Water (CFU/100ml) & 100.0 & 0 & 3 \\
\hline Total Coliform - Water (CFU/100ml) & 666.7 & 808.3 & 3 \\
\hline Fecal Coliform - Sediment (CFU/100ml) & 25.0 & 0 & 2 \\
\hline Total Coliform - Sediment (CFU/100ml) & 175.0 & 106.1 & 2 \\
\hline Colilert (MPN/100ml) & 1.0 & 0 & 1 \\
\hline Nitrates (mg/L) & 1.8 & 0.51 & 3 \\
\hline Phosphates (mg/L) & 0.20 & 0.05 & 3 \\
\hline Ammonia (mg/L) & 0.06 & 0 & 3 \\
\hline Biochemical Oxygen Demand (mg/L as $\mathrm{O}_{2}$ ) & 1.4 & 0.10 & 3 \\
\hline Alkalinity $\left(\mathrm{mg} / \mathrm{L}\right.$ as $\left.\mathrm{CaCO}_{3}\right)$ & 13.3 & 2.1 & 3 \\
\hline Hardness $\left(\mathrm{mg} / \mathrm{L}\right.$ as $\left.\mathrm{CaCO}_{3}\right)$ & 13.0 & 0 & 3 \\
\hline Standard Plate Count (CFU/ml) & 45.0 & 21.2 & 2 \\
\hline Acridine Orange Direct Counts (cells/g) & $1.1 \times 10^{8}$ & $2.8 \times 10^{7}$ & 1 \\
\hline Acid Phosphatase $(\mu \mathrm{g} / \mathrm{g})$ & 113.9 & 52.5 & 3 \\
\hline Alkaline Phosphatase $(\mu \mathrm{g} / \mathrm{g})$ & 450.9 & 90.2 & 3 \\
\hline Dehydrogenase $(\mu \mathrm{g} / \mathrm{g})$ & 18.1 & 9.7 & 3 \\
\hline Galactosidase $(\mu \mathrm{g} / \mathrm{g})$ & 11.8 & 9.3 & 3 \\
\hline Glucosidase $(\mu \mathrm{g} / \mathrm{g})$ & 119.8 & 9.1 & 3 \\
\hline E. coli 0157:H7 (CFU/100ml) & 12.5 & 0 & 3 \\
\hline Shigella sp. (CFU/100ml) & 5.0 & 0 & 3 \\
\hline Bacteriophage (PUF/ml) & 0.50 & 0 & 3 \\
\hline Giardia sp.(cysts/L) & 22.5 & 0 & 1 \\
\hline Cryptosporidium sp. (cysts/L) & 15.0 & 0 & 1 \\
\hline
\end{tabular}


Table 73. Depth, width, velocity and discharge measurements by month and site

\begin{tabular}{|c|c|c|c|c|c|}
\hline $\begin{array}{l}\text { Date Samples } \\
\text { Collected }\end{array}$ & Site & $\begin{array}{l}\text { Mean Depth } \\
(\mathrm{m})\end{array}$ & Width (m) & $\begin{array}{l}\text { Velocity } \\
(\mathrm{m} / \mathrm{s})\end{array}$ & $\begin{array}{r}\text { Discharge } \\
\left(\mathrm{m}^{3} / \mathrm{s}\right)\end{array}$ \\
\hline \multirow{6}{*}{ January 2011} & 2 & 0.27 & 7.1 & 0.2 & 0.117 \\
\hline & 4 & 0.18 & 8.1 & 1.1 & 0.498 \\
\hline & 7 & 0.22 & 3.3 & 1.9 & 0.414 \\
\hline & 10 & 0.16 & 4.1 & 3.5 & 0.714 \\
\hline & 13 & 0.08 & 4.4 & 2.5 & 0.268 \\
\hline & 14 & 0.09 & 3.2 & 1.5 & 0.137 \\
\hline \multirow{6}{*}{ February 2011} & 2 & 0.17 & 5.8 & 0.03 & 0.030 \\
\hline & 4 & 0.12 & 7.4 & 0.18 & 0.167 \\
\hline & 7 & 0.15 & 3.1 & 0.46 & 0.217 \\
\hline & 10 & 0.07 & 4.2 & 0.27 & 0.084 \\
\hline & 13 & 0.07 & 2.4 & 0.52 & 0.091 \\
\hline & 14 & 0.08 & 3.1 & 0.09 & 0.024 \\
\hline \multirow{6}{*}{ March 2011} & 2 & 0.13 & 10.6 & 0.61 & 0.840 \\
\hline & 4 & 0.42 & 7.7 & 0.21 & 0.685 \\
\hline & 7 & 0.19 & 3.3 & 0.73 & 0.459 \\
\hline & 10 & 0.09 & 4.5 & 0.76 & 0.297 \\
\hline & 13 & 0.07 & 5.1 & 0.27 & 0.098 \\
\hline & 14 & 0.06 & 3.0 & 0.09 & 0.017 \\
\hline \multirow{6}{*}{ April 2011} & 2 & 0.15 & 11.3 & 0.58 & 1.003 \\
\hline & 4 & 0.40 & 7.7 & 0.34 & 1.033 \\
\hline & 7 & 0.28 & 3.2 & 0.91 & 0.810 \\
\hline & 10 & 0.20 & 4.5 & 0.46 & 0.405 \\
\hline & 13 & 0.14 & 5.4 & 0.58 & 0.427 \\
\hline & 14 & 0.06 & 3.4 & 0.18 & 0.037 \\
\hline \multirow{6}{*}{ May 2011} & 2 & 0.23 & 11.9 & 0.46 & 1.233 \\
\hline & 4 & 0.31 & 8.2 & 0.18 & 0.460 \\
\hline & 7 & 0.21 & 3.4 & 0.58 & 0.420 \\
\hline & 10 & 0.21 & 4.6 & 0.34 & 0.319 \\
\hline & 13 & 0.10 & 5.6 & 0.18 & 0.099 \\
\hline & 14 & 0.07 & 3.4 & 0.06 & 0.015 \\
\hline \multirow{6}{*}{ June 2011} & 2 & 0.18 & 11.1 & 0.40 & 0.792 \\
\hline & 4 & 0.30 & 5.2 & 0.18 & 0.288 \\
\hline & 7 & 0.15 & 3.5 & 0.46 & 0.245 \\
\hline & 10 & 0.15 & 4.5 & 0.27 & 0.181 \\
\hline & 13 & 0.07 & 5.8 & 0.24 & 0.104 \\
\hline & 14 & 0.03 & 3.0 & 0.06 & 0.005 \\
\hline \multirow{6}{*}{ July 2011} & 2 & 0.16 & 11.5 & 0.27 & 0.515 \\
\hline & 4 & 0.31 & 6.8 & 0.12 & 0.260 \\
\hline & 7 & 0.19 & 3.2 & 0.24 & 0.148 \\
\hline & 10 & 0.14 & 4.3 & 0.12 & 0.072 \\
\hline & 13 & 0.05 & 5.7 & 0.24 & 0.065 \\
\hline & 14 & 0.05 & 2.7 & 0.03 & 0.004 \\
\hline
\end{tabular}


Table 73 (continued)

\begin{tabular}{lccccc}
\hline $\begin{array}{l}\text { Date Samples } \\
\text { Collected }\end{array}$ & Site & $\begin{array}{c}\text { Mean Depth } \\
(\mathbf{m})\end{array}$ & Width $(\mathbf{m})$ & $\begin{array}{c}\text { Velocity } \\
(\mathbf{m} / \mathbf{s})\end{array}$ & $\begin{array}{r}\text { Discharge } \\
\left(\mathbf{m}^{\mathbf{3}} / \mathbf{s}\right)\end{array}$ \\
\hline & 2 & 0.19 & 11.6 & 0.34 & 2.382 \\
& 4 & 0.22 & 7.9 & 0.06 & 0.353 \\
& 7 & 0.18 & 3.1 & 0.27 & 0.502 \\
August 2011 & 10 & 0.15 & 4.1 & 0.13 & 0.077 \\
& 13 & 0.07 & 5.6 & 0.20 & 0.075 \\
& 14 & 0.05 & 2.6 & 0.07 & 0.008 \\
\hline & 2 & 0.14 & 11.3 & 0.67 & 1.055 \\
& 4 & 0.16 & 7.4 & 0.14 & 0.173 \\
September 2011 & 7 & 0.19 & 3.2 & 0.13 & 0.076 \\
& 10 & 0.10 & 4.2 & 0.14 & 0.058 \\
& 13 & 0.06 & 6.0 & 0.17 & 0.063 \\
& 14 & 0.05 & 2.9 & 0.10 & 0.015 \\
\hline & 2 & 0.19 & 11.4 & 0.17 & 0.367 \\
& 4 & 0.14 & 7.7 & 0.14 & 0.150 \\
October 2011 & 7 & 0.23 & 3.2 & 0.25 & 0.184 \\
& 10 & 0.13 & 4.6 & 0.11 & 0.068 \\
& 13 & 0.10 & 7.9 & 0.25 & 0.198 \\
& 14 & 0.07 & 3.7 & 0.06 & 0.015 \\
\hline & 2 & 0.15 & 11.3 & 0.30 & 0.505 \\
November 2011 & 4 & 0.17 & 7.7 & 0.18 & 0.239 \\
& 7 & 0.25 & 3.2 & 0.52 & 0.415 \\
& 10 & 0.19 & 4.4 & 0.30 & 0.259 \\
& 13 & 0.12 & 5.8 & 0.34 & 0.233 \\
& 14 & 0.06 & 4.1 & 0.18 & 0.042 \\
\hline & 2 & 0.11 & 10.8 & 0.27 & 0.326 \\
& 4 & 0.31 & 7.9 & 0.15 & 0.377 \\
& 7 & 0.22 & 3.3 & 0.37 & 0.262 \\
December 2011 & 10 & 0.22 & 4.1 & 0.24 & 0.223 \\
& 13 & 0.08 & 6.0 & 0.18 & 0.084 \\
& 14 & 0.05 & 3.4 & 0.09 & 0.016 \\
\hline
\end{tabular}




\section{Appendix C: Shigella spp. and E. coli O157:H7 Gel Electrophoresis Pictures}
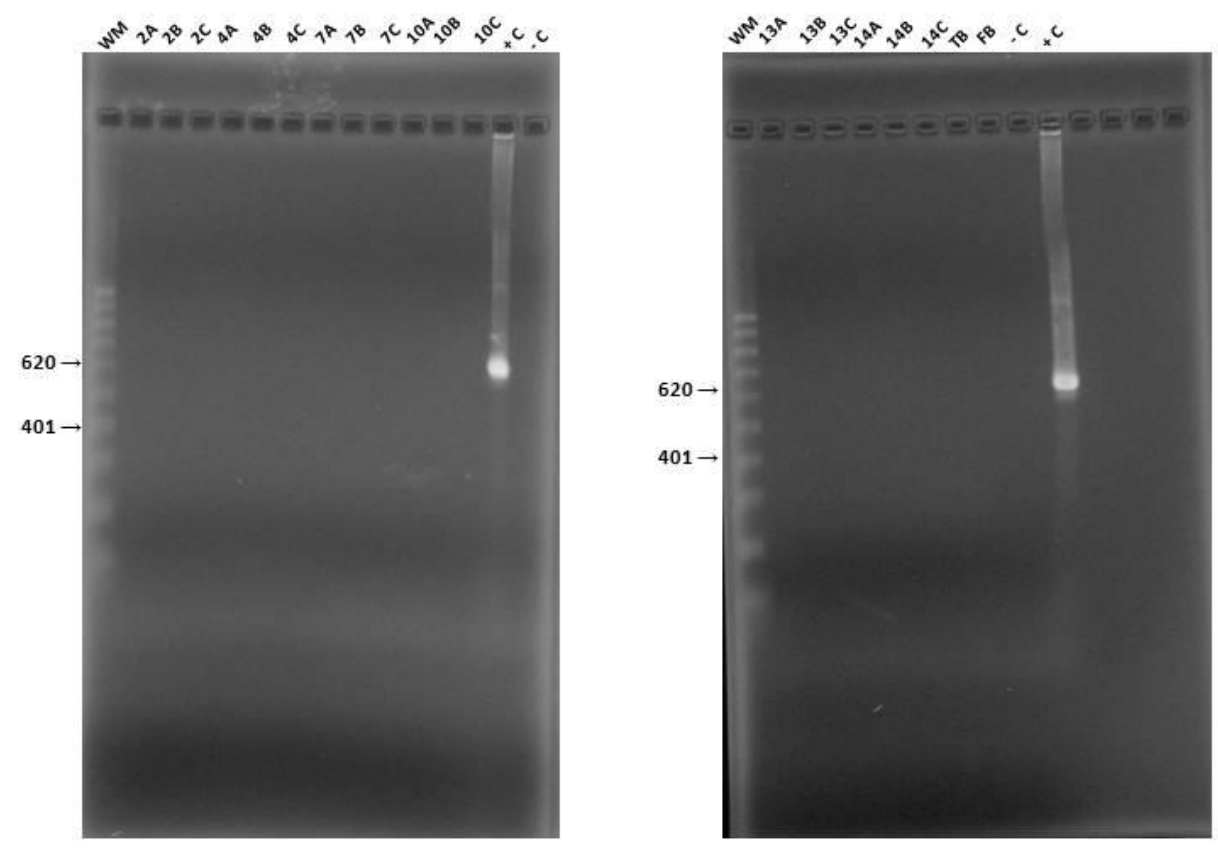

Figure 1. Gel electrophoresis of Shigella sp. PCR products, January 2011. 

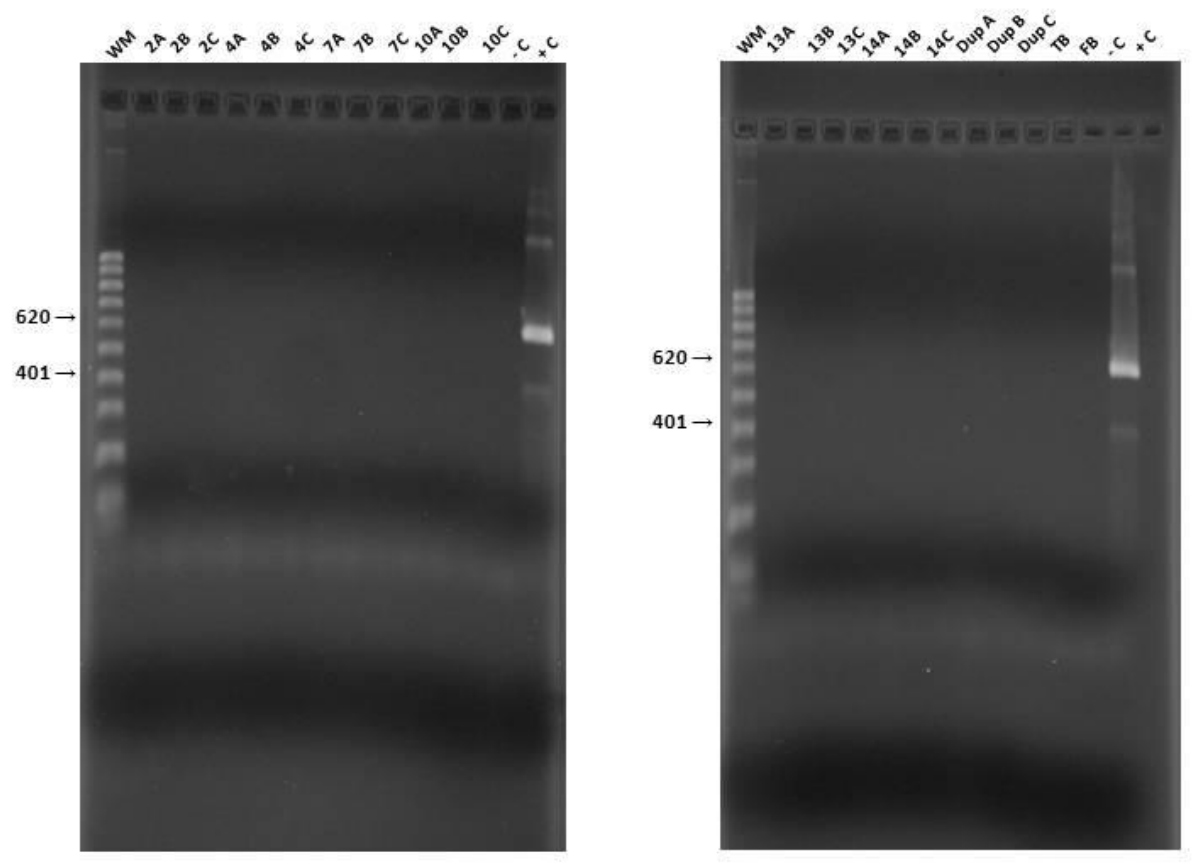

Figure 2. Gel electrophoresis of Shigella sp. PCR products, February 2011. 

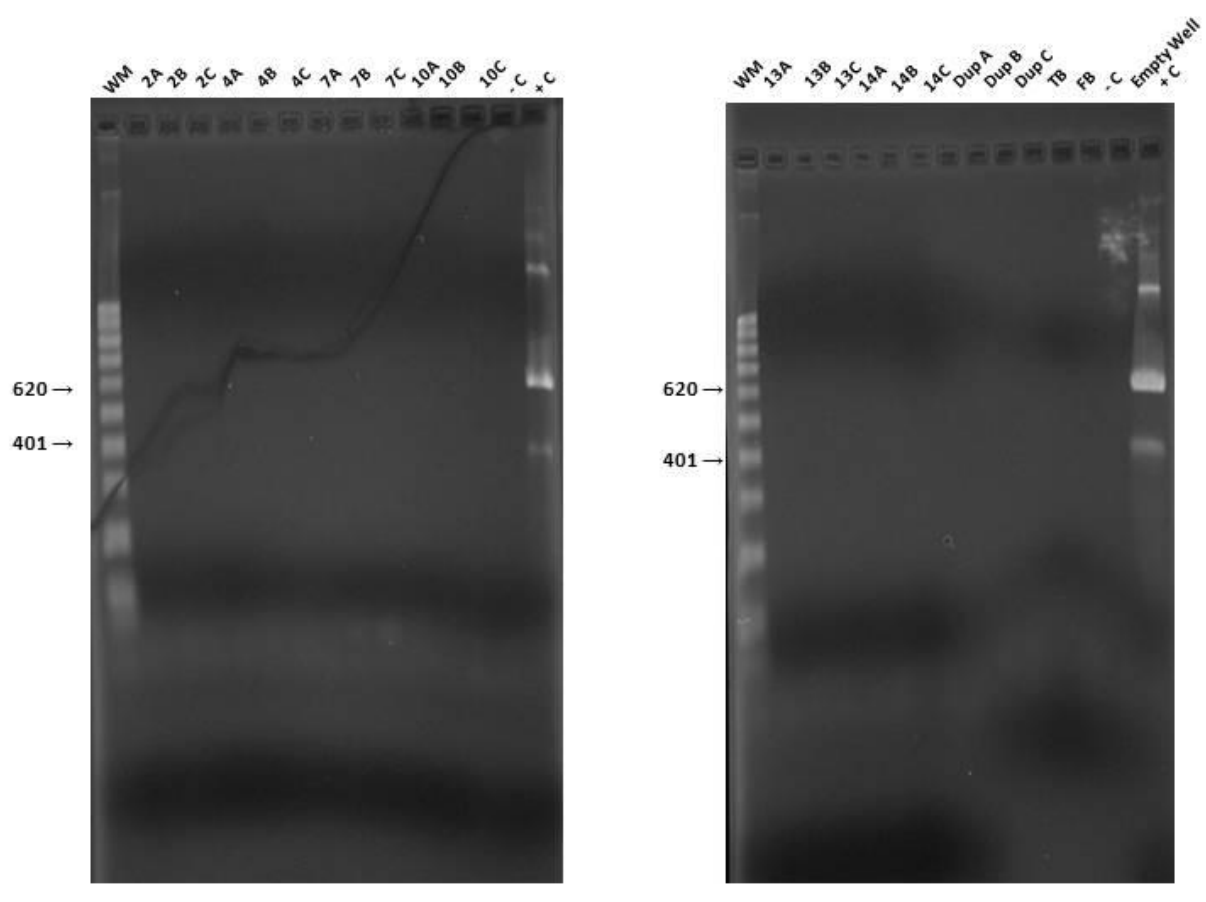

Figure 3. Gel electrophoresis of Shigella sp. PCR products, March 2011. 

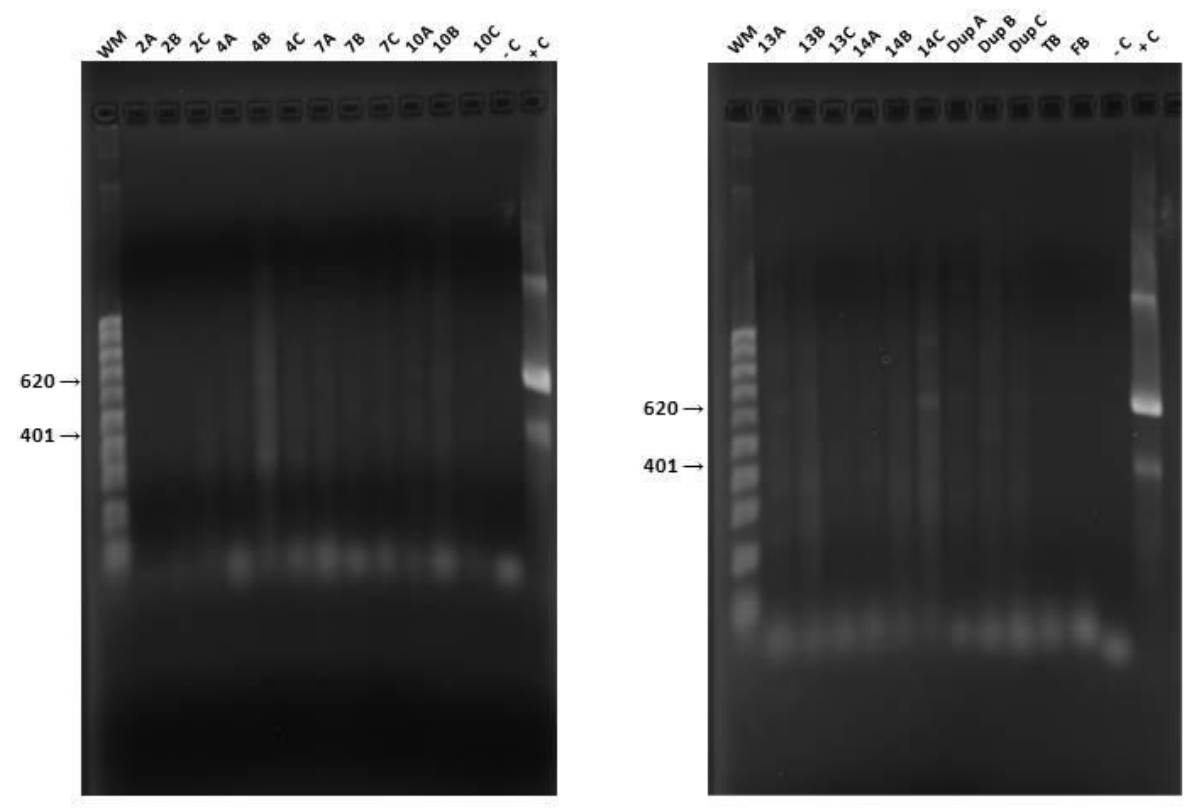

Figure 4. Gel electrophoresis of Shigella sp. PCR products, April 2011. 


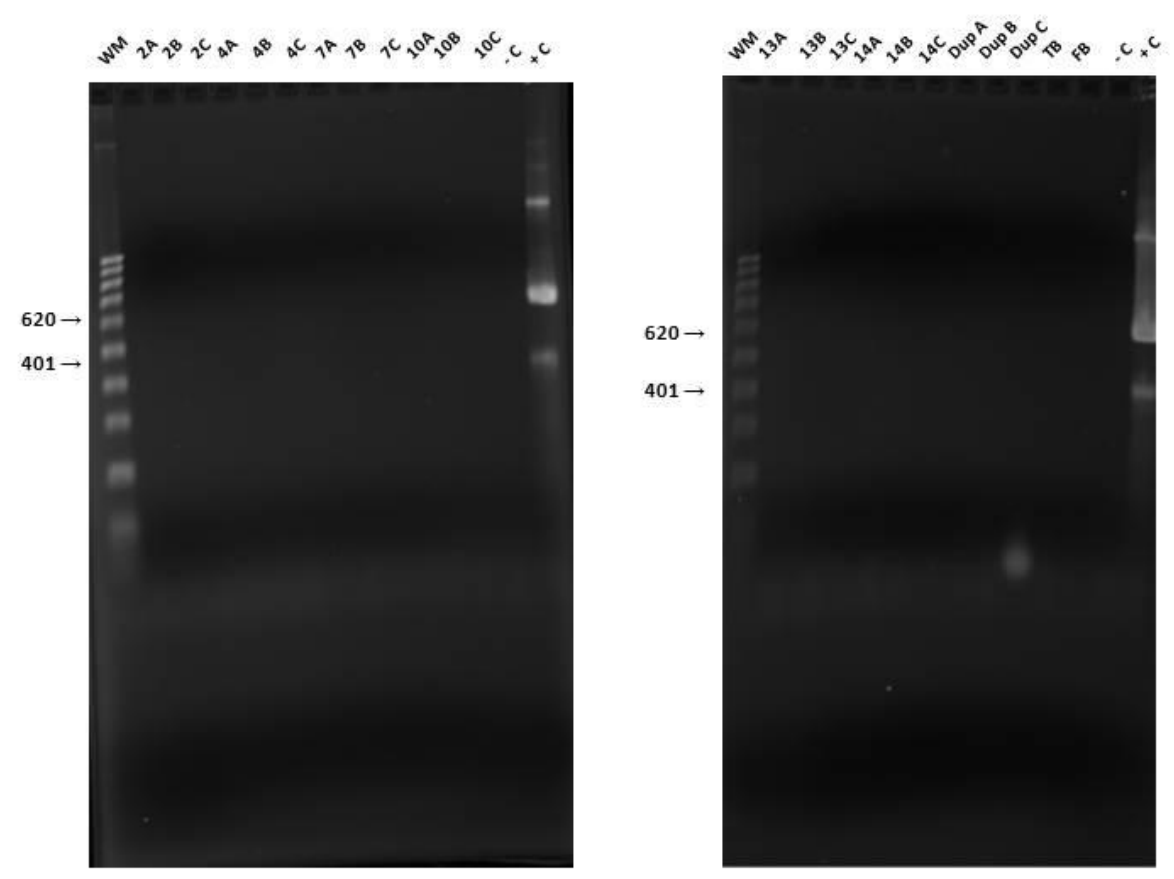

Figure 5. Gel electrophoresis of Shigella sp. PCR products, May 2011. 

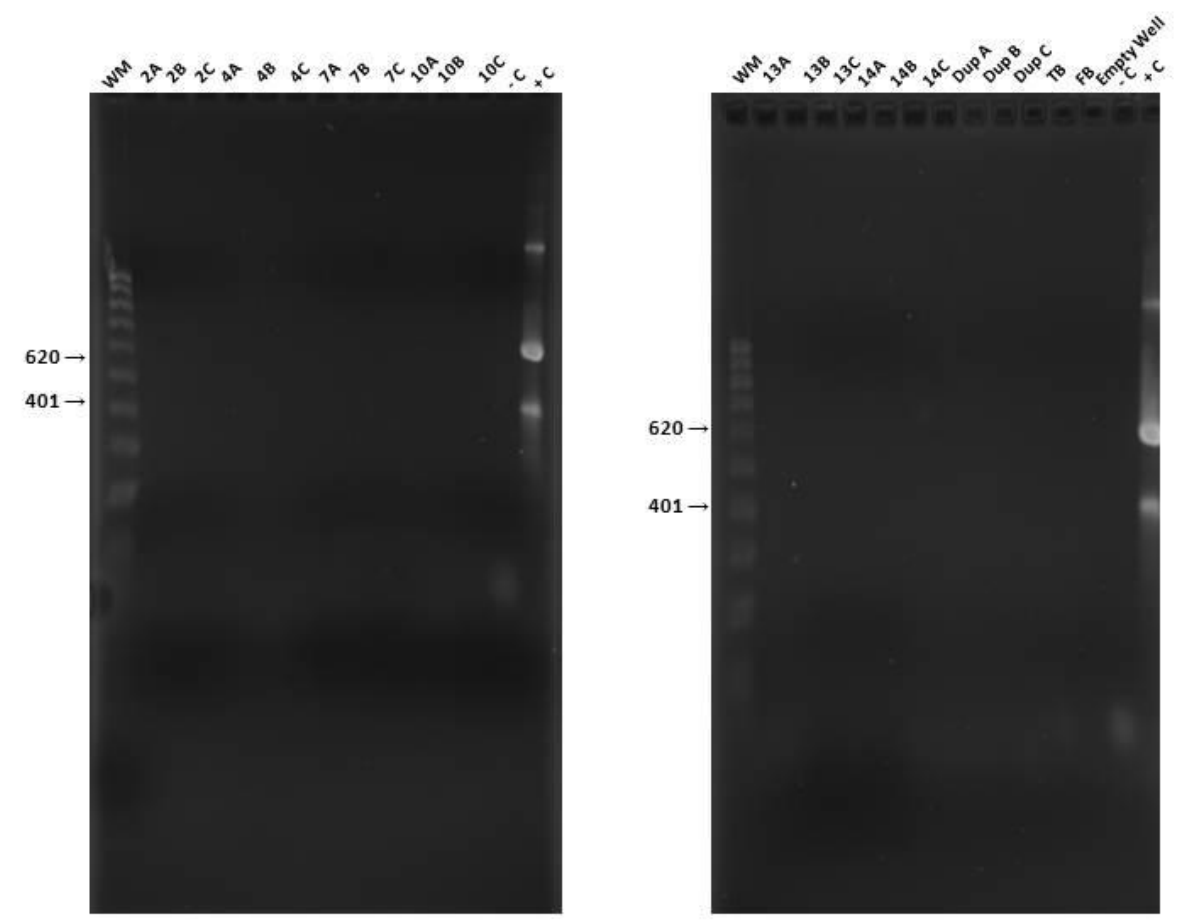

Figure 6. Gel electrophoresis of Shigella sp. PCR products, June 2011. 

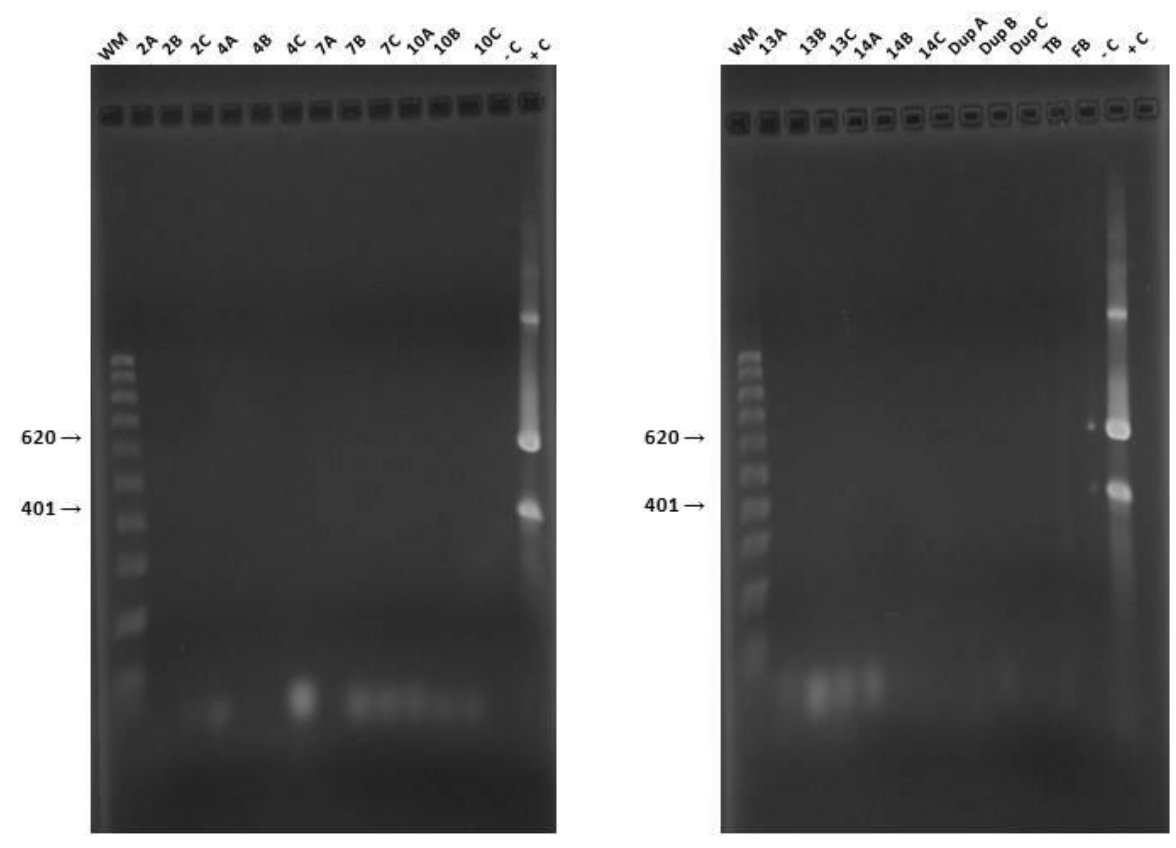

Figure 7. Gel electrophoresis of Shigella sp. PCR products, July 2011. 

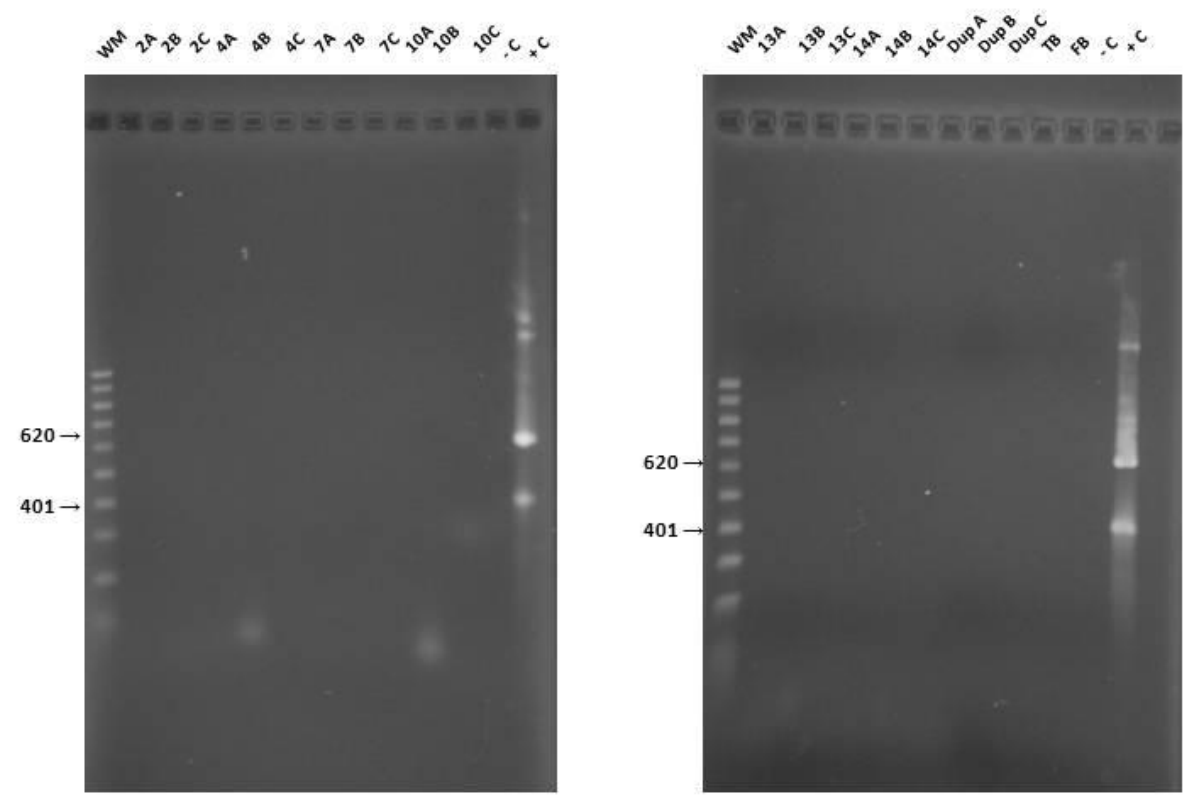

Figure 8. Gel electrophoresis of Shigella sp. PCR products, August 2011. 

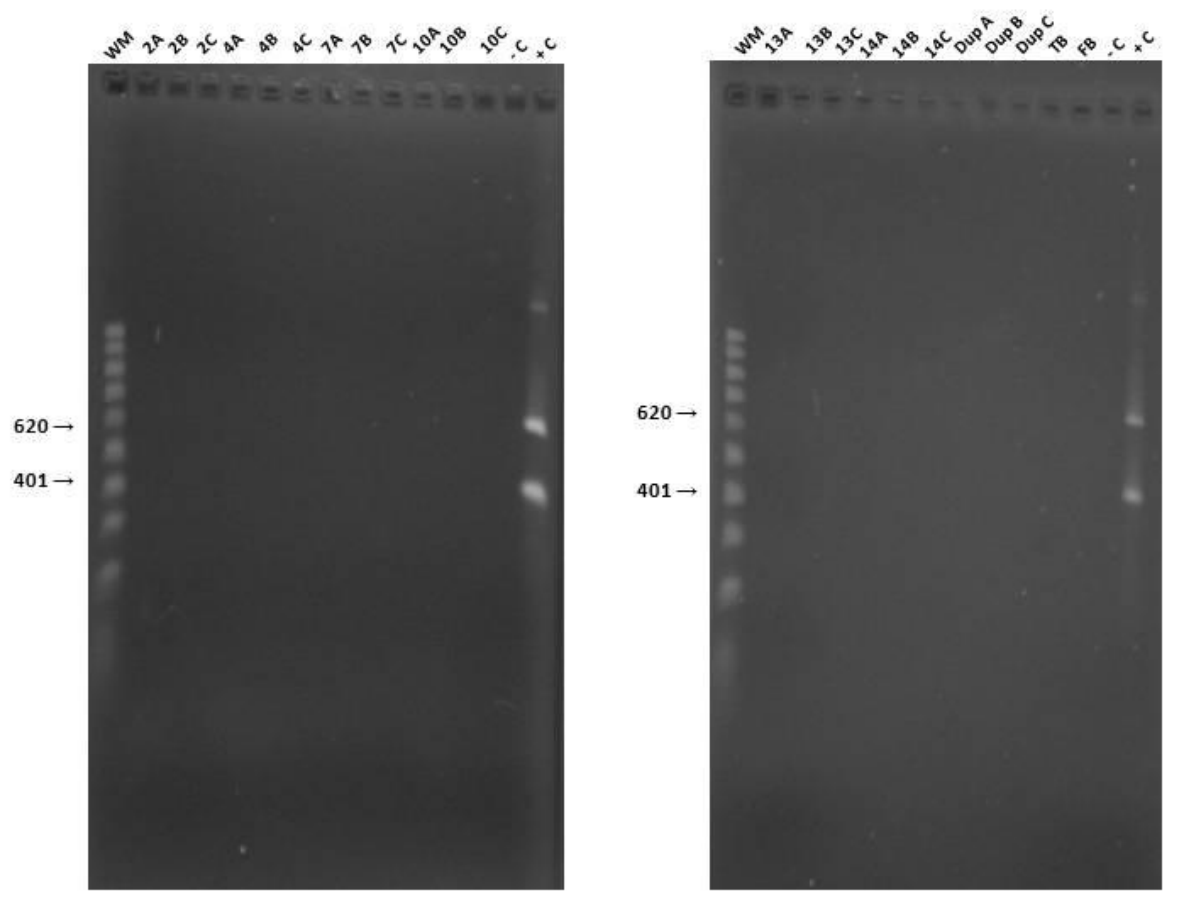

Figure 9. Gel electrophoresis of Shigella sp. PCR products, September 2011. 

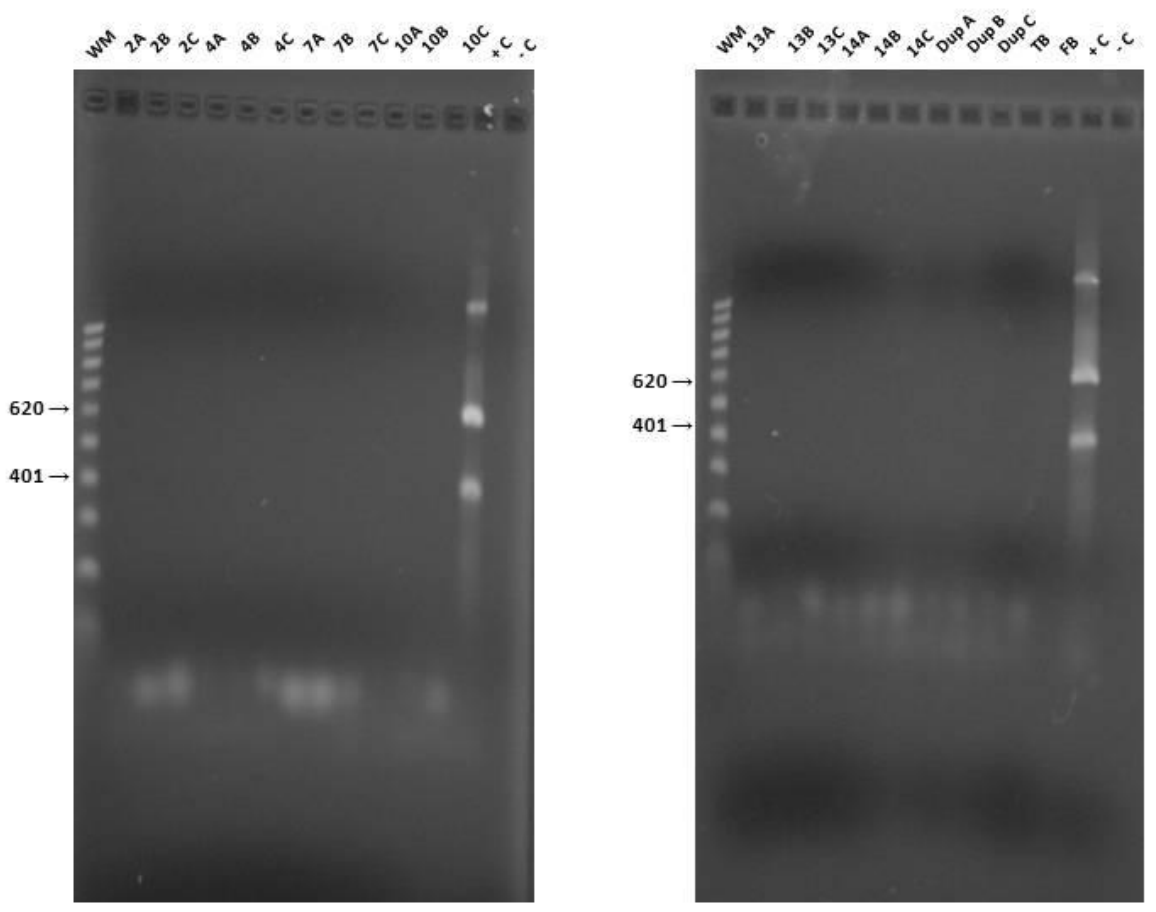

Figure 10. Gel electrophoresis of Shigella sp. PCR products, October 2011. 

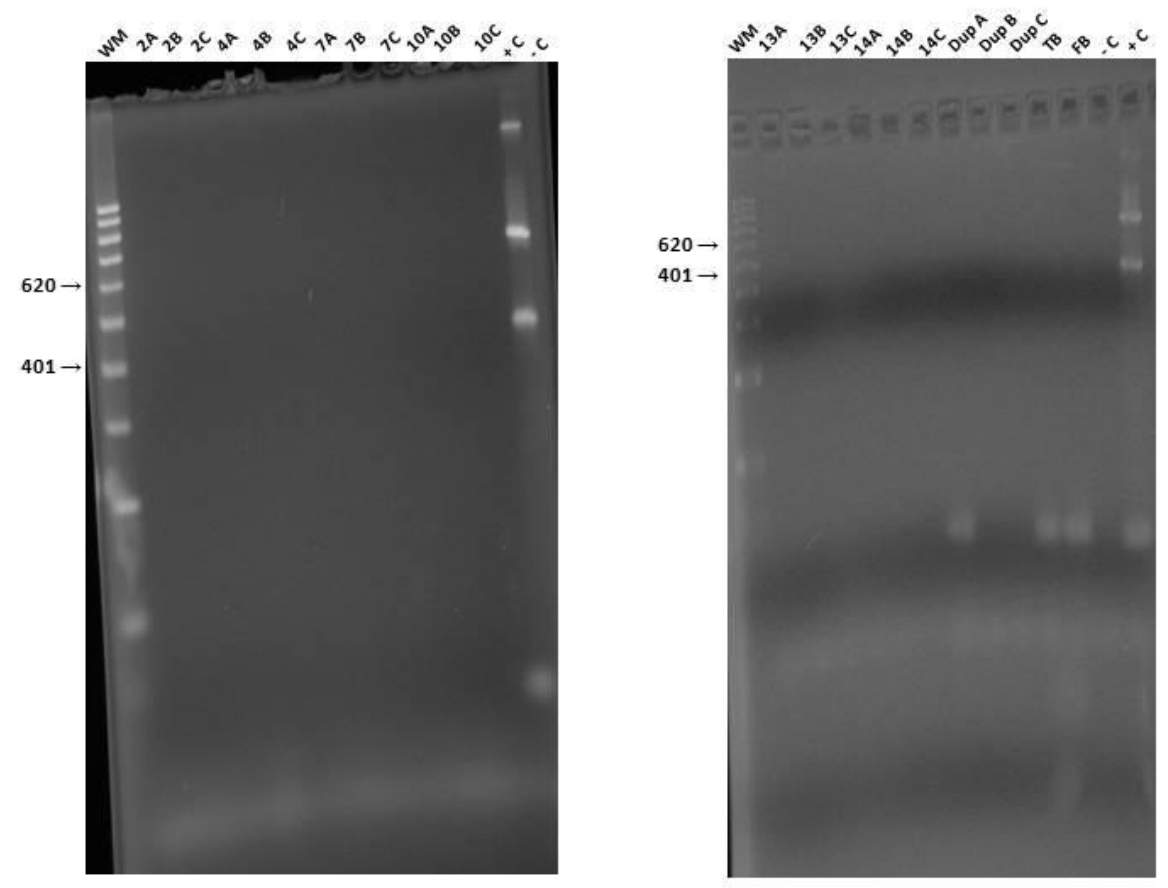

Figure 11. Gel electrophoresis of Shigella sp. PCR products, November 2011. 

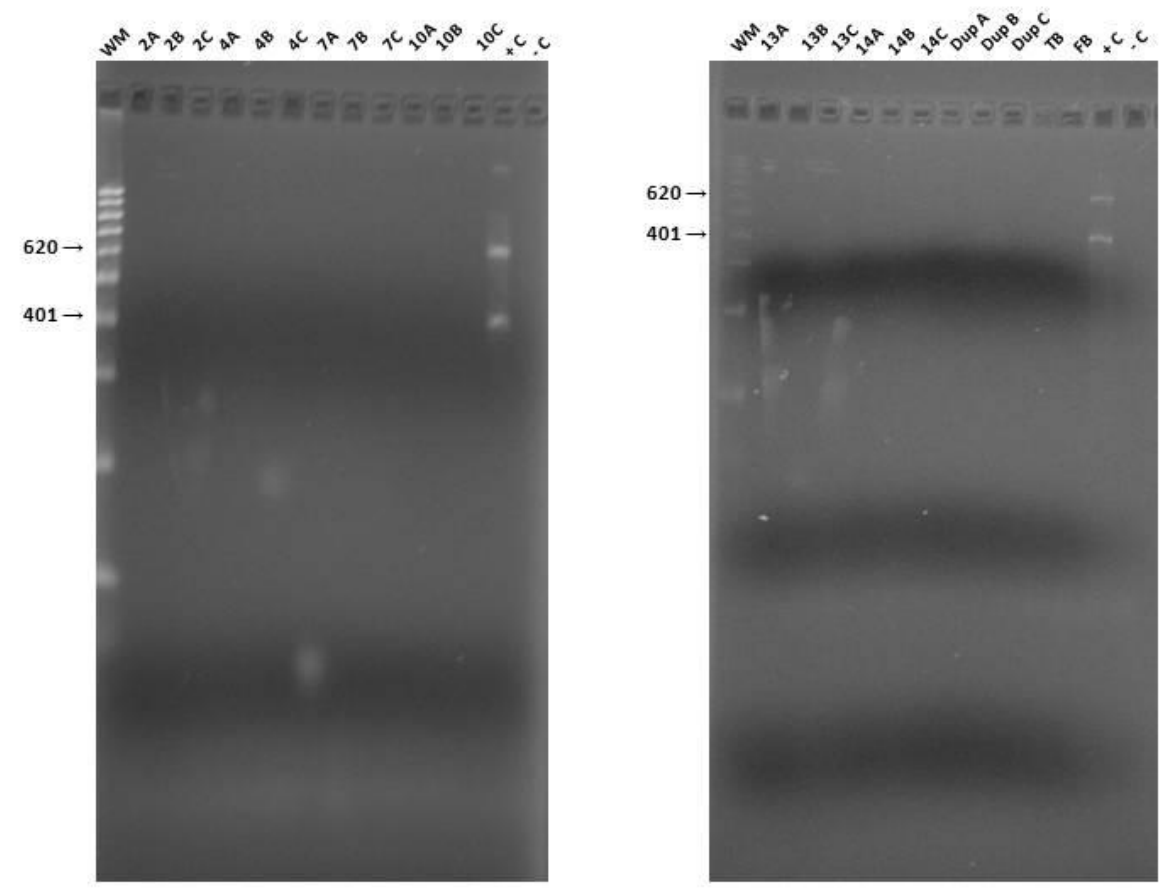

Figure 12. Gel electrophoresis of Shigella sp. PCR products, December 2011. 

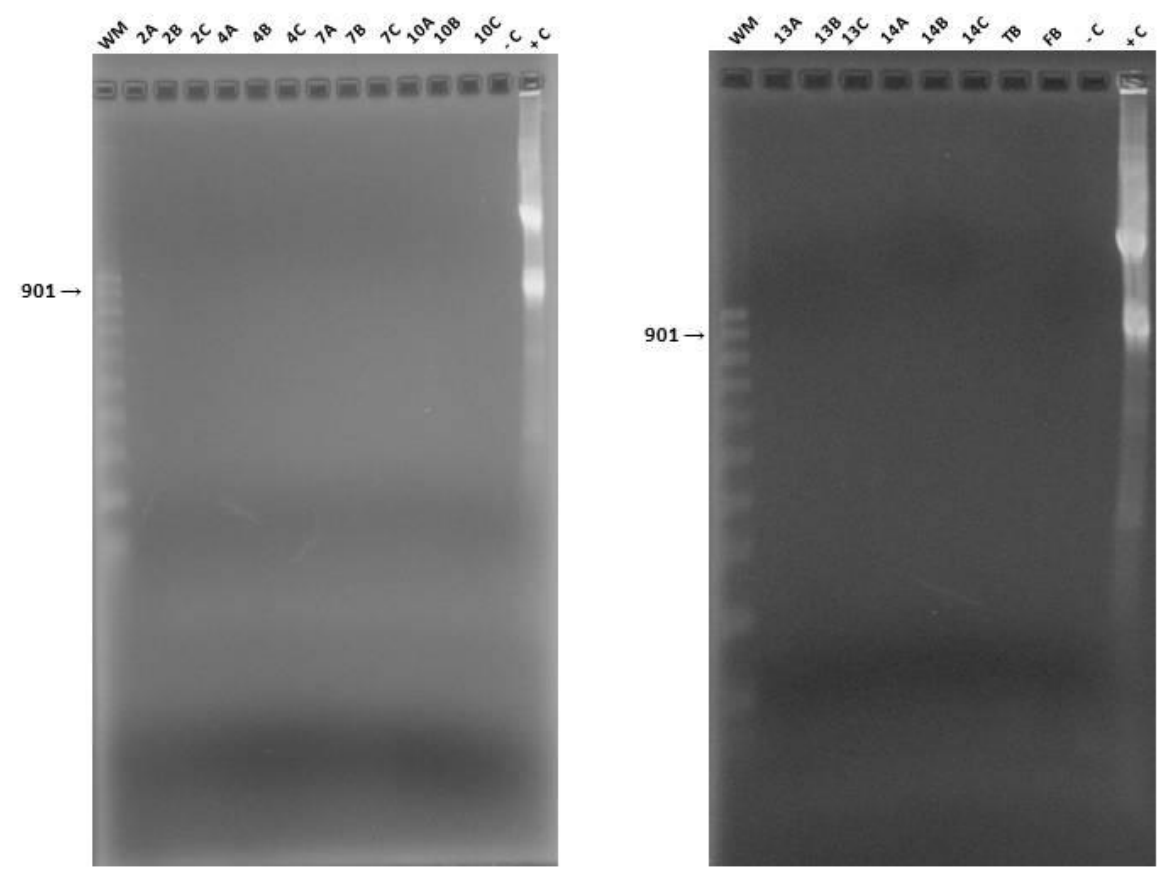

Figure 13. Gel electrophoresis of E. coli O157:H7 PCR products, January 2011. 

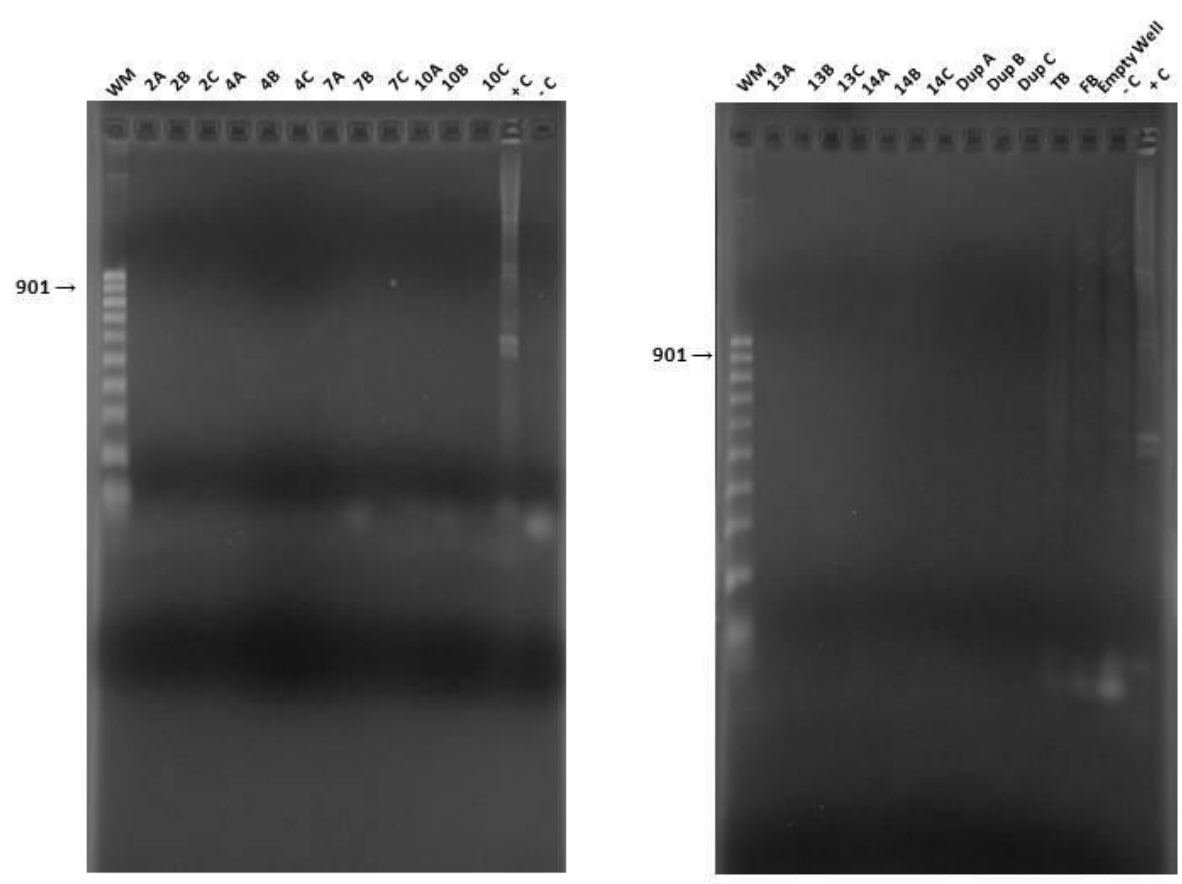

Figure 14. Gel electrophoresis of E. coli O157:H7 PCR products, February 2011. 

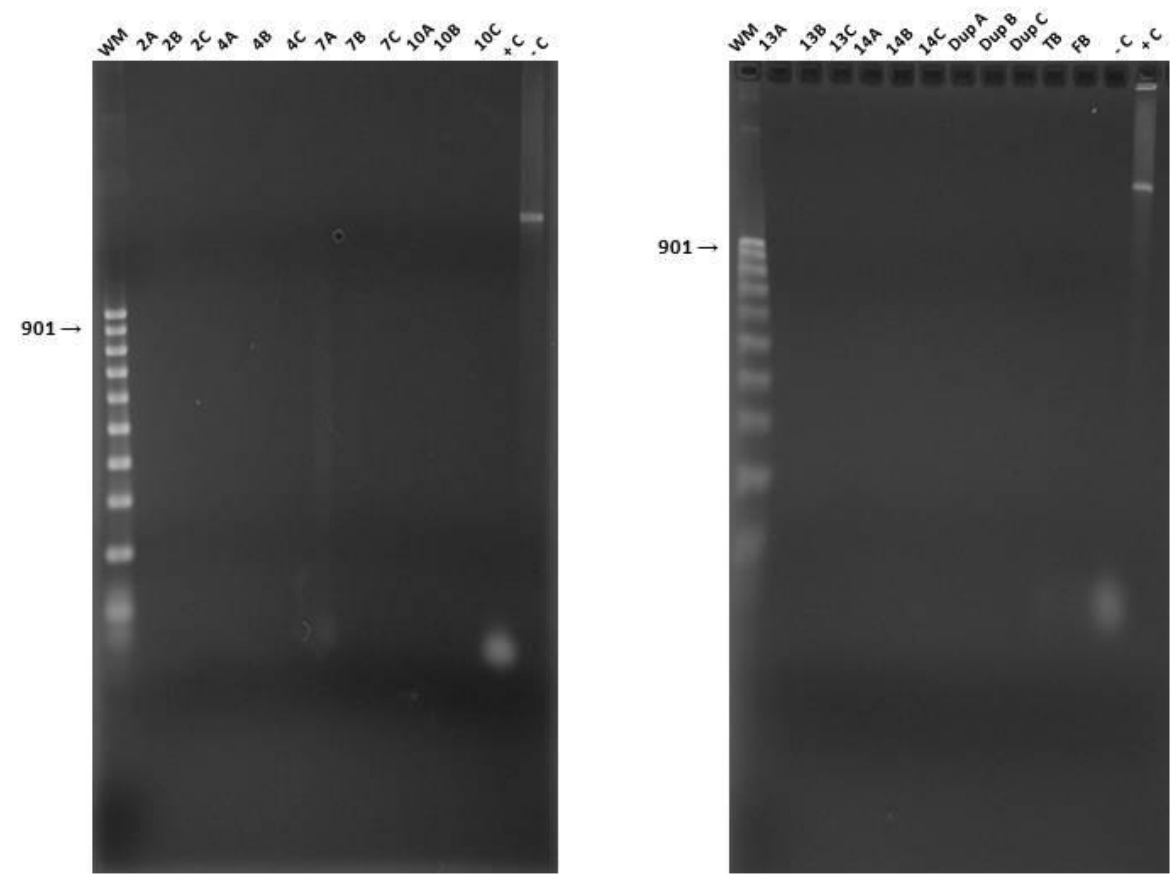

Figure 15. Gel electrophoresis of E. coli O157:H7 PCR products, March 2011. 

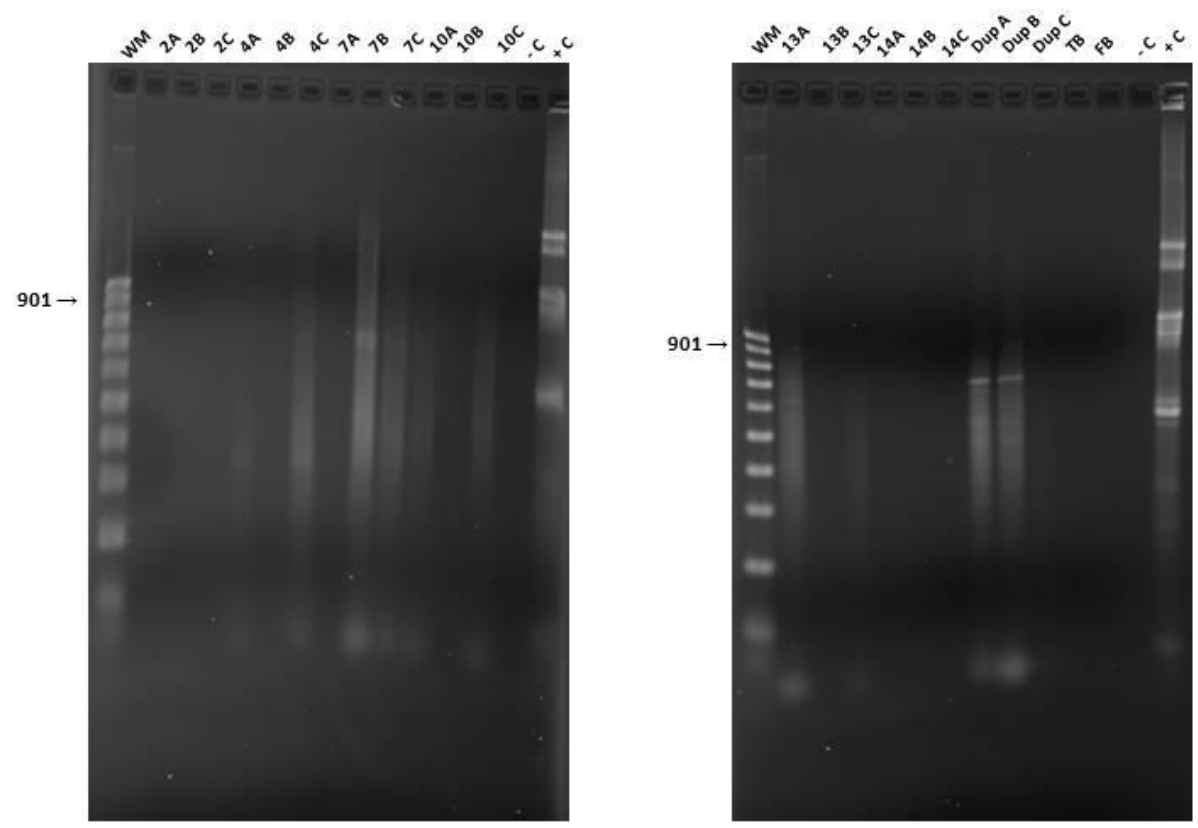

Figure 16. Gel electrophoresis of E. coli O157:H7 PCR products, April 2011. 

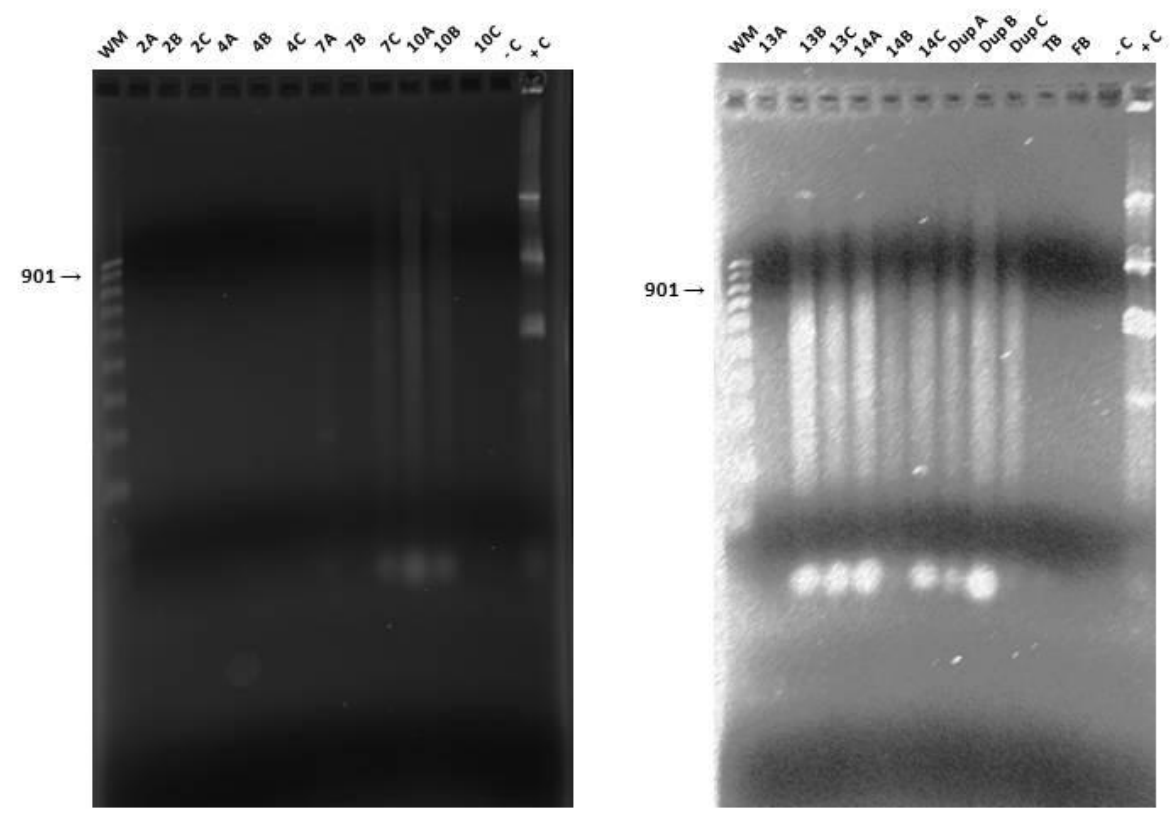

Figure 17. Gel electrophoresis of E. coli O157:H7 PCR products, May 2011. 

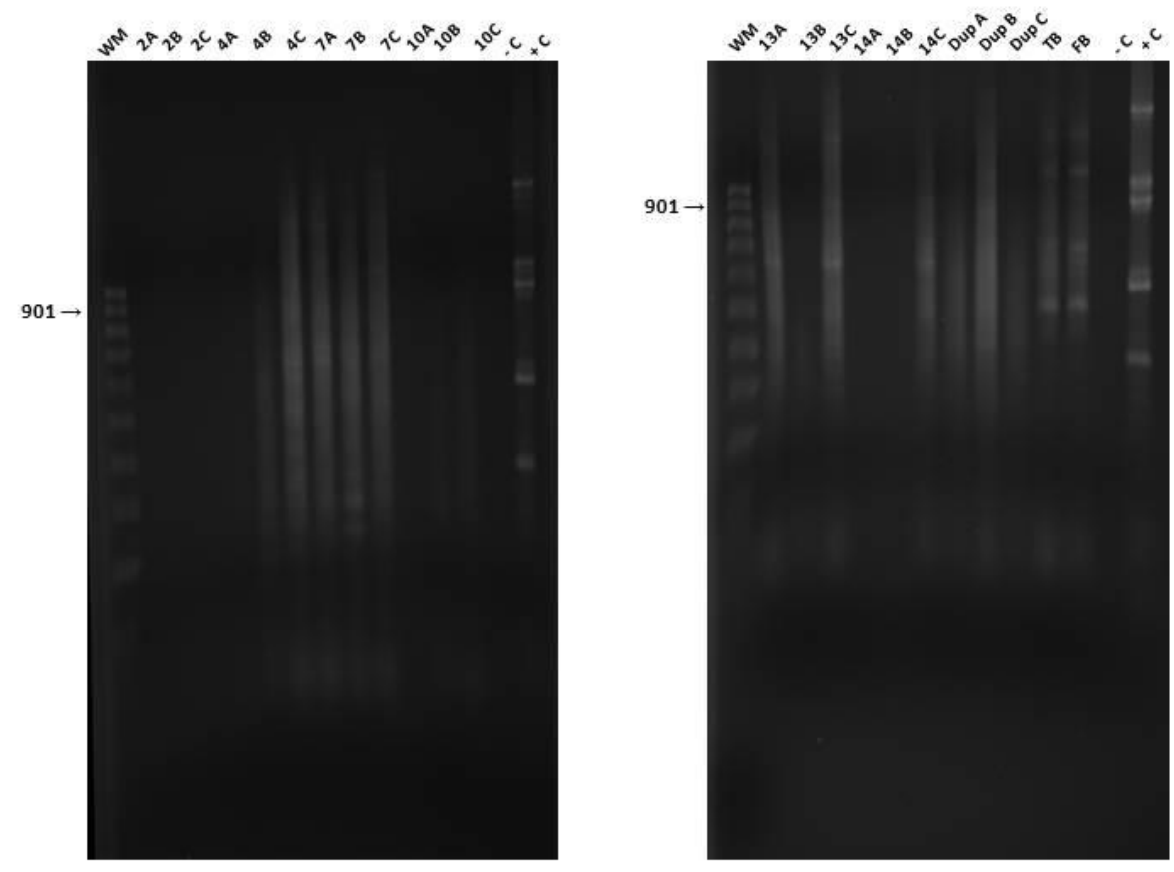

Figure 18. Gel electrophoresis of E. coli O157:H7 PCR products, June 2011. 

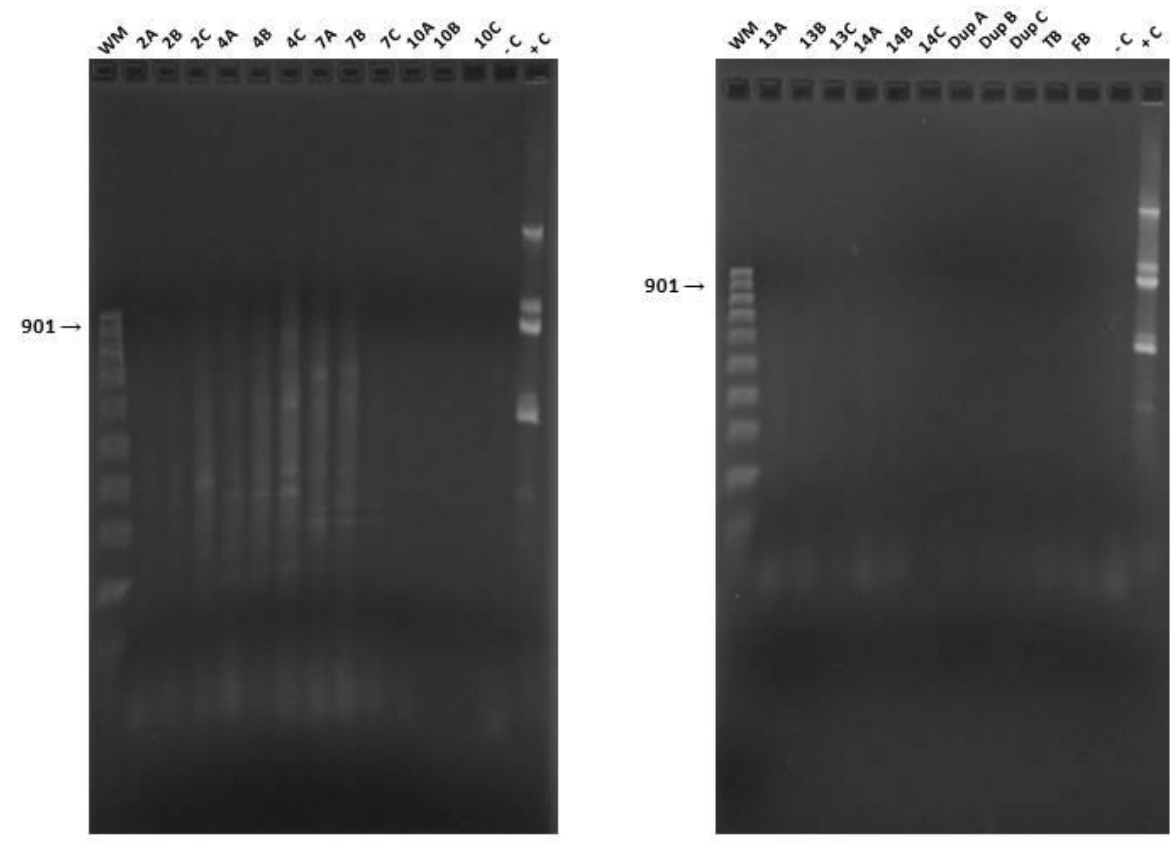

Figure 19. Gel electrophoresis of E. coli O157:H7 PCR products, July 2011. 

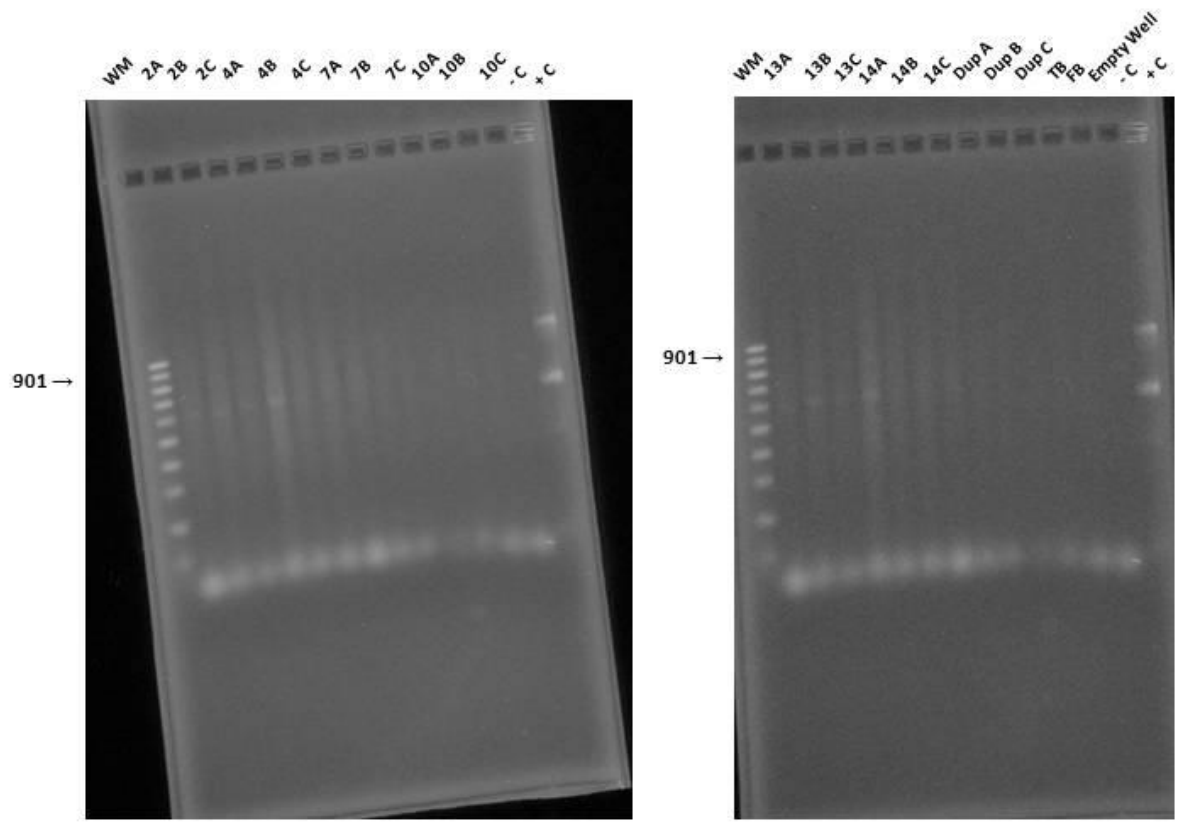

Figure 20. Gel electrophoresis of E. coli O157:H7 PCR products, August 2011. 

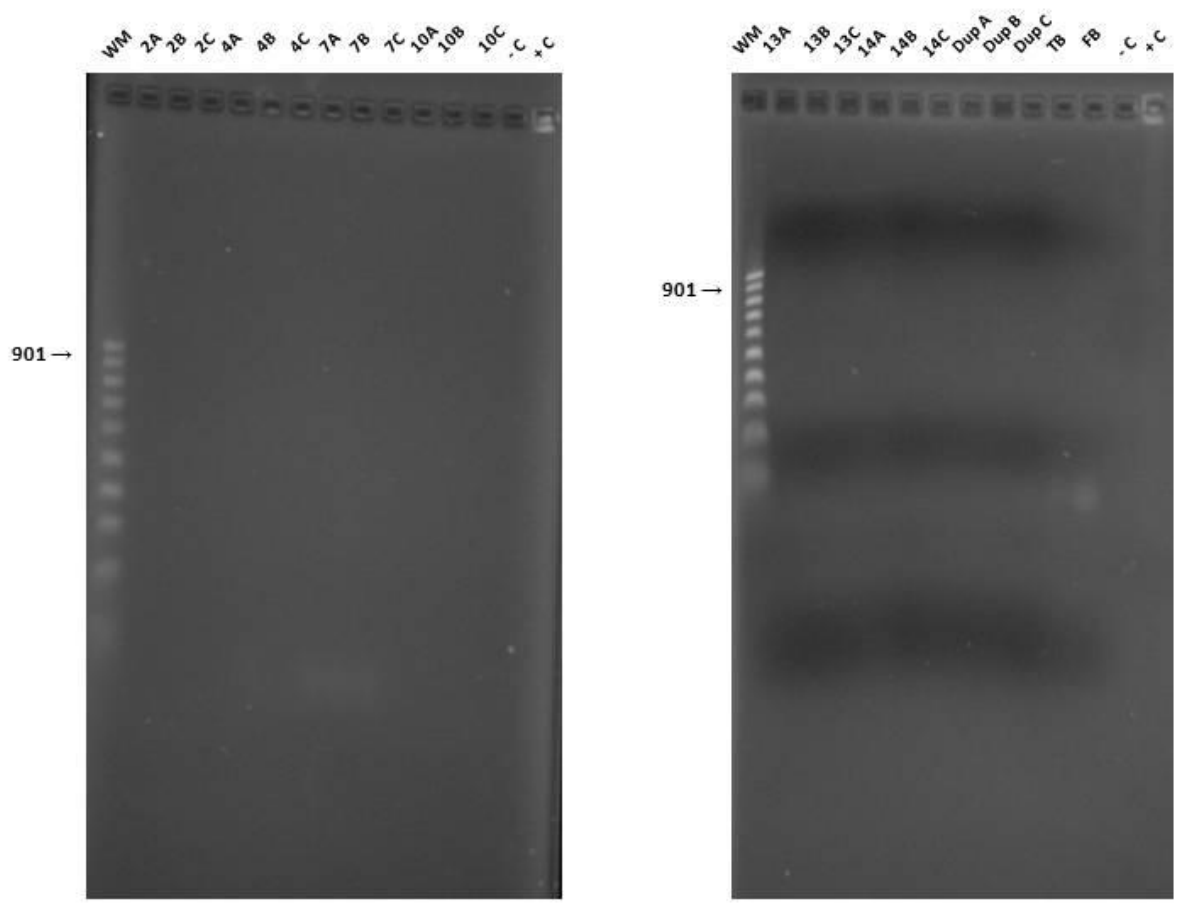

Figure 21. Gel electrophoresis of E. coli O157:H7 PCR products, September 2011. 

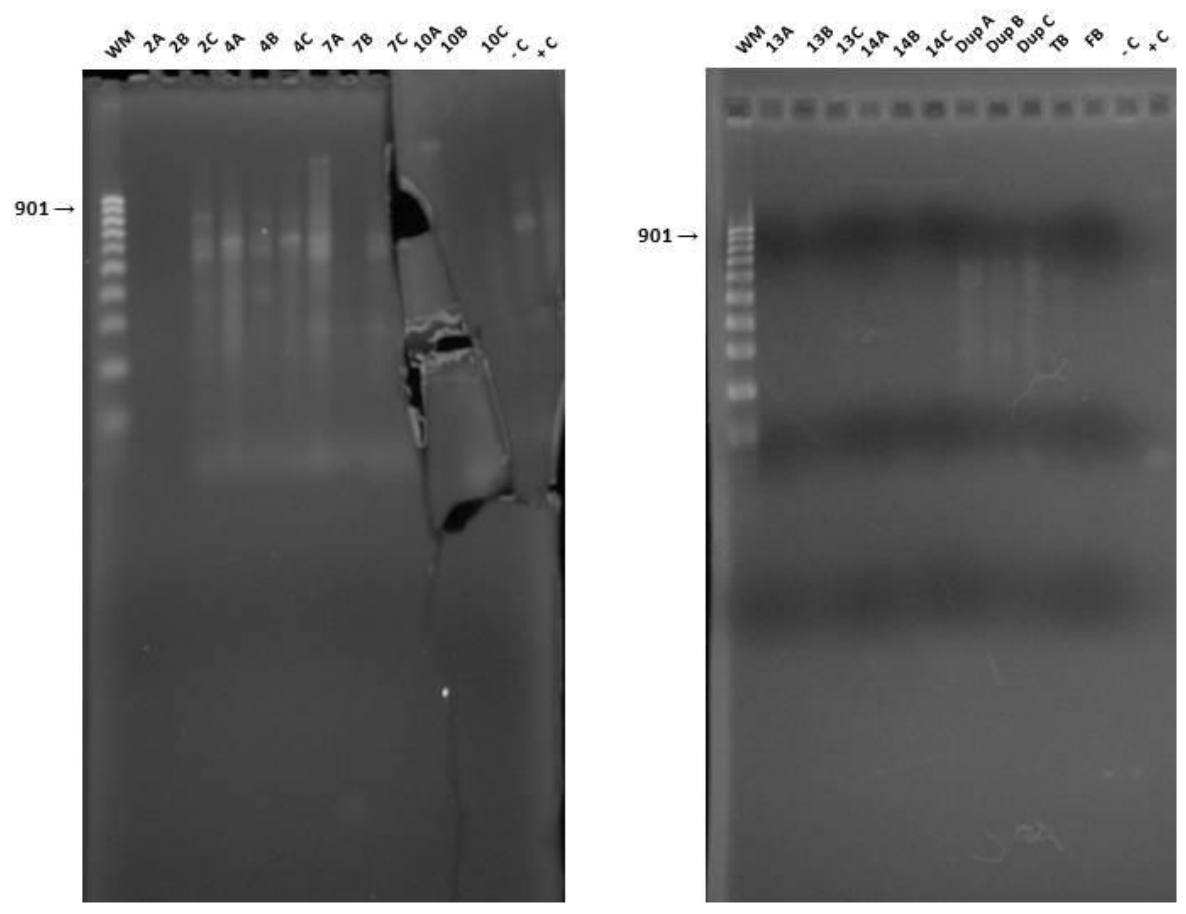

Figure 22. Gel electrophoresis of E. coli O157:H7 PCR products, October 2011. 

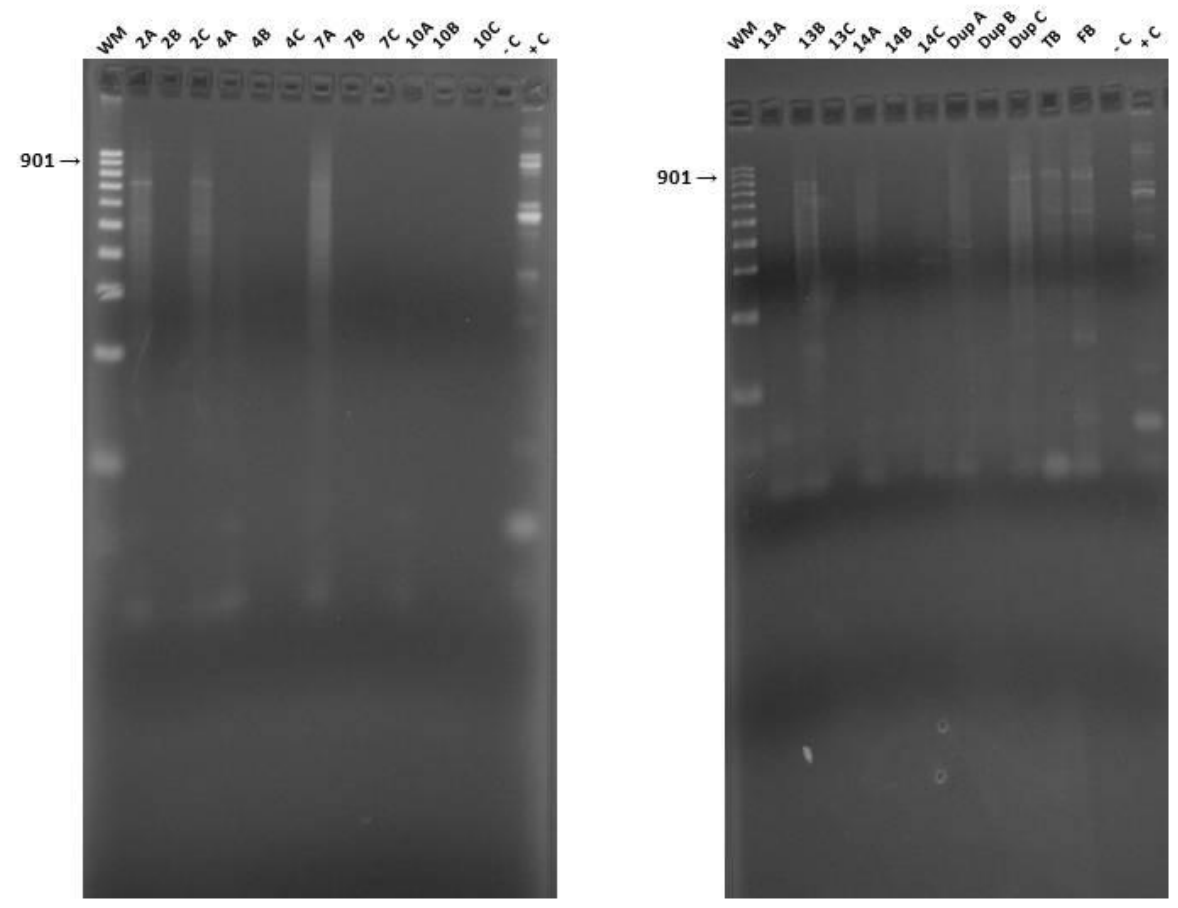

Figure 23. Gel electrophoresis of E. coli O157:H7 PCR products, November 2011. 

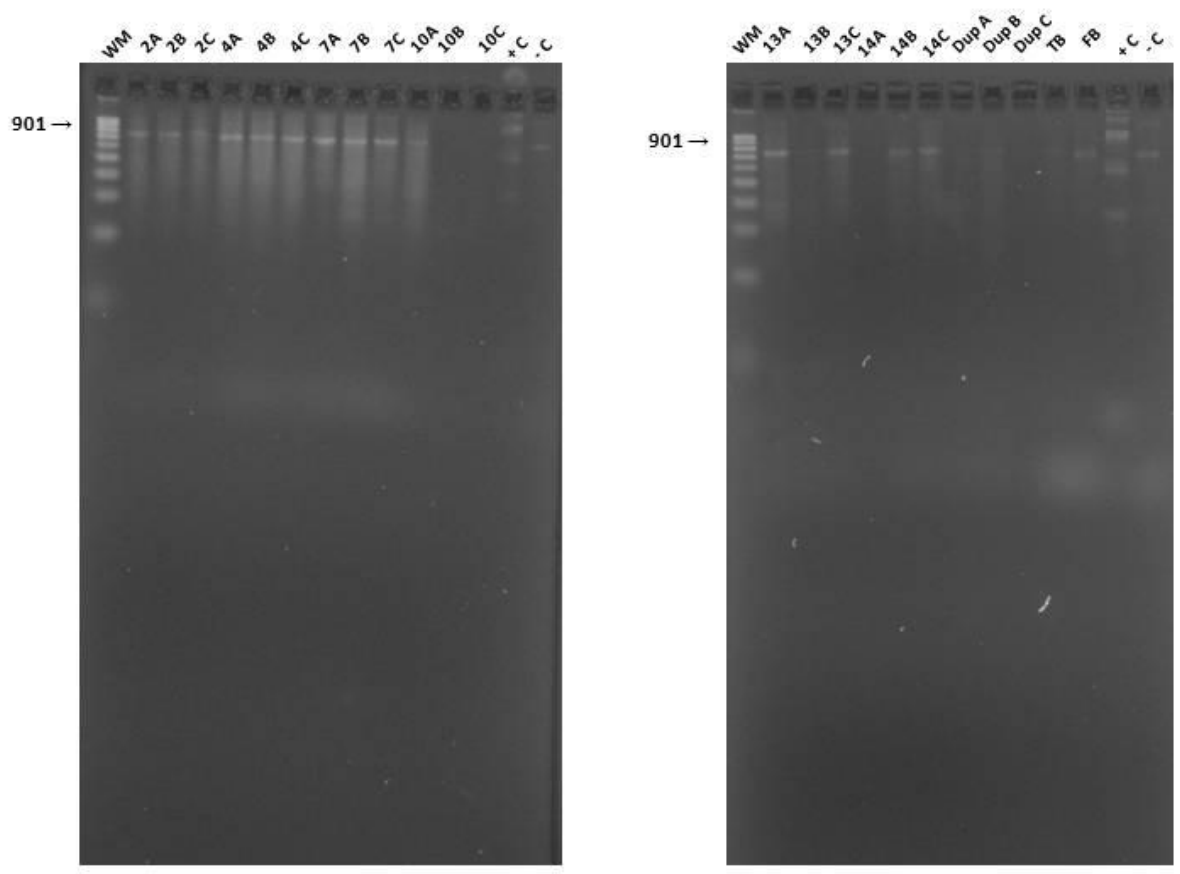

Figure 24. Gel electrophoresis of E. coli O157:H7 PCR products, December 2011. 


\section{Appendix D: Sinking Creek Habitat Assessments}

Table 1. Habitat assessment of site 2

\begin{tabular}{|c|c|}
\hline Land Use & Agriculture \\
\hline Dominant Vegetation & Grasses \\
\hline Erosion & Moderate \\
\hline Inorganic Substrate Components (\%) & $\begin{array}{l}50 \% \text { Cobble } \\
25 \% \text { Gravel } \\
10 \% \text { Sand } \\
10 \% \text { Silt } \\
5 \% \text { Clay }\end{array}$ \\
\hline Detritus (\%) & $10 \%$ \\
\hline Mud/Muck (\%) & $0 \%$ \\
\hline Marl (\%) & $5 \%$ \\
\hline Epifaunal Substrate & 7 \\
\hline Embeddedness & 13 \\
\hline Velocity and Depth Regime & 8 \\
\hline Sediment Deposition & 10 \\
\hline Channel Flow Status & 14 \\
\hline Channel Alteration & 13 \\
\hline Frequency of Riffles & 8 \\
\hline $\begin{array}{l}\text { Bank Stability } \\
\text { Right Bank } \\
\text { Left Bank }\end{array}$ & $\begin{array}{l}7 \\
7\end{array}$ \\
\hline $\begin{array}{l}\text { Vegetative Protection } \\
\text { Right Bank } \\
\text { Left Bank }\end{array}$ & $\begin{array}{l}4 \\
5\end{array}$ \\
\hline $\begin{array}{l}\text { Riparian Vegetative Zone Width } \\
\text { Right Bank } \\
\text { Left Bank }\end{array}$ & $\begin{array}{l}3 \\
5\end{array}$ \\
\hline Total Score (\%) & $52 \%$ \\
\hline
\end{tabular}


Table 2. Habitat assessment for site 4

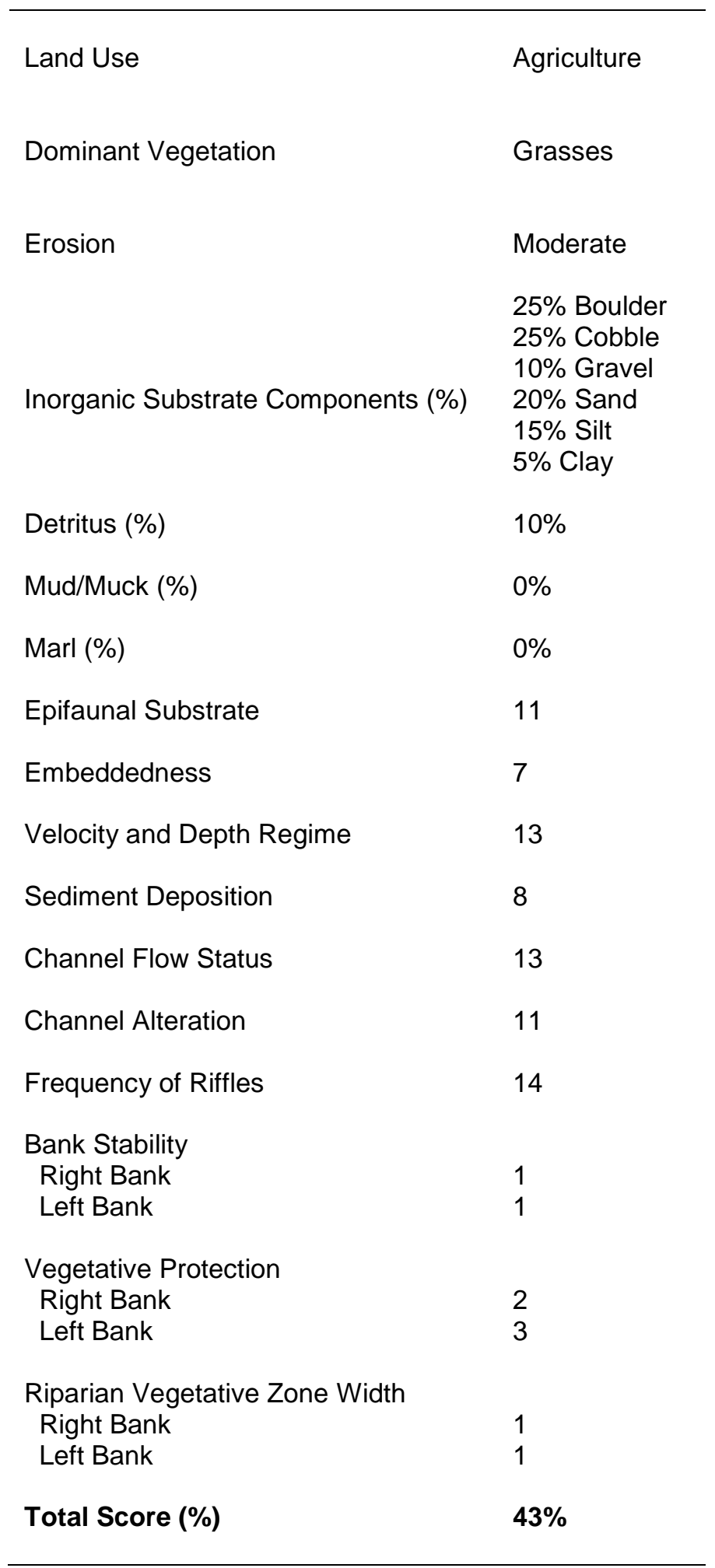


Table 3. Habitat assessment for site 7

\begin{tabular}{|c|c|}
\hline Land Use & Urban \\
\hline Dominant Vegetation & Grasses \\
\hline Erosion & Heavy \\
\hline Inorganic Substrate Components (\%) & $\begin{array}{l}10 \% \text { Boulder } \\
60 \% \text { Cobble } \\
10 \% \text { Gravel } \\
10 \% \text { Sand } \\
5 \% \text { Silt } \\
5 \% \text { Clay }\end{array}$ \\
\hline Detritus (\%) & $10 \%$ \\
\hline Mud/Muck (\%) & $0 \%$ \\
\hline Marl (\%) & $5 \%$ \\
\hline Epifaunal Substrate & 18 \\
\hline Embeddedness & 11 \\
\hline Velocity and Depth Regime & 4 \\
\hline Sediment Deposition & 13 \\
\hline Channel Flow Status & 19 \\
\hline Channel Alteration & 2 \\
\hline Frequency of Riffles & 18 \\
\hline $\begin{array}{l}\text { Bank Stability } \\
\text { Right Bank } \\
\text { Left Bank }\end{array}$ & $\begin{array}{l}5 \\
10\end{array}$ \\
\hline $\begin{array}{l}\text { Vegetative Protection } \\
\text { Right Bank } \\
\text { Left Bank }\end{array}$ & $\begin{array}{l}2 \\
1\end{array}$ \\
\hline $\begin{array}{l}\text { Riparian Vegetative Zone Width } \\
\text { Right Bank } \\
\text { Left Bank }\end{array}$ & $\begin{array}{l}0 \\
2\end{array}$ \\
\hline Total Score (\%) & $53 \%$ \\
\hline
\end{tabular}


Table 4. Habitat assessment for site 10

\begin{tabular}{|c|c|}
\hline Land Use & Urban \\
\hline Dominant Vegetation & Grasses \\
\hline Erosion & Heavy \\
\hline Inorganic Substrate Components (\%) & $\begin{array}{l}40 \% \text { Boulder } \\
40 \% \text { Cobble } \\
10 \% \text { Gravel } \\
3 \% \text { Sand } \\
3 \% \text { Silt } \\
4 \% \text { Clay }\end{array}$ \\
\hline Detritus (\%) & $5 \%$ \\
\hline Mud/Muck (\%) & $0 \%$ \\
\hline Marl (\%) & $5 \%$ \\
\hline Epifaunal Substrate & 18 \\
\hline Embeddedness & 9 \\
\hline Velocity and Depth Regime & 11 \\
\hline Sediment Deposition & 13 \\
\hline Channel Flow Status & 13 \\
\hline Channel Alteration & 6 \\
\hline Frequency of Riffles & 18 \\
\hline $\begin{array}{l}\text { Bank Stability } \\
\text { Right Bank } \\
\text { Left Bank }\end{array}$ & $\begin{array}{l}7 \\
7\end{array}$ \\
\hline $\begin{array}{l}\text { Vegetative Protection } \\
\text { Right Bank } \\
\text { Left Bank }\end{array}$ & $\begin{array}{l}4 \\
4\end{array}$ \\
\hline $\begin{array}{l}\text { Riparian Vegetative Zone Width } \\
\text { Right Bank } \\
\text { Left Bank }\end{array}$ & $\begin{array}{l}2 \\
2\end{array}$ \\
\hline Total Score (\%) & $57 \%$ \\
\hline
\end{tabular}


Table 5. Habitat assessment for site 13

\begin{tabular}{|c|c|}
\hline Land Use & Forest \\
\hline Dominant Vegetation & Trees \\
\hline Erosion & None \\
\hline Inorganic Substrate Components (\%) & $\begin{array}{l}25 \% \text { Boulder } \\
50 \% \text { Cobble } \\
10 \% \text { Gravel } \\
10 \% \text { Sand } \\
3 \% \text { Silt } \\
2 \% \text { Clay }\end{array}$ \\
\hline Detritus (\%) & $40 \%$ \\
\hline Mud/Muck (\%) & $0 \%$ \\
\hline Marl (\%) & $5 \%$ \\
\hline Epifaunal Substrate & 19 \\
\hline Embeddedness & 19 \\
\hline Velocity and Depth Regime & 3 \\
\hline Sediment Deposition & 18 \\
\hline Channel Flow Status & 15 \\
\hline Channel Alteration & 16 \\
\hline Frequency of Riffles & 18 \\
\hline $\begin{array}{l}\text { Bank Stability } \\
\text { Right Bank } \\
\text { Left Bank }\end{array}$ & $\begin{array}{l}7 \\
7\end{array}$ \\
\hline $\begin{array}{l}\text { Vegetative Protection } \\
\text { Right Bank } \\
\text { Left Bank }\end{array}$ & $\begin{array}{l}3 \\
3\end{array}$ \\
\hline $\begin{array}{l}\text { Riparian Vegetative Zone Width } \\
\text { Right Bank } \\
\text { Left Bank }\end{array}$ & $\begin{array}{l}7 \\
7\end{array}$ \\
\hline Total Score (\%) & $71 \%$ \\
\hline
\end{tabular}


Table 6. Habitat assessment for site 14

\begin{tabular}{|c|c|}
\hline Land Use & Forest \\
\hline Dominant Vegetation & Trees \\
\hline Erosion & None \\
\hline Inorganic Substrate Components (\%) & $\begin{array}{l}25 \% \text { Boulder } \\
25 \% \text { Cobble } \\
25 \% \text { Gravel } \\
15 \% \text { Sand } \\
5 \% \text { Silt } \\
5 \% \text { Clay }\end{array}$ \\
\hline Detritus (\%) & $10 \%$ \\
\hline Mud/Muck (\%) & $0 \%$ \\
\hline Marl (\%) & $0 \%$ \\
\hline Epifaunal Substrate & 18 \\
\hline Embeddedness & 18 \\
\hline Velocity and Depth Regime & 4 \\
\hline Sediment Deposition & 18 \\
\hline Channel Flow Status & 18 \\
\hline Channel Alteration & 19 \\
\hline Frequency of Riffles & 19 \\
\hline $\begin{array}{l}\text { Bank Stability } \\
\text { Right Bank } \\
\text { Left Bank }\end{array}$ & $\begin{array}{l}9 \\
9\end{array}$ \\
\hline $\begin{array}{l}\text { Vegetative Protection } \\
\text { Right Bank } \\
\text { Left Bank }\end{array}$ & $\begin{array}{l}7 \\
7\end{array}$ \\
\hline $\begin{array}{l}\text { Riparian Vegetative Zone Width } \\
\text { Right Bank } \\
\text { Left Bank }\end{array}$ & $\begin{array}{l}10 \\
10\end{array}$ \\
\hline Total Score (\%) & $83 \%$ \\
\hline
\end{tabular}



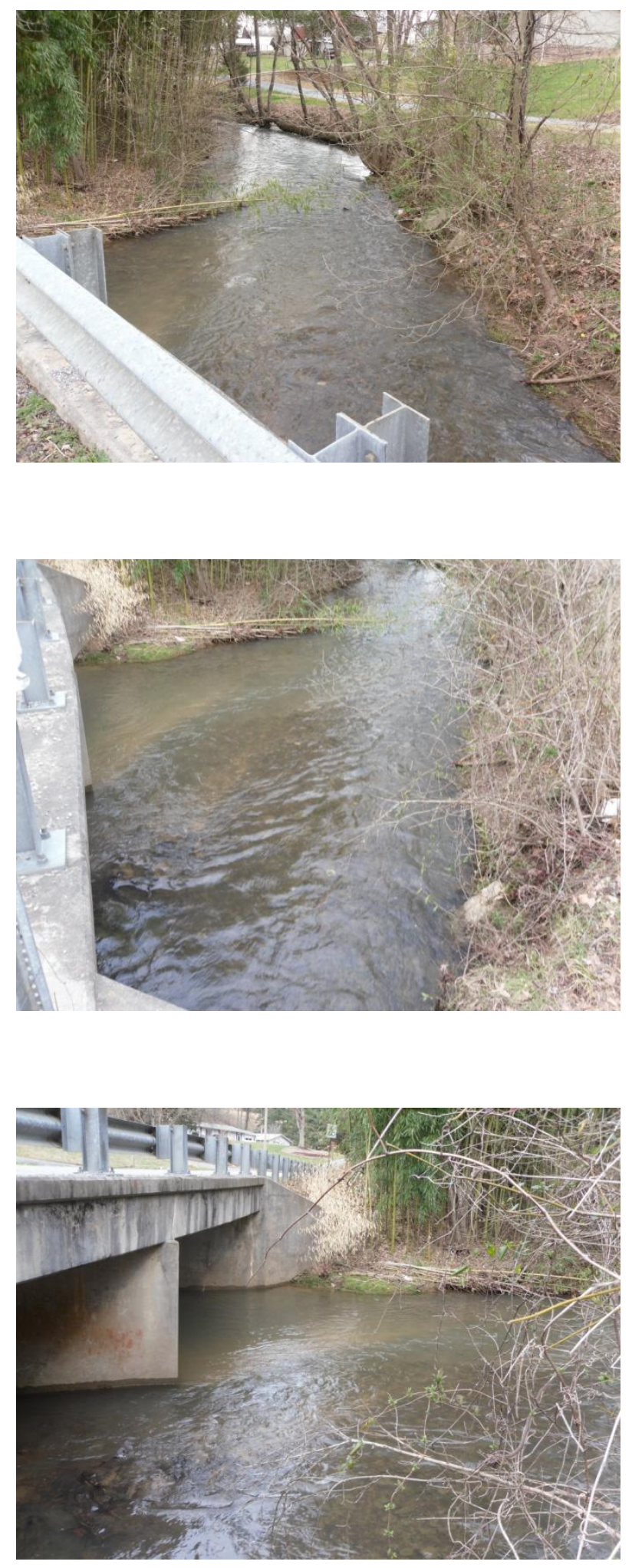

Figure 1. Site 2 - Bob Peoples Bridge on Sinking Creek Road 

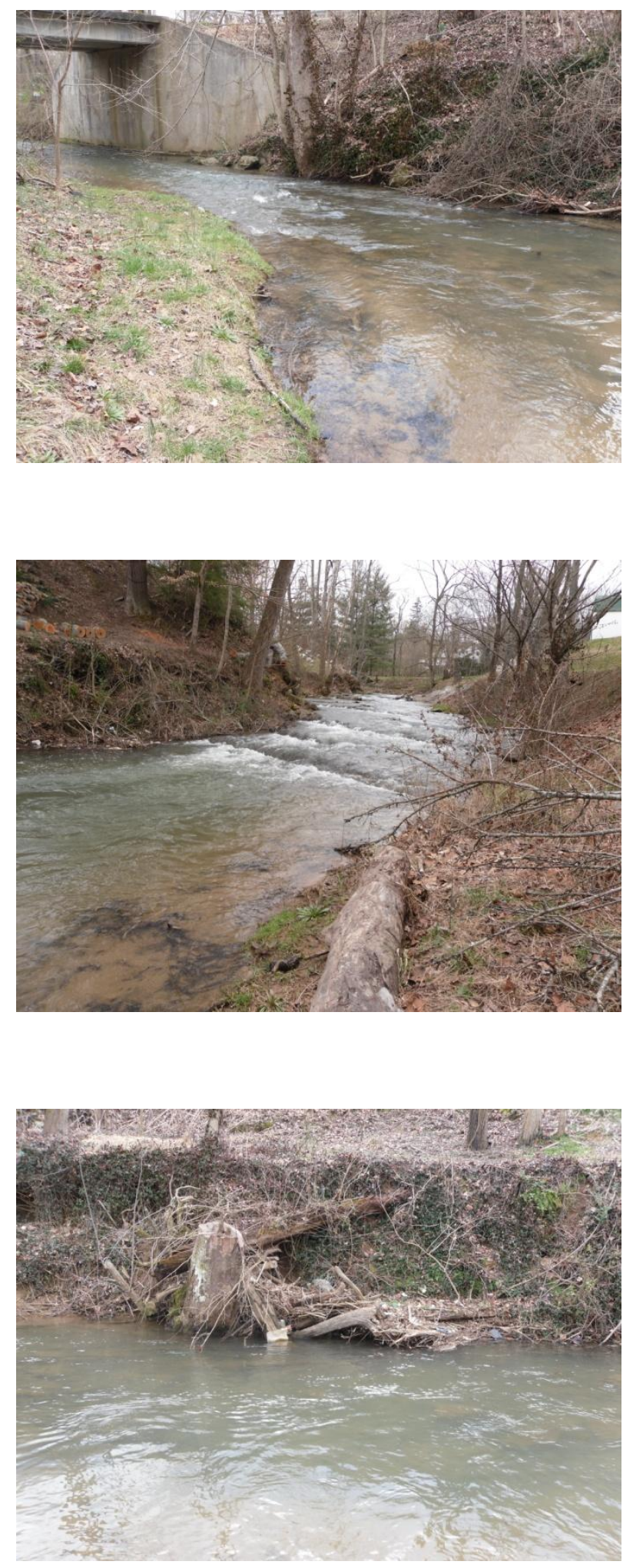

Figure 2. Site 4 - Joe Carr Road 

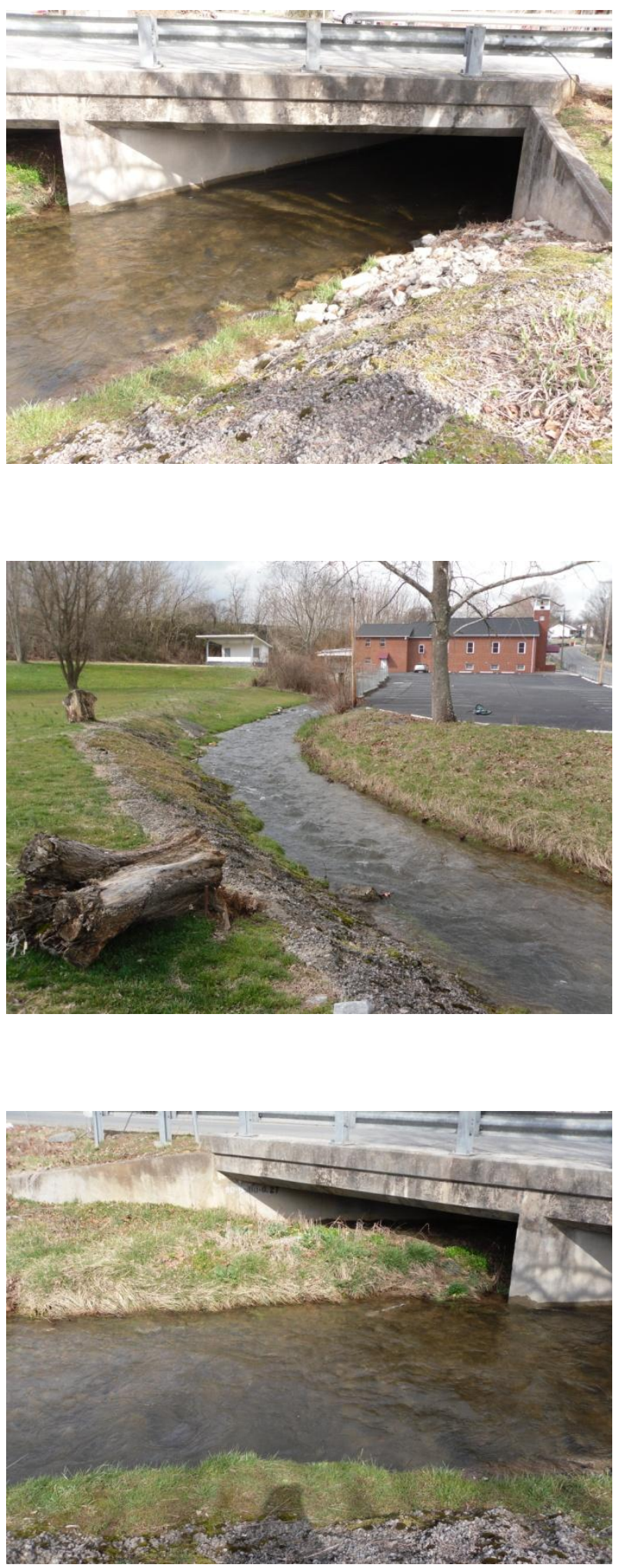

Figure 3. Site 7 - Miami Drive, King Springs Baptist Church 

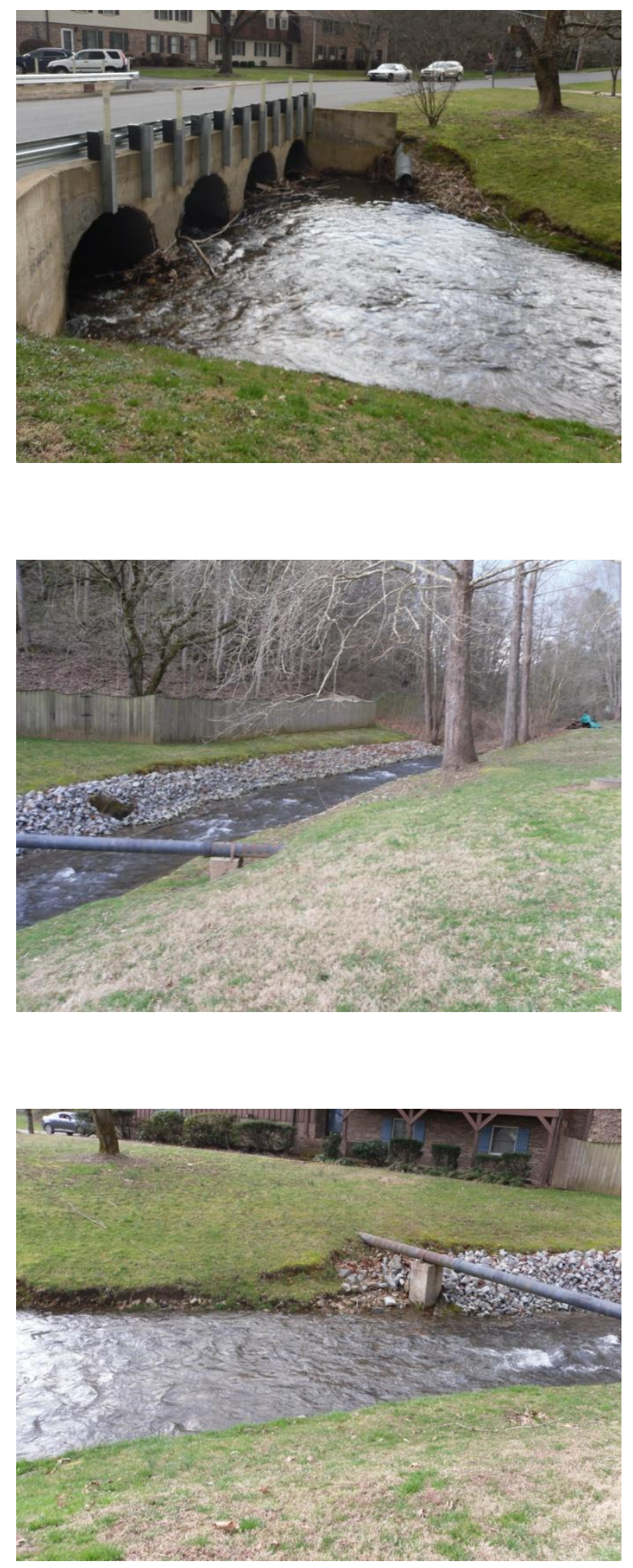

Figure 4. Site 10 - Hickory Springs Road 

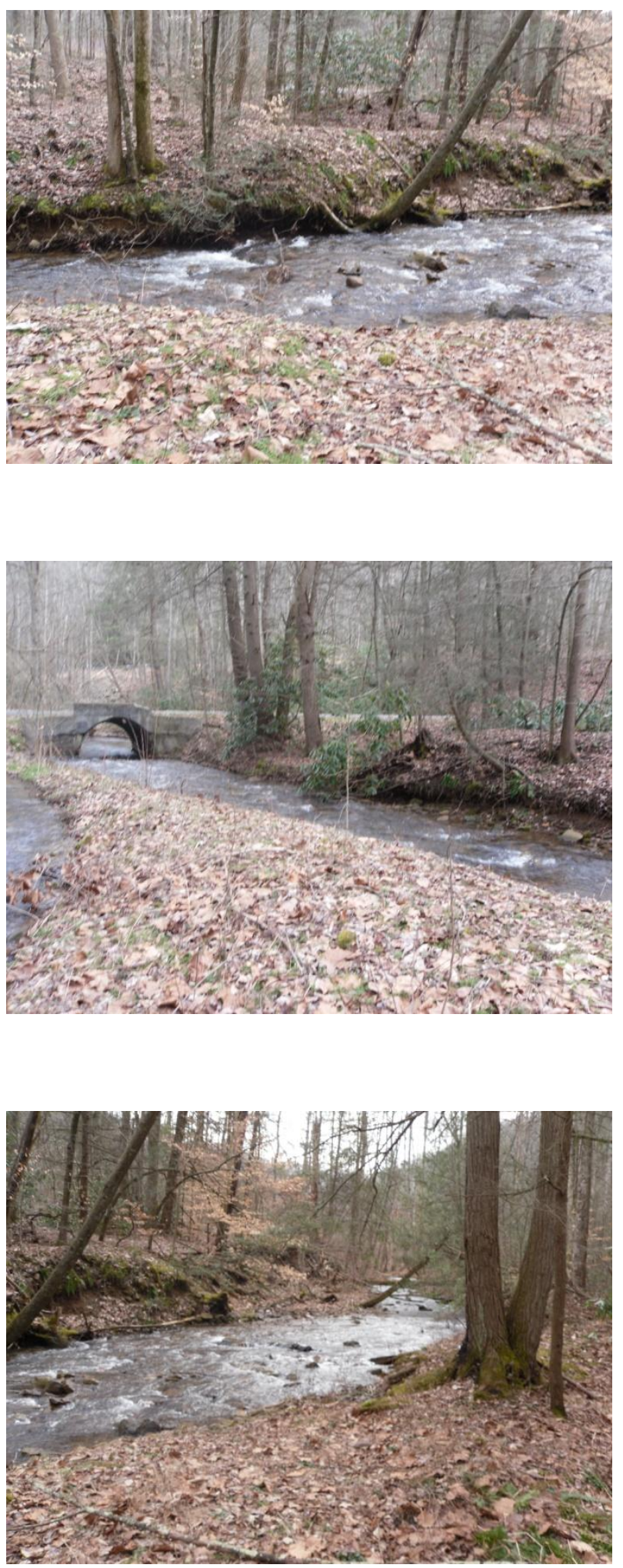

Figure 5. Site 13 - Jim McNeese Road 

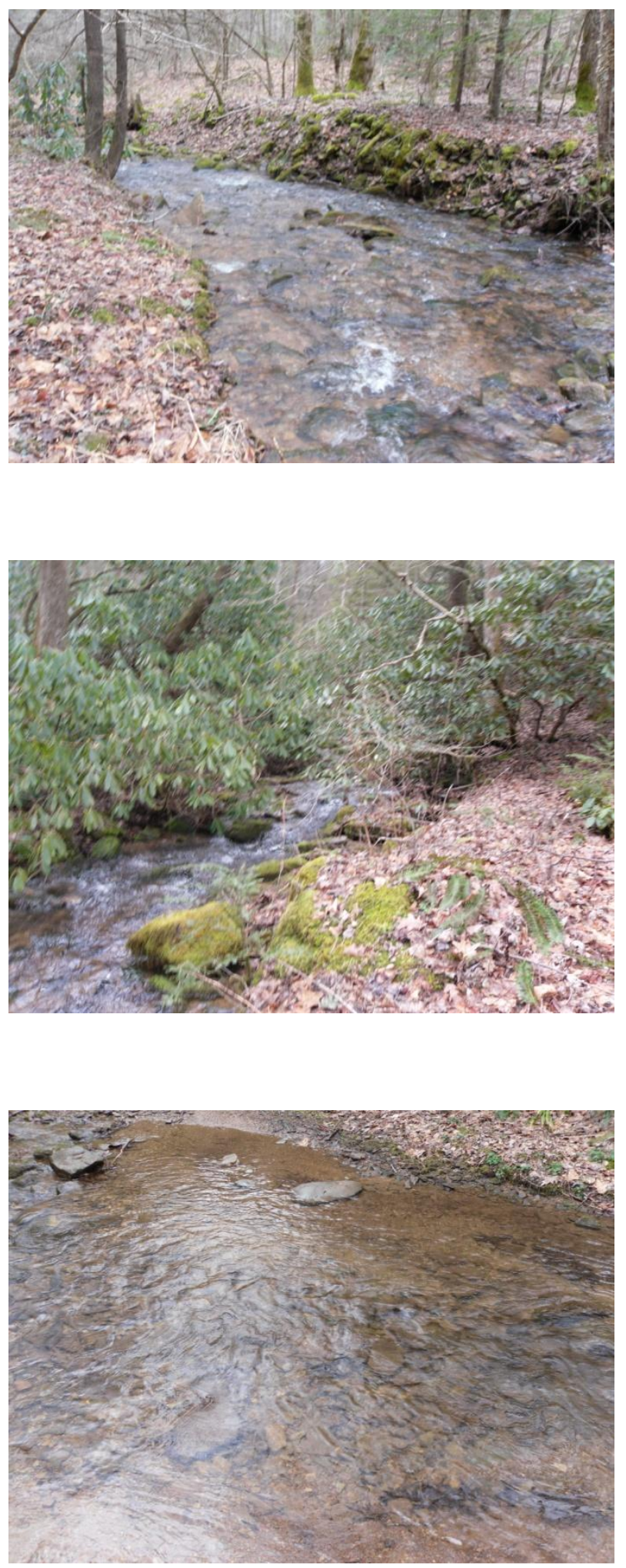

Figure 6. Site 14 - Dry Springs Road 


\section{VITA}

\section{KIMBERLEE K HALL}

Personal Data:

Eductation:

Professional Experience: Graduate Research Assistant, East Tennessee State University, Department of Environmental Health, $2004-2006$

Graduate Research Assistant and Teaching Associate, East Tennessee State University, Department of Environmental Health, $2006-2012$

Poster Presentations: $\quad$ Hall KK, Evanshen BG, Maier KJ, Scheureman PR. 2008. Application of multivariate statistical analyses to microbial water quality parameters in four geographically similar creeks in Northeast Tennessee to identify patterns associating land use to fecal pollution sources. Abstract, $107^{\text {th }}$ Annual Meeting for the American Society for Microbiology, Toronto, Ontario, Canada

Hall KK, Evanshen BG, Maier KJ, Scheureman PR. 2011. Analysis of water quality data using multivariate statistics to patterns associating land use to fecal pollution sources. $111^{\text {th }}$ Annual Meeting for the American Society for Microbiology, New Orleans, LA USA

Awards:
ETSU Graduate Council Teaching Excellence Award, East Tennessee State University, April, 2009 